$$
\begin{gathered}
\text { UNIVERSIDADE DE SÃO PAULO } \\
\text { FFCLRP - DEPARTAMENTO DE FÍSICA E MATEMÁTICA }
\end{gathered}
$$

PAULO SÉRGIO DE MATOS.

\title{
Avaliação de Parâmetros Ultra-Sônicos Utilizados na Caracterização de Tecidos Ósseos.
}


PAULO SÉRGIO DE MATOS.

\section{Avaliação de Parâmetros Ultra-Sônicos Utilizados na Caracterização de Tecidos Ósseos.}

Tese de Doutorado apresentada à Faculdade de Filosofia, Ciências e Letras de Ribeirão Preto- USP, como parte das exigências para a obtenção do Título de Doutor em Ciências.

Área de Concentração: Física Aplicada à Medicina e Biologia.

Orientador: Prof.Dr. Carlos Alberto Pelá.

RIBEIRÃO PRETO - SP

2006 
FICHA CATALOGRÁFICA

Matos, Paulo Sérgio de

Avaliação de Parâmetros Ultra-Sônicos Utilizados na Caracterização de Tecidos Ósseos.. Ribeirão Preto, 2006.

246 p. : il. ; 30cm

Tese de Doutorado, apresentada à Faculdade de Filosofia Ciências

e Letras de Ribeirão Preto/USP - Área de concentração: Física

Aplicada a Medicina e Biologia.

Orientador: Pelá,Carlos Alberto.

1. Velocidade do som. 2. BUA. 3. Ultra-som. 4.Calo ósseo. 


\section{AGRADECIMENTOS}

pesquisa.

Ao Prof. Dr. Carlos Alberto Pelá pela orientação e pelo o apoio na

Ao técnico Elcio Aparecido Navas pelo apoio técnico na construção da eletrônica do sistema, o que muito contribuiu para o desenvolvimento deste trabalho e também ao técnico José Luis Aziane pelo apoio na construção e confecção dos componentes mecânicos do equipamento.

A Faride Cecílio Abrão Justino diretora do grupo de terceira idade da cidade de São Joaquim da Esperança, pela participação como voluntários.

A Giuliano Barbiere e Cláudio Henrique Barbiere pelo trabalho em conjunto na análise ultrassonométrica das tíbias de carneiro.

Ao Departamento de Física desta faculdade pela oportunidade de cursar o doutorado, também pelo apoio encontrado por todos os professores e funcionários deste departamento e também pela disponibilidade de equipamentos e de espaço físico para que a pesquisa pudesse ser realizada.

E a CAPES pelo apoio financeiro.

Enfim a todos que participaram direta e ou indiretamente na realização deste trabalho. 
Epígrafe

“A morte não é a maior perda da vida.

A maior perda da vida é o que morre dentro de nós enquanto vivemos."

Norman Cuisins. 


\section{RESUMO}

Matos, PS. Avaliação de Parâmetros Ultra-Sônicos Utilizados na Caracterização de Tecidos Ósseos. 2006. 246f. Tese (Doutorado) - Faculdade de Filosofia Ciências e Letras de Ribeirão Preto, São Paulo, 2006.

A transmissão do ultra-som no organismo humano tem sido objeto de estudos a várias décadas, com a finalidade de promover diagnóstico. Recentemente tem sido usada para avaliar a densidade óssea e poder diagnosticar precocemente o aparecimento da osteoporose e prever o risco de fratura. Nesse trabalho foi desenvolvido um sistema capaz de gerar, receber e amplificar sinais ultra-sônicos para a avaliação da velocidade do som e atenuação em função da freqüência (BUA). A técnica usada foi a de transmissão do sinal ultra-sônico, com acoplamento por gel de ultra-som e por água (tanque acústico), que consiste no uso de dois transdutores, um para transmissão e outro para recepção, sendo a amostra posicionada entre eles. Devido ao alto índice de dispersão nas medidas ultra-sônicas, será buscado um material de referência, o qual deve possuir características tanto de velocidade do som e atenuação em função da freqüência, parecidas com a do osso (calcâneo), que será usado para calibração do equipamento e para o acompanhamento da medida óssea. Foram utilizados os parâmetros ultra-sônicos para avaliação da consolidação óssea (em tíbias de carneiro) em diferentes períodos e nos diversos tipos de fraturas. O sistema foi caracterizado em termos de temperatura e reprodutibilidade utilizando diferentes materiais. Medidas no calcâneo de voluntários, de velocidade e atenuação em função da freqüência, independente de associações patológicas, mostrou resultados compatíveis com os encontrados na literatura. Foram feitas diversas análises, com pequenas mudanças nas condições geométricas, de sinal e freqüência dos transdutores, para observar sua influência sobre as medidas de atenuação e velocidade. Isto com a finalidade de tentar relacionar as variações nas medidas de atenuação obtidas por diferentes autores.

Palavras chaves: velocidade do som; BUA; ultra-som; calo ósseo. 


\begin{abstract}
Matos, PS. Assessment of Ultrasonics Parameters Utility in Customization of Bone Tissues, 2006. Doctoral Thesis by Matos, Paulo Faculdade de Filosofia Ciências e Letras de Ribeirão Preto - São Paulo, 2006.
\end{abstract}

Ultrasound transmission in human bodies has been studied for several decades in order to facilitate diagnosis. It has also been used to evaluate bone density and to diagnose early osteoporosis and future fracture risks. For this study, a system to generate, receive and amplify ultrasonic signs for speed of sound assessment and broad band ultrasound attenuation (BUA) was developed. Transmission of ultrasonic signals was performed by coupling using ultrasound gel and water (acoustic tank) and the sample placed between two transducers, one for transmission and the other for reception. Due to the high rate of the dispersion of ultrasonic measures, some reference material having the characteristics of the speed of sound and broad band ultrasound attenuation, similar to the heel bone that will be used for equipment calibration and follow-up of bone measure will have to be found. Ultrasonic parameters were used to evaluate bone consolidation (tibia of a sheep), in different periods and several kinds of fractures. Temperature and reproducibility using different materials were used to customize the system. Measures of volunteers's heel bone speed and broad band ultrasound attenuation showed results consistent with the ones from literature. Several analyses with little changes in geometric, signal and transducer frequency conditions were performed in order to observe their influence on attenuation and speed measures. Those steps were carried out in order to try to relate the variations in attenuation measures to those obtained by other authors.

Key-words: speed of the sound; BUA; ultrasound; bone callus bone of sheep. 


\section{SUMÁRIO}

PÁGINA

Resumo VI

$\begin{array}{lll}\text { Abstract } & \text { VII }\end{array}$

1. INTRODUÇÃO 1

$1.1 \quad$ Anatomia óssea. $\quad 2$

1.2 Formas de avaliação da massa óssea. $\quad 4$

$\begin{array}{lll}1.3 & \text { Novas aplicações da ultrassonometria óssea. } & 7\end{array}$

1.4. Este trabalho. 11

2. MÉTODO TEÓRICO 14

2.1. Velocidade do som. $\quad 14$

2.1.1 Introdução 14

2.1.2 Testes sobre materiais padrão. 15

2.1.3 Determinação da velocidade do som pela técnica de inserção convencional 16 (acoplamento por água).

2.1.4 Determinação da velocidade do som pela técnica de contato (acoplamento 17 por gel ultra-sônico).

2.1.5 Marcadores no sinal temporal (referência para o tempo de chegada). $\quad 18$

2.1.6 Curva de calibração da velocidade do som para o teflon como função da 20 temperatura.

2.1.7 Valores da velocidade do som adquiridos na literatura. 21

$2.2 \quad$ Atenuação do ultra-som. 24

2.2.1 Atenuação no tecido de uma onda de ultra-som. 24

2.2.2. Intensidade. 25

2.2.3 “BROADBAND ULTRASOUND ATTENUATION” (BUA). 26

2.2.3.1 Introdução. 26

2.2.3.2 Técnica de inserção convencional (acoplamento com água). 27

2.2.3.3. Técnica de inserção por contato (acoplamento com gel). 30 
2.2.3.4. Sinal temporal total na análise da BUA. 30

2.2.3.5 Janela do sinal temporal na análise da BUA. 31

2.2.3.6. Faixa em freqüência escolhida pelos autores. 33

2.3. Transdutores e sistemas ultra-sônicos. 38

2.3.1. O efeito piezoelétrico. 38

2.3.2. Projeto de um transdutor de ultra-som. 39

2.3.3. Feixe de ultra-som (campo acústico). $\quad 44$

2.3.4. Características da pastilha de ultra-som. $\quad 45$

2.3.5 Sistemas ultra-sônicos. $\quad 47$

3. MÉTODO EXPERIMENTAL 51

3.1 Tanque acústico. $\quad 51$

3.2 Transdutores. 53

$\begin{array}{lll} & \text { Sistema ultra-sônico. } & 57\end{array}$

3.3.1. Gerador de pulso. $\quad 59$

3.3.2. Fonte de alta tensão. $\quad 61$

3.3.3. Fonte de baixa tensão $\quad 62$

3.3.4. Circuito amplificador do sinal recebido 62

3.4. Amostras. 63

3.5. Medidas de calibração do sistema ultra-sônico e dos transdutores como 64 função da temperatura da água.

3.5.1. Introdução 64

3.5.2. Transdutores de $1 \mathrm{MHz}$, par AB. 65

3.5.3. Transdutores de $1 \mathrm{MHz}$, par NO. 68

$\begin{array}{lll}\text { 3.5.4. Transdutores de } 1 \mathrm{MHz} \text {, par EF. } & 71\end{array}$

$\begin{array}{lll}\text { 3.5.5. Transdutores de } 0,75 \mathrm{MHz} \text {, par CD. } & 74\end{array}$

$\begin{array}{ll}\text { 3.5.6. } & \text { Transdutores de 2MHz, par IG. }\end{array}$

3.5.7. Transdutores de 2MHz, par LM. 80

3.5.8. Transdutores de 1,5MHz, par PQ.

3.5.9. Transdutores de 0,5MHz, par RS. 86

3.6. Considerações finais. 89

3.6.1 Transdutores de $1 \mathrm{MHz} \quad 89$ 
$\begin{array}{llr}\text { 3.6.1.1. } & \text { PAR AB. } & 89\end{array}$

3.6.1.2. PAR NO. $\quad 89$

$\begin{array}{lll}\text { 3.6.1.3 PAR EF. } & 90\end{array}$

3.6.2 Transdutores de $0,75 \mathrm{MHz} \quad 90$

3.6.2.1. PAR CD. 90

3.6.3. Transdutores de $2 \mathrm{MHz} \quad 91$

3.6.3.1. PAR IG. $\quad 91$

3.6.3.2. PAR LM. $\quad 91$

3.6.4 Transdutores de $1,5 \mathrm{MHz} \quad 92$

3.6.4.1. PAR PQ. $\quad 92$

3.6.5. Transdutores de 0,5MHz. 92

3.6.5.1. PAR RS. $\quad 92$

4. RESULTADOS E DISCUSSÕES 93

4.1. Medidas em materiais plásticos e metais, para análise da velocidade do 93 som pela técnica de contato e inserção convencional.

4.1.1. Introdução 93

4.1.2. Transdutores de $1 \mathrm{MHz} . \quad 94$

$\begin{array}{lll}\text { 4.1.3. } & \text { Transdutores de 2MHz. } & 105\end{array}$

4.1.4. Transdutores de 1,5MHz. 112

4.1.5. Transdutores de 750KHz. 116

4.1.6. Transdutores de 500KHz. $\quad 121$

4.1.7. Considerações finais. 125

4.2 Avaliação do teflon como meio de referência na análise da BUA, 127 velocidade do som e na análise da dispersão da técnica.

$\begin{array}{lll}\text { 4.2.1. Introdução } & 127\end{array}$

$\begin{array}{llr}\text { 4.2.2. } & \text { BUAtot. } & 127\end{array}$

4.2.2.1. Cálculo da BUAtot através das técnicas de inserção convencional e de 127 contato com gel ultra-sônico.

4.2.2.2. Velocidade do som avaliada pela técnica de inserção convencional e de 137 contato com acoplamento com gel ultra-sônico.

4.2.3. Avaliando a reprodutibilidade da BUAtot, em curto prazo, para as duas 140 
técnicas.

4.2.4. Cálculo da BUAsel, para as técnicas de inserção convencional e de contato 149 com acoplamento por gel.

4.2.5. Considerações finais entre BUAtot e BUAsel. 158

4.2.6. Variação da posição do teflon em relação ao transdutor emissor (TE). 161

4.2.7. Avaliação da influência do circuito amplificador sobre os valores de BUA 163 (BUAtot e BUAsel).

4.3 Avaliação, através da ultrassonometria óssea, do calo ósseo em tíbias de 169 carneiro.

$\begin{array}{lll}\text { 4.3.1 Introdução. } & 169\end{array}$

$\begin{array}{lll}\text { 4.3.2 Metodologia. } & 170\end{array}$

$\begin{array}{lll}\text { 4.3.2.1 Osso analisado. } & 170\end{array}$

4.3.2.1.1 Considerações anatômicas (osso longo). 170

4.3.2.2 Calo Ósseo. 170

4.3.2.2.1 Consolidação óssea. $\quad 170$

4.3.2.2.2. Fixador externo. 173

4.3.2.3. Preparação das amostras. 174

4.3.2.4. Conservação das tíbias (congelamento e descongelamento). 175

4.3.2.5. Região de interesse. 175

4.3.2.5.1. Comparação entre a espessura da tíbia e dias pós fratura. 178

4.3.2.6. Técnicas utilizadas. $\quad 179$

4.3.2.6.1. BUAtot e velocidade do som (técnicas de inserção e de contato) 179

4.3.2.6.2. Velocidade do som (técnica de contato longitudinal). 182

4.3.2.6.3. Modelo experimental de cálculo da BUA. 185

4.3.2.7. Procedimento para as análises ultra-sônicas. 186

$\begin{array}{lll}\text { 4.3.3. } & \text { Resultados e discussões. } & 187\end{array}$

4.3.3.1. Resultados para a técnica de inserção. 187

4.3.3.1.1. Velocidade do som como função da espessura. 187

4.3.3.1.2. Velocidade do som no calo em função da velocidade na tíbia do mesmo 188 animal.

4.3.3.1.3. Comparação entre a velocidade do som na tíbia em função de dias pós 190 fratura.

4.3.3.1.4. BUAtot como função da espessura. 
4.3.3.1.5. BUAtot dos calos como função da BUAtot da respectiva tíbia.

4.3.3.1.6. BUAtot como função da respectiva velocidade do som.

4.3.3.2. Resultados para a técnica de contato.

4.3.3.2.1. Velocidade do som como função da espessura. 196

4.3.3.2.2. Velocidade no calo em função da velocidade na tíbia do mesmo animal.

4.3.3.2.3. Comparação entre a velocidade na tíbia em função de dias pós-fratura.

4.3.3.2.4. BUAtot como função da espessura.

4.3.3.2.5. BUAtot dos calos como função da BUAtot da respectiva tíbia.

4.3.3.2.6. BUAtot como função da respectiva velocidade do som.

202

4.3.3.3. Velocidade avaliada pela técnica de contato longitudinal nas amostras

4.3.3.4. Resultados da técnica BUAnews.

4.3.3.4.1. BUAnews como função da espessura.

4.3.3.5. Considerações finais.

4.4. Valores da BUA e da velocidade do som para o calcanhar de 212 voluntários de diferentes idades.

4.4.1. Introdução

4.4.2 Ficha dos voluntários.

4.4.3. Calcanhar.

4.4.4 Características dos voluntários.

4.4.5. Análise da reprodutibilidade em curto prazo dos resultados da BUA e da 215 velocidade do som para o calcanhar de um único voluntário.

4.4.5.1. Introdução.

4.4.5.2. Resultados obtidos das BUAs (BUAtot e BUAsel,) e das velocidades do 216 som (Vzero e Vpico).

4.4.6. Resultados da BUA e da velocidade do som para o calcanhar de voluntários. 220

4.4.6.1 Resultados da velocidade do som para os voluntários. 220

4.4.6.2 Resultados da BUA para os voluntários.

5. CONCLUSÃO.

6.

REFERÊNCIAS.

7. 


\section{INTRODUÇÃO}

Estudos recentes têm mostrado que a expectativa de vida aumentou dramaticamente no decorrer do século XX, para todas as idades e para ambos os sexos. Segundo a Organização das Nações Unidas (ONU), no ano 2000, a população mundial de faixa etária acima de 60 anos era formada por cerca de 610 milhões de pessoas e estima-se que em 2025 contabilizará uma população de 1,1 bilhão de idosos.(Rodrigues, 2003).

As últimas informações revelam que dentro de poucos anos nosso país deverá ter a sexta população em idosos do planeta com 34 milhões de idosos com mais de 60 anos, o que representará 14\% da nossa população.(Censo, 2002).

Com este aumento considerável da população idosa tanto no Brasil quanto no mundo surgiu uma preocupação com as doenças características desta idade, entre elas destaca-se a osteoporose.

A osteoporose é uma doença crônica, progressiva, de múltiplas causas, que representa a redução da massa óssea que afeta todo o esqueleto humano, com microdeteriorização dos ossos, aumento da fragilidade óssea e aumento do risco de fratura óssea. (Rena, 2003).

Com o passar dos anos os seres humanos têm perda de massa óssea, deixando assim os ossos mais frágeis e susceptíveis a fraturas provocando osteoporose (McCloskey, 1990b). A osteoporose é uma patologia de caráter clínico que atinge principalmente a população idosa, por se tratar de uma doença degenerativa, isto é, que ocorre gradativamente com o passar dos anos. Causada principalmente por disfunções hormonais e alimentares, esta doença vem se tornando um dos principais temas de pesquisa de caráter universal.

A osteoporose é identificada por um decréscimo na massa óssea de ambas porções (osso cortical e osso trabecular), apresentando um maior efeito sobre o osso trabecular (Tavokoli, 1991). O osso trabecular sendo altamente sensível a estímulos metabólicos é considerado Sítio de Interesse, para detecção de perdas ósseas precoces assim como na monitoração de diversos tratamentos (CEPOR, 2004). A melhor forma de se evitar a instalação e as complicações resultantes da osteoporose é a prevenção, seja na identificação de fatores de risco para o desenvolvimento da doença, seja o diagnóstico precoce do enfraquecimento dos ossos. 
Para determinar se existe ou não osteoporose ou mesmo se há risco de desenvolvê-la, deve-se fazer uma avaliação para determinar a densidade ou, por outro lado, a fragilidade dos ossos.

O sinal do ultra-som tem sido muito empregado na observação da estrutura óssea, por apresentar características que podem discriminar essa estrutura e também por ser livre de radiação ionizante, diferenciando-a dos métodos densitométricos que freqüentemente utilizam radiação ionizante. Existem algumas controvérsias com relação a esta técnica, especialmente no que diz respeito à precisão e coeficientes de variação (Castro, (2000), Frost, (2000a), Ekman, (2001), Cetin, (2001) e Cheng, (1999)).

\subsection{Anatomia Óssea}

Nosso corpo é formado por um tecido ósseo denominado esqueleto que possui uma divisão em esqueleto axial (coluna, bacia) e esqueleto apendicular (braços, pernas, mãos, pés), compondo um total de 206 ossos. (Rena, 2003).

Os ossos possuem uma camada externa compacta chamada de cortical (figura 1.1b) que representa $80 \%$ do material ósseo, e uma camada interna denominada de medular (trabecular, figura 1.1a) em que temos $20 \%$ da massa óssea formada por traves entrelaçadas, gerando a estrutura interna como uma esponja com pontos de apoio que tornam rígida a estrutura. Entre essas traves temos a medula óssea que tem um papel importante na formação de células sanguíneas. (Rena, 2003).

Um dos ossos que tem sido usado para fazer medidas ultra-sônicas é o calcâneo, pois ele apresenta uma grande porcentagem de osso trabecular (figura 1.2). Esta escolha se baseia em um trabalho publicado por Wasnich (1987), onde o pesquisador estudou vários ossos e a sua composição, mostrando características relacionadas com o custo do exame, reprodutibilidade e a facilidade para se fazer à medida da densidade mineral óssea (BMD).

Os últimos trabalhos feitos sobre o estudo da osteoporose e também da variação da densidade óssea usando ultra-som foram feitos avaliando o osso calcâneo (Frost, (2000a), Ekman, (2001), Cheng, (1999), Landin, (2000), Jaworski, (2000), Chappard, (2000), Heldan, (2000), Michalska, (2000) e Hamanaka, (1999)), entretanto, está sendo aplicada a técnica em outros sítios (falanges, tíbia, radio e metatarsos) (Ekman, (2001), Weiss, (2000a), Weiss, 
(2000b), Prevrhal, (2001), Greenfield, (2001), Dong, (1999), Gnudi, (2000), Montagnani, (2000), Hollevoet, (2000) e Feltrin, (2000)). Estes estudos tem a finalidade de comparar resultados da técnica de ultra-som com exames de densitometria óssea convencional.
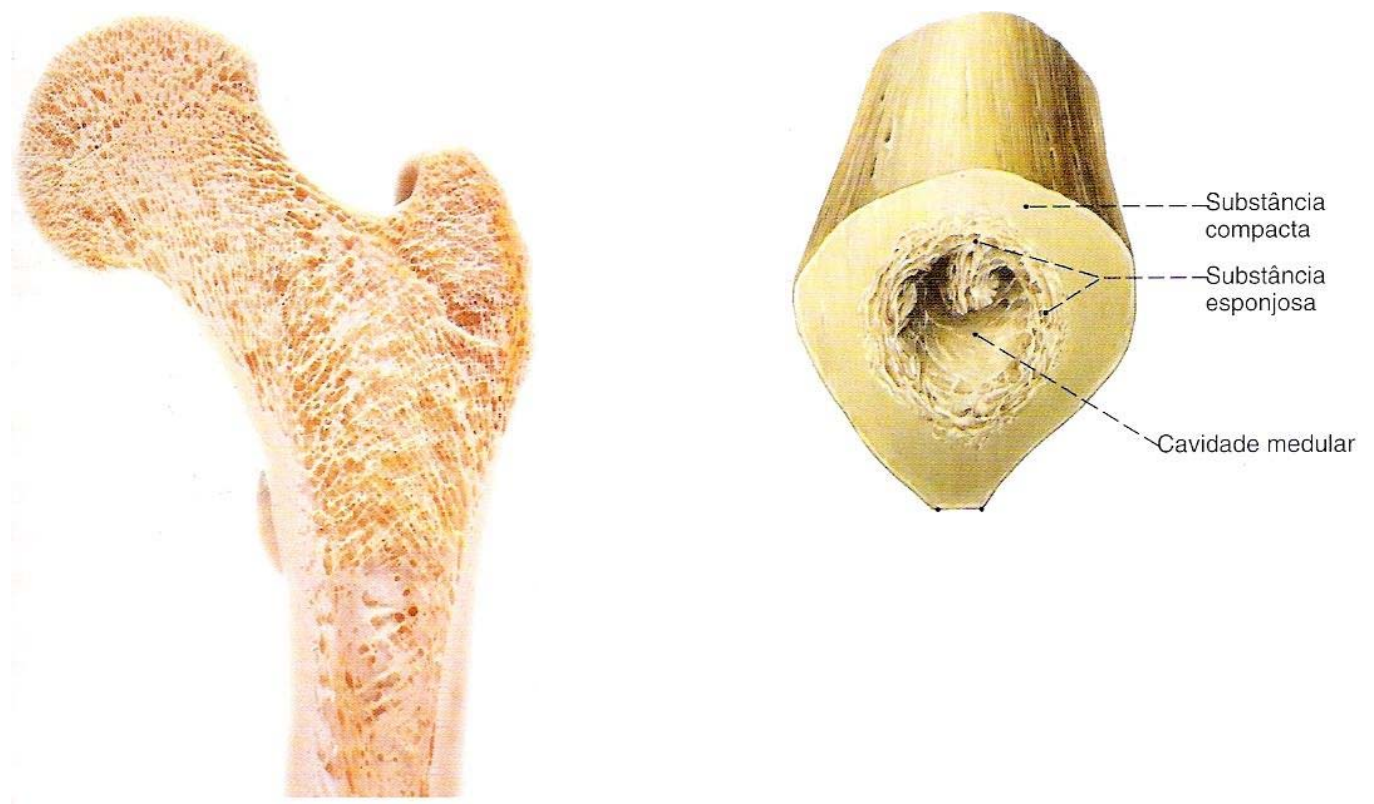

Figura 1.1. a) Osso trabecular (fêmur, corte no plano do ângulo de anteversão). b) Osso cortical (corte transversal do fêmur direito). (Sobotta, 1993).

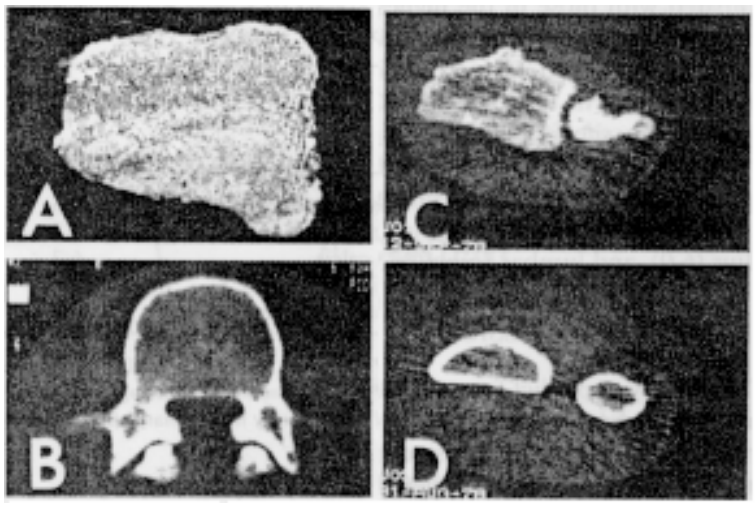

Figura 1.2. Porcentagem de osso trabecular no calcâneo ( $\mathrm{A}=95 \%$ ), vértebra lombar ( $\mathrm{B}=60-70 \%)$, rádio distal ( $C=30-40 \%)$ e rádio medial ( $\mathrm{D}=4 \%)$ (Washinck, 1987). 


\subsection{Formas de Avaliação da Massa Óssea}

Do ponto de vista clínico, o diagnóstico da osteoporose é muito difícil, pois é uma doença que não apresenta sinais ou sintomas. Em geral, somente após a fratura ou desabamento de uma vértebra sobre a outra é que o paciente sentirá dor, só então se pensará em osteoporose.

A tabela a seguir dá as informações a respeito de vários métodos de medida de massa óssea.

Tabela 1.1 - Métodos de medida de massa óssea (CEPOR, 2004).

\begin{tabular}{|c|c|c|c|}
\hline MÉTODOS & $\begin{array}{c}\text { SÍTIO DE } \\
\text { INTERESSE }\end{array}$ & VANTAGENS & DESVANTAGENS \\
\hline RAIOS X & - & - & $\begin{array}{l}\text { Detectam osteoporose somente quando já } \\
\text { houve } 30 \% \text { de diminuição de massa óssea }\end{array}$ \\
\hline $\begin{array}{c}\text { Tomografia } \\
\text { Computadorizada } \\
\text { (QCT) }\end{array}$ & Coluna Lombar & $\begin{array}{c}\text { Calcula densidade } \\
\text { volumétrica real } \\
\text { Alta resolução }\end{array}$ & $\begin{array}{l}\text { Elevada radiação } \\
\text { Baixa acurácia } \\
\text { Resultados comprometidos em pacientes } \\
\text { idosos devido à infiltração da medula óssea } \\
\text { por gordura }\end{array}$ \\
\hline PQCT & Antebraço & $\begin{array}{l}\text { Discrimina osso } \\
\text { trabecular e } \\
\text { cortical }\end{array}$ & $\begin{array}{l}\text { Baixa acurácia } \\
\text { Impossibilidade de monitoramento }\end{array}$ \\
\hline DEXA & $\begin{array}{l}\text { Coluna } \\
\text { lombar em antero } \\
\text { posterior e lateral } \\
\text { Fêmur } \\
\text { Corpo } \\
\text { inteiro }\end{array}$ & $\begin{array}{l}\text { Avaliação } \\
\text { esqueleto central e } \\
\text { periférico } \\
\text { Baixo RX } \\
\text { Dupla emissão } \\
\text { de feixes de RX }\end{array}$ & $\begin{array}{l}\text { Interferência de osteofitos e calcificação da } \\
\text { aorta em pacientes idosos podem levar a falso } \\
\text { positivo em exames de antero posterior }\end{array}$ \\
\hline PDEXA & $\begin{array}{l}\text { Calcâneo e } \\
\text { antebraço }\end{array}$ & $\begin{array}{l}\text { Baixa radiação / } \\
\text { elevada precisão }\end{array}$ & Impossibilidade de monitoramento \\
\hline SXA & $\begin{array}{l}\text { Calcâneo e } \\
\text { antebraço }\end{array}$ & $\begin{array}{l}\text { Precisão } \\
\text { elevada } \\
\text { Baixa radiação } \\
\text { Emissão única } \\
\text { de RX }\end{array}$ & \begin{tabular}{l}
\multicolumn{4}{c}{ Restrito à sítios periféricos } \\
Não podendo ser usado para a \\
monitoração de tratamento
\end{tabular} \\
\hline
\end{tabular}


Continua.

\begin{tabular}{|c|c|c|c|}
\hline MÉTODOS & $\begin{array}{c}\text { SÍTIO DE } \\
\text { INTERESSE }\end{array}$ & VANTAGENS & DESVANTAGENS \\
\hline QUS & Calcâneo & $\begin{array}{l}\text { Ausência de RX } \\
\text { Interesse em triagem } \\
\text { populacional. } \\
\text { Auxilia na predição do risco } \\
\text { de fratura no colo do fêmur em } \\
\text { pacientes idosos }\end{array}$ & $\begin{array}{l}\text { Avalia somente a } \\
\text { fragilidade óssea (e não a } \\
\text { BMD). } \\
\text { Correlação da BMD x } \\
\text { US somente na idade } \\
\text { avançada. } \\
\text { Precisão necessita ser } \\
\text { melhorada. }\end{array}$ \\
\hline
\end{tabular}

QCT: Tomografia Computadorizada Quantitativa;

PQCT: Tomografia Computadorizada Quantitativa Periférica;

DEXA: Raios X de Absorção de Dupla Energia;

PDEXA: Raios X de Absorção de Dupla Energia Periférica;

SXA: Raios X de Absorção de um Nível de Energia;

QUS: Ultra-som Quantitativo.

Os raios $\mathrm{X}$, apesar de limitados podem dar os primeiros sinais de perdas ósseas, mostrando em suas imagens áreas acinzentadas que correspondem a desmineralização, ou seja, perda óssea. Somente aparecem em casos avançados, em geral com perdas acima de 30\% ou $40 \%$ de cálcio no osso, e muitas vezes já demonstram fraturas ou desabamentos ósseos sem sintomas, porém é difícil quantificar essa perda de cálcio com a utilização de raios X.

A tomografia computadorizada quantitativa (QCT) e a periférica (PQCT) também podem ser utilizadas para a análise de massa óssea. Seu custo é muito elevado e com maior radiação do que os aparelhos de densitometria óssea (DEXA) e não apresenta diferenças significativas nos resultados quando comparados com os aparelhos de densitometria.

A densidade mineral óssea (BMD) é um exame que utiliza raios $\mathrm{X}$, que possibilita determinar nas áreas examinadas as quantidades de cálcio presente, ou seja, um exame quantitativo e que através de comparação da idade do paciente é possível saber se está dentro de uma faixa normal para a idade, acima da média ou abaixo dela.

O SXA (single-energy x ray absorptiometry - raios $X$ de absorção de um nível de energia) é a avaliação da BMD através da medida da atenuação de um nível de energia ionizante emitida por uma fonte de raios $\mathrm{X}$.

Os aparelhos usados para a densitometria óssea atualmente chamados de DEXA (dualenergy X Ray absorptiometry - raios X de absorção de dupla energia) e a periférica 
(PDEXA), medem a massa óssea superficial e profunda dos ossos em geral. É possível medir neste exame a massa óssea nas vértebras, fêmur, antebraços e bacia.

Na densitometria óssea são seguidos os padrões da Organização Mundial de Saúde (WHO) e da Fundação Européia de Osteoporose e Doenças Ósseas, que têm como nível normal ou padrão uma mulher com 30 anos de idade. Consideram-se normais perdas ósseas de até 10\% (1 desvio padrão). A osteopenia é quando a perda óssea em relação a mulher de 30 anos for maior que 10\% (1 desvio padrão) e menor que 25\% (2,5 desvios padrões). Osteoporose é quando a perda de massa óssea está acima de 25\% (2,5 desvios padrões). Essa medida é chamada de T-score, ou seja, medida comparativa com adulto jovem no pico de massa óssea entre 20 e 40 anos de idade. Outra medida que aparece no resultado do exame é a chamada Z-score que representa o resultado dos seus ossos comparados com os de pesssoas do mesmo sexo e idade. (Alves, 1996; Kim, 2000; Hadji, 2000b; Drozdzowska, 2001; Rena, 2003 e Pluskiewicz, 2004a).

Alguns pesquisadores dizem que o exame de densitometria óssea deveria medir não a densidade óssea e sim o remodelamento ósseo. E, além disso, apesar da densidade mineral óssea estar intimamente relacionada com a resistência óssea e as medições da densidade óssea serem capazes de predizer o risco de fratura, nem todos os indivíduos com densidade mineral óssea diminuída chegam a apresentar fraturas. Portanto, mesmo que a densidade mineral óssea explique uma porção significativa da resistência óssea, há evidências de que outros aspectos estruturais do osso e de sua qualidade também sejam importantes na determinação do risco de fratura. Os parâmetros de microarquitetura (como a quantidade e a espessura das trabéculas) e os fatores de qualidade óssea (como as propriedades materiais da matriz óssea) são aspectos estruturais importantes na avaliação do risco de fratura não considerados por meio do exame de densitometria óssea. (Rodrigues, 2003).

Na década de 90, começaram as aplicações do ultra-som com a finalidade de diagnosticar a osteoporose e também prever o risco de fratura óssea. A ultrassonometria óssea (USO), ou ultra-som quantitativo (QUS), é capaz de discriminar pacientes saudáveis daqueles que apresentam fraturas de quadril ou de coluna, a USO do calcanhar avalia o risco de fratura com a mesma eficiência do que a densitometria óssea e, o risco relativo de fraturas avaliados pela USO não varia com a massa (“peso”), altura, idade, tempo de menopausa e densidade óssea (Castro, (2000), Cheng, (1999), Pocock, (2000) e Philipov, (2000)).

O ultra-som pode ser usado para caracterizar as propriedades do osso. Dois parâmetros ultra-sônicos usados para essa análise são a medida da velocidade do som (VS) e a “Broadband Ultrasound Attenuation” (BUA), que podem mudar de acordo com a variação da 
densidade, da estrutura, da elasticidade e outros parâmetros biomecânicos do osso (Greenfield, 1981; Heaney, 1989; McCloskey, 1990a; Evans, 1990; Zagzebski, 1991; Tavokoli, 1991; Waud, 1992; Kaufman, 1993; Herd, 1993; Xu, 1993; Kotzki, 1994; Clarke, 1994; Gluer, 1994; Funke, 1995; Hans, 1995; Serpe, 1996; Hodgskinson, 1996; Han, 1997; Njeh, 1997 e Strelitzki, 1998). O objetivo das pesquisas é selecionar as propriedades de ossos saudáveis e ossos patológicos em função destes parâmetros conduzindo a uma melhor perspectiva da avaliação do risco de fratura (Tavokoli, 1991).

A BUA é um parâmetro que foi introduzido por Langton em 1984, o qual propõe o ultra-som como um meio alternativo para a determinação do risco de fratura e da osteoporose (Han, 1997).

\subsection{Novas Aplicações da Ultrassonometria Óssea}

A ultrassonometria óssea tem sido utilizada para fazer a triagem populacional da osteoporose, através do ultra-som do calcanhar. Este é um bom método para identificar (filtrar) pacientes com osteoporose numa grande população. Esses indivíduos identificados como portadores de osteoporose pelo ultra-som devem ser examinados através da densitometria óssea da coluna, fêmur e punho, para o diagnóstico seguro da doença e estimativa do risco de fraturas nesses locais, que são mais freqüentes.

Como método de traigem populacional tem sido feito por vários autores em diferentes países, dentre os quais citamos: Pluskiewicz (1999), que avaliou uma população polonesa de 740 mulheres (entre normais e com osteoporose) e 224 homens (entre normais e com osteoporose); Hadji (1999a), avaliou uma população de 1333 mulheres alemãs saudáveis com média de idade 50,5£11,5 anos; Kim (2000), avaliou uma população de 790 mulheres coreanas de idade entre 20 e 75 anos; Wehbe (2003), avaliou uma população de 4320 mulheres libanesas, para criar uma fonte de dados, de idade entre 20 e 79 anos e Panichkul (2004), avaliou uma população de 107 mulheres tailandesas com osteoporose para fazer comparação entre os parâmetros QUS e DXA.

Têm sido feitas novas aplicações da técnica de ultrassonometria óssea, com o objetivo de analisar suas habilidades em avaliar outras patologias ósseas além da osteoporose. Dentre elas destacamos os seguintes trabalhos. 
Adam (1998), tinha como objetivo determinar a espessura da cartilagem do joelho em indivíduos idosos. A exatidão e a reprodutibilidade das medidas da espessura das cartilagens foram determinadas utilizando o ultra-som modo-A e a distribuição da espessura da cartilagem foi examinada em ambos os joelhos de nove indivíduos de idade entre 62 e 94 anos. Como resultados o valor absoluto das cartilagens são consideravelmente menores em pessoas idosas quando comparados com a de jovens. O ultra-som modo-A apresentou resultados consistentes com o método estabelecido e apresentou uma boa reprodutibilidade e precisão nos seus valores. Concluiu-se que a espessura da cartilagem pode ser determinada pela utilização do ultra-som.

Cepollaro (1999), avaliou pacientes com osteogenisis imperfeita (OI), foram estudados 21 pacientes com OI e 21 voluntários saudáveis de mesma idade e sexo. A densidade mineral foi medida no radio distal e na espinha lombar utilizando a DEXA. As medidas de ultra-som, (BUA e velocidade do som) realizadas no calcanhar, foram feitas utilizando o equipamento Lunar Achilles, e as medidas de falange utilizaram o DBM Sonic 1200. Uma redução significante foi observada na BMD e nos parâmetros ultra-sônicos para os pacientes com OI quando comparados com os indivíduos normais. Concluíram que pacientes com OI apresentaram baixos valores de BMD e parâmetros ultra-sônicos, portanto nestes pacientes não existe somente uma variação na massa óssea, mas também na qualidade óssea. Estes defeitos podem contribuir para a fragilidade de ossos com OI interferindo com a mineralização completa e ou na estrutura do tecido normal.

Peretz (2000), fez a comparação entre os parâmetros ultra-sônicos (QUS) e a DEXA, avaliando anormalidades da estrutura óssea observada em osteodistrofia renal. O QUS e a BMD do calcanhar foram medidos em 30 pacientes constantes da hemodiálise e 34 de controle de mesmo sexo e idade. Os parâmetros QUS e a BMD foram significantemente menores em pacientes da hemodiálise do que os de controle. Portanto, o QUS do calcanhar pode ser usado para avaliar o osso de pacientes da hemodiálise.

Hadji (2000b), teve como objetivo em seu estudo avaliar o impacto da terapia de reposição hormonal sobre os resultados da ultrassonometria quantitativa do calcanhar. Um total de 2006 mulheres perimenopausal sendo que, 611 tinham recebido terapia de reposição hormonal e 1395 não.

As mulheres que utilizavam a terapia de reposição hormonal tinham valores significantemente maiores do que as que não usavam, para todos os parâmetros ultra-sônicos. Mulheres que utilizavam terapia de reposição hormonal por mais de três anos apresentaram valores significantemente maiores do que os do grupo de controle para todas as variáveis 
ultra-sônicas. A diferença aumenta com a duração do uso da terapia de reposição hormonal. Concluiu-se que as medidas de QUS no calcanhar diferenciam usuários de reposição hormonal dos não usuários, refletem a duração do uso da terapia de reposição hormonal e pode ter sucesso em ambas, na triagem clínica e acompanhamento do paciente.

Njeh (2000a), fez uma revisão das várias técnicas que são utilizadas para avaliar a artrite reumatóide (RA), entre elas a ultrassonometria óssea. Existe um interessante crescimento no uso do ultra-som do calcanhar e da falange para avaliar a condição óssea de pacientes com RA. Um decréscimo significante foi observado na BUA e velocidade do som medidos no calcanhar de pacientes com RA em comparação com os de controle. A mão é uma área de considerável atividade de doenças. Portanto, medidas de BMD na mão ou ultra-som podem ter sucesso na administração de pacientes com RA.

Njeh (2000b), observou, a densidade mineral óssea em adultos pode ser avaliada pela DXA, mas esta técnica não tem sido utilizada em crianças. O ultra-som quantitativo (QUS) pode providenciar um método alternativo para a avaliação do status ósseo. O objetivo deste estudo foi comparar a QUS com a DXA em pacientes com artrite adiopatica juvenil (JIA). Vinte e duas crianças caucasianas com JIA e idade entre 7-17 anos, foram avaliadas. Os resultados da DXA foram comparados com a QUS usando regressão linear. Medidas da BMD de corpo total e da espinha se correlacionaram significantemente com a velocidade do som na tíbia. A altura e peso dos pacientes foram fortes prognósticos da BMD, mas moderados prognósticos da velocidade do som.

Em suma, a velocidade do som mostrou uma correlação significante com a BMD. QUS foi bem tolerado e tecnicamente fácil na aquisição das medidas nas crianças. Adicionando a vantagem de ser livre de radiação ionizante, que favorece a avaliação do status ósseo em crianças.

Lequin (2000), diz que a densitometria óssea em crianças é relativamente um novo tópico dentro do campo da osteoporose. A ultrassonometria quantitativa da tíbia é ideal e sutil para crianças por ser livre de radiação ionizante e as medidas interativas providenciam um controle de qualidade em tempo real. Foram estudadas 596 crianças saudáveis de idade entre 6 e 19 anos. Este foi um primeiro estudo para apresentar dados normativos da QUS da tíbia para crianças e adolescentes caucasianas.

Wüsche (2000), procurou obter dados de referência, em crianças e adolescentes normais (sem patologias ósseas), e examinar se existem diferenças entre os parâmetros ultrasônicos quantitativos e o peso, altura, idade e sexo para crianças e adolescentes saudáveis. Um total de 3299 crianças caucasianas saudáveis e adolescentes de idade entre 6 e 18 anos. A 
velocidade do som praticamente não variou com a idade, altura e peso. Em suma, considerou a ultrassonometria óssea um proveitoso método de medida mostrando o desenvolvimento fisiológico do osso em crianças e adolescentes.

Cvijetic (2003), realizou medidas do ultra-som em crianças croatas. A relação entre a puberdade, antropometria, nutrição e atividade física com os parâmetros ultra-sônicos dos ossos foram analisadas. Um total de 501 voluntários foram estudados (242 crianças e 259 adolescentes). Como resultado obteve-se que os meninos adolescentes apresentaram um maior BUA do que as meninas.

Pluskiewicz (2004a), avaliou a velocidade do som em falanges de pessoas com leucemia aguda. A velocidade do som mostrou que com dois anos de tratamento o seu valor aumentou, providenciando uma informação sobre a melhoria da qualidade óssea do paciente.

Pluskiewicz (2004b), fez medidas de velocidade do som em falanges de pacientes com último estágio de falência renal. Concluiu que os pacientes, no último estágio de falência renal, tratados com hemodiálise, o status do esqueleto avaliado com o uso do ultra-som teve seus valores afetados (diminuiu o valor da velocidade para os pacientes), podendo, a partir destes resultados, utilizar o ultra-som para o acompanhamento dos pacientes.

Valério (2004), estudou a influência da duração do diabetes e do controle metabólico sobre o ultra-som quantitativo da falange, estudou um grupo de crianças e adolescentes com diabetes tipo 1. A duração do diabetes e o fraco controle metabólico foram os principais determinantes nos valores da velocidade do som. Considerou que, o QUS pode ser um bom método de triagem de distúrbios ósseos em pacientes jovens com diabetes.

Hartman (2004a), pesquisou crianças com paralisia cerebral, as quais têm uma grande prevalência de fraturas patológicas. Foi aplicada a técnica QUS para investigar a qualidade óssea em crianças e adolescentes. No grupo de crianças e adolescentes com paralisia cerebral um quinto delas tem baixo status ósseo como sugerido pela baixa razão da velocidade da tíbia/rádio.

Hartman (2004b), diz que a osteoporose é a manifestação mais comum de doenças celiac (CD). Foi avaliado o status ósseo em crianças com CD, utilizando a DEXA e o ultrasom quantitativo. Os valores do ultra-som quantitativo para método de triagem de crianças com CD se mostraram um bom método para esta avaliação.

Estudos epidemiológicos, que envolvem mulheres asiáticas, têm revelado que sua densidade mineral óssea é menor do que as de mulheres européias e americanas. O objetivo do estudo de Chang (2004), foi o de elucidar a relação entre, demografia, conhecimento da 
osteoporose e densidade mineral óssea. Para isso foram utilizados os parâmetros da ultrassonometria óssea e medidas de densitometria óssea.

Camozzi (2004), avaliou a habilidade do ultra-som quantitativo das falanges da mão em detectar diferentes tipos de osteoporose como resultado de diferentes mecanismos patogênicos. Foram examinadas 30 mulheres com Síndrome de Cushing (CS), três com adenal adenoma e 32 mulheres osteoporoticas pós-menopausa. Concluíram que estes tipos de osteoporose podem ser distinguidos pela ultrassonometria.

Magkos (2005), comenta que o ultra-som quantitativo do calcanhar tem se tornado popular para a avaliação do status do esqueleto. A proposta do estudo foi a de avaliar diferenças na ultrassonometria óssea nos calcanhares (pé direto e esquerdo) dentro de uma população em geral, incluindo crianças (406, entre 10-15 anos), adultos (339, entre 26-33 anos) e idosos (455, entre 60-75 anos) de ambos os sexos e examinar o impacto dessas diferenças sobre a estimativa de osteoporose e risco de fratura. Os resultados sugerem, que as medidas de ultrassonometria óssea dos dois calcanhares podem não ser equivalentes com respeito a evolução do status ósseo e classificação do risco de fratura individual.

Zadik (2005), pesquisou a Doença de Crohn (CD), sendo caracterizada, entre outros aspectos, pela má absorção de minerais, vitaminas e vários ingredientes dos alimentos. Isto pode provocar um falso pico de massa óssea e, portanto deixando pessoas jovens susceptíveis a fraturas osteoporoticas. O objetivo do trabalho foi de avaliar o osso em pacientes com CD durante a ação da doença e durante sua diminuição. Foram feitas medidas de velocidade do som na tíbia. Observaram que, existiu uma variação no valor da velocidade do som (foi menor) em pacientes que a doença ainda estava ativa. Concluíram que em pacientes com a doença ativa, pode ser detectado precocemente um padrão de deterioração na qualidade óssea.

\subsection{Este Trabalho}

A simples comparação entre pacientes e pessoas normais utilizando ultra-som é complicado devido ao disparate entre os resultados obtidos utilizando diferentes equipamentos. Para quantificar estas diferenças entre equipamentos, uma série de dados normativos seria necessária, de modo a unificar os resultados de diagnósticos obtidos dos vários equipamentos. 
Como os sistemas de ultra-som tornam-se amplamente utilizados tanto em diagnostico clínico como triagem, a questão é, como comparar os resultados obtidos dos diferentes equipamentos. Sistemas clínicos que possuem diferenças no diâmetro do transdutor utilizado, na variação de freqüência e no método de medida de velocidade, todos resultam em uma grande disparidade nos resultados obtidos. Causas das variações incluem:

- $\quad$ O diâmetro do transdutor resulta em valores diferentes do calcanhar que é avaliado pela onda ultra-sônica;

- $\quad$ O uso de transdutores focados e não focados;

- $\quad$ A região de interesse (ROI), resultando em diferentes áreas medidas no calcanhar, lembrando que o calcanhar é muito heterogêneo;

- A definição do tempo de trânsito, resultando em uma variação significante da velocidade;

- Definição de velocidade também adiciona outros fatores, como velocidade óssea, velocidade no membro (calcanhar, tíbia, falange, etc) e velocidade no material de acoplamento, são todas freqüentemente comentadas (avaliadas);

- $\quad$ Considerar a espessura do calcanhar como sendo fixa no cálculo da velocidade;

- Diferentes algoritmos para o cálculo da BUA, resultando em diferenças sistemáticas na BUA entre os diferentes equipamentos.

Existe uma necessidade de identificar com exatidão a fonte e a magnitude de todas as variações encontradas nos sistemas de calibração para que possam ser avaliadas.

Um estudo da BUA e velocidade do som em relação a região de interesse, quando o sinal incide no calcanhar, mostra que a normalização das variáveis ultra-sônicas pela área melhora a discriminação dos estudos clínicos (Damilakis, (2000)).

Pode-se perceber nesta técnica a necessidade de se melhorar os algoritmos e tentar entender todas variáveis que influenciam a formação do sinal ultra-sônico de modo a assegurar medidas consistentes com a patologia óssea, com baixo índice de variabilidade de modo a melhorar sua aceitação pela comunidade médica (Castro, (2000)).

A motivação inicial deste trabalho foi à expectativa de produzir um sistema capaz de diagnosticar a osteoporose e prever o risco de fratura livre de radiação ionizante, diminuindo assim a dose nos pacientes devido à radiação nos exames de densitometria óssea.

Com finalidade de melhorar a técnica de ultrassonometria óssea e poder garantir a sua reprodutibilidade, será trabalhado o algoritmo de análise do sinal ultra-sônico a fim de deixar esta técnica útil para o acompanhamento terapêutico. 
Os objetivos gerais do presente trabalho são apresentados a seguir:

a) Construir um equipamento capaz de gerar, receber e amplificar pulsos de ultra-som com controle sobre a potência aplicada nos transdutores.

b) Trabalhar com transdutores de freqüência: 0,5MHz, 0,75 MHz, $1 \mathrm{MHz}, 1,5 \mathrm{MHz}$ e $2 \mathrm{MHz}$, e avaliar as diferentes respostas que cada um pode produzir, uma vez que os equipamentos comerciais trabalham em diferentes faixas de freqüência.

c) Fazer a medida da velocidade do som em materiais homogêneos (materiais plásticos e metais) a fim de analisar as possíveis dispersões relacionadas com o equipamento desenvolvido.

d) Utilizar o teflon como material de referência com a finalidade de calibração do sistema, garantindo a reprodutibilidade a longo e curto prazo e também acompanhar a perda de massa óssea com a idade.

e) Aplicar a técnica em voluntários jovens e idosos a fim de observar possíveis variações nos resultados.

f) Como nova aplicabilidade da técnica de ultrassonometria óssea avaliaremos o calo ósseo, em diferentes períodos de consolidação óssea, formado em tíbias de carneiro. 


\section{MÉTODO TEÓRICO}

\subsection{VELOCIDADE DO SOM}

\subsubsection{INTRODUÇÃO}

A velocidade do som é uma quantidade de fácil medição em níveis moderados de precisão (1\%), mas é difícil medi-la se uma exatidão absoluta e/ou se uma precisão maior for necessária. No caso de tecidos biológicos, por exemplo, a precisão dos métodos usada por alguns pesquisadores é raramente boa o bastante para observar a dispersão da velocidade sobre a variação de freqüência de interesse médico. (Hill, 1986)

A velocidade de uma onda de US tem uma dependência sobre as propriedades do meio ao qual está se propagando e o modo de propagação.

Um material para o qual a seção transversal é menor em relação ao comprimento de onda do ultra-som, geralmente produz uma velocidade baixa de US, quando comparado com uma seção transversal maior. Por exemplo, uma pessoa com um grande calcanhar pode mostrar um valor diferente para a velocidade do US, ainda que a densidade óssea possa ser equivalente à de uma pessoa com um pequeno calcanhar (Kaufman, 1993).

A velocidade do US pode ser classificada como: de fase ou de grupo. A velocidade de fase refere-se à velocidade de uma onda que viaja através de um meio em uma freqüência simples. A velocidade de grupo é um termo usado para descrever a velocidade de um pacote de onda ou pulso. Para certos meios, como a água, as velocidades de fase e de grupo são essencialmente equivalentes. Um meio onde a velocidade de fase ou de grupo não é equivalente, é conhecido como dispersivo. O osso calcâneo é um exemplo de material dispersivo, isto acontece porque o osso trabecular é significativamente mais dispersivo do que o osso cortical (Kaufman, 1993). 


\subsubsection{Testes Sobre Materiais Padrão}

É aconselhável avaliar a precisão e exatidão de um sistema de medidas, na ausência de algum padrão fundamental, fazendo medidas sobre materiais que tenham sido estudados e para o qual as propriedades medidas sejam conhecidas. A substância mais comumente usada para a proposta da verificação da medida da velocidade do som é a água pura, mas a água salina, conhecida sua concentração de cloreto de sódio, também pode ser usada. É importante conhecer a temperatura em que as medidas são feitas, pois controlando e variando a temperatura, pode-se obter um meio conveniente para testar o sistema através de uma variação das velocidades de propagação.

Existe um ajuste polinomial de quinta ordem que pode ser usado para calcular a velocidade do som em pressão atmosférica normal em água pura, numa variação de temperatura de $0^{\circ} \mathrm{C}$ a $100^{\circ} \mathrm{C}$ :

$$
C_{w}=\sum_{i=0}^{5} k_{i} T^{i}
$$

visto que, $\mathrm{C}_{\mathrm{w}}$ é a velocidade da água e tendo como coeficientes:

$$
\begin{array}{ll}
\mathbf{i} & \mathbf{k}_{\mathbf{i}}(\mathbf{m} / \mathbf{s}) \\
0 & 1402,38754 \\
1 & 5,03711129 \\
2 & -5,80852166.10^{-2} \\
3 & 3,34198834.10^{-4} \\
4 & -1,47800417.10^{-6} \\
5 & 3,14643091 \cdot 10^{-9}
\end{array}
$$

Muitos dos dados para a velocidade do som em soluções salinas têm origem no interesse sobre acústica da água e propagação do som no mar. (Hill, 1986 e Hoffmeister, 2000). 


\subsubsection{DETERMINAÇÃO DA VELOCIDADE DO SOM PELA TÉCNICA DE INSERÇÃO CONVENCIONAL. (ACOPLAMENTO POR ÁGUA)}

Para calcular a velocidade do som na água e em outros meios, foi usado o princípio do tempo de chegada da energia do sinal recebido.

Nesta situação mede-se o tempo de chegada de um meio de referência e depois é feito à mesma medida com a amostra entre os transdutores. Sejam $\tau_{\mathrm{s}}$ e $\tau_{\mathrm{r}} \mathrm{o}$ tempo de chegada do sinal com a amostra e do sinal de referência (água), respectivamente, e $V_{s}$ e $V_{r}$ a velocidade do som na amostra e no meio de referência (água), respectivamente. Sejam $\mathrm{d}_{\mathrm{t}}$ à distância entre os transdutores, d o comprimento da amostra (figura 2.1.1) e $\mathrm{T}_{\mathrm{s}}$ o tempo de percurso do sinal ultra-sônico na amostra.

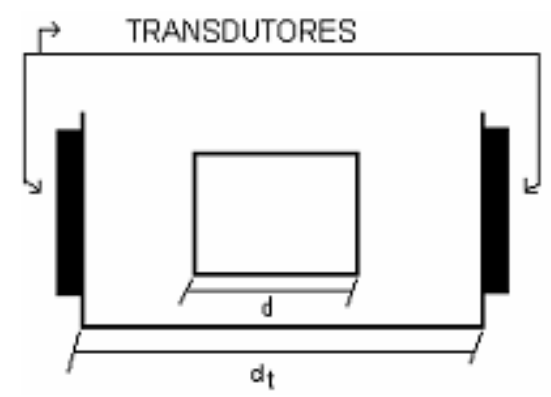

Figura 2.1.1. Diagrama com a disposição da amostra no tanque utilizado para as medidas de tempo.

Podemos, encontrar as seguintes equações:

$$
\begin{gathered}
V_{s}=\frac{d}{T_{s}} \\
V_{r}=\frac{d_{t}}{\tau_{r}} \\
V_{r}=\frac{d_{t}-d}{\tau_{s}-T_{s}}
\end{gathered}
$$

substituindo a equação (3) na equação (4), obtêm-se: 


$$
T_{s}=\left(\tau_{s}-\tau_{r}\right)+\frac{d}{V_{r}}
$$

substituindo este resultado na equação (2), chegamos a:

$$
V_{s}=\frac{1}{\frac{1}{V_{r}}-\frac{\left(\tau_{r}-\tau_{s}\right)}{d}}
$$

que é a equação da medida da velocidade do US na amostra (Evans e Tavokoli, 1990; Kotzki et al 1994; McCloskey et al, 1990; Zagzebski et al, 1991; Tavokoli e Evans, 1991; Alves, 1996 e Nicholson et al, 1996).

\subsubsection{DETERMINAÇÃO DA VELOCIDADE DO SOM PELA TÉCNICA DE INSERÇÃO POR CONTATO (ACOPLAMENTO POR GEL ULTRA- SÔNICO).}

A equação utilizada para o cálculo da velocidade do ultra-som pela técnica de inserção por contato, é a seguinte:

$$
V_{S}=\frac{d}{\tau_{S}}
$$

sendo que: d é o tamanho da amostra, $\tau_{\mathrm{S}}$ é o tempo de chegada do sinal com a amostra e com o gel de acoplamento e $\mathrm{V}_{\mathrm{S}}$ é a velocidade do ultra-som na amostra.

Não foi feita nenhuma correção na expressão da velocidade na técnica de contato (equação 7), pois os transdutores eram bem pressionados nas faces das amostras que estavam sendo analisadas, deixando a distância entre os transdutores e a amostra muito pequena. Portanto, isto está condizente com o que é encontrada em alguns equipamentos de ultrassonometria óssea, que utilizam a técnica de contato como técnica de medida. (Langton; Njeh, 2004). 


\subsubsection{MARCADORES NO SINAL TEMPORAL (REFERÊNCIA PARA O TEMPO DE CHEGADA)}

A maioria das medidas de velocidade no osso trabecular têm sido feitas pela medida do tempo de trânsito, utilizando a técnica de transmissão. Para conhecer o tempo que o pulso ultra-sônico gasta ao atravessar uma amostra, é utilizada uma característica (marcadores) sobre a forma de onda; e a velocidade é calculada conhecendo-se a distância que a onda viajou. O marcador pode ser colocado sobre a primeira transição em torno do zero (1), um ponto a meia altura (2), um primeiro pico (3) ou uma segunda transição em torno do zero (4), como ilustrado na figura 2.1.2 para uma peça de acrílico. Entretanto, não existe nenhum consenso sobre o marcador padrão ou um protocolo para determinar a velocidade no osso. (Langton; Njeh, 2004).

Classicamente duas velocidades são definidas para o movimento da onda: a velocidade de fase e a velocidade de grupo. Em sólidos homogêneos como o PERPEX, alumínio ou osso cortical, onde a dispersão é mínima, as velocidades de fase ou de grupo serão aproximadamente idênticas. Onde existe uma atenuação significante, como em tecidos biológicos, a velocidade será influenciada pela modificação da forma de onda, pela atenuação e dispersão. No osso trabecular, a atenuação dependente da freqüência sofre uma perda na freqüência central e na largura do pulso, e o sinal da velocidade depende sobre que tipo de marcador foi utilizado para definir o tempo de trânsito, como tem sido confirmado em medidas do calcanhar in vivo. Uma outra conseqüência deste alargamento do pulso é o efeito sobre o tempo de trânsito na medida da velocidade, muitas vezes se faz utilizando um marcador padrão. Diferentes resultados na velocidade dependem da freqüência central dos transdutores utilizados. (Langton; Njeh, 2004).

Na figura 2.1.3, é apresentado o gráfico da velocidade do ultra-som para o acrílico, como forma de ilustração da variação do marcador sobre o sinal temporal, como função da variação de tempo de acordo com o marcador utilizado.

Mesmo o acrílico não demonstrando uma variação tão significativa como o osso calcâneo (em termos de deformação do sinal), o efeito do marcador sobre o valor da velocidade do ultra-som pôde ser observado, estando condizente com o que é observado na literatura (Hill, 1986 e Langton; Njeh, 2004). 


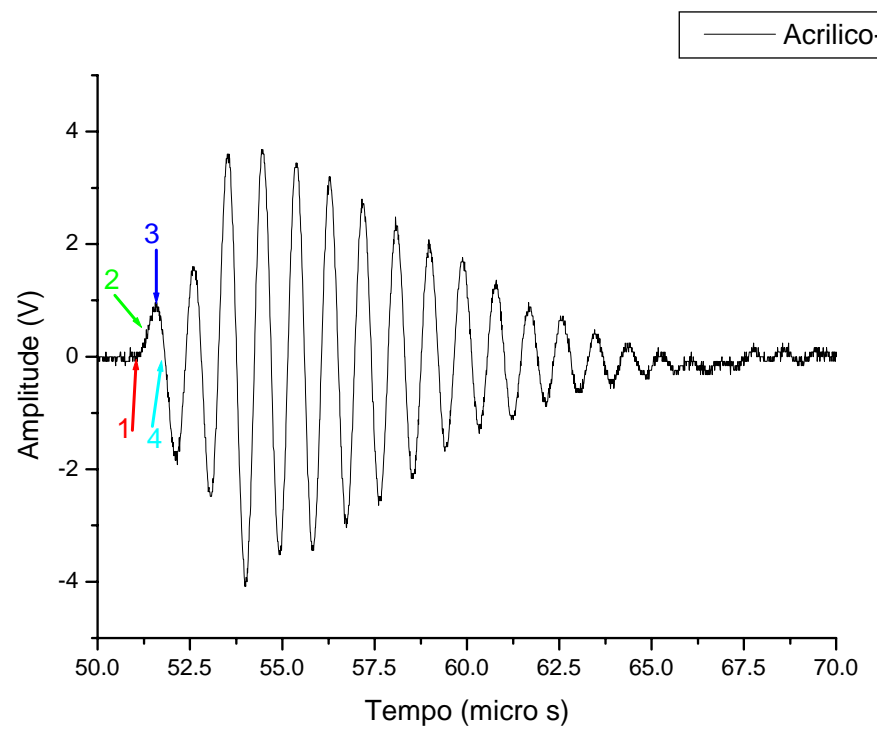

Figura 2.1.2: Sinal temporal da peça de acrílico (para ilustração). Marcadores: 1, representa a primeira transição em torno do zero, 2, posição a meia altura, 3, primeiro pico e 4, segunda transição em torno do zero.

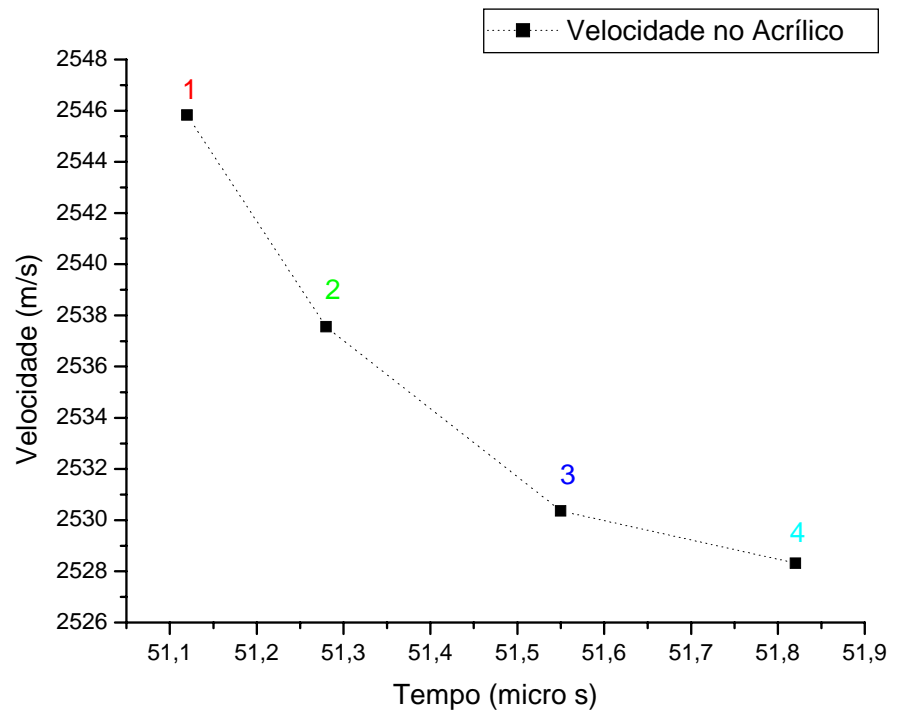

Figura 2.1.3: Variação do valor da velocidade do som de acordo com o marcador utilizado como referência no sinal temporal, para a peça de acrílico. 


\subsubsection{CURVA DE CALIBRAÇÃO DA VELOCIDADE DO SOM PARA O TEFLON COMO FUNÇÃO DA TEMPERATURA}

A curva de calibração da velocidade como função da temperatura foi feita para a peça de teflon grande (espessura 62,35mm) utilizando a técnica de inserção convencional (acoplamento com água) e para o par de transdutores de $1 \mathrm{MHz}$ (par AB). O conjunto, peça mais água, foi aquecido até 55 graus Celsius e esperou-se o conjunto diminuir sua temperatura naturalmente sem nenhum agente externo para acelerar o processo. Ao atingir a temperatura de 39 graus Celsius começou a ser realizada as tomadas de tempo para o cálculo de velocidade.

Na figura 2.1.4, é apresentada a curva de calibração da velocidade como função da temperatura para a peça de teflon grande.

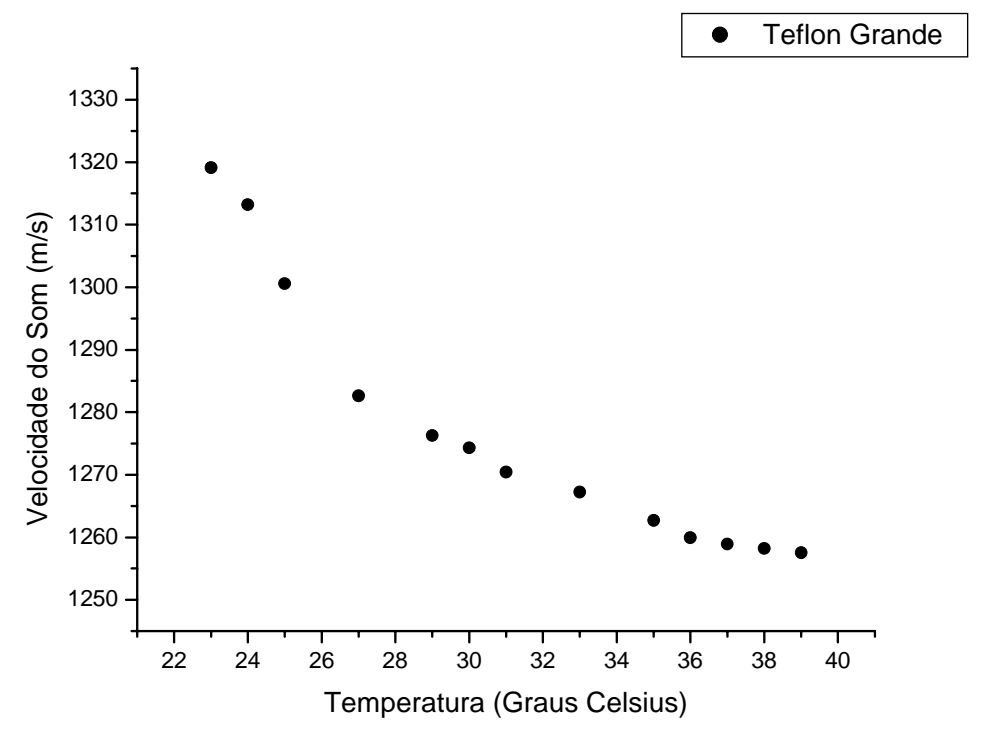

Figura 2.1.4. Curva de calibração da velocidade do som como função da temperatura para a peça de teflon grande, para o par de transdutores de $1 \mathrm{MHz}$ (par $\mathrm{AB}$ ) e utilizando a técnica de inserção convencional.

Na figura 2.1.4, é possível observar que da temperatura de 30 até 38 graus Celsius a variação da velocidade é de aproximadamente $10 \mathrm{~m} / \mathrm{s}$. Sendo então, considerada aproximadamente constante, pois este valor corresponde a uma variação menor que $0,8 \%$ do valor da velocidade do teflon, na temperatura de 30 graus Celsius $(1274,3 \mathrm{~m} / \mathrm{s})$. Este fato é importante, pois o teflon é utilizado como peça de calibração do sistema. Os sistemas 
comerciais utilizam a técnica de inserção convencional, com a temperatura da água próxima dos 30 graus Celsius (Langton; Njeh, 2004).

\subsubsection{VALORES DA VELOCIDADE DO SOM ENCONTRADOS NA LITERATURA.}

A tabela a seguir apresenta alguns dos valores encontrados na literatura sobre a velocidade do som na tíbia, rádio, metatarso, tornozelo, no calcanhar e falanges.

Tabela 2.1.1-Valores da velocidade do som medida (utilizando sistemas comerciais e sistemas produzidos em laboratório) no calcanhar, nas falanges, na tíbia, no tornozelo, no rádio, no metatarso e no punho, encontrados na literatura.

\begin{tabular}{|c|c|c|c|}
\hline AUTOR & EQUIPAMENTO & AMOSTRA & $\begin{array}{c}\text { VELOCIDADE } \pm \text { SD } \\
(\mathrm{m} / \mathrm{s})\end{array}$ \\
\hline \multirow{2}{*}{$\begin{array}{c}\text { Pluskiewicz et } \\
\text { al (1997) }\end{array}$} & Lunar Achilles & calcanhar & $1531 \pm 30$ \\
\hline & DBM Sonic 1200 & falange & $2025 \pm 53$ \\
\hline $\begin{array}{c}\text { Baroncelli et al } \\
\text { (2001) }\end{array}$ & DBM Sonic 1200 & falange & $2119 \pm 39$ \\
\hline \multirow{4}{*}{$\begin{array}{c}\text { Weiss et al } \\
\text { (2000a) }\end{array}$} & \multirow[t]{4}{*}{ Sunlight Omnisense } & rádio & $4082 \pm 151$ \\
\hline & & tíbia & $3844 \pm 163$ \\
\hline & & metatarso & $3573 \pm 244$ \\
\hline & & falange & $3916 \pm 216$ \\
\hline \multirow{2}{*}{$\begin{array}{c}\text { Sievänen et al } \\
\text { (2001) }\end{array}$} & \multirow[t]{2}{*}{ Sunlight Omnisense } & rádio & $4014 \pm 142$ \\
\hline & & tíbia & $3825 \pm 143$ \\
\hline \multirow{2}{*}{$\begin{array}{c}\text { Bouxsein et al } \\
\text { (1999) }\end{array}$} & Sound Scan 2000 & tíbia & $3865 \pm 207$ \\
\hline & UBA 575, HOLOGIC & calcanhar & $1498 \pm 13$ \\
\hline \multirow{2}{*}{$\begin{array}{l}\text { Ingle et al } \\
\text { (2002) }\end{array}$} & Lunar Achilles & tornozelo & $1554 \pm 34$ \\
\hline & CUBA Clinical & tornozelo & $1638 \pm 39$ \\
\hline $\begin{array}{c}\text { Foldes et al } \\
\text { (1995) }\end{array}$ & Sound Scan 2000 & tíbia & $3867 \pm 145$ \\
\hline
\end{tabular}


Continua.

\begin{tabular}{|c|c|c|c|}
\hline AUTOR & EQUIPAMENTO & AMOSTRA & $\begin{array}{c}\text { VELOCIDADE } \pm \text { SD } \\
(\mathrm{m} / \mathrm{s})\end{array}$ \\
\hline Warden et al (2002) & CUBA Clinical & calcanhar & $1638 \pm 44$ \\
\hline \multirow{2}{*}{$\begin{array}{c}\text { Rosenthall et al } \\
\text { (1996) }\end{array}$} & Lunar Achilles & calcanhar & $1594 \pm$ \\
\hline & Sound Scan 2000 & tíbia & 4051 \\
\hline Pande et al (2000) & Sound Scan 2000 & tíbia & $3840 \pm 164$ \\
\hline \multirow[t]{2}{*}{ Tromp et al (1999) } & CUBA clinical & calcanhar & $1582 \pm 34$ \\
\hline & Sound Scan 2000 & tíbia & $3861 \pm 140$ \\
\hline \multirow{4}{*}{ Njeh et al (2001a) } & \multirow{4}{*}{ Sunlight Omnisense } & falange & $3984 \pm 221$ \\
\hline & & tíbia & $4087 \pm 147$ \\
\hline & & rádio & $3893 \pm 150$ \\
\hline & & metatarso & $3690 \pm 246$ \\
\hline Lee et al (1997) & Sound Scan 2000 & tíbia & $3865 \pm 207$ \\
\hline \multirow{2}{*}{$\begin{array}{c}\text { Pluskiewicz et al } \\
\text { (2001) }\end{array}$} & DBM Sonic 1200 & falange & $1879 \pm 90$ \\
\hline & Lunar Achilles & calcanhar & $1498 \pm 25$ \\
\hline $\begin{array}{c}\text { Naganathan et al } \\
\text { (2002) }\end{array}$ & McCue Cuba Mark II & calcanhar & 1676 \\
\hline Karlsson et al (2001) & Lunar Achilles & calcanhar & 1641 \\
\hline $\begin{array}{c}\text { Drozdozowska et al } \\
\text { (2001) }\end{array}$ & Lunar Achilles & calcanhar & $1478 \pm 22$ \\
\hline Chaffai et al (2002) & $\mathrm{NC}$ & calcanhar & $1516 \pm 27$ \\
\hline $\begin{array}{c}\text { Nicholson et al } \\
\text { (2002a) }\end{array}$ & $\mathrm{NC}$ & calcanhar & $1520 \pm 36$ \\
\hline \multirow{2}{*}{$\begin{array}{c}\text { Cepollaro et al } \\
\text { (1999) }\end{array}$} & Lunar Achilles & calcanhar & $1574 \pm 21$ \\
\hline & DBM Sonic 1200 & falange & $2064 \pm 42$ \\
\hline Peretz et al (2000) & Lunar Achilles & calcanhar & $1506 \pm 28$ \\
\hline Hadji et al (2000a) & Lunar Achilles & calcanhar & $1549 \pm 31$ \\
\hline Njeh et al (2000b) & Sound Scan 2000 & tíbia & $3675 \pm 134$ \\
\hline Lequin et al (2000) & Sound Scan 2000 & tíbia & $3656 \pm 93$ \\
\hline Wünsche et al(2000) & SAHARA(HOLOGIC) & calcanhar & $1574 \pm 28$ \\
\hline
\end{tabular}


Conclusão.

\begin{tabular}{|c|c|c|c|}
\hline AUTOR & EQUIPAMENTO & AMOSTRA & $\begin{array}{c}\text { VELOCIDADE } \pm \text { SD } \\
(\mathbf{m} / \mathbf{s})\end{array}$ \\
\hline $\begin{array}{c}\text { Drozdzowska } \text { et al } \\
(2005)\end{array}$ & Lunar Achilles & calcanhar & $1504 \pm 26$ \\
\hline Magkos et al (2005) & SAHARA (Hologic) & calcanhar & $1561 \pm 26$ \\
\hline
\end{tabular}

NC - Não Comercial. Significa que foi utilizado um sistema gerador de pulsos ou um sistema produzido em laboratório. 


\subsection{ATENUAÇÃO DO ULTRA-SOM}

\subsubsection{Atenuação no Tecido de Uma Onda de US.}

A propagação da onda sonora é determinada pelos parâmetros inerciais, de restauração e de perda devida às características do meio. A densidade e a compressibilidade determinam a velocidade do som, variações das quais resultam em refração. As flutuações espaciais na densidade ou compressibilidade (as quais juntas determinam a impedância acústica característica) e absorção sonora, promovem um aumento no espalhamento ou reflexão. A refração, reflexão, espalhamento e absorção, contribuem, juntas, para a perda total (atenuação) da energia sonora nos tecidos biológicos.

Na prática, as variações da velocidade, impedância, absorção, espalhamento e atenuação são usadas para fornecer informações sobre a estrutura do tecido: em particular, todas contribuem para o complicado processo de formação de imagens pulso eco. Portanto, o conhecimento destes parâmetros e suas variações com a freqüência, amplitude, temperatura, idade, patologia, entre outros, é de grande importância para a habilidade de entender e fazer uso mais eficiente da técnica de diagnóstico ultra-sônico. Os coeficientes de atenuação e absorção também participam, em parte, na determinação da potência sonora, depositada em um determinado tecido biológico.

Têm sido criados muitos métodos para se fazer as medidas da atenuação ultra-sônica em uma variedade de meios, contudo, apenas poucos têm sido apropriados para o estudo de tecidos em freqüências médicas. Desde aproximadamente 1973, um grande número de novas técnicas para medida de atenuação tem surgido, em particular, alguns métodos que fazem das medidas uma função contínua da freqüência para a observação da variação espacial do coeficiente de atenuação, e fazendo-as in vivo. Estes são aspectos importantes do assunto em relação ao ultra-som médico (Hill, 1986). 


\subsubsection{Intensidade}

A atenuação de uma onda de US que ocorre pela redução em amplitude, é resultado da diminuição da energia acústica.

A atenuação do ultra-som segue uma lei exponencial, como no caso dos raios X:

$$
I=I_{0} e^{-\alpha x}
$$

sendo que, I é a intensidade do sinal do ultra-som em uma determinada profundidade, $\mathrm{I}_{0}$ é a intensidade inicial do sinal que chega ao meio material, x é o deslocamento do sinal ultrasônico e $\alpha$ é o coeficiente de atenuação para um determinado material.

O coeficiente de atenuação tem a unidade do Decibel (dB). O decibel é uma unidade muito utilizada para especificar a intensidade de sons, e se refere normalmente a intensidades relativas $\left(\mathrm{I} / \mathrm{I}_{0}\right)$. Para a faixa audível do som toma-se $\mathrm{I}_{0}=10^{-12} \mathrm{~W} / \mathrm{m}^{2}$ (limiar de audição). No caso do US, não existe uma intensidade $\mathrm{I}_{0}$ de referência, entretanto, em alguns casos toma-se $\mathrm{I}_{0}$ como a intensidade da onda emitida pelo transdutor.

Existem dois mecanismos que podem produzir a atenuação: reflexão, dispersão e absorção. Na dispersão, a amplitude da onda que se propaga é reduzida pelo fato da energia ter sido redistribuída em uma ou mais direções. Neste caso, a importância da dispersão depende do comprimento de onda do sinal do US usado e das propriedades acústicas do meio. Um tipo simples de dispersão é o retro-espalhamento, que ocorre quando uma porção de uma onda de US transmitida é refletida de volta em direção a fonte, sendo que isto acontece quando uma onda de US se propaga de um meio para outro.

Quando uma onda de US sofre o processo de absorção, uma porção da energia de propagação da onda é convertida diretamente para calor. Esta conversão é um processo extremamente complexo e depende da composição molecular do material e da freqüência da onda de US.

Então, pode-se dizer que o coeficiente de atenuação $(\alpha)$ pode ser dado como:

$$
\alpha=\alpha_{\mathrm{s}}+\alpha_{\mathrm{a}}
$$


sendo que, $\alpha_{\mathrm{s}}$ e $\alpha_{\mathrm{a}}$ são os coeficientes de dispersão e absorção do meio, respectivamente. (Hill, 1986).

O coeficiente de atenuação $\alpha$ de um meio como o osso pode ser relacionado com a espessura d do meio para encontrar a atenuação específica $(\mu)$ de acordo com a equação:

$$
\mu=\frac{\alpha}{d}
$$

\subsection{3. “BROADBAND ULTRASOUND ATTENUATION” (BUA)}

\subsubsection{Introdução.}

Diversos estudos sobre a avaliação ultra-sônica no osso têm usado a atenuação do ultra-som para caracterizar o tecido ósseo. Muitos pesquisadores têm adotado o termo “Broadband Ultrasound Attenuation” (BUA) para indicar a inclinação da curva da atenuação em freqüência do ultra-som (figura 2.2.1). A BUA não é denotada em termos da espessura sendo dado na unidade $\mathrm{dB} / \mathrm{MHz}$, então, a BUA reflete a geometria óssea total. Valores medidos da BUA dependem da faixa de freqüência a qual é calculada. A inclinação (BUA) é dependente da freqüência (Kaufman, 1993 e Funke, 1995).

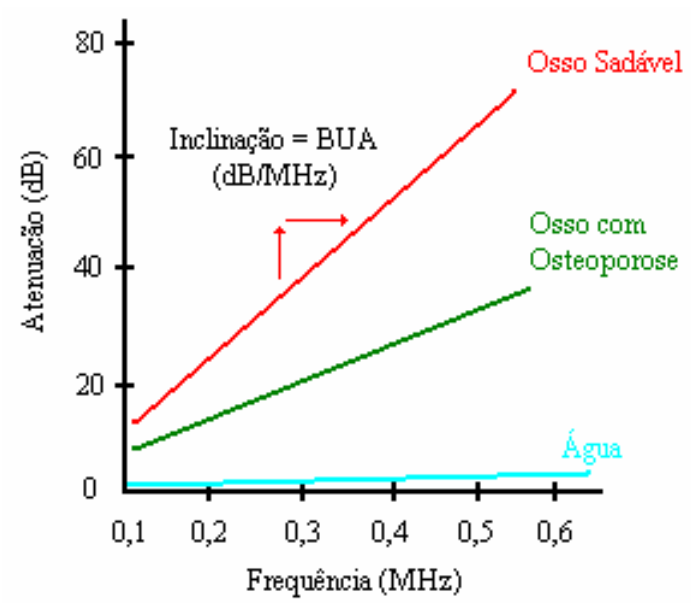

Figura 2.2.1. Ilustração da Broadband Ultrasound Attenuation (BUA). Relação entre atenuação e freqüência da onda ultra-sônica que se propaga através de amostras ósseas saudáveis e com osteoporose. 


\subsubsection{Técnica de Inserção Convencional (acoplamento com água)}

Para calcular a BUA, usam-se dois sinais ultra-sônicos um quando o pulso atravessa a amostra e outro quando se faz a medida sem a amostra entre os transdutores (sinal de referência). São obtidos dois sinais em função do tempo, $a_{S}(t)$ e $r_{R}(t)$ para o sinal recebido com a amostra e sem a amostra, respectivamente. A Transformada de Fourier (FFT), destes sinais, no espaço de freqüência, permite obter as equações 11 e 12.

Na equação 11, $\left|T_{t}(f)\right|$ e $\left|T_{R}(f)\right|$ são a magnitude das funções de transferência dos transdutores de transmissão e recepção, respectivamente. $|U(f)|$ é a magnitude da transformada de Fourier do sinal de entrada, u(t). A função de transferência é adotada como sendo unitária, isto é, a água não tem efeito significativo na magnitude do espectro, $\left|R_{R}(f)\right|$, a FFT do sinal recebido $\mathrm{r}_{\mathrm{R}}(\mathrm{t})$.

$$
\left|R_{R}(f)\right|=T_{t}(f) T_{R}(f)|U(f)|
$$

Se uma amostra óssea de espessura d é inserida entre os transdutores, e o transdutor de transmissão é excitado com o mesmo sinal $\mathrm{u}(\mathrm{t})$, a transformada de Fourier $\left|A_{S}(f)\right|$, do sinal recebido as(t) é dado pela equação 12 .

$$
\left|A_{S}(f)\right|=T_{t}(f) T_{R}(f)|H(f)| U(f) \mid
$$

Fazendo a razão do sinal da amostra pelo sinal de referência, é obtido:

$$
|H(f)|=\left|\frac{A_{S}(f)}{R_{R}(f)}\right|
$$

sendo que, $|\mathrm{H}(\mathrm{f})|$ é a magnitude da função de transferência da amostra, e essa função (transferência da amostra) pode ser reescrita em termos da atenuação $\alpha(f)$, da seguinte forma:

$$
|H(f)|=e^{-\alpha(f)}
$$


Aplicando o logaritmo neperiano nos dois lados da equação 14, é obtido

$$
\ln |H(f)|=-\alpha(f)
$$

A função $\ln |\mathrm{H}(\mathrm{f})|$ tem um comportamento linear com a freqüência, para um dado intervalo (figura 2.2.2).

De acordo com a equação 15, o logaritmo neperiano da função transferência é igual ao coeficiente de atenuação. O coeficiente angular desta reta, que será denominada inclinação (I) se relaciona com a grandeza BUA através do fator multiplicativo $20 * \log e$, ou seja,

$$
B U A=20 \times \log e \times I \quad(\mathrm{~dB} / \mathrm{MHz})
$$

a)

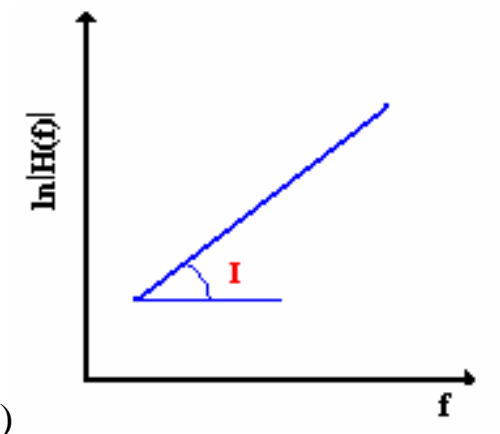

Figura 2.2.2. Ilustração do comportamento da função transferência como função da freqüência, destacando a região linear.

O uso do teflon como material de referência se justifica muito mais pelas medidas de atenuação do que as de velocidade. A água como referência para a velocidade, devidamente analisado, continua sendo um bom parâmetro. As medidas temporais podem ser melhor interpretadas, enquanto que as de atenuação podem sofrer influências da eletrônica e do envelhecimento dos transdutores de forma não prevista. Isto sem mencionar os problemas associados à geometria do próprio experimento.

Das figuras 2.2.3 a 2.2.5, são apresentados os gráficos de forma ilustrativa (exemplificando) para o cálculo da BUA. Na figura 2.2.3, são apresentados os sinais temporais para a água, para o teflon e para o calcanhar em a, c e e, respectivamente. Em b, d e f são apresentados as FFT dos sinais da água, do teflon e do calcanhar, respectivamente.

Na figura 2.2.4, têm-se os gráficos da função transferência em termos da freqüência para o teflon e para o calcanhar em a e b, respectivamente. 
Selecionando, a região linear da função transferência do calcanhar, e fazendo o ajuste linear, pode-se extrair o valor da inclinação para o cálculo da BUA (figura 2.2.5), de acordo com a equação 16.
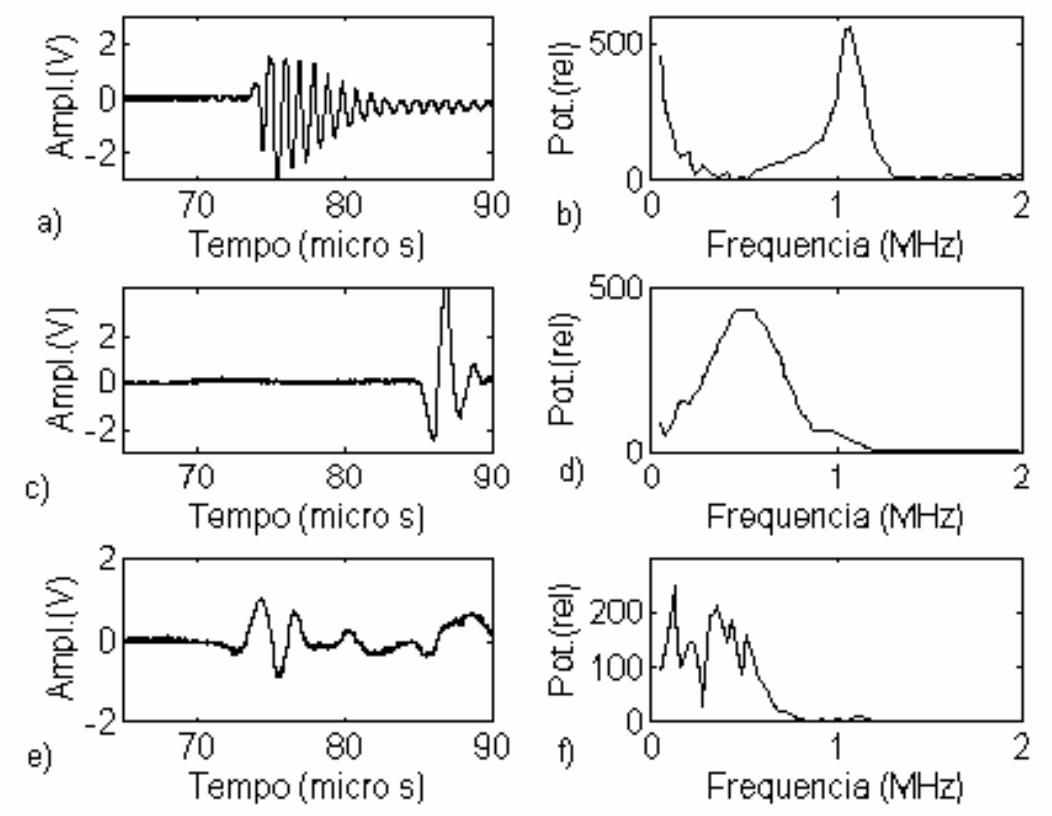

Figura 2.2.3. Em a, c e e são os sinais da água, do teflon e do calcanhar, respectivamente, enquanto em b, d e f são os sinais de potência da água, do teflon e do calcanhar, respectivamente.
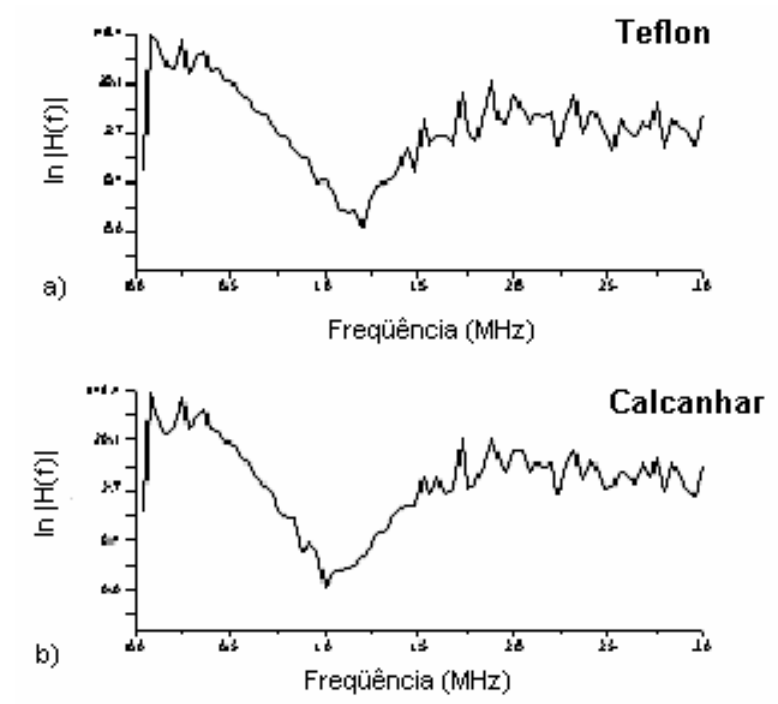

Figura 2.2.4. Gráficos da função transferência para o teflon e para o calcanhar em a e b, respectivamente. 


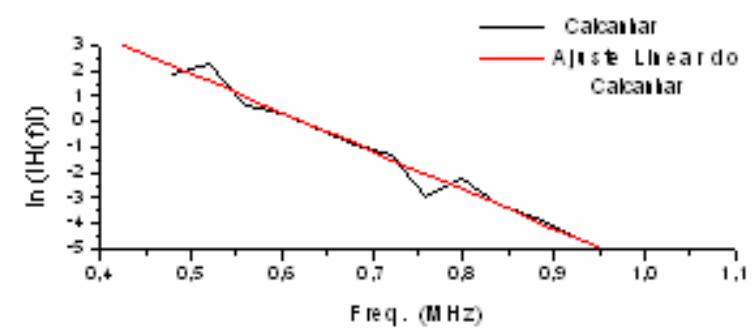

Figura 2.2.5. Região de linearidade da função transferência em termos da frequiência e o ajuste linear para o cálculo da BUA.

\subsubsection{Técnica de Inserção por Contato (acoplamento com gel)}

As medidas ultra-sônicas no modo de transmissão podem ser realizadas utilizando-se gel de acoplamento ou uma almofada de gel, ao invés de água, entre os transdutores e a amostra. Nesta técnica as equações 11 à 14, também podem ser utilizadas para a medida de atenuação, considerando-se que a função de transferência do gel, em contato com a amostra óssea, é aproximadamente unitária em comparação com a magnitude da função de transferência da amostra (Alves, 1996).

\subsubsection{Sinal temporal total na análise da BUA}

No sistema desenvolvido neste trabalho, o sinal temporal adquirido pelo osciloscópio é capturado em uma janela de $25 \mu \mathrm{s}$. Sempre se tentou adquirir o primeiro trem de pulsos de resposta para todos os pares de transdutores independentes de sua freqüência nominal. Na figura 2.2.6, são apresentados os sinais temporais, para os de transdutores de $1 \mathrm{MHz}$, do teflon, do calcanhar, da tíbia de carneiro e do calo da tíbia em a, b, c e d, respectivamente. A partir deste sinal é calculada o valor da BUA, que será chamada de "BUAtot”. 
a)
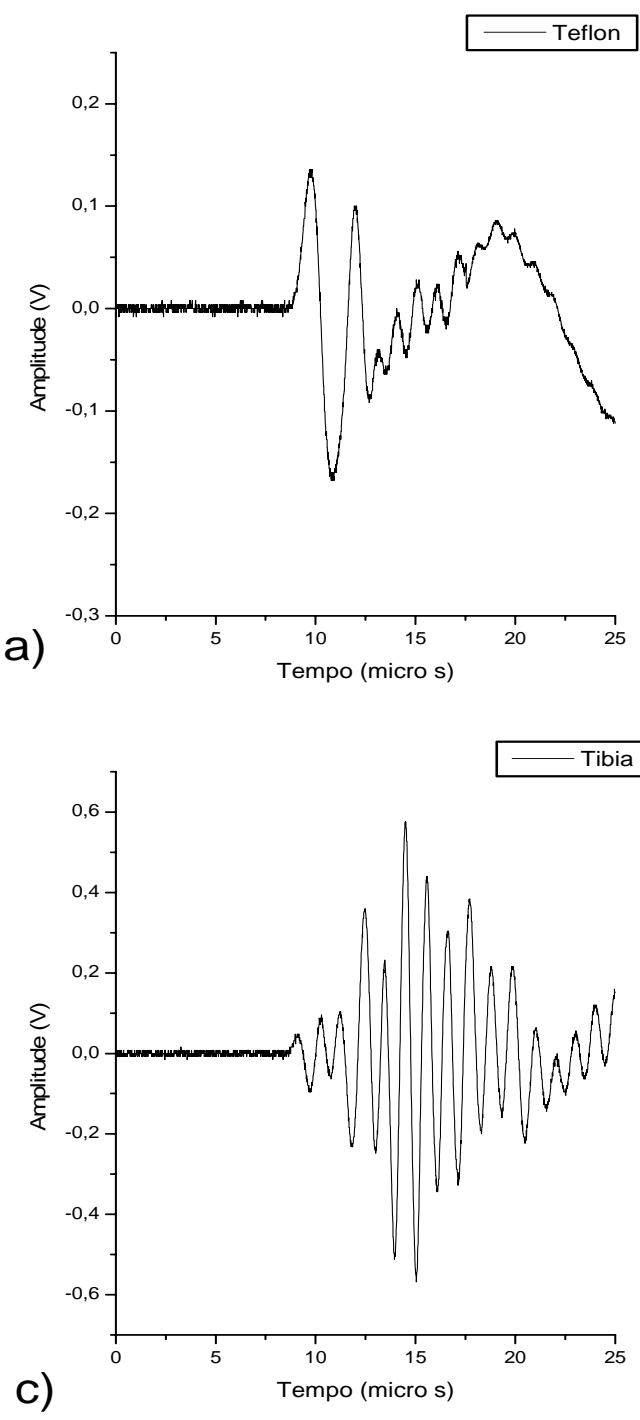
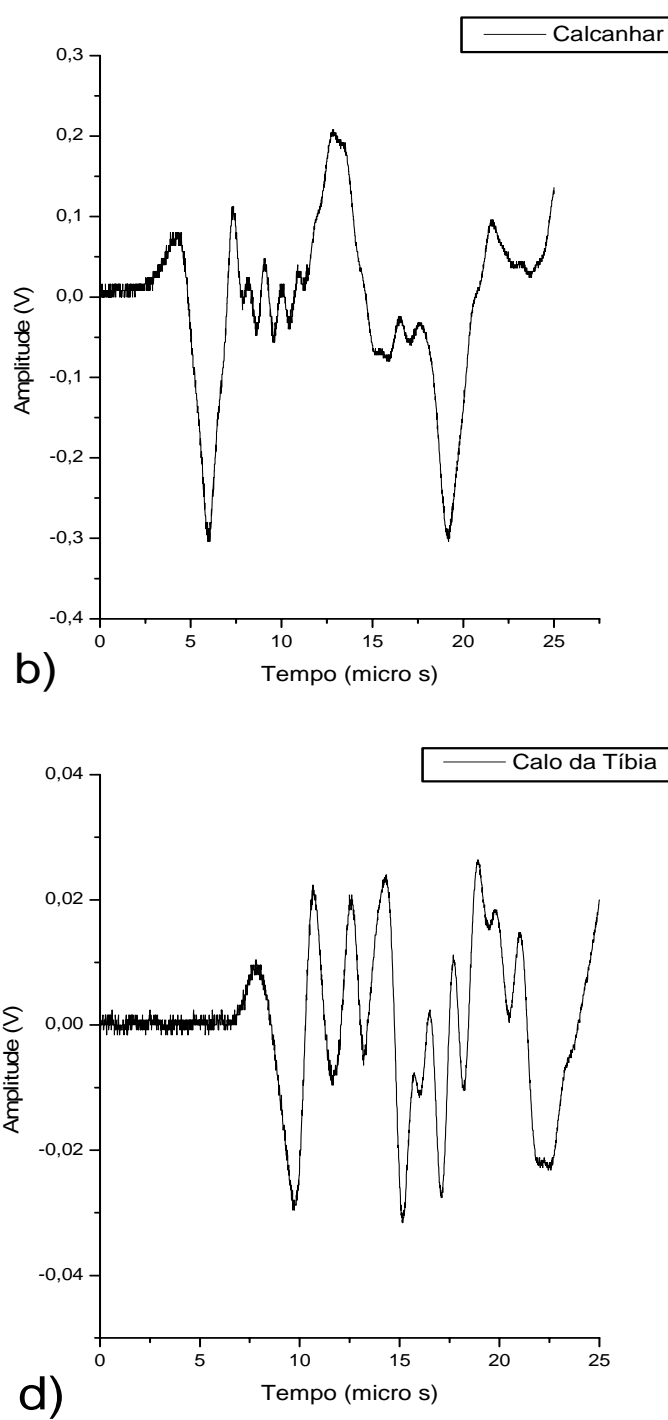

Figura 2.2.6. Sinais temporais do teflon, do calcanhar, da tíbia de carneiro e do calo da tíbia, para os transdutores de $1 \mathrm{MHz}$, em a, b, c e d, respectivamente.

\subsubsection{Janela do Sinal Temporal na Análise da BUA}

Foi feita análise sobre uma seleção (janela) do sinal temporal, onde foi tomada a parte inicial do sinal sempre tentando manter o mesmo número de comprimentos de onda independente do par de transdutores utilizados. O objetivo desta seleção era a de evitar possíveis reflexões que acontecem nas faces das amostras tanto na chegada como na saída do pulso de ultra-som da amostra. A partir desta janela é calculado o valor correspondente da 
BUA, que será chamada de “BUAsel”. Na figura 2.2.7, são apresentados os sinais temporais, para os de transdutores de $1 \mathrm{MHz}$, do teflon, do calcanhar, da tíbia de carneiro e do calo da tíbia em a, b, c e d, respectivamente, em destaque (em vermelho) para a região selecionada no cálculo da BUAsel.

a)

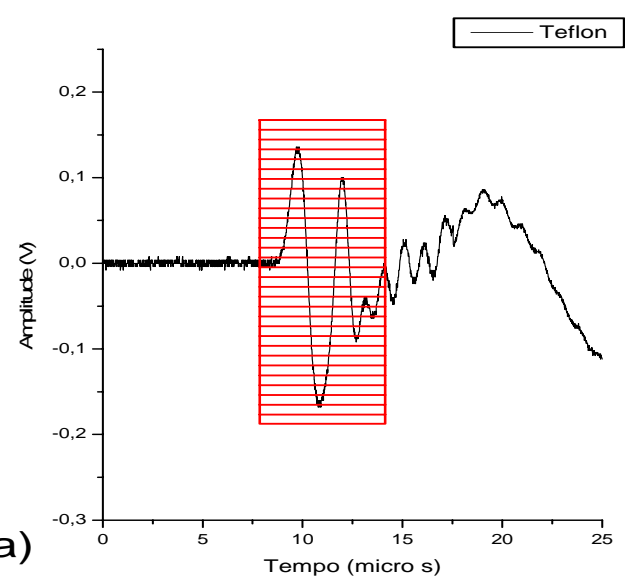

c)

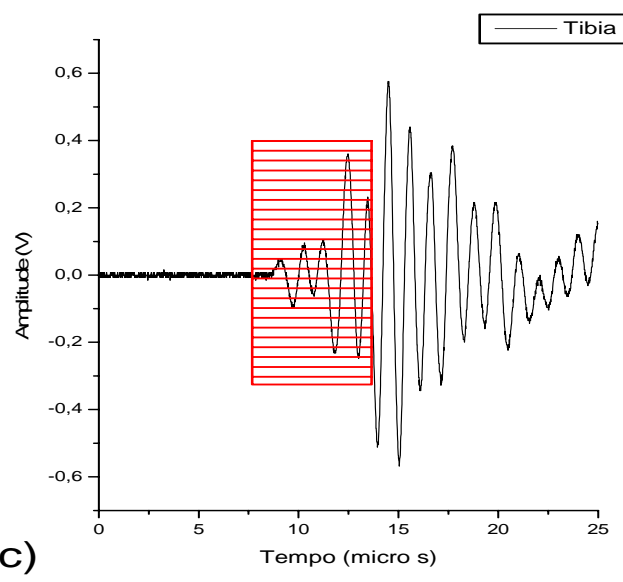

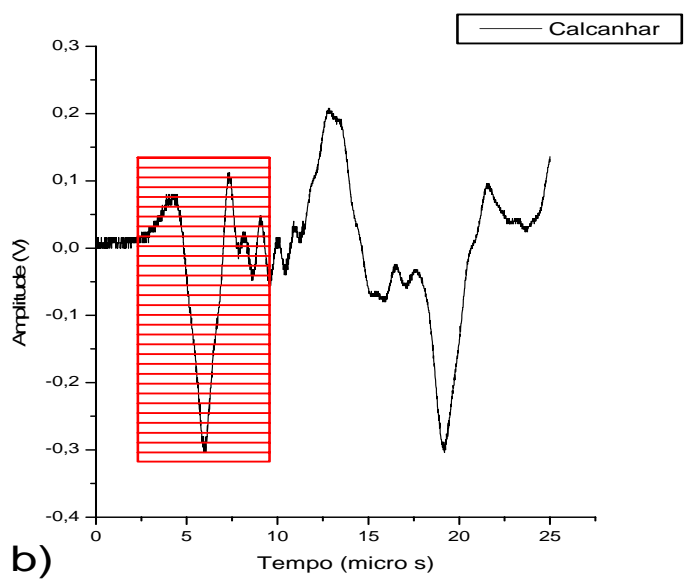

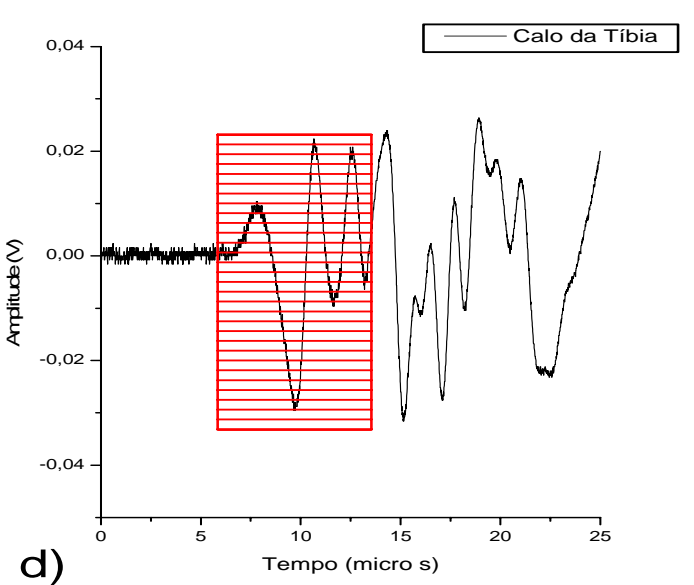

Figura 2.2.7. Sinais temporais, para os de transdutores de $1 \mathrm{MHz}$, do teflon, do calcanhar, da tíbia de carneiro e do calo da tíbia em a, b, c e d, respectivamente, em destaque (em vermelho) para a região selecionada no cálculo da BUA.

Então, quando for mencionado que foi calculado o valor da "BUAtot”, estará sendo considerado o sinal por inteiro sem excluir nenhum fragmento do início ou do final do mesmo, como explicado na seção 2.2.3.4. E quando for calculada a "BUAsel”, estará sendo considerada a janela no sinal temporal, como explicado nesta seção 2.2.3.5. 


\subsubsection{FAIXA EM FREQUENCIA ESCOLHIDA PELOS AUTORES}

A análise da BUA tem sido feita por diversos autores em diferentes faixas de freqüência. Estes valores são apresentados na tabela a seguir (tabela 2.2.1), junto com os valores da freqüência nominal do transdutor, o equipamento (se é comercial ou não) e o diâmetro dos transdutores.

Tabela 2.2.1 - Faixa linear de freqüência (para o cálculo da BUA) escolhida por diferentes autores para diferentes freqüências nominais, diâmetros dos transdutores e equipamentos.

\begin{tabular}{|c|c|c|c|c|}
\hline Autor & $\begin{array}{c}\text { Faixa de } \\
\text { Freqüência } \\
\text { (MHz) }\end{array}$ & Equipamento & $\begin{array}{c}\text { Freqüência do } \\
\text { transdutor } \\
(\mathrm{MHz})\end{array}$ & $\begin{array}{c}\text { Diâmetro do } \\
\text { transdutor } \\
(\mathrm{mm})\end{array}$ \\
\hline Clarke et al, 1994. & $0,2-0,6$ & $\mathrm{NC}$ & 0,75 & ND \\
\hline \multirow[t]{2}{*}{ Langton et al, 1997.} & $0,2-0,6$ & CUBAclinical-I & 1,0 & 12,5 \\
\hline & $0,2-0,6$ & CUBAclinical-II & 1,0 & 19,0 \\
\hline \multirow{2}{*}{$\begin{array}{c}\text { Hodgskinson et al, } \\
1996 .\end{array}$} & $0,2-0,6$ & CUBAsystem & 1,0 & 19,0 \\
\hline & $0,2-0,6$ & CUBAsystem & 1,0 & 13,0 \\
\hline Chaffai et al, 2002. & $0,2-0,6$ & $\mathrm{NC}$ & 0,5 & ND \\
\hline Wear et al, 2000a. & $0,69-0,92$ & $\mathrm{NC}$ & 0,5 & 25,4 \\
\hline $\begin{array}{l}\text { Nicholson et al, } \\
2000 .\end{array}$ & $0,2-0,6$ & $\mathrm{NC}$ & 0,5 & ND \\
\hline $\begin{array}{l}\text { Hoffmeister et al, } \\
2000 .\end{array}$ & $\begin{array}{l}0,1-1,0 \\
1,0-2,0\end{array}$ & $\mathrm{NC}$ & 2,25 & 13,0 \\
\hline $\begin{array}{l}\text { Nicholson et al, } \\
\text { 2002b. }\end{array}$ & $0,2-0,6$ & $\mathrm{NC}$ & 1,0 & 19,0 \\
\hline Wear et al, 1998. & $0,1-0,6$ & NC & 2,25 & ND \\
\hline \multirow{2}{*}{$\begin{array}{c}\text { Strelitzki et al, } \\
1998 .\end{array}$} & $0,2-0,6$ & CUBAclinical & 1,0 & 6,5 \\
\hline & $0,2-0,6$ & Lunar Achilles & 0,5 & 12,7 \\
\hline \multirow[t]{2}{*}{ Xu et al, 1993.} & $0,75-1,25$ & $\mathrm{NC}$ & 1,0 & 9,5 \\
\hline & $0,35-0,6$ & $\mathrm{NC}$ & 0,5 & 9,5 \\
\hline Tavakoli et al 1992. & $0,4-1,0$ & $\mathrm{NC}$ & 0,6 & 25,0 \\
\hline $\begin{array}{c}\text { Tavokoli et al, } \\
1991 .\end{array}$ & $0,3-0,8$ & $\mathrm{NC}$ & 0,6 & 25,0 \\
\hline
\end{tabular}


Conclusão.

\begin{tabular}{|c|c|c|c|c|}
\hline Autor & $\begin{array}{c}\text { Faixa de } \\
\text { Freqüência } \\
\text { (MHz) }\end{array}$ & Equipamento & $\begin{array}{l}\text { Freqüência do } \\
\text { transdutor } \\
(\mathrm{MHz})\end{array}$ & $\begin{array}{c}\text { Diâmetro do } \\
\text { transdutor } \\
(\mathrm{mm})\end{array}$ \\
\hline $\begin{array}{c}\text { Strelitzki et al, } \\
1999 .\end{array}$ & ND & $\mathrm{NC}$ & 1,0 & 13,0 \\
\hline \multirow[t]{2}{*}{ Не, 1999.} & ND & $\mathrm{NC}$ & 5,0 & 12,7 \\
\hline & ND & $\mathrm{NC}$ & 3,5 & 6,35 \\
\hline $\begin{array}{c}\text { Litniewski et al, } \\
2000 .\end{array}$ & $0,3-0,7$ & $\mathrm{NC}$ & 0,58 & 25,0 \\
\hline $\begin{array}{c}\text { Pluskiewicz et } \\
\text { al, } 1997 .\end{array}$ & $0,2-0,6$ & Lunar Achilles & 0,5 & 12,7 \\
\hline $\begin{array}{c}\text { Bouxsein et al, } \\
1999 .\end{array}$ & ND & $\begin{array}{c}\text { UBA } \\
\text { 575;Hologic }\end{array}$ & 0,5 & 18,0 \\
\hline Rho et al, 1997. & $0,2-0,6$ & $\mathrm{NC}$ & 0,5 & 19,0 \\
\hline $\begin{array}{c}\text { Rosenthall et al, } \\
1996 .\end{array}$ & $0,2-0,6$ & Lunar Achilles & 0,5 & ND \\
\hline $\begin{array}{c}\text { Tromp et al, } \\
1999 .\end{array}$ & $0,2-0,6$ & CUBAclinical & 1,0 & ND \\
\hline $\begin{array}{c}\text { Pluskiewicz et } \\
\text { al, } 2001 .\end{array}$ & $0,2-0,6$ & Lunar Achilles & 0,5 & 25,4 \\
\hline $\begin{array}{l}\text { Warden et al, } \\
2002 .\end{array}$ & $0,2-0,6$ & CUBAclinical & 1,0 & ND \\
\hline $\begin{array}{c}\text { Cepallaro et al, } \\
1999 .\end{array}$ & $0,2-0,6$ & Lunar Achilles & 0,5 & ND \\
\hline $\begin{array}{c}\text { Peretz et al, } \\
2000 .\end{array}$ & $0,2-0,6$ & Lunar Achilles & 0,5 & ND \\
\hline
\end{tabular}

NC - Não Comercial. Significa que foi utilizado um sistema gerador de pulsos ou um sistema confeccionado em laboratório.

ND - Não Declarado. Significa que esta informação não foi declarada no trabalho.

A faixa em freqüência escolhida pela maioria dos autores, de acordo com a tabela 2.2.1, está entre 0,2 e 0,6 MHz para transdutores de 0,5 ou 1,0MHz de freqüência nominal. Esta é a faixa em freqüência que os equipamentos comerciais trabalham. É possível observar 
que existem outras variações, principalmente quando trabalharam com transdutores de freqüências diferentes das citadas anteriormente e quando a pesquisa (o estudo) foi realizada utilizando um sistema não comercial.

Neste estudo, foi utilizado transdutores em diferentes freqüências e diâmetros para buscar melhor faixa em freqüência para cada par de transdutores, sendo ainda feita, uma comparação entre as técnicas de inserção convencional e de contato.

Nas tabelas 2.2.2 e 2.2.3, tem-se a faixa em freqüência para o cálculo da BUA (total e seleção) para as peças de teflon, feitas para a técnica de inserção convencional e de contato com gel.

Nas tabelas 2.2.4 e 2.2.5, tem-se a faixa em freqüência para o cálculo da BUA (total e seleção) para o calcanhar, feitas para a técnica de inserção convencional e de contato com gel.

$\mathrm{Na}$ análise da tíbia de carneiro, é utilizado somente o par de transdutores EF (1MHz) devido ao pequeno diâmetro das amostras. A sua faixa em freqüência é a mesma utilizada para o calcanhar (tabelas 2.2.4 e 2.2.5).

Tabela 2.2.2 - Valores da faixa em freqüência utilizadas neste trabalho para todos os pares de transdutores e para a técnica de inserção convencional, para o teflon.

\begin{tabular}{|c|c|c|c|}
\hline & & \multicolumn{2}{|c|}{ Faixa em Freqüência (MHz) } \\
\hline Par de transdutores & $\begin{array}{c}\text { Freqüência Nominal } \\
(\mathrm{MHz})\end{array}$ & BUAtot & BUAsel \\
\hline $\mathrm{RS}$ & 0,50 & $0,28-0,60$ & $0,30-0,90$ \\
\hline $\mathrm{CD}$ & 0,75 & $0,36-0,76$ & $0,38-1,00$ \\
\hline $\mathrm{AB}$ & 1,00 & $0,44-1,08$ & $0,30-1,18$ \\
\hline NO & 1,00 & $0,44-1,08$ & $0,30-1,18$ \\
\hline EF & 1,00 & $0,44-1,08$ & $0,30-1,18$ \\
\hline PQ & 1,50 & $0,85-1,35$ & $0,25-1,15$ \\
\hline IG & 2,00 & $0,40-1,32$ & $0,30-1,18$ \\
\hline LM & 2,00 & $0,40-1,32$ & $0,30-1,18$ \\
\hline
\end{tabular}


Tabela 2.2.3: Valores da faixa em freqüência utilizadas neste trabalho para todos os pares de transdutores e para a técnica de contato, para o teflon.

\begin{tabular}{|c|c|c|c|}
\hline & & \multicolumn{2}{|c|}{ Faixa em Freqüência (MHz) } \\
\hline Par de transdutores & $\begin{array}{c}\text { Freqüência Nominal } \\
(\mathrm{MHz})\end{array}$ & BUAtot & BUAsel \\
\hline RS & 0,50 & $0,55-0,98$ & $0,30-1,18$ \\
\hline CD & 0,75 & $0,48-0,80$ & $0,50-1,25$ \\
\hline AB & 1,00 & $0,44-0,76$ & $0,35-1,10$ \\
\hline NO & 1,00 & $0,44-0,76$ & $0,35-1,10$ \\
\hline EF & 1,00 & $0,44-0,76$ & $0,35-1,10$ \\
\hline PQ & 1,50 & $0,44-0,76$ & $0,30-1,18$ \\
\hline IG & 2,00 & $0,40-0,80$ & $0,30-1,10$ \\
\hline LM & 2,00 & $0,40-0,80$ & $0,30-1,10$ \\
\hline
\end{tabular}

Tabela 2.2.4: Valores da faixa em freqüência utilizadas neste trabalho para todos os pares de transdutores e para a técnica de inserção convencional, para o calcanhar.

\begin{tabular}{|c|c|c|c|}
\hline & & \multicolumn{2}{|c|}{ Faixa em Freqüência (MHz) } \\
\hline Par de transdutores & $\begin{array}{c}\text { Freqüência Nominal } \\
(\mathrm{MHz})\end{array}$ & BUAtot & BUAsel \\
\hline $\mathrm{RS}$ & 0,50 & $0,20-0,60$ & $0,20-0,90$ \\
\hline $\mathrm{CD}$ & 0,75 & $0,37-0,75$ & $0,38-1,10$ \\
\hline $\mathrm{AB}$ & 1,00 & $0,44-1,08$ & $0,20-0,90$ \\
\hline $\mathrm{NO}$ & 1,00 & $0,44-1,08$ & $0,20-0,90$ \\
\hline EF & 1,00 & $0,44-1,08$ & $0,20-0,90$ \\
\hline PQ & 1,50 & $0,80-1,40$ & $0,50-1,15$ \\
\hline IG & 2,00 & $0,25-1,00$ & $0,30-1,18$ \\
\hline LM & 2,00 & $0,25-1,00$ & $0,30-1,18$ \\
\hline
\end{tabular}


Tabela 2.2.5: Valores da faixa em frequiência utilizadas neste trabalho para todos os pares de transdutores e para a técnica de contato, para o calcanhar.

\begin{tabular}{|c|c|c|c|}
\hline & & \multicolumn{2}{|c|}{ Faixa em Freqüência (MHz) } \\
\hline Par de transdutores & $\begin{array}{c}\text { Freqüência Nominal } \\
(\mathrm{MHz})\end{array}$ & Total & Seleção \\
\hline RS & 0,50 & $0,55-0,98$ & $0,50-1,00$ \\
\hline CD & 0,75 & $0,46-0,80$ & $0,40-0,90$ \\
\hline AB & 1,00 & $0,44-0,76$ & $0,44-0,88$ \\
\hline NO & 1,00 & $0,44-0,76$ & $0,44-0,88$ \\
\hline EF & 1,00 & $0,44-0,76$ & $0,44-0,88$ \\
\hline PQ & 1,50 & $0,44-0,76$ & $0,55-0,77$ \\
\hline IG & 2,00 & $0,40-0,80$ & $0,50-1,20$ \\
\hline LM & 2,00 & $0,40-0,80$ & $0,50-1,20$ \\
\hline
\end{tabular}

Uma descrição mais completa sobre cada par de transdutores será apresentada no capítulo de materiais e métodos.

Conforme as tabelas anteriores (de 2.2.2 a 2.2.5), tentou-se manter uma variação na faixa em freqüência entre 300 e $500 \mathrm{KHz}$, sendo possível para alguns pares amplificar esta faixa, como pôde ser observado para os transdutores de $1 \mathrm{MHz}$ de freqüência nominal (tabela 2.2.2). Utilizou-se sempre a maior faixa em freqüência possível, por isso que existe essa variação entre os pares.

Um fato importante a ser destacado quando se trabalha a BUAsel, é que, a faixa em freqüência fica praticamente constante como pode ser observado nas tabelas de 2.2.2 a 2.2.5, independente do par de transdutores. 


\subsection{TRANSDUTOR}

Os transdutores são quaisquer dispositivos que convertem uma forma de energia para outra. Transdutores de ultra-som são algumas vezes chamados de sondas ou cabeças de varredura. Eles convertem energia elétrica em energia ultra-sônica e vice-versa. A corrente elétrica aplicada sobre ele é convertida em ultra-som e o ultra-som nele incidente produz corrente elétrica (Krenkau, 1996).

Um transdutor consiste de um ou mais cristais ou elementos piezoelétricos, como mostra a tabela seguinte:

Tabela 2.3.1-Tipos de transdutores usados em ultra-sonografia clínica de acordo com o número de cristais piezoelétricos usados (Krenkau, 1996).

\begin{tabular}{|c|c|}
\hline \multirow{2}{*}{\begin{tabular}{c} 
Tipos de \\
Transdutores Aplicados \\
Em \\
\cline { 2 - 2 } Ultra-sonografia
\end{tabular}} & Cristal único fixo \\
\cline { 2 - 2 } & Mecânicos \\
\cline { 2 - 2 } & $\begin{array}{c}\text { Especiais: oftálmico, intravascular, doppler, } \\
\text { trans-cavitários }\end{array}$ \\
\hline
\end{tabular}

\subsubsection{O EFEITO PIEZOELÉTRICO}

Os transdutores piezoelétricos são dispositivos que possuem a propriedade de variar as suas dimensões, quando submetidos a um campo elétrico e vice-versa. Tal fenômeno é conhecido como Efeito Piezoelétrico (figura 2.3.1). O efeito piezoelétrico foi descrito primeiramente por Pierre e Jacques Currie em 1880. Posteriormente, Cady, W.G. deu uma melhor definição para o efeito piezoelétrico: "piezoeletricidade é a geração de eletricidade devido a uma pressão mecânica aplicada ao material e o fenômeno inverso também ocorre”.

Na natureza encontram-se vários materiais que apresentam a piezoeletricidade, como exemplo, o quartzo e a turmalina. Artificialmente novos materiais estão sendo desenvolvidos e, dadas as suas propriedades, estão ganhando espaço nas aplicações. Em 1955, foi descoberto o material titanato zirconato de chumbo (PZT), um material cerâmico com propriedades excelentes, porém, frágil mecanicamente. 

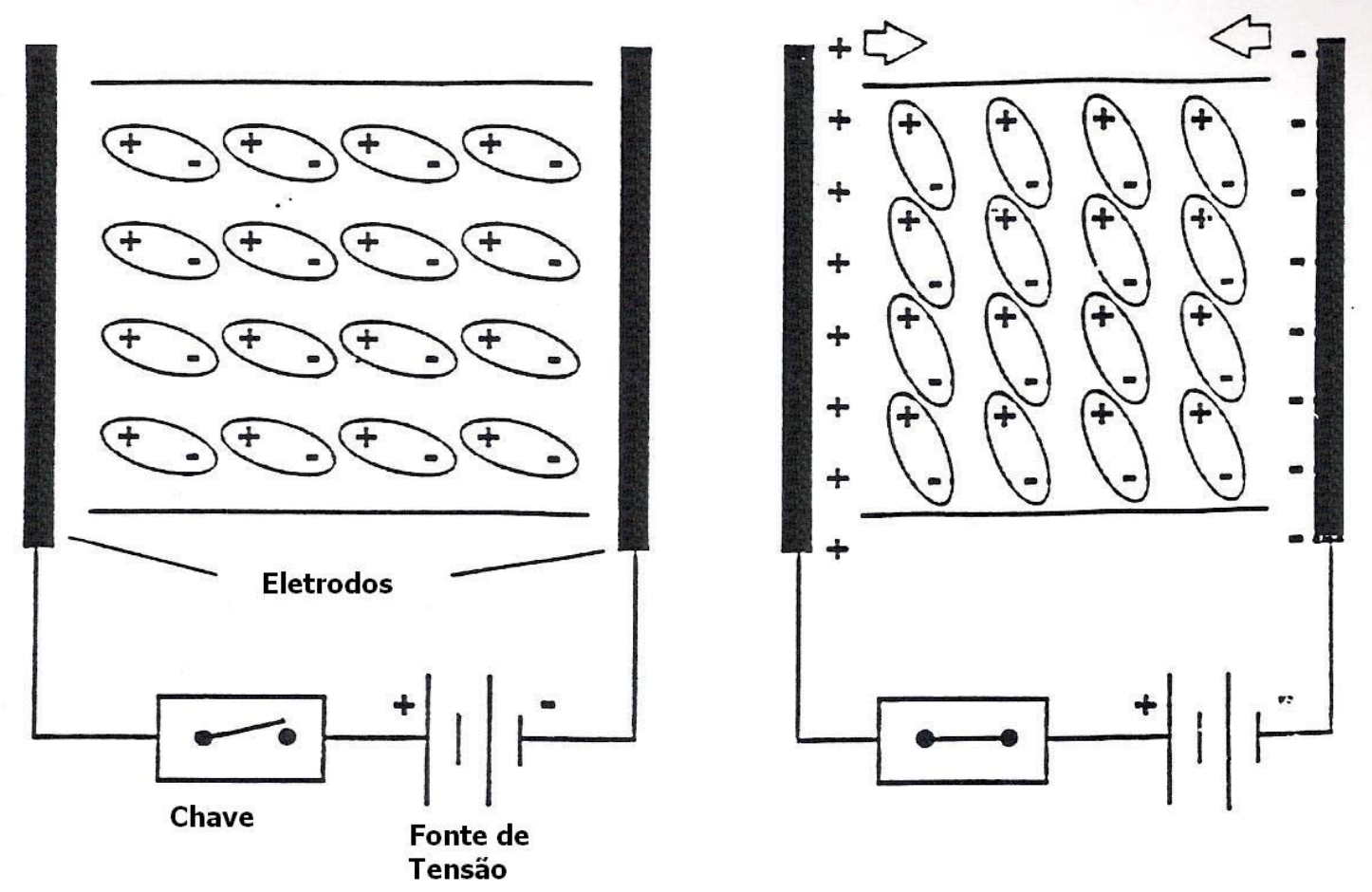

Figura 2.3.1. O mecanismo da piezoeletricidade. Quando uma voltagem é aplicada através do cristal, o realinhamento resultante das moléculas permanentemente polarizadas provoca uma mudança na espessura do cristal. De modo inverso, tensões mecânicas no cristal podem causar a geração de uma voltagem. (Herdade,1998).

\subsubsection{PROJETO DE UM TRANSDUTOR DE ULTRA-SOM}

As peças das quais um transdutor de US médico é formado são mostrados na figura 2.3.2.

No transdutor a peça mais importante, é a pastilha (ou cristal) de US que pode ser de vários materiais diferentes como: PZT, quartzo, turmalina e PVDF.

Para se ter um melhor aproveitamento da energia convertida pelo transdutor, procurase trabalhar na sua freqüência fundamental, que também é chamada de freqüência de ressonância, isto é, nesta condição o transdutor tem máxima eficiência, pois vibra com maior amplitude para essa freqüência.

A freqüência de ressonância (equação 18) é determinada pela velocidade de propagação no material transdutor e pela espessura do cristal do mesmo. Esta relação é tal, 
que a espessura do material do cristal corresponde à metade do comprimento de onda (equação 17):

$$
\begin{aligned}
\lambda_{\text {res }} & =2 \mathrm{~d} \\
\mathrm{f}_{\text {res }} & =\frac{V}{\lambda_{\text {res }}}
\end{aligned}
$$

sendo que, $\lambda_{\text {res }}$ é o comprimento de onda de ressonância, d é a espessura do cristal, V é a velocidade do US no cristal e $\mathrm{f}_{\text {res }}$ é a freqüência de ressonância.

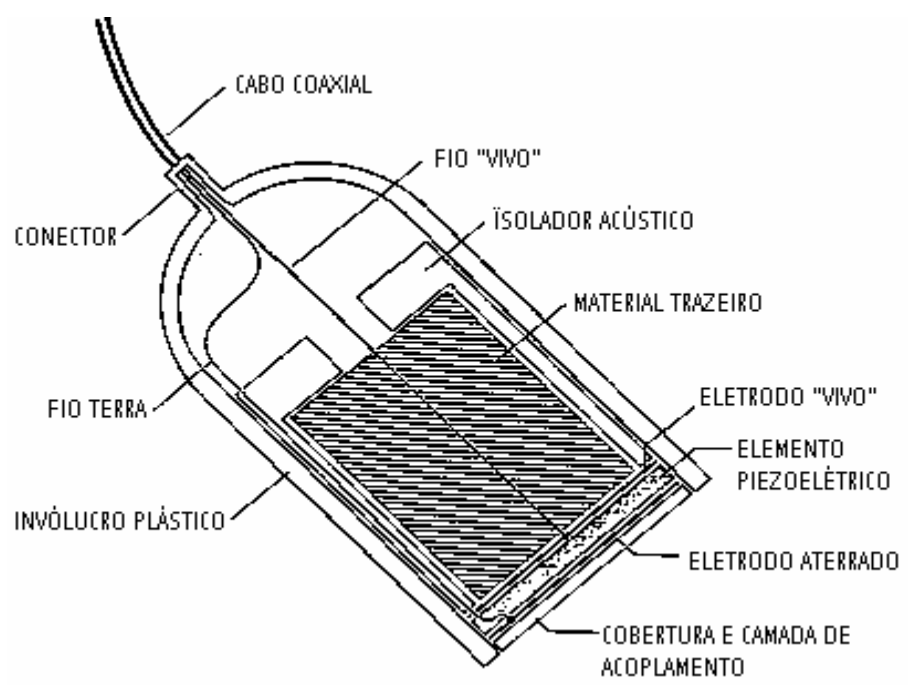

Figura 2.3.2. Corte longitudinal para um transdutor de ultra-som médico consistindo de um único elemento piezoelétrico. O material traseiro (“backing”) é destinado a absorver toda energia ultra-sônica dirigida ao mesmo. (Herdade,1998).

Um outro componente importante no transdutor é o material que faz acoplamento com o meio de propagação. Este material tem função importante que é a de fazer o acoplamento das impedâncias, colocando-o na face frontal do transdutor como se pode ver na figura 2.3.2. Normalmente tem uma impedância de valor intermediário entre o valor da pastilha do transdutor e o valor da amostra. Isso reduz a reflexão do US na superfície do cristal do transdutor e, portanto, melhora a transmissão do som através dele. A espessura ideal para essas camadas de interposição é a de um quarto (1/4) do comprimento de onda ( $\lambda$ ). (Hill, 1986; Krautkramer, 1990; Herdade, 1998 e Wells, 1977). 
Um outro componente, é o material amortecedor, o qual é conectado à face posterior do cristal do transdutor para reduzir o número de ciclos em cada pulso (figura 2.3.3).

Quando a pastilha oscila, ela apresenta além da sua freqüência de ressonância outras freqüências adicionais a essa. Quanto mais curto o pulso (menor número de ciclos), maior a quantidade de freqüências que estarão presentes. A escala de freqüências envolvidas no pulso é denominada largura de banda (figura 2.3.4).

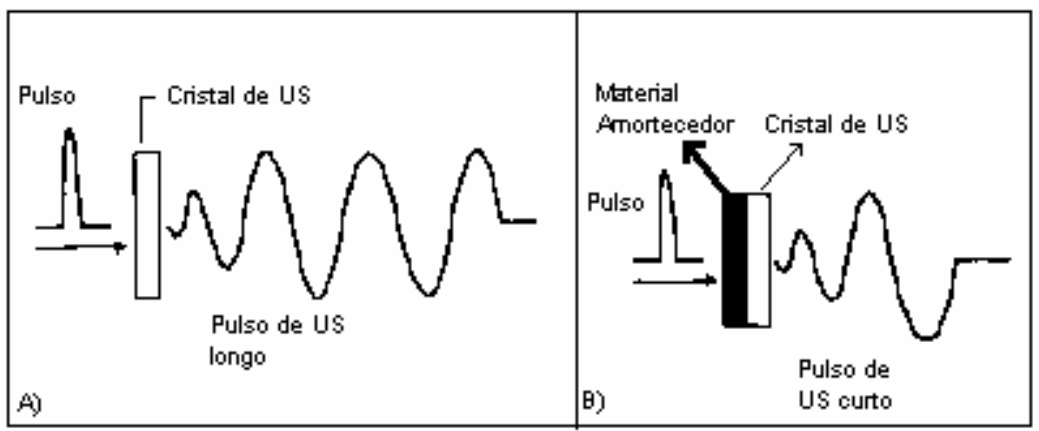

Figura 2.3.3. Sem amortecimento (A), um impulso de corrente elétrica aplicada ao cristal do transdutor gera um pulso de ultra-som longo, de muitos ciclos. Com o material amortecedor colocado na face posterior do cristal do transdutor (B) a aplicação do impulso de corrente elétrica resulta num pulso curto de ultra-som, de poucos ciclos (Krenkau,1996).

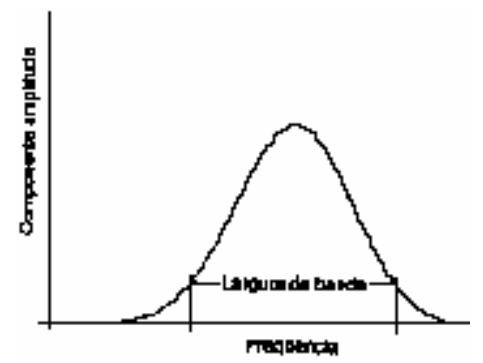

Figura 2.3.4: O gráfico acima ilustra uma largura de banda, pulso amortecido. (Krenkau, 1996).

Se uma pastilha de US é seguida de oscilações livres, sua oscilação senoidal não permanece constante porque a pastilha perde constantemente sua energia por dois mecanismos: fricção interna e energia de convecção (na forma de onda transmitida para o material e para a vizinhança). Devido a perda de energia a oscilação é amortecida e a amplitude decresce de uma oscilação para a outra por um fator $\delta$ conhecido como fator de amortecimento (figura 2.3.5). Na figura 2.3.6, é mostrada a composição do backing para cada transdutor, o tipo de cristal e o material a ser analisado, sendo que esses são os correspondentes para os transdutores da figura 2.3.5. No caso de osciladores amortecidos a freqüência de oscilação é, na prática, igual a freqüência característica do oscilador sem amortecimento. Somente para grandes valores de amortecimento o desvio na freqüência é apreciado (figura 2.3.5c). (Krautkramer et al 1990) 
Se um cristal de US é excitado por uma voltagem de freqüência diferente de sua freqüência fundamental, ela oscilará na sua freqüência aplicada, como um oscilador forçado com amplitude constante. A amplitude resultante dependerá da freqüência de excitação (figura 2.3.6). Acima da freqüência de ressonância $f_{\text {res }}$ ele cresce para um valor máximo, o qual depende do valor do coeficiente de amortecimento, depois ele decresce novamente. $\mathrm{Na}$ figura 2.3.6, são apresentados os valores do fator de qualidade B para diferentes tipos de transdutores.

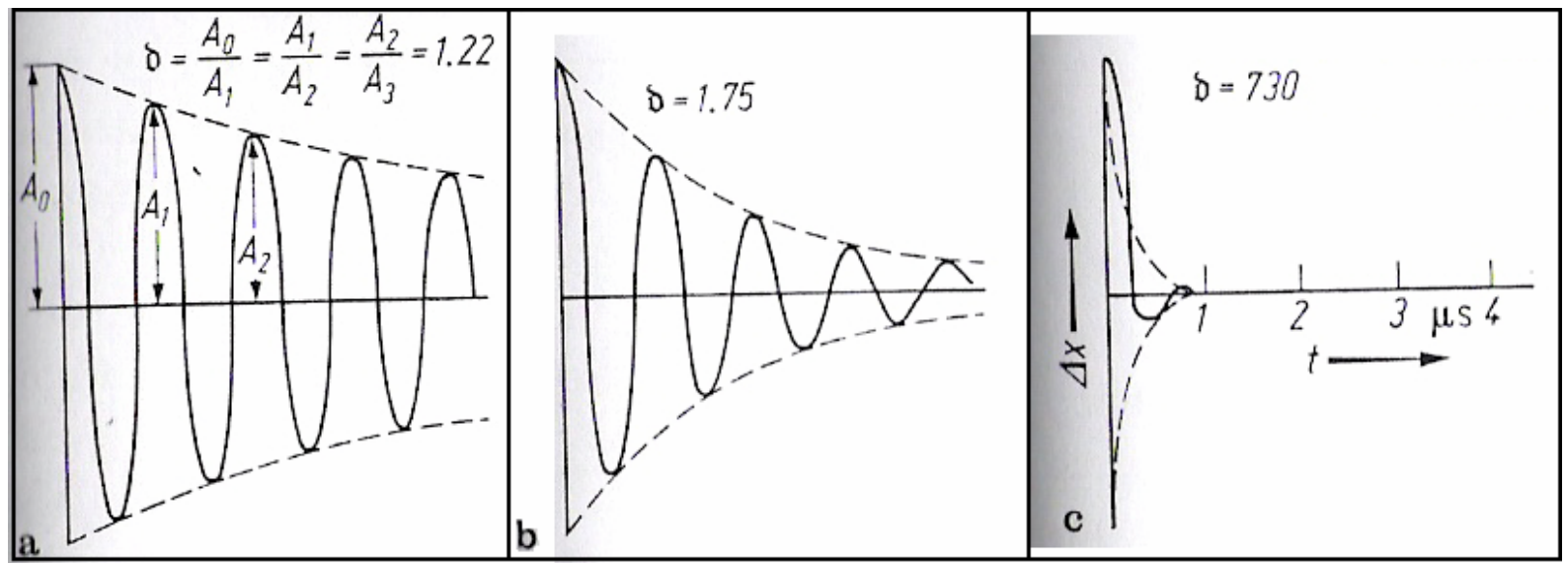

Figura 2.3.5. Decaimento de oscilação de um transdutor para diferentes coeficientes de amortecimento. Em a, b e c os coeficientes de amortecimento foram 1,22, 1,75 e 730, respectivamente. (Krautkramer, 1990)

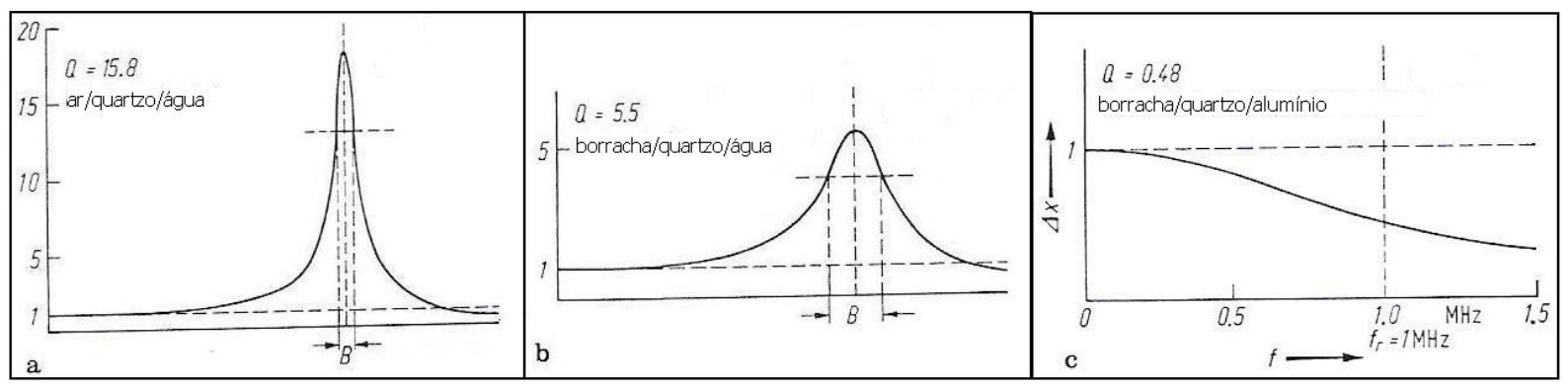

Figura 2.3.6. Curvas de ressonância de um oscilador forçado. Em a, b e c são apresentados os fatores de qualidade (Q) para cada amortecimento, sendo de, 15,8, 5,5 e 0,48, respectivamente. (Krautkramer, 1990)

Na freqüência de ressonância $f_{\text {res }}$ a pastilha é excitada para a maior amplitude. Esta freqüência usualmente difere um pouco da freqüência característica $f_{0}$ a qual é a freqüência de oscilação livre da pastilha, amortecida ou não.

Este aumento na ressonância é igual ao fator de qualidade Q, que está relacionado com a freqüência de ressonância, e é dado pela equação seguinte:

$$
\mathrm{Q}=\frac{f_{\text {res }}}{F W H M}
$$


onde FWHM (full width at half maximum), é a largura à meia potência do pico de ressonância (figura 2.3.7).

O fator de qualidade está ligado ao coeficiente de amortecimento $\delta$, pela seguinte equação:

$$
Q=\frac{\pi}{\ln \delta}(\ln \delta=2,303 \log \delta)
$$

O fator de qualidade está associado à largura de banda da curva de ressonância. A largura de banda B, da máxima ressonância, está definida de acordo com a figura 2.3.6, e é medida em 70\% do valor máximo. Pode ser dada pela equação abaixo se o amortecimento não for muito excessivo:

$$
B=\frac{f_{R}}{Q}
$$

O fator Q não tem unidade. A inclusão do material amortecedor no receptáculo do transdutor aumenta a largura de banda e diminui o fator Q.

Um alto valor de Q significa que o transdutor responde a um pequeno intervalo de freqüência e possui sintonia crítica. No caso de um baixo Q, o transdutor responde a um grande intervalo de freqüência. Dependendo do tipo de aplicação escolhe-se alto ou baixo Q para o transdutor.
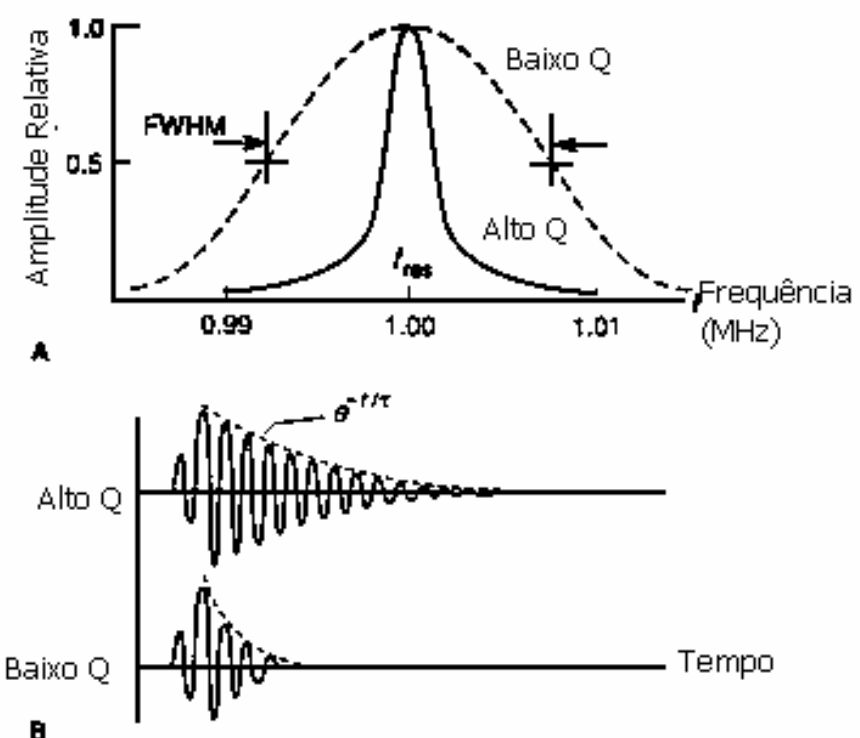

Figura 2.3.7. O Q de um sistema é uma medida de agudeza de sua ressonância (A). Quanto mais aguda for a ressonância de um sistema (B), e quanto maior for o seu Q, mais tempo ficará soando.(Herdade,1998). 


\subsubsection{FEIXE DE ULTRA-SOM (CAMPO ACÚSTICO)}

As frentes de onda podem ser geradas por fontes extensas de grandes dimensões (campos planos paralelos e perpendiculares à direção de propagação) e por fontes pontuais (superfícies esféricas concêntricas). Os transdutores são fontes extensas e podem ser consideradas como uma coleção de fontes pontuais, cada uma irradiando ondas esféricas (ondículas); interferência das ondículas esféricas resultam em ondas planas (princípio de Huygens). (Krautkramer, 1990 e Herdade, 1998)

A região próxima à fonte, onde a interferência das ondículas é mais aparente, é chamada Zona de Fresnel ou Campo Próximo (figura 2.3.8). Para um transdutor em forma de disco, de diâmetro $\mathrm{D}$, a zona próxima pode ser calculada por:

$$
N=\frac{D^{2}-\lambda^{2}}{4 \lambda}
$$

em que, $\mathrm{N}$ é o comprimento da Zona de Fresnel, $\lambda$ é o comprimento de onda de ressonância da pastilha de US e D é o diâmetro da pastilha de US. (Krautkramer, 1990 e Herdade, 1998)

A região após a zona de Fresnel é chamada de Zona de Fraunhofer ou Campo Distante (figura 2.3.8).

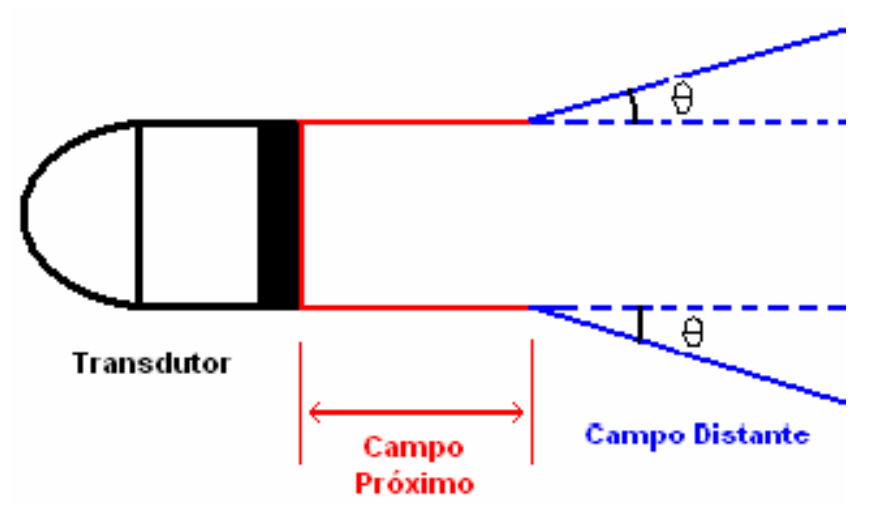

Figura 2.3.8. Ilustração do Campo Próximo e Campo Distante de um transdutor em forma de disco. O ângulo $\theta$ é o ângulo de divergência do campo distante.

Além da zona de Fresnel, alguma energia escapa ao longo da periferia do feixe produzindo uma divergência do feixe dada por: 


$$
\operatorname{sen} \theta=0,612 \frac{\lambda}{r}
$$

onde r é o raio da pastilha de ultra-som, $\lambda$ é o comprimento de onda de ressonância da pastilha de US e $\theta$ é o ângulo de divergência do campo ultra-sônico.

\subsubsection{CARACTERÍSTICAS DA PASTILHA DE ULTRA-SOM (Morgan, 2004 e HTMG, 2004).}

A cerâmica piezoelétrica é exposta a uma alternância do campo elétrico variando assim suas dimensões ciclicamente de acordo com a freqüência do campo. Toda cerâmica tem uma freqüência única, ou freqüência de ressonância, na qual vibra mais facilmente na resposta da entrada elétrica, e converte com maior eficiência a energia elétrica de entrada para energia mecânica. A freqüência de ressonância é determinada pela composição do material cerâmico e em uma relação inversa pelo volume e forma do elemento (geralmente elementos que possuem maior espessura têm menor freqüência de ressonância).

A reatância de um elemento cerâmico variará como descrito na figura 2.3.9. Como a freqüência aumenta, a primeira freqüência de oscilação aproxima-se da freqüência de ressonância $\left(f_{R}\right)$ em série do elemento cerâmico, é a freqüência na qual a impedância elétrica em um circuito elétrico é zero quando a resistência causada pela perda mecânica é ignorada. Nesta freqüência, o comportamento do elemento cerâmico pode ser descrito pelo circuito elétrico equivalente da figura 2.3.10.

Como a freqüência continua crescendo, a impedância aumenta (figura 2.3.9). A freqüência na qual a impedância torna-se máxima, $f_{A}$, (chamada de freqüência de antiressonância) aproxima-se da freqüência de ressonância paralela, e é a freqüência na qual a resistência paralela no circuito elétrico equivalente torna-se infinita, quando a resistência causada pela perda mecânica é ignorada.

Abaixo da $f_{R}$ e acima da $f_{A}$ o elemento cerâmico comporta-se capacitivamente, entre $f_{R}$ e $f_{A}$ comporta-se indutivamente, e a máxima resposta deste elemento será em um ponto entre $f_{R}$ e $f_{A}$. 


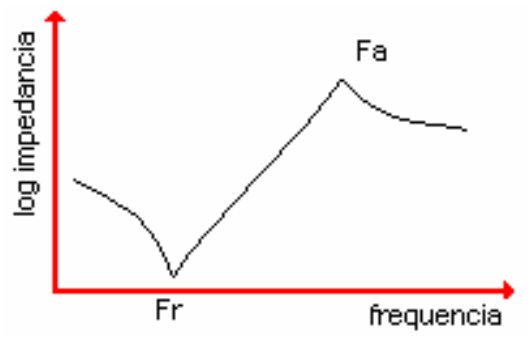

Figura 2.3.9. Figura ilustrativa da impedância como função da frequiência para um cristal piezoelétrico, sendo $f_{R}$ e $f_{A}$ freqüência de ressonância e anti-ressônancia respectivamente.

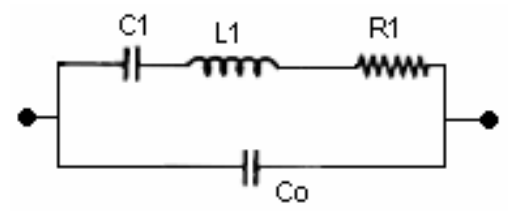

Figura 2.3.10. Circuito elétrico equivalente para um transdutor de cerâmica piezoelétrica.

Valores de $f_{R}$ e $f_{A}$ podem ser determinados experimentalmente. Na figura 2.3.11 é mostrado um sistema para a obtenção destes valores.

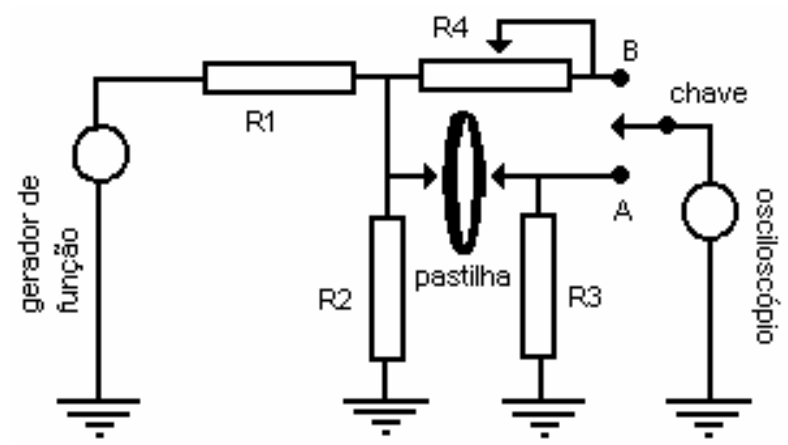

Figura 2.3.11. Sistema para determinação da freqüência de ressonância e anti-ressonância de um elemento

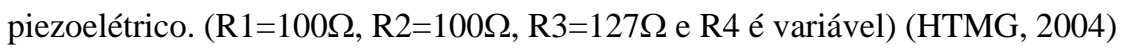

Procedimento para obtenção das freqüências características:

1. Posicione a chave em A;

2. Posicione a pastilha piezoelétrica;

3. Ajuste o gerador de função (gerador de freqüência) para fornecer o valor máximo de voltagem no osciloscópio. Esta é a freqüência de ressonância.

4. Coloque a chave em A;

5. Ajuste a freqüência no gerador de função para dar o valor mínimo de voltagem no osciloscópio. Esta é a freqüência de anti-ressonância. 


\subsubsection{Sistemas ultra-sônicos}

Já existem equipamentos comerciais usados para fazer as medidas de USO, estes são apresentados na tabela 2.3.2. Nos Estados Unidos, a Food and Drug Administration (FDA) tem liberado o uso clínico de alguns equipamentos de ultra-sonometria óssea, em especial aqueles que utilizam o calcâneo como sítio de medida e sistemas de transmissão, mas já existem equipamentos que avaliam outros sítios anatômicos (Philipov, Holsman e Philips (2000) e Langton e Njeh (2004)).

Tabela 2.3.2- Instrumentos comerciais de ultra-sonometria (Philipov, Holsman e Philips (2000) e Langton e Njeh (2004)).

\begin{tabular}{|c|c|c|c|}
\hline Aparelho (fabricante) & $\begin{array}{c}\text { Data de } \\
\text { Aprovação }\end{array}$ & $\begin{array}{c}\text { Osso } \\
\text { analisado }\end{array}$ & $\begin{array}{c}\text { Descrição de medidas e aplicações } \\
\text { aprovadas }\end{array}$ \\
\hline Sahara (Hologic Inc) & $12 / 03 / 98$ & calcâneo & $\begin{array}{l}\text { Mede VS e BUA } \\
\text { Determinação do risco de fratura } \\
\text { Diagnóstico de osteoporose baseado } \\
\text { sobre escore T. } \\
\text { Acoplamento por gel. }\end{array}$ \\
\hline Achilles+(Lunar Corp) & $26 / 06 / 98$ & calcâneo & $\begin{array}{l}\text { Determinação do risco de fratura. } \\
\text { Diagnóstico de osteoporose baseado } \\
\text { sobre escore T. } \\
\text { Acoplamento por água. } \\
\text { Monitorização das variações ósseas } \\
\text { em mulheres idosas. }\end{array}$ \\
\hline $\begin{array}{l}\text { CUBAclinical (McCue } \\
\text { Corp) }\end{array}$ & $06 / 01 / 00$ & calcâneo & $\begin{array}{l}\text { Mede BUA. } \\
\text { Determinação do risco de fratura. } \\
\text { Diagnóstico de osteoporose baseado } \\
\text { sobre escore T. } \\
\text { Acoplamento por gel. }\end{array}$ \\
\hline
\end{tabular}


Conclusão.

\begin{tabular}{|c|c|c|c|}
\hline $\begin{array}{c}\text { Aparelho } \\
\text { (fabricante) }\end{array}$ & $\begin{array}{c}\text { Data de } \\
\text { Aprovação }\end{array}$ & $\begin{array}{c}\text { Osso } \\
\text { analisado }\end{array}$ & $\begin{array}{c}\text { Descrição de medidas e aplicações } \\
\text { aprovadas }\end{array}$ \\
\hline $\begin{array}{l}\text { Omnisense (Sunlight } \\
\text { Ultrasound } \\
\text { Technologies) }\end{array}$ & $20 / 01 / 00$ & Radio & $\begin{array}{l}\text { Mede VS. } \\
\text { Diagnóstico de osteoporose } \\
\text { baseado sobre escore T. } \\
\text { Determinação do risco de } \\
\text { fratura. } \\
\text { Monitorização das variações } \\
\text { ósseas em mulheres entre } 50 \text { à } 65 \\
\text { anos.. }\end{array}$ \\
\hline $\begin{array}{l}\text { DMS UBIS } 3000 \\
\text { (5000 novo modelo) }\end{array}$ & ND & calcâneo & $\begin{array}{l}\text { Mede VS e BUA; } \\
\text { Faz Imagem do calcanhar; } \\
\text { Acoplamento com água; }\end{array}$ \\
\hline Osteometer DTU-1 & ND & calcâneo & $\begin{array}{l}\text { Mede VS e BUA; } \\
\text { Faz Imagem do calcanhar; } \\
\text { Acoplamento com água; }\end{array}$ \\
\hline IGEA & ND & falanges & $\begin{array}{l}\text { Mede VS (córtex); } \\
\text { Acoplamento por gel ultra- } \\
\text { sônico. }\end{array}$ \\
\hline DBM Sonic 1200 & ND & falanges & $\begin{array}{l}\text { Mede VS (córtex); } \\
\text { Acoplamento por gel ultra- } \\
\text { sônico. }\end{array}$ \\
\hline Myriad & ND & Tíbia & $\begin{array}{l}\text { Mede a VS; } \\
\text { Córtex da tíbia; } \\
\text { Acoplamento por gel. }\end{array}$ \\
\hline Soundscan & ND & Tíbia & $\begin{array}{l}\text { Mede a VS; } \\
\text { Córtex da tíbia; } \\
\text { Acoplamento por gel. }\end{array}$ \\
\hline
\end{tabular}

ND: significa que não foi declarada a data de aprovação na devida referência. 
Os equipamentos acoplados com água tais como o Achilles+ e o UBIS 5000, utilizam um regulador de temperatura (da água) para o tanque acústico. O tanque é mantido em $37^{\circ} \mathrm{C}$ no Achilles+ e $32^{\circ} \mathrm{C}$ no UBIS 5000. É essencial regular a temperatura do tanque acústico desde que tenha sido estabelecido o efeito da temperatura sobre ambos a VS e a BUA. Os transdutores são montados coaxial em uma separação fixa de 95mm para o Achilles e 100mm para o UBIS (figura 2.3.12).

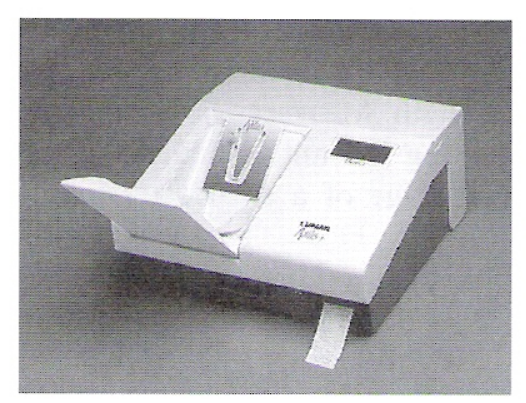

(a)

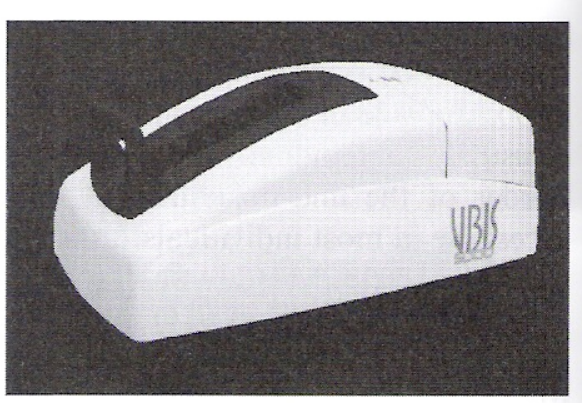

(b)

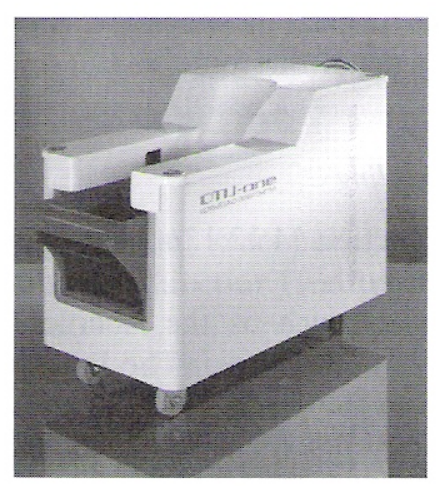

(c)

Figura 2.3.12. Alguns equipamentos de ultrassonometria óssea que utilizam o acoplamento por água. a) Achilles, b) UBIS 5000 e c) DTU-1. (Langton e Njeh (2004)).

Equipamentos do QUS que utilizam acoplamento por gel, incluem, CUBAClinical, Sahara, DBM-sonic e QUS II. Nos aparelhos acoplados por gel os transdutores são colocados em contato direto com o calcanhar. O posicionamento é feito por molas no DBM-sonic e o posicionamento é motorizado no CUBAClinical, Sahara e QUS II. Com o Omnisense multisystem, os transdutores são manualmente movidos sobre a região de interesse. (figura 2.3.13)

Para sistemas de contato direto, diferentes aproximações têm sido usadas para solucionar o problema da não uniformidade do calcanhar. O Sahara e o CUBAClinical possuem almofadas macias de silicone que supostamente se adaptam a forma do calcanhar. 


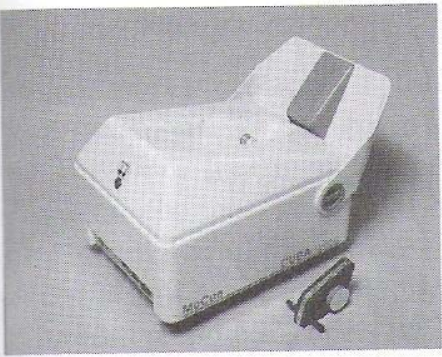

(a)

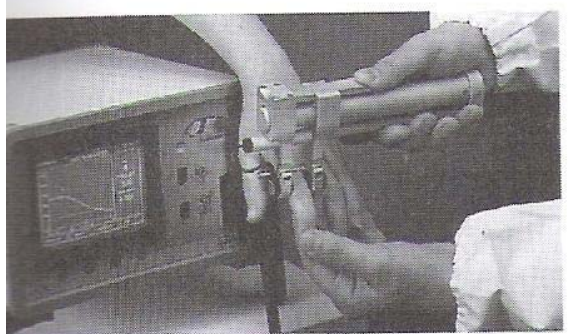

(c)

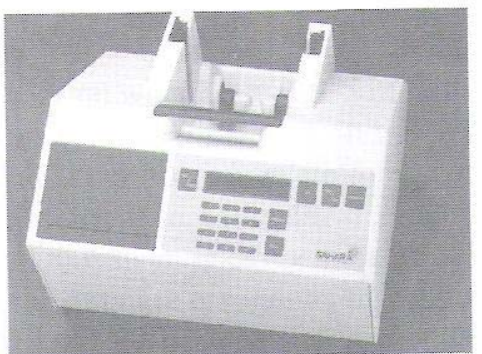

(b)

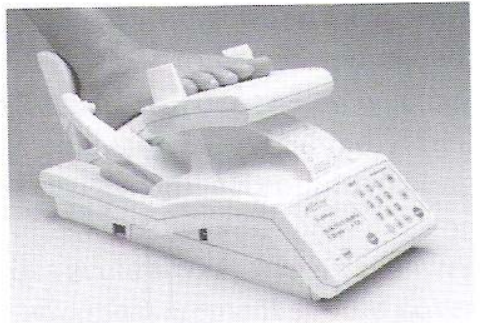

(d)

Figura 2.3.13: Alguns equipamentos de ultrassonometria óssea que utilizam o acoplamento por gel ultra-sônico.

a) CUBAclinical, b) Sahara Clinical, c) DBM Sonic 1200 e d) QUS-2. (Langton e Njeh (2004)) 


\section{MÉTODO EXPERIMENTAL}

\subsection{TANQUE ACÚSTICO}

Para as medidas de velocidade do som e BUA, para técnica de inserção convencional (acoplamento com água), foi confeccionado um tanque acústico de $18 \mathrm{~cm}$ x $40 \mathrm{~cm}$ x $45 \mathrm{~cm}$, de acrílico (figura 3.1.1).

No interior do tanque acústico era posicionada uma base na qual os transdutores eram presos em suportes e estes, por sua vez, eram presos em trilhos onde podiam se movimentar livremente na direção horizontal, posicionando-os em qualquer região da amostra (figura 3.1.2a). Os transdutores eram presos ao suporte através de parafusos, e estes por sua vez, fixados em trilhos, também com parafusos para facilitar o ajuste (figura 3.1.2b).

Os suportes possuíam fixadores onde se adaptavam buchas para melhor fixar os transdutores independentes do seu diâmetro (figura 3.1.3a e 3.1.3b).

Para as medidas na técnica de contato (acoplamento com gel ultra-sônico) foi confeccionado outro suporte idêntico ao descrito para a técnica de inserção convencional. Entretanto, este foi confeccionado em uma base de madeira e não possuía trilhos, mas com mesmo sistema de fixação dos transdutores (figura 3.1.4a e 3.1.4b).

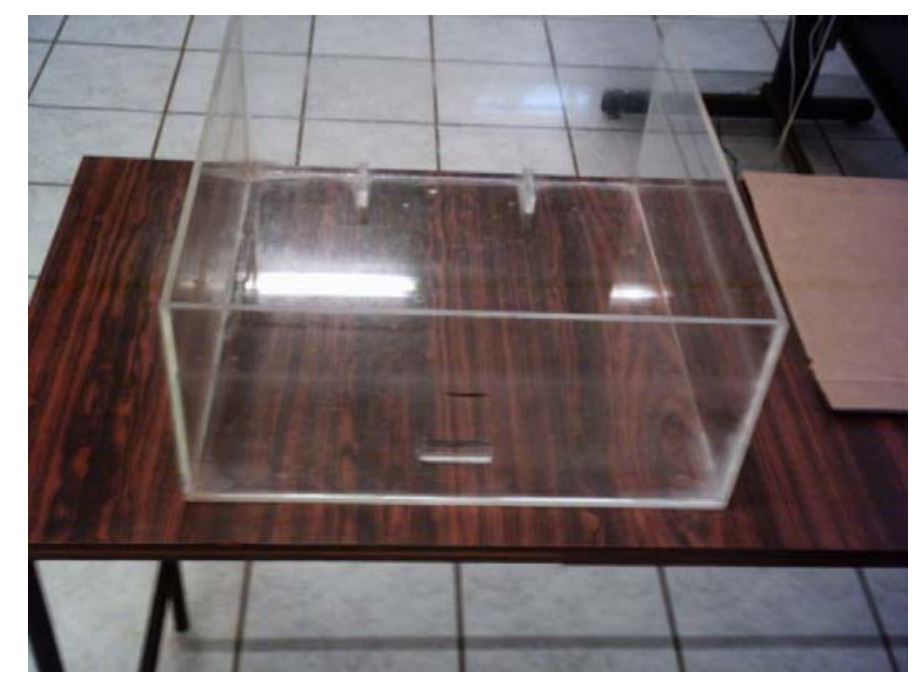

Figura 3.1.1. a) Tanque acústico utilizado para as medidas de velocidade do som e BUA para a técnica de inserção convencional (acoplamento com água). 
a)

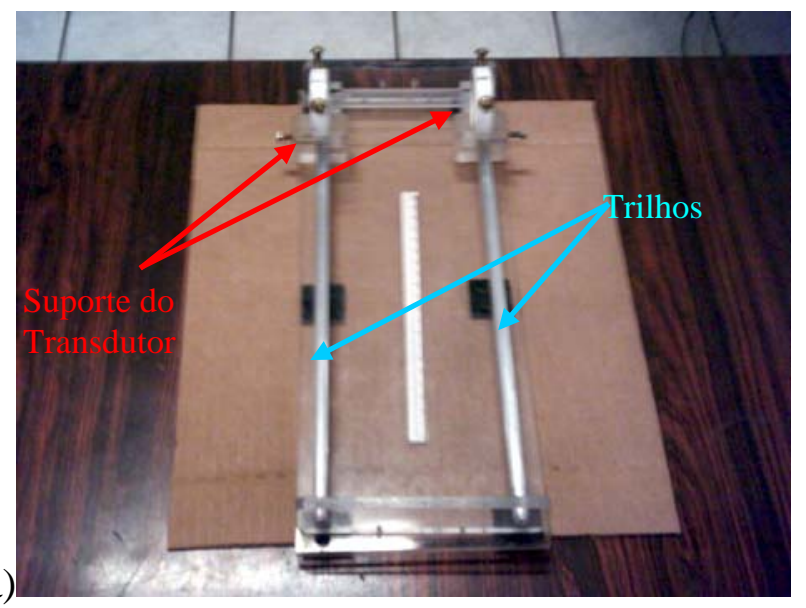

b)

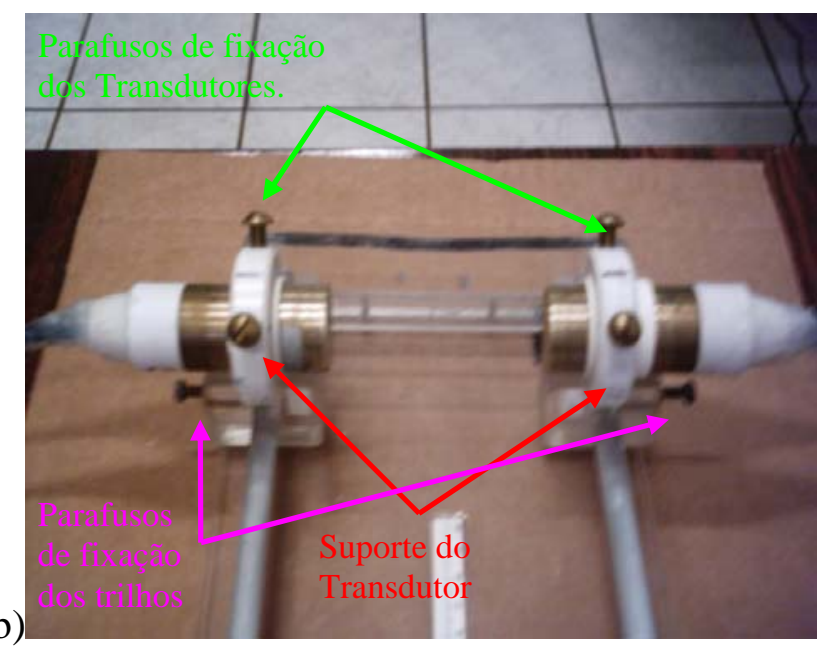

Figura 3.1.2. a) Trilhos para movimentação e suporte para fixação dos transdutores. b) Transdutores encaixados nos devidos suportes.

a)
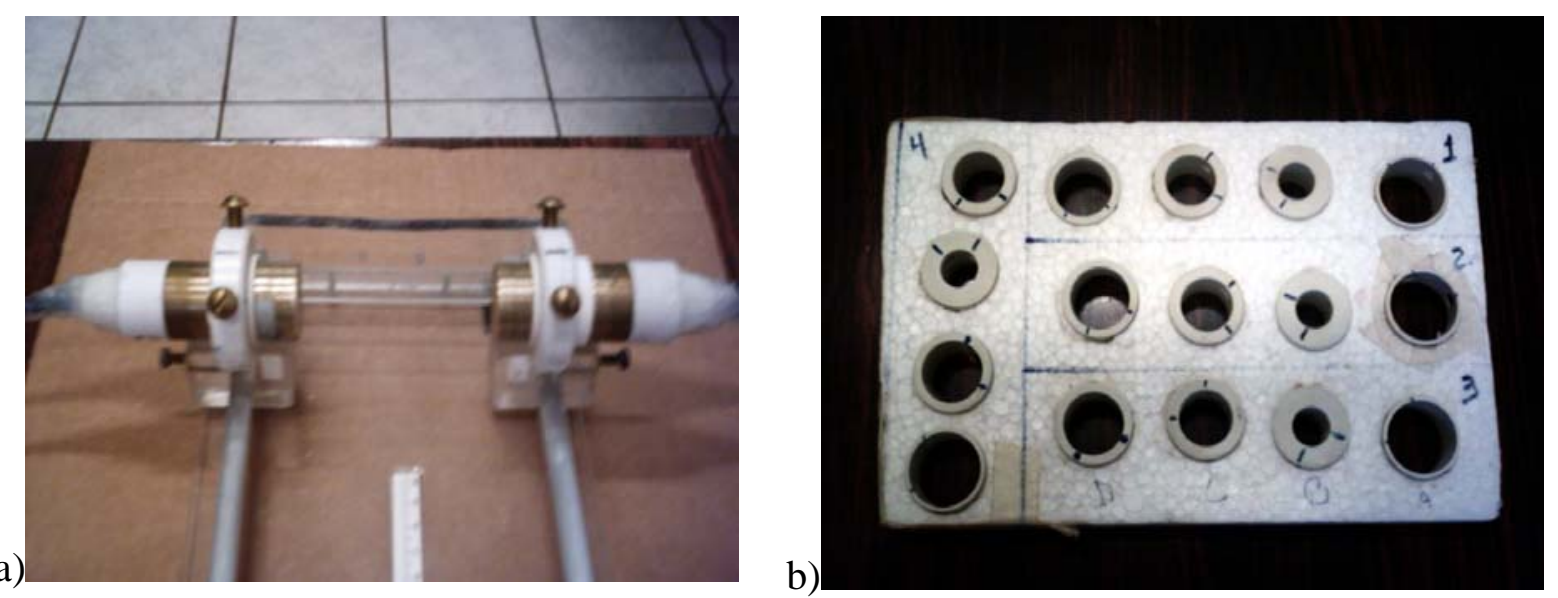

Figura 3.1.3. a) Transdutores fixos, através das buchas, nos adaptadores presos aos trilhos. b) Buchas de diferentes diâmetros para os diferentes transdutores.
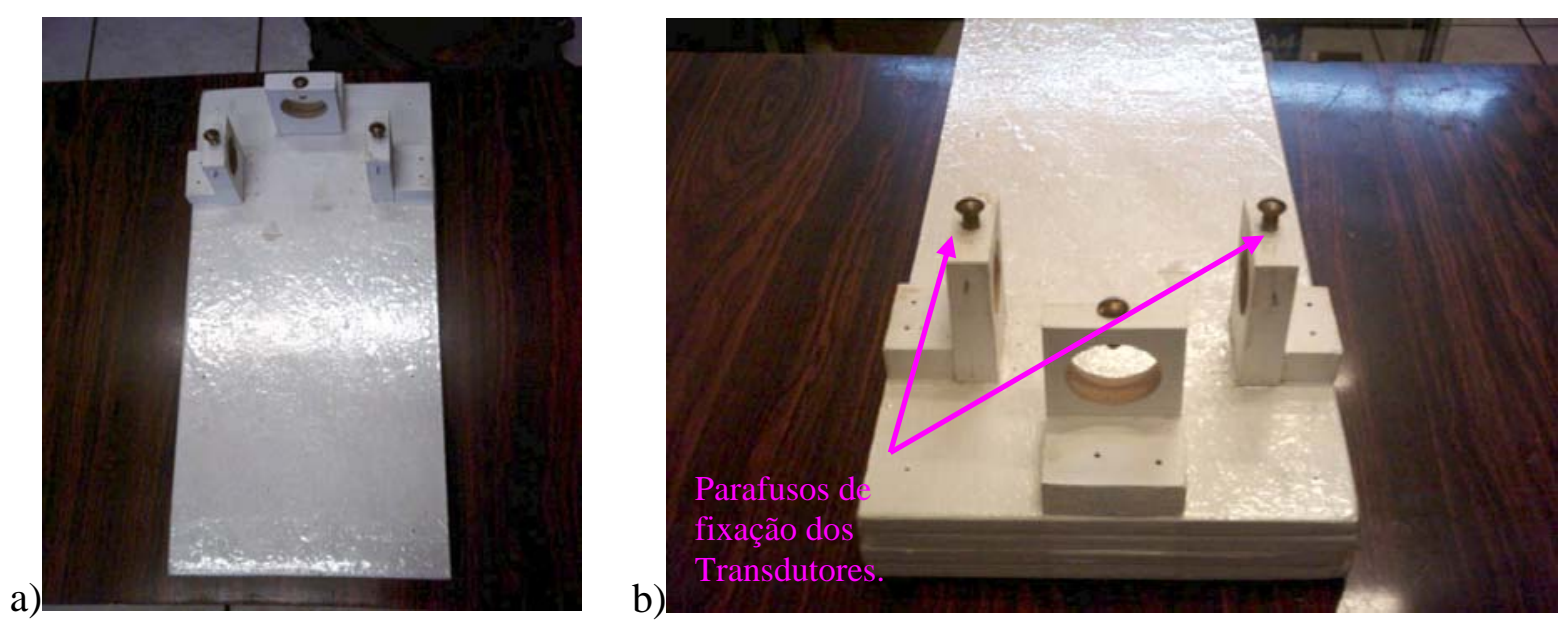

Figura 3.1.4. a) Suporte para as medidas feitas pela técnica de contato com acoplamento por gel ultra-sônico. b) Suporte de fixação dos transdutores com os parafusos fixadores. 
Na figura 3.1.5, para exemplificar, é apresentado o posicionamento da amostra de teflon para a técnica de contato com acoplamento por gel ultra-sônico.

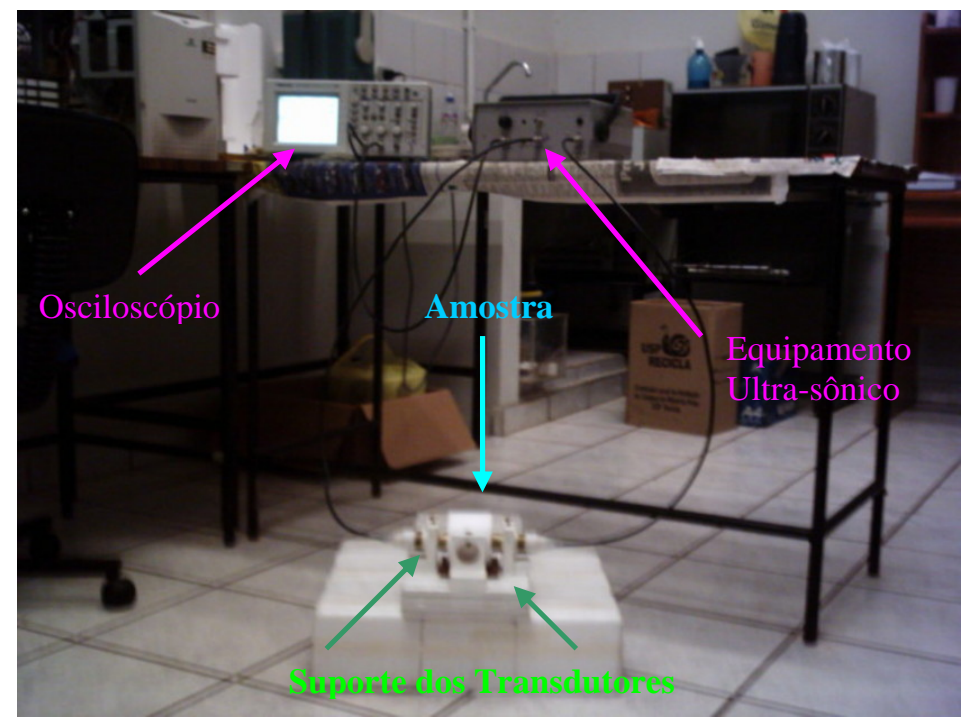

Figura 3.1.5. Posicionamento da amostra de teflon para a técnica de contato com acoplamento por gel ultrasônico.

\subsection{TRANSDUTORES}

Os transdutores foram montados da seguinte forma (figura 3.2.6):

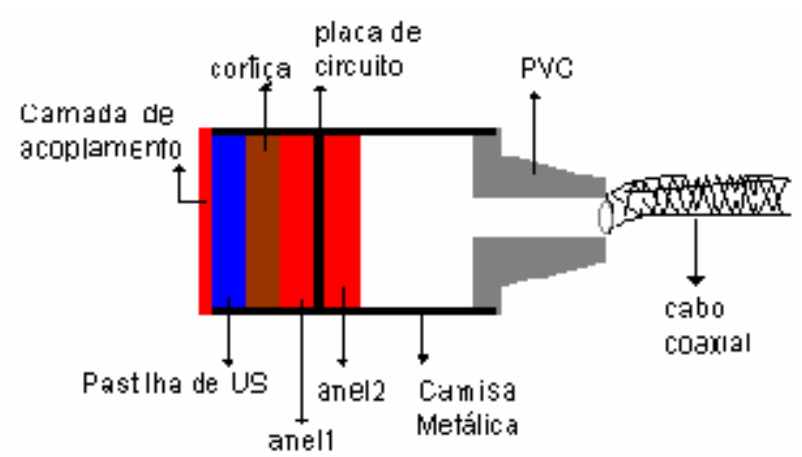

Figura 3.2.6. Corte longitudinal de um transdutor utilizado para fazer as medidas ultra-sônicas.

A parte externa do transdutor é constituída de uma camisa metálica com rosca interna, servindo como um isolador eletromagnético.

Como material de acoplamento foi usada uma resina líquida de poliester com endurecimento por catalisador. A resina, ainda líquida, foi colocada na extremidade do transdutor e endureceu em dois dias. 
Atrás da pastilha de PZT foi colado um disco de cortiça com 3mm de espessura para facilitar a montagem e adaptação da pastilha na camisa metálica.

Foram feitos dois anéis de metal com rosca sendo que, o anel 1 serviu para regular a espessura do material de acoplamento, podendo diminuir ou aumentar a sua espessura, e o anel 2, que serviu para fixar a placa de circuito, suporte para os fios provenientes da pastilha e do cabo coaxial.

Na outra extremidade do transdutor foi colocada uma peça de PVC que enroscada na camisa, serviu para segurar o cabo coaxial.

Na figura 3.2.7, são apresentados os transdutores confeccionados para este trabalho. Na figura 3.2.7a, temos, da esquerda para a direita, os pares AB, LM e NO de freqüências $1 \mathrm{MHz}, 2 \mathrm{MHz}$ e $1 \mathrm{MHz}$, respectivamente. Na figura 3.2.7b, temos, da esquerda para a direita, os pares de transdutores RS, GI, CD, PQ e EF de freqüências $500 \mathrm{KHz}, 2 \mathrm{MHz}, 750 \mathrm{KHz}$, $1,5 \mathrm{MHz}$ e $1 \mathrm{MHz}$, respectivamente.
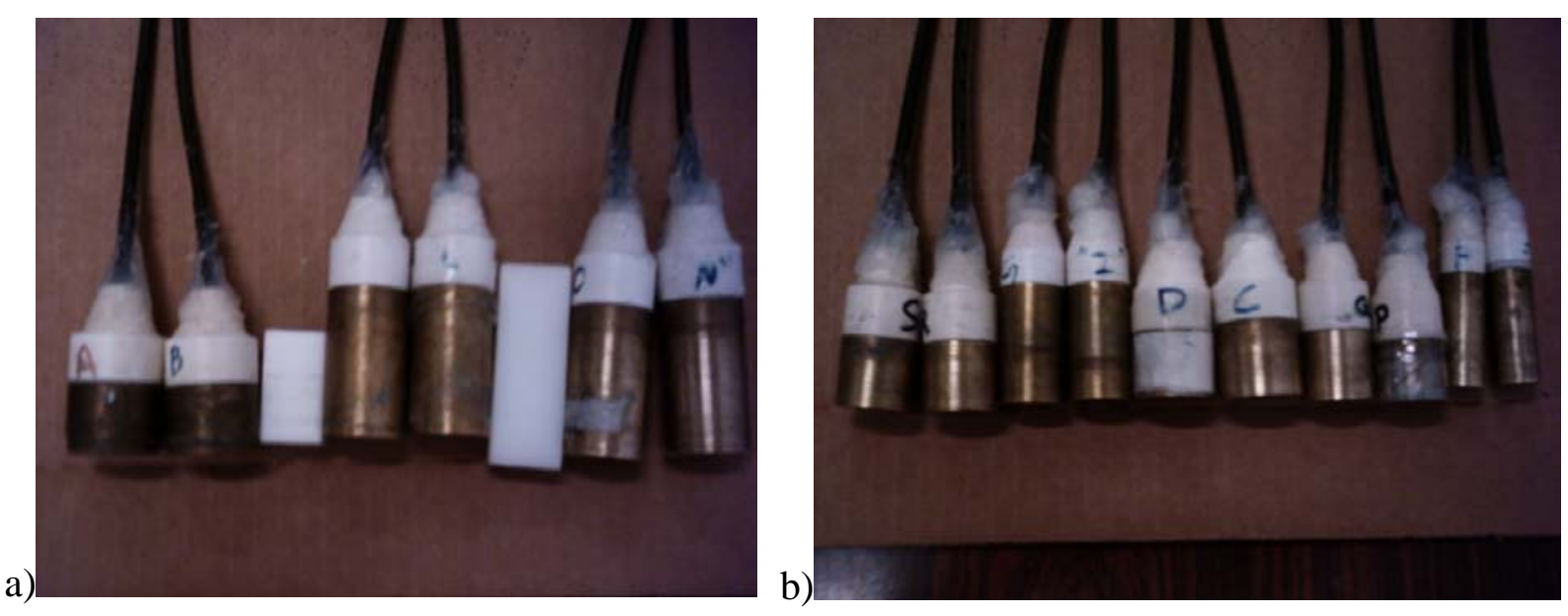

Figura 3.2.7. Transdutores confeccionados para este trabalho. Em a, da esquerda para a direita, os pares AB, LM e $\mathrm{NO}$ de freqüências $1 \mathrm{MHz}, 2 \mathrm{MHz}$ e $1 \mathrm{MHz}$, respectivamente. Em b, da esquerda para a direita, os pares de transdutores RS, IG, CD, PQ e EF de freqüências $500 \mathrm{KHz}, 2 \mathrm{MHz}, 750 \mathrm{KHz}, 1,5 \mathrm{MHz}$ e $1 \mathrm{MHz}$, respectivamente.

Na tabela 3.2.1, é mostrado o valor do diâmetro, da espessura e da freqüência nominal de ressonância (fornecida pelo fabricante) dos transdutores utilizados neste trabalho como, também, o fabricante da pastilha.

Na tabela 3.2.2, são mostrados os valores obtidos para a freqüência de ressonância e anti-ressonância (obtidos através do esquema descrito na figura 2.3.11, do capítulo 2 e seção 2.3.4) e a espessura do material de acoplamento (é igual a um quarto do comprimento de onda de ressonância). Foi usado como material de acoplamento uma resina acrílica endurecida por catalisador. 
Tabela 3.2.1 - Valores do diâmetro, da espessura, da freqüência de ressonância (valores fornecidos pelo fabricante) e nome do fabricante.

\begin{tabular}{|c|c|c|c|c|}
\hline Transdutores & $\begin{array}{c}\text { Diâmetro } \\
(\mathbf{m m})\end{array}$ & $\begin{array}{c}\text { Espessura } \\
(\mathrm{mm})\end{array}$ & $\begin{array}{c}\text { Freqüência } \\
\text { de } \\
\text { Ressonância } \\
\text { (MHz) }\end{array}$ & Fabricante \\
\hline $\bar{A}$ & 25 & 2,0 & 1,00 & Multisonic \\
\hline B & 25 & 2,0 & 1,00 & Multisonic \\
\hline $\mathrm{C}$ & 25 & 3,0 & 0,75 & Multisonic \\
\hline $\mathrm{D}$ & 25 & 3,0 & 0,75 & Multisonic \\
\hline $\mathrm{E}$ & 12 & 2,0 & 1,00 & Multisonic \\
\hline $\bar{F}$ & 12 & 2,0 & 1,00 & Multisonic \\
\hline G & 16 & 1,0 & 2,00 & Multisonic \\
\hline I & 16 & 1,0 & 2,00 & Multisonic \\
\hline $\mathrm{L}$ & 25 & 1,0 & 2,00 & Multisonic \\
\hline $\mathrm{M}$ & 25 & 1,0 & 2,00 & Multisonic \\
\hline $\mathrm{N}$ & 25 & 2,0 & 1,00 & HTMG \\
\hline $\mathrm{O}$ & 25 & 2,0 & 1,00 & HTMG \\
\hline $\mathrm{P}$ & 20 & 1,6 & 1,50 & Morgan \\
\hline $\mathrm{Q}$ & 20 & 1,6 & 1,50 & Morgan \\
\hline $\mathrm{R}$ & 21 & 4,0 & 0,50 & Multisonic \\
\hline$S$ & 21 & 4,0 & 0,50 & Multisonic \\
\hline
\end{tabular}

Tabela 3.2.2 - Valores para a freqüência de ressonância (Fr) e anti-ressonância (Fa), e espessura do material de acoplamento, todos obtidos experimentalmente.

\begin{tabular}{cccc}
\hline Transdutores & Fr (MHz) & Fa (MHz) & $\begin{array}{c}\text { Espessura do } \\
\text { Material de } \\
\text { Acopl.(mm) }\end{array}$ \\
\hline A & 0,965 & 1,012 & 1,0 \\
\hline B & 0,960 & 1,120 & 1,0 \\
\hline C & 0,650 & 0,698 & 1,5 \\
\hline D & 0,673 & 0,719 & 1,5 \\
\hline E & 0,925 & 0,979 & 1,0 \\
\hline F & 0,892 & 0,920 & 1,0 \\
\hline G & 1,981 & 2,221 & 0,5 \\
\hline I & 1730 & 2000 & 0,5 \\
\hline L & 1,744 & 2,066 & 0,5 \\
\hline M & 1,716 & 1,940 & 0,5 \\
\hline
\end{tabular}


Conclusão.

\begin{tabular}{cccc}
\hline Transdutores & Fr (MHz) & Fa (MHz) & $\begin{array}{c}\text { Espessura do } \\
\text { Material de } \\
\text { Acopl.(mm) }\end{array}$ \\
\hline $\mathrm{N}$ & 1,019 & 1,150 & 1,0 \\
\hline $\mathrm{O}$ & 1,020 & 1,149 & 1,0 \\
\hline $\mathrm{P}$ & 1,267 & 1,410 & 0,8 \\
\hline $\mathrm{Q}$ & 1,270 & 1,381 & 0,8 \\
\hline $\mathrm{R}$ & 0,549 & 0,552 & 2,0 \\
\hline $\mathrm{S}$ & 0,519 & 0,533 & 2,0 \\
\hline
\end{tabular}

Na tabela 3.2.3, são apresentados os valores da espessura da pastilha de ultra-som e do comprimento de onda de ressonância.

Tabela 3.2.3 - Valores da espessura da pastilha de ultra-som e do comprimento de onda de ressonância.

\begin{tabular}{|c|c|c|}
\hline Transdutores & $\begin{array}{c}\text { Espessura } \\
(\mathrm{mm})\end{array}$ & $\lambda_{\text {RES }}(\mathrm{mm})$ \\
\hline A & 2,0 & 4,0 \\
\hline B & 2,0 & 4,0 \\
\hline $\mathrm{C}$ & 3,0 & 6,0 \\
\hline $\mathrm{D}$ & 3,0 & 6,0 \\
\hline $\mathrm{E}$ & 2,0 & 4,0 \\
\hline $\mathrm{F}$ & 2,0 & 4,0 \\
\hline$G$ & 1,0 & 2,0 \\
\hline I & 1,0 & 2,0 \\
\hline $\mathrm{L}$ & 1,0 & 2,0 \\
\hline $\mathrm{M}$ & 1,0 & 2,0 \\
\hline $\mathrm{N}$ & 2,0 & 4,0 \\
\hline $\mathrm{O}$ & 2,0 & 4,0 \\
\hline$P$ & 1,6 & 3,2 \\
\hline $\mathrm{Q}$ & 1,6 & 3,2 \\
\hline $\mathrm{R}$ & 4,0 & 8,0 \\
\hline$S$ & 4,0 & 8,0 \\
\hline
\end{tabular}




\subsection{SISTEMA ULTRA-SÔNICO}

O sistema de aquisição de sinal é ilustrado na figura 3.3.8, que consiste em: (1) de um tanque acústico (ou suporte para as medidas por contato) onde estão acoplados os transdutores (emissor e receptor) e onde são colocadas as amostras a serem analisadas; (2) equipamento que gera, amplifica e recebe pulsos de ultra-som o qual está conectado a um osciloscópio (TDS 210 Digital da Tektronix) (3), que serve para visualizar o sinal recebido, e este, por sua vez, está conectado a um microcomputador para o processamento dos sinais (4).

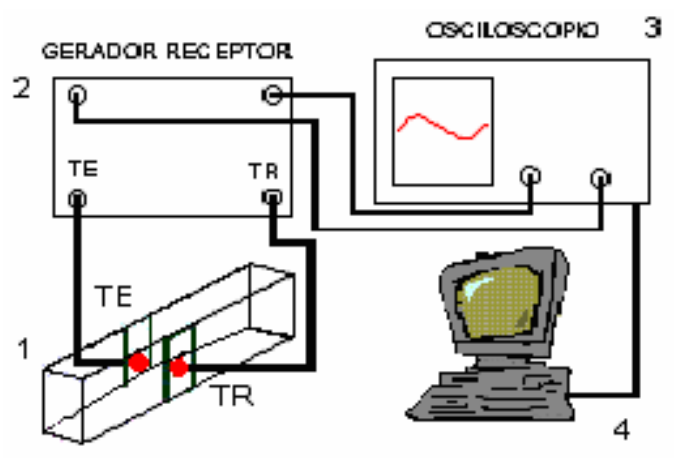

Figura 3.3.8. Configuração do sistema de medidas ultra-sônicas: (1) tanque acústico, (2) gerador e receptor de sinais, (3) osciloscópio e (4) micro computador.

O equipamento desenvolvido para gerar, receber e amplificar os sinais ultra-sônicos foi confeccionado no Laboratório de Eletrônica do Departamento de Física e Matemática da Faculdade de Filosofia Ciências e Letras de Ribeirão Preto-USP. Os controles foram dispostos como na figura 3.3.9.

Os controles primários (figura 3.3.9a) são as conexões de interação direta com o operador que, através destes pode regular (amplificar) o sinal recebido. Este controle é composto pelas seguintes conexões: Trans. Emissor (entrada para o transdutor emissor); Trans. Receptor (entrada para o transdutor receptor); Saída (saída para o osciloscópio sem amplificação); Saída Amplif. (saída amplificada do sinal para o osciloscópio) e Amplif. (botão de amplificação do sinal). A chave (em vermelho) serve para selecionar a saída para o osciloscópio, sendo para a direita com amplificador e para a esquerda sem amplificação.

Os controles secundários (figura 3.3.9b) são aqueles que devem ser ajustados (conectados) antes de iniciar as aquisições dos sinais ultra-sônicos. Este controle é composto 
pelas seguintes conexões: Sincronismo (saída para o trigger do osciloscópio); Tensão (botão que seleciona a tensão (120V, 172V e 224V) que excitará o transdutor emissor); Controle de Tensão (saída para um multímetro digital pelo qual é feito o acompanhamento da tensão de excitação) e a chave LIGA/DESLIGA do equipamento.

\section{Controle Primário}

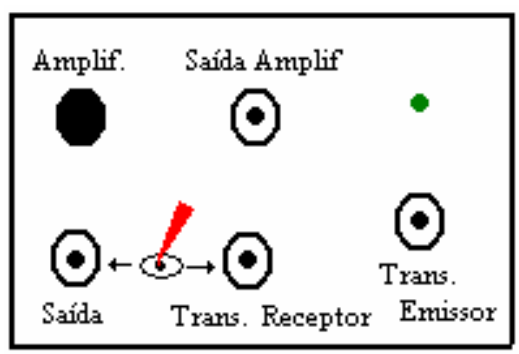

a)

Figura 3.3.9. Controles primários e secundários do sistema de ultra-som. Em a: Controles primários: botão de amplificação, saída do amplificador, saída sem amplificação, entrada do transdutor receptor e entrada do transdutor emissor. Em b: Controles secundários: saída do sincronismo, botão de variação de tensão, saída do controle de tensão e chave Liga/Desliga.

No diagrama em blocos, a seguir (figura 3.3.10), tem-se o esquema interno dos componentes do equipamento desenvolvido.

O sistema ultra-sônico possui duas fontes de alimentação: uma de alta tensão e outra, de baixa tensão. A fonte de alta tensão alimenta o circuito de amplificação do pulso de excitação e, a fonte de baixa tensão alimenta o circuito gerador de pulso e o sistema de amplificação do sinal recebido.

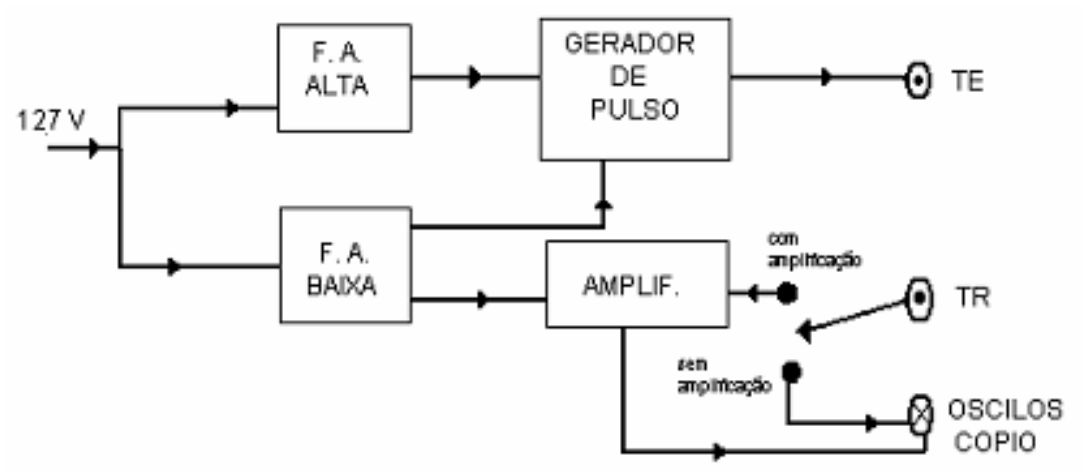

Figura 3.3.10. Diagrama em blocos apresentando os componentes internos do equipamento de ultra-som. 


\subsubsection{Gerador de Pulso}

O gerador é composto por um circuito gerador de pulso e um circuito amplificador de sinal que é capaz de gerar um pulso de até 300V.

O circuito gerador é apresentado na figura 3.3.11, em que o componente gerador de sinal é o LM555CHC e, para o chaveamento do transdutor foi utilizado um IGBT (IRG4BC30u).

De acordo com a figura 3.3.11, o potencial V+ é a tensão de alimentação do LM555CHC, o potencial VDD é a tensão fornecida pela fonte de alta tensão (figura 3.3.14) que pode chegar até um valor de $300 \mathrm{~V}$ e o Sinc é a conexão de saída para o trigger do osciloscópio, do controle secundário (sincronismo).

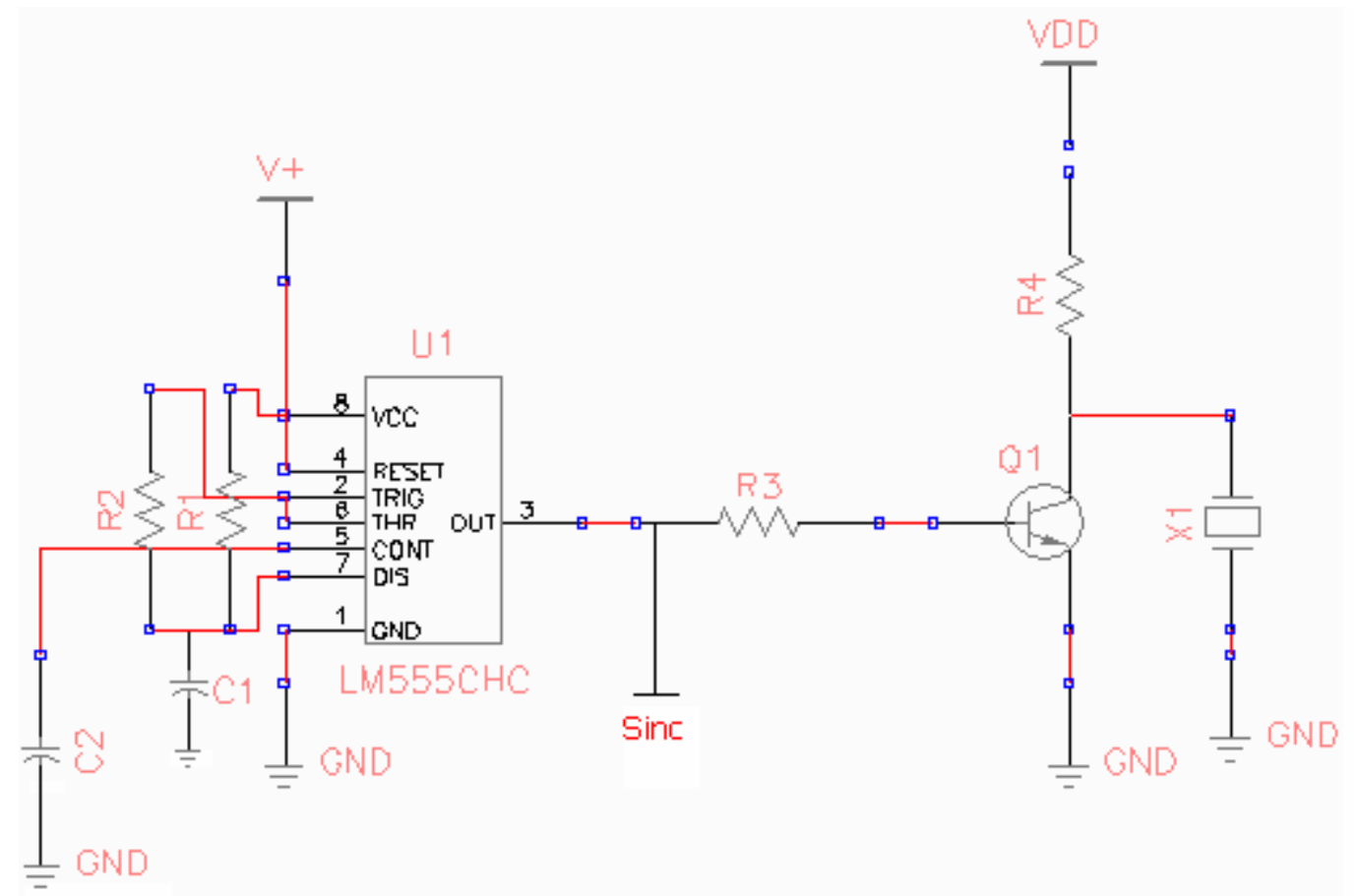

Figura 3.3.11: Circuito gerador de pulsos e excitador do transdutor emissor.

Em que:

$\mathrm{R} 1=680 \Omega, \quad \mathrm{R} 2=13,8 \mathrm{k} \Omega, \quad \mathrm{R} 3=100 \Omega, \quad \mathrm{R} 4=120 \mathrm{k} \Omega, \quad \mathrm{C} 1=100 \mu \mathrm{F}, \quad \mathrm{U} 1=\mathrm{LM} 555 \mathrm{CHC} \quad$, Q1=IRG4BC30u, X1=Transdutor Emissor,V+=12V e VDD (tensão de carga do transdutor).

Na figura 3.3.12 é apresentado o gráfico do comportamento da saída do LM555CHC e do IGBT, obtidos através do osciloscópio (TDS 210 Digital da Tektronix). 


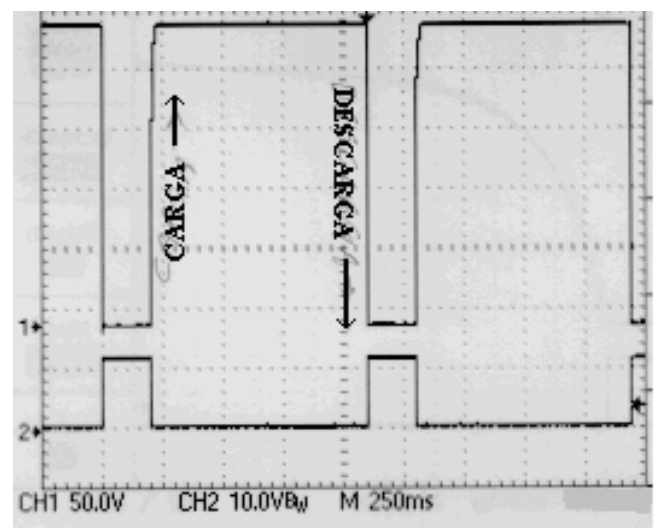

Figura 3.3.12. Sinal de disparo do gerador (CH2) e sinal do pulso de excitação do transdutor (CH1).

Conforme apresentado na figura 3.3.12 (CH2), o sinal proveniente do gerador (LM555CHC) fica quase o tempo todo em zero e o IGBT não conduz, permitindo que o capacitor (transdutor) se carregue através de R4. No disparo o IGBT conduz e descarrega rapidamente o capacitor (transdutor, CH2) emitindo o pulso ultra-sônico.

Na figura 3.3.13, tem-se o gráfico de carga e descarga do transdutor e o sinal de disparo do pulso CH2.

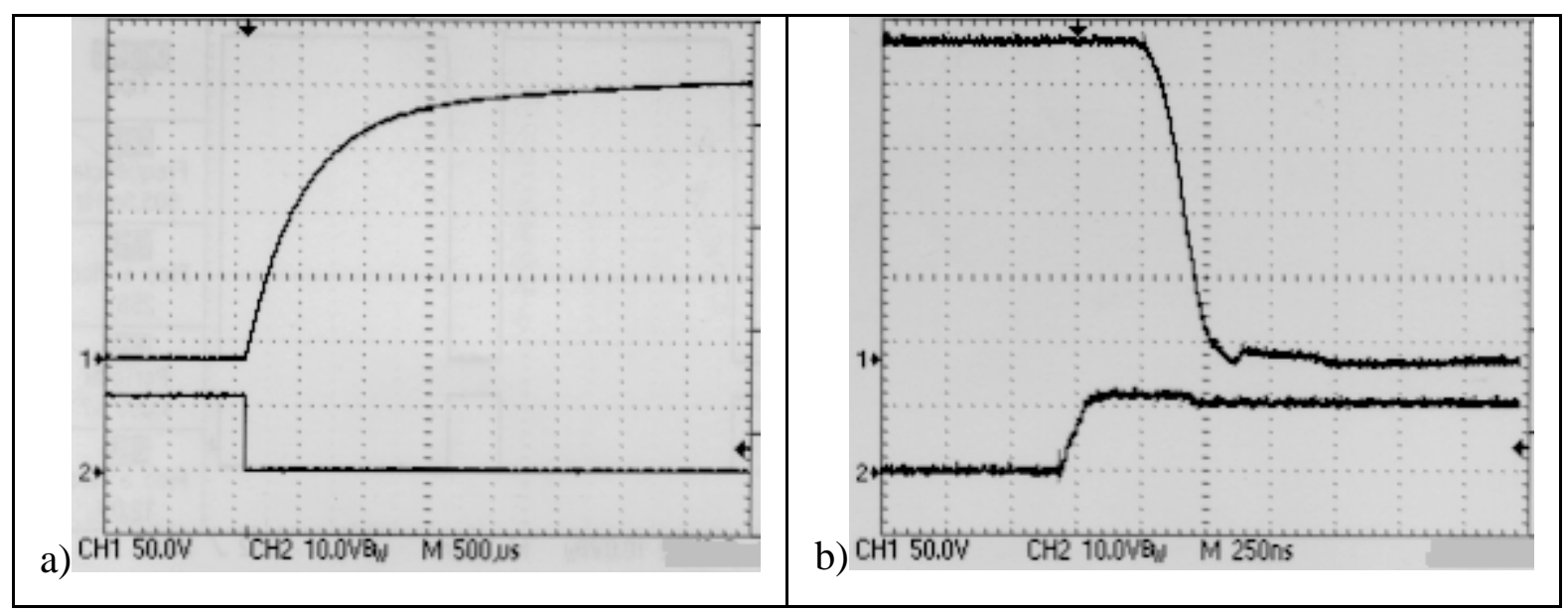

Figura 3.3.13. a) Tempo de carga do IGBT (CH1). b) Tempo de descarga do IGBT (CH1).

Na figura 3.3.13a, é apresentado o tempo de carga do transdutor que leva aproximadamente 3ms, por este motivo foi utilizado um tempo de repetição (dos pulsos) de aproximadamente 1,2s, para que houvesse tempo suficiente para a carga. Na figura 3.3.13b, é apresentado o tempo de descarga (disparo do pulso de excitação) do transdutor que dura aproximadamente 250ns. 


\subsubsection{Fonte de Alta Tensão}

Na figura 3.3.14, é apresentada a fonte chaveada de alta tensão que excita o transdutor emissor.

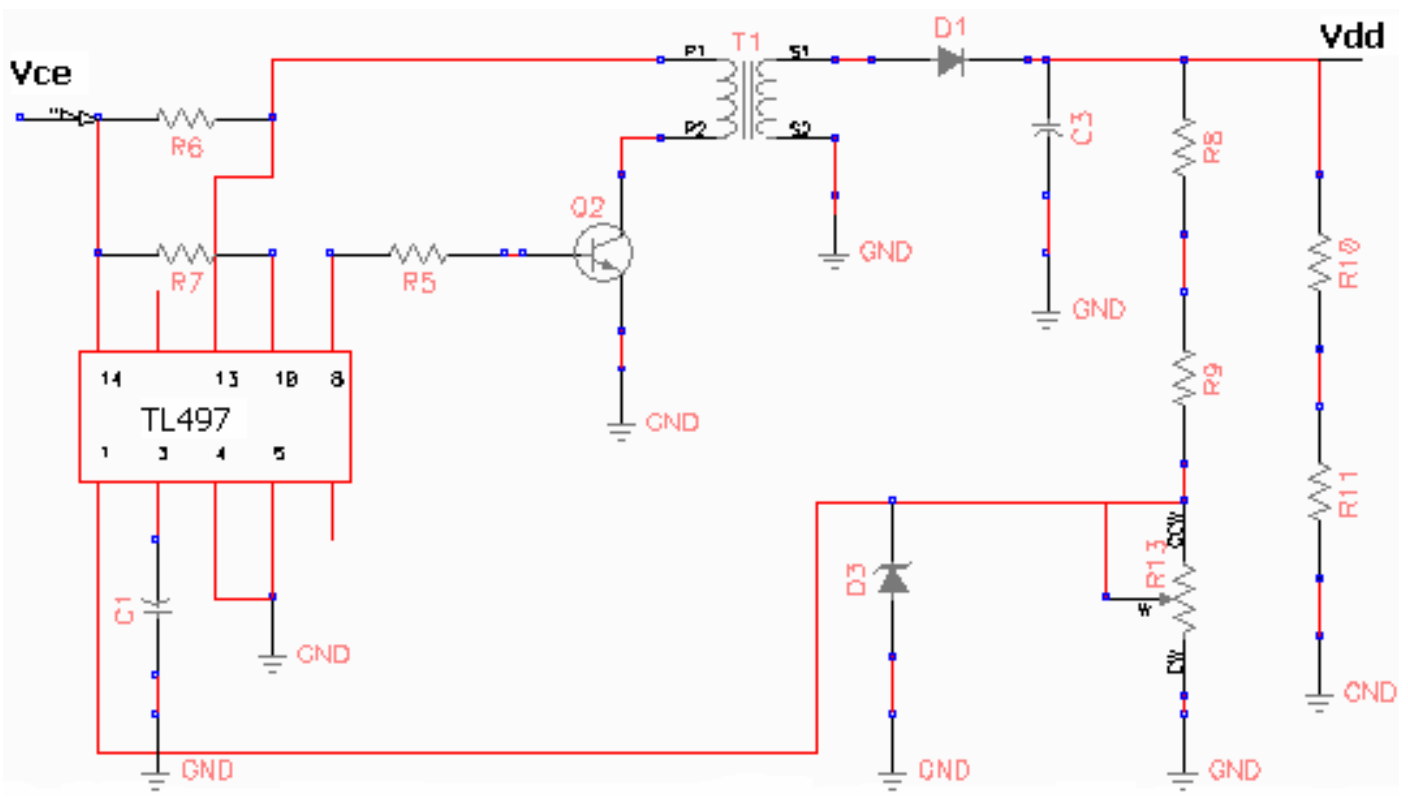

Figura 3.3.14. Fonte de alta tensão para excitação do transdutor emissor.

Em que:

$\mathrm{R} 5=1 \mathrm{k} \Omega, \mathrm{R} 6=1 \Omega, \mathrm{R} 7=100 \Omega, \mathrm{R} 8=\mathrm{R} 9=10 \mathrm{M}, \mathrm{R} 10=1 \mathrm{M}, \mathrm{R} 11=10 \mathrm{k} \Omega, \mathrm{C} 1=2 \mathrm{nF}, \mathrm{C} 3=235 \mathrm{nF}$, D3 $\rightarrow$ diodo zener, D1=N4937, T1=amplificador de ferrite, Q2=IRF720 e a resistência R13 é formada por três resistências como mostra a figura 3.3.15.

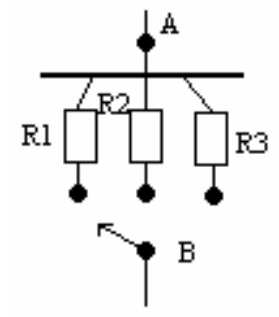

Figura 3.3.15. Resistências responsáveis pelo controle das tensões.

Em que:

$\mathrm{R} 1=100 \mathrm{k} \Omega, \mathrm{R} 2=150 \mathrm{k} \Omega$ e R3=220k $\Omega$. 
O TL497 é um oscilador que produz um sinal pulsado que excita o transformador de ferrite (T1), gerando no secundário tensões de até 300V.

Na figura 3.3.15, são apresentados os resistores que são responsáveis pela tensão de excitação do transdutor, essa seleção é feita através do botão Tensão (do controle secundário, figura 3.3.9b). Quando o botão estiver na posição do resistor R1, R2 ou R3 a tensão de excitação será de $224 \mathrm{~V}, 172 \mathrm{~V}$ e $120 \mathrm{~V}$, respectivamente. Não foi utilizado tensões próximas do limite dos componentes (300V), por causa do aquecimento que ocorre e também para a segurança do operador.

\subsubsection{Fonte de Baixa Tensão}

O diagrama da fonte de alimentação de baixa tensão é mostrado na figura 3.3.16:

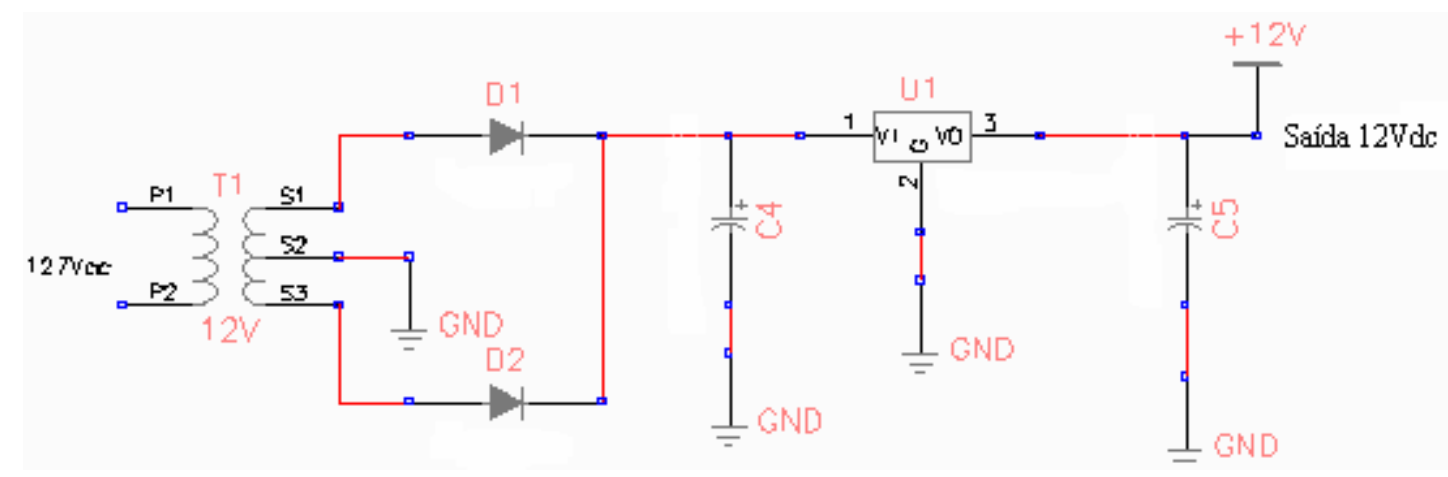

Figura 3.3.16. Esquema do circuito de alimentação de baixa voltagem ( $\mathrm{V}+=12 \mathrm{~V})$.

Em que os componentes têm os seguintes valores: D1= D2= 1N4007, C4=35V/2200 $\mu \mathrm{F}, \mathrm{C} 5=$ 25V/1000 $\mu \mathrm{F}$ e U1=LM7812CTB.

\subsubsection{Circuito Amplificador do Sinal Recebido}

Na figura seguinte (figura 3.3.17) é apresentado o circuito amplificador do sinal recebido pelo transdutor receptor. 


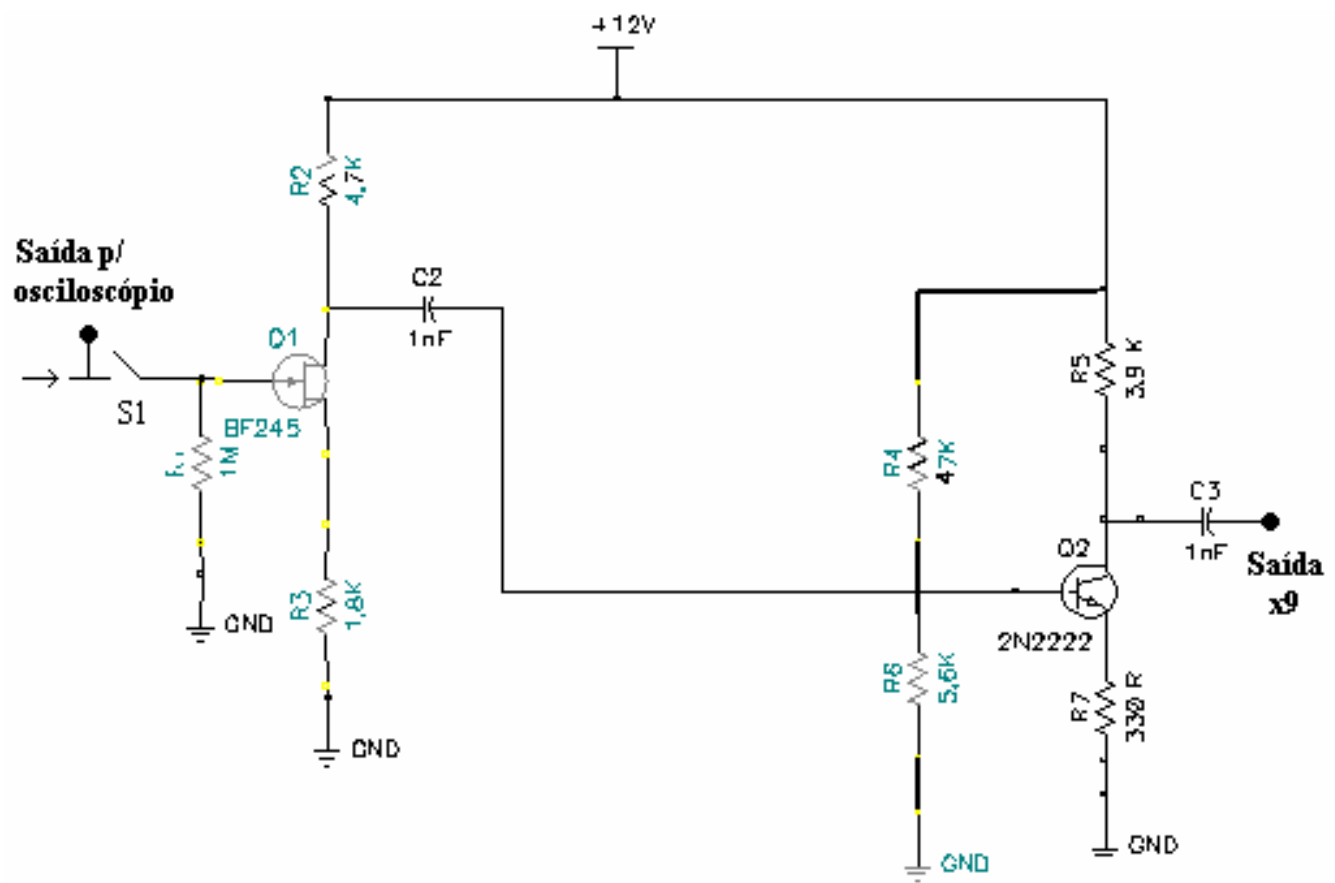

Figura 3.3.17. Circuito amplificador do sinal recebido pelo transdutor receptor.

Em que:

$\mathrm{R} 1=1 \mathrm{M} \Omega, \mathrm{R} 2=4,7 \mathrm{k} \Omega, \mathrm{R} 3=1,8 \mathrm{k} \Omega, \mathrm{R} 4=47 \mathrm{k} \Omega, \mathrm{R} 5=3,9 \mathrm{k} \Omega, \mathrm{R} 6=5,6 \mathrm{k} \Omega, \mathrm{R} 7=330 \Omega, \mathrm{R} 8=10 \mathrm{k} \Omega$, $\mathrm{C} 1=\mathrm{C} 2=\mathrm{C} 3=1 \mathrm{nF}, \mathrm{Q} 1=\mathrm{BF} 245$ e Q2=2N2222.

O sinal recebido pelo transdutor receptor pode seguir dois caminhos: um seria sem amplificação e o outro, com amplificação, e esses caminhos seriam selecionados pela chave (S1) que aparece na figura 3.3.17 (mesma chave do controle primário). Quando a chave está em aberto o sinal vai direto para a saída que está ligada ao osciloscópio sem nenhuma amplificação (Saída no controle primário) e, quando a chave está fechada o sinal passa pelo circuito amplificador, sofre uma amplificação de nove vezes, e vai para a saída que está ligada ao osciloscópio (Saída Amplif do controle primário).

\subsection{AMOSTRAS}

Diferentes materiais, amostras e condições experimentais foram desenvolvidas para teste do sistema e validação da técnica. Na seqüência serão apresentados:

Utilização de materiais plásticos e alumínio para análise de velocidade do som. 
Utilização de peças de teflon como material padrão para a calibração do sistema ultrasônico; comparação das medidas da BUA com os valores obtidos no calcâneo; análises do algoritmo utilizado e a reprodutibilidade da técnica e do sistema.

Como forma de nova aplicação, a técnica de ultrassonometria óssea será aplicada na avaliação de calo ósseo em tíbias de carneiro in vitro.

Medidas em calcanhares de voluntários jovens e idosos para cálculo de velocidade do som e BUA.

Detalhes destas aplicações, dada a diversidade dos procedimentos, serão apresentados nas seções correspondentes no capítulo de resultados e discussões.

\subsection{MEDIDAS DE CALIBRAÇÃO DO SISTEMA ULTRA-SÔNICO E DOS TRANSDUTORES COMO FUNÇÃO DA TEMPERATURA NA ÁGUA.}

\subsubsection{Introdução}

Neste capítulo serão apresentadas às curvas de calibração do sistema ultra-sônico para todos os transdutores. As medidas foram feitas apenas em água (técnica de inserção), que foi aquecida até $40^{\circ} \mathrm{C}$, então foi colocada no tanque acústico e esperou-se que atingisse a temperatura de $35^{\circ} \mathrm{C}$ para o início de cada medida. Foi esperado que a temperatura diminuísse naturalmente, sem nenhuma forma de acelerar o processo, gastando um tempo total nas aquisições de aproximadamente 5 horas (de $35^{\circ} \mathrm{C}$ a $21^{\circ} \mathrm{C}$ ). Para cada temperatura foi feita a aquisição de seis sinais temporais e a velocidade é calculada a partir destes e nos gráficos de velocidade é utilizada a média das velocidades. Será analisada a variação da velocidade do ultra-som na água e serão apresentados os gráficos temporais e os de potência relativa, obtida pelo cálculo da FFT do sinal, como função da temperatura. 


\subsubsection{Transdutores de $1 \mathrm{MHz}$, par AB.}

Na figura 3.5.18, 3.5.19 e 3.5.20 são apresentados os sinais temporais para a água, na tensão de trabalho de $124 \mathrm{~V}, 172 \mathrm{~V}$ e $224 \mathrm{~V}$, respectivamente, como função da temperatura para o par de transdutores $\mathrm{AB}$, para as temperaturas de $25^{\circ} \mathrm{C}$ e $30^{\circ} \mathrm{C}$.

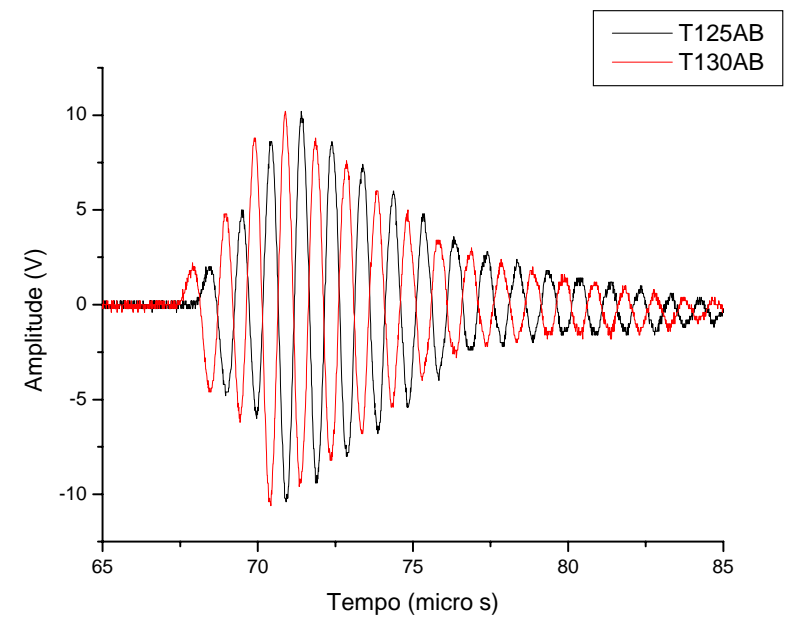

Figura 3.5.18. Sinal temporal para o par de transdutores $\mathrm{AB}(1 \mathrm{MHz})$ em água. Para as temperaturas de $25^{0} \mathrm{C}$ e $30^{\circ} \mathrm{C}$, para a tensão de $124 \mathrm{~V}$.

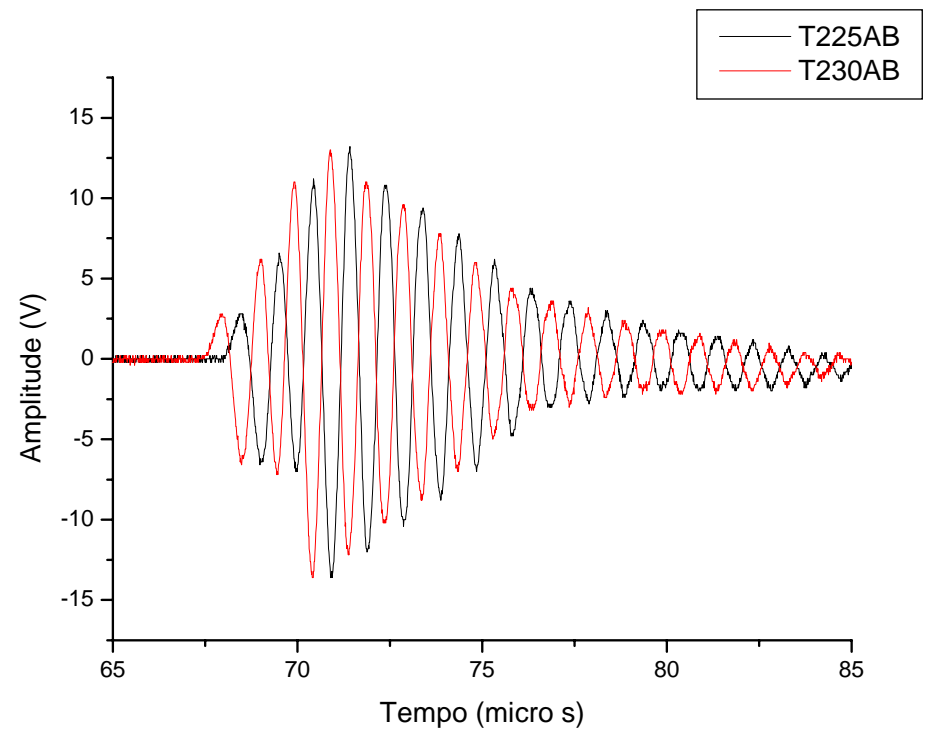

Figura 3.5.19. Sinal temporal para o par de transdutores $\mathrm{AB}(1 \mathrm{MHz})$ em água. Para as temperaturas de $25^{\circ} \mathrm{C}$ e $30^{\circ} \mathrm{C}$, para a tensão de $172 \mathrm{~V}$. 


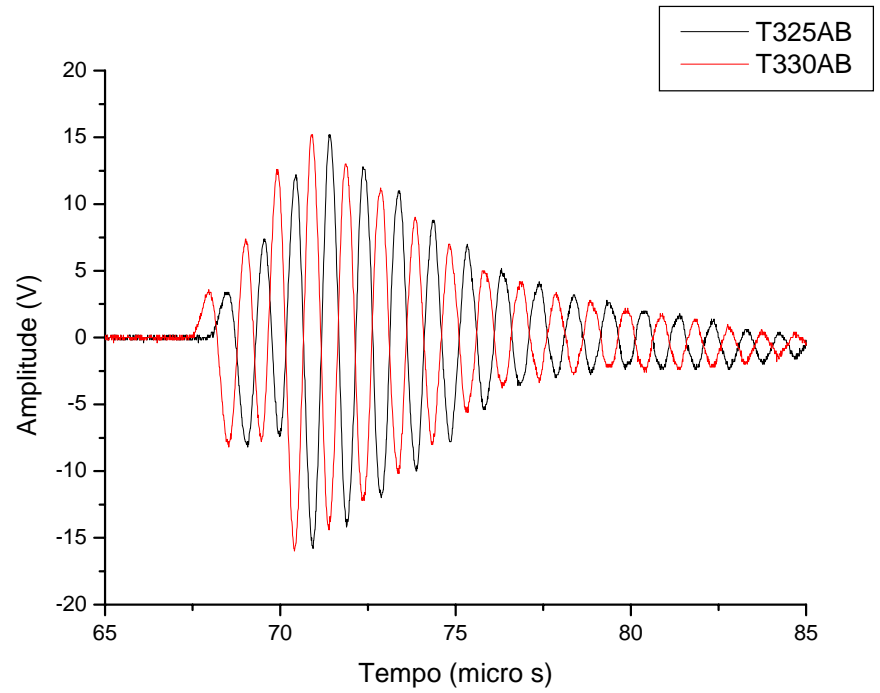

Figura 3.5.20. Sinal temporal para o par de transdutores $\mathrm{AB}(1 \mathrm{MHz})$ em água. Para as temperaturas de $25^{\circ} \mathrm{C}$ e $30^{\circ} \mathrm{C}$, para a tensão de $224 \mathrm{~V}$.

Nas figuras 3.5.21, 3.5.22 e 3.5.23, são apresentados os valores da potência relativa para o sinal na água, nas três tensões de trabalho do equipamento, como função da temperatura para o par de transdutores AB.
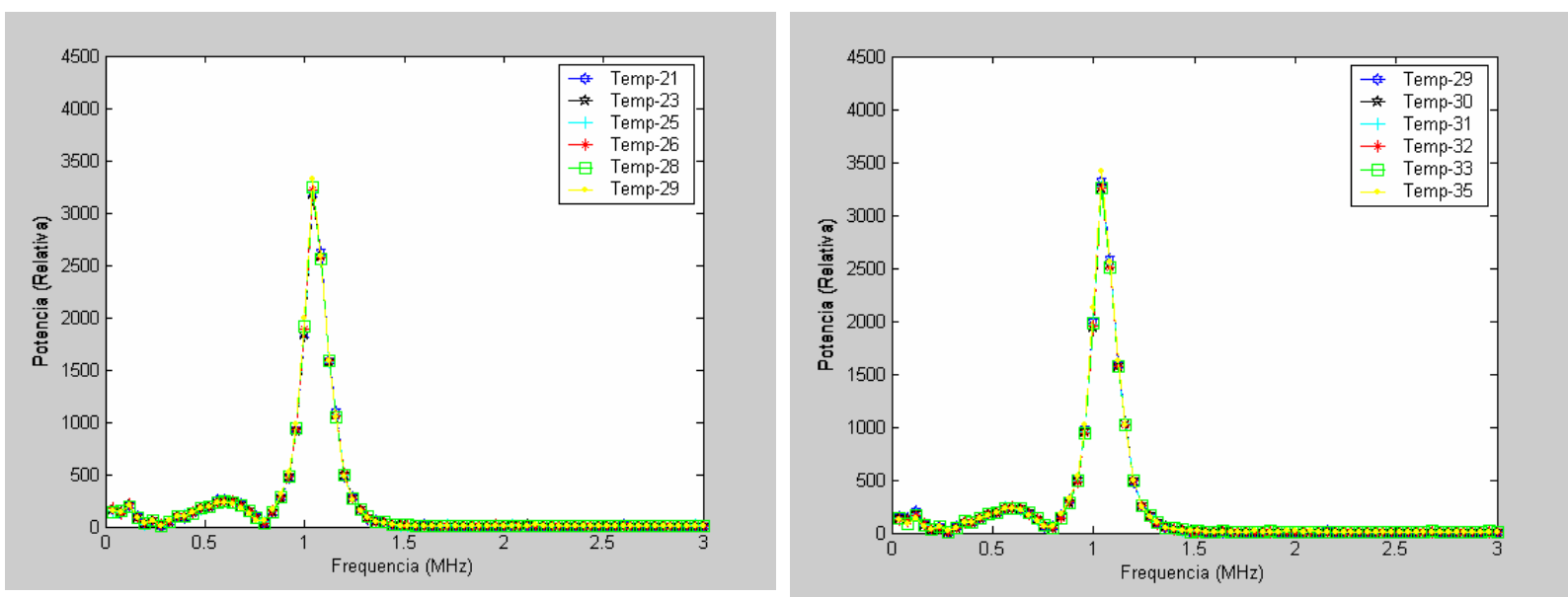

Figura 3.5.21. FFT dos sinais na água em função da temperatura para a tensão de $124 \mathrm{~V}$ para os transdutores AB. 

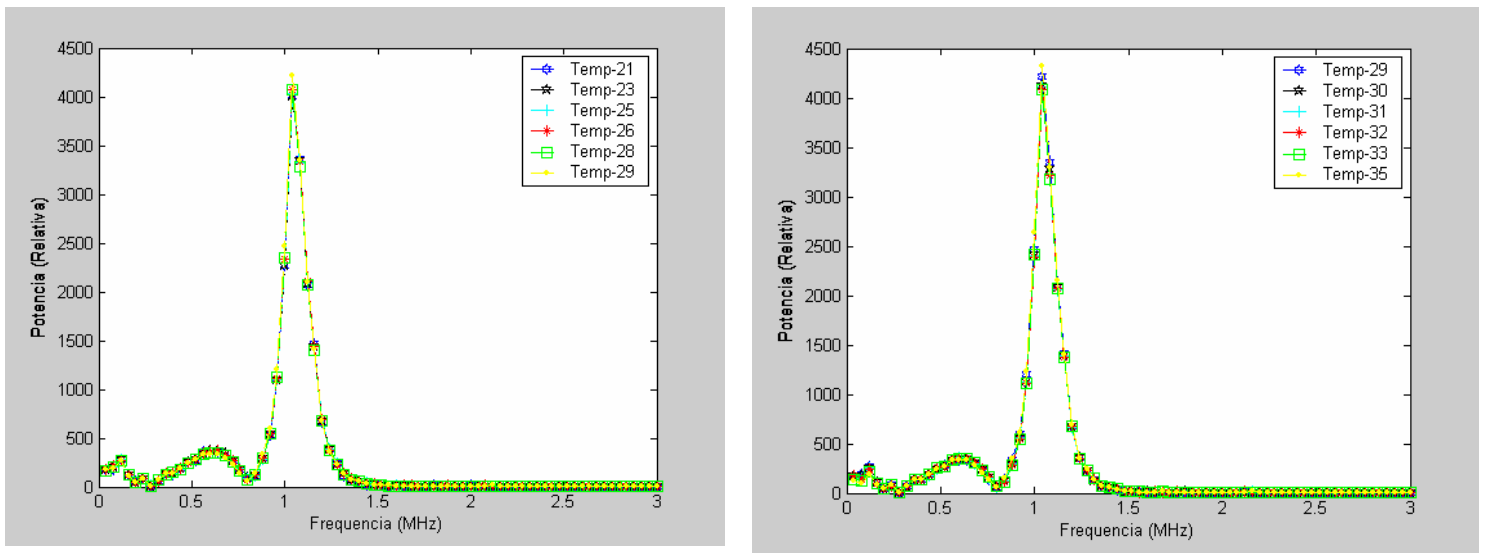

Figura 3.5.22. FFT dos sinais na água em função da temperatura para a tensão de 172V para os transdutores AB.
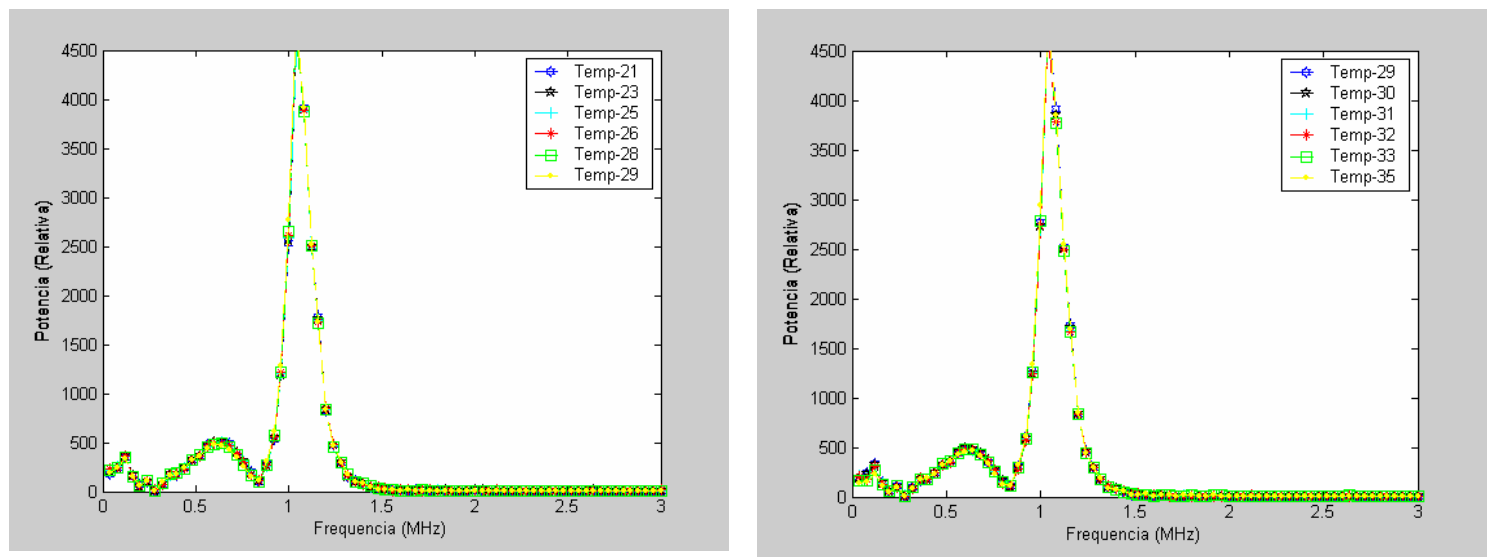

Figura 3.5.23. FFT dos sinais na água em função da temperatura para a tensão de 224V para os transdutores AB.

Na figura 3.5.24 são apresentados os resultados da velocidade do som em função da temperatura para o par AB de transdutores e também os valores teóricos para a velocidade gerados a partir da equação de quinto grau.

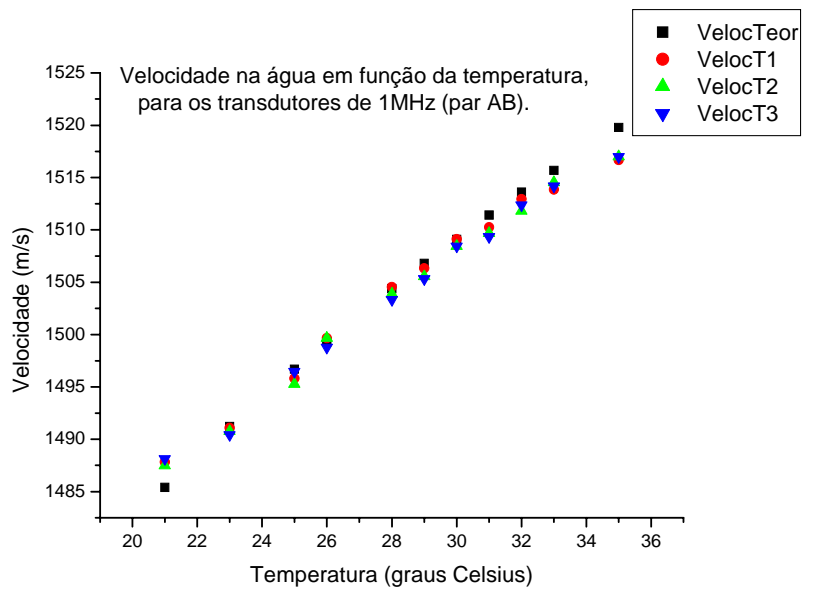

Figura 3.5.24. Velocidade do ultra-som na água como função da temperatura para os transdutores de $1 \mathrm{MHz}$ $(\mathrm{AB})$. 


\subsubsection{Transdutores de 1MHz, par NO.}

Nas figuras 3.5.25, 3.5.26 e 3.5.27 são apresentados os sinais temporais para a água, nas tensões de trabalho de $124 \mathrm{~V}, 172 \mathrm{~V}$ e $224 \mathrm{~V}$, respectivamente, como função da temperatura para o par de transdutores NO, para as temperaturas de $25^{\circ} \mathrm{C}$ e $30^{\circ} \mathrm{C}$.

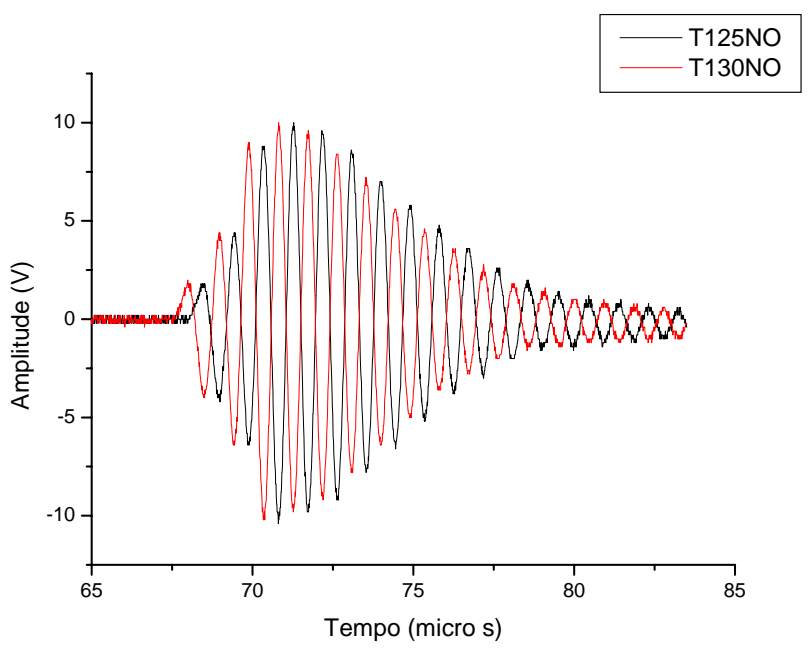

Figura 3.5.25. Sinal temporal para o par de transdutores NO $(1 \mathrm{MHz})$ em água. Para as temperaturas de $25^{0} \mathrm{C}$ e $30^{\circ} \mathrm{C}$, para a tensão de $124 \mathrm{~V}$.

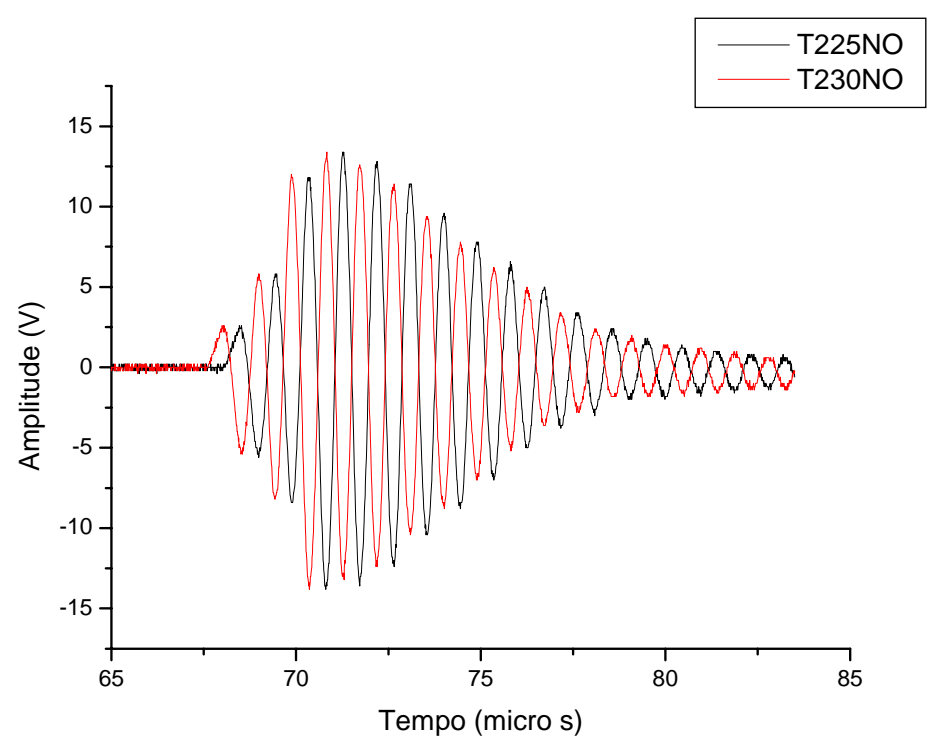

Figura 3.5.26. Sinal temporal para o par de transdutores $\mathrm{NO}(1 \mathrm{MHz})$ em água. Para as temperaturas de $25^{\circ} \mathrm{C}$ e $30^{\circ} \mathrm{C}$, para a tensão de $172 \mathrm{~V}$. 


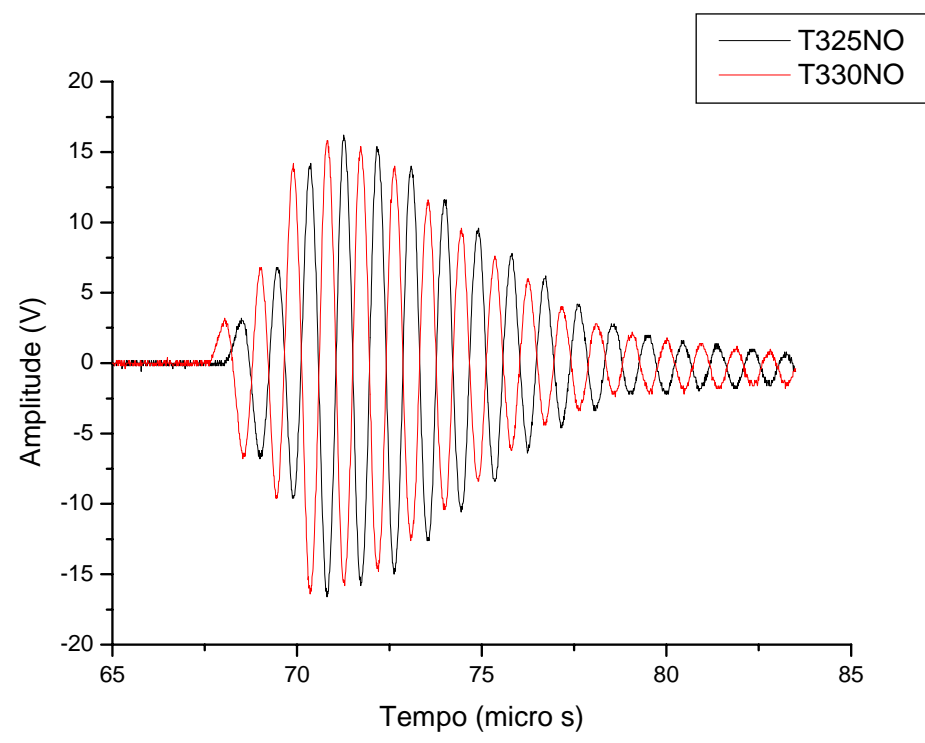

Figura 3.5.27. Sinal temporal para o par de transdutores $\mathrm{NO}(1 \mathrm{MHz})$ em água. Para as temperaturas de $25^{\circ} \mathrm{C}$ e $30^{\circ} \mathrm{C}$, para a tensão de $224 \mathrm{~V}$.

Nas figuras 3.5.28, 3.5.29 e 3.5.30, são apresentados os valores da potência relativa para o sinal na água, nas três tensões de trabalho do equipamento, como função da temperatura para o par de transdutores NO.
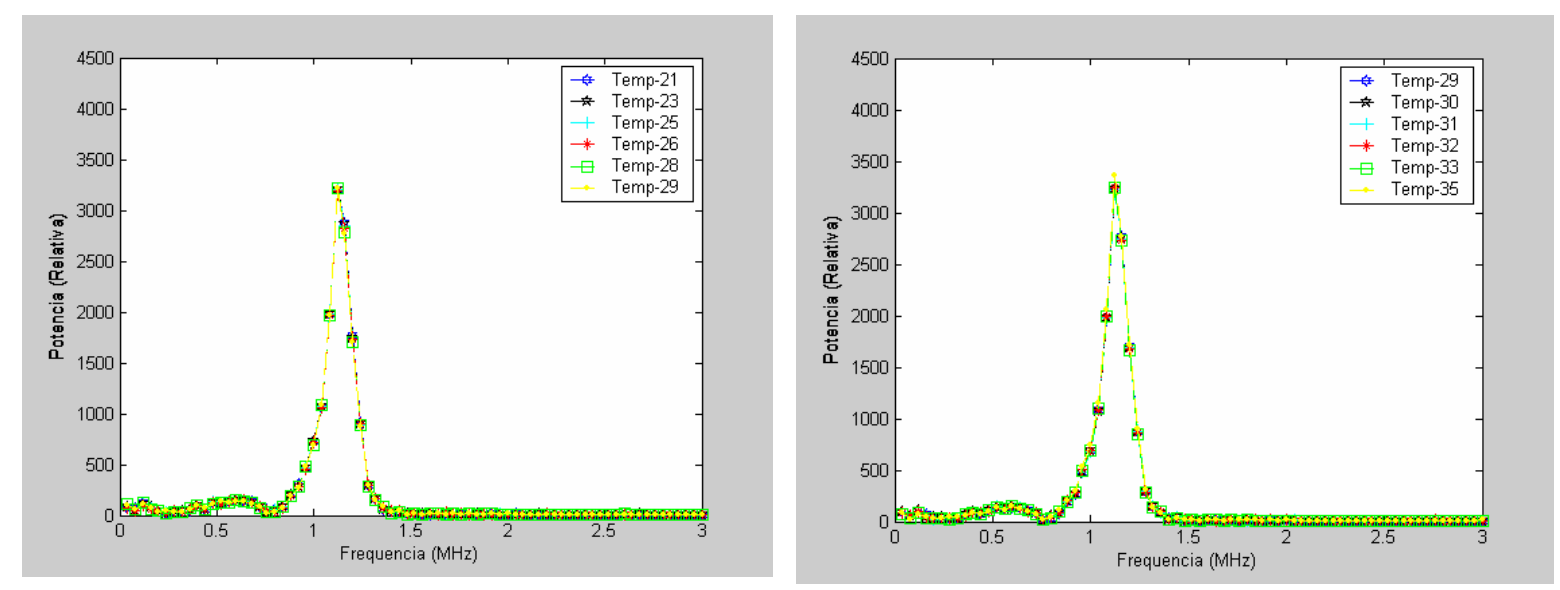

Figura 3.5.28. FFT dos sinais na água em função da temperatura para a tensão de $124 \mathrm{~V}$ para os transdutores NO. 

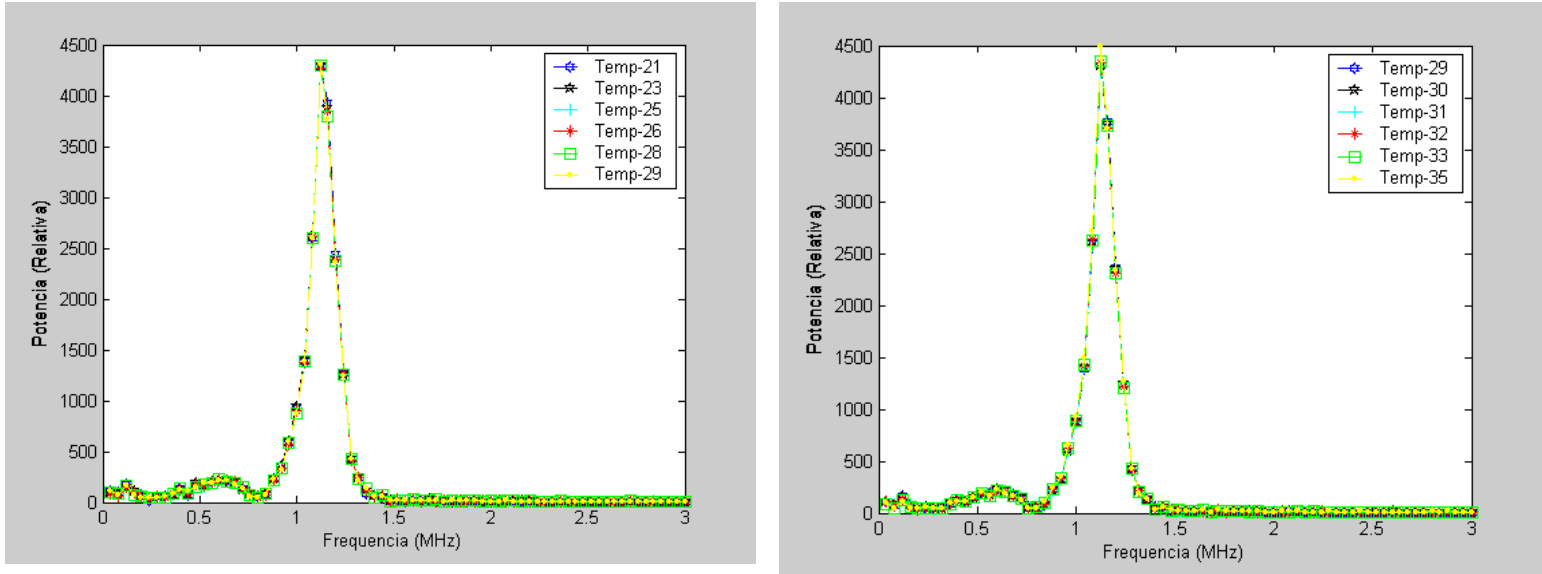

Figura 3.5.29. FFT dos sinais na água em função da temperatura para a tensão de 172V para os transdutores NO.
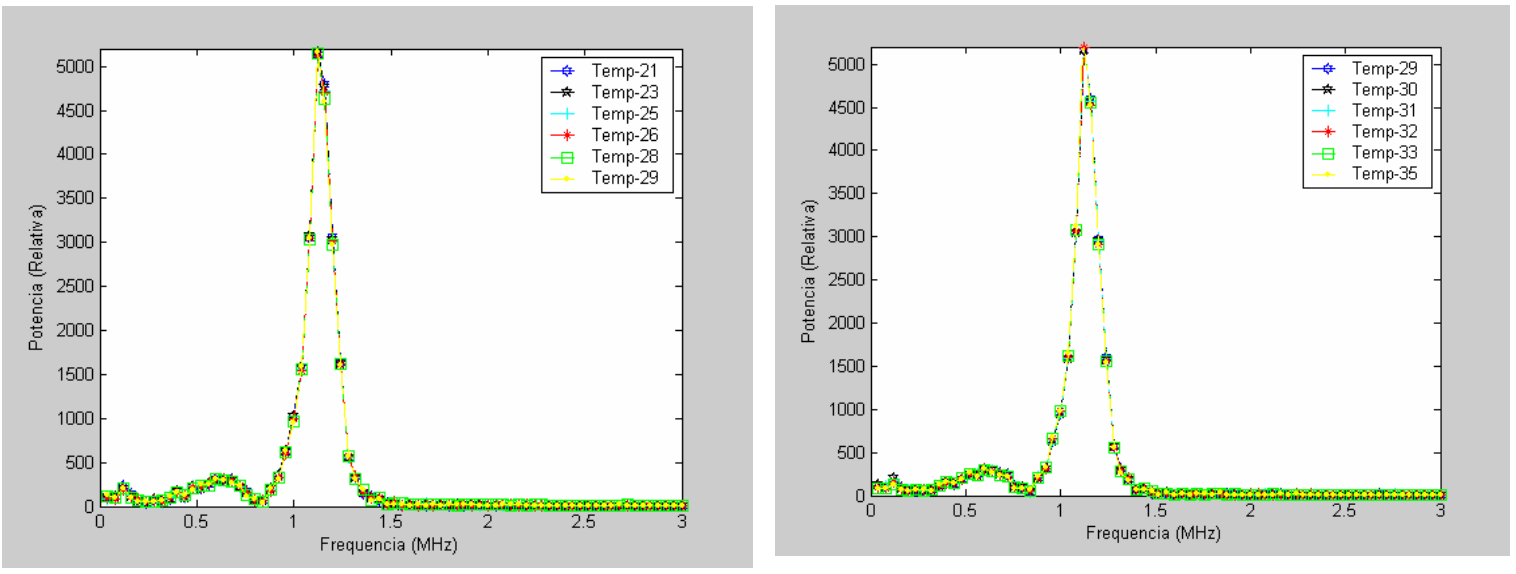

Figura 3.5.30. FFT dos sinais na água em função da temperatura para a tensão de 224V para os transdutores NO.

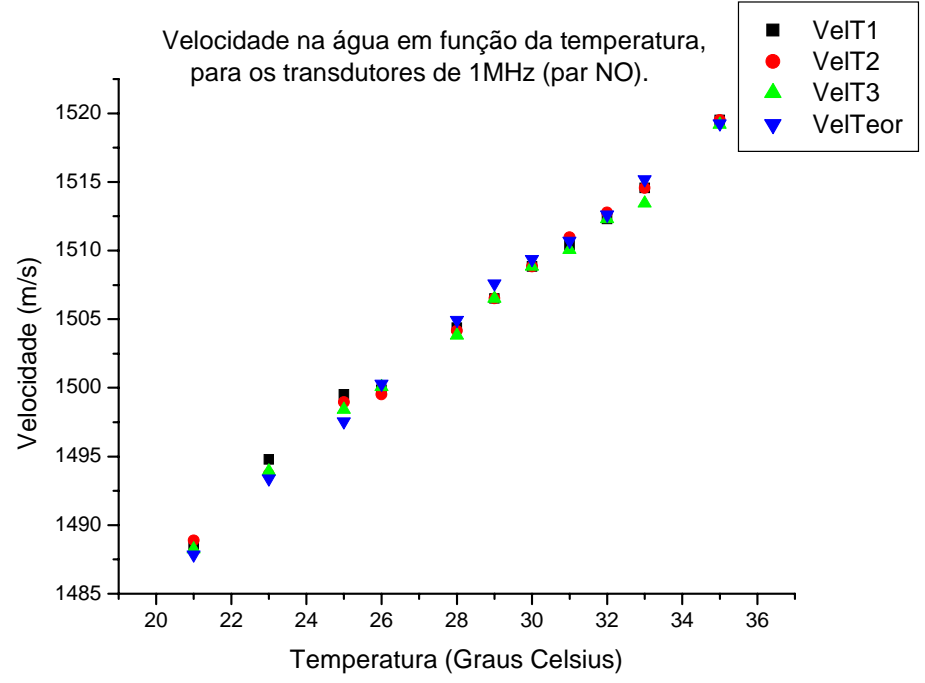

Figura 3.5.31. Velocidade do ultra-som na água como função da temperatura para os transdutores de 1MHz (NO). 


\subsubsection{Transdutores de 1MHz, par EF.}

Nas figuras 3.5.32, 3.5.33 e 3.5.34 são apresentados os sinais temporais para a água, nas tensões de trabalho de $124 \mathrm{~V}, 172 \mathrm{~V}$ e $224 \mathrm{~V}$, respectivamente, como função da temperatura para o par de transdutores $\mathrm{EF}$, para as temperaturas de $25^{\circ} \mathrm{C}$ e $30^{\circ} \mathrm{C}$.

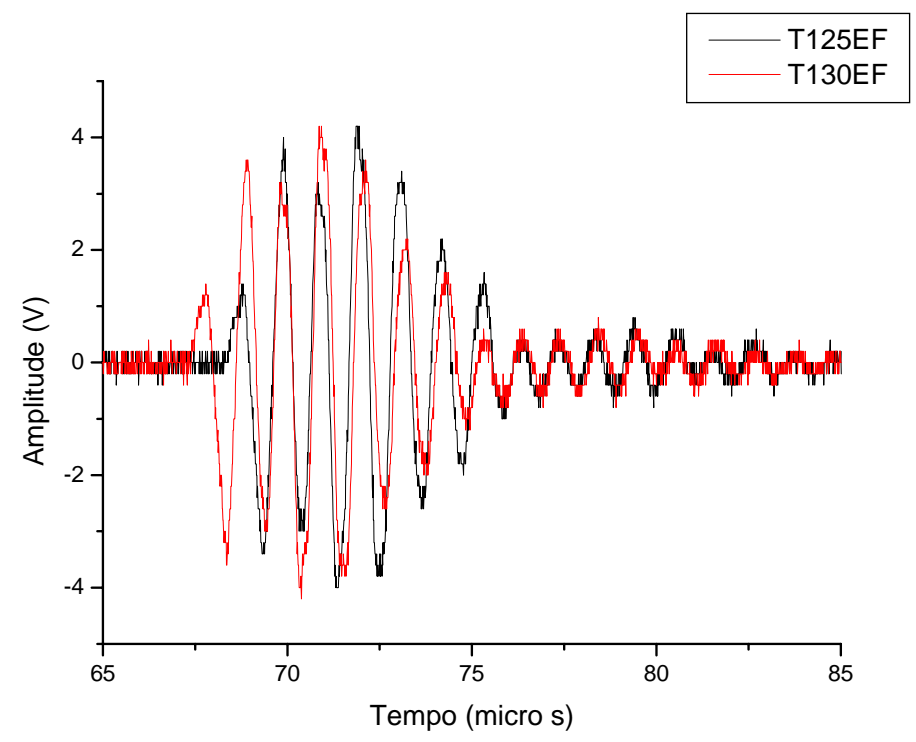

Figura 3.5.32. Sinal temporal para o par de transdutores EF (1MHz) em água. Para as temperaturas de $25^{\circ} \mathrm{C}$ e $30^{\circ} \mathrm{C}$, para a tensão de $124 \mathrm{~V}$.

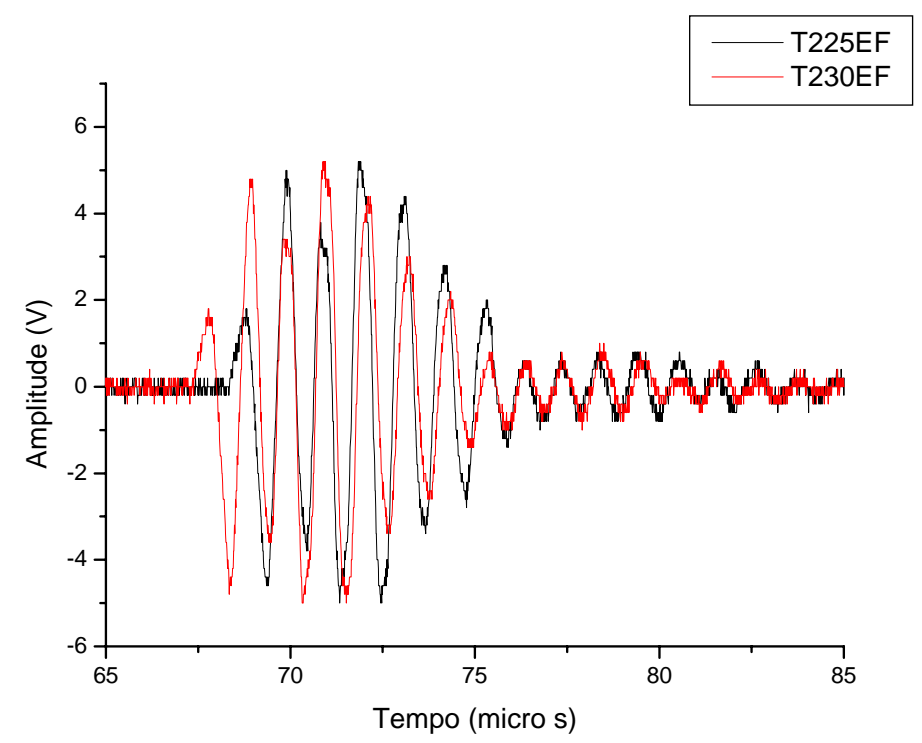

Figura 3.5.33. Sinal temporal para o par de transdutores EF (1MHz) em água. Para as temperaturas de $25^{\circ} \mathrm{C}$ e $30^{\circ} \mathrm{C}$, para a tensão de $172 \mathrm{~V}$. 


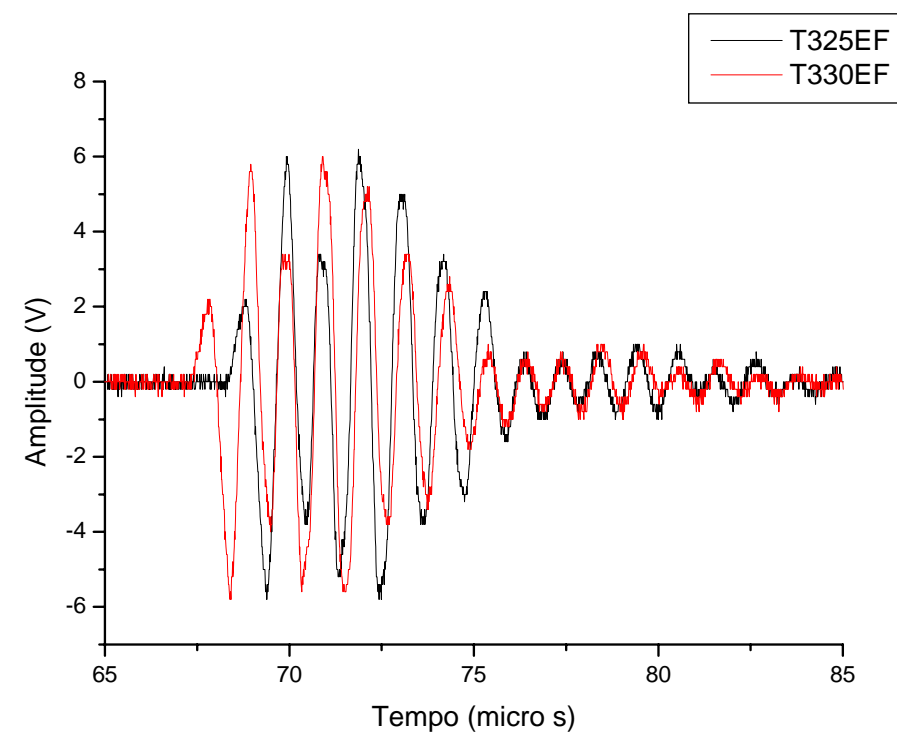

Figura 3.5.34. Sinal temporal para o par de transdutores EF (1MHz) em água. Para as temperaturas de $25^{\circ} \mathrm{C}$ e $30^{\circ} \mathrm{C}$, para a tensão de $224 \mathrm{~V}$.

Nas figuras 3.5.35, 3.5.36 e 3.5.37, são apresentados os valores da potência relativa para o sinal na água, nas três tensões de trabalho do equipamento, como função da temperatura para o par de transdutores EF.
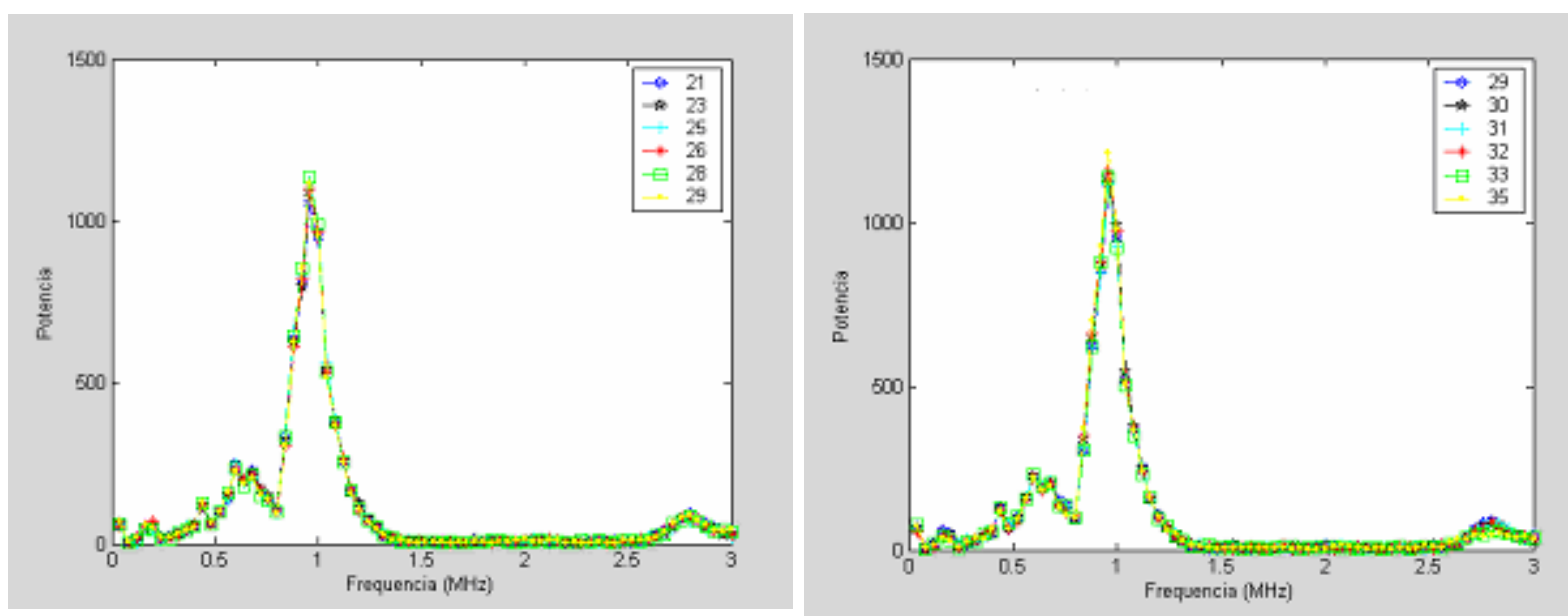

Figura 3.5.35. FFT dos sinais na água em função da temperatura para a tensão de 124V para os transdutores EF. 

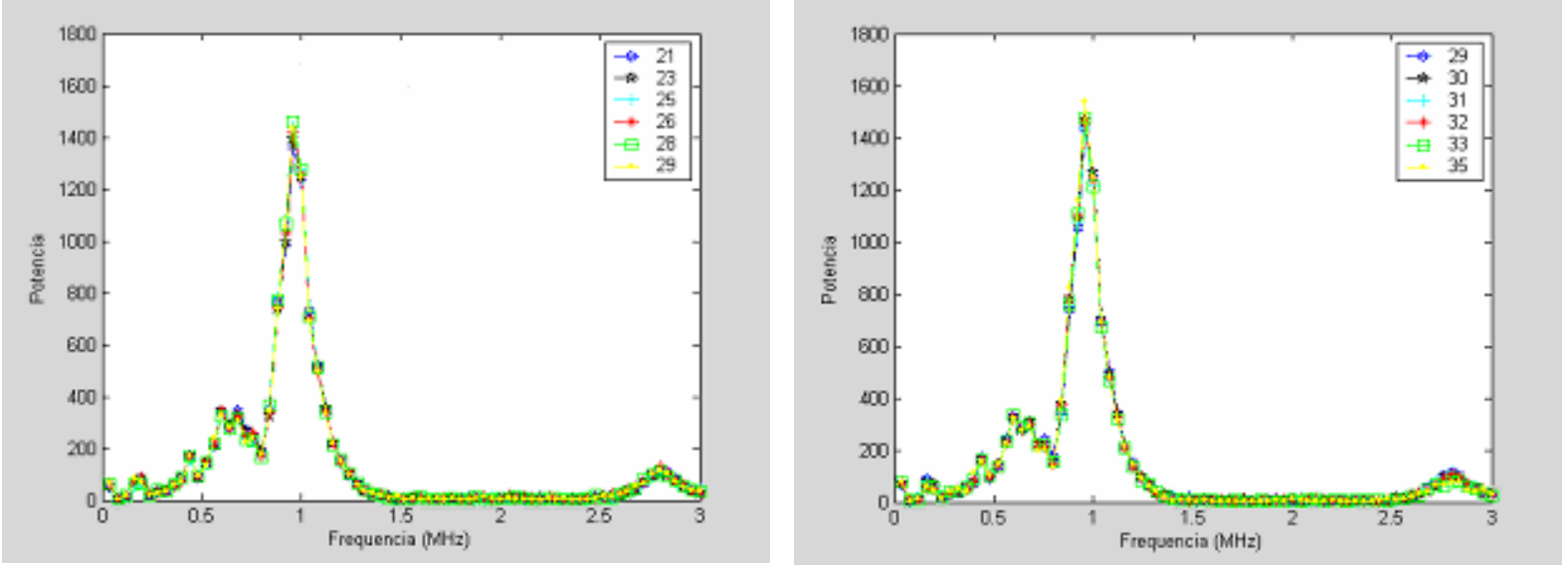

Figura 3.5.36. FFT dos sinais na água em função da temperatura para a tensão de $172 \mathrm{~V}$ para os transdutores EF.
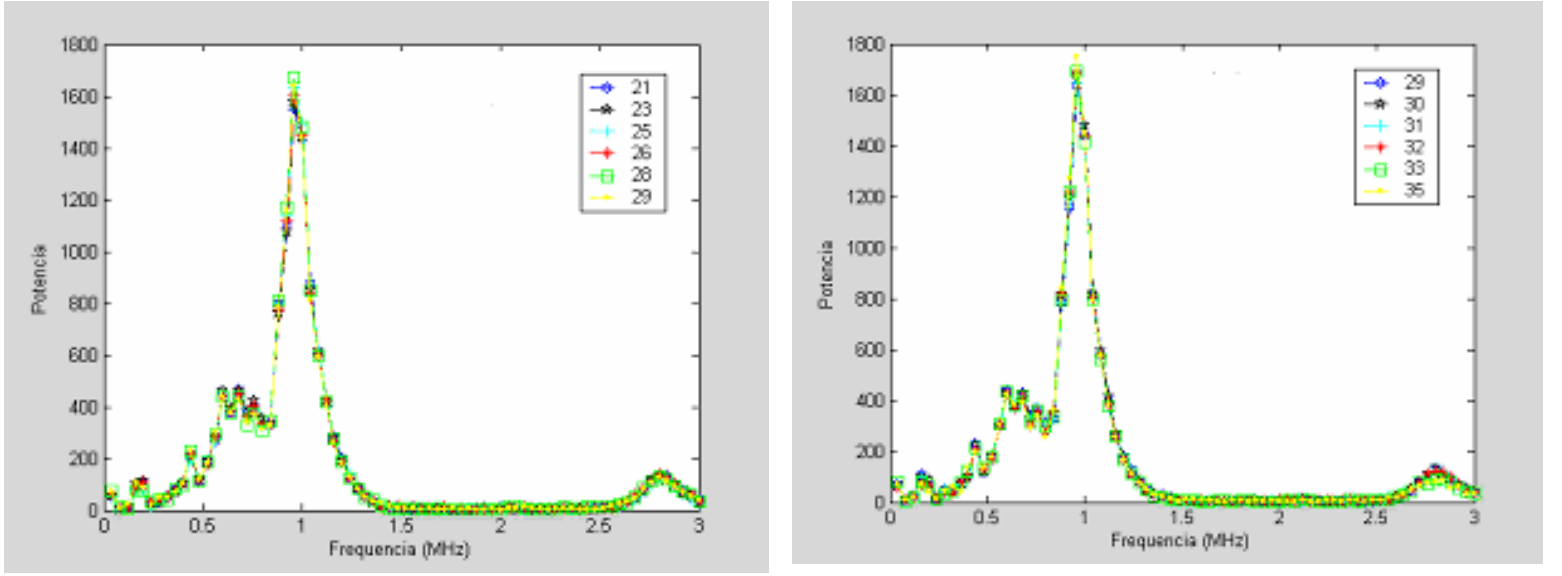

Figura 3.5.37. FFT dos sinais na água em função da temperatura para a tensão de 224V para os transdutores EF.

Na figura 3.5.38 são apresentados os resultados da velocidade do som em função da temperatura para os transdutores de $1 \mathrm{MHz}$ (par EF) e também os valores teóricos para a velocidade gerados a partir da equação de quinto grau.

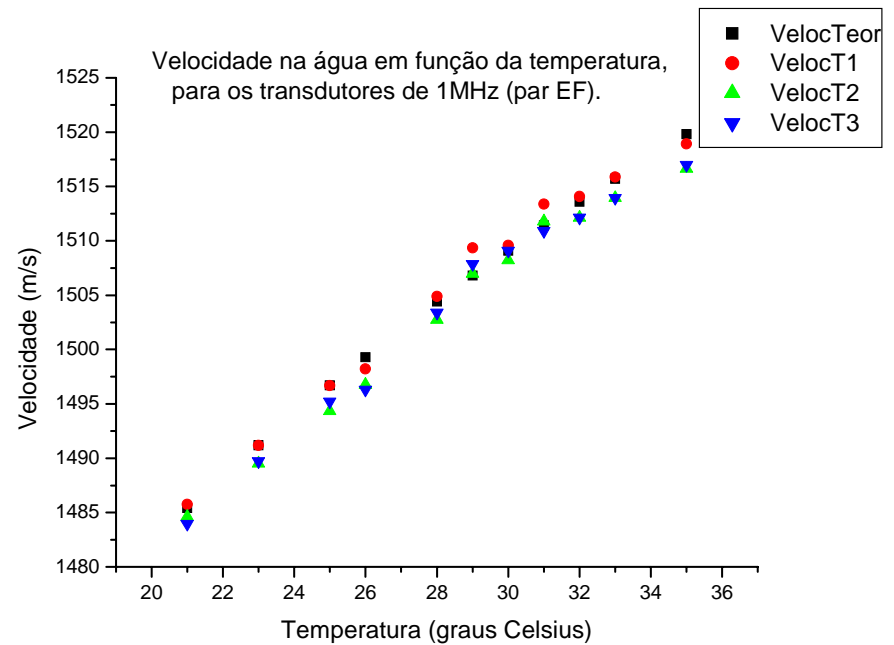

Figura 3.5.38. Velocidade na água em função da temperatura para os transdutores de $1 \mathrm{MHz}$ (EF). 


\subsubsection{Transdutores de 0,75MHz, par CD.}

Nas figuras 3.5.39, 3.5.40 e 3.5.41 são apresentados os sinais temporais para a água, nas tensões de trabalho de $124 \mathrm{~V}, 172 \mathrm{~V}$ e $224 \mathrm{~V}$, respectivamente, como função da temperatura para o par de transdutores $\mathrm{CD}$, para as temperaturas de $25^{\circ} \mathrm{C}$ e $30^{\circ} \mathrm{C}$.

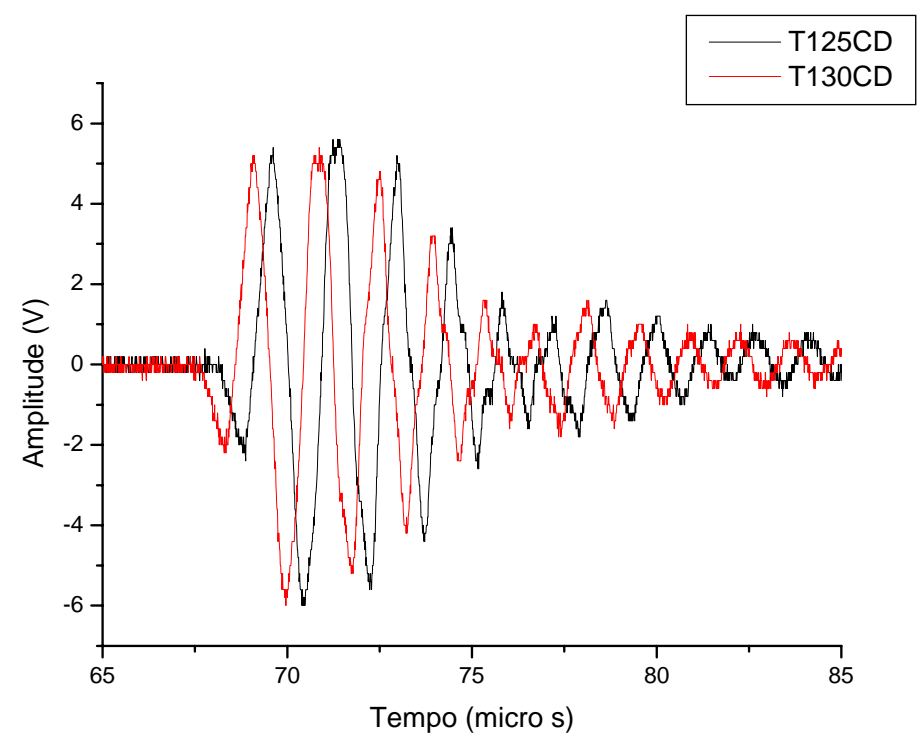

Figura 3.5.39. Sinal temporal para o par de transdutores CD $(0,75 \mathrm{MHz})$ em água. Para as temperaturas de $25^{0} \mathrm{C}$ e $30^{\circ} \mathrm{C}$, para a tensão de $124 \mathrm{~V}$.

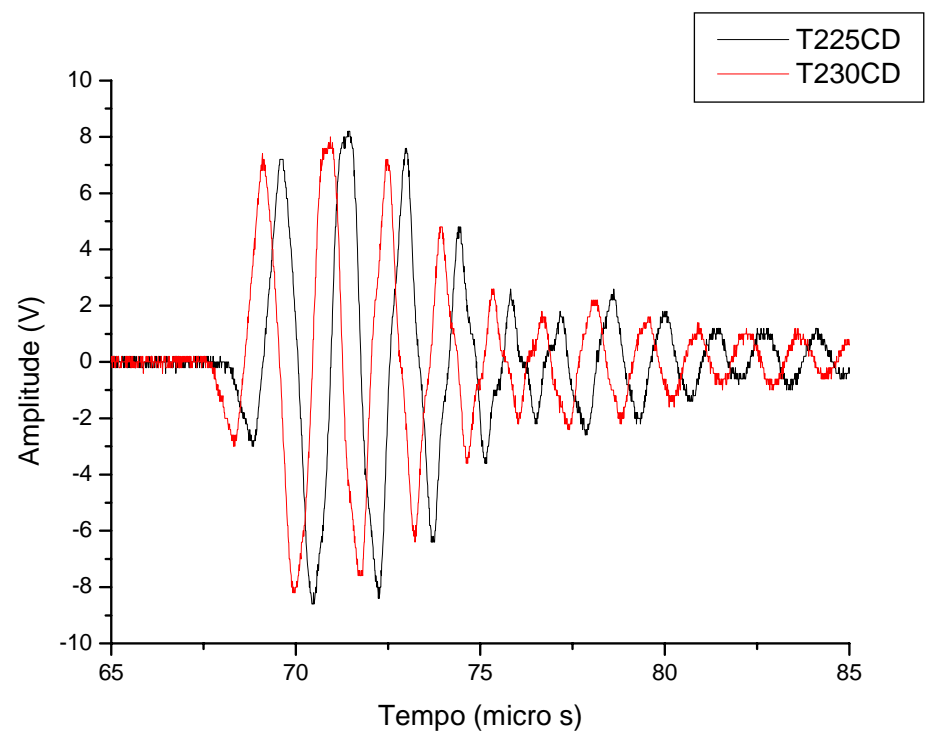

Figura 3.5.40. Sinal temporal para o par de transdutores CD $(0,75 \mathrm{MHz})$ em água. Para as temperaturas de $25^{\circ} \mathrm{C}$ e $30^{\circ} \mathrm{C}$, para a tensão de $172 \mathrm{~V}$. 


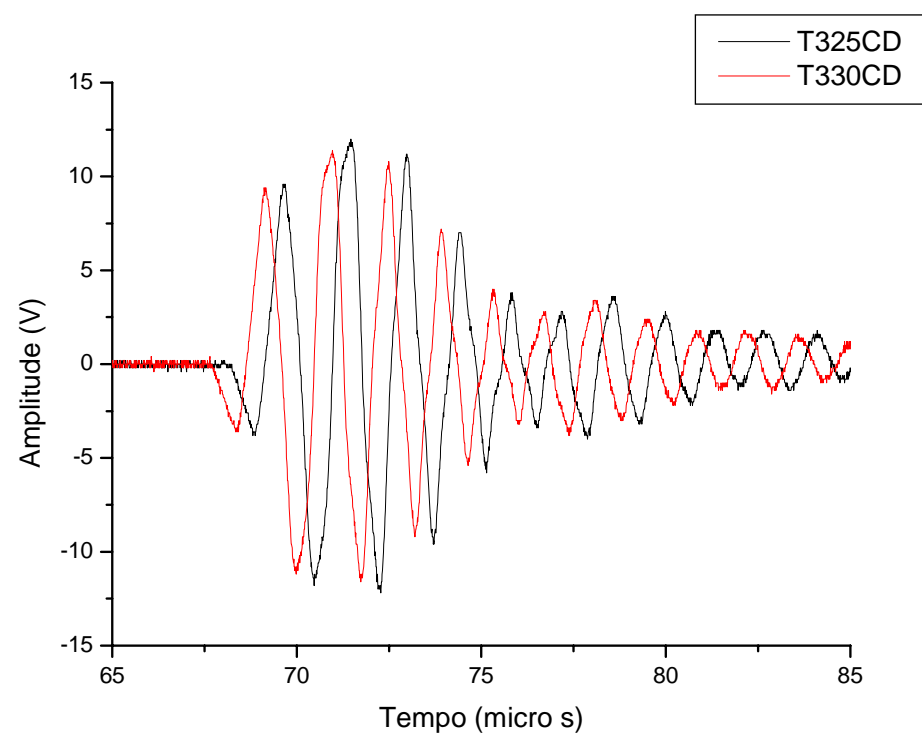

Figura 3.5.41. Sinal temporal para o par de transdutores $\mathrm{CD}(0,75 \mathrm{MHz})$ em água. Para as temperaturas de $25^{0} \mathrm{C}$ e $30^{\circ} \mathrm{C}$, para a tensão de $224 \mathrm{~V}$.

Nas figuras 3.5.42, 3.5.43 e 3.5.44 são apresentados os valores da potência relativa para o sinal na água, nas três tensões de trabalho do equipamento, como função da temperatura para o par de transdutores CD.
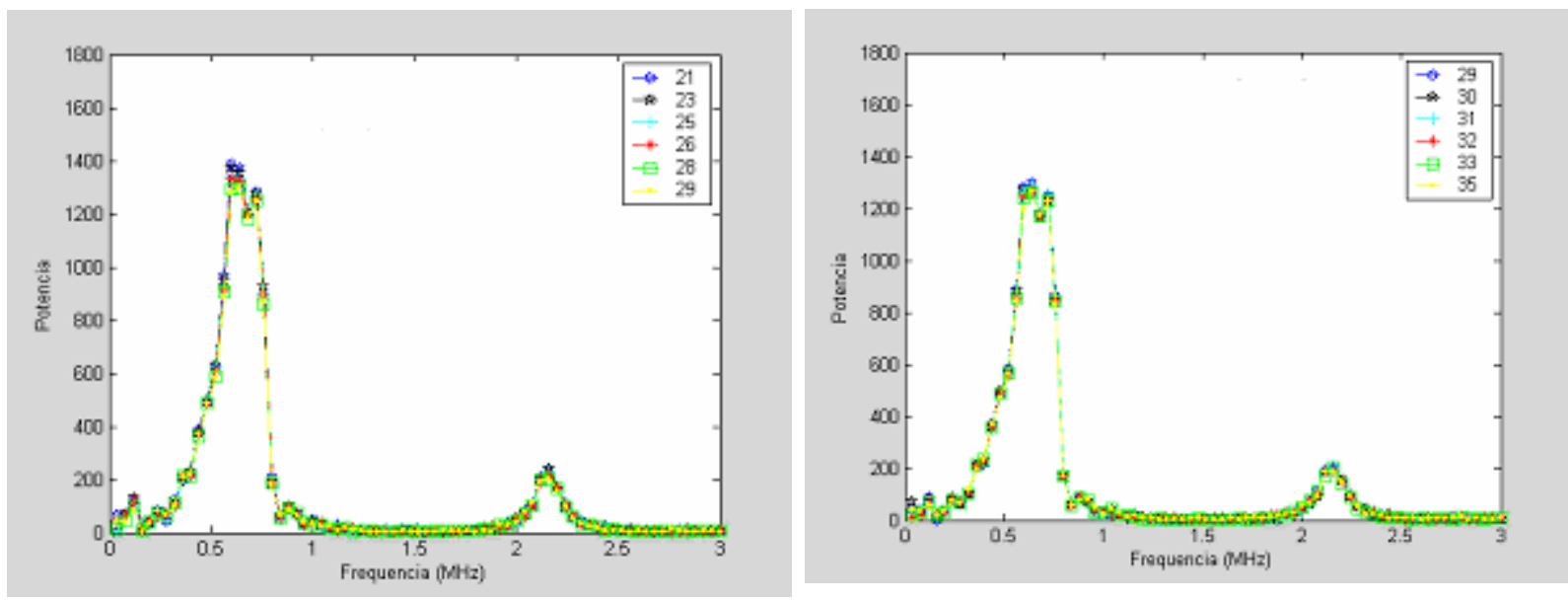

Figura 3.5.42. FFT dos sinais na água em função da temperatura para a tensão de 124V para os transdutores CD. 

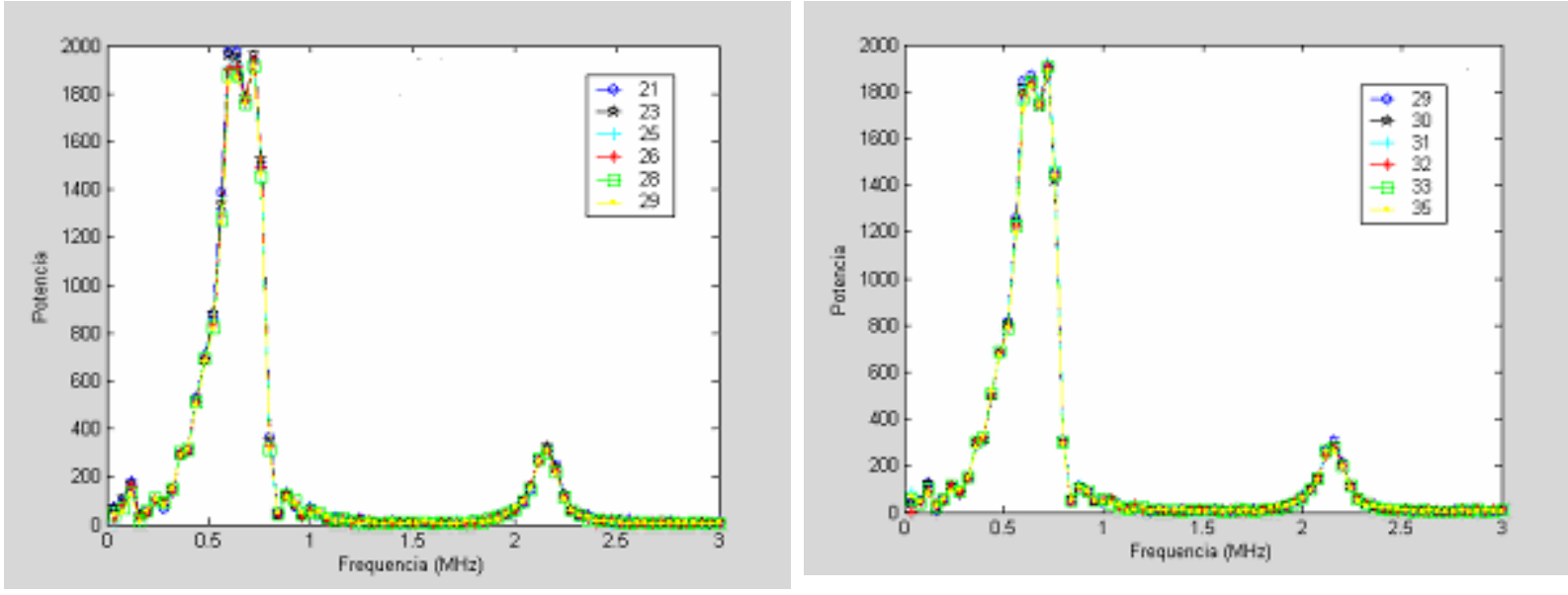

Figura 3.5.43. FFT dos sinais na água em função da temperatura para a tensão de 172V para os transdutores CD.
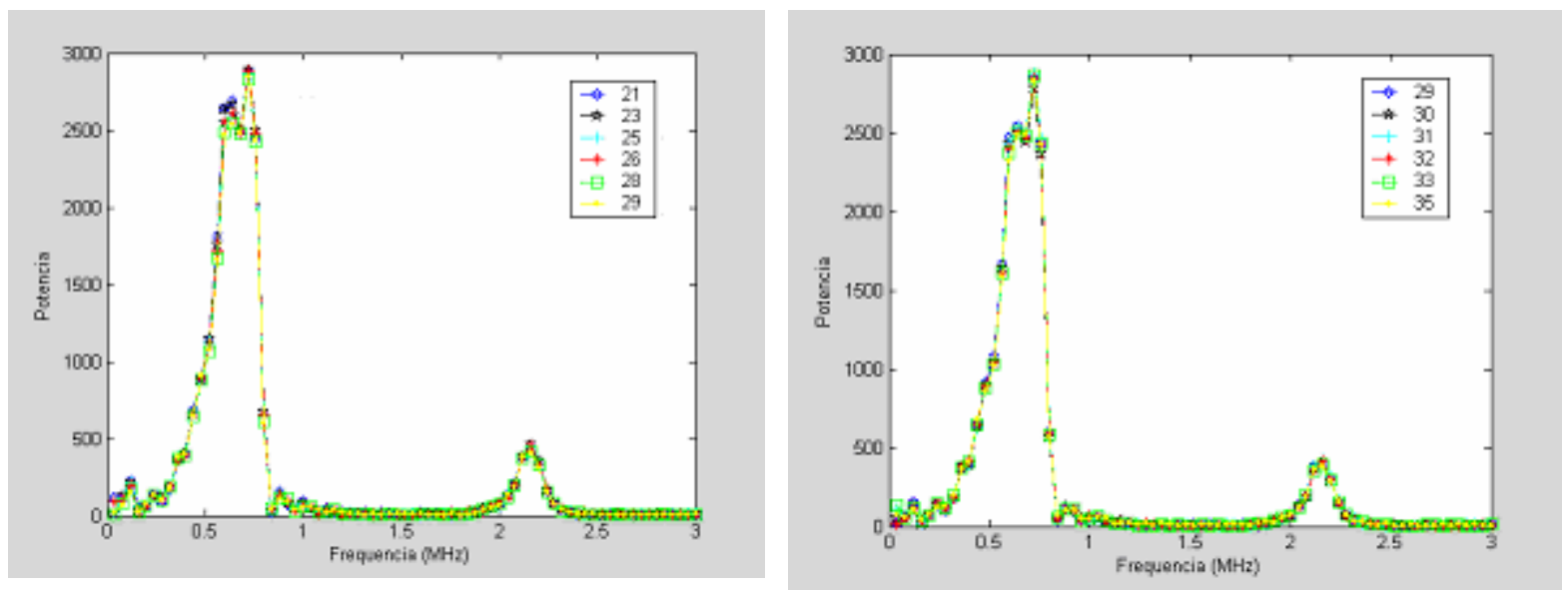

Figura 3.5.44. FFT dos sinais na água em função da temperatura para a tensão de 224V para os transdutores CD.

Na figura 3.5.45 são apresentados os resultados da velocidade do som em função da temperatura para os transdutores de $0,75 \mathrm{MHz}$ (par CD) e também os valores teóricos para a velocidade gerados a partir da equação de quinto grau.

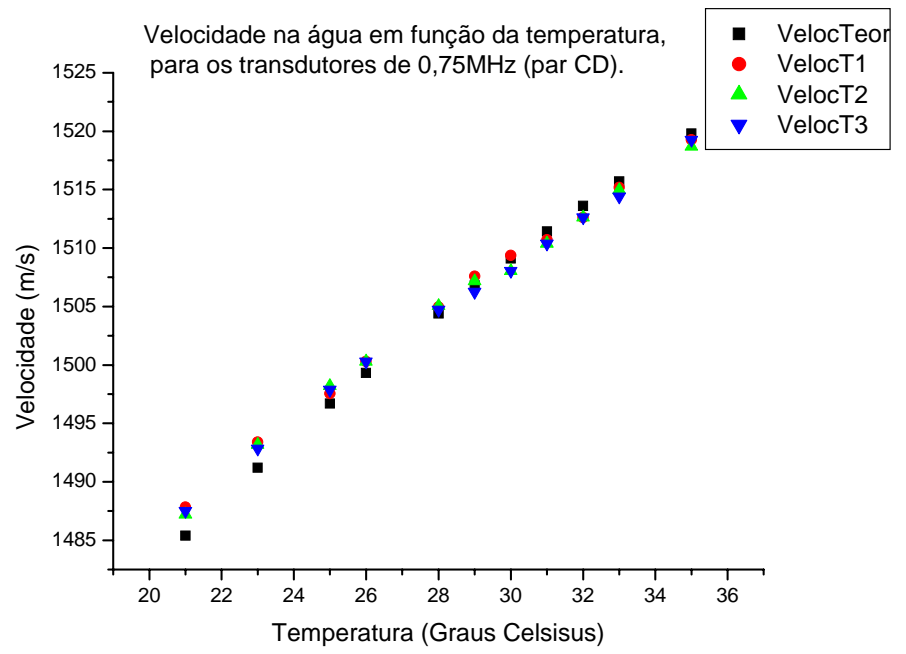

Figura 3.5.46. Velocidade na água em função da temperatura para os transdutores de 0,75MHz (CD). 


\subsubsection{Transdutores de 2MHz, par IG.}

Nas figuras 3.5.47, 3.5.48 e 3.5.49 são apresentados os sinais temporais para a água, nas tensões de trabalho de $124 \mathrm{~V}, 172 \mathrm{~V}$ e $224 \mathrm{~V}$, respectivamente, como função da temperatura para o par de transdutores IG, para as temperaturas de $25^{\circ} \mathrm{C}$ e $30^{\circ} \mathrm{C}$.

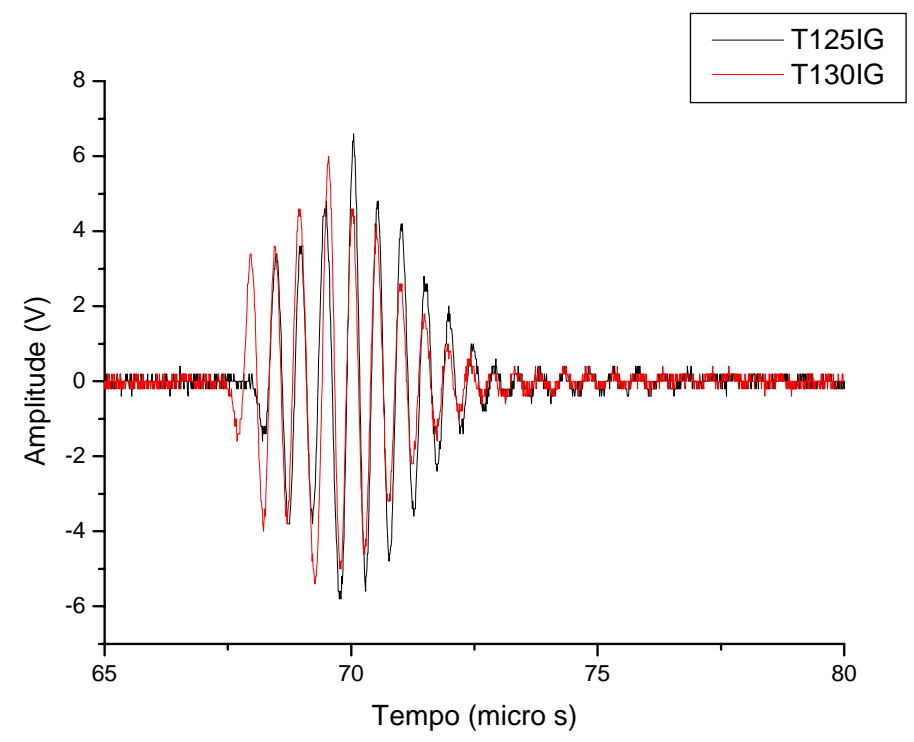

Figura 3.5.47. Sinal temporal para o par de transdutores IG $(2 \mathrm{MHz})$ em água. Para as temperaturas de $25^{\circ} \mathrm{C}$ e $30^{\circ} \mathrm{C}$, para a tensão de $124 \mathrm{~V}$.

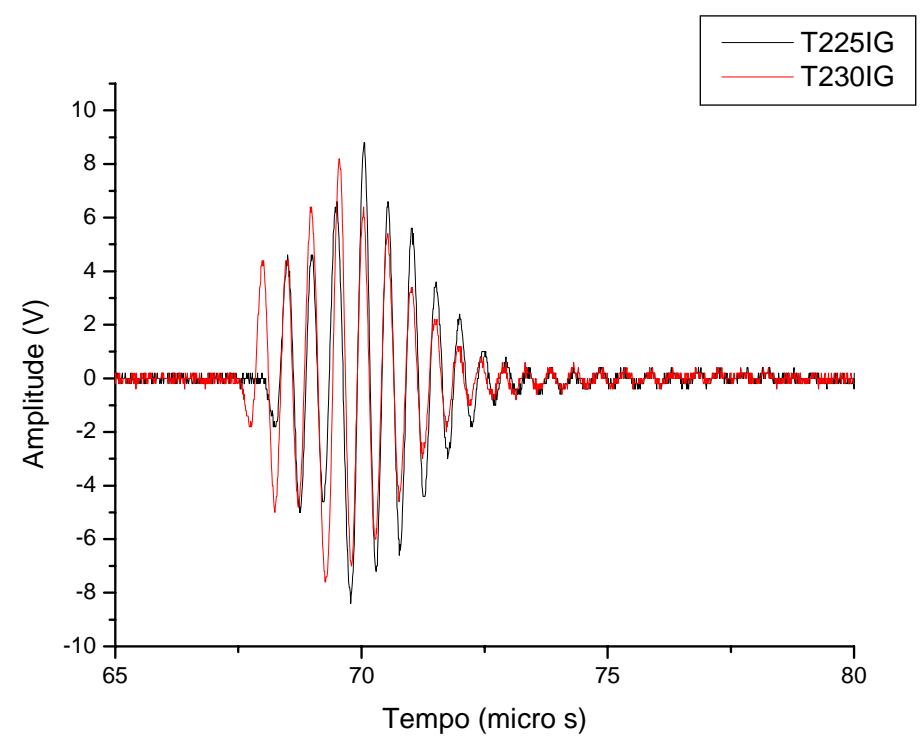

Figura 3.5.48. Sinal temporal para o par de transdutores IG (2MHz) em água. Para as temperaturas de $25^{\circ} \mathrm{C}$ e $30^{\circ} \mathrm{C}$, para a tensão de $172 \mathrm{~V}$. 


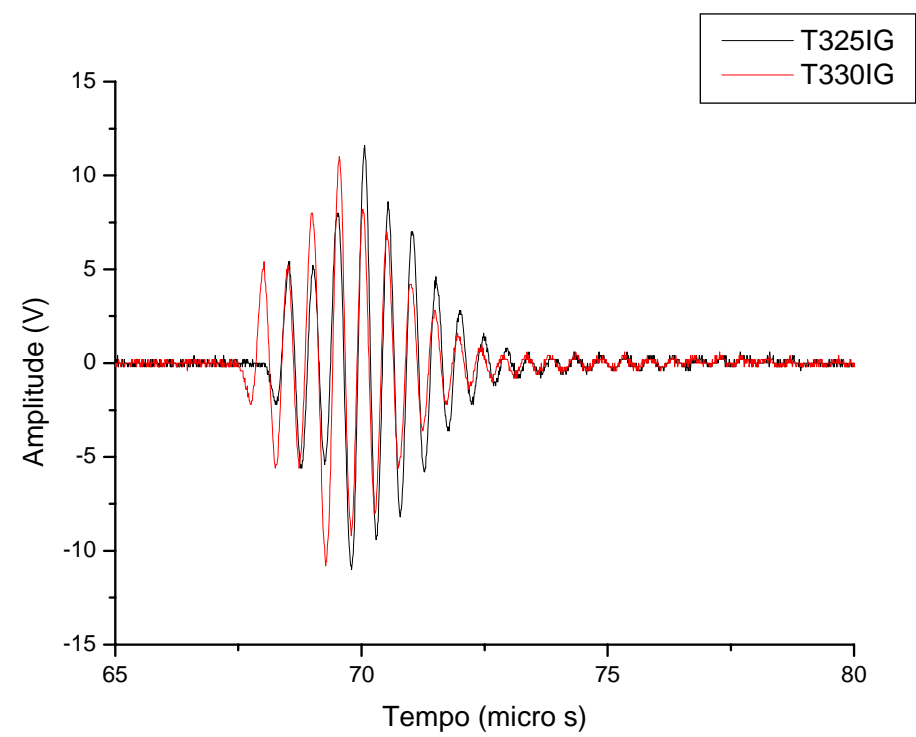

Figura 3.5.49. Sinal temporal para o par de transdutores IG (2MHz) em água. Para as temperaturas de $25^{\circ} \mathrm{C}$ e $30^{\circ} \mathrm{C}$, para a tensão de $224 \mathrm{~V}$.

Nas figuras 3.5.50, 3.5.51 e 3.5.52, são apresentados os valores da potência relativa para o sinal na água, nas três tensões de trabalho do equipamento, como função da temperatura para o par de transdutores IG.
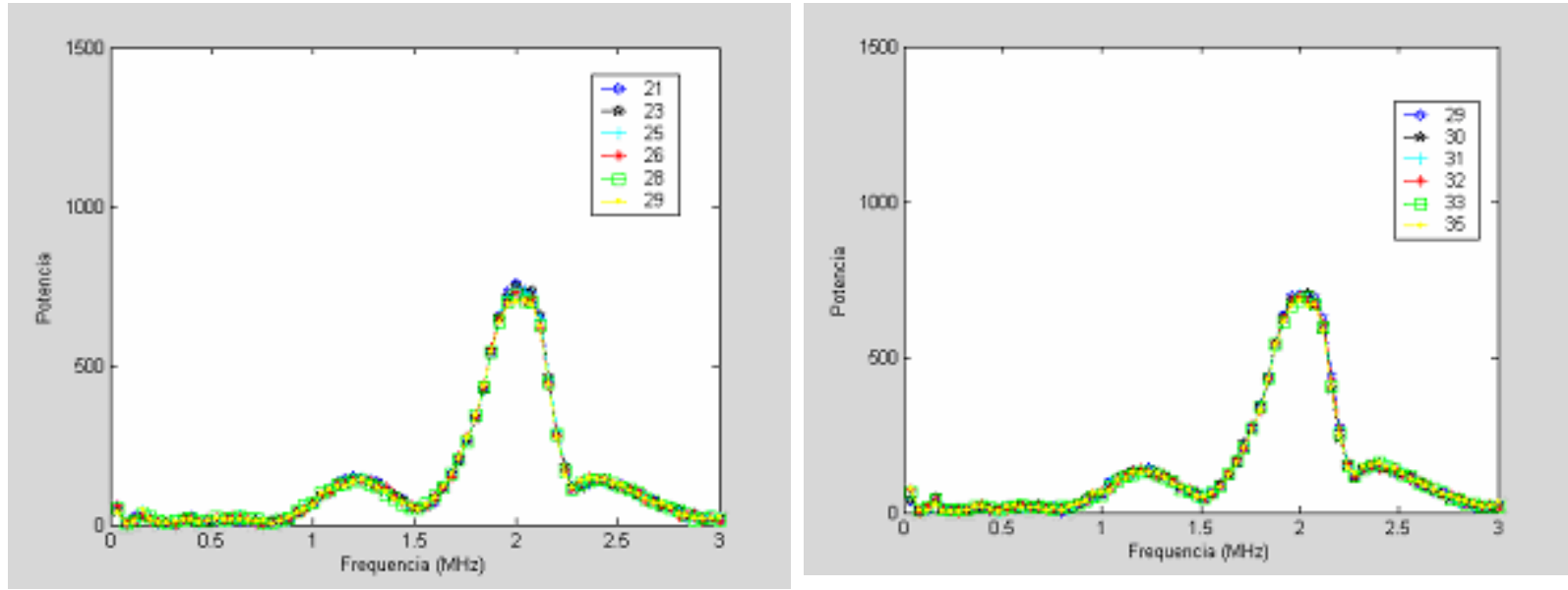

Figura 3.5.50. FFT dos sinais na água em função da temperatura para a tensão de 124V para os transdutores IG. 

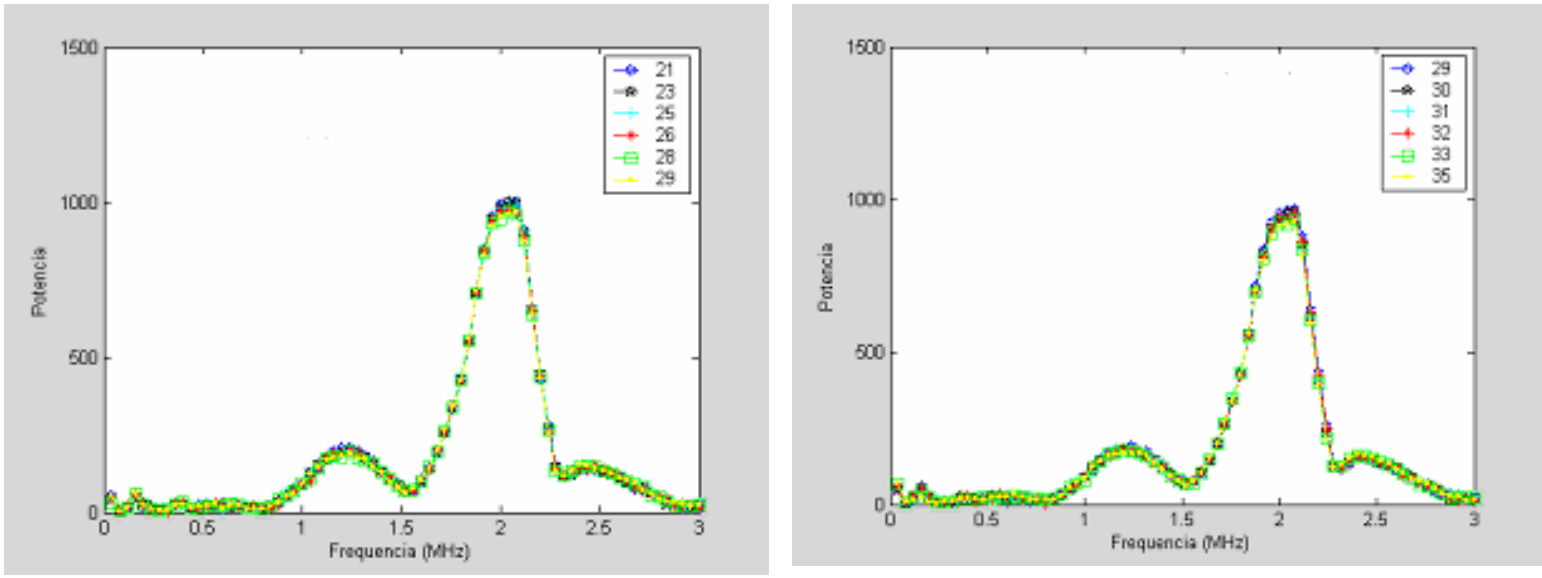

Figura 3.5.51. FFT dos sinais na água em função da temperatura para a tensão de 172V para os transdutores IG.
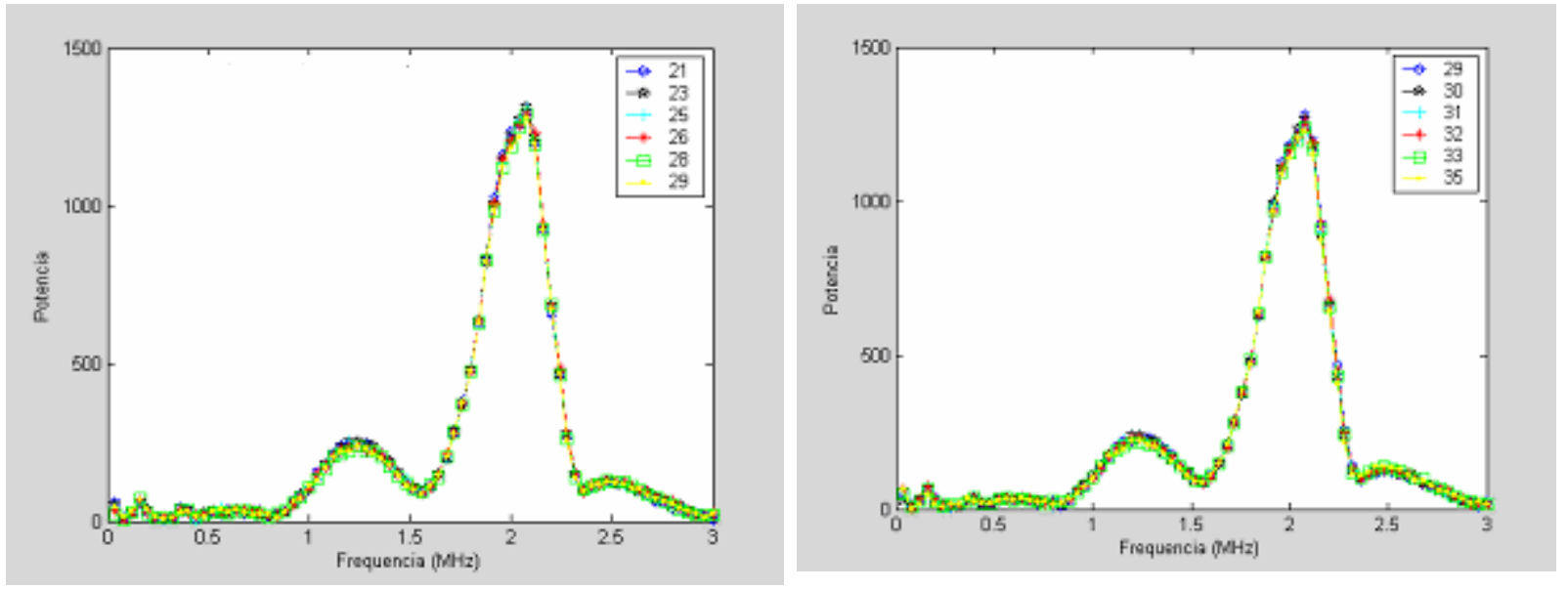

Figura 3.5.52. FFT dos sinais na água em função da temperatura para a tensão de $224 \mathrm{~V}$ para os transdutores IG.

Na figura 3.5.53 são apresentados os resultados da velocidade do som em função da temperatura para os transdutores de $2 \mathrm{MHz}$ (par IG) e também os valores teóricos para a velocidade gerados a partir da equação de quinto grau.

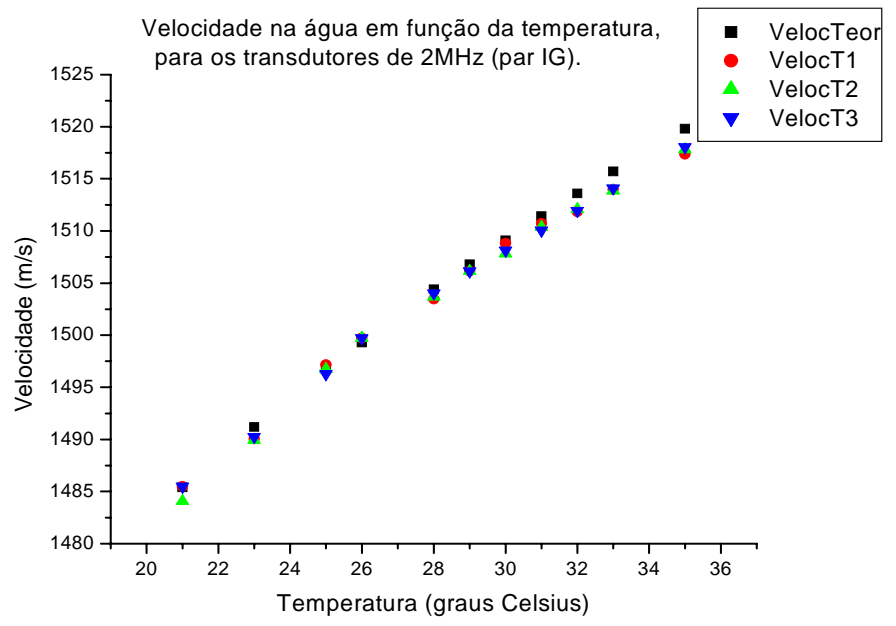

Figura 3.5.53. Velocidade na água em função da temperatura para os transdutores de 2MHz (IG). 


\subsubsection{Transdutores de 2MHz, par LM.}

Nas figuras 3.5.54, 3.5.55 e 3.5.56 são apresentados os sinais temporais para a água, na tensão de trabalho de $124 \mathrm{~V}, 172 \mathrm{~V}$ e $224 \mathrm{~V}$, respectivamente, como função da temperatura para o par de transdutores $\mathrm{LM}$, para as temperaturas de $25^{\circ} \mathrm{C}$ e $30^{\circ} \mathrm{C}$.

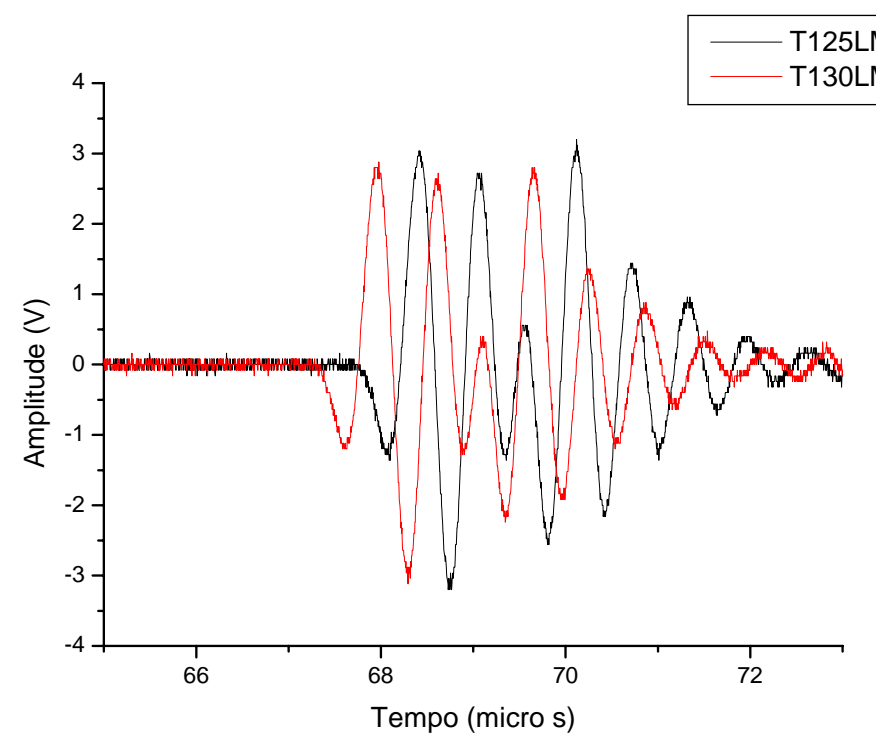

Figura 3.5.54. Sinal temporal para o par de transdutores LM (2MHz) em água. Para as temperaturas de $25^{\circ} \mathrm{C}$ e $30^{\circ} \mathrm{C}$, para a tensão de $124 \mathrm{~V}$.

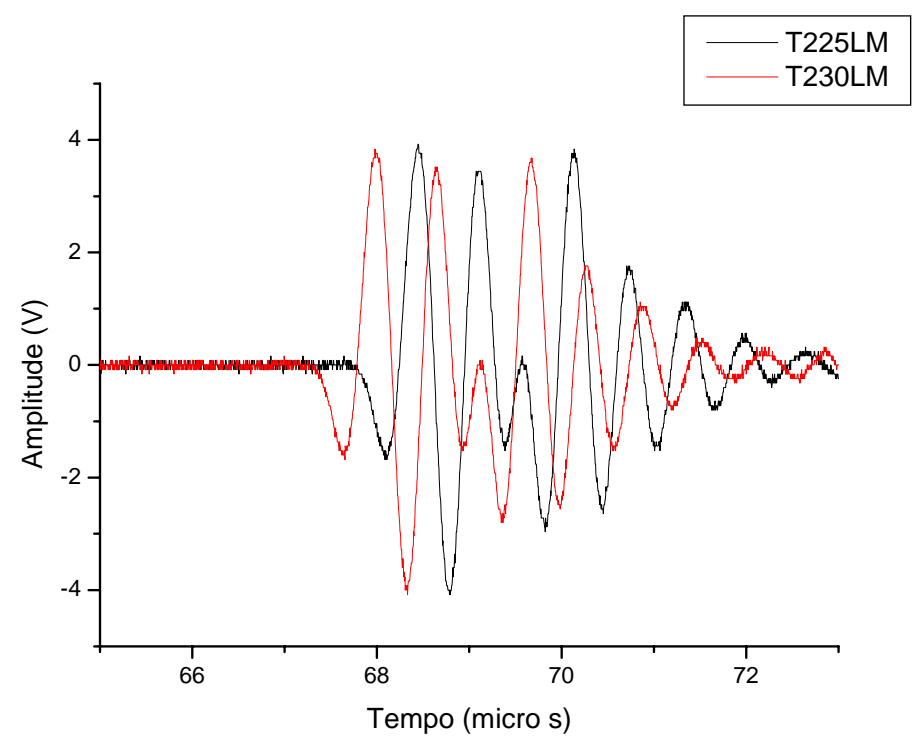

Figura 3.5.55. Sinal temporal para o par de transdutores LM (2MHz) em água. Para as temperaturas de $25^{\circ} \mathrm{C}$ e $30^{\circ} \mathrm{C}$, para a tensão de $172 \mathrm{~V}$. 


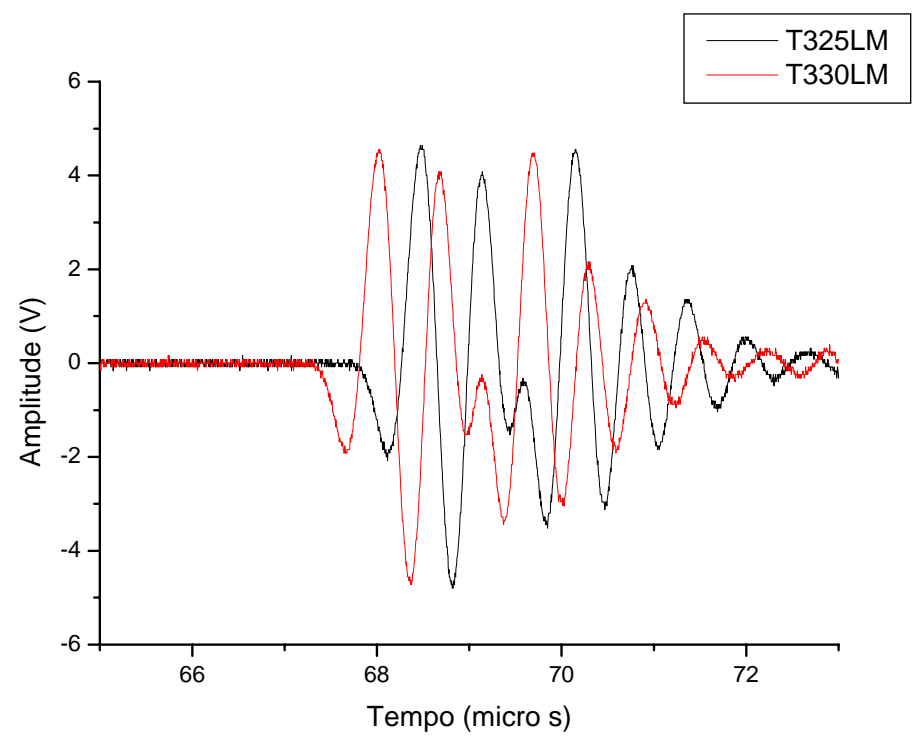

Figura 3.5.56. Sinal temporal para o par de transdutores LM (2MHz) em água. Para as temperaturas de $25^{\circ} \mathrm{C}$ e $30^{\circ} \mathrm{C}$, para a tensão de $224 \mathrm{~V}$.

Nas figuras 3.5.57, 3.5.58 e 3.5.59, são apresentados os valores da potência relativa para o sinal na água, nas três tensões de trabalho do equipamento, como função da temperatura para o par de transdutores LM.
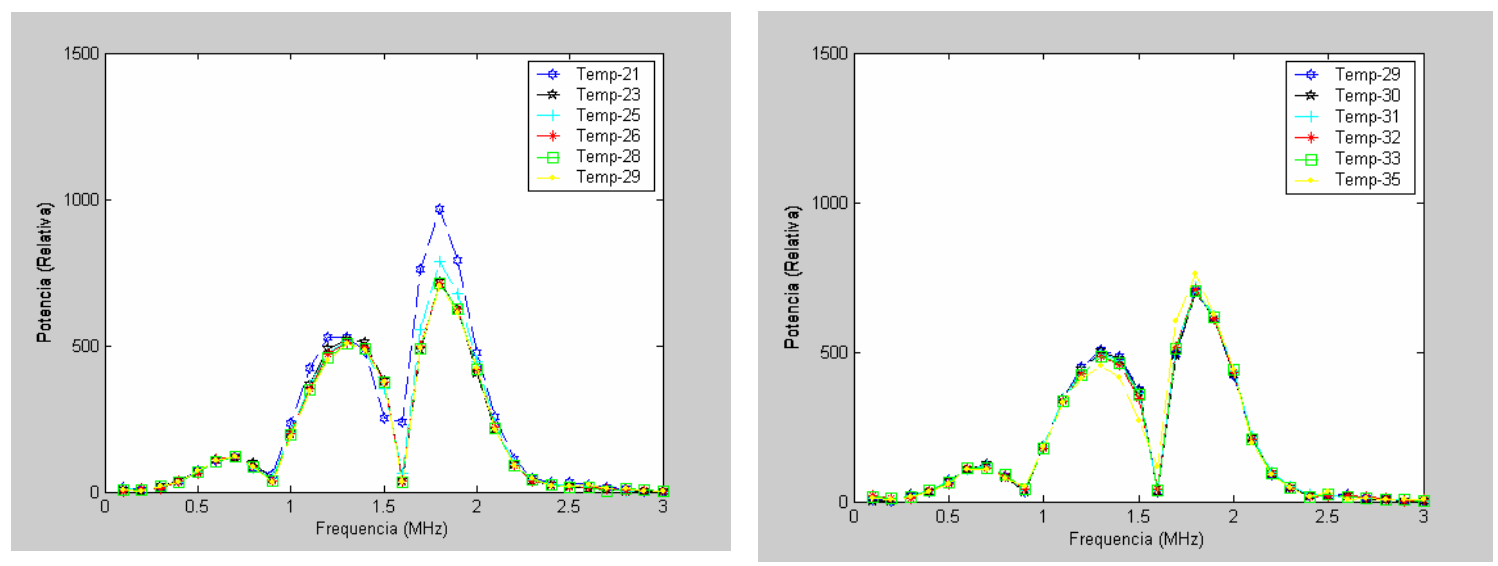

Figura 3.5.57. FFT dos sinais na água em função da temperatura para a tensão de 124V para os transdutores LM. 

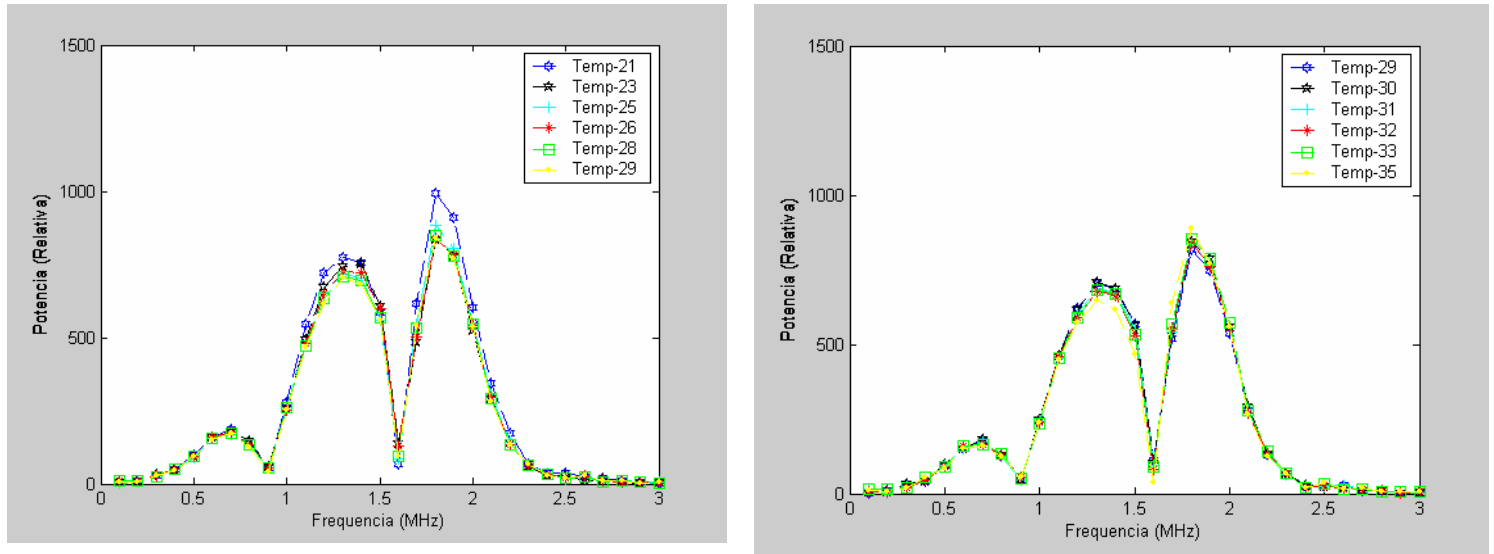

Figura 3.5.58. FFT dos sinais na água em função da temperatura para a tensão de $172 \mathrm{~V}$ para os transdutores LM.
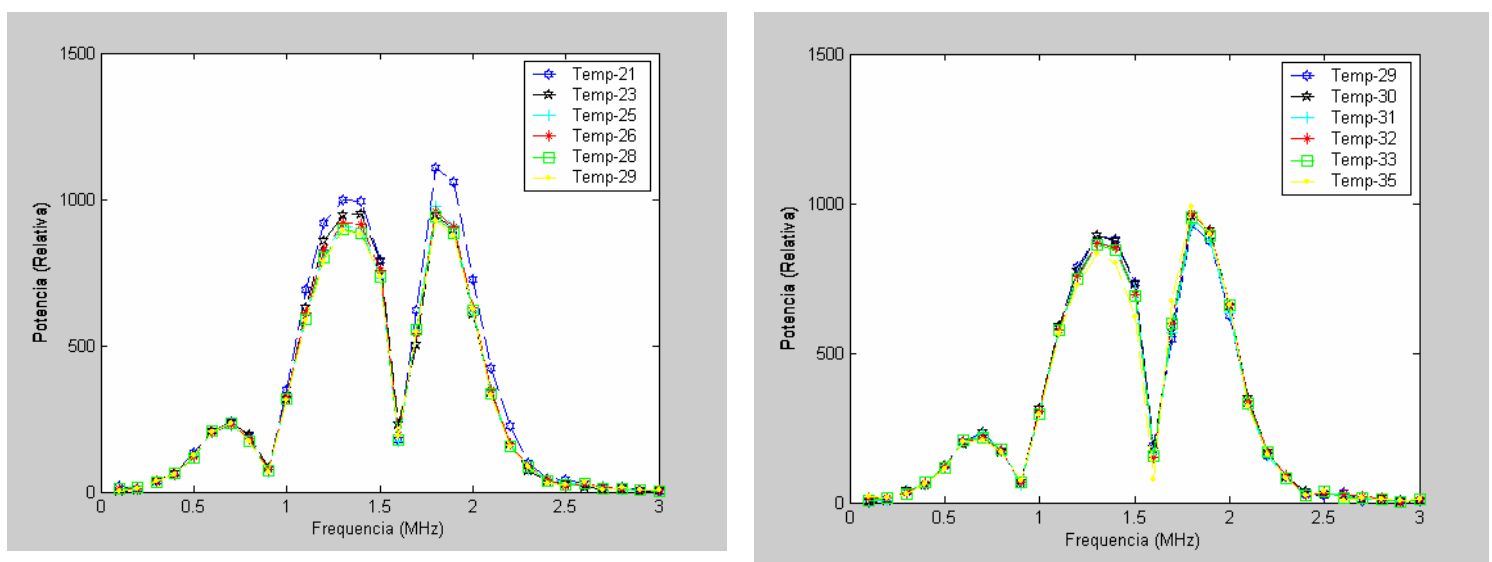

Figura 3.5.59. FFT dos sinais na água em função da temperatura para a tensão de 224V para os transdutores LM.

Na figura 3.5.60 são apresentados os resultados da velocidade do som em função da temperatura para os transdutores de $2 \mathrm{MHz}$ (par LM) e também os valores teóricos para a velocidade gerados a partir da equação de quinto grau.

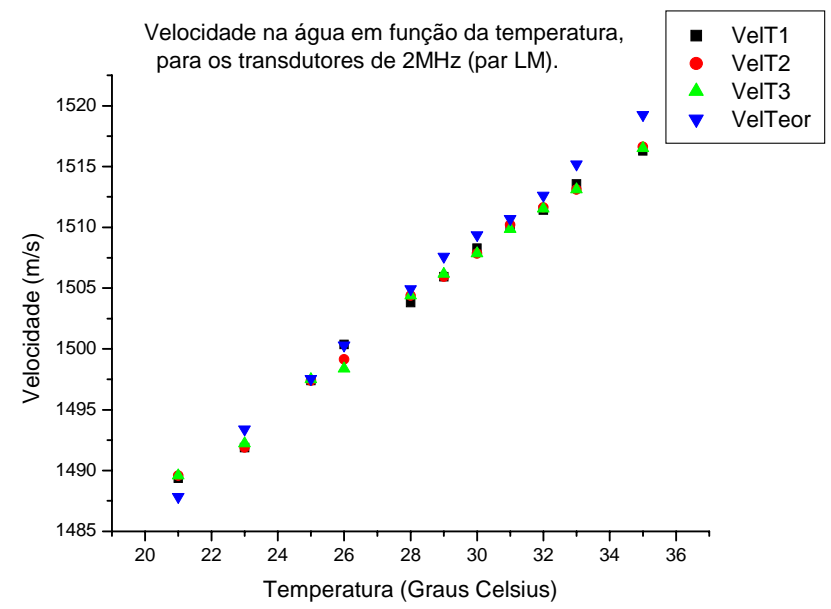

Figura 3.5.60. Velocidade do ultra-som na água como função da temperatura para os transdutores de $2 \mathrm{MHz}$ (LM). 


\subsubsection{Transdutores de 1,5MHz, par PQ.}

Nas figuras 3.5.61, 3.5.62 e 3.5.63 são apresentados os sinais temporais para a água, nas tensões de trabalho de $124 \mathrm{~V}, 172 \mathrm{~V}$ e $224 \mathrm{~V}$, respectivamente, como função da temperatura para o par de transdutores $\mathrm{PQ}$, para as temperaturas de $25^{\circ} \mathrm{C}$ e $30^{\circ} \mathrm{C}$.

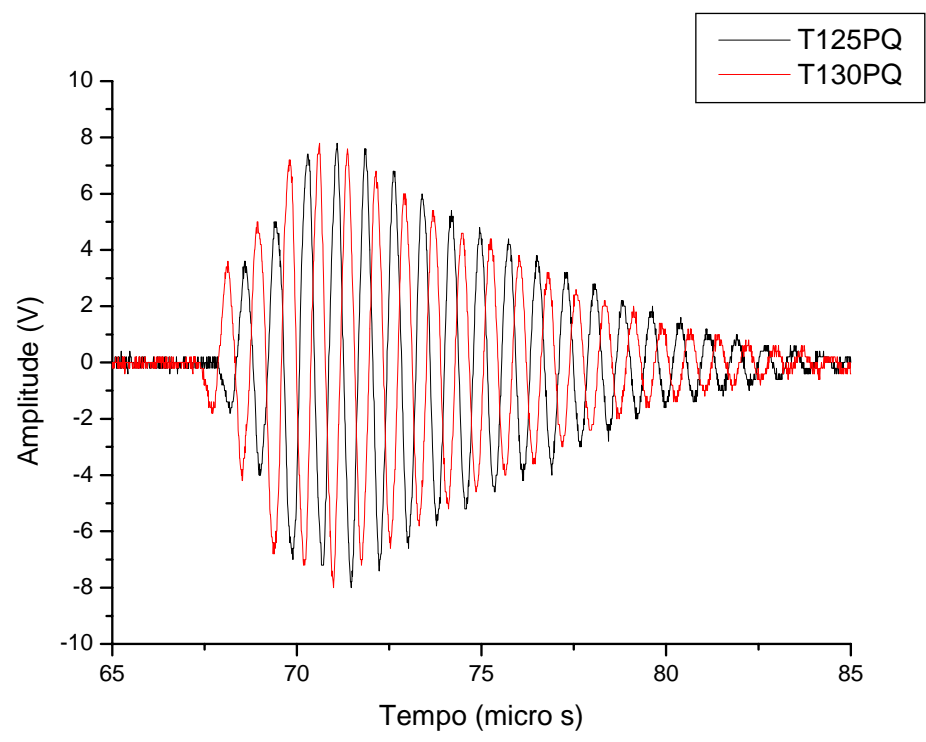

Figura 3.5.61. Sinal temporal para o par de transdutores PQ (1,5MHz) em água. Para as temperaturas de $25^{0} \mathrm{C}$ e $30^{\circ} \mathrm{C}$, para a tensão de $124 \mathrm{~V}$.

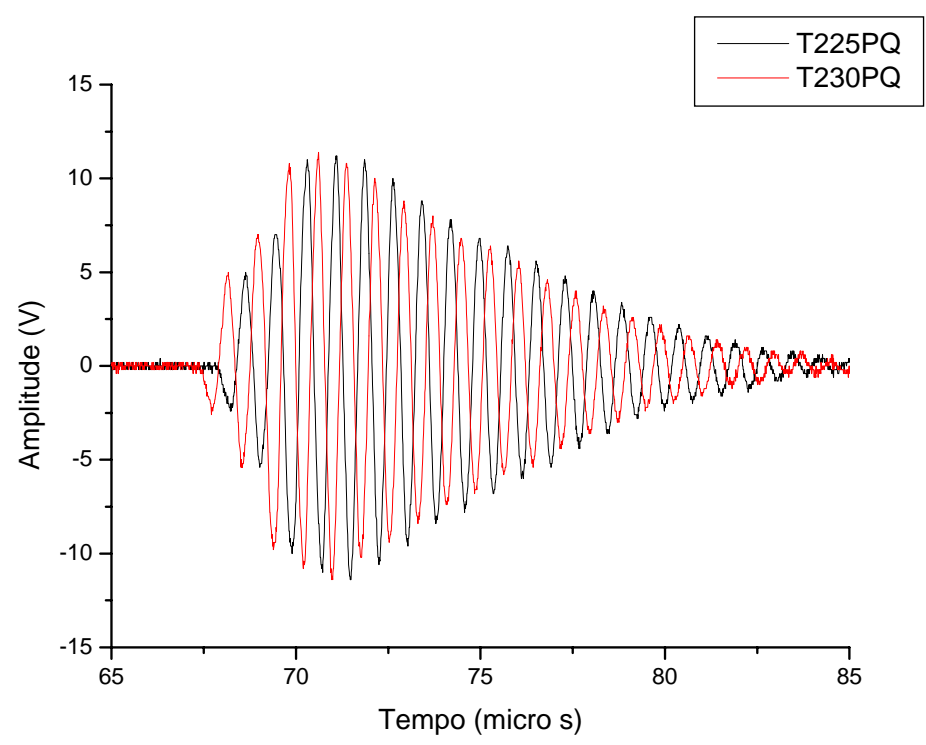

Figura 3.5.62. Sinal temporal para o par de transdutores PQ $(1,5 \mathrm{MHz})$ em água. Para as temperaturas de $25^{\circ} \mathrm{C}$ e $30^{\circ} \mathrm{C}$, para a tensão de $172 \mathrm{~V}$. 


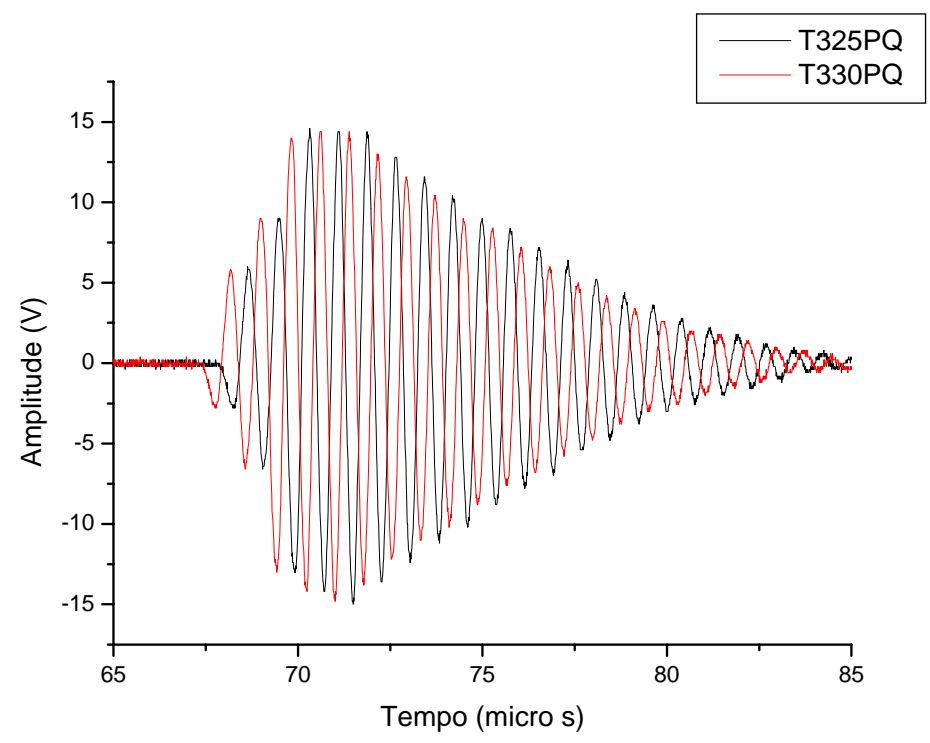

Figura 3.5.63. Sinal temporal para o par de transdutores PQ $(1,5 \mathrm{MHz})$ em água. Para as temperaturas de $25^{\circ} \mathrm{C}$ e $30^{\circ} \mathrm{C}$, para a tensão de $224 \mathrm{~V}$.

Nas figuras 3.5.64, 3.5.65 e 3.5.66, são apresentados os valores da potência relativa para o sinal na água, nas três tensões de trabalho do equipamento, como função da temperatura para o par de transdutores PQ.
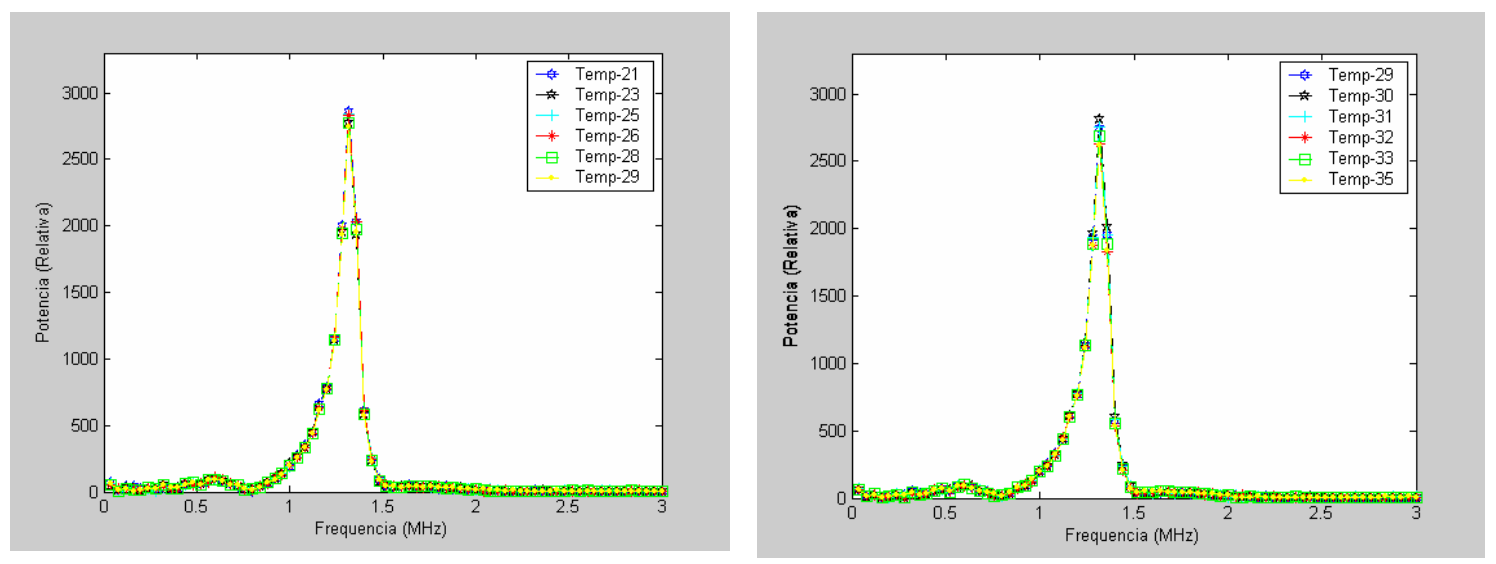

Figura 3.5.64. FFT dos sinais na água em função da temperatura para a tensão de 124V para os transdutores PQ. 

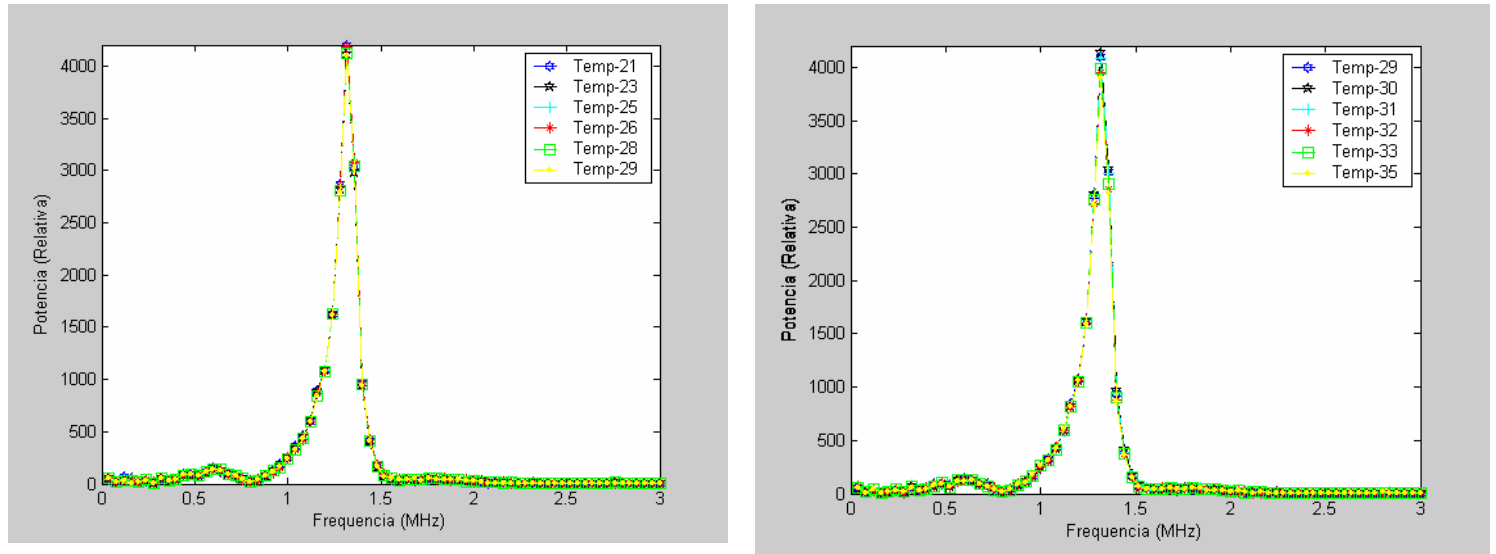

Figura 3.5.65. FFT dos sinais na água em função da temperatura para a tensão de 172V para os transdutores PQ.
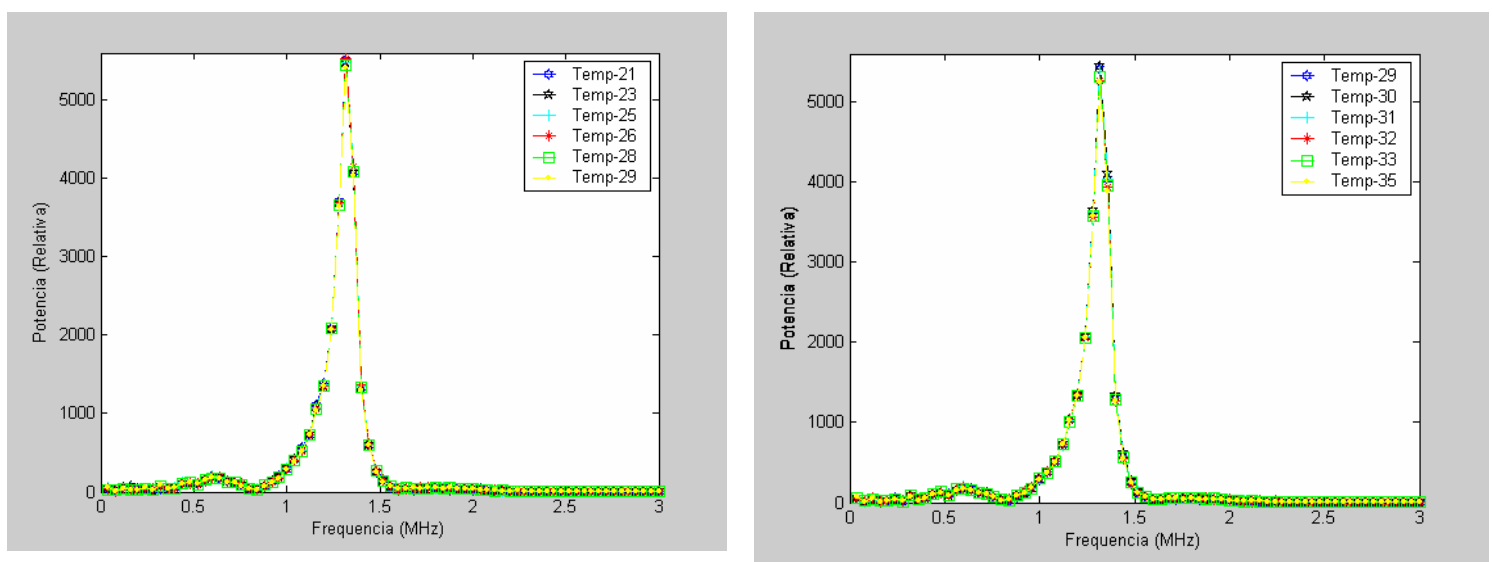

Figura 3.5.66. FFT dos sinais na água em função da temperatura para a tensão de 224V para os transdutores PQ.

Na figura 3.5.67 são apresentados os resultados da velocidade do som em função da temperatura para os transdutores de $1,5 \mathrm{MHz}$ (par PQ) e também os valores teóricos para a velocidade gerados a partir da equação de quinto grau.

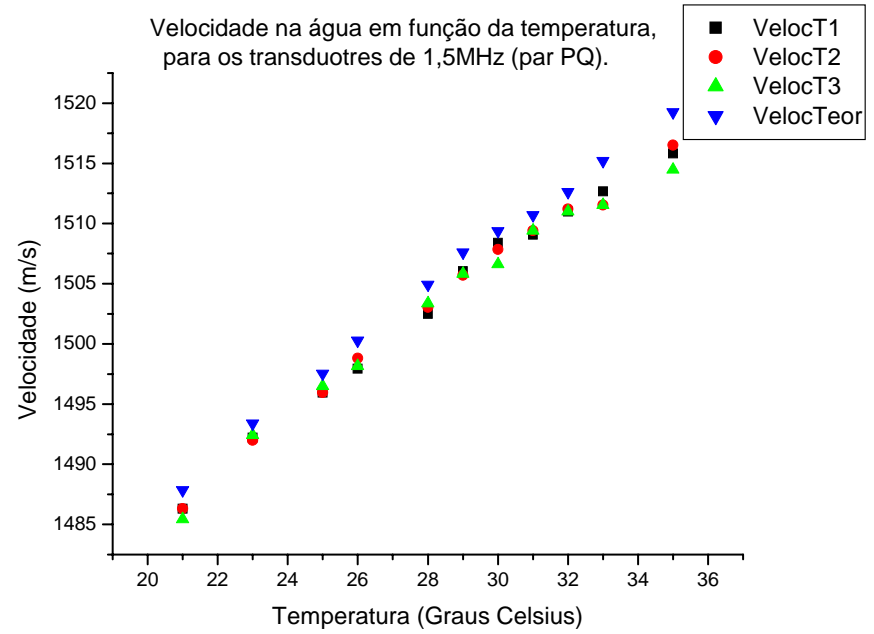

Figura 3.5.67. Velocidade do ultra-som na água como função da temperatura para os transdutores de 1,5MHz (PQ). 


\subsubsection{Transdutores de 0,5MHz, par RS.}

Nas figuras 3.5.68, 3.5.69 e 3.5.70 são apresentados os sinais temporais para a água, nas tensões de trabalho de $124 \mathrm{~V}, 172 \mathrm{~V}$ e $224 \mathrm{~V}$, respectivamente, como função da temperatura para o par de transdutores RS, para as temperaturas de $25^{\circ} \mathrm{C}$ e $30^{\circ} \mathrm{C}$.

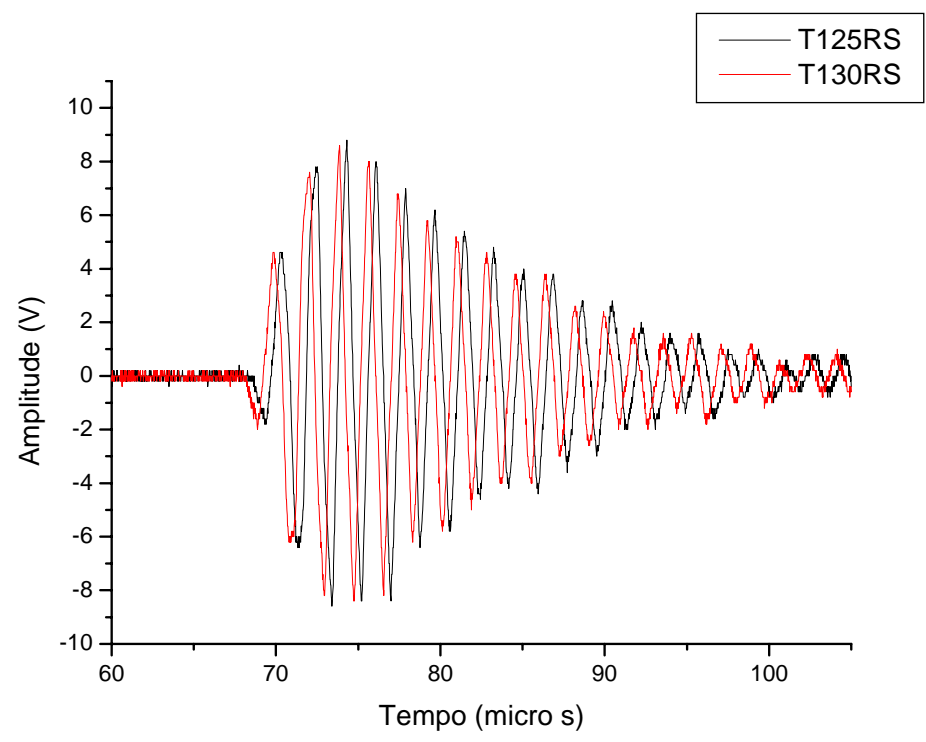

Figura 3.5.68. Sinal temporal para o par de transdutores RS (0,5MHz) em água. Para as temperaturas de $25^{0} \mathrm{C}$ e $30^{\circ} \mathrm{C}$, para a tensão de $124 \mathrm{~V}$.

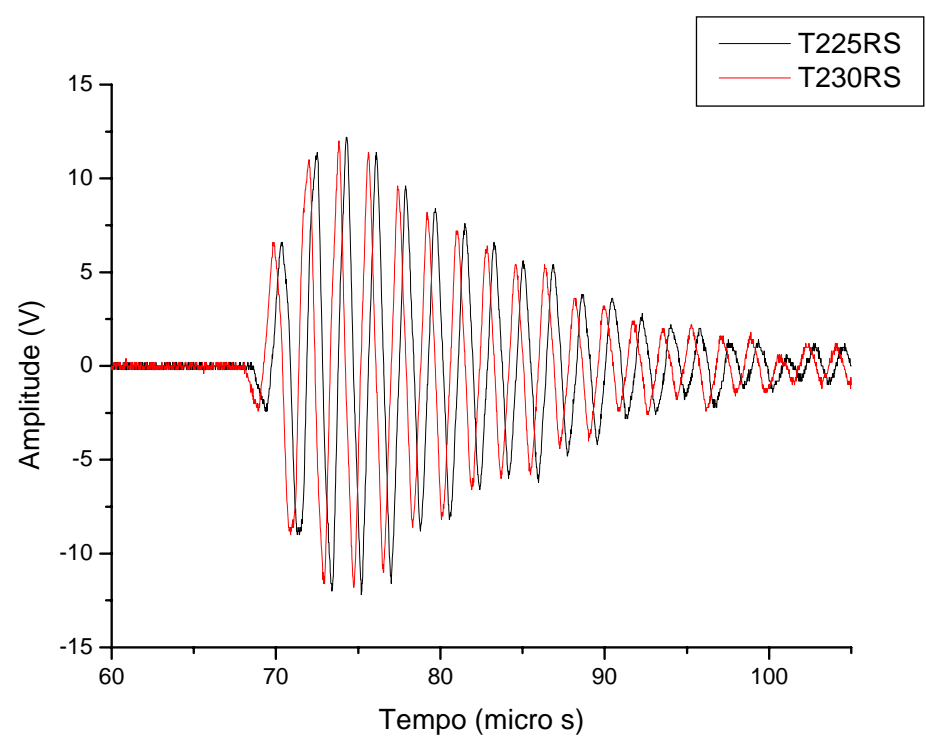

Figura 3.5.69. Sinal temporal para o par de transdutores RS (0,5MHz) em água. Para as temperaturas de $25^{\circ} \mathrm{C} \mathrm{e}$ $30^{\circ} \mathrm{C}$, para a tensão de $172 \mathrm{~V}$. 


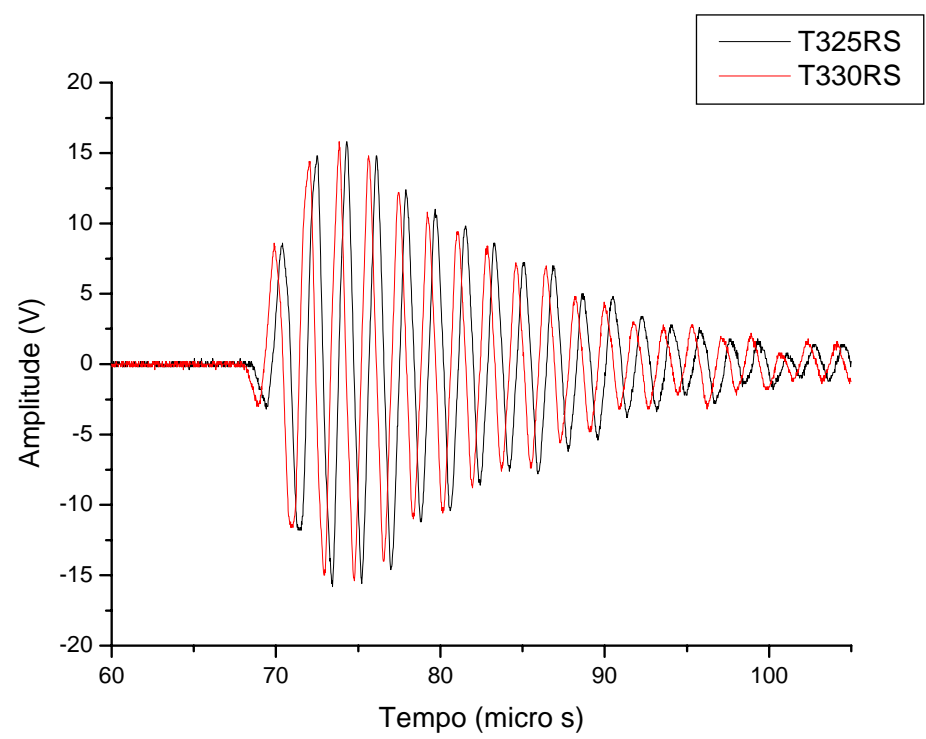

Figura 3.5.70. Sinal temporal para o par de transdutores RS $(0,5 \mathrm{MHz})$ em água. Para as temperaturas de $25^{0} \mathrm{C}$ e $30^{\circ} \mathrm{C}$, para a tensão de $224 \mathrm{~V}$.

Nas figuras 3.5.71, 3.5.72 e 3.5.73, são apresentados os valores da potência relativa para o sinal na água, nas três tensões de trabalho do equipamento, como função da temperatura para o par de transdutores RS.
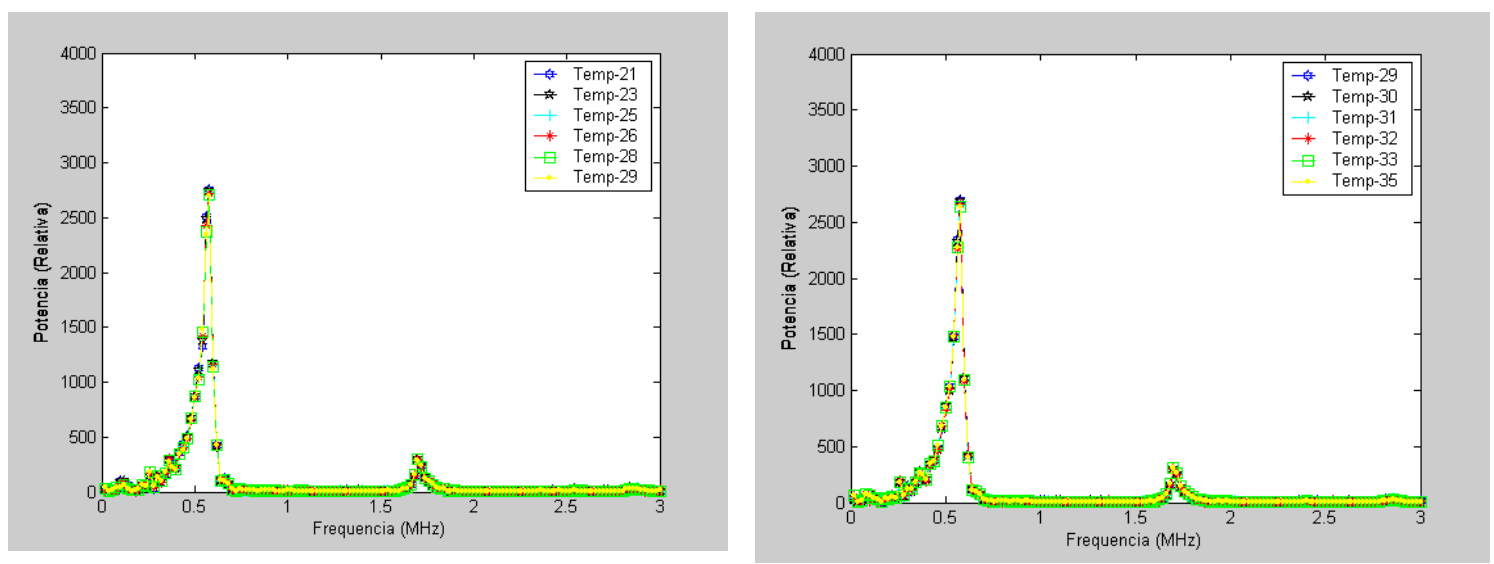

Figura 3.5.71. FFT dos sinais na água em função da temperatura para a tensão de 124V para os transdutores RS. 

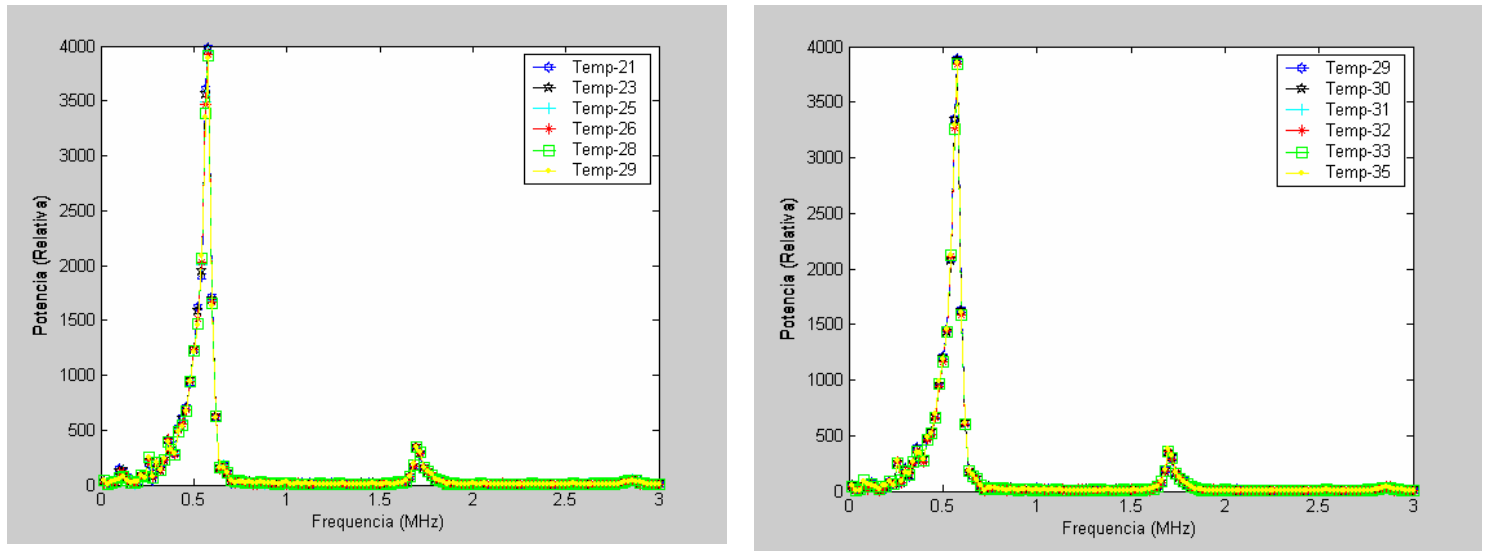

Figura 3.5.72. FFT dos sinais na água em função da temperatura para a tensão de 172V para os transdutores RS.
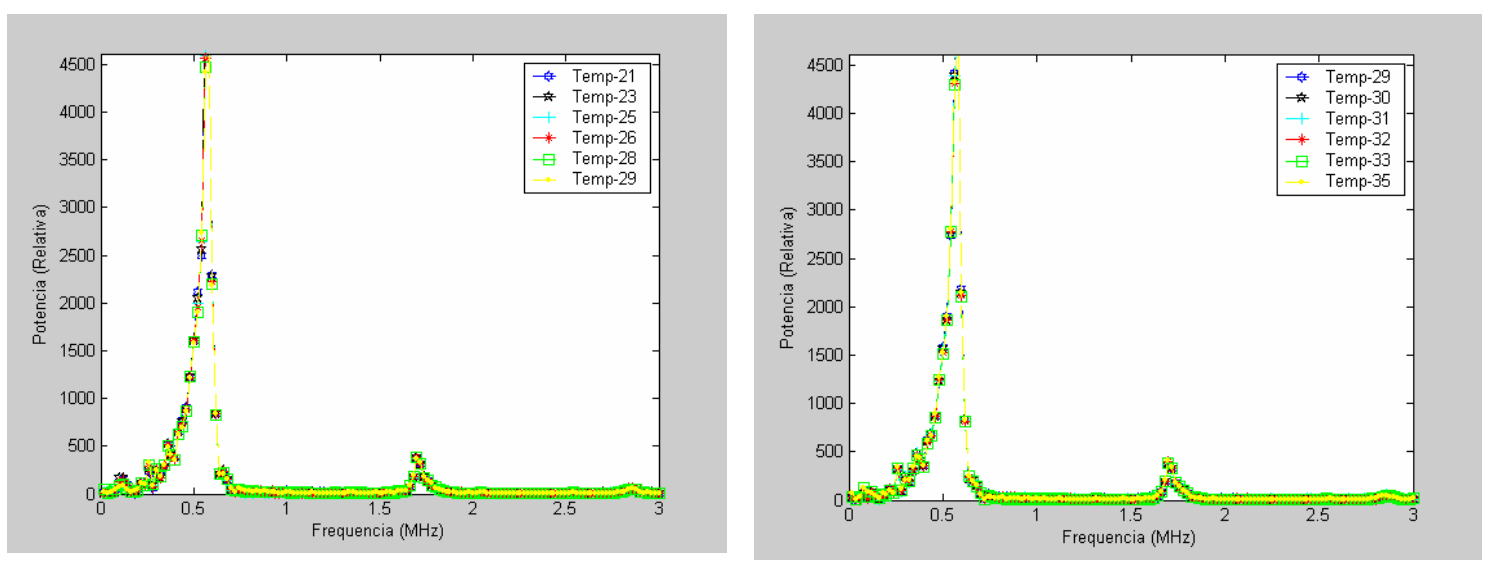

Figura 3.5.73. FFT dos sinais na água em função da temperatura para a tensão de 224V para os transdutores RS.

Na figura 3.5.74 são apresentados os resultados da velocidade do som em função da temperatura para os transdutores de $0,5 \mathrm{MHz}$ (par RS) e também os valores teóricos para a velocidade gerados a partir da equação de quinto grau.

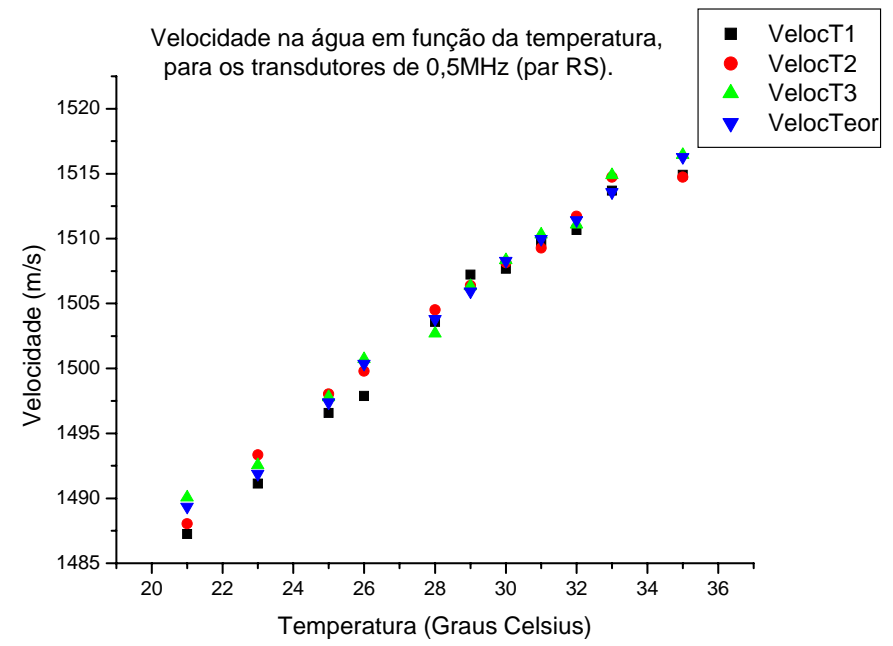

Figura 3.5.74. Velocidade do ultra-som na água como função da temperatura para os transdutores de $0,5 \mathrm{MHz}$ (RS). 


\subsection{Considerações Finais}

\subsubsection{Transdutores de $1 \mathrm{MHz}$.}

\subsubsection{PAR AB}

Fazendo a medida da velocidade do ultra-som e analisando a FFT dos sinais, pode ser observado que, mesmo ocorrendo à variação de temperatura, não se observou nenhuma variação, nas amplitudes e na freqüência, das FFT dos sinais em qualquer uma das tensões analisadas (figuras 3.5.21, 3.5.22 e 3.5.23).

Os resultados para a velocidade foram bem satisfatórios, observando que a maior diferença ocorre na temperatura de $35^{\circ} \mathrm{C}$ (figura 3.5 .24 ). A diferença, em $35^{\circ} \mathrm{C}$, é de aproximadamente de 2,8m/s (para qualquer uma das três tensões de trabalho) quando comparados com o valor teórico $(1519,8 \mathrm{~m} / \mathrm{s})$. Sendo que, esta diferença é de aproximadamente $0,18 \%$.

\subsubsection{PAR NO}

Para os gráficos de potência (figuras 3.5.28, 3.5.29 e 3.5.30) é observada a mesma característica do par AB.

A figura 3.5.31 apresenta o gráfico da velocidade do som na água em função da temperatura para o par de transdutores NO de $1 \mathrm{MHz}$. Sendo que a temperatura que apresenta a maior dispersão, comparando com a velocidade teórica, é a de 25 graus Celsius, com uma variação percentual de 0,13\%, 0,10\% e 0,07\% para as tensões de 124, 172 e 224V, respectivamente. 


\subsubsection{PAR EF}

Para os gráficos de potência (figuras 3.5.35, 3.5.36 e 3.5.37) é observada a mesma característica do par AB.

A maior diferença na velocidade ocorre para os valores obtidos para as maiores tensões (172V e 224V). Entretanto, a maior diferença é observada para a temperatura de 35 graus Celsius a qual apresenta uma variação percentual de 0,21 e 0,18 para as tensões de $172 \mathrm{~V}$ e $224 \mathrm{~V}$, respectivamente, em relação ao seu respectivo valor teórico.

Estas variações, que ocorrem em todas as temperaturas analisadas, podem estar associadas ao comprimento do campo próximo, devido ao menor diâmetro deste par de transdutores $(12 \mathrm{~mm})$.

\subsubsection{Transdutores de $0,75 \mathrm{MHz}$}

\subsubsection{PAR CD}

Para os gráficos de potência (figuras 3.5.42, 3.5.43 e 3.5.44) é observada a mesma característica dos pares de $1 \mathrm{MHz}$. Entretanto, é observado um pico de máximo próximo da freqüência de $750 \mathrm{MHz}$ (freqüência nominal da pastilha) e um pico de menor potência na freqüência de aproximadamente 2,1MHz.

Na figura 3.5.46, a maior dispersão ocorre para as temperaturas de 21 e 23 graus Celsius, as quais apresentam um valor experimental maior que o valor teórico. A maior dispersão percentual foi para a temperatura de 21 graus Celsius, na tensão de $124 \mathrm{~V}$ e não ultrapassou o valor de $0,16 \%$. 


\subsubsection{Transdutores de $2 \mathrm{MHz}$.}

\subsubsection{PAR IG}

Nos gráficos de potência em função da temperatura (figuras 3.5.50, 3.5.51 e 3.5.52), existe um pico de maior potência próxima da freqüência nominal do transdutor que é de $2 \mathrm{MHz}$ e apresenta um pico de menor potência entre 1 e 1,5 MHz.

Na figura 3.5.53, é observado que para as altas temperaturas (acima de 31graus Celsius) ocorreu uma grande dispersão, no valor da velocidade, quando comparado com os respectivos valores teóricos. Este fato pode estar associado que para os transdutores de $2 \mathrm{MHz}$ a relação sinal ruído era grande, dificultando a aquisição do sinal referencial, para o cálculo da velocidade.

\subsubsection{PAR LM}

Para as figuras 3.5.57, 3.5.58 e 3.5.59, os gráficos de potência em função da temperatura, mostram o mesmo comportamento que os gráficos de potência para o par IG de transdutores, os quais apresentam um pico máximo para a freqüência de $2 \mathrm{MHz}$ e um pico mínimo entre as freqüências de 1 e 1,5 MHz. Entretanto, existiu uma variação que não foi observada em nenhum dos outros pares de transdutores utilizados. Esta variação ocorreu para a temperatura de 21 graus Celsius que apresentou uma potência maior quando comparada com as outras temperaturas. Isto foi observado em todas as tensões.

Os valores de velocidade como função da temperatura, demonstraram o mesmo comportamento que o par IG de transdutores, onde as maiores dispersões ocorreram para as temperaturas acima de 31 graus Celsius. Na temperatura de 21 graus existe uma dispersão comparável com as de alta temperatura. 


\subsubsection{Transdutores de $1,5 \mathrm{MHz}$.}

\subsubsection{PAR PQ}

As figuras 3.5.64, 3.5.65 e 3.5.66, apresentam os gráficos de potência para as diversas temperaturas analisadas, com um pico de máximo próximo da freqüência nominal de ressonância da pastilha.

Na figura 3.5.67, o gráfico da velocidade do som como função da temperatura, apresentou uma dispersão, em relação aos valores teóricos da velocidade do som na água, relativamente grande para as temperaturas acima de 30 graus Celsius. Igualmente o que foi observado para os pares de transdutores de $2 \mathrm{MHz}$ (par IG e LM). A maior dispersão foi observada para a temperatura de 35 graus Celsius, tendo uma dispersão de 0,20\% para o valor experimental quando comparado com o respectivo valor teórico.

\subsubsection{Transdutores de $0,5 \mathrm{MHz}$.}

\subsubsection{PAR RS}

Nas figuras 3.5.71, 3.5.72 e 3.5.73, são apresentados os gráficos da potência relativa como função da temperatura, para o par de transdutores de $500 \mathrm{KHz}$ (par RS). Os gráficos de potência apresentam um pico de máxima potência próxima da freqüência nominal de ressonância das pastilhas e um pico de menor intensidade na freqüência de aproximadamente 1,7MHz. Mas a sua melhor resposta está na freqüência de 500KHz.

Para o gráfico da velocidade do som como função da temperatura (figura 3.5.74), as dispersões foram as mínimas observadas. Sendo que, para a temperatura de 26 graus Celsius e para a tensão de $124 \mathrm{~V}$, ocorreu a maior variação, para este par e com relação ao valor teórico foi de $0,13 \%$. 


\section{RESULTADOS E DISCUSSÕES}

\subsection{MEDIDAS EM MATERIAIS PLÁSTICOS E METAIS, PARA ANÁlise DA VELOCIDAdE PELA TÉCNICA DE CONTATO E INSERÇÃO CONVENCIONAL.}

\subsubsection{Introdução}

O objetivo dessas medidas é o de comparar os resultados (da velocidade) da técnica de contato com os da técnica de inserção convencional e tentar determinar qual a melhor técnica quando comparada com os valores de velocidade encontrados na literatura (valores teóricos).

Para o acoplamento de impedâncias foram usados água na técnica de inserção convencional e gel ultra-sônico para a técnica de contato.

Na técnica de contato as medidas foram feitas à temperatura ambiente, que era de aproximadamente $24^{0} \mathrm{C}$, apresentando uma variação de $\pm 1,5^{0} \mathrm{C}$. Para a técnica de inserção convencional as peças ficaram em um banho térmico de 40 minutos a temperatura de $24^{0} \mathrm{C}$, para que fosse possível uma melhor comparação entre as técnicas.

Para a técnica de contato a velocidade foi determinada utilizando a equação 7 e para a técnica de inserção convencional a velocidade foi calculada utilizando a equação 6 .

Como referencial no sinal temporal para a medida de tempo, foi utilizada a primeira transição em torno do zero, como demonstrado na figura 2.1.2, seção 2.1.5 do capítulo 2 .

Foram realizadas seis repetições de cada sinal para cada tensão e as medidas foram feitas em três dias diferentes.

As amostras, de materiais plásticos e metal, eram peças cilíndricas onde o pulso de ultra-som incidia na face plana. O seu comprimento e diâmetro estão apresentados na tabela 4.1.1 a seguir. 
Tabela 4.1.1 - Comprimento e diâmetro de peças plásticas e alumínio.

\begin{tabular}{c|c|c} 
MATERIAL & $\begin{array}{c}\text { COMPRIMENTO } \\
(\mathbf{m m})\end{array}$ & $\begin{array}{c}\text { DIÂMETRO } \\
\mathbf{( m m )}\end{array}$ \\
\hline Acrílico (P)* & 48,00 & 42,30 \\
\hline Acrílico (G)* & 62,50 & 42,30 \\
\hline PVC (P) & 46,50 & 52,40 \\
\hline PVC (G) & 60,00 & 52,40 \\
\hline Alumínio & 51,00 & 61,35 \\
\hline Nylon & 30,20 & 51,15
\end{tabular}

*as peças de acrílico foram feitas, em uma forma cilíndrica, com uma resina acrílica endurecida por catalisador.

Na tabela 4.1.2, são apresentados os valores teóricos da velocidade do som e das impedâncias acústicas para as peças plásticas e para o alumínio (Hill, 1986, Wells, 1977 e Krautkrämer, 1990).

Tabela 4.1.2 - Velocidade do som teórica para algumas peças plásticas e para o alumínio

\begin{tabular}{ccc}
\hline AMOSTRA & $\begin{array}{c}\text { VELOCIDADE } \\
\text { TEÓRICA }(\mathbf{m} / \mathbf{s})\end{array}$ & $\begin{array}{c}\text { IMPEDÂNCIA } \\
\text { ACÚSTICA } \\
\left.\mathbf{( 1 0}^{\mathbf{6}} \mathbf{K g} / \mathbf{m}^{\mathbf{}} \mathbf{. s}\right)\end{array}$ \\
\hline PVC & 2380,0 & 3,27 \\
\hline Acrílico & 2610,0 & 3,26 \\
\hline Alumínio & 6420,0 & 17,0 \\
\hline Nylon & 2700,0 & 3,15 \\
\hline
\end{tabular}

\subsubsection{Transdutores de $1 \mathrm{MHz}$}

Nas figuras de 4.1.1 a 4.1.3, são apresentados os sinais temporais, para as três tensões do equipamento, medidas pela técnica de contato e inserção convencional. Para a peça de acrílico, com o objetivo de ilustração, serão apresentados apenas os gráficos do acrílico G. Foram utilizados os transdutores $\mathrm{AB}$, NO e EF de freqüência 1MHz. 


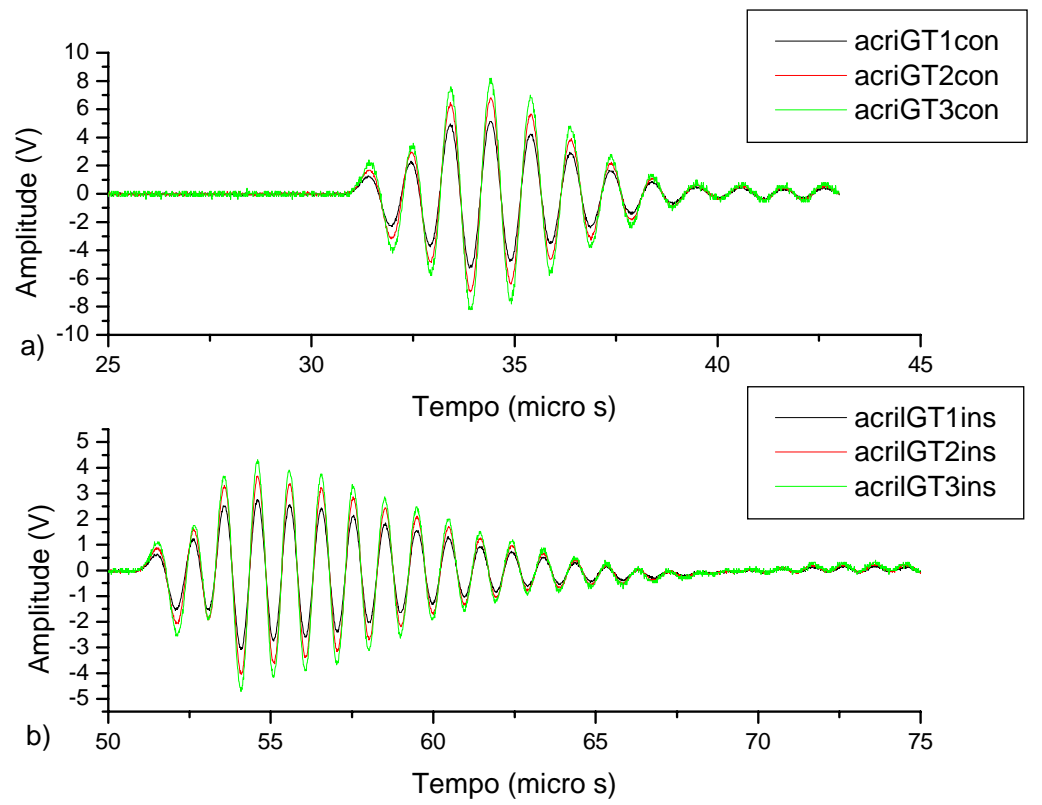

Figura 4.1.1. a e b são os sinais temporais do acrílico $G$ medidos pela técnica de contato e inserção, respectivamente, nas tensões de $124 \mathrm{~V}$ (T1), $172 \mathrm{~V}$ (T2) e 224V (T3), para o par de transdutores AB de freqüência $1 \mathrm{MHz}$.

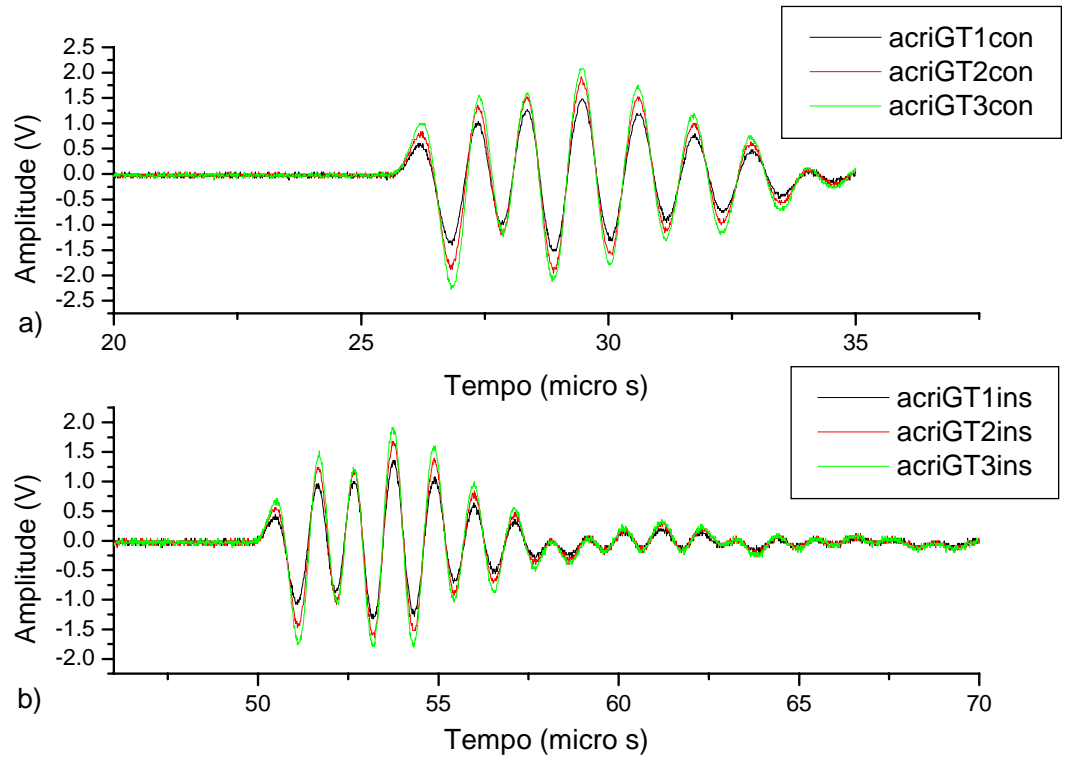

Figura 4.1.2. a e b são os sinais temporais do acrílico $G$ medidos pela técnica de contato e inserção, respectivamente, nas tensões de 124V (T1), 172V (T2) e 224V (T3), para o par de transdutores EF de freqüência $1 \mathrm{MHz}$ 


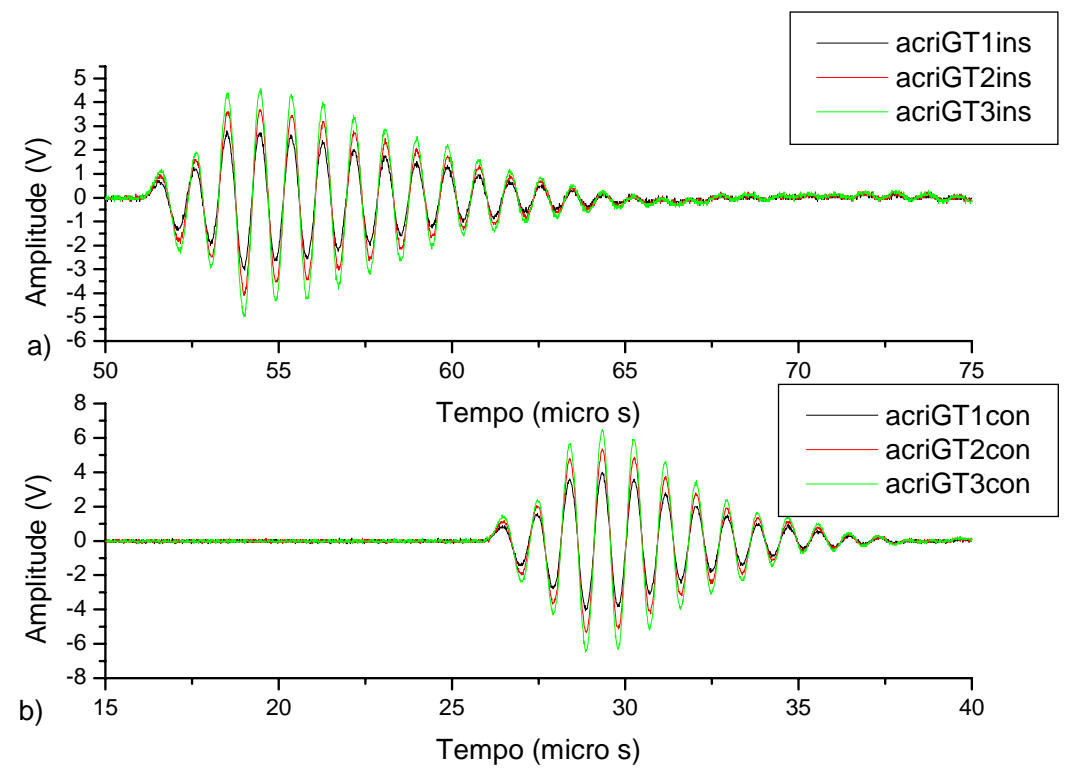

Figura 4.1.3. a e b são os sinais temporais do acrílico $G$ medidos pela técnica de inserção e contato, respectivamente, nas tensões de 124V (T1), 172V (T2) e 224V (T3), para o par de transdutores NO de freqüência $1 \mathrm{MHz}$.

Na figura 4.1.4 são apresentados os valores experimentais da velocidade do som para o acrílico G e P, com a sua respectiva velocidade teórica para os pares de transdutores AB, EF e NO todos de $1 \mathrm{MHz}$ de freqüência nominal. Não foi feita a discriminação entre as tensões (estão misturadas).

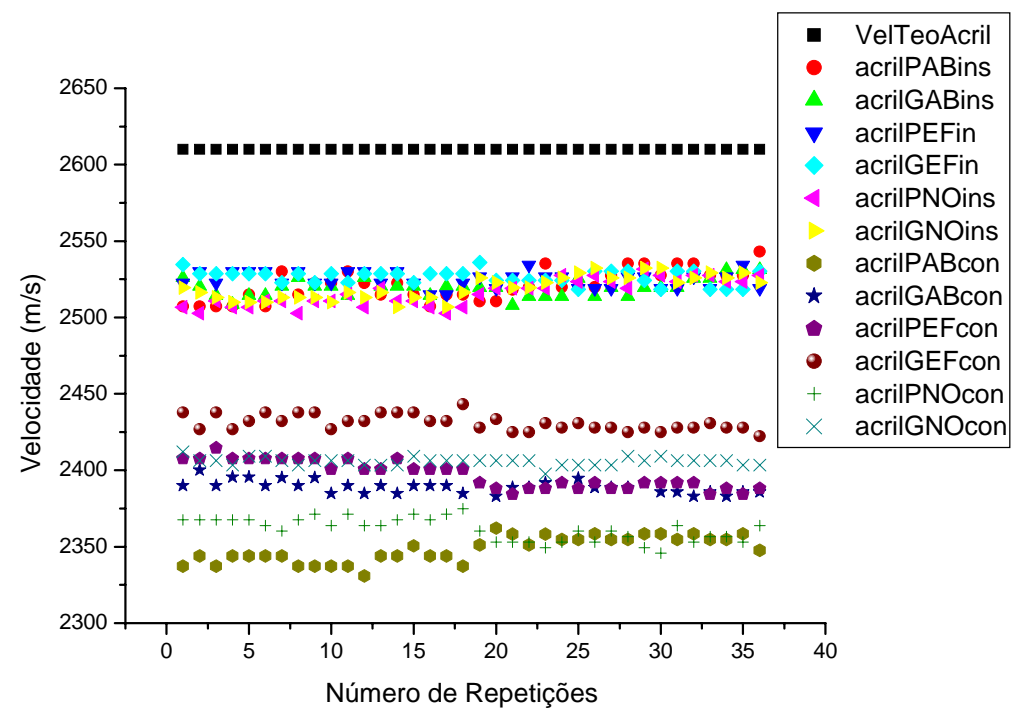

Figura 4.1.4. Velocidade do som experimental, medida pelas técnicas de contato e inserção, para as peças de acrílico, para os transdutores AB, EF e NO. 
Nas figuras de 4.1.5 a 4.1.7, são apresentados os sinais temporais, para as três tensões do equipamento, medidas pela técnica de contato e inserção convencional. Para a peça de PVC, com o objetivo de ilustração, serão apresentados apenas os gráficos do PVC G. Foram utilizados os transdutores AB, NO e EF de freqüência $1 \mathrm{MHz}$.

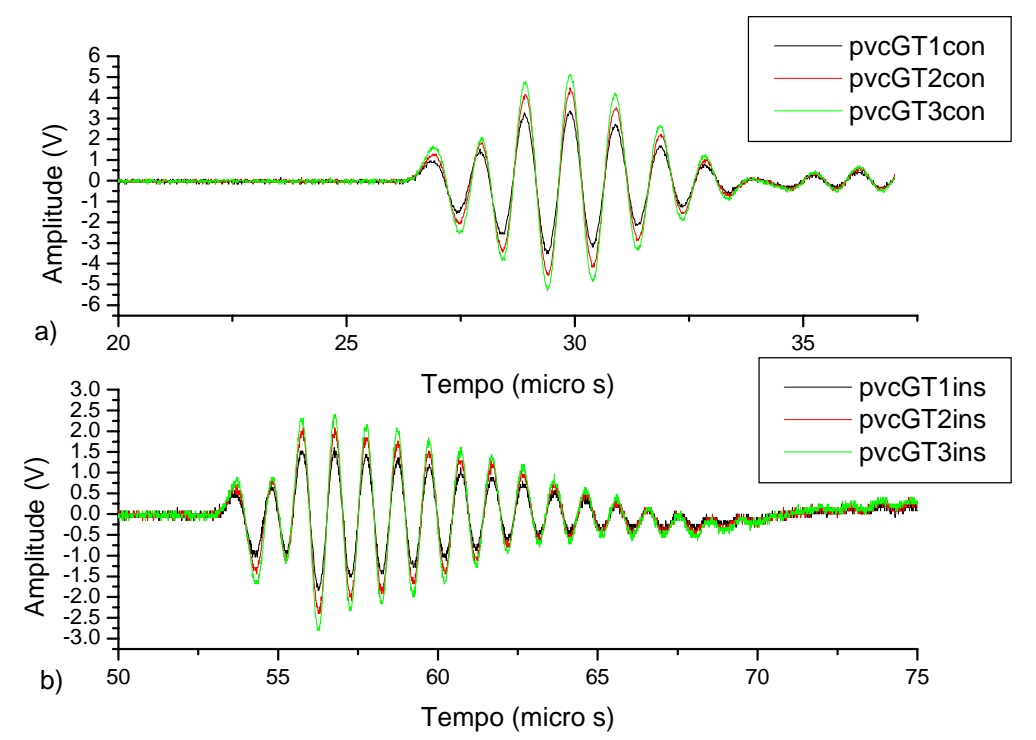

Figura 4.1.5. a e b são os sinais temporais do PVC G, medidos pela técnica de contato e inserção, respectivamente, nas tensões de $124 \mathrm{~V}$ (T1), 172V (T2) e 224V (T3), para o par de transdutores AB de freqüência $1 \mathrm{MHz}$.

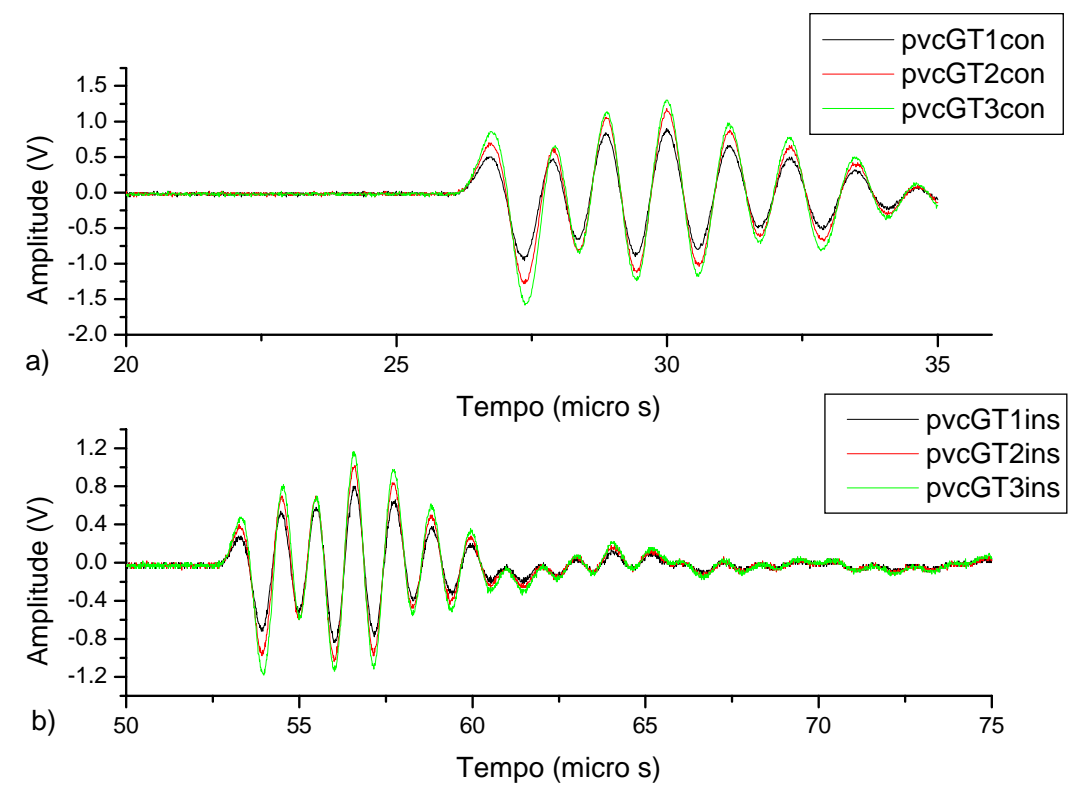

Figura 4.1.6. a e b são os sinais temporais do PVC G, medidos pela técnica de contato e inserção, respectivamente, nas tensões de 124V (T1), 172V (T2) e 224V (T3), para o par de transdutores EF de freqüência $1 \mathrm{MHz}$. 


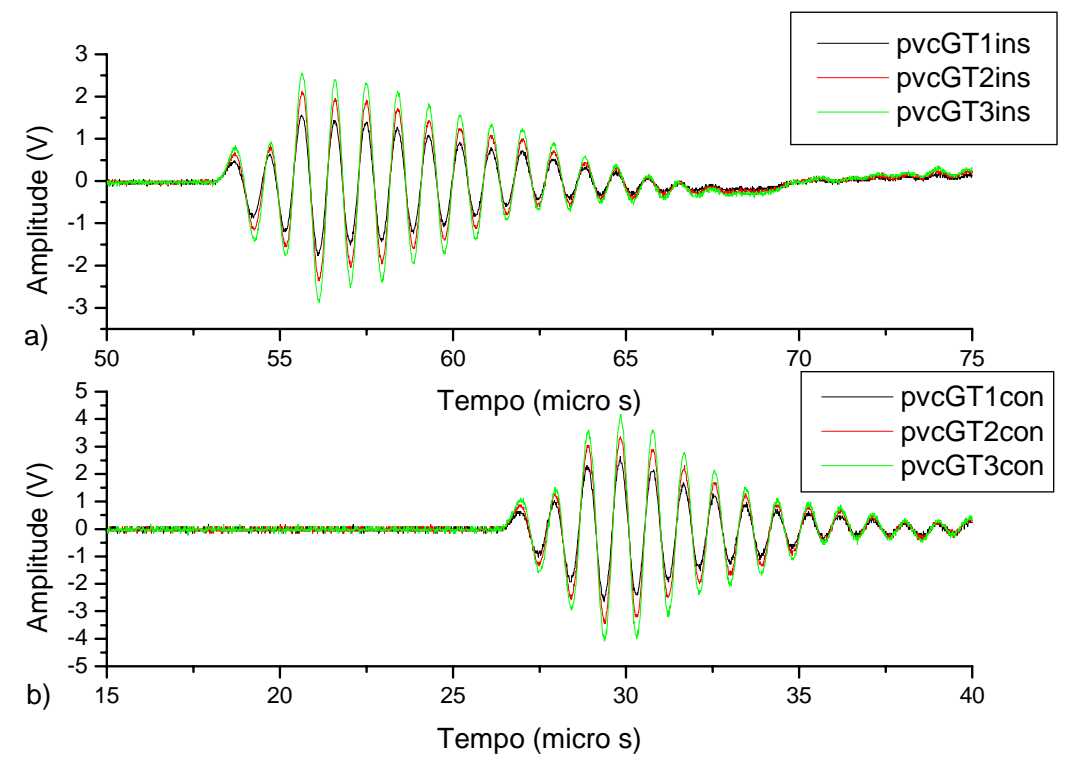

Figura 4.1.7. a e b são os sinais temporais do PVC G, medidos pela técnica de inserção e contato, respectivamente, nas tensões de 124V (T1), 172V (T2) e 224V (T3), para o par de transdutores NO de freqüência $1 \mathrm{MHz}$.

Na figura 4.1.8 são apresentados os valores experimentais da velocidade do som para o PVC G e P, com a sua respectiva velocidade teórica para os pares de transdutores AB, EF e NO todos de $1 \mathrm{MHz}$ de freqüência nominal. Não foi feita discriminação entre as tensões (estão misturadas).

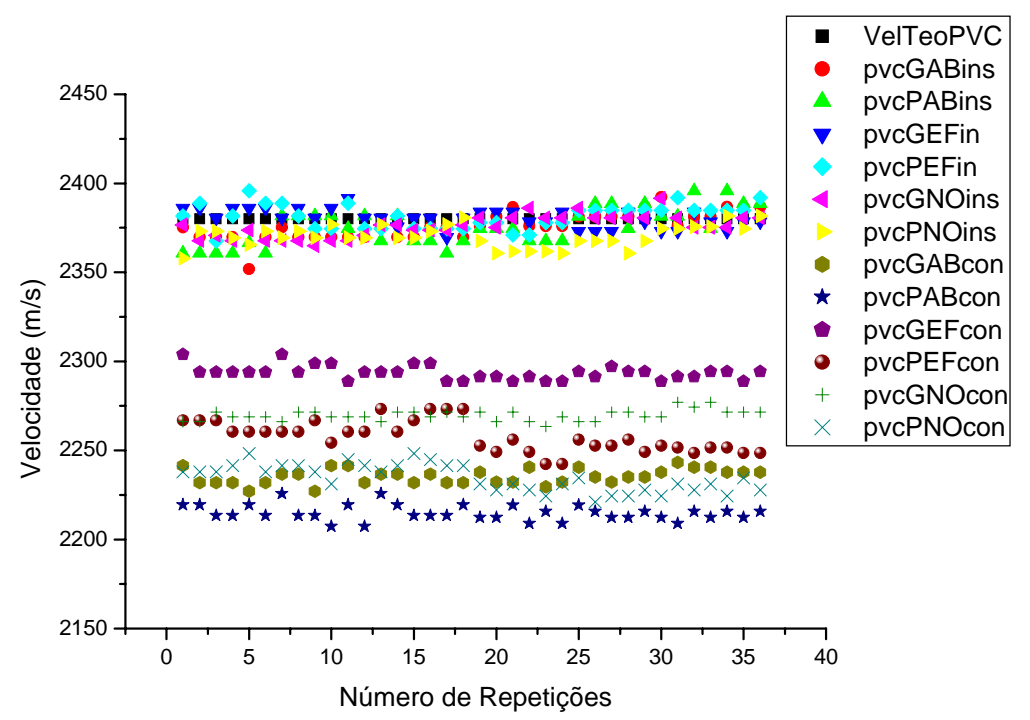

Figura 4.1.8. Velocidade do som experimental, medida pelas técnicas de contato e inserção, para as peças de PVC, e para os transdutores AB, EF e NO. 
Nas figuras de 4.1.9 a 4.1.11, são apresentados os sinais temporais para as três tensões do equipamento, medidas pela técnica de contato e inserção convencional, para a peça de nylon. Foram utilizados os transdutores AB, NO e EF de freqüência $1 \mathrm{MHz}$.

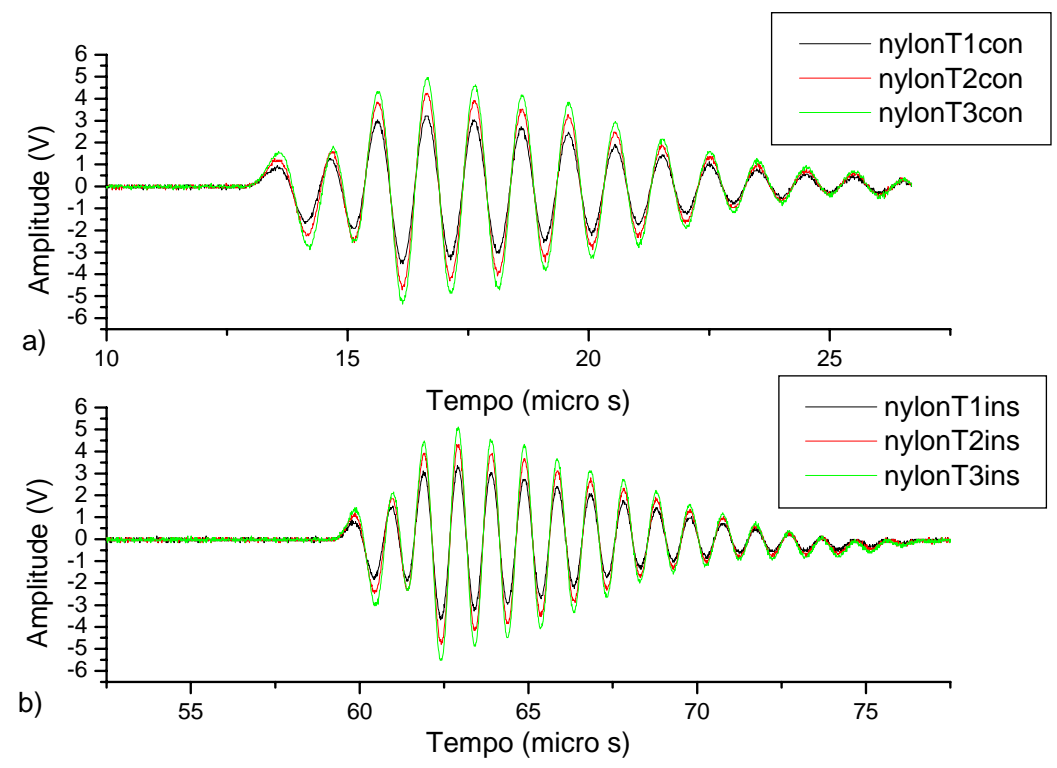

Figura 4.1.9. a e b são os sinais temporais do nylon, medidos pela técnica de contato e inserção, respectivamente, nas tensões de 124V (T1), 172V (T2) e 224V (T3), para o par de transdutores AB de freqüência 1MHz.

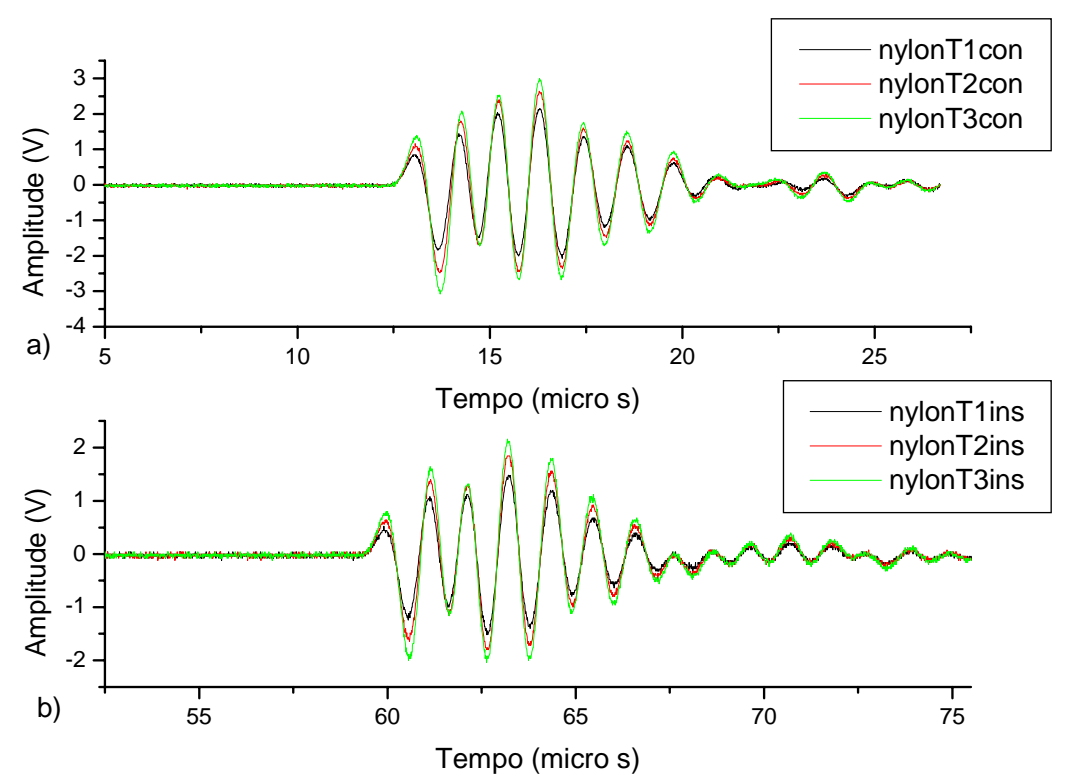

Figura 4.1.10. a e b são os sinais temporais do nylon, medidos pela técnica de contato e inserção, respectivamente, nas tensões de 124V (T1), 172V (T2) e 224V (T3), para o par de transdutores EF de freqüência $1 \mathrm{MHz}$. 


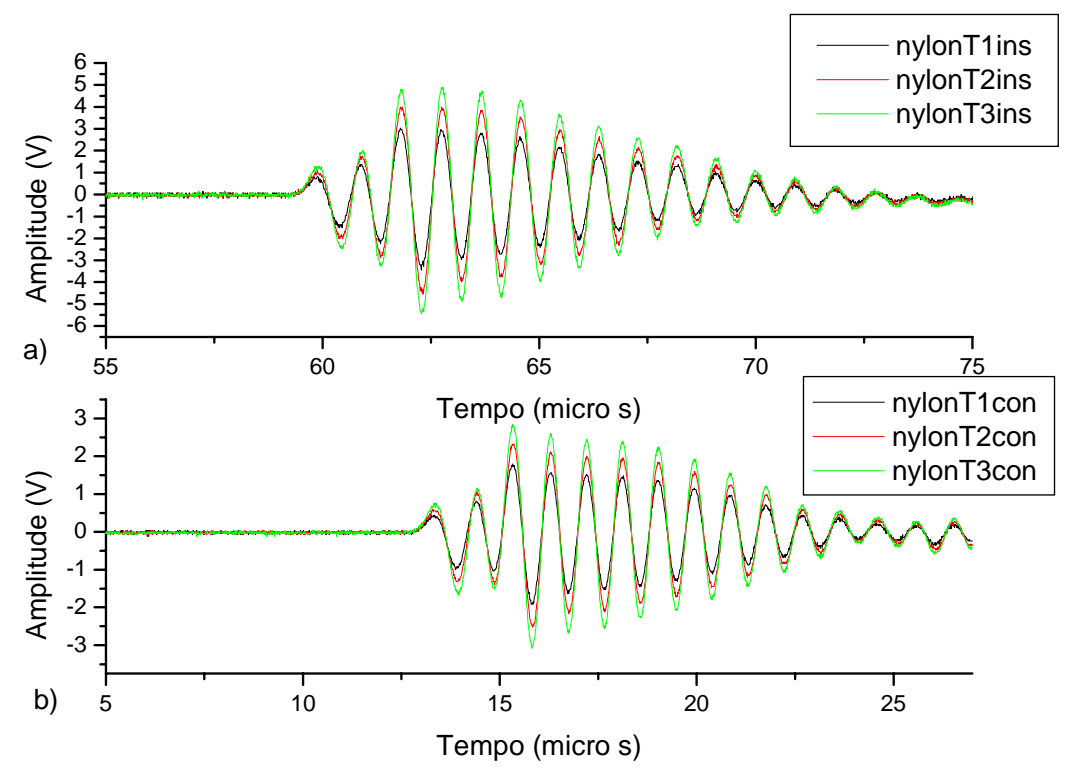

Figura 4.1.11. a e b são os sinais temporais do nylon, medidos pela técnica de inserção e contato, respectivamente, nas tensões de 124V (T1), 172V (T2) e 224V (T3), para o par de transdutores NO de freqüência $1 \mathrm{MHz}$

Na figura 4.1.12 são apresentados os valores experimentais da velocidade do som (técnica de contato e inserção convencional) para o nylon, com a sua respectiva velocidade teórica para os pares de transdutores $\mathrm{AB}, \mathrm{EF}$ e $\mathrm{NO}$, todos de $1 \mathrm{MHz}$ de freqüência nominal. Não foi feita discriminação entre as tensões (estão misturadas).

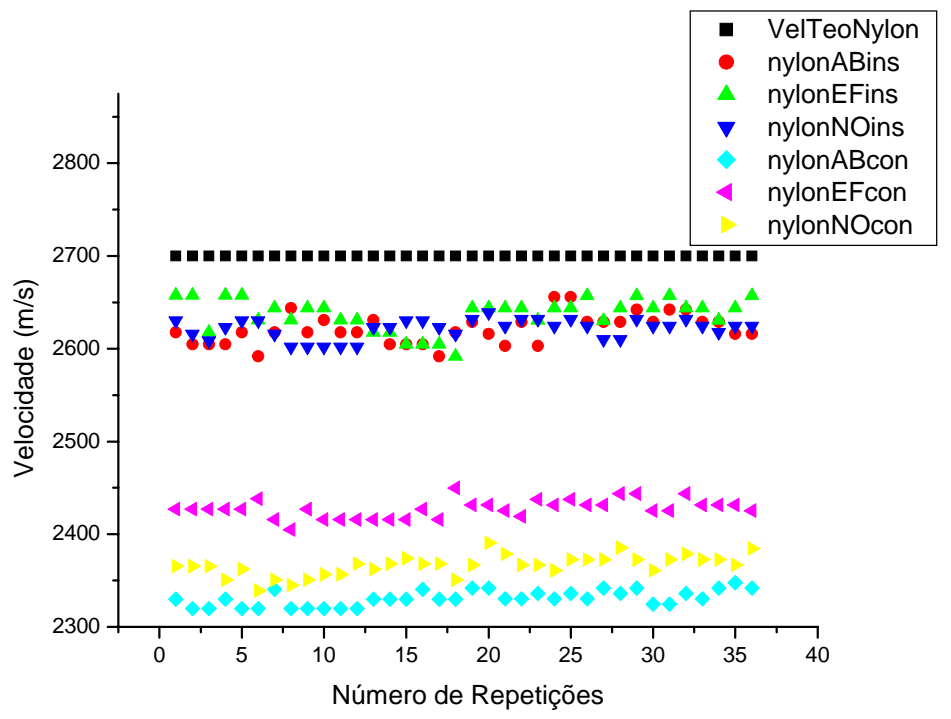

Figura 4.1.12. Velocidade do som experimental, medida pelas técnicas de contato e inserção, para a peça de nylon, para os transdutores AB, EF e NO. 
Nas figuras de 4.1.13 a 4.1.15 estão apresentados os sinais temporais, para as três tensões do equipamento, medidas pela técnica de contato e inserção convencional, para a peça alumínio. Foram utilizados os transdutores AB, NO e EF de freqüência $1 \mathrm{MHz}$.

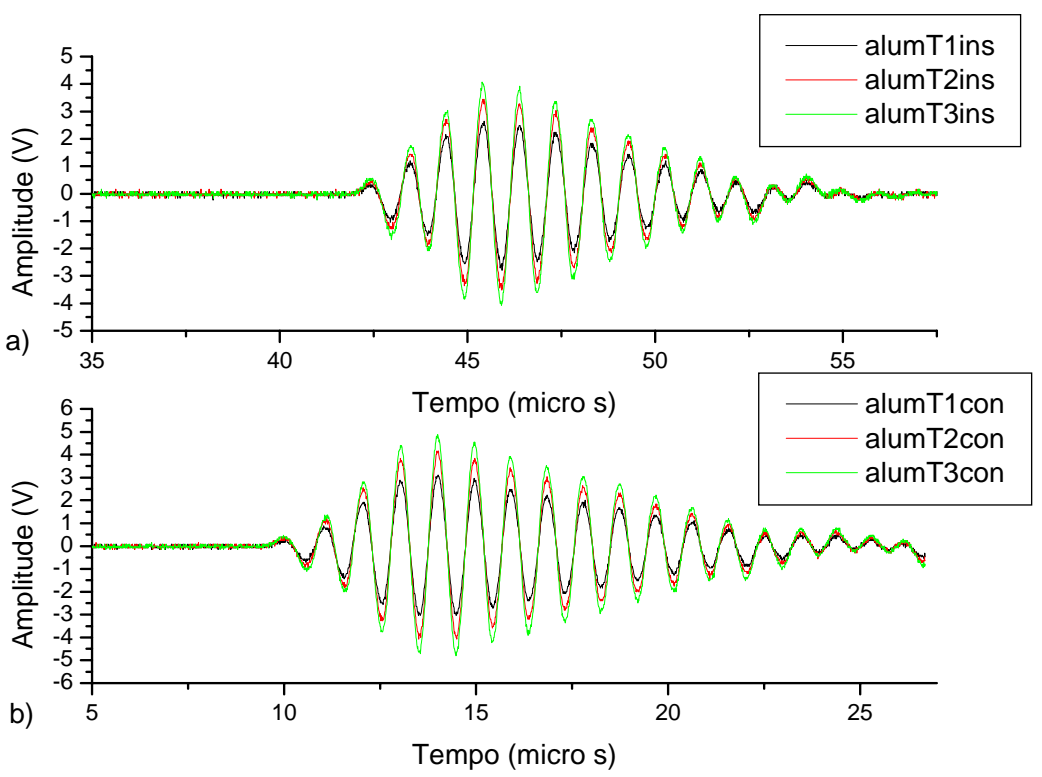

Figura 4.1.13. a e b são os sinais temporais do alumínio, medidos pela técnica de inserção e contato, respectivamente, nas tensões de 124V (T1), 172V (T2) e 224V (T3), para o par de transdutores AB de freqüência $1 \mathrm{MHz}$

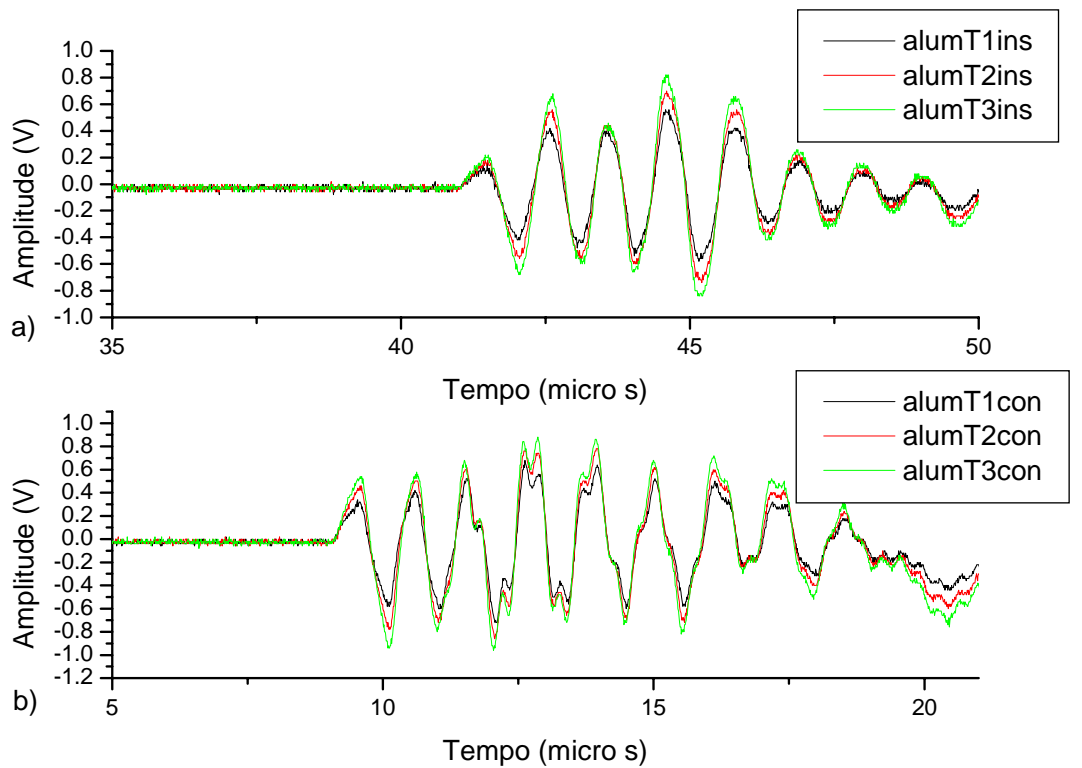

Figura 4.1.14. a e b são os sinais temporais do alumínio, medidos pela técnica de inserção e contato, respectivamente, nas tensões de 124V (T1), 172V (T2) e 224V (T3), para o par de transdutores EF de freqüência $1 \mathrm{MHz}$. 


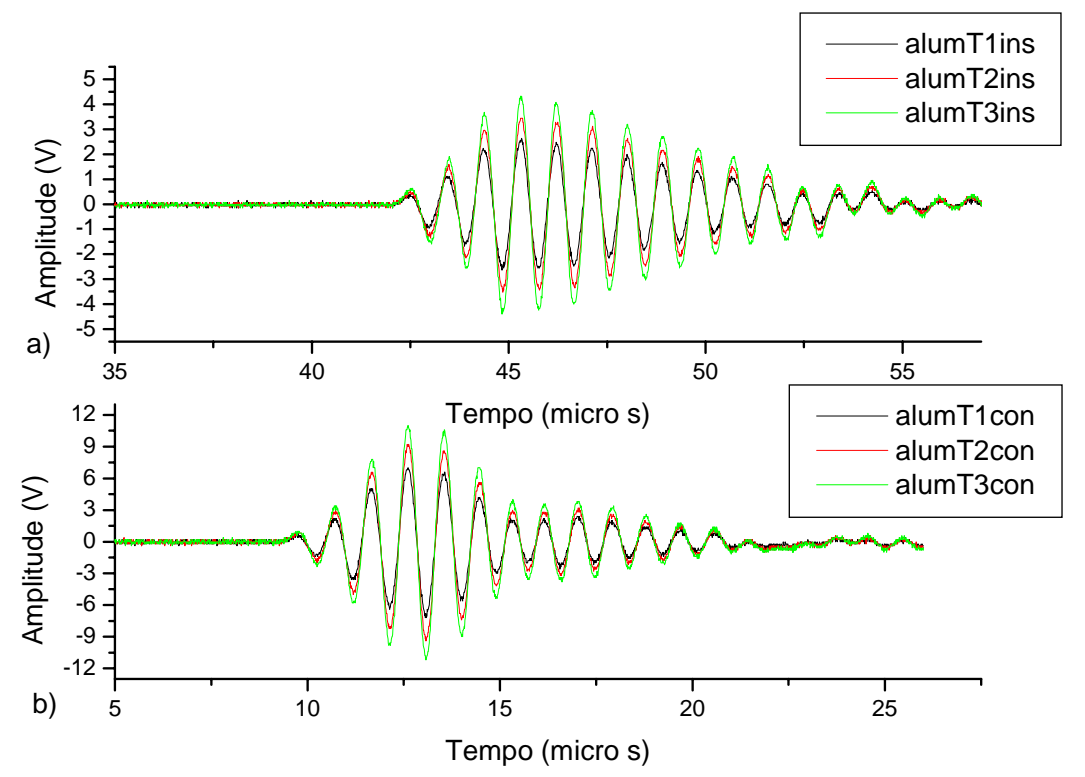

Figura 4.1.15. a e b são os sinais temporais do alumínio, medidos pela técnica de inserção e contato, respectivamente, nas tensões de 124V (T1), 172V (T2) e 224V (T3), para o par de transdutores NO de freqüência $1 \mathrm{MHz}$.

Na figura 4.1.16 são apresentados os valores experimentais da velocidade do som para o alumínio, com a sua respectiva velocidade teórica para os pares de transdutores AB, EF e NO, todos de $1 \mathrm{MHz}$ de freqüência nominal. Não foi feita discriminação entre as tensões (estão misturadas).

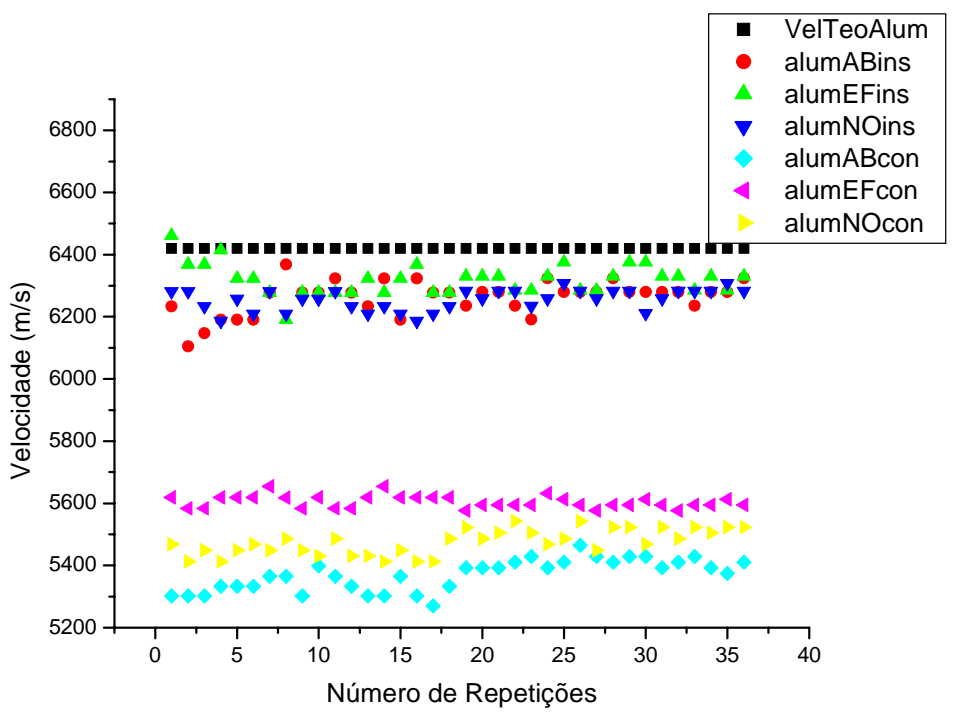

Figura 4.1.16. Velocidade do som experimental, medida pelas técnicas de contato e inserção, para a peça de alumínio, para os transdutores AB, EF e NO. 
Nas tabelas 4.1.3, 4.1.4 e 4.1.5 são apresentados os valores da média das velocidades com os seus respectivos desvios padrão para os três pares de transdutores de $1 \mathrm{MHz}(\mathrm{AB}, \mathrm{EF}$ e NO).

Tabela 4.1.3. Média das velocidades, para o par de transdutores AB, com seus respectivos desvios padrão para as peças plásticas e alumínio.

\begin{tabular}{c|c|c|c|c|c}
\multirow{4}{*}{ Transdutores } & \multirow{2}{*}{ Amostras } & \multicolumn{2}{|c|}{ Inserção } & \multicolumn{2}{c}{ Contato } \\
\cline { 3 - 6 } & & $\begin{array}{c}\text { Velocidade } \\
\mathbf{( m / s )}\end{array}$ & SD (m/s) & $\begin{array}{c}\text { Velocidade } \\
\mathbf{( m / s})\end{array}$ & SD (m/s) \\
\hline \multirow{5}{*}{ AB } & PVC-G & 2376,1 & 7,72 & 2235,4 & 4,21 \\
\cline { 2 - 6 } & PVC-P & 2375,5 & 10,47 & 2214,9 & 4,41 \\
\cline { 2 - 6 } & Acril-P & 2521,0 & 9,95 & 2348,4 & 8,49 \\
\cline { 2 - 6 } & Acril-G & 2519,5 & 5,90 & 2389,2 & 4,09 \\
\cline { 2 - 6 } & Alum & 6262,1 & 55,05 & 5369,2 & 50,2 \\
\cline { 2 - 6 } & Nylon & 2621,2 & 16,14 & 2330,9 & 8,49
\end{tabular}

Tabela 4.1.4. Média das velocidades, para o par de transdutores EF, com seus respectivos desvios padrão para as peças plásticas e alumínio.

\begin{tabular}{c|c|c|c|c|c}
\multirow{4}{*}{ Transdutores } & \multirow{2}{*}{ Amostras } & \multicolumn{2}{|c|}{ Inserção } & \multicolumn{2}{c}{ Contato } \\
\cline { 3 - 6 } & & $\begin{array}{c}\text { Velocidade } \\
\mathbf{( m / s )}\end{array}$ & SD (m/s) & $\begin{array}{c}\text { Velocidade } \\
\mathbf{( m / s )}\end{array}$ & SD (m/s) \\
\hline \multirow{5}{*}{ EF } & PVC-G & 2380,5 & 5,08 & 2293,5 & 3,98 \\
\cline { 2 - 6 } & PVC-P & 2381,3 & 6,76 & 2257,7 & 8,68 \\
\cline { 2 - 6 } & Acril-G & 2524,6 & 5,19 & 2397,1 & 9,02 \\
\cline { 2 - 6 } & Acril-P & 2526,5 & 4,48 & 2431,0 & 5,03 \\
\cline { 2 - 6 } & Alum. & 6319,3 & 49,09 & 5604,6 & 19,88 \\
\cline { 2 - 6 } & Nylon & 2637,4 & 17,37 & 2427,4 & 9,85
\end{tabular}


Tabela 4.1.5. Média das velocidades, para o par de transdutores NO, com seus respectivos desvios padrão para as peças plásticas e alumínio.

\begin{tabular}{c|c|c|c|c|c}
\multirow{4}{*}{ Transdutores } & \multirow{2}{*}{ Amostras } & \multicolumn{2}{|c|}{ Inserção } & \multicolumn{2}{c}{ Contato } \\
\cline { 3 - 6 } & & $\begin{array}{c}\text { Velocidade } \\
\mathbf{( m / s )}\end{array}$ & SD (m/s) & $\begin{array}{c}\text { Velocidade } \\
\mathbf{( m / s )}\end{array}$ & SD (m/s) \\
\hline \multirow{5}{*}{ NO } & PVC-G & 2375,9 & 6,22 & 2269,6 & 3,03 \\
\cline { 2 - 6 } & PVC-P & 2370,3 & 6,24 & 2234,5 & 7,49 \\
\cline { 2 - 6 } & Acril-G & 2516,1 & 8,64 & 2361,4 & 7,61 \\
\cline { 2 - 6 } & Acril-P & 2519,4 & 7,70 & 2405,8 & 2,61 \\
\cline { 2 - 6 } & Alum & 6255,3 & 34,08 & 5474,8 & 40,8 \\
\cline { 2 - 6 } & Nylon & 2621,5 & 10,53 & 2366,2 & 11,2 \\
\end{tabular}

De acordo com as tabelas 4.1.3, 4.1.4 e 4.1.5, é possível observar que os valores de velocidade do som, para os três pares de transdutores $\mathrm{AB}$, EF e NO, obtidos pela técnica de inserção convencional (acoplamento com água) apresentaram os melhores resultados, quando comparados com o valor teórico da velocidade do som (tabela 4.1.2).

Comparando a média das velocidades medidas pela técnica de inserção (tabelas 4.1.3, 4.1.4 e 4.1.5), para todas as amostras e os três pares de transdutores, com os seus valores teóricos da velocidade (tabela 4.1.2), é possível estimar que a diferença percentual não foi superior a 3,6\%, sendo que, a menor diferença foi observada para as peças de PVC (G e P) e a maior diferença foi para as peças de acrílico ( $G$ e P). O par de transdutores EF foi o que apresentou a menor dispersão no valor da velocidade do som para todas as amostras quando comparado com os outros pares também de $1 \mathrm{MHz}$ de freqüência (AB e NO).

As velocidades medidas pela técnica de contato tiveram uma grande variação que foi de 4\% (para o PVC e transdutores EF) chegando a 16,37\% (para o alumínio e transdutores $\mathrm{AB}$ ). As maiores diferenças nos valores de velocidade, medidos pela técnica de contato, foram observadas para o alumínio (16,37\% para o par AB, 12,7\% para o par EF e 14,72\% para o par NO) quando comparado com as outras amostras. Este fato deve estar relacionado com a camada de acoplamento dos transdutores, de acrílico, cuja espessura não foi considerada na equação para o cálculo de velocidade. 


\subsubsection{Transdutores de $2 \mathrm{MHz}$}

Nas figuras 4.1.17 e 4.1.18, são apresentados os sinais temporais, para as três tensões do equipamento, medidas pela técnica de contato e inserção convencional. Para as peças de PVC, com o objetivo de ilustração, serão apresentados apenas os gráficos do PVC G. Foram utilizados os pares de transdutores IG e LM de freqüência $2 \mathrm{MHz}$.

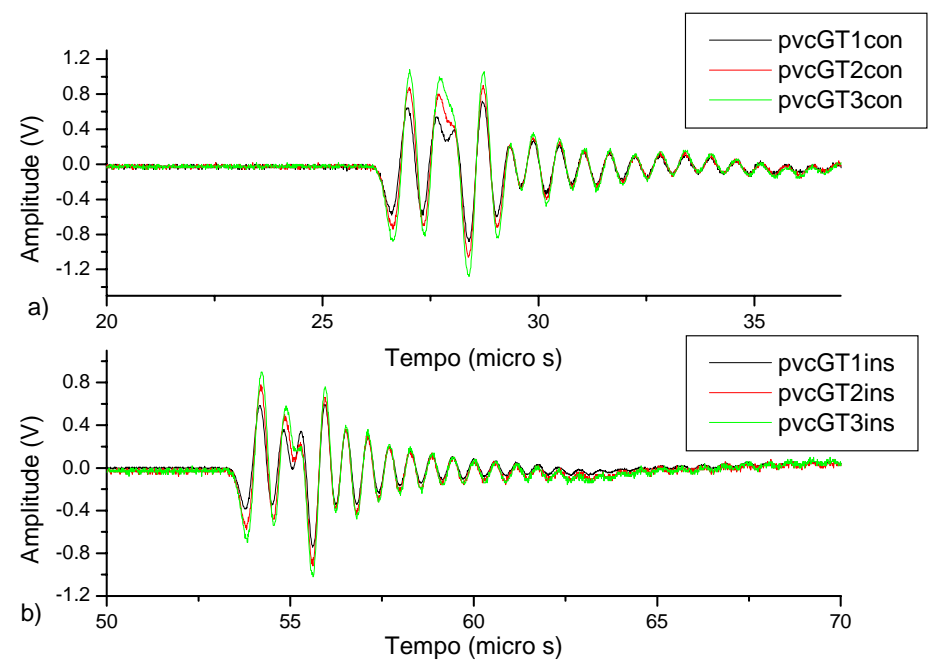

Figura 4.1.17. a e b são os sinais temporais do PVC G, medidos pela técnica de contato e inserção, respectivamente, nas tensões de 124V (T1), 172V (T2) e 224V (T3), para o par de transdutores LM de freqüência $2 \mathrm{MHz}$.

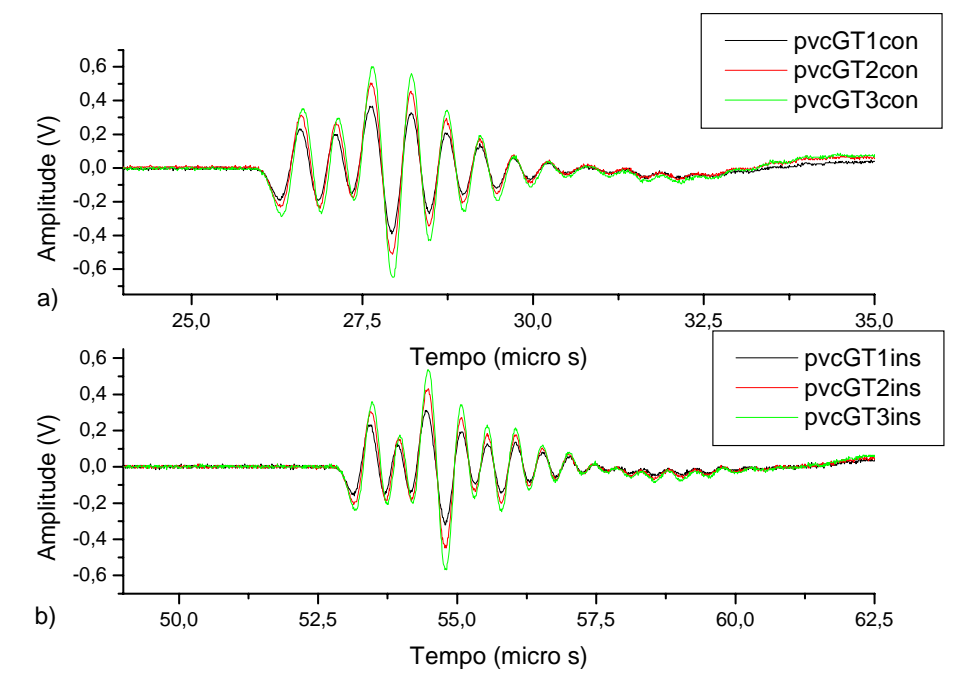

Figura 4.1.18. a e b são os sinais temporais do PVC G, medidos pela técnica de contato e inserção, respectivamente, nas tensões de $124 \mathrm{~V}$ (T1), 172V (T2) e 224V (T3), para o par de transdutores IG de freqüência $2 \mathrm{MHz}$. 
Na figura 4.1.19 são apresentados os valores experimentais da velocidade do som para o PVC G e P, com a sua respectiva velocidade teórica para os pares de transdutores IG e LM todos de $2 \mathrm{MHz}$ de freqüência nominal. Não foi feita discriminação entre as tensões (estão misturadas).

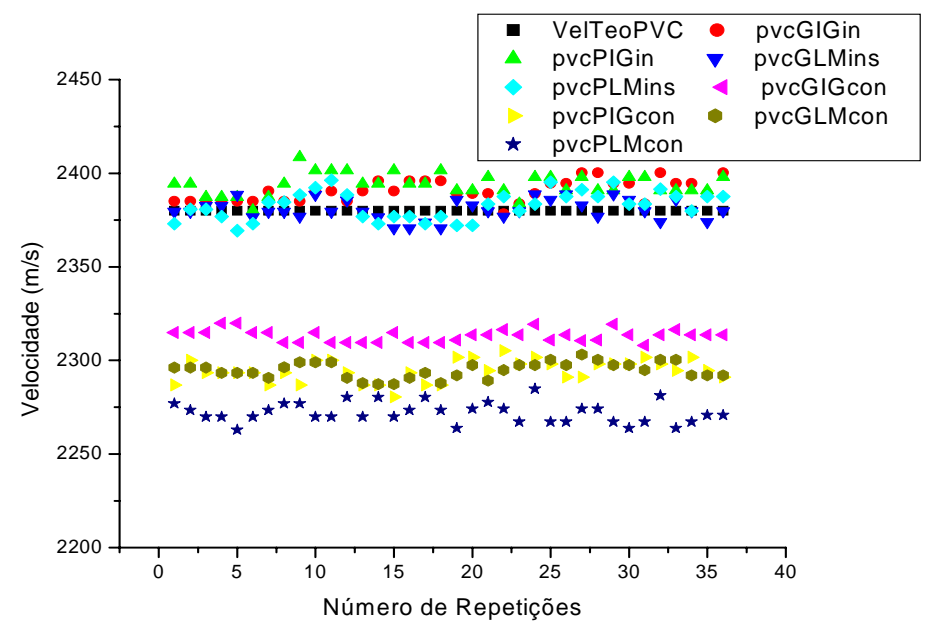

Figura 4.1.19. Velocidade do som experimental, medida pelas técnicas de contato e inserção, para as peças de PVC G e P, para os transdutores IG e LM.

Nas figuras 4.1.20 e 4.1.21, estão apresentados os sinais temporais, para as três tensões do equipamento, medidas pela técnica de contato e inserção convencional. Para as peças de acrílico, com o objetivo de ilustração, serão apresentados apenas os gráficos do acrílico G. Foram utilizados os transdutores IG e LM de freqüência 2MHz.

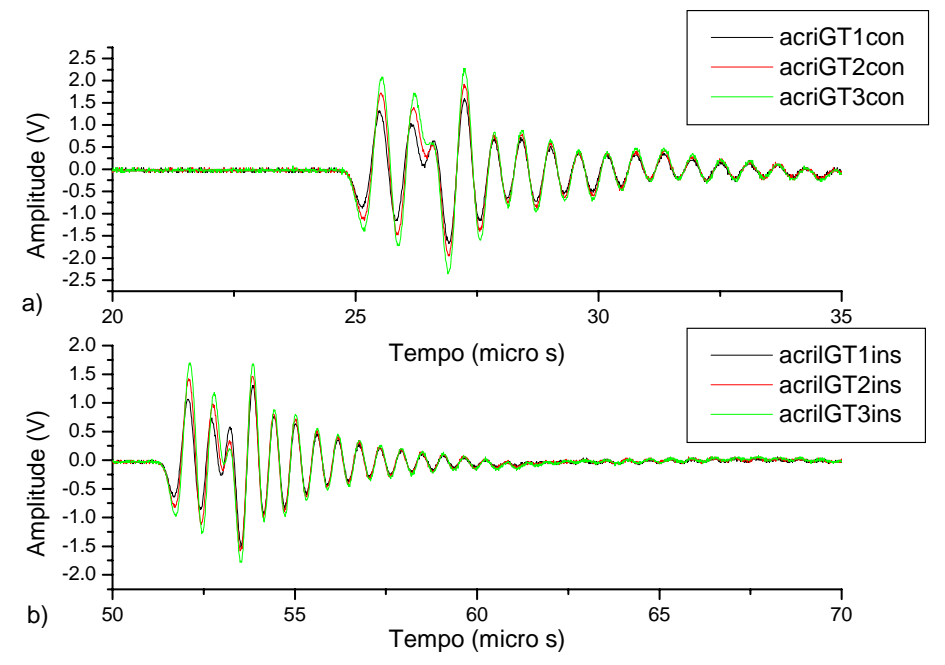

Figura 4.1.20. a e b são os sinais temporais do acrílico $G$ medidos pela técnica de contato e inserção, respectivamente, nas tensões de $124 \mathrm{~V}$ (T1), $172 \mathrm{~V}$ (T2) e $224 \mathrm{~V}$ (T3), para o par de transdutores LM de freqüência $2 \mathrm{MHz}$. 


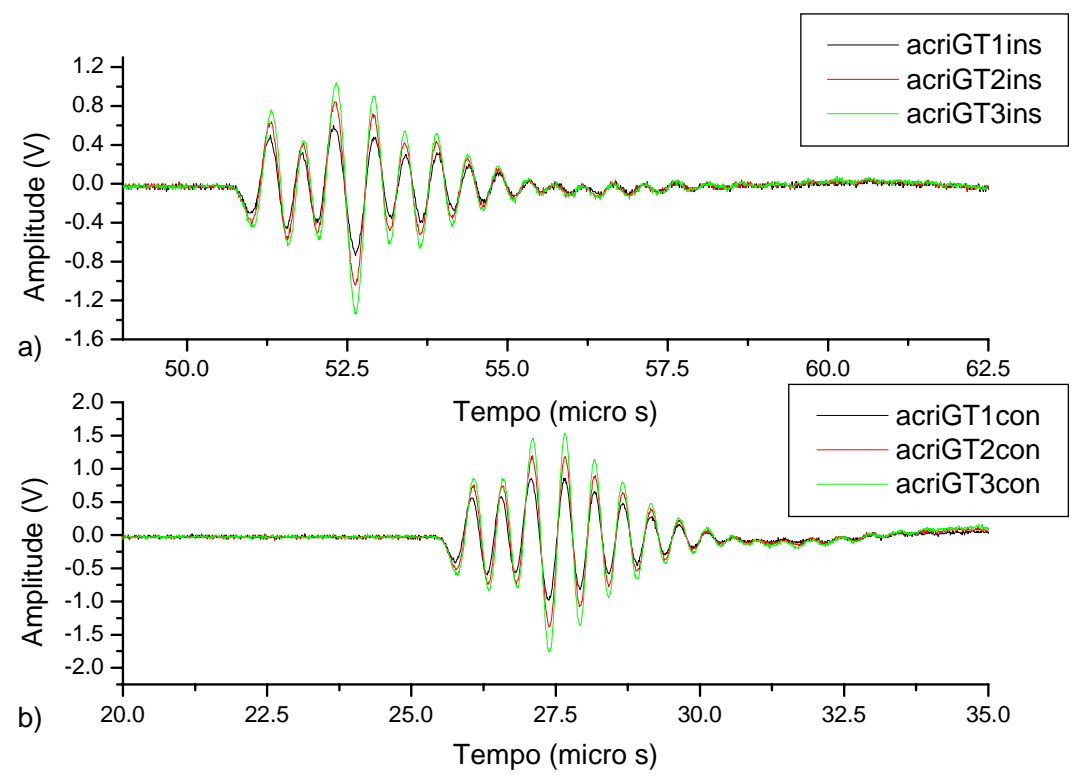

Figura 4.1.21. a e b são os sinais temporais do acrílico $G$ medidos pela técnica de contato e inserção, respectivamente, nas tensões de 124V (T1), 172V (T2) e 224V (T3), para o par de transdutores IG de freqüência $2 \mathrm{MHz}$

Na figura 4.1.22 são apresentados os valores experimentais da velocidade do som para o acrílico G e P, com a sua respectiva velocidade teórica para os pares de transdutores IG e LM todos de $2 \mathrm{MHz}$ de freqüência nominal. Não foi feita discriminação entre as tensões (estão misturadas).

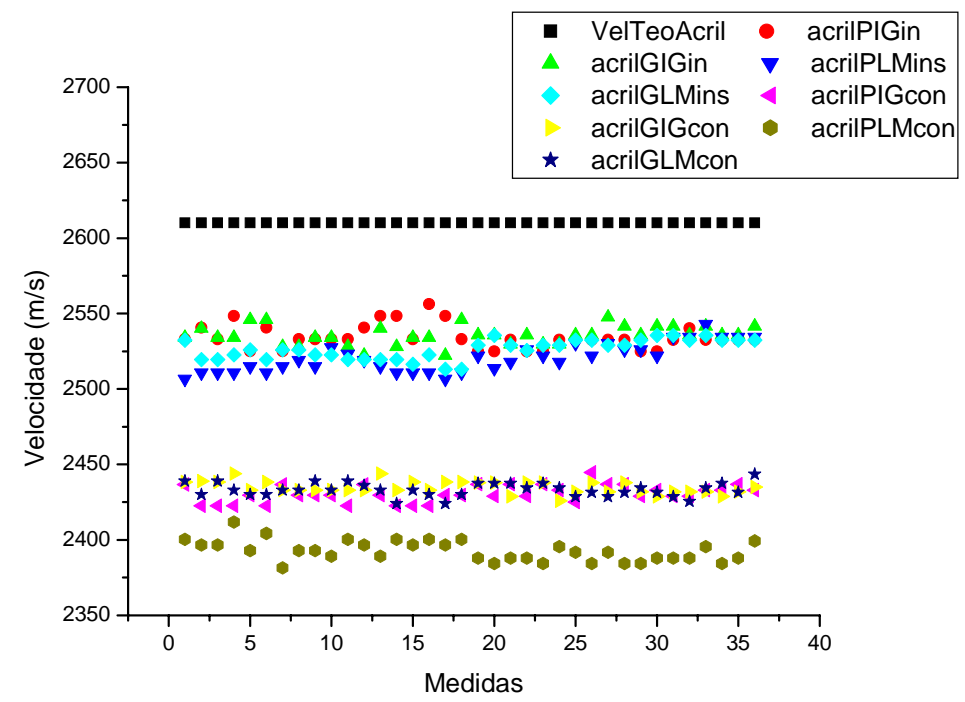

Figura 4.1.22. Velocidade do som experimental, medida pelas técnicas de contato e inserção, para as peças de acrílico, para os transdutores IG e LM. 
Nas figuras 4.1.23 e 4.1.24, são apresentados os sinais temporais, para as três tensões do equipamento, medidas pela técnica de contato e inserção convencional, para a peça de alumínio. Foram utilizados os transdutores IG e LM de freqüência 2MHz.

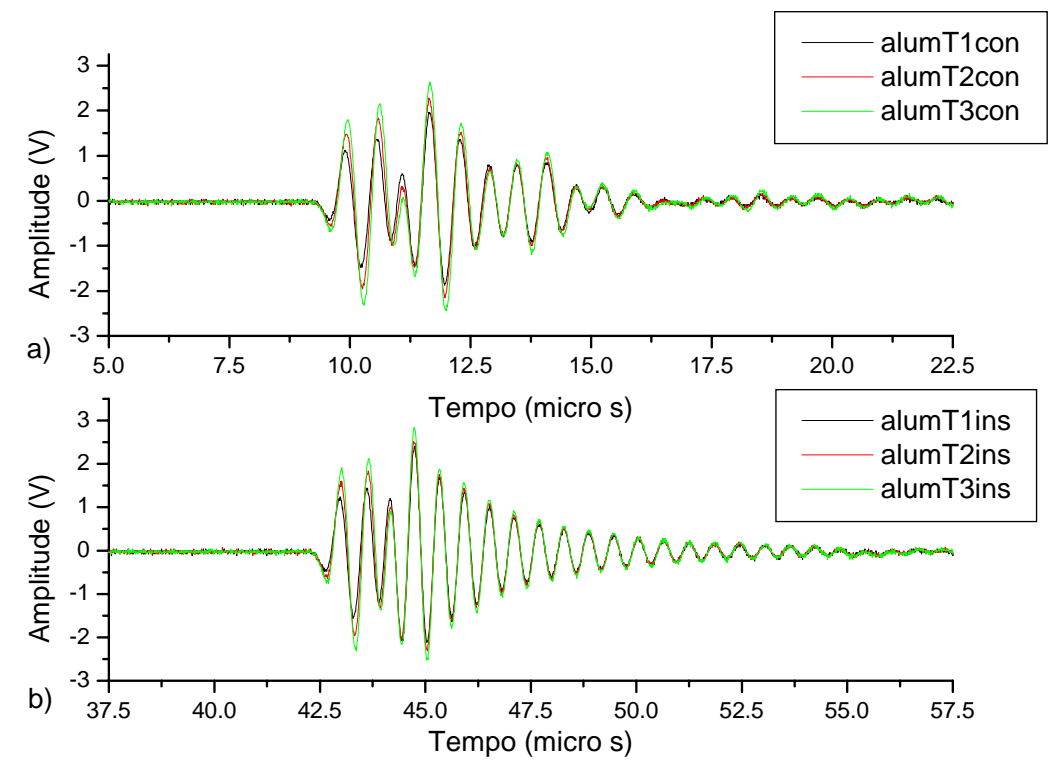

Figura 4.1.23. a e b são os sinais temporais do alumínio, medidos pela técnica de contato e inserção, respectivamente, nas tensões de $124 \mathrm{~V}$ (T1), 172V (T2) e $224 \mathrm{~V}$ (T3), para o par de transdutores LM de freqüência 2MHz.

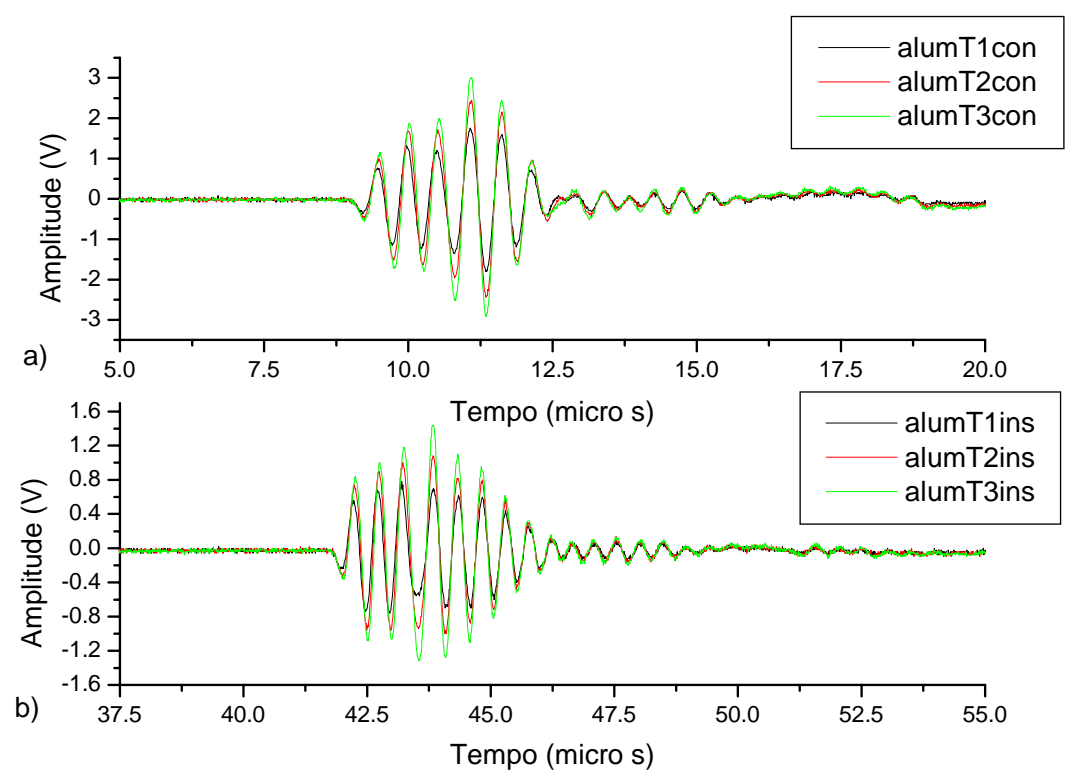

Figura 4.1.24. a e b são os sinais temporais do alumínio, medidos pela técnica de contato e inserção, respectivamente, nas tensões de 124V (T1), 172V (T2) e 224V (T3), para o par de transdutores IG de freqüência $2 \mathrm{MHz}$ 
Na figura 4.1.25 são apresentados os valores experimentais da velocidade do som para o alumínio, com a sua respectiva velocidade teórica para os pares de transdutores IG e LM todos de $2 \mathrm{MHz}$ de freqüência nominal. Não foi feita discriminação entre as tensões (estão misturadas).

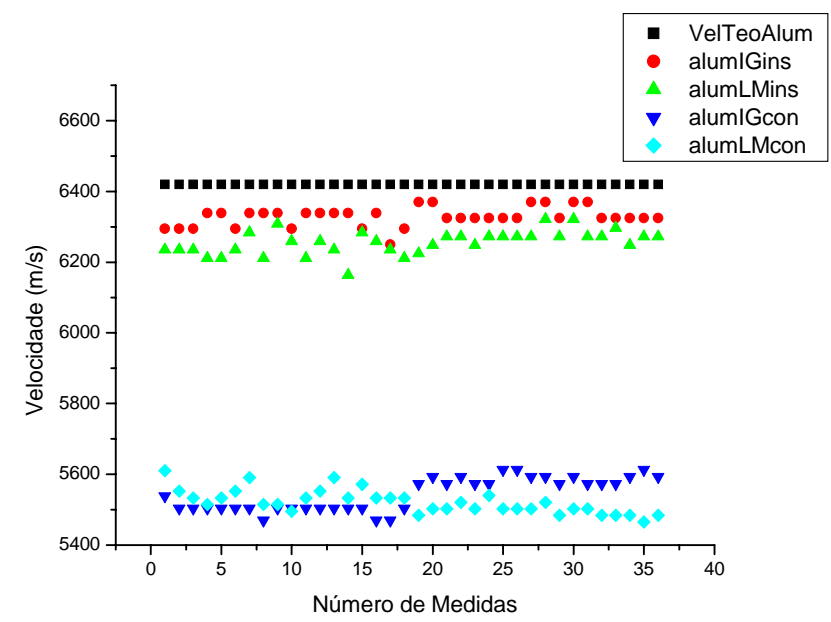

Figura 4.1.25. Velocidade do som experimental, medida pelas técnicas de contato e inserção, para a peça de alumínio, para os transdutores IG e LM.

Nas figuras 4.1.26 e 4.1.27, estão apresentados os sinais temporais, para as três tensões do equipamento, medidas pela técnica de contato e inserção convencional, para a peça de nylon. Foram utilizados os transdutores IG e LM de freqüência 2MHz.

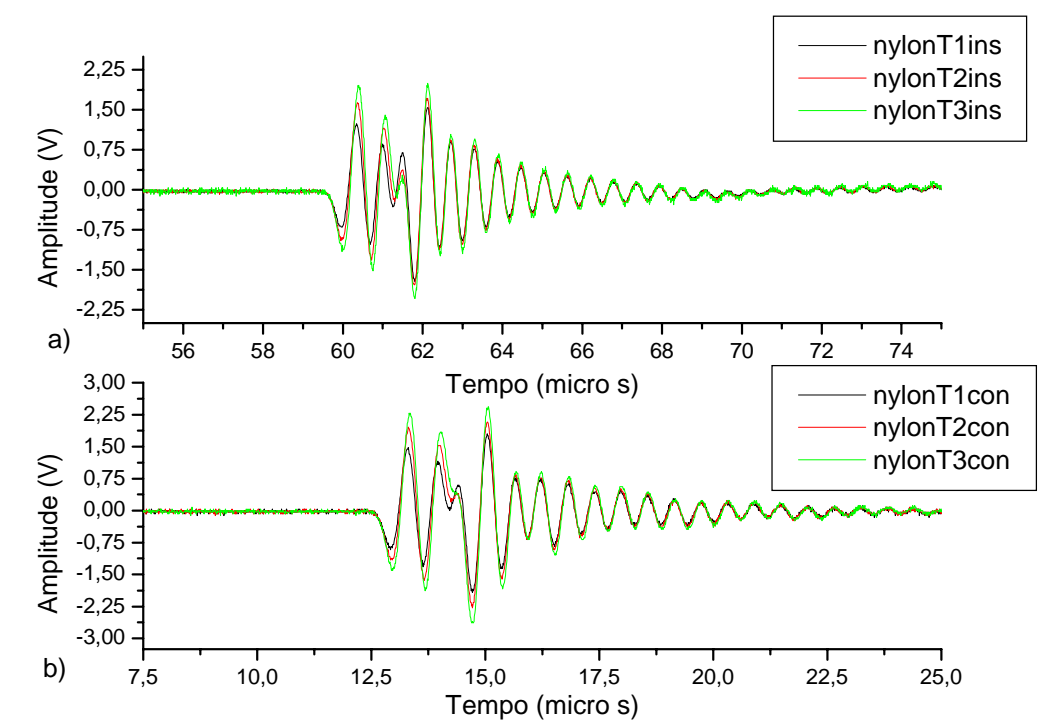

Figura 4.1.26. a e b são os sinais temporais do nylon, medidos pela técnica de inserção e contato, respectivamente, nas tensões de $124 \mathrm{~V}$ (T1), $172 \mathrm{~V}$ (T2) e $224 \mathrm{~V}$ (T3), para o par de transdutores LM de freqüência $2 \mathrm{MHz}$. 


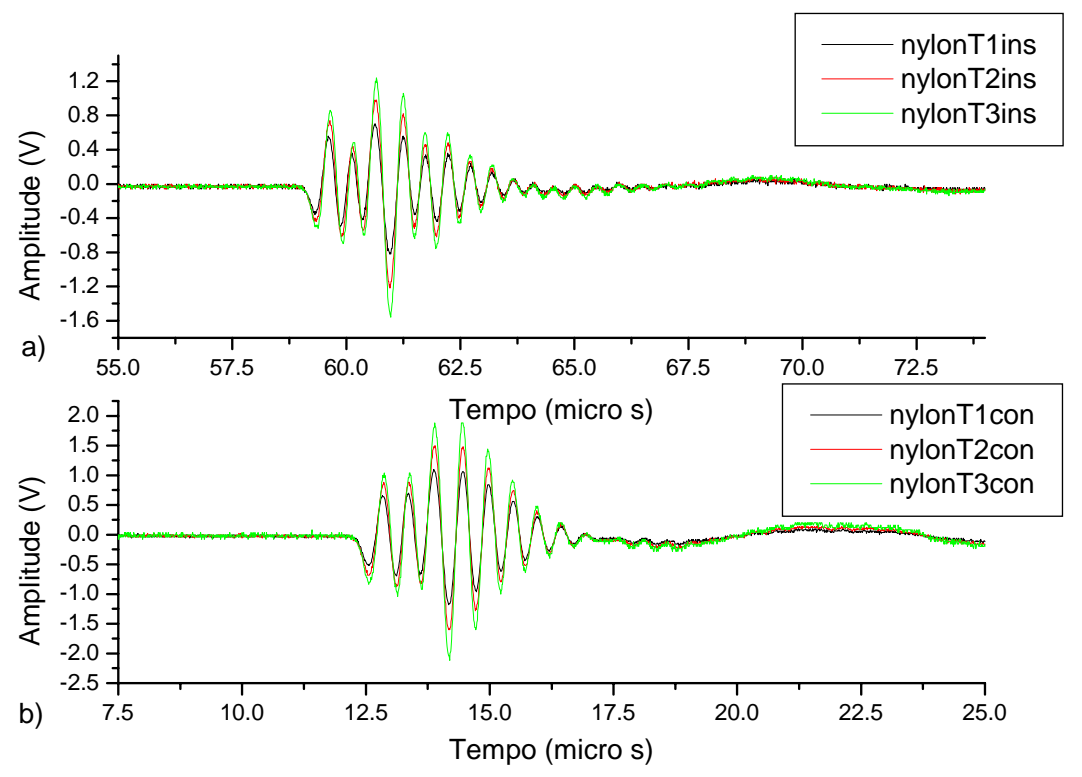

Figura 4.1.27. a e b são os sinais temporais do nylon, medidos pela técnica de inserção e contato, respectivamente, nas tensões de $124 \mathrm{~V}$ (T1), $172 \mathrm{~V}$ (T2) e 224V (T3), para o par de transdutores IG de freqüência $2 \mathrm{MHz}$.

Na figura 4.1.28, são apresentados os valores experimentais da velocidade do som para o nylon, com a sua respectiva velocidade teórica para os pares de transdutores IG e LM todos de $2 \mathrm{MHz}$ de freqüência nominal. Não foi feita discriminação entre as tensões (estão misturadas).

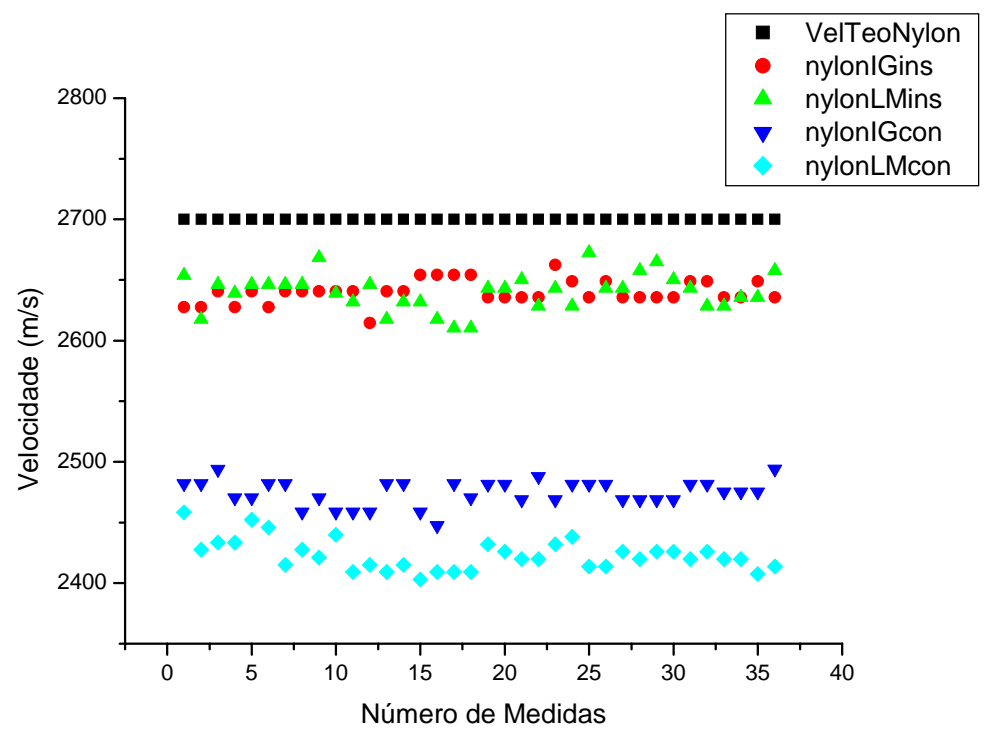

Figura 4.1.28. Velocidade do som experimental, medida pelas técnicas de contato e inserção, para a peça de nylon, para os transdutores IG e LM. 
Nas tabelas 4.1.6 e 4.1.7, são apresentados os valores da média das velocidades com os seus respectivos desvios padrão para os pares de transdutores de 2MHz (IG e LM).

Tabela 4.1.6. Média das velocidades, para o par de transdutores IG, com seus respectivos desvios padrão para as peças plásticas e alumínio.

\begin{tabular}{c|c|c|c|c|c}
\multirow{4}{*}{ Transdutores } & \multirow{2}{*}{ Amostras } & \multicolumn{2}{|c|}{ Inserção } & \multicolumn{2}{c}{ Contato } \\
\cline { 3 - 6 } & & $\begin{array}{c}\text { Velocidade } \\
\mathbf{( m / s )}\end{array}$ & SD (m/s) & $\begin{array}{c}\text { Velocidade } \\
\mathbf{( m / s )}\end{array}$ & SD (m/s) \\
\hline \multirow{4}{*}{ IG } & PVC-G & 2390,6 & 5,67 & 2313,2 & 3,26 \\
\cline { 2 - 6 } & PVC-P & 2393,9 & 5,82 & 2294,5 & 5,84 \\
\cline { 2 - 6 } & Acril-G & 2534,3 & 7,88 & 2430,4 & 5,70 \\
\cline { 2 - 6 } & Acril-P & 2535,5 & 6,26 & 2434,7 & 4,13 \\
\cline { 2 - 6 } & Alum & 6328,1 & 27,2 & 5544,0 & 47,0 \\
\cline { 2 - 6 } & Nylon & 2640,1 & 9,57 & 2474,5 & 10,6
\end{tabular}

Tabela 4.1.7. Média das velocidades, para o par de transdutores LM, com seus respectivos desvios padrão para as peças plásticas e alumínio.

\begin{tabular}{c|c|c|c|c|c}
\multirow{2}{*}{ Transdutores } & \multirow{2}{*}{ Amostras } & \multicolumn{2}{|c|}{ Inserção } & \multicolumn{2}{c}{ Contato } \\
\cline { 3 - 6 } & $\begin{array}{c}\text { Velocidade } \\
\mathbf{( m / s )}\end{array}$ & SD (m/s) & $\begin{array}{c}\text { Velocidade } \\
\mathbf{( m / s )}\end{array}$ & SD (m/s) \\
\hline \multirow{4}{*}{ LM } & PVC-G & 2380,5 & 5,35 & 2294,9 & 4,23 \\
\cline { 2 - 6 } & PVC-P & 2382,7 & 7,41 & 2272,1 & 5,48 \\
\cline { 2 - 6 } & Acril-G & 2520,6 & 9,50 & 2392,6 & 6,88 \\
\cline { 2 - 6 } & Acril-P & 2526,3 & 6,55 & 2433,1 & 4,46 \\
\cline { 2 - 6 } & Alum & 6255,1 & 33,6 & 5521,0 & 33,6 \\
\cline { 2 - 6 } & Nylon & 2640,1 & 15,0 & 2423,1 & 12,8
\end{tabular}

Nas tabelas 4.1.6 e 4.1.7, são apresentados os valores das médias das velocidades para os pares de transdutores de 2MHz (IG e LM), para as peças plásticas e o alumínio. Os valores obtidos para a velocidade do som pela técnica de inserção apresentaram valores mais próximos dos valores teóricos do que os que foram obtidos pela técnica de contato.

Para a técnica de inserção nenhuma variação foi maior que 3,5\%, quando comparado com o valor teórico, para qualquer um dos pares de transdutores (IG e LM), independente da 
peça analisada. Sendo que, o PVC (G e P) apresentou a menor dispersão para ambos os pares de transdutores ficando menor que 0,6\%. Entretanto, a maior dispersão observada na técnica de inserção foi para o acrílico (G e P) sendo de aproximadamente 2,9\% e 3,5\% para os transdutores IG e LM, respectivamente.

Na técnica de contato os valores da velocidade do som apresentaram uma variação percentual maior do que os observados pela técnica de inserção convencional, quando comparados com os valores teóricos. As peças de PVC proporcionaram as menores dispersões, para os transdutores IG ficaram abaixo de 3,59\% e para os transdutores LM ficaram abaixo de 4,53\%. O alumínio por sua vez foi o que apresentou a maior dispersão, sendo de 13,64\% e 14,00\% para os pares de transdutores IG e LM, respectivamente.

\subsubsection{Transdutores de $1,5 \mathrm{MHz}$}

Nas figuras de 4.1.29 a 4.1.32, são apresentados os sinais temporais, para as três tensões do equipamento, medidas pela técnica de contato e de inserção, para as peças de PVC G, acrílico G, alumínio e nylon, para o par de transdutores PQ.

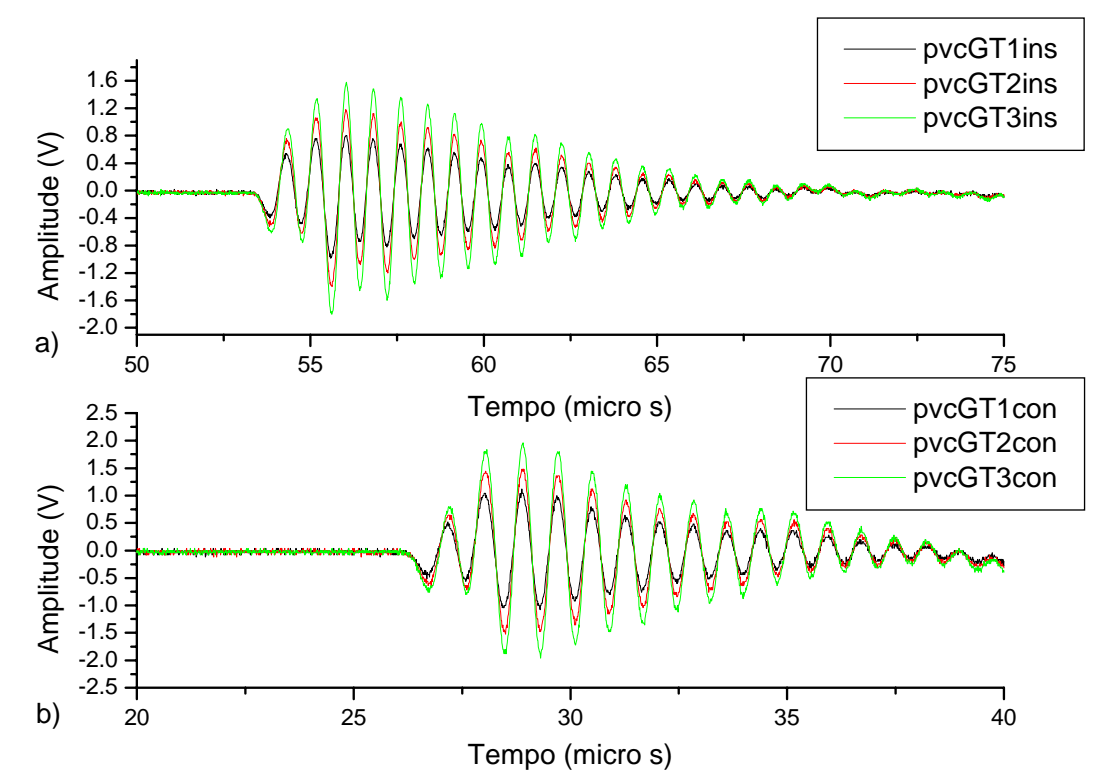

Figura 4.1.29. a e b são os sinais temporais do PVC G, medidos pela técnica de inserção e contato, respectivamente, nas tensões de 124V (T1), 172V (T2) e 224V (T3), para o par de transdutores PQ de freqüência $1,5 \mathrm{MHz}$. 


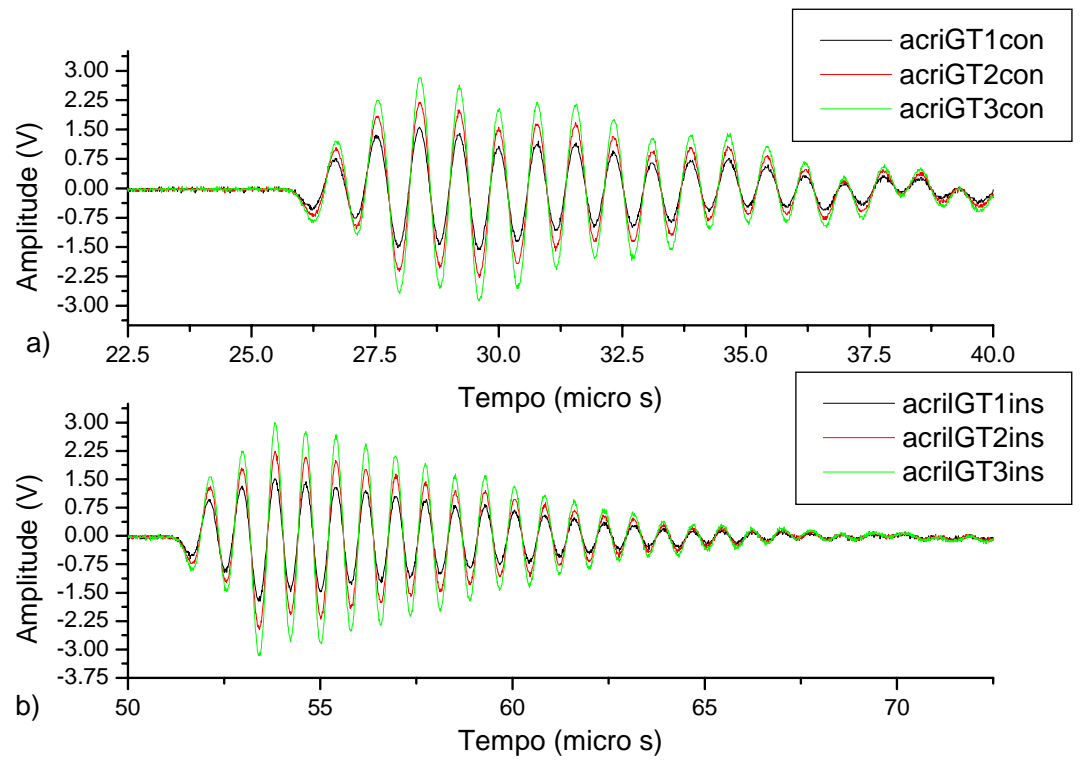

Figura 4.1.30. A e b são os sinais temporais do acrílico $G$ medidos pela técnica de contato e inserção, respectivamente, nas tensões de 124V (T1), 172V (T2) e 224V (T3), para o par de transdutores PQ de freqüência $1,5 \mathrm{MHz}$.

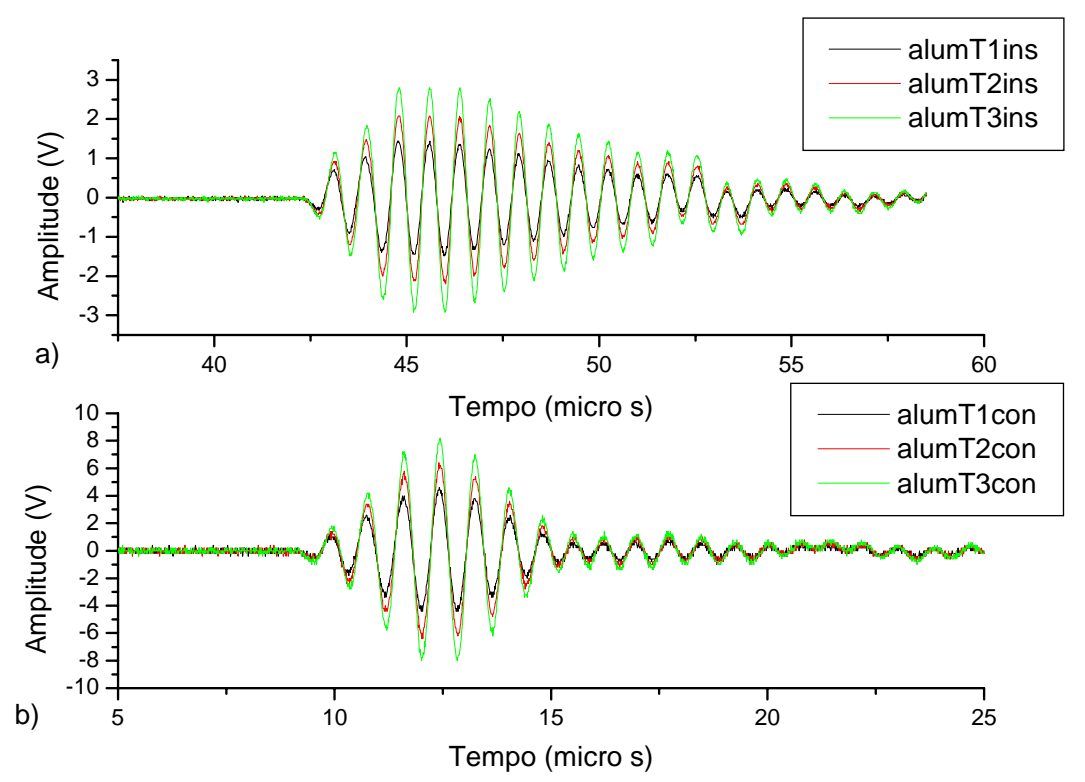

Figura 4.1.31. A e b são os sinais temporais do alumínio, medidos pela técnica de inserção e contato, respectivamente, nas tensões de $124 \mathrm{~V}$ (T1), $172 \mathrm{~V}$ (T2) e 224V (T3), para o par de transdutores PQ de freqüência $1,5 \mathrm{MHz}$. 


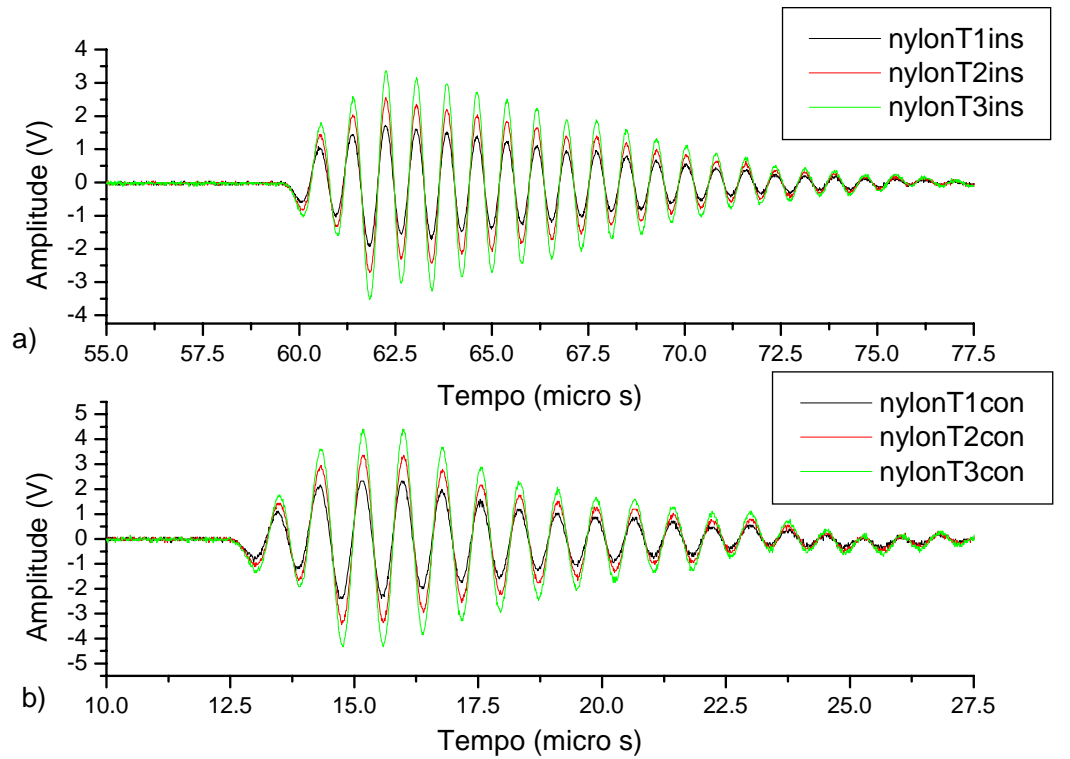

Figura 4.1.32. A e b são os sinais temporais do nylon, medidos pela técnica de inserção e contato, respectivamente, nas tensões de 124V (T1), 172V (T2) e 224V (T3), para o par de transdutores PQ de freqüência $1,5 \mathrm{MHz}$.

Das figuras 4.1.33 a 4.1.35, são apresentados os valores experimentais da velocidade do som para o acrílico G e P, PVC G e P, nylon e para o alumínio, com a sua respectiva velocidade teórica para o par de transdutores $\mathrm{PQ}$ de $1,5 \mathrm{MHz}$ de freqüência nominal. Não foi feita discriminação entre as tensões (estão misturadas).

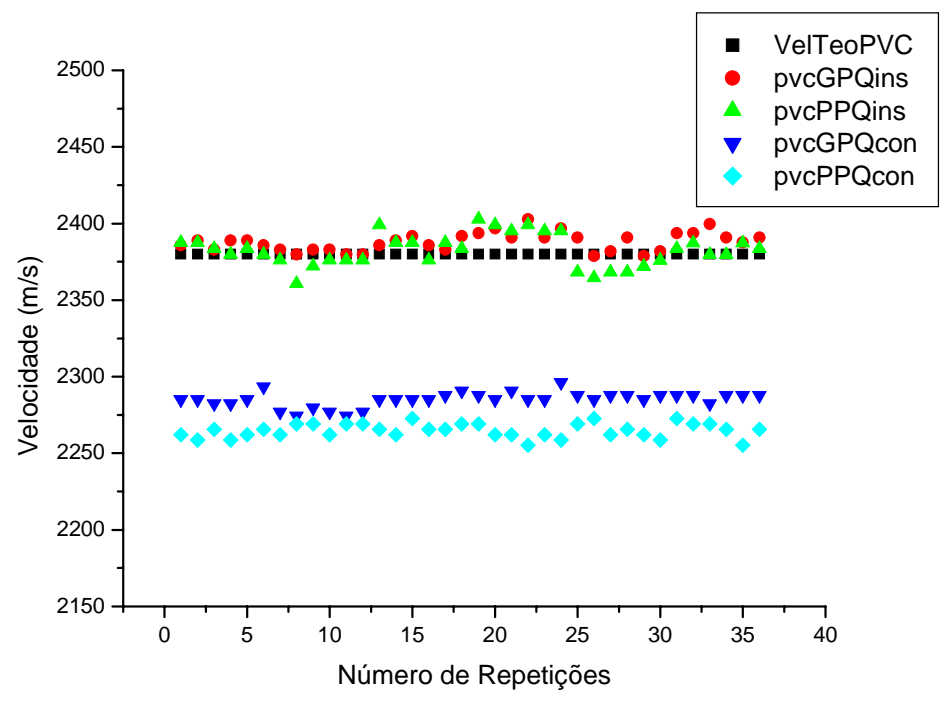

Figura 4.1.33. Velocidade do som experimental, medida pelas técnicas de contato e inserção, para as peças de PVC, para os transdutores PQ. 


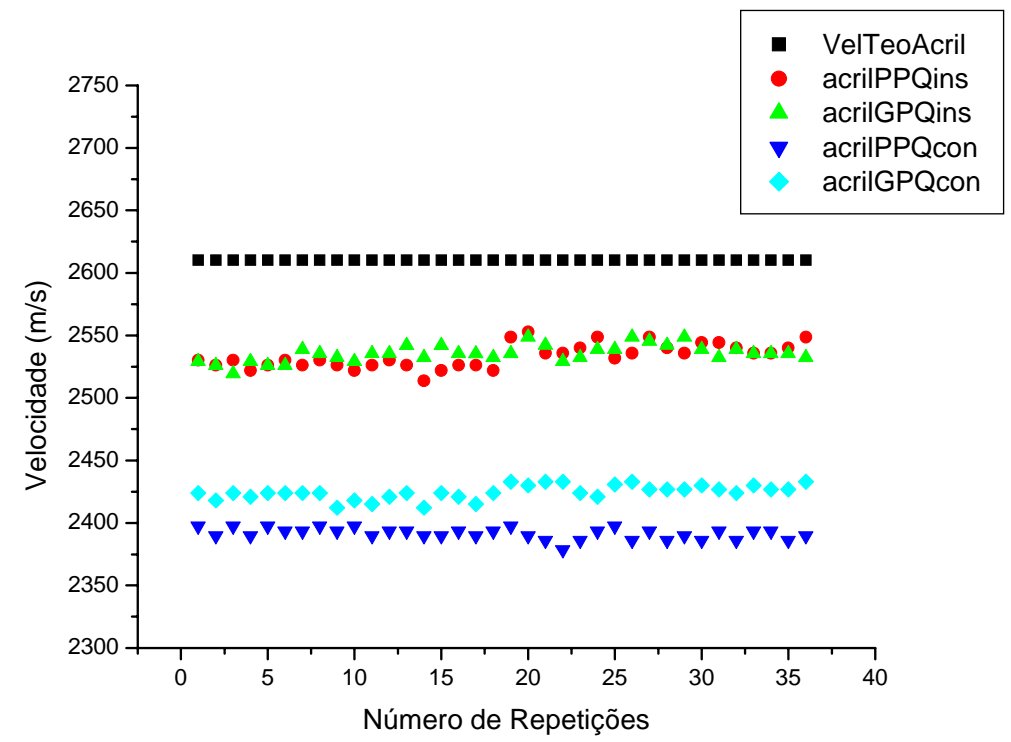

Figura 4.1.34. Velocidade do som experimental, medida pelas técnicas de contato e inserção, para as peças de acrílico, para os transdutores PQ.

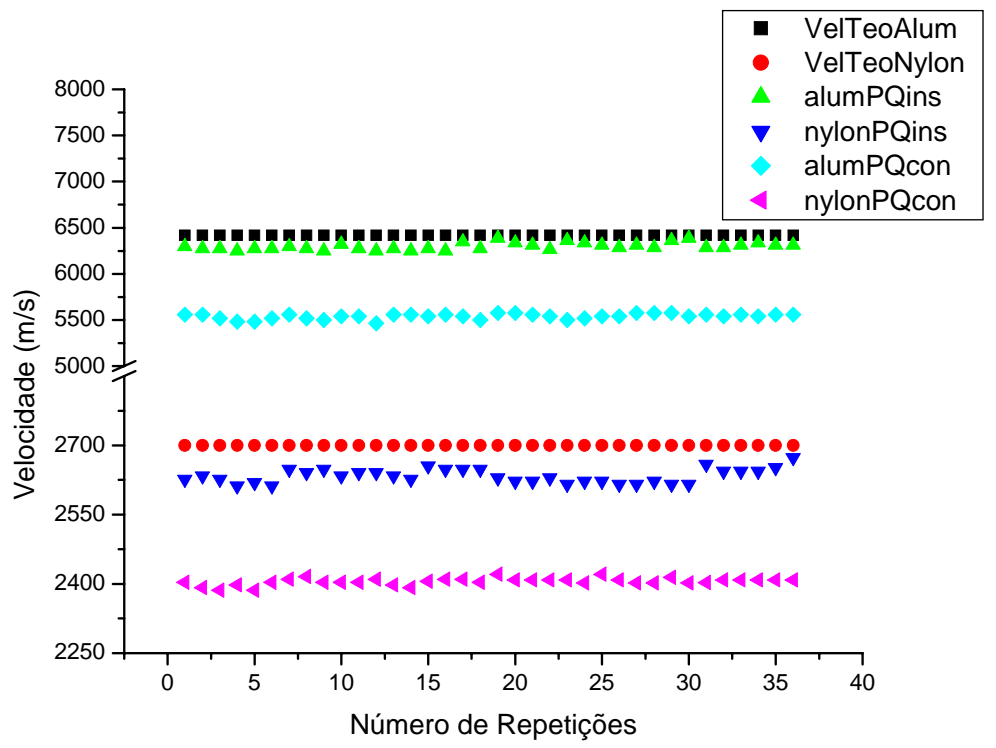

Figura 4.1.35. Velocidade do som experimental, medida pelas técnicas de contato e inserção, para as peças de alumínio e nylon, para os transdutores PQ.

Na tabela 4.1.8, são apresentados os valores da média das velocidades com os seus respectivos desvios padrão para o par de transdutores de $1,5 \mathrm{MHz}(\mathrm{PQ})$. 
Tabela 4.1.8 - Média das velocidades, para o par de transdutores PQ, com seus respectivos desvios padrão para as peças plásticas e alumínio.

\begin{tabular}{c|c|c|c|c|c}
\multirow{2}{*}{ Transdutores } & \multirow{2}{*}{ Amostras } & \multicolumn{2}{|c|}{ Inserção } & \multicolumn{2}{c}{ Contato } \\
\cline { 3 - 6 } & & $\begin{array}{c}\text { Velocidade } \\
\mathbf{( m / s )}\end{array}$ & SD (m/s) & $\begin{array}{c}\text { Velocidade } \\
\mathbf{( m / s )}\end{array}$ & SD (m/s) \\
\hline \multirow{5}{*}{ PQ } & PVC-G & 2388,0 & 6,03 & 2285,2 & 4,84 \\
\cline { 2 - 6 } & PVC-P & 2382,3 & 10,43 & 2264,7 & 4,67 \\
\cline { 2 - 6 } & Acril-G & 2533,5 & 9,48 & 2391,5 & 4,44 \\
\cline { 2 - 6 } & Acril-P & 2535,6 & 6,76 & 2424,6 & 5,68 \\
\cline { 2 - 6 } & Alum & 6297,8 & 38,36 & 5538,3 & 28,69 \\
\cline { 2 - 6 } & Nylon & 2633,6 & 15,29 & 2404,9 & 7,80
\end{tabular}

Na tabela 4.1.8, são apresentados os valores da média das velocidades do som, para as peças plásticas e para o alumínio, para o par de transdutores de 1,5 MHz (PQ). Os valores da velocidade do som obtidos pela técnica de inserção convencional demonstram uma menor dispersão do que os obtidos pela técnica de contato.

Na técnica de inserção convencional as peças de PVC apresentaram a menor variação, de 0,33\% e 0,09\% para o PVC G e P, respectivamente. Entretanto, as peças de acrílico apresentaram a maior variação, de 2,93\% e 2,85\% para os acrílicos G e P, respectivamente.

Na técnica de contato as variações observadas nas velocidades do som para as peças foram maiores que 3,98\% (para o PVC G) chegando até 13,73\% (para o alumínio), quando comparadas com os seus respectivos valores teóricos.

\subsubsection{Transdutores de $750 \mathrm{KHz}$}

Nas figuras de 4.1.36 a 4.1.39, são apresentados os sinais, para as três tensões do equipamento, medidas pela técnica de contato e inserção convencional, para as peças de PVC G, acrílico G, alumínio e nylon, para o par de transdutores CD (750kHz). 


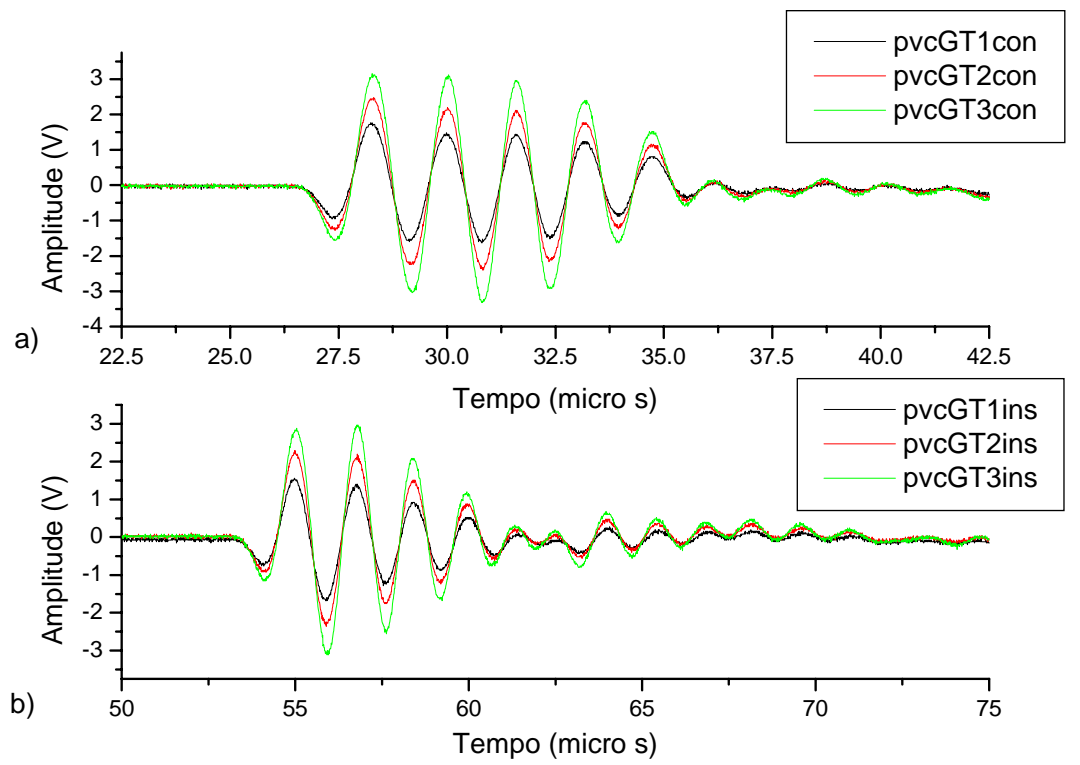

Figura 4.1.36. a e b são os sinais temporais do PVC G, medidos pela técnica de contato e inserção, respectivamente, nas tensões de 124V (T1), 172V (T2) e 224V (T3), para o par de transdutores CD de freqüência $0,75 \mathrm{MHz}$.

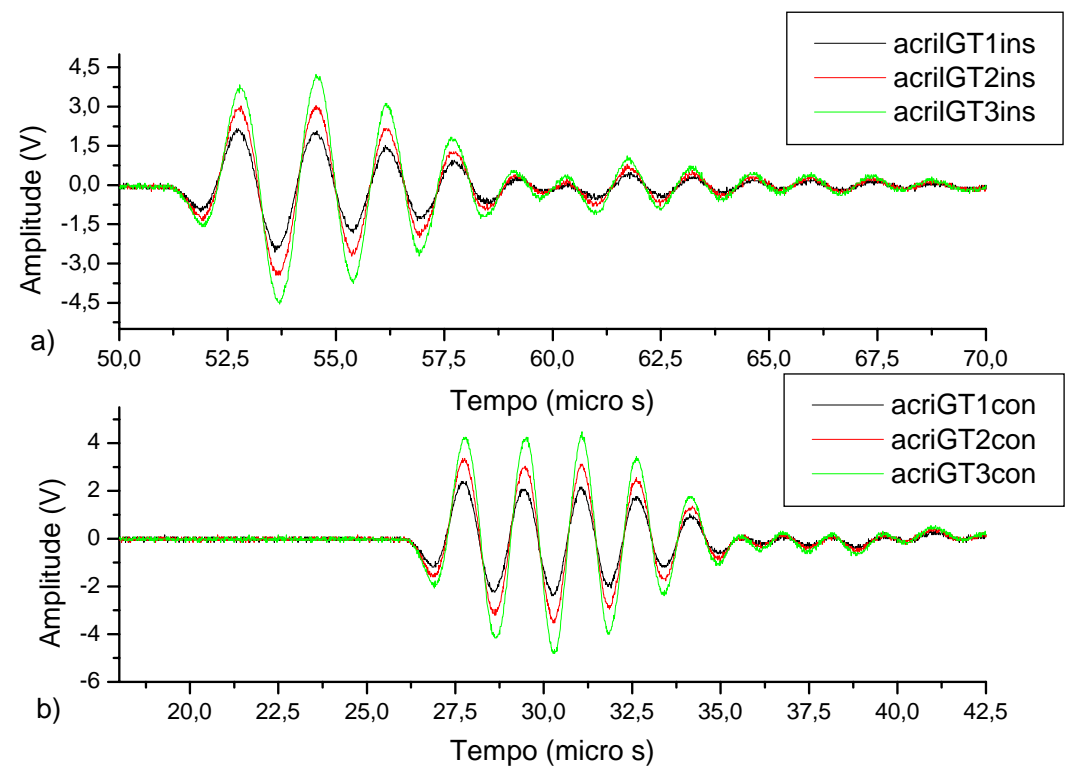

Figura 4.1.37. A e b são os sinais temporais do acrílico $G$ medidos pela técnica de inserção e contato, respectivamente, nas tensões de 124V (T1), 172V (T2) e 224V (T3), para o par de transdutores CD de freqüência $0,75 \mathrm{MHz}$. 


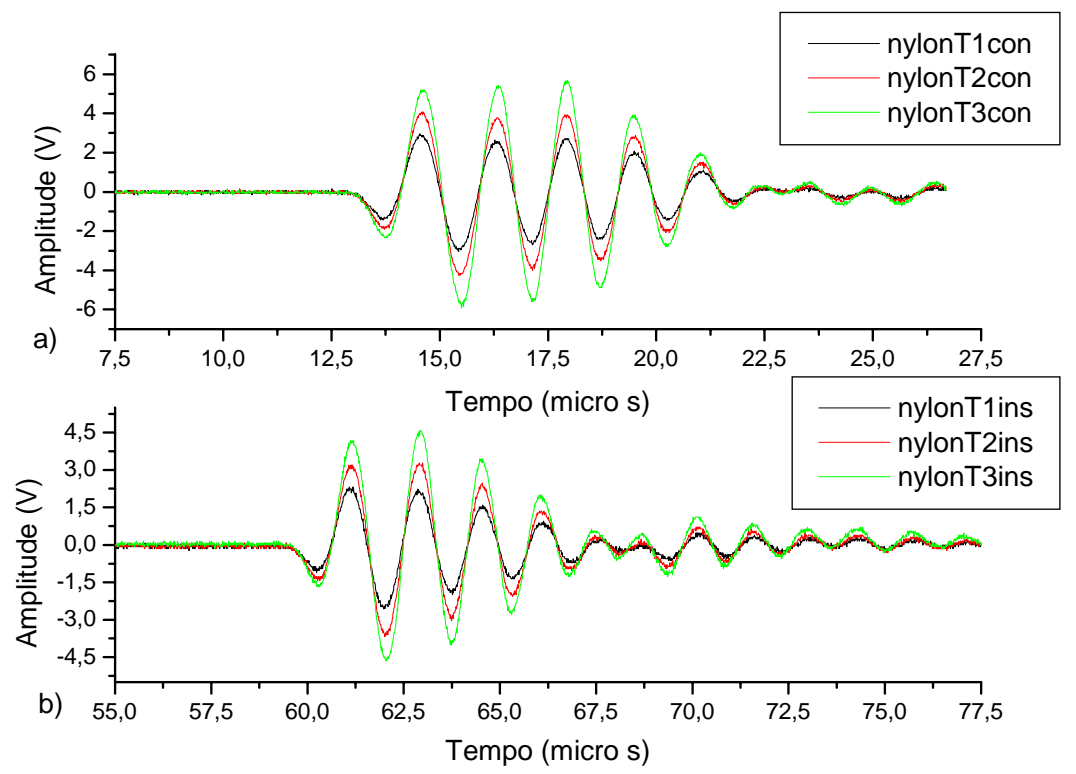

Figura 4.1.38. A e b são os sinais temporais do nylon, medidos pela técnica de contato e inserção, respectivamente, nas tensões de 124V (T1), 172V (T2) e 224V (T3), para o par de transdutores CD de freqüência $0,75 \mathrm{MHz}$.

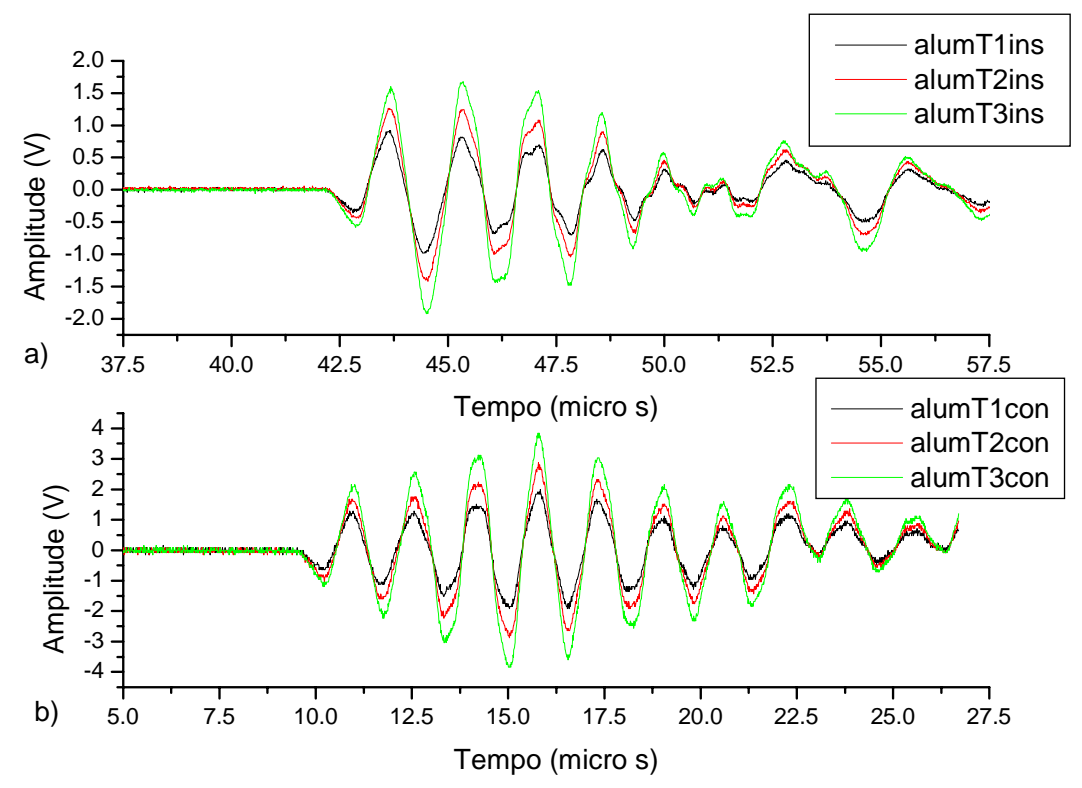

Figura 4.1.39. A e b são os sinais temporais do alumínio, medidos pela técnica de inserção e contato, respectivamente, nas tensões de 124V (T1), 172V (T2) e 224V (T3), para o par de transdutores CD de freqüência $0,75 \mathrm{MHz}$.

Das figuras 4.1 .40 a 4.1.42, são apresentados os valores experimentais da velocidade do som para o acrílico G e P, PVC G e P, nylon e para o alumínio, com a sua respectiva 
velocidade teórica para o par de transdutores $\mathrm{CD}$ de $0,75 \mathrm{MHz}$ de freqüência nominal. Não foi feita discriminação entre as tensões (estão misturadas).

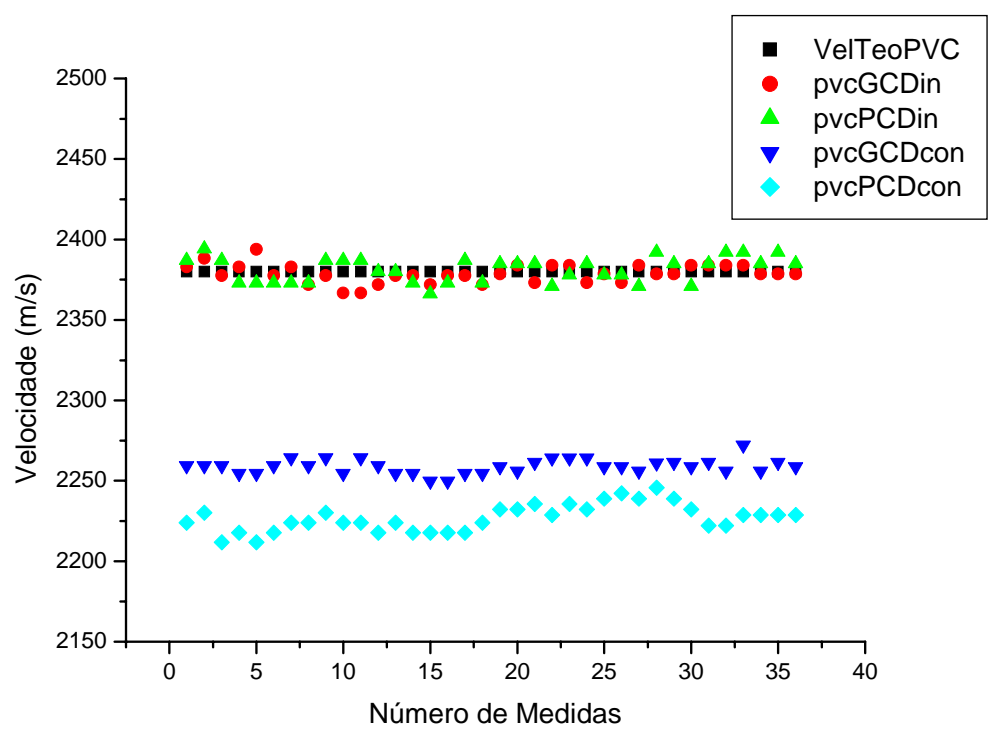

Figura 4.1.40. Velocidade do som experimental, medida pelas técnicas de contato e inserção, para as peças de PVC, para os transdutores CD.

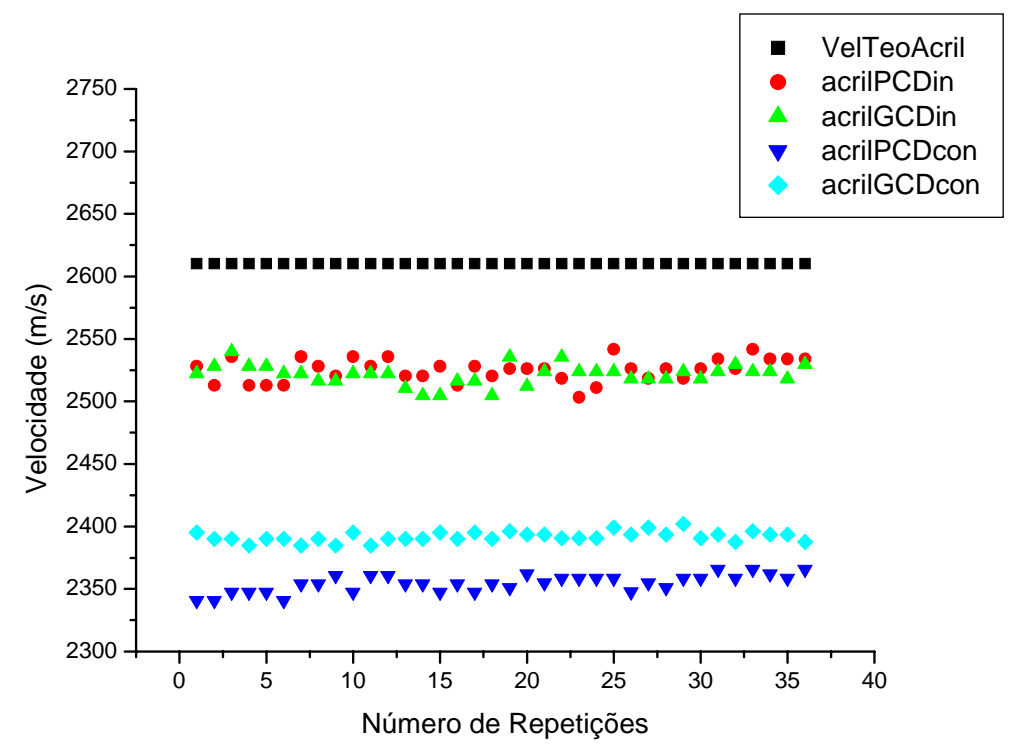

Figura 4.1.41. Velocidade do som experimental, medida pelas técnicas de contato e inserção, para as peças de acrílico, para os transdutores CD. 


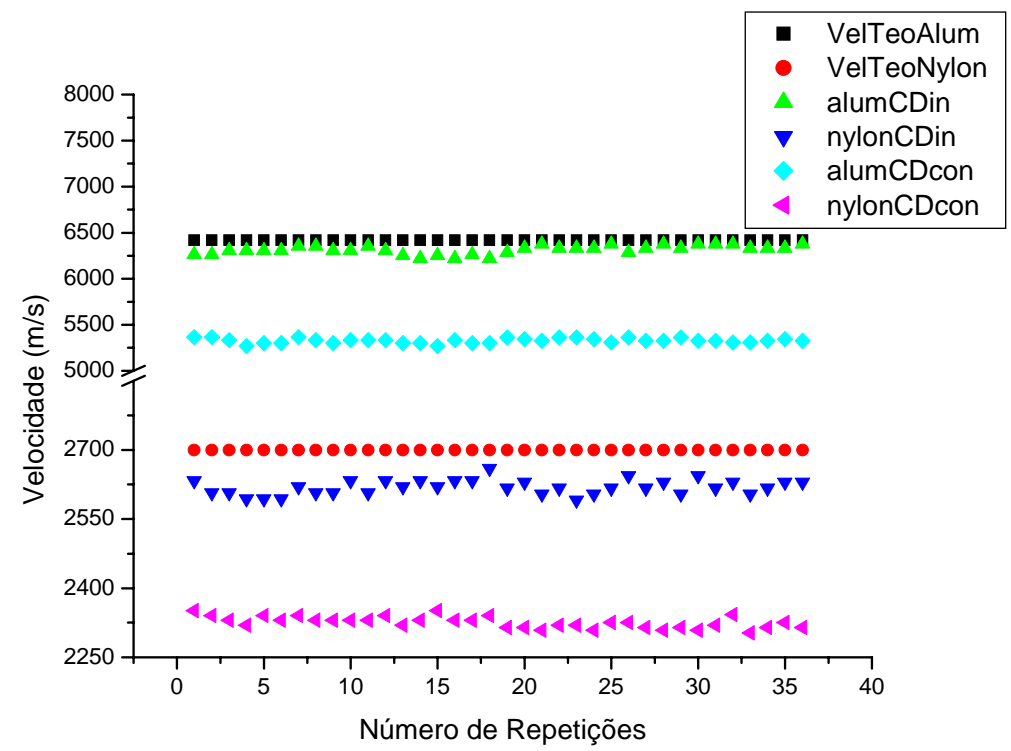

Figura 4.1.42. Velocidade do som experimental, medida pelas técnicas de contato e inserção, para as peças de alumínio e nylon, para os transdutores CD.

Na tabela 4.1.9, são apresentados os valores da média das velocidades com os seus respectivos desvios padrão para o par de transdutores de $0,750 \mathrm{MHz}(\mathrm{CD})$.

Tabela 4.1.9. Média das velocidades, para o par de transdutores CD, com seus respectivos desvios padrão para as peças plásticas e alumínio.

\begin{tabular}{c|c|c|c|c|c}
\multirow{4}{*}{ Transdutores } & \multirow{2}{*}{ Amostras } & \multicolumn{2}{|c|}{ Inserção } & \multicolumn{2}{c}{ Contato } \\
\cline { 3 - 6 } & & $\begin{array}{c}\text { Velocidade } \\
\mathbf{( m / s )}\end{array}$ & SD (m/s) & $\begin{array}{c}\text { Velocidade } \\
\mathbf{( m / s )}\end{array}$ & SD (m/s) \\
\hline \multirow{5}{*}{ CD } & PVC-G & 2378,7 & 5,76 & 2259,0 & 4,51 \\
\cline { 2 - 6 } & PVC-P & 2381,1 & 7,69 & 2226,9 & 8,40 \\
\cline { 2 - 6 } & Acril-G & 2525,0 & 9,26 & 2354,5 & 6,92 \\
\cline { 2 - 6 } & Acril-P & 2521,4 & 8,05 & 2391,7 & 4,10 \\
\cline { 2 - 6 } & Alum & 6314,7 & 47,14 & 5327,2 & 26,08 \\
\cline { 2 - 6 } & Nylon & 2619,3 & 16,02 & 2325,3 & 12,53
\end{tabular}

Os valores da velocidade do som (tabela 4.1.9) obtidos pela técnica de inserção convencional demonstram uma menor dispersão do que os obtidos pela técnica de contato. 
Na técnica de inserção convencional as peças de PVC apresentaram a menor variação, de 0,05\% e 0,04\% para o PVC G e P, respectivamente. Entretanto, as peças de acrílico apresentaram a maior variação, de 3,56\% e 3,39\% para os acrílicos G e P, respectivamente.

Na técnica de contato as variações observadas nas velocidades do som para as peças foram maiores que 5,08\% (para o PVC G) chegando até 17,02\% (para o alumínio), quando comparadas com os seus respectivos valores teóricos.

\subsubsection{Transdutores de $500 \mathrm{KHz}$}

Nas figuras de 4.1.43 a 4.1.46, são apresentados os sinais temporais, para as três tensões do equipamento, medidas pela técnica de inserção, para as peças de PVC G, acrílico G, alumínio e nylon. Para o par de transdutores RS (0,50MHz).

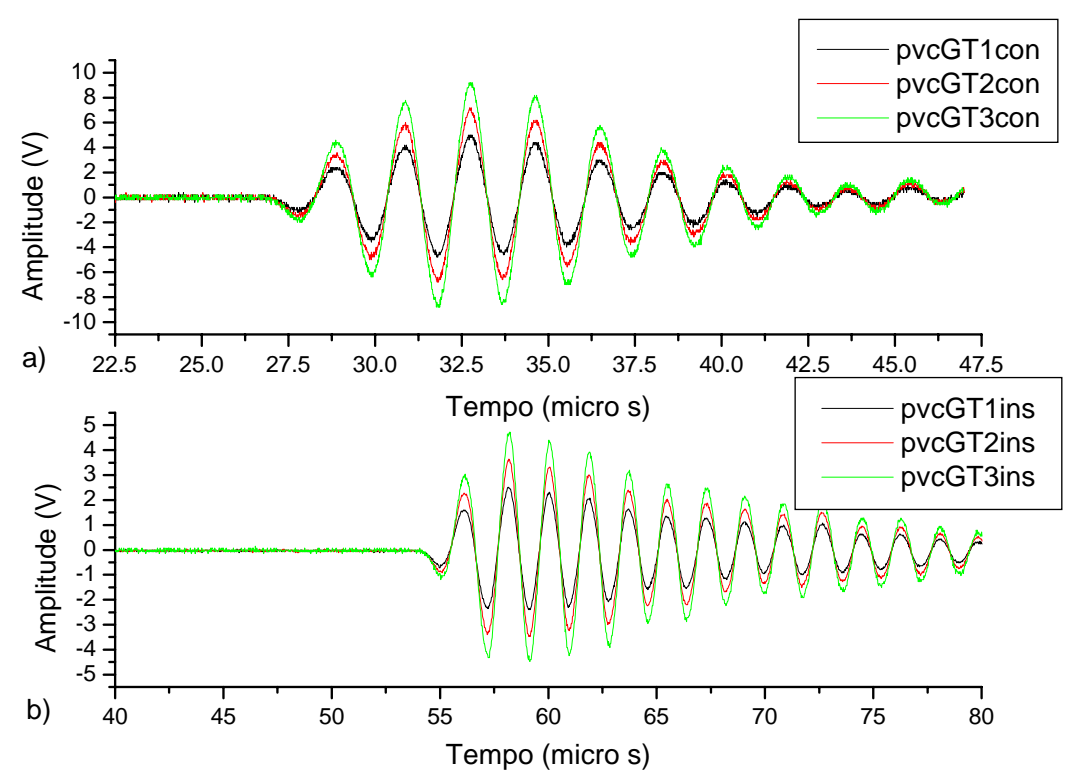

Figura 4.1.43. a e b são os sinais temporais do PVC G, medidos pela técnica de contato e inserção, respectivamente, nas tensões de 124V (T1), 172V (T2) e 224V (T3), para o par de transdutores RS de freqüência $0,5 \mathrm{MHz}$. 


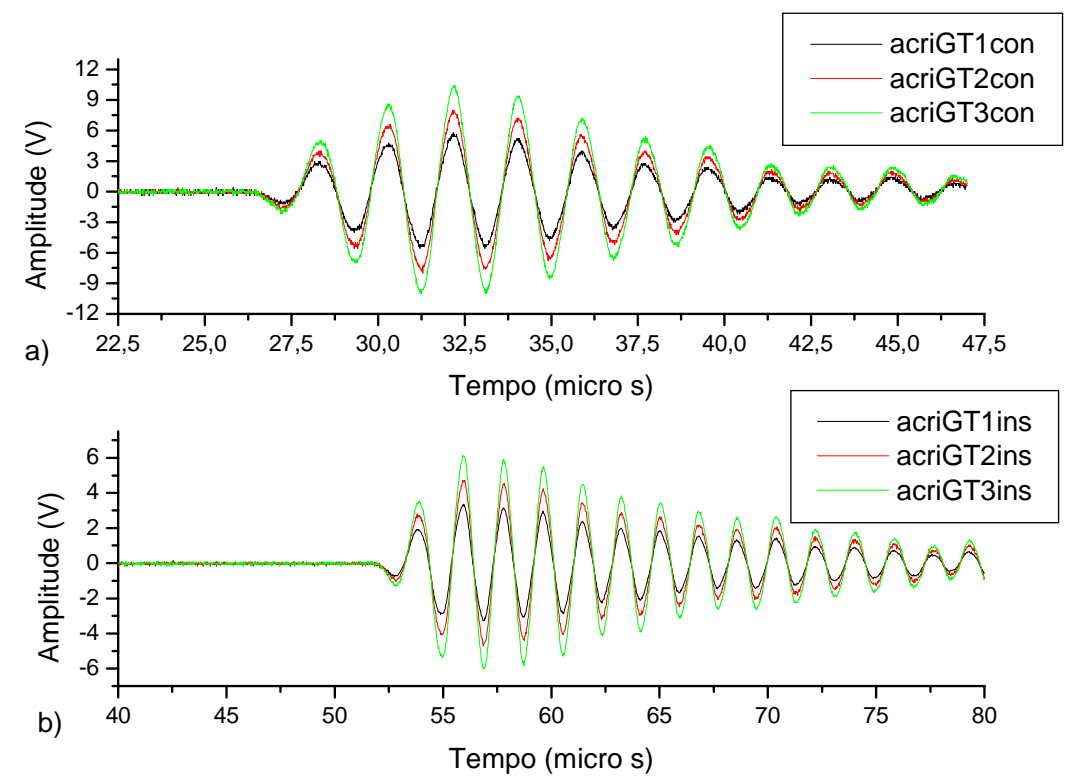

Figura 4.1.44. a e b são os sinais temporais do acrílico $G$ medidos pela técnica de contato e inserção, respectivamente, nas tensões de 124V (T1), 172V (T2) e 224V (T3), para o par de transdutores RS de freqüência $0,5 \mathrm{MHz}$.

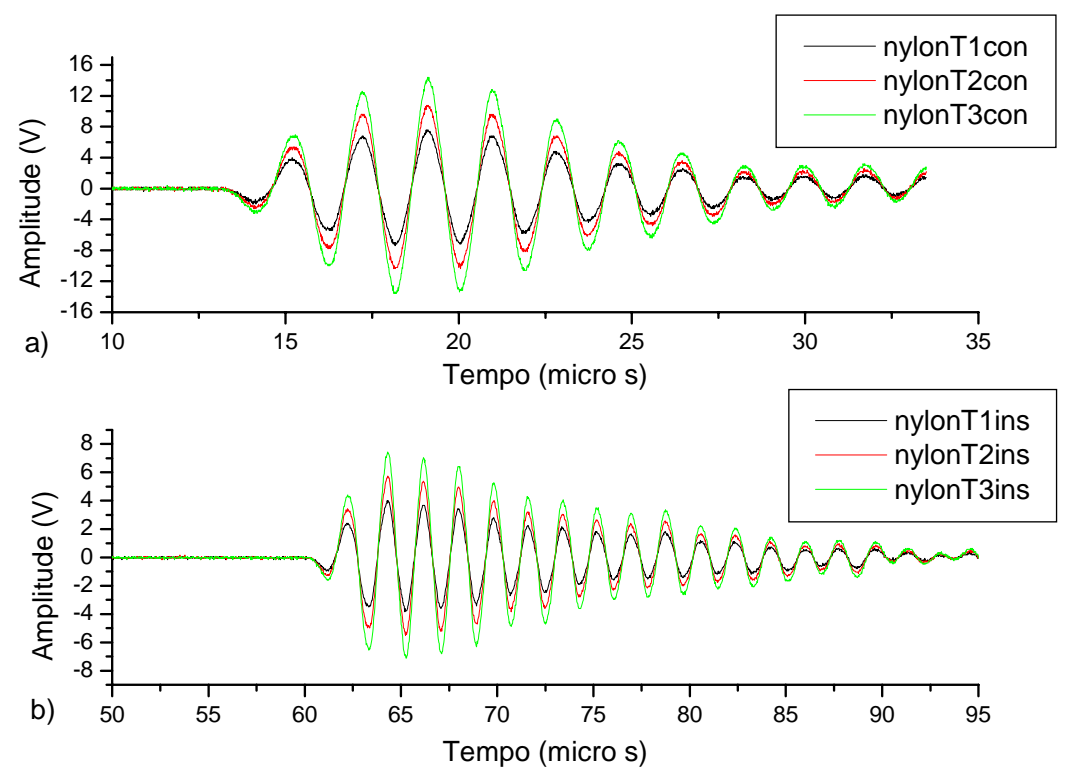

Figura 4.1.45. a e b são os sinais temporais do nylon, medidos pela técnica de contato e inserção, respectivamente, nas tensões de 124V (T1), 172V (T2) e 224V (T3), para o par de transdutores RS de freqüência $0,5 \mathrm{MHz}$. 


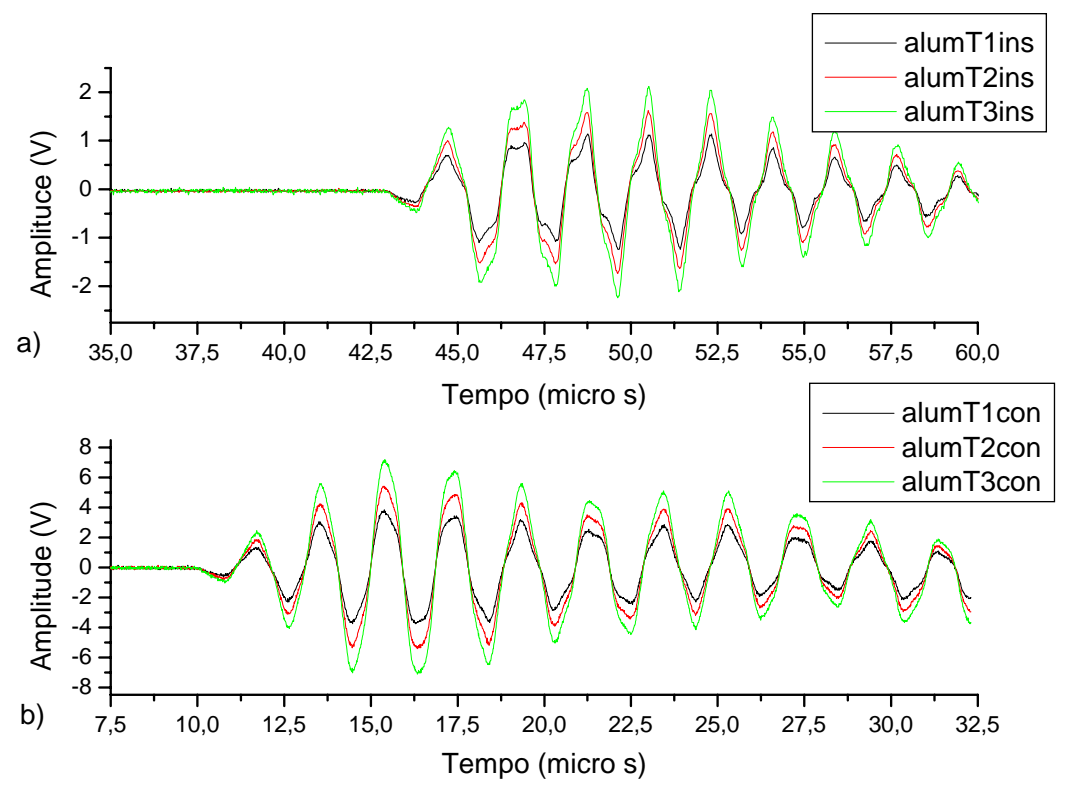

Figura 4.1.46. a e b são os sinais temporais do alumínio, medidos pela técnica de inserção e contato, respectivamente, nas tensões de 124V (T1), 172V (T2) e 224V (T3). Para o par de transdutores RS de freqüência $0,5 \mathrm{MHz}$.

Das figuras 4.1.47 a 4.1.49, são apresentados os valores experimentais da velocidade do som para o acrílico G e P, PVC G e P, nylon e para o alumínio, com a sua respectiva velocidade teórica para o par de transdutores RS de $0,5 \mathrm{MHz}$ de freqüência nominal. Não foi feita discriminação entre as tensões (estão misturadas).

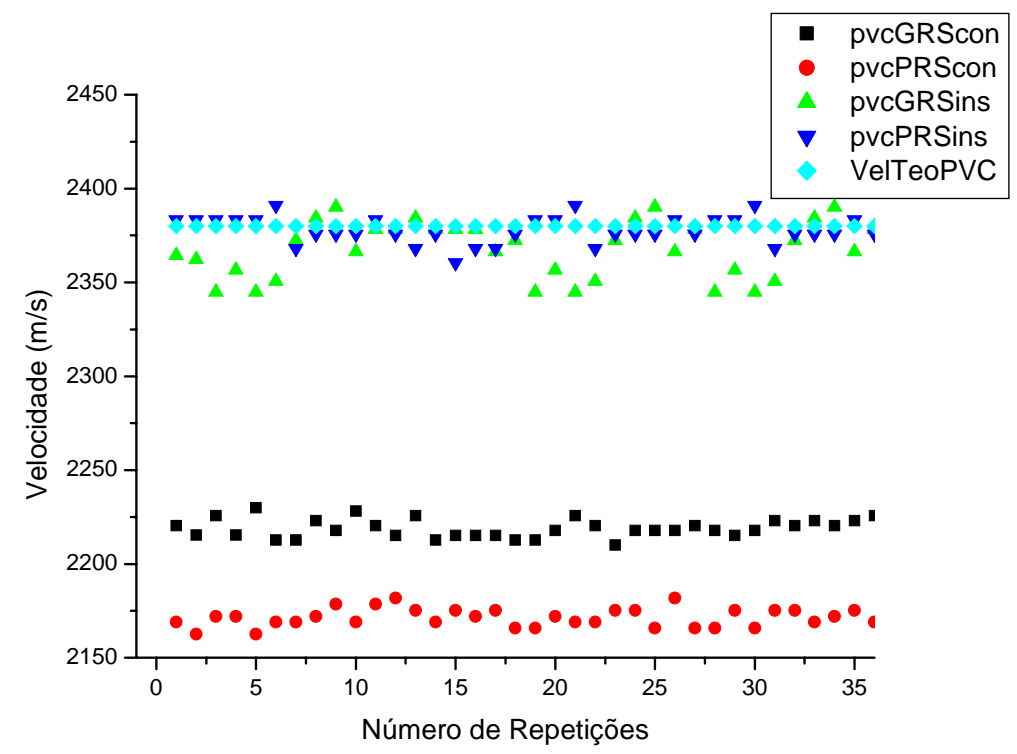

Figura 4.1.47. Velocidade do som experimental, medida pelas técnicas de contato e inserção, para as peças de PVC G e P, para os transdutores RS. 


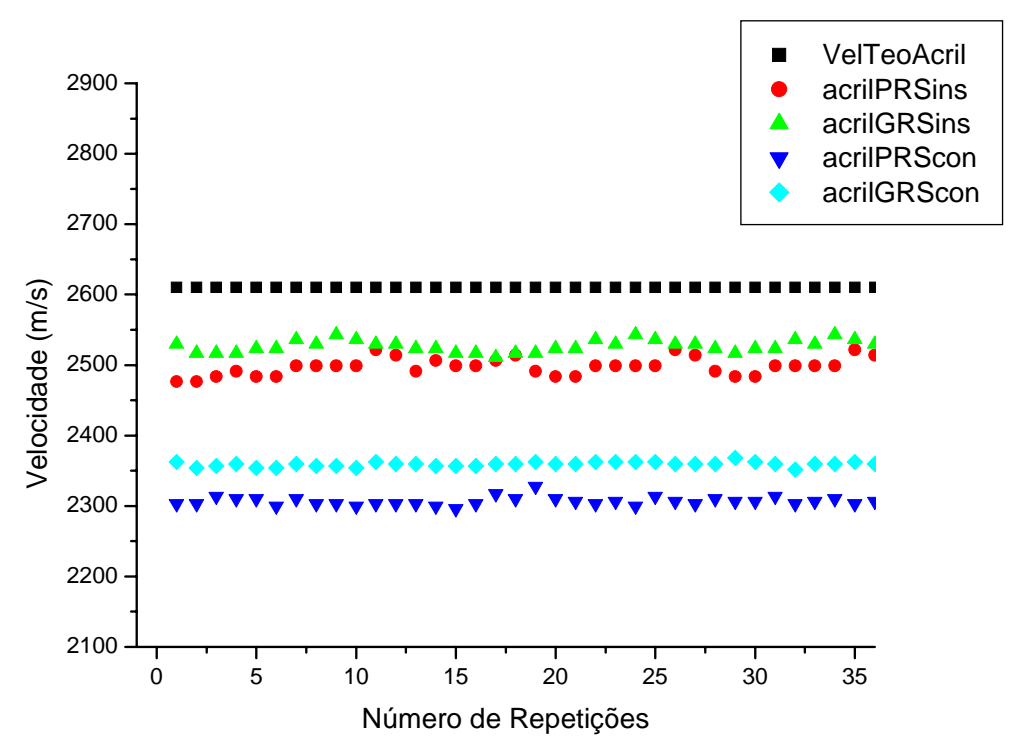

Figura 4.1.48. Velocidade do som experimental, medida pelas técnicas de contato e inserção, para as peças de acrílico G e P, para os transdutores RS.

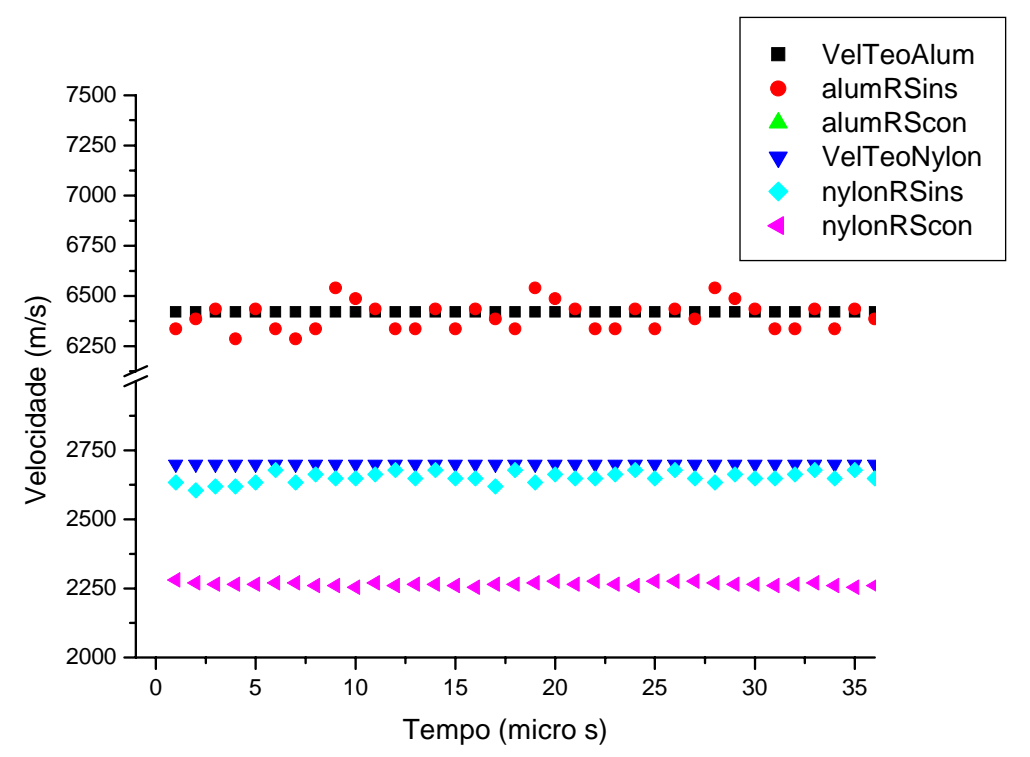

Figura 4.1.49. Velocidade do som experimental, medida pelas técnicas de contato e inserção, para as peças de alumínio e nylon, para os transdutores RS.

Na tabela 4.1.10, são apresentados os valores da média das velocidades com os seus respectivos desvios padrão para o par de transdutores de $0,50 \mathrm{MHz}$ (RS). 
Tabela 4.1.10. Média das velocidades, para o par de transdutores RS, com seus respectivos desvios padrão para as peças plásticas e alumínio.

\begin{tabular}{c|c|c|c|c|c}
\multirow{4}{*}{ Transdutores } & \multirow{2}{*}{ Amostras } & \multicolumn{2}{|c|}{ Inserção } & \multicolumn{2}{c}{ Contato } \\
\cline { 3 - 6 } & $\begin{array}{c}\text { Velocidade } \\
\mathbf{( m / s )}\end{array}$ & SD (m/s) & $\begin{array}{c}\text { Velocidade } \\
\mathbf{( m / s )}\end{array}$ & SD (m/s) \\
\hline \multirow{4}{*}{ RS } & PVC-G & 2367,4 & 15,0 & 2219,6 & 4,30 \\
\cline { 2 - 6 } & PVC-P & 2377,8 & 7,20 & 2173,6 & 6,10 \\
\cline { 2 - 6 } & Acril-G & 2526,9 & 8,50 & 2359,9 & 3,40 \\
\cline { 2 - 6 } & Acril-P & 2497,8 & 12,4 & 2308,8 & 6,60 \\
\cline { 2 - 6 } & Alum & 6398,4 & 71,2 & 5099,8 & 21,7 \\
\cline { 2 - 6 } & Nylon & 2651,8 & 19,5 & 2268,5 & 7,50
\end{tabular}

Nas figuras 4.1.47, 4.1.48 e 4.1.49, os valores obtidos para a velocidade do som para as peças analisadas, pela técnica de inserção convencional, foram mais próximos do valor teórico quando comparado com os valores obtidos pela técnica de contato.

De acordo com a tabela 4.1.10, na técnica de inserção convencional a amostra que apresentou a menor variação percentual foi o PVC P com uma percentagem de 0,09\% quando comparado com o valor teórico. A peça de maior variação percentual foi a de acrílico P com um valor de 4,3\% com relação ao valor teórico. Para a técnica de contato a peça com maior variação percentual foi a de alumínio com $20,56 \%$ e a de menor variação percentual foi a de PVC G com uma variação de 6,74\%.

\subsubsection{Considerações finais.}

Pode-se observar que para qualquer par de transdutores, independente da freqüência, as peças de PVC apresentaram a menor variação com relação ao valor teórico, tanto para a técnica de contato quanto para a de inserção convencional. Foi possível identificar que as peças de acrílico quando analisadas pela técnica de inserção convencional foram as que apresentaram a maior dispersão com relação ao valor teórico, isso ocorreu para todos os transdutores analisados independente da freqüência. Entretanto, nos valores obtidos pela técnica de contato a peça que apresentou uma maior dispersão foi a de alumínio, este fato ocorreu para todos os pares de transdutores. 
Para os pares de transdutores de $1 \mathrm{MHz}$ (AB, NO e EF) e de $2 \mathrm{MHz}$ (IG e LM) os de menor diâmetro obtiveram valores de velocidade do som mais próximo do valor teórico do que os de maior diâmetro. Isso pode ocorrer devido a sua menor área de elemento ativo, pois deve receber menos energia espalhada na amostra e com isso se obtem um valor de velocidade do som mais próximo do valor teórico.

Estes resultados demonstram que a técnica de inserção convencional (acoplamento com água) apresenta um valor para a velocidade do som mais adequado do que a técnica de contato, principalmente quando a velocidade na amostra é muito maior do que a velocidade nos materiais usados no acoplamento. 


\subsection{AVALIAÇÃO DO TEFLON COMO MEIO DE REFERÊNCIA NA ANÁlise DA BUA E VELOCIDADE DO SOM E NA ANÁliSE DA DISPERSÃO DA TÉCNICA.}

\subsubsection{INTRODUÇÃO}

Neste capítulo, serão apresentados os valores obtidos da BUA e da velocidade do som para peças cilíndricas de teflon.

As peças de teflon possuem diferentes comprimentos de caminho por onde o sinal ultra-sônico viaja, estes comprimentos são 40,1mm e 62,35mm, para a peça M e G, respectivamente. Sendo que, tefM representa a peça de menor caminho e tefG representa a peça de maior caminho (o sinal incide sobre a face plana da peça).

O objetivo dessas análises é o de comparar os resultados (da velocidade do som e da BUA) da técnica de contato com os da técnica de inserção convencional e determinar qual é a melhor quando comparada com os valores de velocidade do som encontrados na literatura. A análise das variações que aparecerão nos resultados é com o intuito de avaliar a reprodutibilidade da técnica e do equipamento desenvolvido.

\subsubsection{BUAtot}

\subsubsection{Cálculo da BUAtot através das técnicas de inserção convencional e de contato com gel ultra-sônico.}

Nesta seção, será feito o cálculo da BUAtot para as peças de teflon (tefM e tefG) utilizando ambas as técnicas, de contato e de inserção.

Para o acoplamento de impedâncias foram usados água, na técnica de inserção convencional, e gel ultra-sônico para a técnica de contato. 
Na técnica de contato as medidas foram feitas a temperatura ambiente, de aproximadamente $24^{0} \mathrm{C}$, podendo chegar a $26^{\circ} \mathrm{C}$. Devido a este valor de temperatura, na técnica de inserção convencional as peças ficaram em um banho térmico de 40 minutos a temperatura de $24^{0} \mathrm{C}$, para que fosse possível uma melhor comparação entre as técnicas. Foi feita repetição de 42 vezes, sendo dividida em sete dias diferentes (durante um intervalo de aproximadamente quatro meses para aquisição), fazendo um total de seis sinais em cada dia.

Nas tabelas seguintes, são apresentados os valores obtidos para a BUAtot, para todos os transdutores que são utilizados neste trabalho, como a utilização das três tensões do equipamento e o uso do circuito amplificador. Estes valores foram calculados considerando a inclinação no sinal em freqüência da forma mais apropriada de acordo com a freqüência do transdutor.

Nas tabelas 4.2.1, 4.2.2 e 4.2.3, têm-se os valores da BUAtot para as tensões de 124V, $172 \mathrm{~V}$ e $224 \mathrm{~V}$, respectivamente, para os pares de transdutores de $1 \mathrm{MHz}$ (AB, EF e NO), para ambas peças de teflon e com e sem amplificação do sistema.

Tabela 4.2.1- Valores da média e do desvio padrão (SD) da BUAtot, calculada pelas técnicas de contato e inserção, para as peças de teflon (tefM e tefG) e para os pares de transdutores de $1 \mathrm{MHz}(\mathrm{AB}, \mathrm{EF}$ e $\mathrm{NO})$. Aplicada a tensão de 124V e com (c) e sem (s) o uso da amplificação do sistema.

\begin{tabular}{ccc}
\hline & Inserção & Contato \\
\hline Amostra/Trans./Amplif. & Média \pm SD (dB/MHz) & Média \pm SD (dB/MHz) \\
\hline TefM-AB-s & $35,37 \pm 1,10$ & $55,31 \pm 2,56$ \\
\hline TefM-AB-c & $47,05 \pm 1,03$ & $64,51 \pm 1,47$ \\
\hline TefG-AB-s & $47,09 \pm 0,67$ & $90,07 \pm 1,89$ \\
\hline TefG-AB-c & $58,63 \pm 1,06$ & $91,75 \pm 3,41$ \\
\hline TefM-NO-s & $33,38 \pm 0,81$ & $88,64 \pm 6,80$ \\
\hline TefM-NO-c & $43,88 \pm 0,39$ & $101,71 \pm 2,72$ \\
\hline TefG-NO-s & $49,80 \pm 0,85$ & $96,72 \pm 4,75$ \\
\hline TefG-NO-c & $60,82 \pm 1,37$ & $119,39 \pm 8,12$ \\
\hline TefM-EF-s & $31,75 \pm 0,81$ & $31,47 \pm 2,83$ \\
\hline TefM-EF-c & $40,96 \pm 0,49$ & $37,19 \pm 3,50$ \\
\hline TefG-EF-s & $50,58 \pm 0,98$ & $49,12 \pm 2,09$ \\
\hline TefG-EF-c & $59,08 \pm 1,38$ & $50,67 \pm 2,27$ \\
\hline
\end{tabular}


Tabela 4.2.2- Valores da média e do desvio padrão (SD) da BUAtot, calculada pelas técnicas de contato e inserção, para as peças de teflon (tefM e tefG) e para os pares de transdutores de $1 \mathrm{MHz}$ (AB, EF e NO). Aplicada na tensão de $172 \mathrm{~V}$ e com (c) e sem (s) o uso da amplificação do sistema.

\begin{tabular}{ccc}
\hline & Inserção & Contato \\
\hline Amostra/Trans./Amplif. & Média \pm SD & Média \pm SD (dB/MHz) \\
& $(\mathbf{d B} / \mathbf{M H z})$ & \\
\hline TefM-AB-s & $36,79 \pm 1,25$ & $46,15 \pm 4,85$ \\
\hline TefM-AB-c & $48,06 \pm 1,39$ & $66,57 \pm 1,61$ \\
\hline TefG-AB-s & $47,92 \pm 0,72$ & $83,16 \pm 2,76$ \\
\hline TefG-AB-c & $57,76 \pm 2,70$ & $100,94 \pm 8,61$ \\
\hline TefM-NO-s & $32,54 \pm 2,14$ & $85,35 \pm 5,08$ \\
\hline TefM-NO-c & $43,08 \pm 2,03$ & $97,16 \pm 3,46$ \\
\hline TefG-NO-s & $50,70 \pm 1,94$ & $96,73 \pm 3,30$ \\
\hline TefG-NO-c & $59,87 \pm 1,37$ & $110,12 \pm 10,91$ \\
\hline TefM-EF-s & $32,20 \pm 1,04$ & $22,53 \pm 2,74$ \\
\hline TefM-EF-c & $41,27 \pm 1,01$ & $36,38 \pm 3,04$ \\
\hline TefG-EF-s & $51,26 \pm 1,23$ & $40,05 \pm 2,12$ \\
\hline TefG-EF-c & $59,35 \pm 2,17$ & $46,32 \pm 6,77$ \\
\hline
\end{tabular}


Tabela 4.2.3 - Valores da média e do desvio padrão (SD) da BUAtot, calculada pelas técnicas de contato e inserção, para as peças de teflon (tefM e tefG) e para os pares de transdutores de $1 \mathrm{MHz}$ (AB, EF e NO). Aplicada na tensão de 224V e com (c) e sem (s) o uso da amplificação do sistema.

\begin{tabular}{ccc}
\hline & Inserção & Contato \\
\hline Amostra/Trans./Amplif. & Média \pm SD & Média \pm SD (dB/MHz) \\
(dB/MHz) & \\
\hline TefM-AB-s & $36,71 \pm 1,19$ & $37,32 \pm 4,41$ \\
\hline TefM-AB-c & $47,92 \pm 1,36$ & $52,04 \pm 4,32$ \\
\hline TefG-AB-s & $47,47 \pm 1,26$ & $67,99 \pm 3,63$ \\
\hline TefG-AB-c & $57,05 \pm 2,20$ & $79,49 \pm 4,01$ \\
\hline TefM-NO-s & $33,06 \pm 2,59$ & $73,93 \pm 1,41$ \\
\hline TefM-NO-c & $42,87 \pm 1,95$ & $86,11 \pm 7,30$ \\
\hline TefG-NO-s & $50,56 \pm 2,43$ & $94,54 \pm 6,33$ \\
\hline TefG-NO-c & $58,90 \pm 0,71$ & $104,24 \pm 5,21$ \\
\hline TefM-EF-s & $32,07 \pm 0,99$ & $17,40 \pm 2,14$ \\
\hline TefM-EF-c & $41,18 \pm 1,01$ & $30,18 \pm 3,11$ \\
\hline TefG-EF-s & $51,32 \pm 1,24$ & $33,26 \pm 1,75$ \\
\hline TefG-EF-c & $60,10 \pm 2,13$ & $37,96 \pm 2,68$ \\
\hline
\end{tabular}

Nos resultados das tabelas 4.2.1, 4.2.2 e 4.2.3, para a técnica de inserção, é possível observar que os valores das médias são próximos entre cada tensão, isto é, não existiu diferença significante entre elas para os três pares de transdutores. Para a técnica de inserção, na tabela 4.2.1, o maior CV\% observado foi de 3,11\% (tefM-AB-s) e o menor foi de 0,89\% (tefM-NO-c), na tabela 4.2.2, o maior CV\% foi de 6,57\% (tefM-NO-s) e o menor foi de 1,50\% (tefG-AB-s) e na tabela 4.2.3, o maior CV\% foi de 7,83\% (tefM-NO-s) e o menor foi de 1,20\% (tefG-NO-c). Sendo feita uma comparação entre os pares de transdutores, observase que as médias da BUAtot são aproximadamente iguais, isto demonstra que mesmo trabalhando com transdutores de fabricantes diferentes, (seção 3.2, capítulo 3) como é o caso dos pares AB e NO, nenhuma variação significante foi observada quando o cálculo da BUAtot foi feita pela técnica de inserção.

Nas tabelas 4.2.1, 4.2.2 e 4.2.3, os resultados da BUAtot para a técnica de contato apresentaram valores maiores do que os que foram obtidos pela técnica de inserção convencional, com exceção do par EF, que apresentou, para a técnica de contato, valores 
menores de BUAtot. Na tabela 4.2.1, o maior CV\% observado para a técnica de contato foi de 9,41\% (tefM-EF-c-) e o menor de 2,10\% (tefG-AB-s), na tabela 4.2.2, o maior CV\% foi de $12,16 \%$ (tefM-EF-s) e o menor foi de 2,42\% (tefM-AB-c) e na tabela 4.2.3, o maior CV\% foi de $12,30 \%$ (tefM-EF-s) e o menor foi de 1,91\% (tefM-NO-s). O par EF, de transdutores, apresentou o maior CV\% e os menores CV\% foram obtidos pelos outros dois pares (AB e NO). Um fator de influência neste resultado pode ser o tamanho da área de elemento ativo do par EF, que é menor que dos outros dois pares.

Existiu uma grande variação quando feita a comparação entre as tensões, sendo que, para a maioria dos resultados a tensão de $124 \mathrm{~V}$ combinou com o maior valor de BUAtot e a tensão de $224 \mathrm{~V}$ combinou com o menor valor obtido.

Quando comparado entre os pares de transdutores é possível observar que seus valores de BUAtot são bem distintos. Para a técnica de contato, os valores do par AB são menores que os valores do par NO e os valores do par EF são menores do que dos outros dois pares para ambas peças de teflon.

De acordo com as tabelas 4.2.1, 4.2.2 e 4.2.3, existiu uma grande variação no valor da BUAtot, quando feita à comparação entre as técnicas.

Nas tabelas 4.2.4, 4.2.5 e 4.2.6, têm-se os valores da BUAtot para as tensões de 124V, $172 \mathrm{~V}$ e $224 \mathrm{~V}$,respectivamente, para os pares de transdutores de $2 \mathrm{MHz}$ (IG e LM), para ambas peças de teflon e com e sem amplificação do sistema.

Tabela 4.2.4- Valores da média e do desvio padrão (SD) da BUAtot, calculada pelas técnicas de contato e inserção, para as peças de teflon (tefM e tefG), para os pares de transdutores de $2 \mathrm{MHz}$ (IG e LM). Aplicada na tensão de $124 \mathrm{~V}$ e com (c) e sem (s) o uso da amplificação do sistema.

\begin{tabular}{ccc}
\hline & Inserção & Contato \\
\hline Amostra/Trans./Amplif. & Média \pm SD (dB/MHz) & Média \pm SD (dB/MHz) \\
\hline TefM-IG-s & $45,53 \pm 3,49$ & $41,43 \pm 1,97$ \\
\hline TefM-IG-c & $57,39 \pm 2,03$ & $43,78 \pm 4,53$ \\
\hline TefG-IG-s & $58,70 \pm 2,04$ & $45,32 \pm 3,16$ \\
\hline TefG-IG-c & $58,82 \pm 1,98$ & $49,55 \pm 3,77$ \\
\hline TefM-LM-s & $53,37 \pm 2,89$ & $60,50 \pm 2,66$ \\
\hline TefM-LM-c & $65,72 \pm 1,97$ & $63,33 \pm 4,67$ \\
\hline TefG-LM-s & $61,20 \pm 5,56$ & $65,48 \pm 7,59$ \\
\hline TefG-LM-c & $70,82 \pm 4,14$ & $43,67 \pm 8,40$ \\
\hline
\end{tabular}


Tabela 4.2.5- Valores da média e do desvio padrão (SD) da BUAtot, calculada pelas técnicas de contato e inserção, para as peças de teflon (tefM e tefG), para os pares de transdutores de 2MHz (IG e LM). Aplicada na tensão de $172 \mathrm{~V}$ e com (c) e sem (s) o uso da amplificação do sistema.

\begin{tabular}{ccc}
\hline & Inserção & Contato \\
\hline Amostra/Trans./Amplif. & Média \pm SD (dB/MHz) & Média \pm SD (dB/MHz) \\
\hline TefM-IG-s & $52,72 \pm 5,77$ & $42,70 \pm 4,14$ \\
\hline TefM-IG-c & $57,04 \pm 2,46$ & $43,73 \pm 3,96$ \\
\hline TefG-IG-s & $59,48 \pm 2,65$ & $48,14 \pm 5,21$ \\
\hline TefG-IG-c & $58,91 \pm 1,56$ & $48,45 \pm 3,97$ \\
\hline TefM-LM-s & $55,56 \pm 1,89$ & $46,96 \pm 1,59$ \\
\hline TefM-LM-c & $64,75 \pm 2,07$ & $54,63 \pm 4,00$ \\
\hline TefG-LM-s & $60,06 \pm 2,71$ & $59,43 \pm 5,52$ \\
\hline TefG-LM-c & $68,13 \pm 3,98$ & $35,38 \pm 6,75$ \\
\hline
\end{tabular}

Tabela 4.2.6- Valores da média e do desvio padrão (SD) da BUAtot, calculada pelas técnicas de contato e inserção, para as peças de teflon (tefM e tefG) , para os pares de transdutores de 2MHz (IG e LM). Aplicada na tensão de 224V e com (c) e sem (s) o uso da amplificação do sistema.

\begin{tabular}{ccc}
\hline & Inserção & Contato \\
\hline Amostra/Trans./Amplif. & Média \pm SD & Média \pm SD (dB/MHz) \\
(dB/MHz) & \\
\hline TefM-IG-s & $51,71 \pm 5,59$ & $42,21 \pm 4,24$ \\
\hline TefM-IG-c & $52,03 \pm 3,75$ & $42,76 \pm 3,99$ \\
\hline TefG-IG-s & $57,49 \pm 2,80$ & $43,27 \pm 3,41$ \\
\hline TefG-IG-c & $58,54 \pm 1,95$ & $48,47 \pm 4,56$ \\
\hline TefM-LM-s & $59,58 \pm 3,91$ & $42,08 \pm 3,40$ \\
\hline TefM-LM-c & $66,23 \pm 2,08$ & $51,70 \pm 7,79$ \\
\hline TefG-LM-s & $61,61 \pm 4,35$ & $57,03 \pm 5,05$ \\
\hline TefG-LM-c & $70,26 \pm 4,73$ & $27,19 \pm 6,43$ \\
\hline
\end{tabular}

Nas tabelas 4.2.4, 4.2 .5 e 4.2.6, são apresentados os valores da BUAtot para as duas peças de teflon e para ambas as técnicas (de inserção e contato). Avaliando os valores obtidos para a técnica de inserção as médias estão próximas, quando comparadas as diferentes 
tensões. Já para a técnica de contato, é observado que, para o par IG de transdutores o valor entre as três tensões ficou aproximadamente constante. Entretanto, para o par LM conforme se aumentou o valor da tensão ocorreu uma diminuição no valor da BUAtot.

O CV\%, para a técnica de inserção, de menor valor para a tabela 4.2 .4 foi de 3,00\% (tefM-LM-c) e o maior foi de 9,08\% (tefG-LM-s), para a tabela 4.2.5, o menor foi de 2,65\% (tefG-IG-c) e o maior foi de 10,94\% (tefM-IG-s) e para a tabela 4.2.6, o menor foi de 3,14\% (tefM-LM-c) e o maior de 10,81\% (tefM-IG-s). Entretanto, para a técnica de contato, o menor CV\% foi de 4,40\% (tefM-LM-s) e o maior foi de 19,23\% (tefG-LM-c) para a tensão de 124V (tabela 4.2.4), para a tensão de $172 \mathrm{~V}$ (tabela 4.2.5), o menor CV\% foi de 3,38\% (tefM-LM-s) e o maior foi de 19,09\% (tefG-LM-c) e para a tensão de 224V (tabela 4.2.6), o menor CV\% foi de 7,88\% (tefG-IG-s) e o maior foi de 23,65\% (tefG-LM-c).

A técnica de contato apresentou a maior variação no CV\%.

Os resultados das tabelas 4.2.4, 4.2.5 e 4.2.6, para os transdutores de $2 \mathrm{MHz}$, apresentaram um CV\% grande, isto, está associado ao sistema desenvolvido, pois a relação sinal ruído para estes transdutores foi grande, dificultado a compreensão correta do sinal, e também sendo provocada pela própria atenuação do transdutor.

Nas tabelas 4.2.7, 4.2.8 e 4.2.9, têm-se os valores da BUAtot para as tensões de 124V, $172 \mathrm{~V}$ e $224 \mathrm{~V}$, respectivamente, para os pares de transdutores de 0,75MHz (CD), para ambas peças de teflon e com e sem amplificação do sistema. Entretanto, para a peça tefM não foi feita a aquisição do sinal com o circuito amplificador, devido a saturação provocada pelo sistema amplificador.

Tabela 4.2.7- Valores da média e do desvio padrão (SD) da BUAtot, calculada pelas técnicas de contato e inserção, para as peças de teflon (tefM e tefG), para o par de transdutores de 0,75MHz (CD). Aplicada na tensão de $124 \mathrm{~V}$ e com (c) e sem (s) o uso da amplificação do sistema.

\begin{tabular}{ccc}
\hline & Inserção & Contato \\
\hline Amostra/Trans./Amplif. & $\begin{array}{c}\text { Média } \pm \text { SD } \\
\text { (dB/MHz) }\end{array}$ & Média \pm SD (dB/MHz) \\
\hline TefM-CD-s & $30,27 \pm 0,66$ & $37,67 \pm 2,93$ \\
\hline TefG-CD-s & $45,51 \pm 0,72$ & $53,88 \pm 4,76$ \\
\hline TefG-CD-c & $57,83 \pm 2,04$ & $65,01 \pm 4,40$ \\
\hline
\end{tabular}


Tabela 4.2.8- Valores da média e do desvio padrão (SD) da BUAtot, calculada pelas técnicas de contato e inserção, para as peças de teflon (tefM e tefG), para o par de transdutores de 0,75MHz (CD). Aplicada na tensão de $172 \mathrm{~V}$ e com (c) e sem (s) o uso da amplificação do sistema.

\begin{tabular}{ccc}
\hline & Inserção & Contato \\
\hline Amostra/Trans./Amplif. & Média \pm SD & Média \pm SD (dB/MHz) \\
& $(\mathbf{d B} / \mathbf{M H z})$ & \\
\hline TefM-CD-s & $29,75 \pm 0,76$ & $36,41 \pm 1,46$ \\
\hline TefG-CD-s & $43,03 \pm 2,00$ & $50,71 \pm 4,33$ \\
\hline TefG-CD-c & $55,44 \pm 3,20$ & $61,89 \pm 2,02$ \\
\hline
\end{tabular}

Tabela 4.2.9- Valores da média e do desvio padrão (SD) da BUAtot, calculada pelas técnicas de contato e inserção, para as peças de teflon (tefM e tefG), para o par de transdutores de 0,75MHz (CD). Aplicada na tensão de 224V e com (c) e sem (s) o uso da amplificação do sistema.

\begin{tabular}{ccc}
\hline & Inserção & Contato \\
\hline Amostra/Trans./Amplif. & $\begin{array}{c}\text { Média } \pm \text { SD } \\
\text { (dB/MHz) }\end{array}$ & Média \pm SD (dB/MHz) \\
\hline TefM-CD-s & $29,51 \pm 0,65$ & $33,28 \pm 1,35$ \\
\hline TefG-CD-s & $45,56 \pm 0,38$ & $44,16 \pm 5,03$ \\
\hline TefG-CD-c & $57,08 \pm 0,86$ & $51,06 \pm 1,76$ \\
\hline
\end{tabular}

Nas tabelas 4.2.7, 4.2.8 e 4.2.9, são apresentados os resultados para os pares de transdutores de 0,75MHz (par CD). Os resultados para a técnica de inserção mostram que, independente da tensão aplicada, os valores obtidos foram aproximadamente iguais, entretanto, para técnica de contato conforme se aumentou o valor da tensão diminui o valor da BUAtot calculada nas tensões $124 \mathrm{~V}$ e $172 \mathrm{~V}$ a diferença foi mínima, mas quando analisada a tensão $224 \mathrm{~V}$ a variação obtida foi maior.

O menor CV\%, para a técnica de inserção, obtido para a tensão 124V (tabela 4.2.7) foi de $1,58 \%$ (tefG-CD-s) e o maior 3,53\% (tefG-CD-c), para a tensão $172 \mathrm{~V}$ (tabela 4.2.8) o menor foi de 2,55\% (tefM-CD-s) e o maior 5,77\% (tefG-CD-c) e para a tensão 224V (tabela 4.2.9) o menor foi de $0,83 \%$ (tefG-CD-s) e o maior 2,20\% (tefM-CD-s). Contudo, os valores do CV\% para a técnica de contato foram maiores. Para a tabela 4.2.7, o menor CV\% obtido 
foi de 6,77\% (tefG-CD-c) e o maior 8,83\% (tefG-CD-s), para a tabela 4.2.8, o menor foi $3,26 \%$ (tefG-CD-c) e o maior $8,54 \%$ (tefG-CD-s) e para a tabela 4.2 .9 , sendo de $3,45 \%$ o menor (tefG-CD-c) e o maior 11,39\% (tefG-CD-s).

Nas tabelas 4.2.10, 4.2.11 e 4.2.12, têm-se os valores da BUAtot para as tensões de $124 \mathrm{~V}, 172 \mathrm{~V}$ e $224 \mathrm{~V}$, respectivamente, para os pares de transdutores de 1,5MHz (PQ), para ambas as peças de teflon e com e sem a amplificação do sistema ultra-sônico.

Tabela 4.2.10- Valores da média e do desvio padrão (SD) da BUAtot, calculada pelas técnicas de contato e inserção, para as peças de teflon (tefM e tefG), para o par de transdutores de 1,5MHz (PQ). Aplicada na tensão de $124 \mathrm{~V}$ e com (c) e sem (s) o uso da amplificação do sistema.

\begin{tabular}{ccc}
\hline & Inserção & Contato \\
\hline Amostra/Trans./Amplif. & $\begin{array}{c}\text { Média } \pm \text { SD } \\
(\mathbf{d B} / \mathbf{M H z})\end{array}$ & Média \pm SD (dB/MHz) \\
\hline TefM-PQ-s & $49,14 \pm 0,96$ & $50,74 \pm 2,41$ \\
\hline TefM-PQ-c & $59,50 \pm 0,86$ & $51,52 \pm 3,33$ \\
\hline TefG-PQ-s & $64,42 \pm 2,01$ & $87,30 \pm 6,12$ \\
\hline TefG-PQ-c & $73,41 \pm 3,67$ & $74,25 \pm 8,96$ \\
\hline
\end{tabular}

Tabela 4.2.11- Valores da média e do desvio padrão (SD) da BUAtot, calculada pelas técnicas de contato e inserção, para as peças de teflon (tefM e tefG), para o par de transdutores de 1,5MHz (PQ). Aplicada na tensão de $172 \mathrm{~V}$ e com (c) e sem (s) o uso da amplificação do sistema.

\begin{tabular}{ccc}
\hline & Inserção & Contato \\
\hline Amostra/Trans./Amplif. & $\begin{array}{c}\text { Média } \pm \text { SD } \\
\text { (dB/MHz) }\end{array}$ & Média \pm SD (dB/MHz) \\
\hline TefM-PQ-s & $47,69 \pm 0,70$ & $52,24 \pm 3,49$ \\
\hline TefM-PQ-c & $58,87 \pm 0,51$ & $48,92 \pm 1,53$ \\
\hline TefG-PQ-s & $64,25 \pm 2,09$ & $77,13 \pm 4,95$ \\
\hline TefG-PQ-c & $71,86 \pm 2,13$ & $72,01 \pm 7,15$ \\
\hline
\end{tabular}


Tabela 4.2.12- Valores da média e do desvio padrão (SD) da BUAtot, calculada pelas técnicas de contato e inserção, para as peças de teflon (tefM e tefG), para o par de transdutores de 1,5MHz (PQ). Aplicada na tensão de 224V e com (c) e sem (s) o uso da amplificação do sistema.

\begin{tabular}{ccc}
\hline & Inserção & Contato \\
\hline Amostra/Trans./Amplif. & Média \pm SD & Média \pm SD (dB/MHz) \\
& $(\mathbf{d B} / \mathbf{M H z})$ & \\
\hline TefM-PQ-s & $46,98 \pm 0,63$ & $50,14 \pm 2,98$ \\
\hline TefM-PQ-c & $59,91 \pm 0,99$ & $49,96 \pm 1,56$ \\
\hline TefG-PQ-s & $66,73 \pm 1,44$ & $80,91 \pm 2,96$ \\
\hline TefG-PQ-c & $70,05 \pm 2,17$ & $73,36 \pm 5,15$ \\
\hline
\end{tabular}

Nas tabelas 4.2.10, 4.2.11 e 4.2.12, são apresentados os resultados para os pares de transdutores de 1,5MHz (par PQ). Os resultados para a técnica de inserção mostram que, independente da tensão aplicada, os valores obtidos foram aproximadamente iguais, isso ocorrendo também para técnica de contato, com exceção para o tefG-s (teflon G - sem amplificação) que apresentou valores bem distintos nas três tensões, sendo que, o menor valor da BUAtot foi da tensão $172 \mathrm{~V}$ e o maior foi para a tensão $124 \mathrm{~V}$.

Para a técnica de inserção, na tabela 4.2.10, o menor CV\% foi 1,44\% (tefM-PQ-c) e o maior 5,00\% (tefG-PQ-c), na tabela 4.2.11, o menor foi 0,87\% (tefM-PQ-c) e o maior 3,25\% (tefG-PQ-s) e para a tabela 4.2.12, o menor foi 1,34\% (tefM-PQ-s) e o maior 3,10\% (tefGPQ-c). Entretanto, para a técnica de contato, o menor CV\% observado na tabela 4.2.10, foi 4,75\% (tefM-PQ-s) e o maior foi 12,07\% (tefG-PQ-c), para a tabela 4.2.11, o menor foi $3,13 \%$ (tefM-PQ-c) e o maior foi 9,93\% (tefG-PQ-c) e para a tabela 4.2 .12 , foi de $3,12 \%$ o menor (tefM-PQ-c) e o maior foi de 7,02\% ( tefG-PQ-c).

Na tabela 4.2.13, tem-se os valores da BUAtot para as tensões de $124 \mathrm{~V}, 172 \mathrm{~V}$ e $224 \mathrm{~V}$, respectivamente, sendo que, a análise é para o par de transdutores de 0,5MHz (RS). Para este par de transdutores não foi utilizado o circuito amplificador de sinal, pois a amplificação do sistema saturava o sinal de saída.

Para os resultados da tabela 4.2.13, independente da tensão utilizada pode ser observado que os valores médios da BUAtot são aproximadamente constantes, para a técnica de inserção. Enquanto, para a técnica de contato, conforme aumentou o valor da tensão obteve-se um aumento do valor da BUAtot, sendo mais evidente para o tefM do que o tefG. 
Entretanto, na técnica de inserção quando comparamos os valores obtidos para o tefM e para o tefG, era esperada uma diferença significante entre suas BUAtot, mas isso não ocorreu sendo aproximadamente iguais. Na técnica de contato, ocorreu o esperado, pois os valores das BUAtot do tefM foram menores que os do tefG.

O CV\% de menor valor, para técnica de inserção entre as três tensões, foi de 2,03\% (tefG-T1-Rs) e o maior de 4,59\% (tefG-T2-RS) e para a técnica de contato o menor foi de 0,96\% (tefG-T3-RS) e o maior foi 2,64\% (tefM-T1-RS).

Tabela 4.2.13- Valores da média e do desvio padrão (SD) da BUAtot, calculada pelas técnicas de contato e inserção, para as peças de teflon (tefM e tefG), para o par de transdutores de 0,5MHz (RS). Aplicada para todas as tensões e sem o uso do amplificador do sistema ultra-sônico.

\begin{tabular}{ccc}
\hline & Inserção & Contato \\
\hline Amostra/Tensão/Trans. & Média \pm SD & Média \pm SD (dB/MHz) \\
$\mathbf{( d B / M H z )}$ & \\
\hline TefM-T1-RS & $33,40 \pm 0,87$ & $85,14 \pm 2,25$ \\
\hline TefG-T1-RS & $34,93 \pm 0,71$ & $102,39 \pm 2,55$ \\
\hline TefM-T2-RS & $32,23 \pm 1,31$ & $87,08 \pm 1,64$ \\
\hline TefG-T2-RS & $33,30 \pm 1,53$ & $102,48 \pm 1,78$ \\
\hline TefM-T3-RS & $32,27 \pm 0,87$ & $93,45 \pm 1,94$ \\
\hline TefG-T3-RS & $33,27 \pm 0,96$ & $103,15 \pm 0,99$ \\
\hline
\end{tabular}

\subsubsection{Velocidade do som avaliada pela técnica de inserção convencional e de contato com acoplamento com gel ultra-sônico.}

Nas tabelas seguintes (tabelas 4.2.14 e 4.2.15), são apresentados os valores experimentais da velocidade do som para as peças de teflon. A velocidade foi avaliada utilizando as duas técnicas: a de contato com acoplamento por gel ultra-sônico e a de inserção convencional. A velocidade, pela técnica de contato, foi calculada utilizando a equação 7 (capítulo 2, seção 2.1), enquanto que, pela técnica de inserção, foi calculada usando a equação 6 (capítulo 2, seção 2.1). 
Não foi feita discriminação entre as tensões devido ao fato de a variação observada nos valores de velocidade, para ambas as técnicas, ter sido pequena, menor que $1 \%$ da média de cada tensão. Então, os valores apresentados nas tabelas seguintes (tabelas 4.2.14 e 4.2.15), são os valores médios da velocidade do som das três tensões do equipamento como um todo, para cada transdutor e cada peça de teflon. Foram 126 sinais adquiridos e utilizados para o cálculo. Foi feita repetição de 42 vezes (para cada tensão), sendo dividida em sete dias diferentes (durante um intervalo de aproximadamente quatro meses de aquisição), fazendo um conjunto de seis sinais em cada dia.

Mesmo fazendo a junção das três tensões de trabalho para avaliar a velocidade do som, foi obtido um bom resultado com relação ao CV\%. Na tabela 4.2.14, são apresentados os resultados da velocidade do som para todos os transdutores, calculados pela técnica de inserção convencional. É possível notar que o CV\% não ultrapassou o 0,50\%, para os valores de velocidade com ou sem amplificação. Para a técnica de contato, tabela 4.2.15, os resultados não apresentaram nenhum valor acima de 0,53\%, para o CV\%. Entretanto, uma observação cabível, é que os valores de velocidade, quando utilizado o circuito amplificador, foram um pouco menor que o sem amplificação, mas essa variação está dentro do desvio padrão obtido para cada um, isso acontecendo em ambas às técnicas.

Um fato a ser destacado, é que os valores obtidos pela técnica de inserção estão mais próximos do valor teórico $(1350 \mathrm{~m} / \mathrm{s})$ do que os valores obtidos pela técnica de contato. 
Tabela 4.2.14- Valores da média das velocidades, na temperatura de $24^{0} \mathrm{C}$ medidas pela técnica de inserção, com seus respectivos desvios padrão (SD), para as peças de teflon e para todos os pares de transdutores.

\begin{tabular}{|c|c|c|c|c|c|}
\hline \multirow[b]{2}{*}{$\begin{array}{c}\text { Par de } \\
\text { Transdutores }\end{array}$} & \multirow[b]{2}{*}{ Teflon } & \multicolumn{2}{|c|}{ Sem Amplificação } & \multicolumn{2}{|c|}{ Com amplificação } \\
\hline & & $\begin{array}{c}\text { Média das } \\
\text { Velocidades } \\
(\mathrm{m} / \mathrm{s})\end{array}$ & $\mathrm{SD}(\mathrm{m} / \mathrm{s})$ & $\begin{array}{c}\text { Média das } \\
\text { Velocidades } \\
(\mathrm{m} / \mathrm{s})\end{array}$ & $\mathrm{SD}(\mathrm{m} / \mathrm{s})$ \\
\hline \multirow[t]{2}{*}{$\mathrm{AB}$} & M & 1312,34 & 3,82 & 1307,66 & 3,27 \\
\hline & G & 1312,74 & 2,93 & 1306,26 & 3,34 \\
\hline \multirow[t]{2}{*}{$\mathrm{CD}$} & $\mathrm{M}$ & 1311,50 & 5,36 & $*$ & $*$ \\
\hline & $\mathrm{G}$ & 1313,45 & 3,82 & 1312,82 & 3,00 \\
\hline \multirow[t]{2}{*}{$\overline{E F}$} & $\bar{M}$ & 1318,99 & 2,90 & 1310,50 & 3,07 \\
\hline & G & 1317,55 & 3,68 & 1312,97 & 3,76 \\
\hline \multirow[t]{2}{*}{$\mathrm{IG}$} & M & 1324,10 & 4,31 & 1318,93 & 3,6 \\
\hline & G & 1324,34 & 2,50 & 1321,01 & 2,48 \\
\hline \multirow[t]{2}{*}{ LM } & $\mathrm{M}$ & 1326,30 & 5,16 & 1318,32 & 3,58 \\
\hline & G & 1321,62 & 2,42 & 1320,24 & 2,49 \\
\hline \multirow[t]{2}{*}{$\mathrm{NO}$} & M & 1322,81 & 3,06 & 1317,83 & 3,95 \\
\hline & G & 1321,94 & 2,39 & 1312,68 & 2,97 \\
\hline \multirow[t]{2}{*}{ PQ } & M & 1327,51 & 3,77 & 1320,52 & 5,38 \\
\hline & G & 1322,84 & 2,50 & 1317,38 & 3,05 \\
\hline \multirow[t]{2}{*}{$\mathrm{RS}$} & $\mathrm{M}$ & 1304,83 & 3,37 & $*$ & $*$ \\
\hline & $G$ & 1308,55 & 2,95 & $*$ & $*$ \\
\hline
\end{tabular}

\footnotetext{
* estes valores não foram possíveis de serem avaliados devido a saturação do sinal que ocorre no equipamento.
} 
Tabela 4.2.15- Valores da média das velocidades, na temperatura de $24^{0} \mathrm{C}$, medido pela técnica de contato, com os seus respectivos desvios padrão (SD), para as peças de teflon e para todos os pares de transdutores.

\begin{tabular}{|c|c|c|c|c|c|}
\hline \multirow[b]{2}{*}{$\begin{array}{c}\text { Par de } \\
\text { Transdutores }\end{array}$} & \multirow[b]{2}{*}{ Teflon } & \multicolumn{2}{|c|}{ Sem Amplificação } & \multicolumn{2}{|c|}{ Com amplificação } \\
\hline & & $\begin{array}{c}\text { Média das } \\
\text { Velocidade } \\
\text { (m/s) }\end{array}$ & $\mathrm{SD}(\mathrm{m} / \mathrm{s})$ & $\begin{array}{c}\text { Média das } \\
\text { Velocidade } \\
\text { (m/s) }\end{array}$ & $\mathrm{SD}(\mathrm{m} / \mathrm{s})$ \\
\hline \multirow[t]{2}{*}{$\mathrm{AB}$} & $\mathrm{M}$ & 1274,16 & 3,69 & 1274,87 & 3,27 \\
\hline & G & 1299,30 & 5,51 & 1290,81 & 4,87 \\
\hline \multirow[t]{2}{*}{$\mathrm{CD}$} & $\mathrm{M}$ & 1271,24 & 2,50 & $*$ & * \\
\hline & $G$ & 1286,54 & 2,58 & 1284,43 & 3,75 \\
\hline \multirow[t]{2}{*}{$\mathrm{EF}$} & $\mathrm{M}$ & 1287,78 & 3,92 & 1281,60 & 5,25 \\
\hline & $\mathrm{G}$ & 1302,63 & 2,31 & 1295,83 & 3,41 \\
\hline \multirow[t]{2}{*}{ IG } & M & 1297,91 & 4,15 & 1288,31 & 6,06 \\
\hline & G & 1306,13 & 3,09 & 1304,28 & 1,99 \\
\hline \multirow[t]{2}{*}{ LM } & $\mathrm{M}$ & 1294,19 & 2,93 & 1291,84 & 3,92 \\
\hline & G & 1308,11 & 4,36 & 1305,43 & 4,50 \\
\hline \multirow[t]{2}{*}{$\mathrm{NO}$} & $\mathrm{M}$ & 1282,33 & 4,38 & 1273,16 & 2,72 \\
\hline & G & 1297,05 & 6,95 & 1287,66 & 4,92 \\
\hline \multirow[t]{2}{*}{ PQ } & M & 1281,15 & 6,41 & 1275,71 & 4,42 \\
\hline & G & 1301,76 & 3,17 & 1299,45 & 1,72 \\
\hline \multirow[t]{2}{*}{ RS } & $\mathrm{M}$ & 1236,36 & 3,06 & $*$ & $*$ \\
\hline & $G$ & 1270,73 & 1,77 & $*$ & $*$ \\
\hline
\end{tabular}

* estes valores não foram possíveis de serem avaliados devido a saturação do sinal que ocorre no equipamento.

\subsubsection{Avaliando a reprodutibilidade da BUAtot, em curto prazo, para as duas técnicas.}

Nas tabelas seguintes são apresentados os valores obtidos para a BUAtot, para todos os pares de transdutores, bem como a utilização das três tensões de trabalho e o uso do circuito amplificador do equipamento. Estes valores foram calculados considerando a inclinação no sinal em freqüência, da forma mais apropriada, de acordo com a freqüência do 
transdutor. Foi feita uma repetição de 12 vezes, sem fazer o re-posicionamento da peça. Estes valores foram determinados através da técnica de inserção convencional e de contato.

Nas tabelas 4.2.16, 4.2.17 e 4.2.18, são apresentados os valores da BUAtot para as tensões de $124 \mathrm{~V}, 172 \mathrm{~V}$ e $224 \mathrm{~V}$, respectivamente. Para os pares de transdutores de $1 \mathrm{MHz}$ (AB, EF e NO), para ambas peças de teflon (tefM e tefG) e com e sem amplificação do sistema, feitos pela técnica de inserção convencional e pela técnica de contato, com repetição de 12 vezes.

Tabela 4.2.16- Média e desvio padrão (SD) da BUAtot, para uma seqüência de 12 repetições, para as peças de teflon e para os transdutores de 1,0MHz de freqüência (AB, EF e NO), na tensão de 124V. Feitos pela técnica de inserção e de contato e com (c) e sem (s) a amplificação do sistema.

\begin{tabular}{ccc}
\hline & Inserção & Contato \\
\hline Amostra/Trans./Amplif. & Média \pm SD & Média \pm SD (dB/MHz) \\
& $\mathbf{( d B / M H z )}$ & \\
\hline TefM-AB-s & $33,88 \pm 0,14$ & $57,70 \pm 3,05$ \\
TefM-AB-c & $45,96 \pm 0,04$ & $63,77 \pm 0,62$ \\
TefG-AB-s & $47,39 \pm 0,09$ & $89,21 \pm 1,83$ \\
TefG-AB-c & $58,03 \pm 0,25$ & $93,68 \pm 1,88$ \\
TefM-NO-s & $32,17 \pm 0,10$ & $98,12 \pm 7,61$ \\
TefM-NO-c & $43,39 \pm 0,07$ & $100,97 \pm 1,98$ \\
TefG-NO-s & $48,66 \pm 0,17$ & $100,61 \pm 4,34$ \\
TefG-NO-c & $60,02 \pm 1,16$ & $121,62 \pm 6,07$ \\
TefM-EF-s & $31,16 \pm 0,11$ & $29,55 \pm 0,83$ \\
TefM-EF-c & $40,27 \pm 0,10$ & $34,82 \pm 0,73$ \\
TefG-EF-s & $50,37 \pm 0,18$ & $47,39 \pm 1,06$ \\
TefG-EF-c & $57,69 \pm 0,33$ & $49,39 \pm 0,76$ \\
\hline
\end{tabular}


Tabela 4.2.17- Média e desvio padrão (SD) da BUAtot, para uma seqüência de 12 repetições, para as peças de teflon e para os transdutores de 1,0MHz de freqüência (AB, EF e NO), na tensão de 172V. Feitos pela técnica de inserção e de contato e com (c) e sem (s) a amplificação do sistema.

\begin{tabular}{ccc}
\hline & Inserção & Contato \\
\hline Amostra/Trans./Amplif. & Média \pm SD & Média \pm SD (dB/MHz) \\
\hline (dB/MHz) & \\
\hline TefM-AB-s & $35,42 \pm 0,04$ & $47,19 \pm 1,19$ \\
TefM-AB-c & $46,71 \pm 0,08$ & $65,64 \pm 0,74$ \\
TefG-AB-c & $46,88 \pm 0,07$ & $82,61 \pm 0,69$ \\
TefM-NO-s & $53,63 \pm 0,31$ & $107,09 \pm 4,29$ \\
TefM-NO-c & $29,83 \pm 0,83$ & $88,19 \pm 1,65$ \\
TefG-NO-s & $40,38 \pm 0,16$ & $94,09 \pm 1,50$ \\
TefG-NO-c & $48,25 \pm 0,14$ & $100,51 \pm 1,69$ \\
TefM-EF-s & $58,75 \pm 0,80$ & $116,79 \pm 5,00$ \\
TefM-EF-c & $31,13 \pm 0,04$ & $19,93 \pm 0,90$ \\
TefG-EF-s & $40,21 \pm 0,13$ & $27,57 \pm 0,35$ \\
TefG-EF-c & $50,59 \pm 0,24$ & $37,35 \pm 0,89$ \\
\hline
\end{tabular}


Tabela 4.2.18- Média e desvio padrão (SD) da BUAtot, para uma seqüência de 12 repetições, para as peças de teflon e para os transdutores de 1,0MHz de freqüência (AB, EF e NO), na tensão de 224V,. Feitos pela técnica de inserção e com (c) e sem (s) a amplificação do sistema.

\begin{tabular}{ccc}
\hline & Inserção & Contato \\
\hline Amostra/Trans./Amplif. & Média \pm SD & Média \pm SD (dB/MHz) \\
\hline (dB/MHz) & \\
\hline TefM-AB-s & $35,23 \pm 0,12$ & $34,08 \pm 0,43$ \\
TefM-AB-c & $46,65 \pm 0,04$ & $50,60 \pm 0,44$ \\
TefG-AB-s & $45,67 \pm 0,09$ & $65,89 \pm 0,72$ \\
TefG-AB-c & $53,65 \pm 0,31$ & $82,92 \pm 1,28$ \\
TefM-NO-s & $30,31 \pm 0,13$ & $74,91 \pm 0,98$ \\
TefM-NO-c & $40,74 \pm 0,08$ & $82,86 \pm 1,04$ \\
TefG-NO-s & $48,05 \pm 0,27$ & $92,93 \pm 0,76$ \\
TefG-NO-c & $58,86 \pm 1,01$ & $105,96 \pm 1,08$ \\
TefM-EF-s & $31,19 \pm 0,04$ & $12,83 \pm 1,10$ \\
TefM-EF-c & $40,09 \pm 0,15$ & $23,03 \pm 0,60$ \\
TefG-EF-s & $50,70 \pm 0,11$ & $31,53 \pm 0,86$ \\
TefG-EF-c & $57,80 \pm 0,33$ & $36,26 \pm 0,63$ \\
\hline
\end{tabular}

De acordo com as tabelas 4.2.16, 4.2.17 e 4.2.18, a reprodutibilidade em curto prazo foi positiva para a técnica de inserção, sendo que, na tabela 4.2.16 não se obteve nenhum valor maior que $1,93 \%$ para o $C V \%$, para a tabela 4.2 .17 , não foi maior que $2,78 \%$ e para a tabela 4.2.18, os valores foram menores que 1,71\%. Entretanto, para a técnica de contato os valores obtidos para o CV\% foram maiores. Na tabela 4.2.16, chegou ao valor de 7,75\%, na tabela 4.2.17, chegou ao valor de 4,51\% e na tabela 4.2.18, foi de 8,57\%. Estes resultados do CV\% obtidos na técnica de contato demonstram uma perda considerável na dispersão do sinal da amostra. Os valores obtidos para a técnica de inserção permaneceram aproximadamente constantes, independente da tensão utilizada. Entretanto, para a técnica de contato conforme se aumentou o valor da tensão ocorreu uma diminuição no valor da BUAtot.

Nas tabelas 4.2.19, 4.2.20 e 4.2.21 são apresentados os valores da BUAtot para as tensões de $124 \mathrm{~V}, 172 \mathrm{~V}$ e $224 \mathrm{~V}$, respectivamente, para os pares de transdutores de $2 \mathrm{MHz}$ (IG e LM), para ambas peças de teflon (tefM e tefG) e com e sem amplificação do sistema. Feitos 
pela técnica de inserção convencional e contato, com repetição de 12 vezes sem fazer o reposicionamento da peça.

Tabela 4.2.19- Média e desvio padrão (SD) da BUAtot para uma seqüência de 12 repetições, para as peças de teflon e para os transdutores de 2,0MHz de freqüência (IG e LM), na tensão de 124V. Feitos pela técnica de inserção e de contato e com (c) e sem (s) a amplificação do sistema.

\begin{tabular}{ccc}
\hline & Inserção & Contato \\
\hline Amostra/Trans./Amplif. & Média \pm SD & Média \pm SD (dB/MHz) \\
& $(\mathbf{d B} / \mathbf{M H z})$ & \\
\hline TefM-IG-s & $43,58 \pm 4,01$ & $41,29 \pm 0,51$ \\
TefM-IG-c & $58,57 \pm 0,86$ & $41,87 \pm 0,42$ \\
TefG-IG-s & $59,28 \pm 3,47$ & $43,16 \pm 2,79$ \\
TefG-IG-c & $59,72 \pm 1,39$ & $46,60 \pm 0,60$ \\
TefM-LM-s & $50,54 \pm 0,36$ & $62,25 \pm 2,17$ \\
TefM-LM-c & $63,51 \pm 1,15$ & $66,24 \pm 3,89$ \\
TefG-LM-s & $61,07 \pm 2,36$ & $62,62 \pm 7,06$ \\
TefG-LM-c & $69,80 \pm 5,26$ & $35,71 \pm 4,37$ \\
\hline
\end{tabular}

Tabela 4.2.20- Média e desvio padrão (SD) da BUAtot para uma seqüência de 12 repetições, para as peças de teflon e para os transdutores de 2,0MHz de freqüência (IG e LM), na tensão de 172V. Feitos pela técnica de inserção e de contato e com (c) e sem (s) a amplificação do sistema.

\begin{tabular}{ccc}
\hline & Inserção & Contato \\
\hline Amostra/Trans./Amplif. & Média \pm SD & Média \pm SD (dB/MHz) \\
& $(\mathbf{d B} / \mathbf{M H z})$ & \\
\hline TefM-IG-s & $48,22 \pm 2,47$ & $41,64 \pm 0,34$ \\
TefM-IG-c & $59,45 \pm 1,03$ & $41,51 \pm 0,33$ \\
TefG-IG-s & $60,75 \pm 3,28$ & $42,91 \pm 1,75$ \\
TefG-IG-c & $59,81 \pm 1,50$ & $47,42 \pm 0,90$ \\
TefM-LM-s & $53,57 \pm 0,19$ & $47,78 \pm 1,40$ \\
TefM-LM-c & $64,27 \pm 0,49$ & $53,35 \pm 1,06$ \\
TefG-LM-s & $59,14 \pm 1,19$ & $59,03 \pm 3,47$ \\
TefG-LM-c & $67,38 \pm 4,02$ & $33,32 \pm 3,42$ \\
\hline
\end{tabular}


Tabela 4.2.21- Média e desvio padrão (SD) da BUAtot para uma seqüência de 12 repetições, para a peça de teflon e para os transdutores de 2,0MHz de freqüência (IG e LM), na tensão de 224V. Feitos pela técnica de inserção e de contato e com (c) e sem (s) a amplificação do sistema.

\begin{tabular}{ccc}
\hline & Inserção & Contato \\
\hline Amostra/Trans./Amplif. & Média \pm SD & Média \pm SD (dB/MHz) \\
& $(\mathbf{d B} / \mathbf{M H z})$ & \\
\hline TefM-IG-s & $41,14 \pm 2,19$ & $41,45 \pm 0,21$ \\
TefM-IG-c & $56,80 \pm 0,65$ & $40,92 \pm 0,34$ \\
TefG-IG-s & $55,95 \pm 3,20$ & $41,58 \pm 0,41$ \\
TefG-IG-c & $58,19 \pm 1,71$ & $46,60 \pm 0,50$ \\
TefM-LM-s & $38,69 \pm 0,13$ & $44,77 \pm 1,97$ \\
TefM-LM-c & $47,57 \pm 0,47$ & $51,20 \pm 1,86$ \\
TefG-LM-s & $58,99 \pm 1,70$ & $59,74 \pm 4,80$ \\
TefG-LM-c & $68,86 \pm 2,30$ & $26,43 \pm 3,50$ \\
\hline
\end{tabular}

Os resultados da BUAtot para os transdutores de 2MHz (tabelas 4.2.19, 4.2.20 e 4.2.21) demonstraram um CV\% oscilante para ambas as técnicas. Para a técnica de inserção na tensão de $124 \mathrm{~V}$ o menor CV\% foi de 0,71\% (tefM-LM-s) e o maior 9,20\% (tefM-IG-s), para a tensão de $172 \mathrm{~V}$ o menor foi $0,35 \%$ (tefM-LM-s) e o maior foi 5,97\% (tefG-LM-c) e para a tensão de $224 \mathrm{~V}$ o menor foi $0,33 \%$ (tefM-LM-s) e o maior foi 5,72\% (tefG-IG-s). Coincidentemente, os menores CV\% foram para a peça tefM, para o par de transdutores LM e sem amplificação, este fato pode estar associado ao diâmetro do transdutor combinado com o tamanho da peça de teflon (de menor caminho ultra-sônico).

Para a técnica de contato, na tabela 4.2.19, o menor CV\% foi 1,00\% (tefM-IG-c) e o maior foi 12,23\% (tefG-LM-c), na tabela 4.2.20, o menor CV\% foi $0,79 \%$ (tefM-IG-c) e o maior foi $10,26 \%$ (tefG-LM-c) e na tabela 4.2.21, o menor CV\% foi $0,50 \%$ (tefM-IG-s) e o maior foi 13,24\% (tefG-LM-c). Na técnica de contato o menor CV\% foi observado para o tefM e par de transdutores IG e o maior para tefG, par LM de transdutores e com amplificação do sistema.

Nas tabelas 4.2.22, 4.2.23 e 4.2.24, são apresentados os valores da BUA para as tensões de $124 \mathrm{~V}, 172 \mathrm{~V}$ e $224 \mathrm{~V}$, respectivamente, para os pares de transdutores de $0,75 \mathrm{MHz}$ (CD), para ambas peças de teflon (M e G) e com e sem amplificação do sistema, feitos pela 
técnica de inserção convencional e de contato, com repetição de 12 vezes sem fazer o reposicionamento das peças.

Tabela 4.2.22- Média e desvio padrão (SD) da BUAtot para uma seqüência de 12 repetições, para as peças de teflon e para os transdutores de $0,75 \mathrm{MHz}$ de freqüência (CD), na tensão de 124V. Feitos pela técnica de inserção e contato e com (c) e sem (s) a amplificação do sistema.

\begin{tabular}{ccc}
\hline & Inserção & Contato \\
\hline Amostra/Trans./Amplif. & Média \pm SD & Média \pm SD (dB/MHz) \\
& $(\mathbf{d B} / \mathbf{M H z})$ & \\
\hline TefM-CD-s & $29,34 \pm 0,20$ & $36,37 \pm 1,55$ \\
TefG-CD-s & $45,22 \pm 0,70$ & $50,51 \pm 1,33$ \\
TefG-CD-c & $59,34 \pm 0,24$ & $62,86 \pm 1,17$ \\
\hline
\end{tabular}

Tabela 4.2.23- Média e desvio padrão (SD) da BUAtot para uma seqüência de 12 repetições, para as peças de teflon e para os transdutores de $0,75 \mathrm{MHz}$ de freqüência (CD), na tensão de $172 \mathrm{~V}$. Feitos pela técnica de inserção e contato e com (c) e sem (s) a amplificação do sistema.

\begin{tabular}{ccc}
\hline & Inserção & Contato \\
\hline Amostra/Trans./Amplif. & Média \pm SD & Média \pm SD (dB/MHz) \\
& $(\mathbf{d B} / \mathbf{M H z})$ & \\
\hline TefM-CD-s & $28,72 \pm 0,15$ & $36,11 \pm 0,61$ \\
TefG-CD-s & $45,28 \pm 0,34$ & $48,37 \pm 0,47$ \\
TefG-CD-c & $58,46 \pm 0,16$ & $59,52 \pm 0,96$ \\
\hline
\end{tabular}

Tabela 4.2.24- Média e desvio padrão (SD) da BUAtot para uma seqüência de 12 repetições, para as peças de teflon e para os transdutores de $0,75 \mathrm{MHz}$ de freqüência (CD), na tensão de 224V. Feitos pela técnica de inserção e contato e com (c) e sem (s) a amplificação do sistema.

\begin{tabular}{ccc}
\hline & Inserção & Contato \\
\hline Amostra/Trans./Amplificação & Média \pm Desvio & Média \pm Desvio Padrão \\
& Padrão (dB/MHz) & (dB/MHz) \\
\hline TefM-CD-s & $28,60 \pm 0,09$ & $32,38 \pm 0,52$ \\
TefG-CD-s & $45,16 \pm 0,14$ & $41,53 \pm 0,73$ \\
TefG-CD-c & $57,15 \pm 0,34$ & $50,56 \pm 0,44$ \\
\hline
\end{tabular}


Para o par de transdutores de $0,75 \mathrm{MHz}(\mathrm{CD})$, independente da tensão utilizada, pode ser observada que o CV\% não passou de $2 \%$ em nenhum caso, exceto, para o tefM-CD-s (por contato, tabela 4.2.22).

Nas tabelas 4.2.25, 4.2.26 e 4.2.27 são apresentados os valores do BUA para as tensões de $124 \mathrm{~V}, 172 \mathrm{~V}$ e $224 \mathrm{~V}$, respectivamente, para os pares de transdutores de $1,5 \mathrm{MHz}$ (PQ), para ambas peças de teflon (M e G) e com e sem amplificação do sistema, feitos pela técnica de inserção convencional e contato, com repetição de 12 vezes sem fazer o reposicionamento.

Tabela 4.2.25- Média e desvio padrão (SD) da BUAtot para uma seqüência de 12 repetições, para as peças de teflon e para os transdutores de 1,5MHz de freqüência (PQ), na tensão de 124V. Feitos pela técnica de inserção e contato e com (c) e sem (s) a amplificação do sistema.

\begin{tabular}{ccc}
\hline & Inserção & Contato \\
\hline Amostra/Trans./Amplif. & Média \pm SD & Média \pm SD (dB/MHz) \\
& $(\mathbf{d B} / \mathbf{M H z})$ & \\
\hline TefM-PQ-s & $47,96 \pm 0,18$ & $52,84 \pm 0,89$ \\
TefM-PQ-c & $59,12 \pm 0,33$ & $50,83 \pm 0,55$ \\
TefG-PQ-s & $63,26 \pm 0,35$ & $84,67 \pm 5,10$ \\
TefG-PQ-c & $71,57 \pm 1,22$ & $75,63 \pm 3,02$ \\
\hline
\end{tabular}

Tabela 4.2.26- Média e desvio padrão (SD) da BUAtot para uma seqüência de 12 repetições, para as peças de teflon e para os transdutores de 1,5MHz de freqüência (PQ), na tensão de 172V. Feitos pela técnica de inserção e contato e com (c) e sem (s) a amplificação do sistema.

\begin{tabular}{ccc}
\hline & Inserção & Contato \\
\hline Amostra/Trans./Amplif. & Média \pm SD & Média \pm SD (dB/MHz) \\
& $(\mathbf{d B} / \mathbf{M H z})$ & \\
\hline TefM-PQ-s & $46,84 \pm 0,16$ & $52,29 \pm 0,67$ \\
TefM-PQ-c & $58,33 \pm 0,22$ & $50,18 \pm 0,62$ \\
TefG-PQ-s & $62,73 \pm 0,30$ & $80,34 \pm 2,31$ \\
TefG-PQ-c & $70,40 \pm 0,51$ & $74,56 \pm 1,54$ \\
\hline
\end{tabular}


Tabela 4.2.27- Média e desvio padrão (SD) da BUAtot para uma seqüência de 12 repetições, para as peças de teflon e para os transdutores de 1,5MHz de freqüência (PQ), na tensão de 224V. Feitos pela técnica de inserção e contato e com (c) e sem (s) a amplificação do sistema.

\begin{tabular}{ccc}
\hline & Inserção & Contato \\
\hline Amostra/Trans./Amplif. & Média \pm SD (dB/MHz) & Média \pm SD (dB/MHz) \\
\hline TefM-PQ-s & $46,67 \pm 0,32$ & $50,39 \pm 0,60$ \\
TefM-PQ-c & $58,50 \pm 0,25$ & $49,03 \pm 0,60$ \\
TefG-PQ-s & $65,70 \pm 0,52$ & $81,61 \pm 1,54$ \\
TefG-PQ-c & $71,78 \pm 1,64$ & $72,28 \pm 0,91$ \\
\hline
\end{tabular}

Os resultados apresentados nas tabelas 4.2.25, 4.2.26 e 4.2.27, são os valores da BUAtot para o par de transdutores de $1,5 \mathrm{MHz}$ (par PQ). Os valores referentes à técnica de inserção não apresentaram CV\% maior que 2,28\%, observado nas três tensões. Para a técnica de contato os valores do CV\% foram menores que 3,99\%, com exceção para o tefG-PQ-s, que apresentou um valor de 6,02\%, na tensão de $124 \mathrm{~V}$.

Na tabela 4.2.28, são apresentados os valores do BUA para as tensões de $124 \mathrm{~V}, 172 \mathrm{~V}$ e $224 \mathrm{~V}$, respectivamente, para os pares de transdutores de $0,5 \mathrm{MHz}$ (RS), para ambas peças de teflon (M e G) e sem amplificação do sistema, pois existe saturação do sinal quando é usado este par de transdutores, feitos pela técnica de inserção convencional e de contato, com repetição de 12 vezes e sem fazer o re-posicionamento.

TABELA 4.2.28: Média e desvio padrão (SD) da BUAtot para uma seqüência de 12 repetições, para as peças de teflon e para os transdutores de 0,5MHz de freqüência (RS), nas três tensões de trabalho. Feitos pela técnica de inserção e contato e sem a amplificação do sistema.

\begin{tabular}{ccc}
\hline & Inserção & Contato \\
\hline Amostra/Tensão/Transdutor & Média \pm SD (dB/MHz) & Média \pm SD (dB/MHz) \\
\hline TefM-T1-RS & $34,29 \pm 0,18$ & $86,80 \pm 1,96$ \\
TefG-T1-RS & $35,29 \pm 0,32$ & $104,95 \pm 3,33$ \\
TefM-T2-RS & $34,01 \pm 0,22$ & $88,86 \pm 1,05$ \\
TefG-T2-RS & $35,17 \pm 0,37$ & $103,54 \pm 1,91$ \\
TefM-T3-RS & $33,39 \pm 0,18$ & $94,14 \pm 1,06$ \\
TefG-T3-RS & $34,21 \pm 0,23$ & $103,32 \pm 0,75$ \\
\hline
\end{tabular}


Na tabela 4.2.28, são apresentados os valores da BUAtot para o par de transdutores de 0,5MHz para as três tensões de trabalho. Na técnica de inserção pode ser observado que o CV\% não foi maior que 1,05\% e para a técnica de contato não foi maior que 3,17\%.

\subsubsection{Cálculo da BUAsel, para as técnicas de inserção convencional e de contato com acoplamento por gel.}

Nas tabelas seguintes, serão apresentados os valores obtidos para a BUAsel, para todos os pares de transdutores que são utilizados neste trabalho, como também a utilização das três tensões de trabalho $(124 \mathrm{~V}, 172 \mathrm{~V}$ e 224$)$ e o uso do circuito amplificador do equipamento. Estes valores foram calculados considerando a inclinação no sinal em freqüência da forma mais apropriada, e também, de acordo com a freqüência do transdutor feita à seleção do sinal temporal. Foi realizada uma repetição de 12 vezes sem fazer o re-posicionamento das peças. Estes valores foram determinados através da técnica de inserção convencional e de contato.

Nas tabelas 4.2.29, 4.2.30 e 4.2.31 são apresentados os valores da BUAsel para as tensões de $124 \mathrm{~V}, 172 \mathrm{~V}$ e $224 \mathrm{~V}$, respectivamente, para os pares de transdutores de $1 \mathrm{MHz}(\mathrm{AB}$, EF e NO), para ambas peças de teflon (TefM e TefG) e com e sem amplificação do sistema, feitos pela técnica de inserção convencional e pela técnica de contato, com repetição de 12 vezes. 
Tabela 4.2.29- Média e desvio padrão (SD) da BUAsel para uma seqüência de 12 repetições, para as peças de teflon e para os transdutores de 1,0MHz de freqüência (AB, EF e NO), na tensão de 124V. Feitos pela técnica de inserção e de contato, para o sinal selecionado e com (c) e sem (s) a amplificação do sistema.

\begin{tabular}{ccc}
\hline & Inserção & Contato \\
\hline Amostra/Trans./Amplif. & Média \pm SD (dB/MHz) & Média \pm SD (dB/MHz) \\
\hline TefM-AB-s & $25,93 \pm 0,11$ & $28,41 \pm 0,59$ \\
TefM-AB-c & $37,43 \pm 0,03$ & $19,70 \pm 0,19$ \\
TefG-AB-s & $41,45 \pm 0,11$ & $56,98 \pm 1,93$ \\
TefG-AB-c & $53,15 \pm 0,15$ & $53,61 \pm 1,32$ \\
TefM-NO-s & $30,66 \pm 0,10$ & $24,01 \pm 0,43$ \\
TefM-NO-c & $40,71 \pm 0,11$ & $32,08 \pm 1,11$ \\
TefG-NO-s & $46,23 \pm 0,23$ & $35,87 \pm 0,94$ \\
TefG-NO-c & $57,79 \pm 0,34$ & $45,67 \pm 1,75$ \\
TefM-EF-s & $25,20 \pm 0,13$ & $46,37 \pm 2,35$ \\
TefM-EF-c & $35,32 \pm 0,12$ & $30,43 \pm 0,50$ \\
TefG-EF-s & $39,77 \pm 0,16$ & $33,19 \pm 0,45$ \\
TefG-EF-c & $52,24 \pm 0,18$ & $35,50 \pm 0,47$ \\
\hline
\end{tabular}


Tabela 4.2.30- Média e desvio padrão (SD) da BUAsel para uma seqüência de 12 repetições, para as peças de teflon e para os transdutores de 1,0MHz de freqüência (AB, EF e NO), na tensão de 172V. Feitos pela técnica de inserção e de contato, para o sinal selecionado e com (c) e sem (s) a amplificação do sistema.

\begin{tabular}{ccc}
\hline & Inserção & Contato \\
\hline Amostra/Trans./Amplif. & Média \pm SD (dB/MHz) & Média \pm SD (dB/MHz) \\
\hline TefM-AB-s & $26,52 \pm 0,31$ & $28,77 \pm 0,51$ \\
TefM-AB-c & $39,01 \pm 0,07$ & $20,05 \pm 0,18$ \\
TefG-AB-s & $43,15 \pm 0,09$ & $57,86 \pm 1,12$ \\
TefG-AB-c & $55,41 \pm 0,20$ & $52,92 \pm 1,65$ \\
TefM-NO-s & $30,05 \pm 0,11$ & $24,02 \pm 0,35$ \\
TefM-NO-c & $41,66 \pm 0,13$ & $31,56 \pm 1,05$ \\
TefG-NO-s & $46,67 \pm 0,11$ & $39,29 \pm 0,66$ \\
TefG-NO-c & $57,70 \pm 0,21$ & $44,53 \pm 2,00$ \\
TefM-EF-s & $26,20 \pm 0,09$ & $52,24 \pm 2,18$ \\
TefM-EF-c & $36,42 \pm 0,12$ & $32,22 \pm 0,29$ \\
TefG-EF-s & $41,59 \pm 0,11$ & $33,36 \pm 0,27$ \\
TefG-EF-c & $53,58 \pm 0,10$ & $33,83 \pm 0,51$ \\
& &
\end{tabular}


Tabela 4.2.31- Média e desvio padrão (SD) da BUAsel para uma seqüência de 12 repetições, para as peças de teflon e para os transdutores de 1,0MHz de freqüência (AB, EF e NO), na tensão de 224V. Feitos pela técnica de inserção e de contato, para o sinal selecionado e com (c) e sem (s) a amplificação do sistema.

\begin{tabular}{ccc}
\hline & Inserção & Contato \\
\hline Amostra/Trans./Amplif. & Média \pm SD & Média \pm SD (dB/MHz) \\
& $\mathbf{( d B / M H z )}$ & \\
\hline TefM-AB-s & $29,75 \pm 0,21$ & $33,07 \pm 0,69$ \\
TefM-AB-c & $39,87 \pm 0,09$ & $20,92 \pm 0,18$ \\
TefG-AB-s & $44,20 \pm 0,10$ & $56,89 \pm 0,93$ \\
TefG-AB-c & $54,96 \pm 0,35$ & $49,70 \pm 0,81$ \\
TefM-NO-s & $28,43 \pm 0,10$ & $22,89 \pm 0,25$ \\
TefM-NO-c & $41,28 \pm 0,08$ & $31,35 \pm 0,60$ \\
TefG-NO-s & $46,14 \pm 0,09$ & $35,87 \pm 0,94$ \\
TefG-NO-c & $56,87 \pm 0,12$ & $45,06 \pm 1,21$ \\
TefM-EF-s & $26,76 \pm 0,09$ & $52,63 \pm 2,53$ \\
TefM-EF-c & $36,93 \pm 0,07$ & $34,54 \pm 0,75$ \\
TefG-EF-s & $42,22 \pm 0,11$ & $33,79 \pm 0,16$ \\
TefG-EF-c & $54,32 \pm 0,09$ & $30,22 \pm 1,00$ \\
\hline
\end{tabular}

Os resultados das tabelas 4.2.29, 4.2.30 e 4.2.31, são da BUAsel para os transdutores de $1 \mathrm{MHz}$ de freqüência. Os valores obtidos pela técnica de inserção, quando avaliados as três tensões, não apresentou nenhum valor maior de 1,16\% para o CV\%, sendo que, para a tensão de $124 \mathrm{~V}$ foi menor que $0,59 \%$ e para a de $224 \mathrm{~V}$ foi menor que $0,70 \%$. Na técnica de contato o CV\% foi menor que 5,07\% (tefM-EF-s), 4,49\% (tefG-NO-c) e 4,81\% (tefM-EF-s), para as tensões de $124 \mathrm{~V}, 172 \mathrm{~V}$ e $224 \mathrm{~V}$, respectivamente.

Nas tabelas 4.2.32, 4.2.33 e 4.2.34 são apresentados os valores da BUA para as tensões de $124 \mathrm{~V}, 172 \mathrm{~V}$ e $224 \mathrm{~V}$, respectivamente, para os pares de transdutores de $2 \mathrm{MHz}$ (IG e LM), para ambas peças de teflon (M e G) e com e sem amplificação do sistema, feitos pela técnica de inserção convencional e contato, com repetição de 12 vezes sem fazer o reposicionamento da peça e feita a seleção do sinal temporal. 
Tabela 4.2.32- Média e desvio padrão (SD) da BUAsel para uma seqüência de 12 repetições, para as peças de teflon e para os transdutores de 2,0MHz de freqüência (IG e LM), na tensão de $124 \mathrm{~V}$. Feitos pela técnica de inserção e de contato, para o sinal selecionado e com (c) e sem (s) a amplificação do sistema.

\begin{tabular}{ccc}
\hline & Inserção & Contato \\
\hline Amostra/Trans./Amplif. & Média \pm SD & Média \pm SD (dB/MHz) \\
& $(\mathbf{d B} / \mathbf{M H z})$ & \\
\hline TefM-IG-s & $36,04 \pm 0,23$ & $18,56 \pm 0,72$ \\
TefM-IG-c & $49,12 \pm 0,27$ & $22,73 \pm 2,90$ \\
TefG-IG-s & $60,74 \pm 1,27$ & $40,92 \pm 3,14$ \\
TefG-IG-c & $65,22 \pm 1,28$ & $41,18 \pm 2,86$ \\
TefM-LM-s & $28,61 \pm 0,45$ & $43,65 \pm 1,53$ \\
TefM-LM-c & $40,27 \pm 0,43$ & $47,09 \pm 0,89$ \\
TefG-LM-s & $46,77 \pm 0,96$ & $63,90 \pm 3,03$ \\
TefG-LM-c & $58,21 \pm 0,97$ & $56,18 \pm 2,14$ \\
\hline
\end{tabular}

Tabela 4.2.33- Média e desvio padrão (SD) da BUAsel para uma seqüência de 12 repetições, para as peças de teflon e para os transdutores de 2,0MHz de freqüência (IG e LM), na tensão de 172V. Feitos pela técnica de inserção e de contato, para o sinal selecionado e com (c) e sem (s) a amplificação do sistema.

\begin{tabular}{ccc}
\hline & Inserção & Contato \\
\hline Amostra/Trans./Amplif. & Média \pm SD & Média \pm SD (dB/MHz) \\
& $(\mathbf{d B} / \mathbf{M H z})$ & \\
\hline TefM-IG-s & $34,97 \pm 0,19$ & $17,71 \pm 0,55$ \\
TefM-IG-c & $48,03 \pm 0,19$ & $23,39 \pm 1,94$ \\
TefG-IG-s & $60,23 \pm 1,73$ & $46,31 \pm 3,12$ \\
TefG-IG-c & $63,67 \pm 0,57$ & $42,34 \pm 2,41$ \\
TefM-LM-s & $28,35 \pm 0,54$ & $50,13 \pm 1,06$ \\
TefM-LM-c & $39,88 \pm 0,31$ & $47,42 \pm 0,83$ \\
TefG-LM-s & $46,11 \pm 0,54$ & $59,77 \pm 1,50$ \\
TefG-LM-c & $56,98 \pm 0,65$ & $58,66 \pm 2,46$ \\
\hline
\end{tabular}


Tabela 4.2.34- Média e desvio padrão (SD) da BUAsel para uma seqüência de 12 repetições, para as peças de teflon e para os transdutores de 2,0MHz de freqüência (IG e LM), na tensão de 224V. Feitos pela técnica de inserção e de contato, para o sinal selecionado e com (c) e sem (s) a amplificação do sistema.

\begin{tabular}{ccc}
\hline & Inserção & Contato \\
\hline Amostra/Trans./Amplif. & Média \pm SD & Média \pm SD (dB/MHz) \\
& (dB/MHz) & \\
\hline TefM-IG-s & $35,91 \pm 0,11$ & $17,18 \pm 0,49$ \\
TefM-IG-c & $48,79 \pm 0,17$ & $22,26 \pm 1,29$ \\
TefG-IG-s & $60,74 \pm 1,27$ & $45,93 \pm 4,75$ \\
TefG-IG-c & $64,35 \pm 0,49$ & $45,14 \pm 2,06$ \\
TefM-LM-s & $28,99 \pm 0,21$ & $54,44 \pm 0,91$ \\
TefM-LM-c & $40,25 \pm 0,20$ & $46,8 \pm 0,32$ \\
TefG-LM-s & $46,45 \pm 0,27$ & $60,88 \pm 1,61$ \\
TefG-LM-c & $57,70 \pm 0,51$ & $60,50 \pm 2,20$ \\
\hline
\end{tabular}

Na tabela 4.2.32 (tensão 124V), o valor do CV\% para a técnica de inserção ficou entre 0,55\% e $2,09 \%$ e para a técnica de contato ficou entre 1,89\% e 12,76\%. Para a tensão de $172 \mathrm{~V}$ (tabela 4.2.33), os CV\% variaram entre $0,39 \%$ e 2,87\%, 1,75\% e 8,29\%, para as técnicas de inserção e contato, respectivamente. Na tabela 4.2 .34 (tensão 224V), para a técnica de inserção e contato os CV\% variaram entre 0,30\% e 2,09\%, 0,68\% e 10,34\%, respectivamente. Entretanto, pode ser observado que para a técnica de inserção a amostra que apresentou a maior CV\% foi sempre o tefG-IG-s nas três tensões. Na técnica de contato, o maior valor do CV\% foi para a tensão de 124V, e para a amostra tefM-IG-c.

Nas tabelas 4.2.35, 4.2.36 e 4.2.37 são apresentados os valores da BUA para as tensões de $124 \mathrm{~V}, 172 \mathrm{~V}$ e $224 \mathrm{~V}$, respectivamente, para os pares de transdutores de $0,75 \mathrm{MHz}$ (CD), para ambas peças de teflon (M e G) e com e sem amplificação do sistema, feitos pela técnica de inserção convencional e de contato, com repetição de 12 vezes sem fazer o reposicionamento das peças e feita a seleção do sinal temporal. 
Tabela 4.2.35- Média e desvio padrão (SD) da BUAsel para uma seqüência de 12 repetições, para as peças de teflon e para os transdutores de $0,75 \mathrm{MHz}$ de freqüência (CD), na tensão de 124V. Feitos pela técnica de inserção e de contato, para o sinal selecionado e com (c) e sem (s) a amplificação do sistema.

\begin{tabular}{ccc}
\hline & Inserção & Contato \\
\hline Amostra/Trans./Amplif. & Média \pm SD & Média \pm SD (dB/MHz) \\
& $(\mathbf{d B} / \mathbf{M H z})$ & \\
\hline TefM-CD-s & $24,50 \pm 0,35$ & $39,54 \pm 0,50$ \\
TefG-CD-s & $35,61 \pm 0,74$ & $50,72 \pm 1,64$ \\
TefG-CD-c & $45,98 \pm 0,54$ & $58,72 \pm 3,36$ \\
\hline
\end{tabular}

Tabela 4.2.36- Média e desvio padrão (SD) da BUAsel para uma seqüência de 12 repetições, para as peças de teflon e para os transdutores de $0,75 \mathrm{MHz}$ de freqüência (CD), na tensão de $172 \mathrm{~V}$. Feitos pela técnica de inserção e de contato, para o sinal selecionado e com (c) e sem (s) a amplificação do sistema.

\begin{tabular}{ccc}
\hline & Inserção & Contato \\
\hline Amostra/Trans./Amplif. & Média \pm SD & Média \pm SD (dB/MHz) \\
& $(\mathbf{d B} / \mathbf{M H z})$ & \\
\hline TefM-CD-s & $24,94 \pm 0,15$ & $39,46 \pm 0,36$ \\
TefG-CD-s & $35,39 \pm 0,71$ & $46,85 \pm 1,02$ \\
TefG-CD-c & $41,69 \pm 0,51$ & $57,43 \pm 1,66$ \\
\hline
\end{tabular}

Tabela 4.2.37- Média e desvio padrão (SD) da BUAsel para uma seqüência de 12 repetições, para as peças de teflon e para os transdutores de 0,75MHz de freqüência (CD), na tensão de 224V. Feitos pela técnica de inserção e de contato, para o sinal selecionado e com (c) e sem (s) a amplificação do sistema.

\begin{tabular}{ccc}
\hline & Inserção & Contato \\
\hline Amostra/Trans./Amplif. & Média \pm SD & Média \pm SD (dB/MHz) \\
& $(\mathbf{d B} / \mathbf{M H z})$ & \\
\hline TefM-CD-s & $24,46 \pm 0,25$ & $38,73 \pm 0,33$ \\
TefG-CD-s & $36,56 \pm 0,53$ & $45,61 \pm 1,11$ \\
TefG-CD-c & $35,69 \pm 0,82$ & $53,23 \pm 0,93$ \\
\hline
\end{tabular}

Nas tabelas 4.2.35, 4.2.36 e 4.2.37, são apresentados os valores da BUAsel para o par de transdutores de $0,75 \mathrm{MHz}$ (par CD), avaliados pela técnica de contato e inserção. Para a técnica de inserção, avaliando as três tensões, o CV\% está entre 0,60\% (tefM-CD-s, tensão de 
172 V) e 2,30\% (tefG-CD-c, tensão de 224V). Entretanto, para a técnica de contato a variação do CV\% está entre 0,85\% (tefM-CD-s, tensão 224V) e 5,72\% (tefG-CD-c, tensão de 124V).

Nas tabelas 4.2.38, 4.2.39 e 4.2.40 são apresentados os valores do BUA para as tensões de $124 \mathrm{~V}, 172 \mathrm{~V}$ e $224 \mathrm{~V}$, respectivamente, para os pares de transdutores de $1,5 \mathrm{MHz}$ (PQ), para ambas peças de teflon (M e G) e com e sem amplificação do sistema, feitos pela técnica de inserção convencional e contato, com repetição de 12 vezes sem fazer o reposicionamento e feita a seleção do sinal temporal.

Tabela 4.2.38- Média e desvio padrão (SD) da BUAsel para uma seqüência de 12 repetições, para as peças de teflon e para os transdutores de 1,5MHz de freqüência (PQ), na tensão de 124V. Feitos pela técnica de inserção e de contato, para o sinal selecionado e com (c) e sem (s) a amplificação do sistema.

\begin{tabular}{ccc}
\hline & Inserção & Contato \\
\hline Amostra/Trans./Amplif. & Média \pm SD & Média \pm SD (dB/MHz) \\
& $(\mathbf{d B} / \mathbf{M H z})$ & \\
\hline TefM-PQ-s & $30,14 \pm 0,10$ & $31,53 \pm 0,86$ \\
TefM-PQ-c & $41,47 \pm 0,18$ & $44,79 \pm 3,18$ \\
TefG-PQ-s & $48,05 \pm 0,18$ & $33,77 \pm 0,78$ \\
TefG-PQ-c & $60,30 \pm 0,20$ & $39,42 \pm 1,04$ \\
\hline
\end{tabular}

Tabela 4.2.39- Média e desvio padrão (SD) da BUAsel para uma seqüência de 12 repetições, para as peças de teflon e para os transdutores de 1,5MHz de frequencia (PQ), na tensão de 172V. Feitos pela técnica de inserção e de contato, para o sinal selecionado e com (c) e sem (s) a amplificação do sistema.

\begin{tabular}{ccc}
\hline & Inserção & Contato \\
\hline Amostra/Trans./Amplif. & Média \pm SD & Média \pm SD (dB/MHz) \\
& $(\mathbf{d B} / \mathbf{M H z})$ & \\
\hline TefM-PQ-s & $30,50 \pm 0,11$ & $30,47 \pm 0,52$ \\
TefM-PQ-c & $41,83 \pm 0,13$ & $43,36 \pm 2,21$ \\
TefG-PQ-s & $49,05 \pm 0,14$ & $33,79 \pm 0,58$ \\
TefG-PQ-c & $62,08 \pm 0,29$ & $37,74 \pm 0,72$ \\
\hline
\end{tabular}


Tabela 4.2.40- Média e desvio padrão (SD) da BUAsel para uma seqüência de 12 repetições, para as peças de teflon e para os transdutores de 1,5MHz de freqüência (PQ), na tensão de 224V. Feitos pela técnica de inserção e de contato, para o sinal selecionado e com (c) e sem (s) a amplificação do sistema.

\begin{tabular}{ccc}
\hline & Inserção & Contato \\
\hline Amostra/Trans./Amplif. & Média \pm SD (dB/MHz) & Média \pm SD (dB/MHz) \\
\hline TefM-PQ-s & $28,55 \pm 0,06$ & $31,03 \pm 0,60$ \\
TefM-PQ-c & $39,99 \pm 0,08$ & $46,99 \pm 2,08$ \\
TefG-PQ-s & $47,41 \pm 0,14$ & $34,36 \pm 0,47$ \\
TefG-PQ-c & $63,13 \pm 1,20$ & $37,78 \pm 0,71$ \\
\hline
\end{tabular}

Nas tabelas 4.2.38, 4.2 .39 e 4.2.40, são apresentados os resultados para a técnica de inserção e contato nas três tensões de trabalho, para as duas peças de teflon e para o par de transdutores de 1,5MHz. Sendo que, na técnica de inserção o CV\% permaneceu entre 0,20\% (tefM-PQ-c, tensão 224V) e 1,90\% (tefG-PQ-c, tensão de 224V), na técnica de contato, ficou entre 1,37\% (tefG-PQ-s, tensão de 224V) e 7,10\% (tefM-PQ-c, tensão de 124V).

Na tabela 4.2.41, são apresentados os valores da BUAsel nas três tensões de trabalho, para os pares de transdutores de 0,5MHz (RS), para ambas peças de teflon e sem amplificação do sistema, pois ocorre saturação do sinal, feitos pela técnica de inserção convencional e de contato, com repetição de 12 vezes, sem fazer o re-posicionamento da peça e feita a seleção do sinal temporal.

Tabela 4.2.41- Média e desvio padrão (SD) da BUAsel para uma seqüência de 12 repetições, para as peças de teflon e para os transdutores de 0,5MHz de freqüência (RS), nas três tensões de trabalho. Feitos pela técnica de inserção e de contato, para o sinal selecionado e sem a amplificação do sistema.

\begin{tabular}{ccc}
\hline & Inserção & Contato \\
\hline Amostra/Trans./Amplif. & Média \pm SD (dB/MHz) & Média \pm SD (dB/MHz) \\
\hline TefM-T1-RS & $11,60 \pm 0,10$ & $20,68 \pm 0,53$ \\
TefG-T1-RS & $13,13 \pm 0,36$ & $30,04 \pm 0,61$ \\
TefM-T2-RS & $11,26 \pm 0,07$ & $20,41 \pm 0,45$ \\
TefG-T2-RS & $11,99 \pm 0,11$ & $30,82 \pm 0,57$ \\
TefM-T3-RS & $10,64 \pm 0,07$ & $21,02 \pm 0,36$ \\
TefG-T3-RS & $11,19 \pm 0,09$ & $29,61 \pm 0,27$ \\
\hline
\end{tabular}


Na tabela 4.2.41, têm-se os resultados para as técnicas de inserção e contato, para o par de transdutores de $0,5 \mathrm{MHz}$ (par RS) e aplicada as três tensões do sistema ultra-sônico. $\mathrm{Na}$ técnica de inserção o CV\% permaneceu entre 0,62\% (tefM-T2-RS) e 2,74\% (tefG-T1-RS) e na técnica de contato ficou entre 0,91\% (tefG-T3-RS) e 2,56\% (tefM-T1-RS).

\subsubsection{Considerações finais entre BUAtot e BUAsel.}

Comparando os resultados obtidos nas seções 2.1, 2.3 e 3, quando analisada a variação dos valores obtidos, pela técnica de inserção, para as BUAs (BUAtot e BUAsel) como função da tensão, observou-se o mesmo comportamento para todos os pares de transdutores, e, conforme se aumentou a tensão não foi obtido uma mudança significativa no valor da BUA, permanecendo aproximadamente constante. Entretanto, para o BUAsel (tabelas 4.2.35, 4.2.36 e 4.2.37), a peça tefG, com amplificação, apresentou uma diminuição significativa, no seu valor de BUA, conforme se aumentou a tensão do equipamento.

Para a técnica de contato, fazendo a comparação dos resultados das seções 2.1, 2.3 e 3, os valores obtidos para a BUAsel demonstram que, mesmo variando a tensão de excitação eles permaneceram aproximadamente constantes, para todos os transdutores, sem nenhuma exceção. Este fato, foi observado nos resultados da BUAtot para os seguintes transdutores: IG (2MHz), CD (0,75MHz), PQ (1,5MHz) e RS (0,5MHz). Entretanto, para os pares de $1 \mathrm{MHz}$ ( $\mathrm{AB}, \mathrm{NO}$ e EF) e para o par LM de $2 \mathrm{MHz}$, observou-se que, conforme aumentou a tensão ocorreu uma diminuição no valor da BUAtot.

Os resultados das seções 2.1, 2.3 e 3, são exemplificados na figura 4.2.1. Na figura 4.2.1 é apresentada a região linear da função transferência da amostra, para o par de transdutores de $1 \mathrm{MHz}(\mathrm{AB})$ como ilustração, para a peça de teflon grande (tefG) e nas três tensões do equipamento.

Na figura 4.2.1b, nota-se que, quando foi calculada a BUAtot a região linear ficou menor e a separação entre as curvas foi maior. Enquanto, na figura 4.2.1a, a região linear da BUAsel ficou maior e a separação entre as curvas menor. Isto ocorre, porque quando se calculada a BUAtot considera-se o sinal inteiro, enquanto que, na BUAsel utiliza-se uma janela do sinal temporal, como apresentada no capítulo 2 (seção 2.2.3.5). Então, no caso da 
BUAtot a análise completa do sinal introduz efeitos das possíveis reflexões nas faces da peça, aumentando a complexidade do sinal.

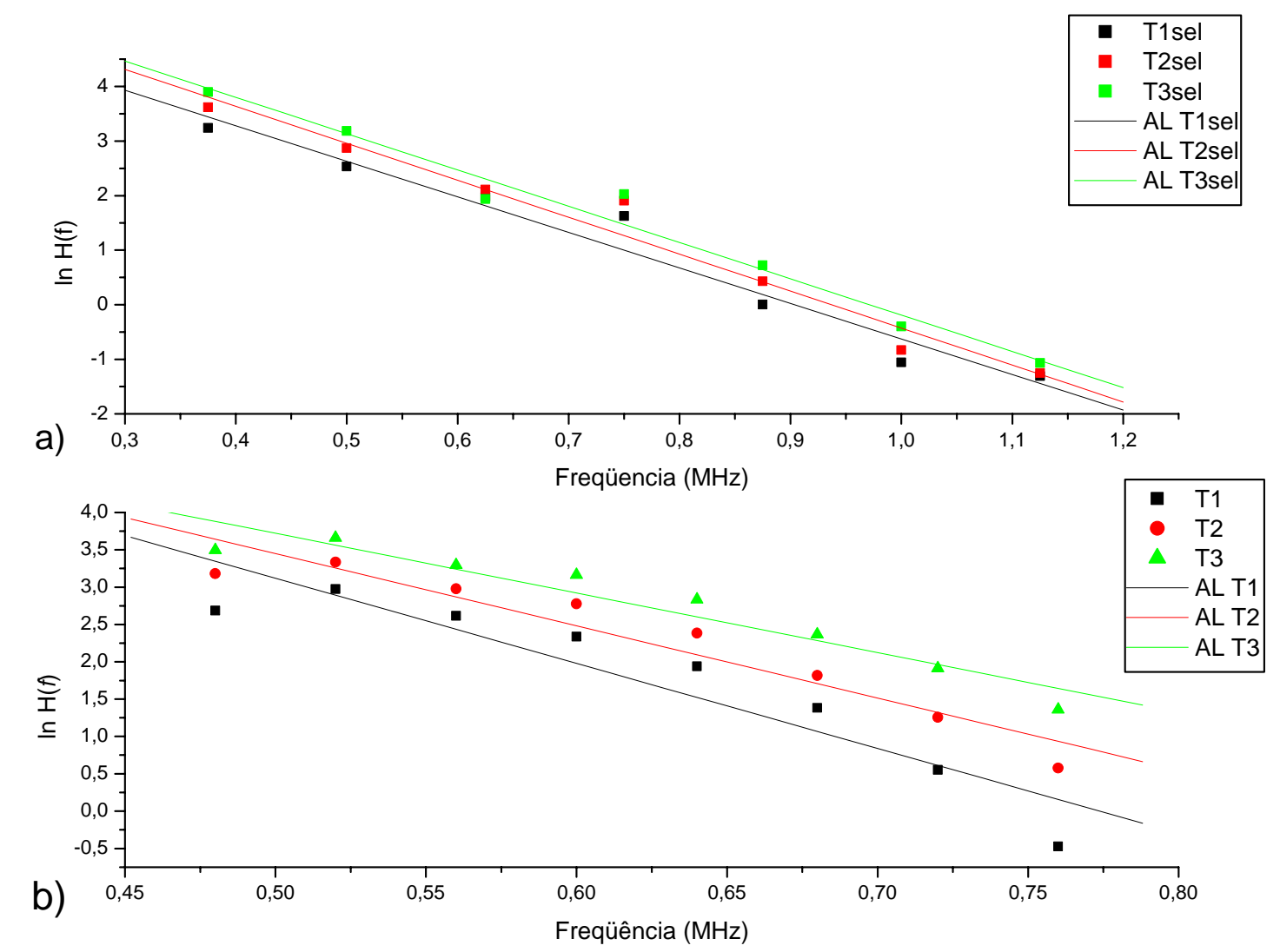

Figura 4.2.1. Região linear da função transferência para a peça de teflon (tefG), para o par de transdutores de $1 \mathrm{MHz}(\mathrm{AB})$, nas três tensões do equipamento $(\mathrm{T} 1=124 \mathrm{~V}, \mathrm{~T} 2=172 \mathrm{~V}$ e T3=224V). A região linear para o cálculo da BUAsel e BUAtot, pela técnica de contato, em a e b, respectivamente.

Na comparação entre os valores obtidos para a BUAtot e BUAsel (seções 4.2.3 e 4.2.4), os transdutores de $1 \mathrm{MHz}$, na técnica de inserção, apresentaram uma pequena diferença para os pares AB e EF, entretanto, para o par NO, fazendo a comparação entre as três tensões, foi observado que são aproximadamente iguais. Na técnica de contato a diferença, entre os valores obtidos para a BUAtot e BUAsel, foi maior, sendo que, alguns valores da BUAsel são menores que a metade do valor na BUAtot. Contudo, a diferença observada para o par EF foi pequena, quando comparada com a dos outros dois pares (AB e NO).

Para os pares de 2MHz (IG e LM), na técnica de inserção e de contato a BUAsel foi menor, em todas as tensões, do que a BUAtot. Quando analisada a peça tefG a variação observada foi bem menor, para os dois pares de transdutores (IG e LM). 
Nos transdutores de $0,75 \mathrm{MHz}$, para a técnica de inserção as diferenças para a BUAsel foram menores se compararmos com os outros pares de transdutores. Entretanto, para a técnica de contato os dois valores, da BUAsel e BUAtot, são aproximadamente iguais quando considerado a margem de erro.

Nos pares PQ $(1,5 \mathrm{MHz})$ e RS $(0,5 \mathrm{MHz})$, a diferença foi grande entre as duas formas de cálculo, para ambas as técnicas, sendo que, os valores de BUAsel são menores que os valores de BUAtot, contudo, o par RS foi o que apresentou a maior diferença entre os resultados.

Fazendo a comparação entre os CV\% obtidos na seção 4.2.2.1 (reprodutibilidade em longo prazo) e 4.2 .3 (reprodutibilidade em curto prazo), somente lembrando que, na seção 2.1, os resultados da BUAtot são para uma aquisição em sete dias diferentes (seis sinais em cada dia) durante um período de 4 meses, enquanto que, na seção 2.3, são os resultados da BUAtot para aquisição em um único dia sem fazer o re-posicionamento da peça de teflon, para 12 repetições.

Nas seções 4.2.2.1 e 4.2.3, os CV\%, obtidos para a técnica de inserção foram sempre menores que os obtidos na técnica de contato, exceto para o par RS (seção 4.2.2.1, tabela 4.2.13). Para o par RS, a técnica de contato não apresentou nenhum valor superior a 2,64\%, enquanto, na técnica de inserção, não obteve valor superior a 4,59\%, mas sendo maior que a da técnica de contato.

A dispersão em curto prazo foi sempre menor que a dispersão em longo prazo, para qualquer um dos pares de transdutores e qualquer tensão.

Na comparação entre as seções 4.2.3 e 4.2.4 (BUAtot e BUAsel com repetição de doze vezes) os valores do CV\% na BUAsel foram menores que na BUAtot, apresentando assim uma melhor resposta com relação ao sinal utilizado no cálculo da BUA, entretanto, os valores obtidos para a BUAsel pela técnica de inserção, foram menores, mas a variação foi menor, enquanto, pela técnica de contato a variação foi maior. 


\subsubsection{VARIAÇÃO DA POSIÇÃO DO TEFLON EM RELAÇÃO AO TRANSDUTOR EMISSOR (TE).}

Nesta seção será avaliada a velocidade do som e da BUAtot de acordo com a posição da peça de teflon em relação ao transdutor emissor (TE). A peça de teflon utilizada foi a grande (tefG) e o par de transdutores utilizados foi o NO (1,0MHz). São assumidas três posições distintas: na primeira, a peça está próxima do transdutor emissor (a uma distância de 10,8mm do TE); na segunda, a peça encontra-se eqüidistantes dos transdutores (a uma distância de 19,0mm do TE) e na terceira posição a peça encontra-se próxima do transdutor receptor (a uma distância de 27,15mm do TE), como apresentado na figura 4.2.2.

A técnica utilizada é a de inserção convencional com acoplamento por água. A BUAtot foi calculada usando o sinal total adquirido e para o cálculo de velocidade foi usada a equação 6 (capítulo 2, seção 2.1), sendo que, o referencial, para o cálculo da velocidade, foi a primeira transição em torno do zero. A temperatura de trabalho foi de $24^{0} \mathrm{C}$, antes de iniciar as aquisições dos sinais a peça ficou num banho térmico de 40 minutos nesta temperatura. Foram realizadas doze repetições para cada tensão e em cada posição.

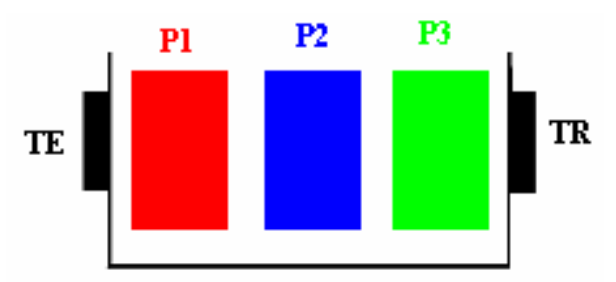

Figura 4.2.2. Vista lateral do tanque acústico, com a indicação das posições (P1=10,8mm, P2=19,0mm e P3=27,15mm) da peça de teflon em relação ao transdutor emissor (TE).

Na figura 4.2.3, são apresentadas as curvas temporais para o teflon nas três posições avaliadas.

Nas tabelas 4.2.42 e 4.2.43, são apresentados os resultados da velocidade e da BUAtot para esta análise, respectivamente. 


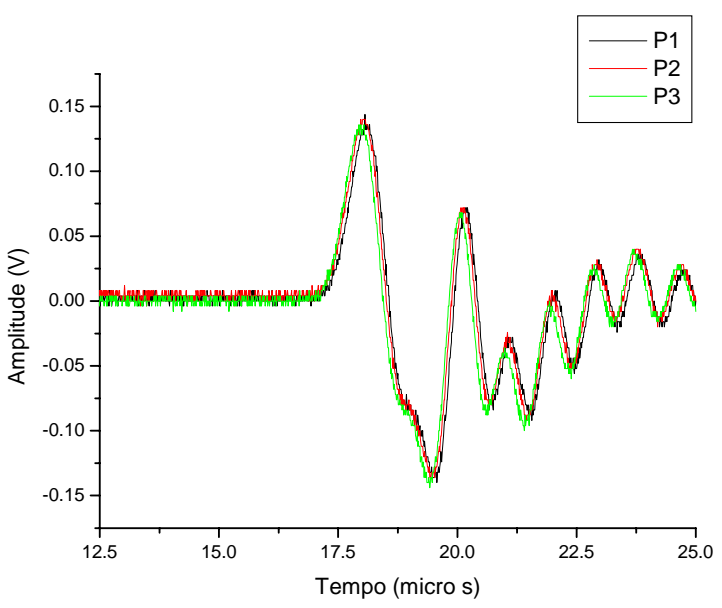

Figura 4.2.3. Sinais temporais para a peça de teflon grande, para três posições (P1 (posição 1), P2 (posição 2) e P3 (posição 3)) analisadas.

Tabela 4.2.42- Valores da média das velocidades com o seu respectivo desvio padrão (SD), para as três posições analisadas.

\begin{tabular}{|ccc|}
\hline POSIÇÃO & $\begin{array}{c}\text { Média das Velocidades } \\
\mathbf{( m / s )}\end{array}$ & SD (m/s) \\
\hline P1 & 1322,25 & 1,30 \\
\hline P2 & 1323,34 & 1,45 \\
\hline P3 & 1324,45 & 1,75 \\
\hline
\end{tabular}

Tabela 4.2.43- Valores da média da BUAtot com seus respectivos desvios padrão (SD), para as três posições analisadas.

\begin{tabular}{|c|c|c|c|}
\hline \multicolumn{2}{|c|}{ POSIÇÃO/TENSÃO } & \multicolumn{2}{|c|}{ BUAtot } \\
\hline & & Média (dB/MHz) & SD (dB/MHz) \\
\hline \multirow{3}{*}{ P1 } & $\mathrm{T} 1$ & 50,20 & 0,16 \\
\hline & $\mathrm{T} 2$ & 51,24 & 0,11 \\
\hline & T3 & 51,15 & 0,11 \\
\hline \multirow{3}{*}{ P2 } & $\mathrm{T} 1$ & 50,22 & 0,11 \\
\hline & $\mathrm{T} 2$ & 51,29 & 0,14 \\
\hline & T3 & 51,19 & 0,12 \\
\hline \multirow{3}{*}{ P3 } & $\mathrm{T} 1$ & 50,42 & 0,21 \\
\hline & $\mathrm{T} 2$ & 51,45 & 0,09 \\
\hline & T3 & 51,42 & 0,10 \\
\hline
\end{tabular}


De acordo com os resultados apresentados nas tabelas 4.2.42 e 4.2.43, mesmo ocorrendo a variação da peça de teflon com relação ao transdutor emissor, não ocorreu nenhuma variação significante nos valores de velocidade e BUAtot, sendo aproximadamente constantes. Entretanto, tem-se que lembrar que a peça de teflon é homogênea e isotrópica que a diferencia do osso calcâneo que, devido a sua estrutura trabecular e cortical, é heterogêneo e anisotrópica.

Mesmo ocorrendo a variação da posição não ocorreu nenhuma variação significativa nos valores de velocidade e de BUAtot. Isso demonstra que o equipamento possui uma boa estabilidade com relação ao seu sinal e as possíveis variações que ocorrem nos valores de BUA e velocidade devem estar associados à técnica utilizada e a amostra analisada (caso do osso calcâneo).

\subsubsection{AVALIAÇÃO DA INFLUÊNCIA DO CIRCUITO AMPLIFICADOR SOBRE OS VALORES DE BUA (BUAtot e BUAsel).}

Nesta seção será avaliado o comportamento da região linear (função transferência dependente da freqüência) quando se variam as tensões do sistema ultra-sônico, e se utiliza o circuito amplificador. Como forma de análise e ilustração será avaliada apenas a peça grande de teflon (tefG) para os pares AB (figura 4.2.4) e LM (figura 4.2.5) de transdutores de $1 \mathrm{MHz}$ e $2 \mathrm{MHz}$ de freqüência nominal, respectivamente. Serão analisadas as duas técnicas, a de inserção convencional e a de contato, com o cálculo da BUAtot. 

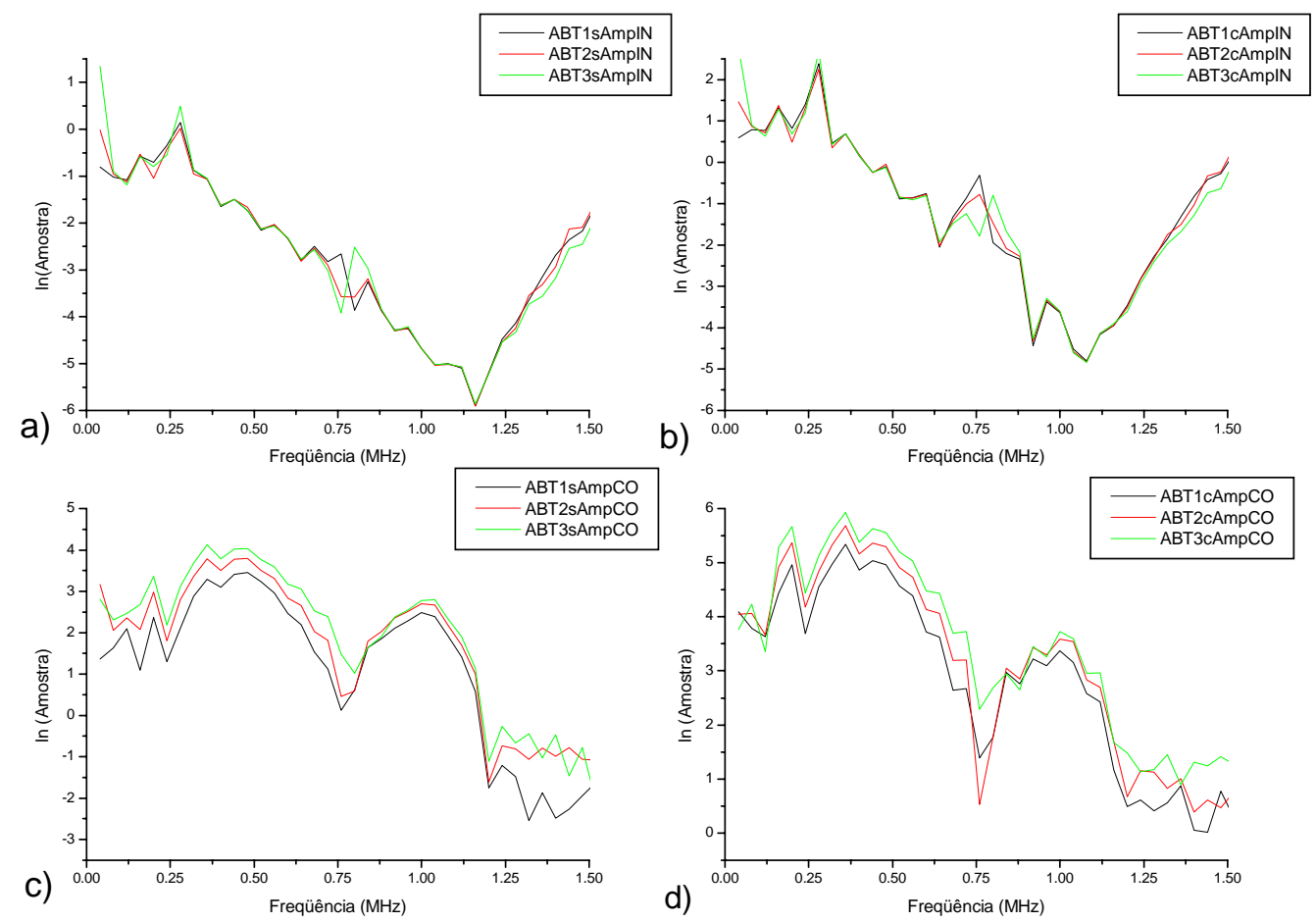

Figura 4.2.4. Gráficos demonstrando a região linear para a peça de teflon grande, para o par de transdutores AB (1MHz) e para as três tensões (T1, T2 e T3). Em a: foi aplicada a técnica de inserção convencional (IN) e sem amplificação do sistema (sAmp). Em b: foi aplicada a técnica de inserção convencional (IN) e com amplificação do sistema (cAmp). Em c: foi aplicada a técnica de contato (CO) e sem amplificação do sistema (sAmp). Em d: foi aplicada a técnica de contato (CO) e com amplificação do sistema (cAmp).

Na figura 4.2.4, é possível observar que existe um pico na posição de $0,75 \mathrm{MHz}$, para a técnica de inserção (figura 4.2.4a e 4.2.4b) e este pico está para cima, enquanto, para a técnica de contato (figura 4.2.4c e 4.2.4d) está para baixo. Observa-se que, nas figuras 4.2.4b e 4.2.4d, o uso do amplificador provocou um maior ruído no sinal e aumentou a inclinação, por isso quando utilizado o circuito amplificador obtemos valores maiores da BUA, sendo que, estes resultados também são influenciados pela freqüência do transdutor.

Na técnica de inserção (figura 4.2.4a e 4.2.4b), não é observada variação entre as tensões, entretanto, na técnica de contato essa variação é visível mostrando que o valor da BUAtot para a tensão 1 (124V) será maior que o da tensão 3 (224V). 

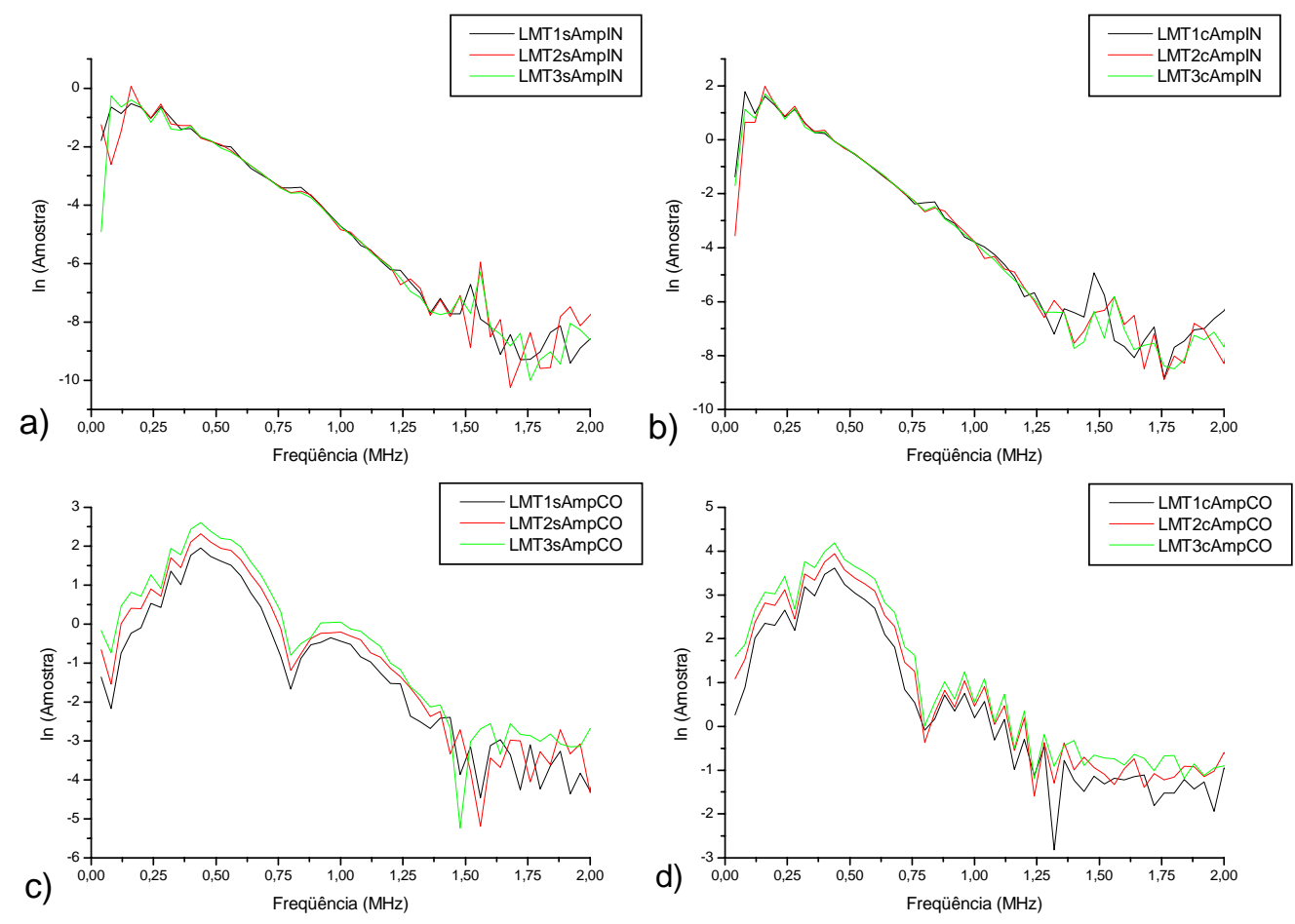

Figura 4.2.5. Gráficos demonstrando a região linear para a peça de teflon grande e para o par de transdutores LM (2MHz) e para as três tensões (T1, T2 e T3). Em a: foi aplicada a técnica de inserção convencional (IN) e sem amplificação do sistema (sAmp). Em b: foi aplicada a técnica de inserção convencional (IN) e com amplificação do sistema (cAmp). Em c: foi aplicada a técnica de contato (CO) e sem amplificação do sistema (sAmp). Em d: foi aplicada a técnica de contato (CO) e com amplificação do sistema (cAmp).

Nas figuras 4.2.5a e 4.2.5b, são apresentadas a região linear da função de transferência para o teflon (tefG), avaliada pela técnica de inserção, com e sem a amplificação do equipamento, respectivamente. Neste caso não foi possível observar a existência do pico em 0,75MHz, como na figura 4.2.4. Para a técnica de contato, figura 4.2.5c e 4.2.5d, o pico de corte do sinal se tornaram evidente. É possível notar o aumento da inclinação da região linear, em 4.2.5b e 4.2.5d, conseqüentemente, provocando um aumento no valor da BUAtot.

Este pico, em torno do $0,75 \mathrm{MHz}$ de freqüência, é visível em todos os pares de transdutores, sendo que, ocorre um certo deslocamento, em relação ao eixo de freqüência, dependendo da freqüência do transdutor.

O pico, que aparece nesses sinais das figuras 4.2.4 e 4.2.5, são picos de oscilação na forma do sinal e este comportamento aconteceu para os outros pares de transdutores, sendo que, para alguns de forma mais acentuada como para o par AB (figura 4.2.4) e outros de forma menos acentuada como no caso do par LM (figura 4.2.5). Entretanto, em todos os 
transdutores, o pico de corte é mais aparente quando se utiliza o sistema de amplificação de sinal e quando se trabalha com a técnica de contato na análise de BUAtot.

Nas figuras 4.2.6 e 4.2.7, são apresentados os sinais temporais, do teflon grande, para os pares de transdutores de $1 \mathrm{MHz}$ (par AB) e $2 \mathrm{MHz}$ (par LM), respectivamente. Nestas figuras, são mostradas, as formas do sinal de ultra-som quando se utiliza o sistema de amplificação do equipamento ultra-sônico como também a forma do sinal temporal adquirido pelas técnicas de inserção e de contato.

Pode ser observado que, nas figuras 4.2.6c e 4.2.6d, quando é utilizado o circuito amplificador de sinal, este amplifica o sinal como um todo, isto quer dizer, amplifica o ruído e os ecos provenientes das faces da peça de teflon, provocando uma certa mudança no formato do sinal recebido, como pode ser observado na comparação das figuras 4.2.6a com 4.2.6c e 4.2.6b com 4.2.6d. Isto ocorre na figura 4.2.7, para o par LM de transdutores em ambas as técnicas, e como se observa ainda comparando as figuras 4.2.7a com 4.2.7c e 4.2.7b com 4.2.7d.

Nas figuras 4.2.8 e 4.2.9, são apresentadas as regiões lineares da função de transferência para os pares de transdutores AB e LM, respectivamente, e para uma única tensão de excitação. São avaliadas pelas técnicas de inserção e contato e calculadas para BUAtot e BUAsel.

Nas figuras 4.2.8a e 4.2.8c, é possível observar que, quando se calcula a BUAsel, o sinal se torna menos ruidoso deixando a região linear mais visível e fácil de dimensionar, isso em ambas as técnicas. Verifica-se que, na técnica de contato, a presença do pico de corte está em 0,75MHz, isto para a BUAtot (figura 4.2.8d), enquanto, na técnica de inserção (figura 4.2.8b) o pico é menos acentuado, mas o ruído é bem aparente.

Para o par LM de transdutores, avaliados pela técnica de inserção (figuras 4.2.9a e 4.2.9b), tanto para a região linear da BUAtot como da BUAsel, são bem definidas, entretanto, a região linear, na BUAtot, é menor (figura 4.2.9a) e seu ruído é maior. Já na técnica de contato, figuras 4.2.9c e 4.2.9d, o pico de 0,75MHz se torna acentuado provocando um encurtamento drástico no comprimento da região linear do sinal, para a BUAtot (figura 4.2.9c). Na análise da BUAsel (figura 4.2.9d), quando utilizado o circuito amplificador, a região linear sofre uma redução, sendo que, sem amplificação a região linear é maior. 


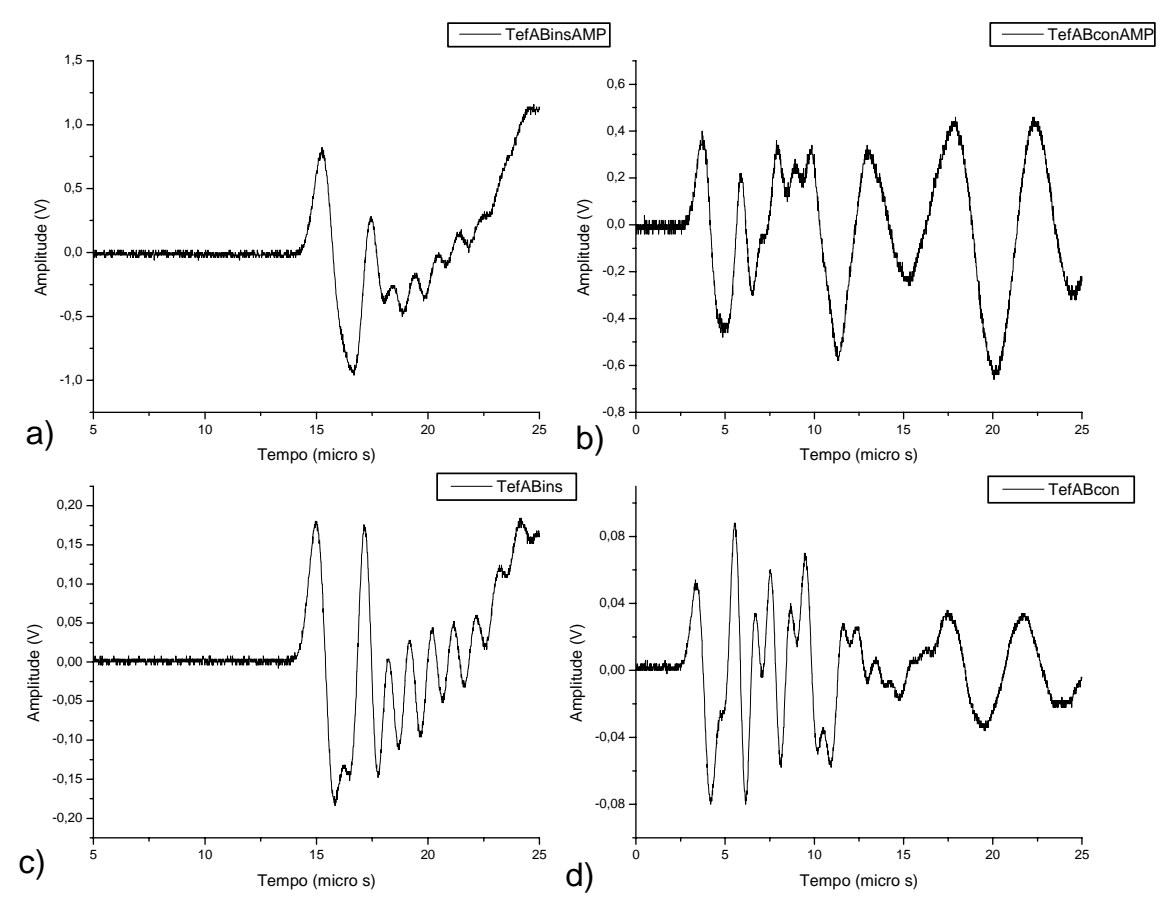

Figura 4.2.6. Sinais temporais para a peça de teflon grande (tefG) e para o par de transdutor de $1 \mathrm{MHz}(\mathrm{AB})$, adquiridos pela técnica e inserção e contato e sem a amplificação do sistema, em c e d, respectivamente. Em a e b, são os sinais adquiridos pela técnica e inserção e contato e com a amplificação do sistema, respectivamente.

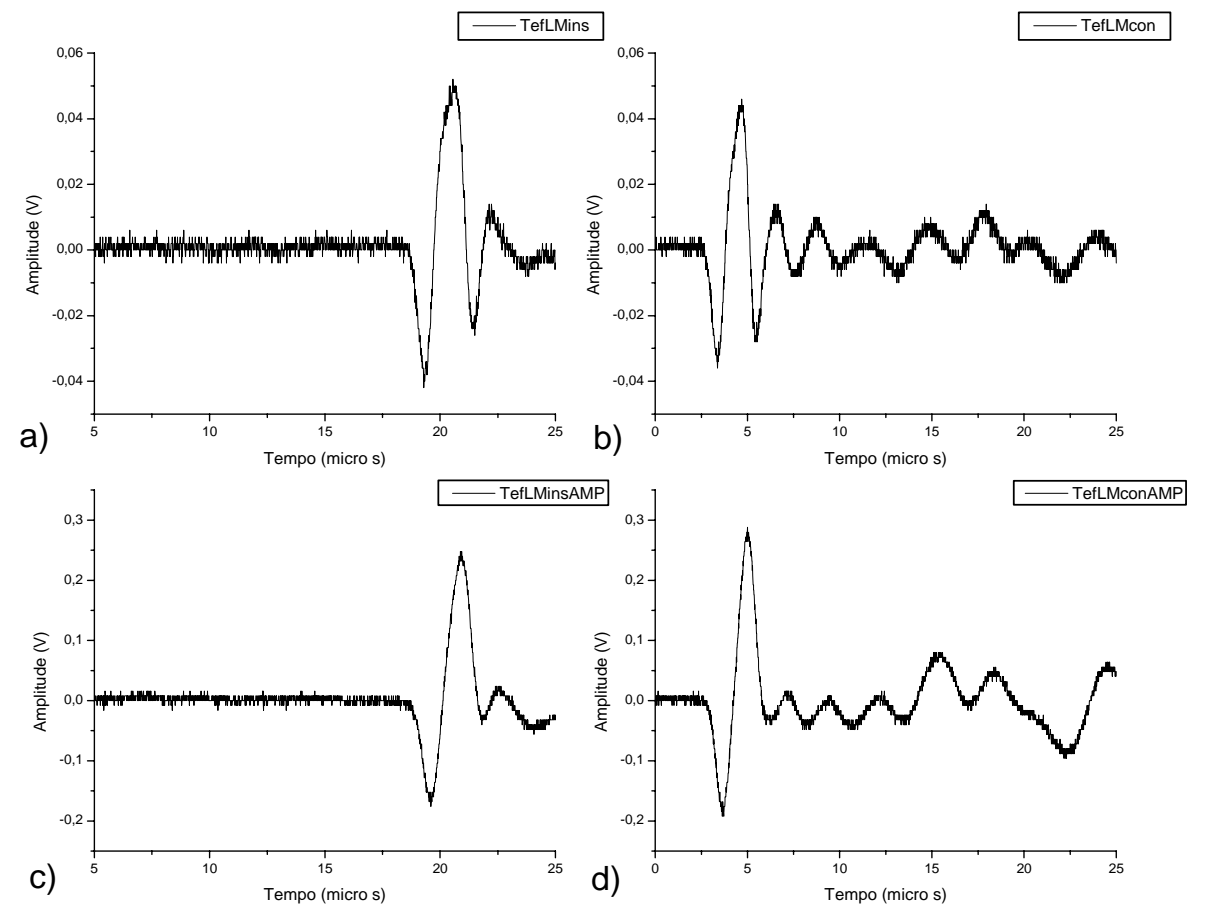

Figura 4.2.7. Sinais temporais para a peça de teflon grande (tefG) e para o par de transdutor de $2 \mathrm{MHz}$ (LM) adquiridos pela técnica e inserção e contato e sem a amplificação do sistema, em a e b, respectivamente. Em c e d, são os sinais adquiridos pela técnica e inserção e contato e com a amplificação do sistema, respectivamente. 


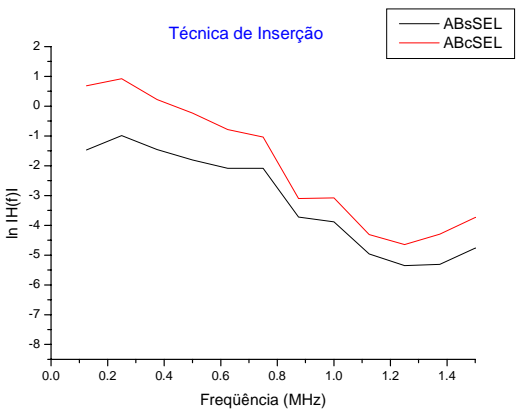

a)

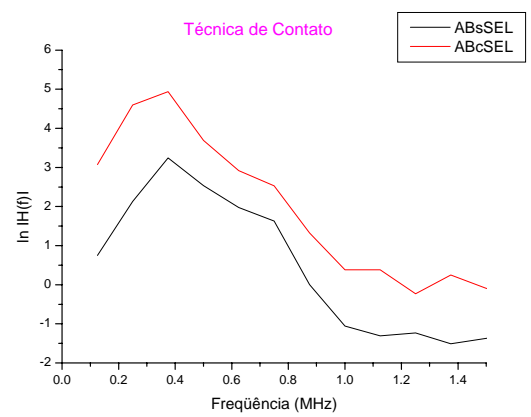

c)

Figura 4.2.8. Gráficos da região linear da função de transferência para a peça de teflon grande, para o par AB de transdutores e com (c) e sem (s) a amplificação do sistema. Em a e b, são os sinais obtidos pela técnica de inserção avaliados pela BUAsel e BUAtot, respectivamente. Em c e d, são os sinais obtidos pela técnica de contato avaliados pela BUAsel e BUAtot, respectivamente.
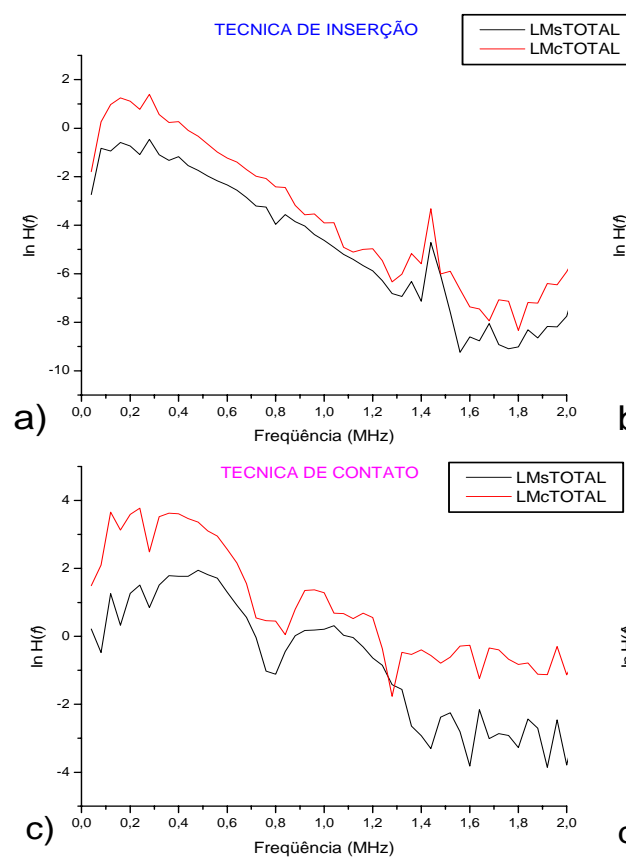

b)
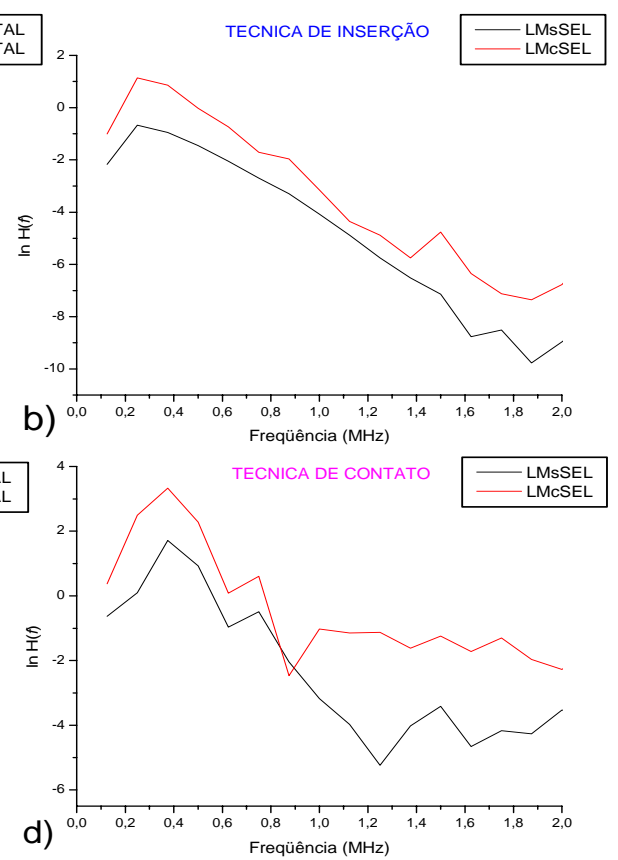

Figura 4.2.9. Gráficos da região linear da função de transferência para a peça de teflon grande, para o par LM de transdutores e com (c) e sem (s) a amplificação do sistema. Em a e b, são os sinais obtidos pela técnica de inserção avaliados pela BUAtot e BUAsel, respectivamente. Em c e d, são os sinais obtidos pela técnica de contato avaliados pela BUAtot e BUAsel, respectivamente. 


\subsection{AVALIAÇÃO, ATRAVÉS DA ULTRASSONOMETRIA ÓSSEA, DO CALO ÓSSEO EM TIBIAS DE CARNEIRO.}

\subsubsection{INTRODUÇÃO}

Apesar de toda a evolução que vem mostrando as técnicas de densitometria e tomografia computadorizada, como métodos de diagnóstico da osteoporose e também na avaliação da consolidação óssea, a procura por métodos sensíveis, de menor custo e maior praticidade, vem ensejando uma corrida tecnológica poucas vezes testemunhada pela medicina.

O ultra-som tem surgido como uma nova forma de avaliar a qualidade óssea, desde a introdução da ultrassonometria óssea de calcâneo, que tem por finalidade avaliar a qualidade óssea e discriminar um osso saudável de um com osteoporose, até várias novas aplicações desta técnica que têm sido empregadas em patologias que afetam os ossos de alguma forma.

O ultra-som não mede a densidade óssea da forma que costumamos avaliar, na densitometria em $\mathrm{g} / \mathrm{cm}^{2}$ ou pela tomografia computadorizada, em $\mathrm{g} / \mathrm{cm}^{3}$, uma vez que diferentemente das técnicas de densitometria, as medidas obtidas são referentes às mudanças da velocidade, que envolve a determinação do tempo de trânsito da onda sonora emitida quando atravessa uma estrutura como o calcâneo ou quando percorrem um osso cortical como a tíbia e a "Broadband Ultrasound Attenuation" (BUA), que mede o quanto das ondas sonoras emitidas foram absorvidas pelo segmento ósseo durante a passagem através do mesmo.

Acreditamos na eficácia da utilização dos parâmetros ultra-sônicos (velocidade do som e BUA) para avaliação da consolidação óssea nos diversos tipos de fraturas, o que seria de grande utilidade clínica e ainda não disponível comercialmente.

Neste capítulo será avaliada a resposta da velocidade do som e da BUA na análise do calo ósseo nos diferentes períodos de consolidação óssea. Como também será feita uma comparação entre estas técnicas (de inserção e contato) para uma melhor análise do calo. 


\subsubsection{METODOLOGIA}

\subsubsection{Osso analisado}

\subsection{Considerações anatômicas (osso longo)}

A tíbia por ser um osso longo pode ser dividida arbitrariamente em três regiões: o corpo, chamado diáfise; as extremidades do osso, as epífises; e uma região intermediária, a metáfise.

A diáfise é composta pelo osso cortical compacto na forma de um cilindro que circunda a cavidade medular, a qual contém a medula óssea. A cavidade medular, particularmente na região metafisária, também contém osso esponjoso ou reticular, que é constituído de finas espículas ósseas denominadas trabéculas. As epífises são compostas de osso reticular circundado por uma delgada camada de osso compacto (Swenson; Reece, 1996).

\subsubsection{Calo Ósseo}

\subsection{Consolidação óssea}

Todos os processos fisiológicos que ocorrem dentro do osso, compreendendo os processos de reparo durante a cicatrização da fratura, são dependentes de suprimento sanguíneo adequado. A circulação normal para ossos longos consiste de suprimento aferente da artéria nutriente principal, artérias metafiseais proximal e distal e artérias periosteais que penetram no osso em áreas de forte ligação fascial. A direção do fluxo sanguíneo através da diáfise é centrífuga (do canal medular para o periósteo). Em condições normais, é provável 
que a pressão medular restrinja o fluxo sanguíneo periosteal para o terço externo do córtex (Figura 4.3.1).

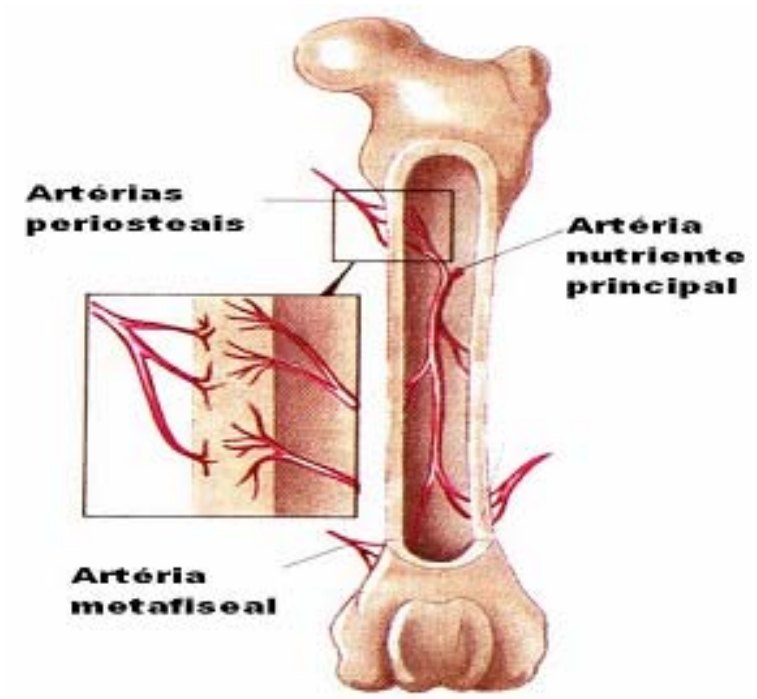

Figura 4.3.1. Suprimento sanguíneo de um osso normal (Fossum, 2001).

A circulação medular é interrompida na maioria das fraturas de ossos longos. No início, os componentes existentes da vasculatura normal aumentam para suprir a área lesada. Além disso, desenvolve-se suprimento vascular extra-ósseo temporário nos tecidos moles e fraturas circundantes para nutrir o calo periosteal inicial (Figura 4.3.2).

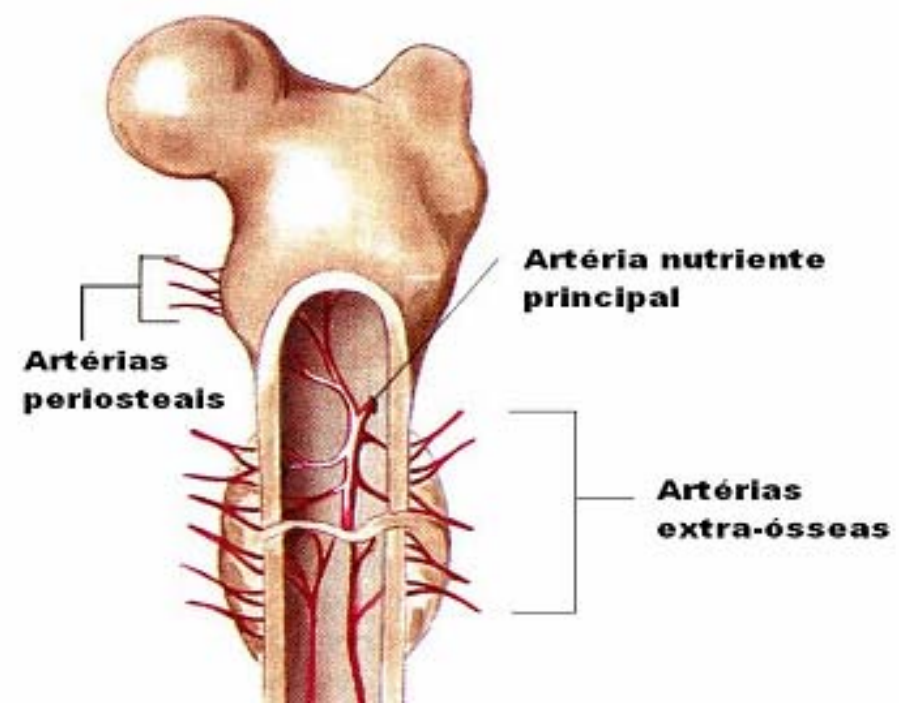

Figura 4.3.2. Osso fraturado com suprimento sanguíneo extra-ósseo (Fossum, 2001).

À medida que a cicatrização óssea progride e a estabilidade se restaura, é restabelecido o suprimento sanguíneo. A circulação extra-óssea diminui e predomina o fluxo medular centrífugo (Figura 4.3.3). 


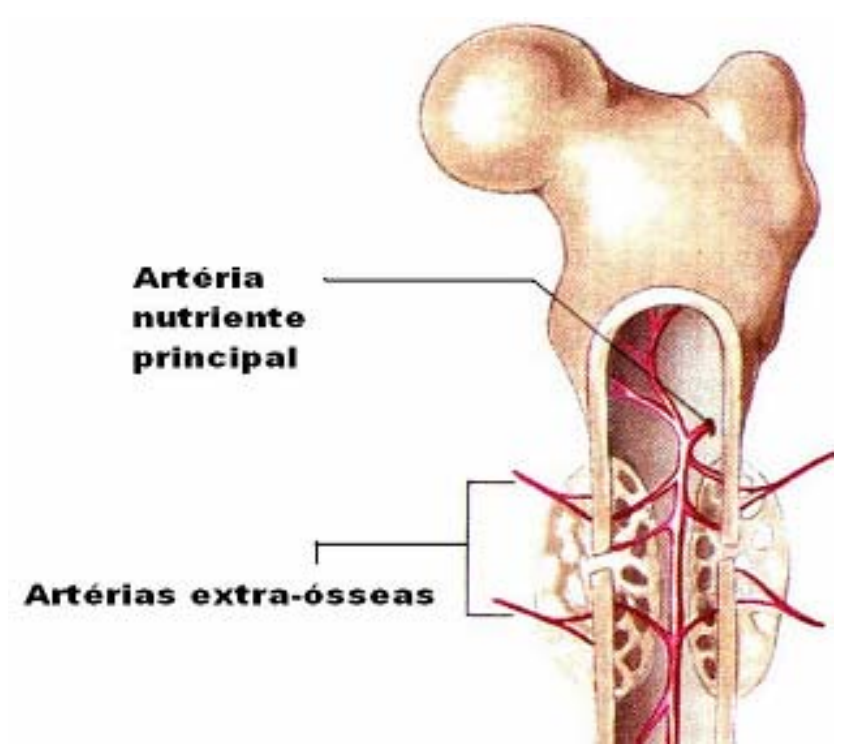

Figura 4.3.3: Cicatrização óssea (Fossum, 2001).

A redução fechada da fratura com a utilização de fixadores externos provocam, no mínimo, ruptura nos tecidos moles circundantes e suprimento sanguíneo extra-ósseo recém formado, portanto, sendo a técnica mais indicada, sempre que possível (Figura 4.3.4).

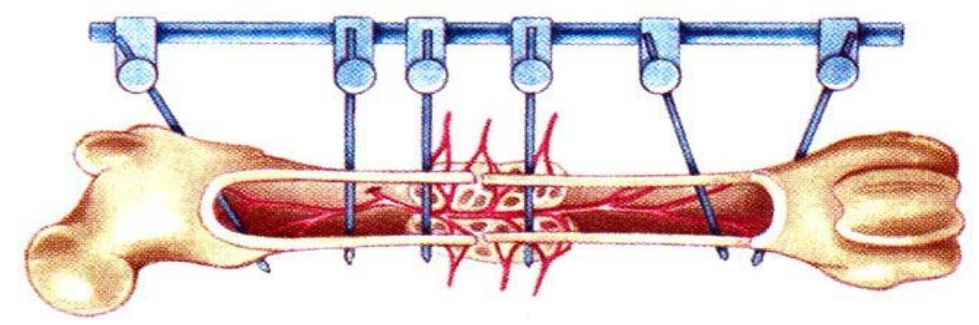

Figura 4.3.4. Redução de fratura com fixador externo (Fossum, 2001).

De início, como demonstra a Figura 4.3.5, as fendas da fratura são ligadas por tecidos que resistem a alguns movimentos existentes no foco (hematoma e tecido de granulação); esses tecidos são substituídos em seqüência por aqueles que aumentam a rigidez óssea (tecido conjuntivo fibroso, fibrocartilagem, osso lamelar). A seqüência mais antiga de formação tecidual nas fendas da fratura, que ocorre na cicatrização óssea indireta, culmina em mineralização da fibrocartilagem, que começa nas superfícies de fragmentos e continua em direção ao centro da fenda, formando osso trabecular e trançado. Ocorre reabsorção local do osso inicial, seguida de vascularização das cavidades de reabsorção e substituição de osso lamelar. A formação e reabsorção contínuas de osso lamelar nos locais da fratura resultam em remodelagem do calo ósseo cortical (Swenson; Reece, 1996 e Fossum, 2001). 

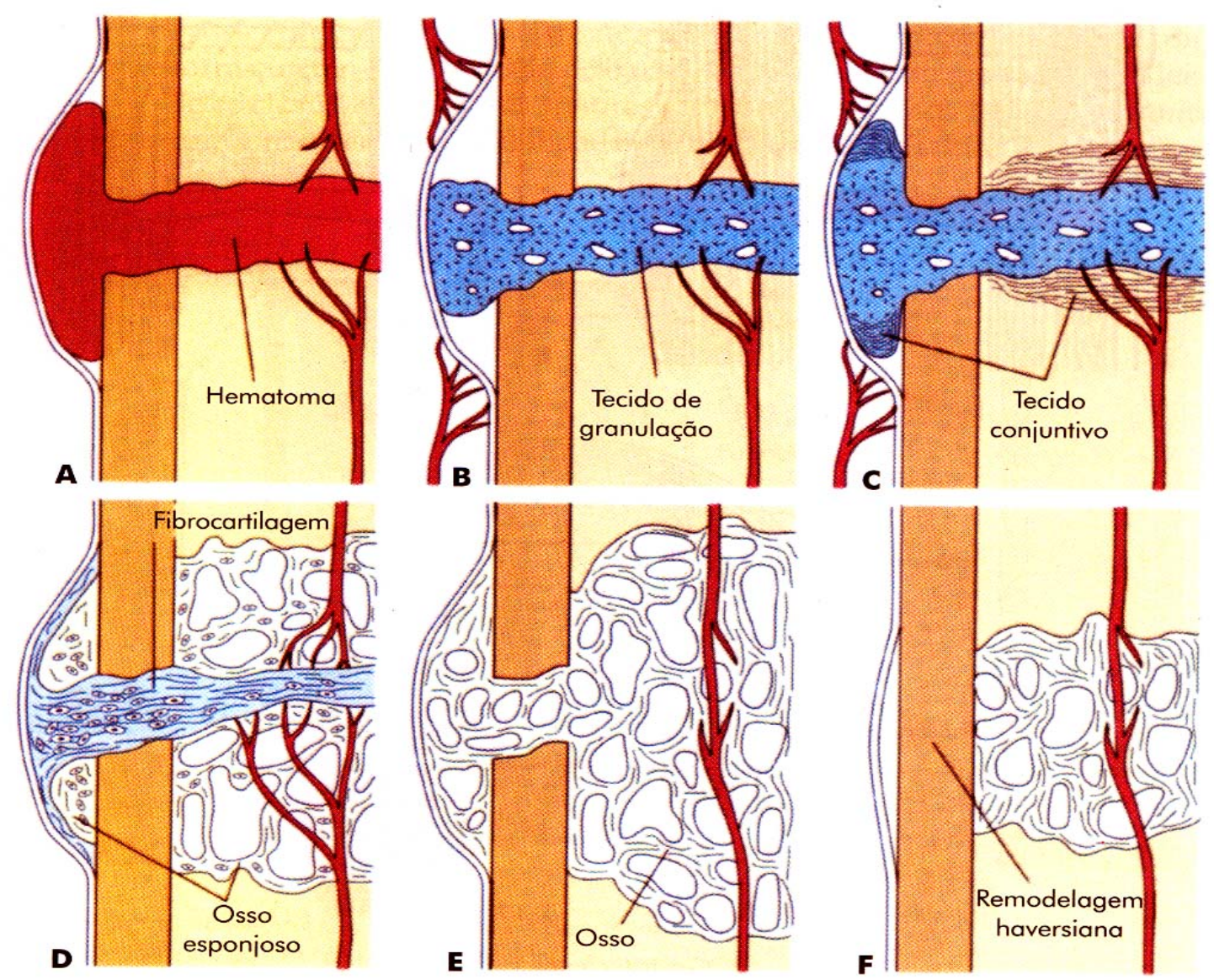

Figura 4.3.5: A. O defeito é primeiro preenchido por um hematoma, B. substituído por tecido de granulação, C. fibrocartilagem, D. a fibrocartilagem é mineralizada, formando osso esponjoso e, E. finalmente osso, F. ocorre remodelagem haversiana para eliminar o calo (Fossum et al., 2001).

\subsection{Fixador externo}

O desenvolvimento e o aprimoramento dos fixadores externos, com o propósito de associar simplicidade e eficiência, vem sendo a principal preocupação de diversos autores.

A Figura 4.3.6 mostra esquematicamente o princípio de funcionamento do fixador, onde a haste, ao se deformar, transmite movimento e carga ao foco da fratura. 


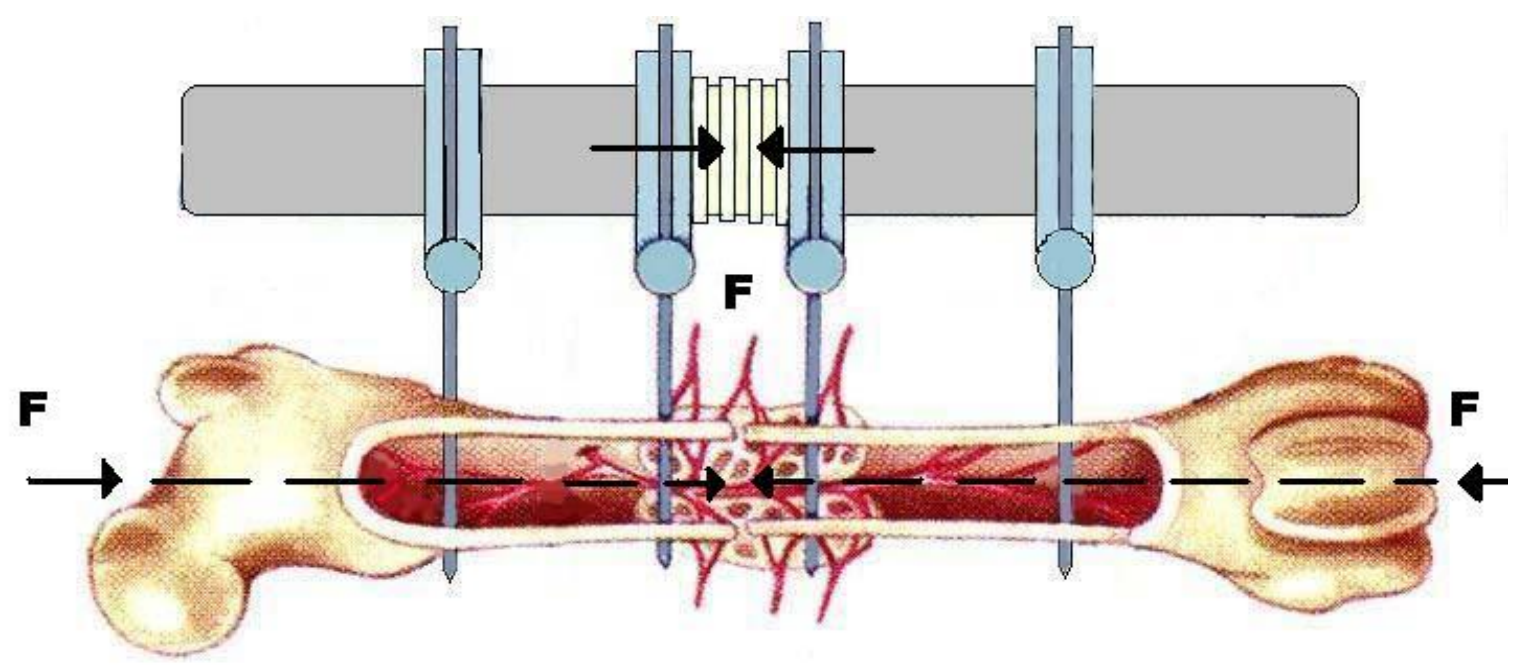

Figura 4.3.6: Esquema do princípio de funcionamento do fixador externo (figura adaptada de Moro; Paccola; Paulin, 1989; Fossum, 2001).

\subsubsection{Preparação das amostras}

Foram utilizados 15 carneiros adultos jovens (idade média de 10 meses), com massa corporal média de $37 \mathrm{~kg}$, da raça Santa Inês, procedentes do Biotério Geral da Faculdade de Medicina de Ribeirão Preto da USP. Após um período de avaliação, onde receberam cuidados veterinários como, vermifugação, vacinação e revisão dos cascos para evitar defeitos de aprumo, os animais considerados aptos foram submetidos à cirurgia e mantidos isoladamente por um período de cinco dias no Biotério do Laboratório de Bioengenharia da FMRP. Posteriormente, foram enviados a uma baia coletiva de até 5 animais. A dieta durante todo o período experimental constou de ração ovina balanceada, sal mineral, capim, feno selecionado e água ad libitum.

Foram utilizadas as duas tíbias de cada animal para a experimentação, por se tratar de um osso longo e de fácil acesso cirúrgico. Padronizou-se a tíbia direita para a realização do procedimento cirúrgico. As tíbias de ambos os lados foram utilizadas na análise ultrasonométrica.

Os animais foram divididos em três grupos experimentais com cinco animais cada. $\mathrm{O}$ tempo de permanência do fixador externo nos animais foi de 30, 45 e 60 dias. Os grupos foram divididos de acordo com o tempo de permanência do fixador externo. 


\subsubsection{Conservação das tíbias (congelamento * descongelamento)}

Após o sacrifício dos animais, as tíbias foram ressecadas, completamente limpas das partes moles e armazenadas em freezer a $-20^{\circ} \mathrm{C}$ até a véspera da realização das análises ultrasônicas.

$\mathrm{Na}$ véspera da realização das análises, as tíbias foram transferidas do freezer de estocagem $\left(-20^{0} \mathrm{C}\right)$ para outro a $-12^{0} \mathrm{C}$ por 12 horas, após este período, foram transferidas para um refrigerador a $+4^{0} \mathrm{C}$ por mais 12 horas. Antes da realização das análises, as tíbias permaneceriam por mais duas horas em temperatura ambiente controlada $\left(24^{0} \mathrm{C}\right)$.

\subsubsection{Região de Interesse}

Para se determinar à região de interesse a tíbia foi medida em seu comprimento para ser encontrado o seu meio, onde este estaria focalizado com o centro dos transdutores. Este procedimento também foi adotado para as tíbias tratadas (calos), fazendo sempre com que o sinal ultra-sônico incida no centro (figura 4.3.7).

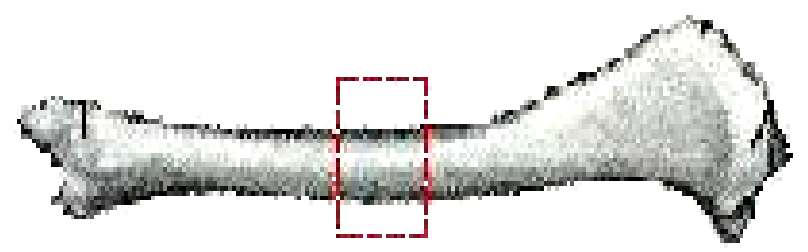

Figura 4.3.7. Região de interesse na tíbia de carneiro para análise ultra-sônica (em vermelho).

Considerando-se que as amostras têm tamanhos diferentes, faz-se o acerto no posicionamento da tíbia, para que a incidência do pulso fique dentro da região de interesse. Para fazer essa correção, deve-se, se necessário, usar apoios e também movê-la para frente ou para trás corrigindo assim, o seu posicionamento. O acerto é feito visualmente (manualmente).

Foram adotadas duas orientações para a incidência do sinal ultra-sônico. A primeira quando a crista da tíbia está perpendicular ao sinal de ultra-som emitido pelo transdutor emissor e a segunda a crista da tíbia está com $180^{\circ}$ em relação ao transdutor emissor (Figura 
4.3.8). Os índices 90 e 180, nos sinais adquiridos, servem para diferenciá-los quanto a sua orientação (tib90, tib180, calo90 e calo180). O prefixo "tib” corresponde à tíbia saudável, enquanto, o prefixo “calo” corresponde à tíbia tratada.

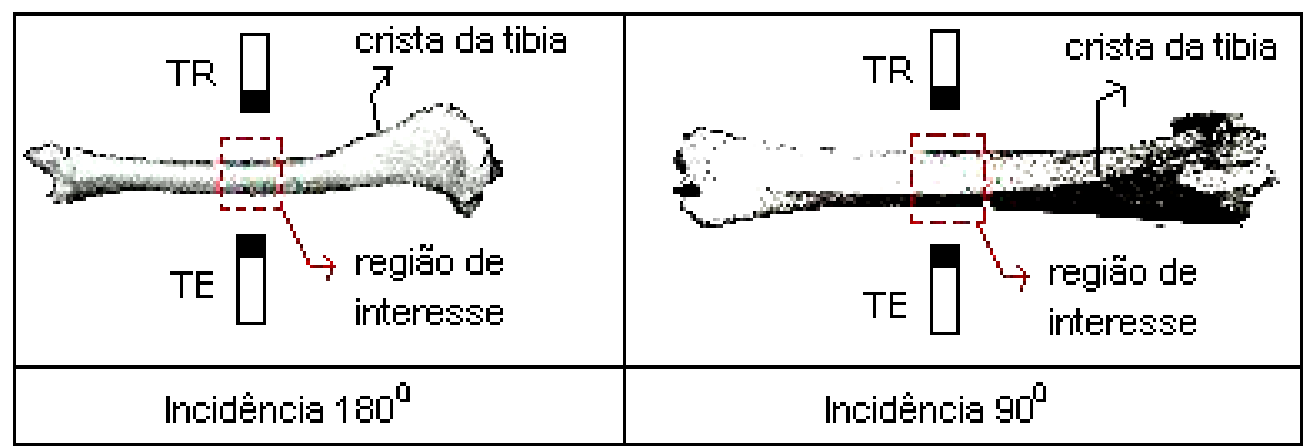

Figura 4.3.8: Orientação da tíbia quanto à posição da sua crista com relação ao transdutor emissor (TE).

Na tabela 4.3.1, é apresentado o valor da espessura da tíbia e do calo nas duas orientações (90 e 180 graus).

Tabela 4.3.1- Espessura da tíbia e do calo para os animais de todos os grupos nas orientações 90 e 180 graus.

\begin{tabular}{|c|c|c|}
\hline ANIMAL & ORIENTAÇÃO/OSSO & COMPRIMENTO (mm) \\
\hline \multirow[t]{4}{*}{ A1 } & Tib90 & 14,90 \\
\hline & Tib180 & 13,45 \\
\hline & Calo90 & 24,45 \\
\hline & Calo180 & 22,25 \\
\hline \multirow[t]{4}{*}{ A2 } & Tib90 & 14,25 \\
\hline & Tib180 & 12,60 \\
\hline & Calo90 & 24,60 \\
\hline & Calo180 & 23,10 \\
\hline \multirow[t]{4}{*}{ A3 } & Tib90 & 15,45 \\
\hline & Tib180 & 13,70 \\
\hline & Calo90 & 21,35 \\
\hline & Calo180 & 20,25 \\
\hline \multirow[t]{4}{*}{ A4 } & Tib90 & 14,80 \\
\hline & Tib180 & 12,10 \\
\hline & Calo90 & 20,75 \\
\hline & Calo180 & 17,70 \\
\hline
\end{tabular}




\begin{tabular}{|c|c|c|}
\hline ANIMAL & ORIENTAÇÃO/OSSO & COMPRIMENTO (mm) \\
\hline \multirow[t]{4}{*}{ A5 } & Tib90 & 15,90 \\
\hline & Tib180 & 13,35 \\
\hline & Calo90 & 23,60 \\
\hline & Calo180 & 21,20 \\
\hline \multirow[t]{4}{*}{ A6 } & Tib90 & 15,25 \\
\hline & Tib180 & 13,00 \\
\hline & Calo90 & 22,60 \\
\hline & Calo180 & 20,10 \\
\hline \multirow[t]{4}{*}{ A7 } & Tib90 & 16,25 \\
\hline & Tib180 & 13,80 \\
\hline & Calo90 & 25,25 \\
\hline & Calo180 & 24,00 \\
\hline \multirow[t]{4}{*}{ A8 } & $\begin{array}{l}\text { Tib90 } \\
\end{array}$ & 14,70 \\
\hline & Tib180 & 12,60 \\
\hline & Calo90 & 22,10 \\
\hline & Calo180 & 18,50 \\
\hline \multirow[t]{4}{*}{ A9 } & Tib90 & 15,45 \\
\hline & Tib180 & 13,8 \\
\hline & Calo90 & 23,85 \\
\hline & Calo180 & 23,90 \\
\hline \multirow[t]{4}{*}{ A11 } & Tib90 & 15,15 \\
\hline & Tib180 & 13,35 \\
\hline & Calo90 & 27,15 \\
\hline & Calo180 & 24,75 \\
\hline \multirow[t]{4}{*}{ A12 } & Tib90 & 16,50 \\
\hline & Tib180 & 13,80 \\
\hline & Calo90 & 25,60 \\
\hline & Calo180 & 23,80 \\
\hline
\end{tabular}




\begin{tabular}{|c|c|c|}
\hline ANIMAL & ORIENTAÇÃO/OSSO & COMPRIMENTO (mm) \\
\hline \multirow[t]{4}{*}{ A13 } & Tib90 & 14,45 \\
\hline & Tib180 & 12,30 \\
\hline & Calo90 & 25,20 \\
\hline & Calo180 & 21,80 \\
\hline \multirow[t]{4}{*}{ A14 } & Tib90 & 16,00 \\
\hline & Tib180 & 14,35 \\
\hline & Calo90 & 32,65 \\
\hline & Calo180 & 33,50 \\
\hline \multirow[t]{4}{*}{ A15 } & Tib90 & 17,00 \\
\hline & Tib180 & 13,50 \\
\hline & Calo90 & 30,85 \\
\hline & Calo180 & 26,05 \\
\hline \multirow[t]{4}{*}{ A16 } & Tib90 & 16,80 \\
\hline & Tib180 & 14,00 \\
\hline & Calo90 & 30,55 \\
\hline & Calo180 & 28,55 \\
\hline
\end{tabular}

\subsection{Comparação entre a espessura da tíbia e dias pós fratura.}

Na figura 4.3.9a, é apresentado o gráfico da média das espessuras de cada grupo em função dos dias pós fratura, em (b) está demonstrada a variação exponencial da espessura em função dos dias pós fratura para as tíbias tratadas (calo).

É observado que, para as tíbias, a espessura permanece praticamente constante nas duas orientações. Enquanto, na tíbia fraturada (calo) existe um decaimento na forma exponencial da espessura em função do tempo, onde existe a tendência da espessura do calo em se aproximar da espessura da tíbia saudável (figura 4.3.9b). 
a)
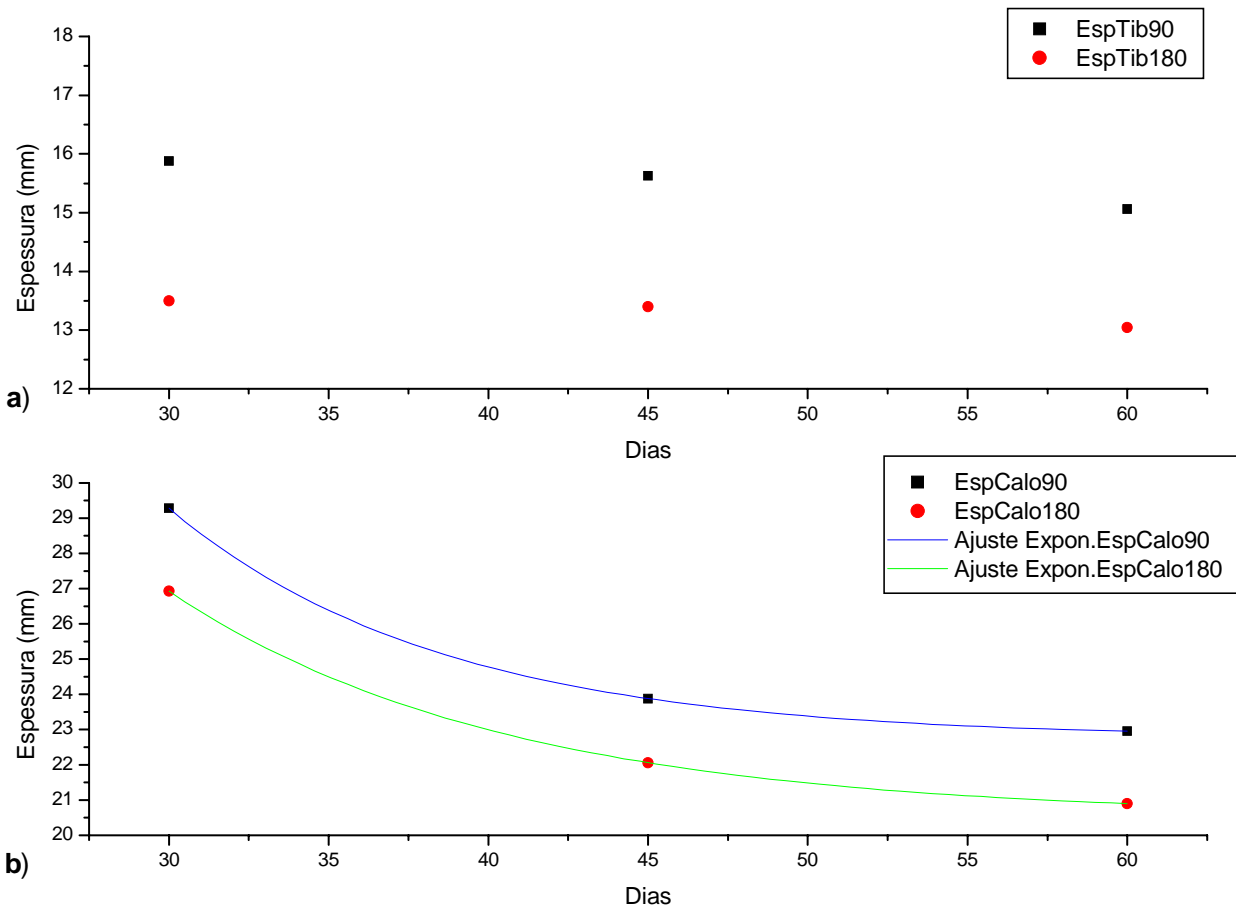

Figura 4.3.9. a) Gráfico da média das espessuras da tíbia por onde viaja o sinal ultra-sônico em função dos dias pós fratura. b) Gráfico das espessuras das tíbias tratadas com seus respectivos ajustes exponenciais.

\subsubsection{Técnicas utilizadas}

\subsection{BUAtot e velocidade do som (Técnicas de Inserção e de Contato)}

Para as técnicas de inserção convencional (acoplamento com água) e de contato (acoplamento com gel) que chamaremos de "contato transversal”, são usadas as mesmas técnicas explicadas no capítulo 2 (seções 2.1 e 2.2). Contudo, o sistema ultra-sônico utilizado nas análises pela técnica de inserção é o mesmo que foi apresentado no capítulo de materiais e métodos. Entretanto, para a técnica de contato transversal foi utilizado um suporte específico, como apresentado na figura 4.3.10. 


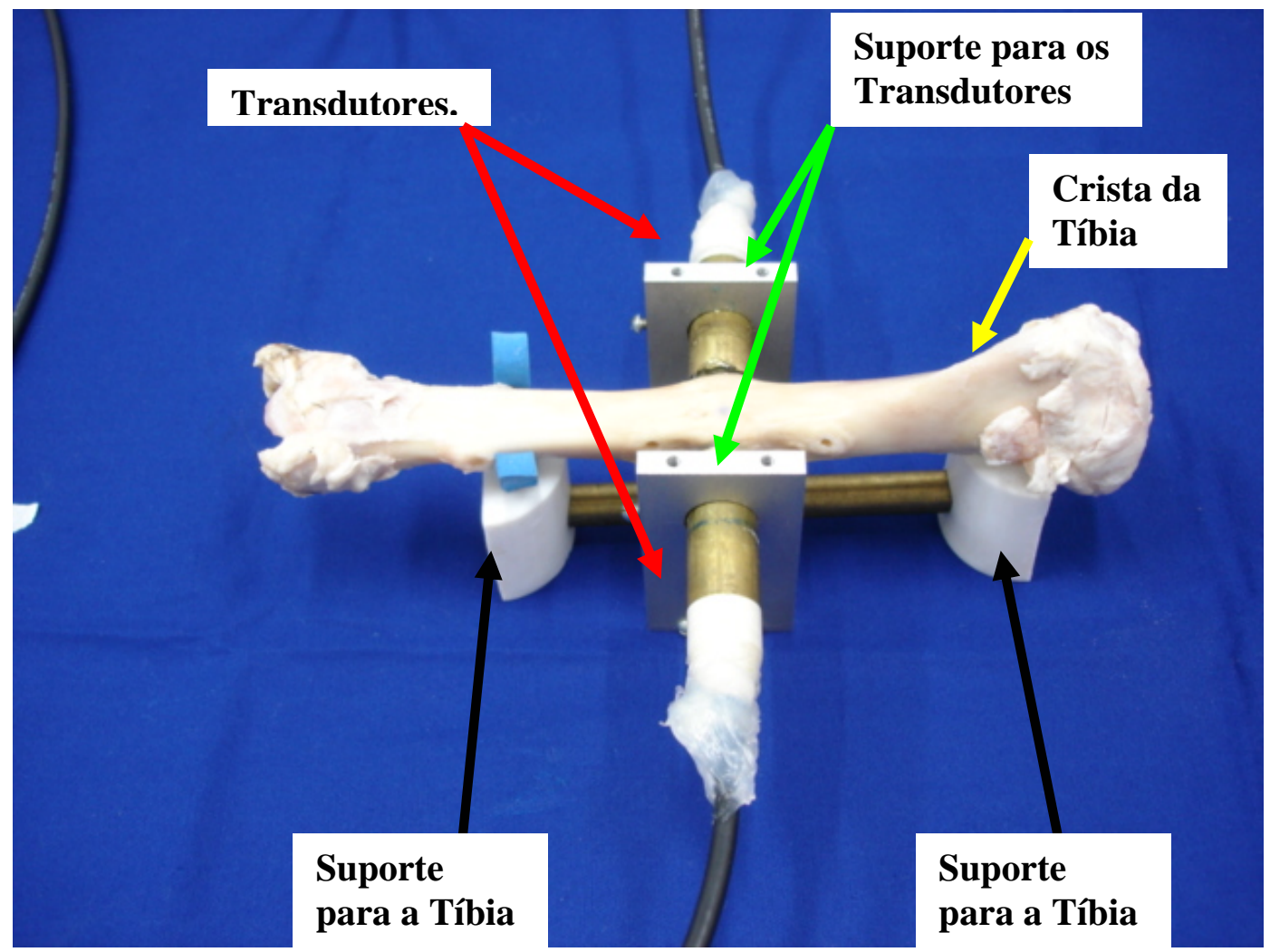

Figura 4.3.10. Suporte específico para fixação da tíbia e calo ósseo da tíbia de carneiro. Para a técnica de contato transversal.

O suporte, figura 4.3.10, utilizado na técnica de contato transversal é composto por um suporte para a tíbia (ou calo) e por fixadores de alumínio onde são afixados os transdutores e estes são presos por parafusos, para que não ocorra a movimentação da amostra.

Nas figuras 4.3.11 e 4.3.12, são apresentados a tíbia e o calo ósseo no suporte utilizado na técnica de contato transversal. 


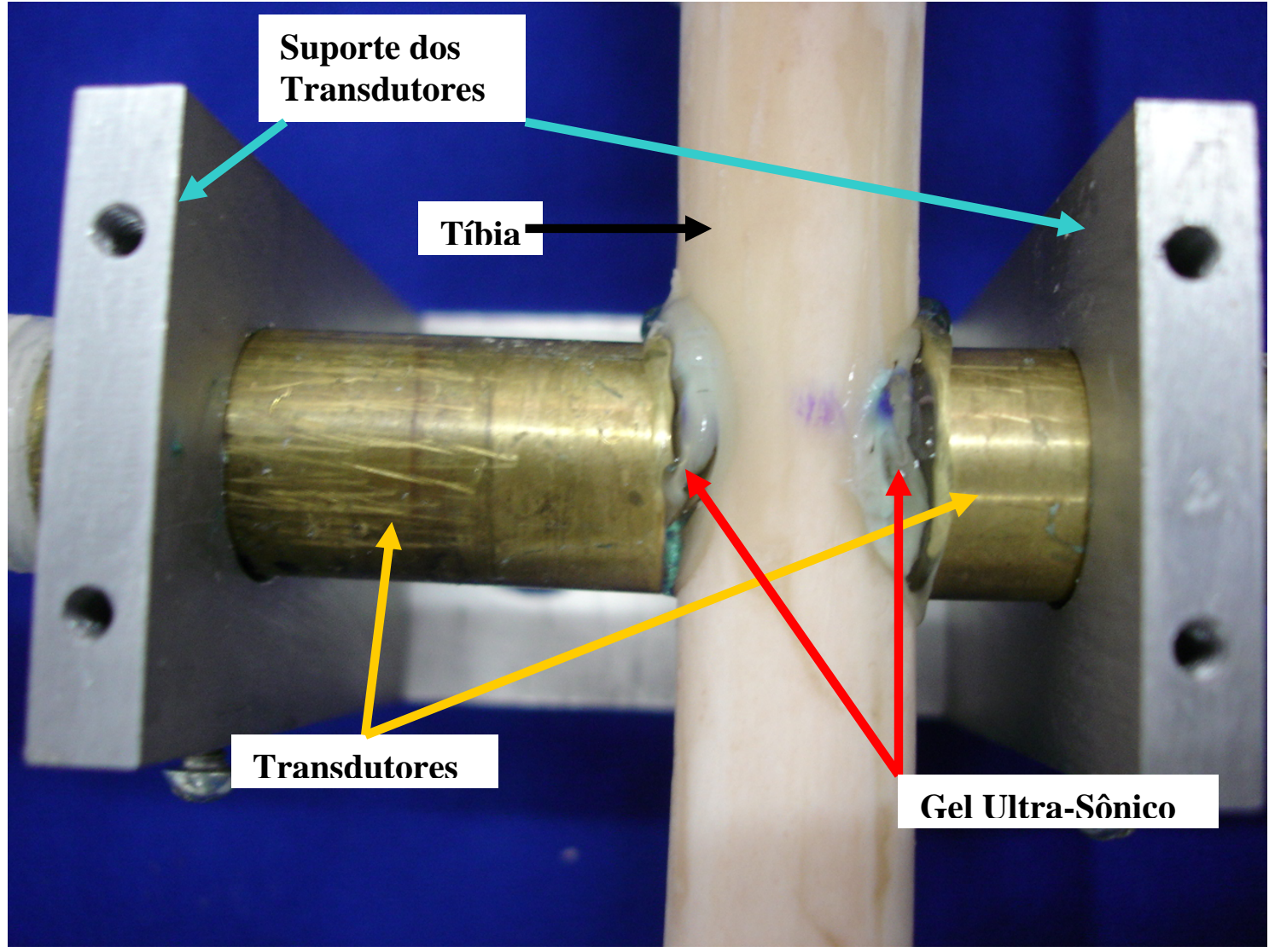

Figura 4.3.11. Tíbia de carneiro presa no suporte utilizado na técnica de contato transversal.

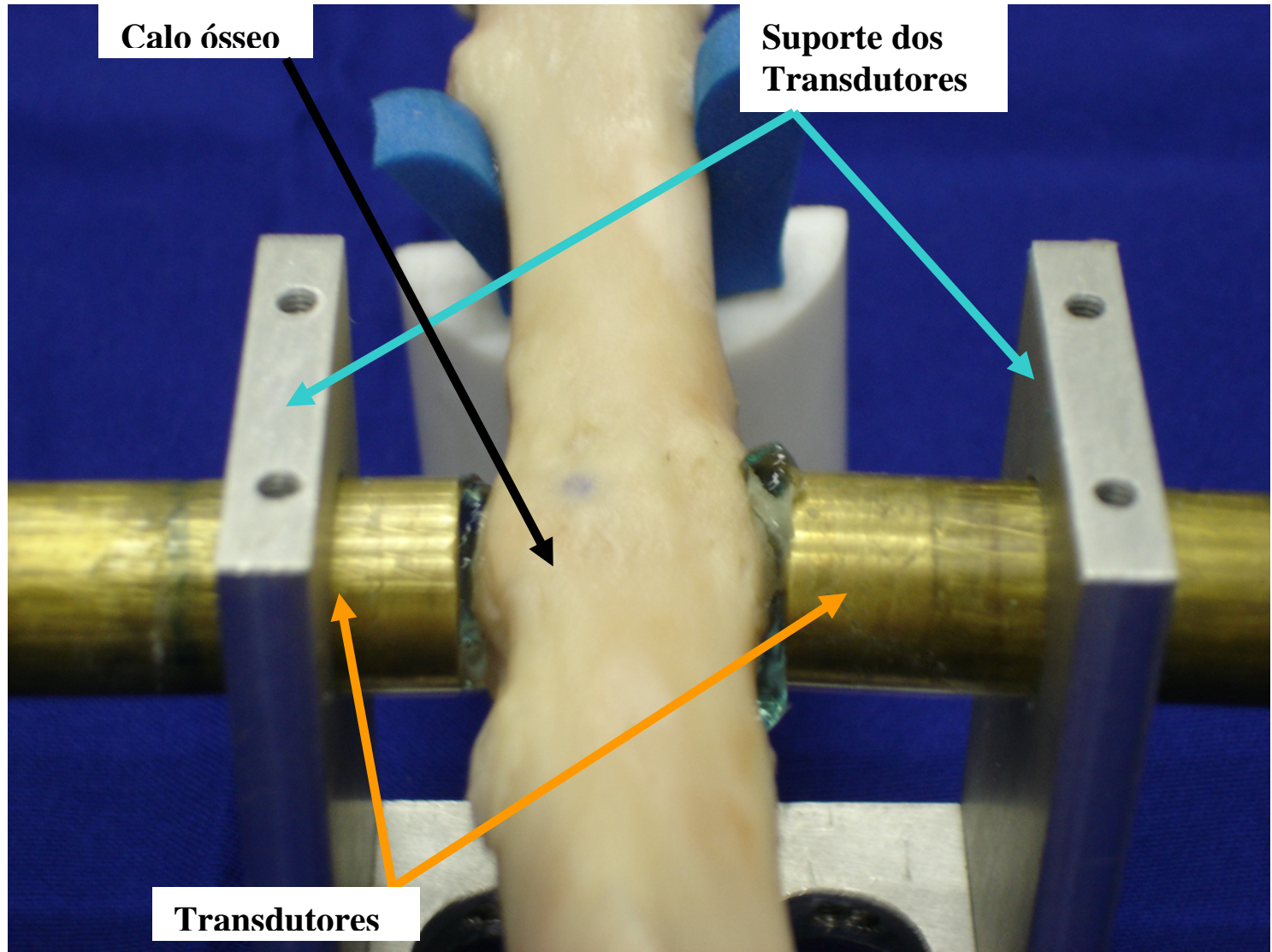

Figura 4.3.12. Calo ósseo da tíbia de carneiro presa no suporte utilizado na técnica de contato transversal. 


\subsection{Velocidade do som (Técnica de Contato Longitudinal).}

Na técnica de contato, com acoplamento com gel, na direção longitudinal, será realizada apenas a análise de velocidade do som através da superfície da tíbia e do calo. Nas figuras 4.3.14 e 4.3.15, são apresentadas, a vista frontal e superficial, respectivamente, do sistema ultra-sônico com a tíbia posicionada sobre os transdutores para análise longitudinal. Os transdutores formam com a tíbia um ângulo de 90 graus, ficando paralelos entre si e a distância de separação entre eles é fixa. Portanto, não foi feita nenhuma correção, na inclinação dos transdutores, com relação ao ângulo crítico de incidência sobre a tíbia. Na análise longitudinal foi escolhida a melhor posição da peça (tíbia e calo) com relação ao transdutor (melhor superfície, a mais plana possível), por isso não será referido para esta análise as posições 90 e 180 graus na rotação com relação à crista da tíbia, o único cuidado tomado foi o de a crista da tíbia estar posicionada do lado do transdutor emissor.

Nas figuras 4.3.16 e 4.3.17, são apresentados a tíbia e o calo ósseo da tíbia de carneiro, respectivamente. Na figura 4.3.16, tem-se em destaque o posicionamento da tíbia e o gel ultra-sônico. Na figura 4.3.17, tem-se em destaque a posição do calo ósseo entre os transdutores.

A figura 4.3.13 apresenta um desenho esquemático da distância entre os transdutores, sendo que, esta distância é fixa e o seu valor de 26,77mm será utilizado para o cálculo da velocidade sobre a tíbia e o calo. Essa distância é considerada entre os centros de cada transdutor, como apresentado na figura 4.3.13.

Não será feita uma varredura sobre a tíbia e calo, pois devido aos pinos dos fixadores externos, nas amostras, existem buracos, sendo (a distância) de 26,77mm a maior distância possível sem que os transdutores ficassem sobre algum desses buracos (figura 4.3.17).

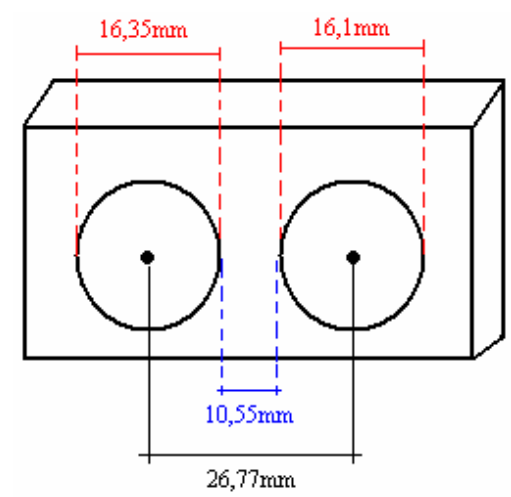

Figura 4.3.13: Distância entre os transdutores para o cálculo da velocidade do som na técnica de contato longitudinal. 


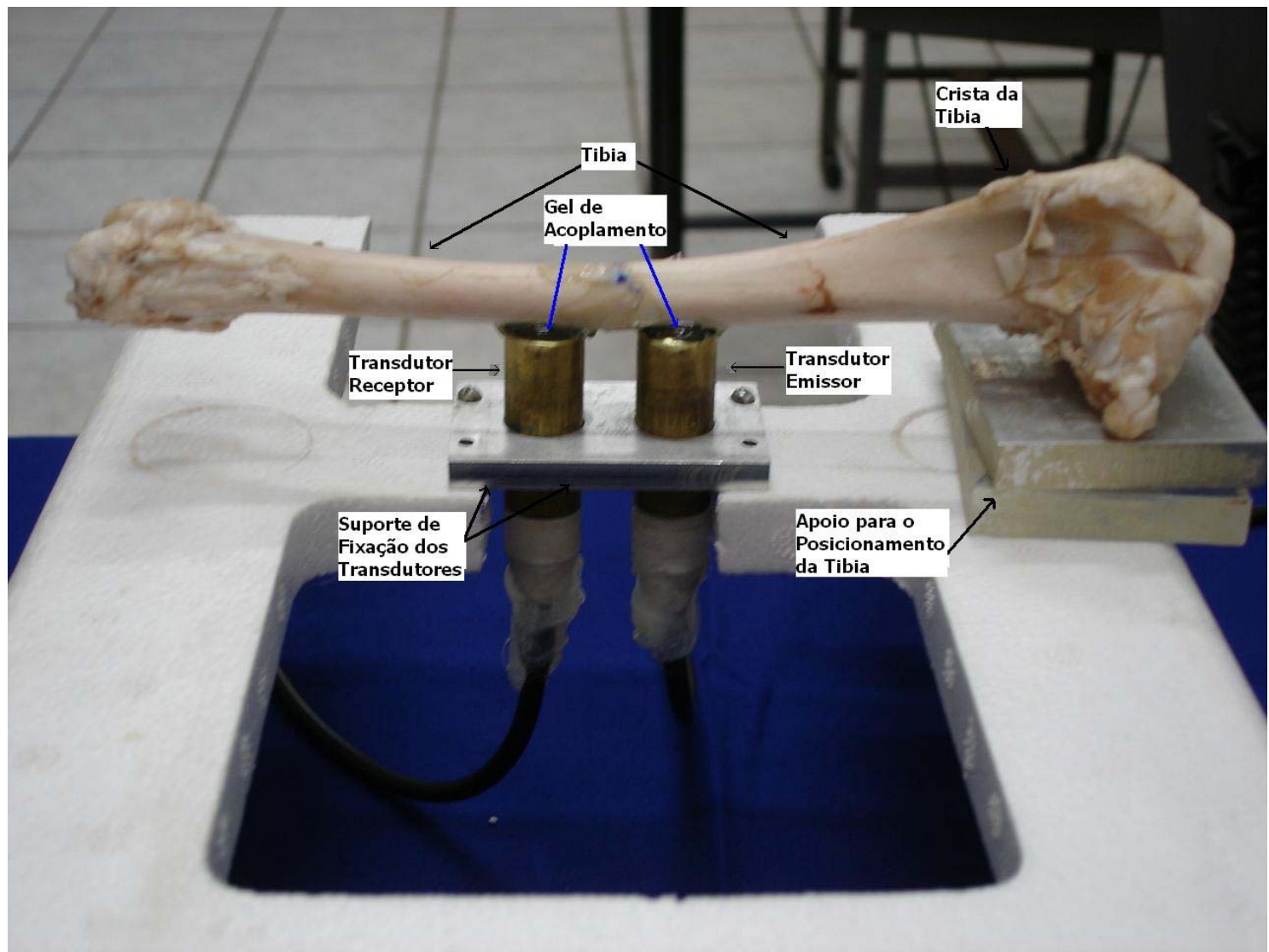

Figura 4.3.14: Vista Frontal. Tíbia posicionada sobre os transdutores para as análises da técnica de contato longitudinal (através da superfície cortical da tíbia e do calo).

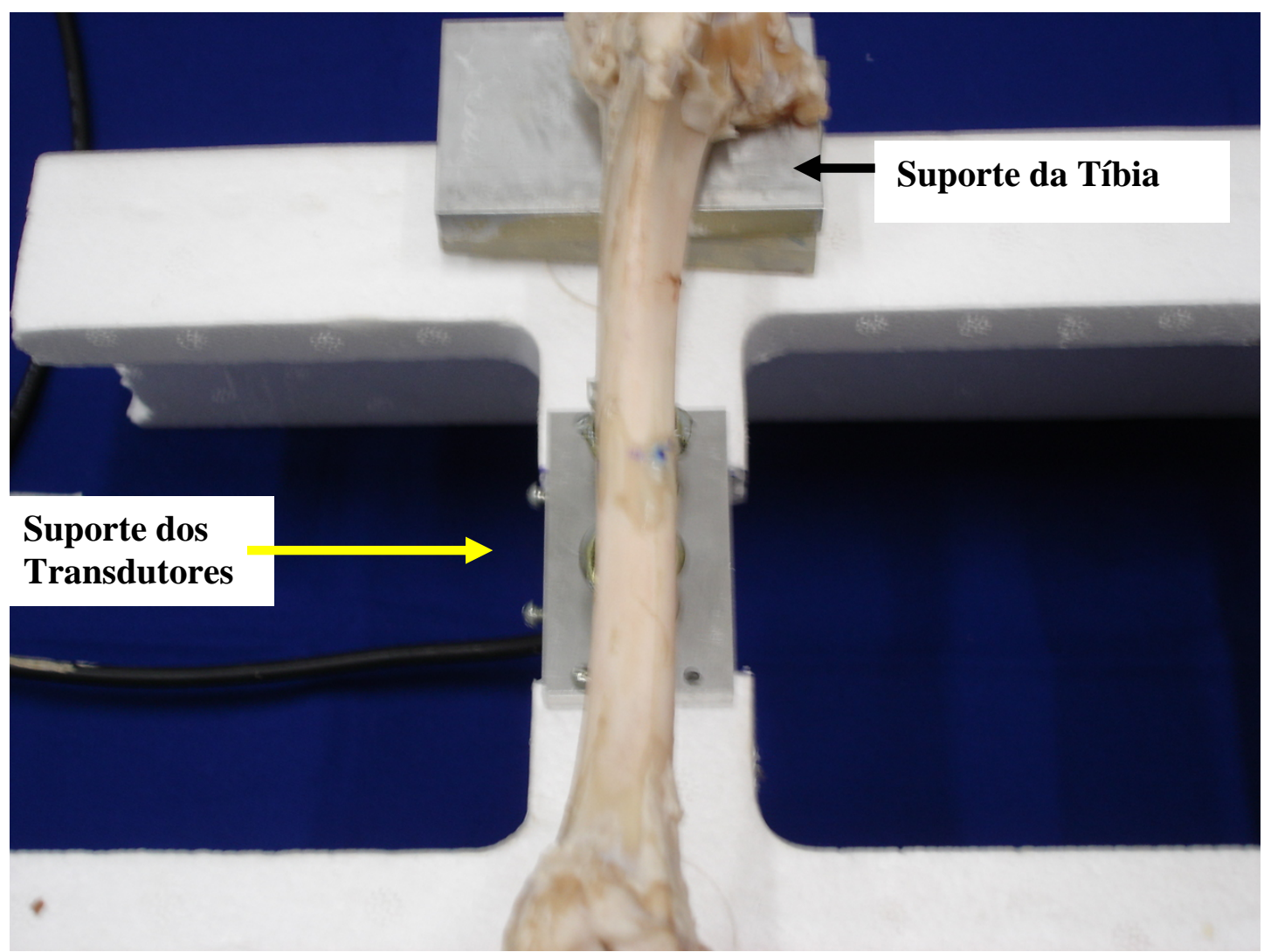

Figura 4.3.15: Vista Superficial. Tíbia posicionada sobre os transdutores para as análises da técnica de contato longitudinal (através da superfície cortical da tíbia e do calo). 


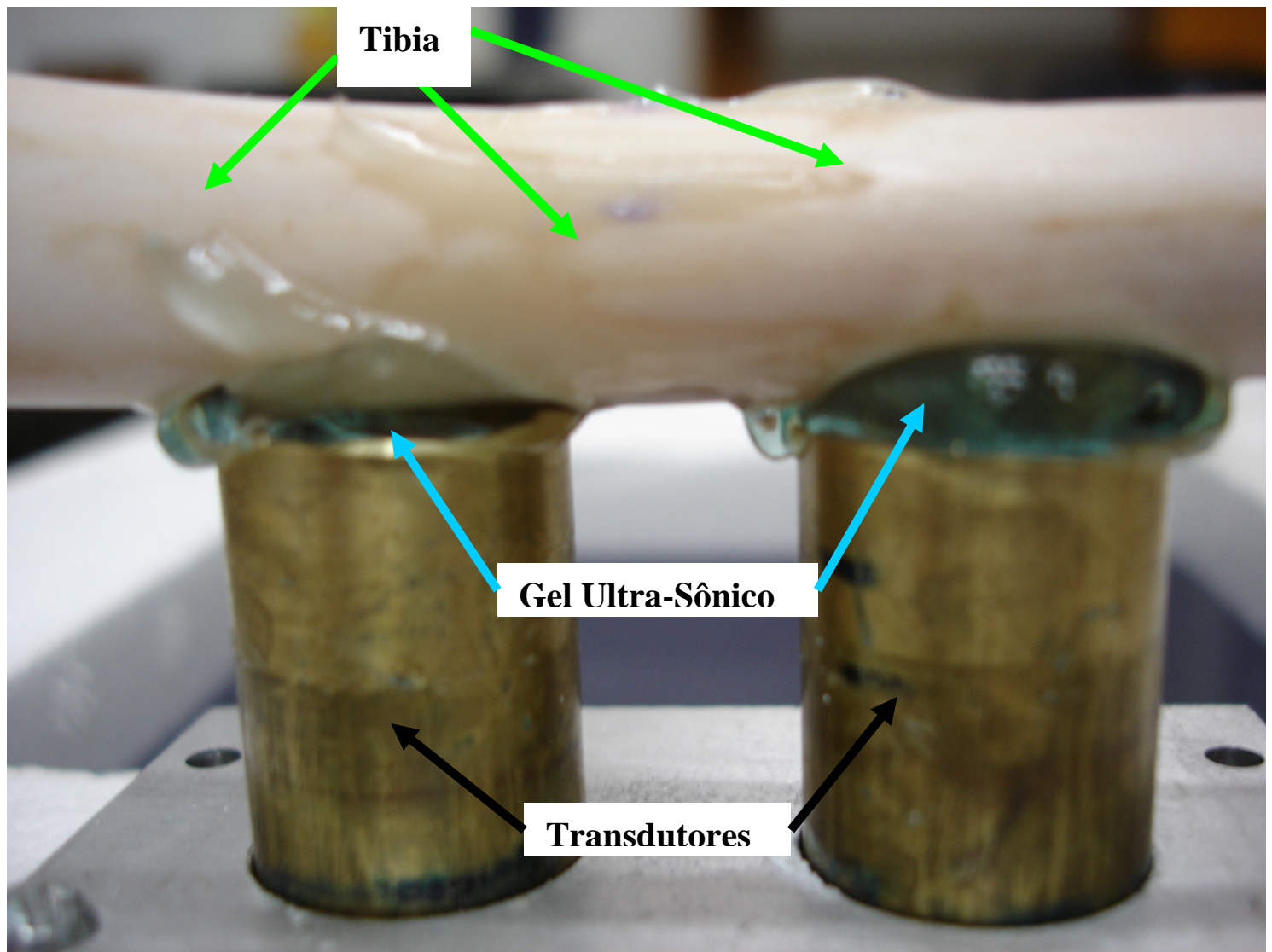

Figura 4.3.16. Técnica de contato longitudinal para análise da tíbia de carneiro.

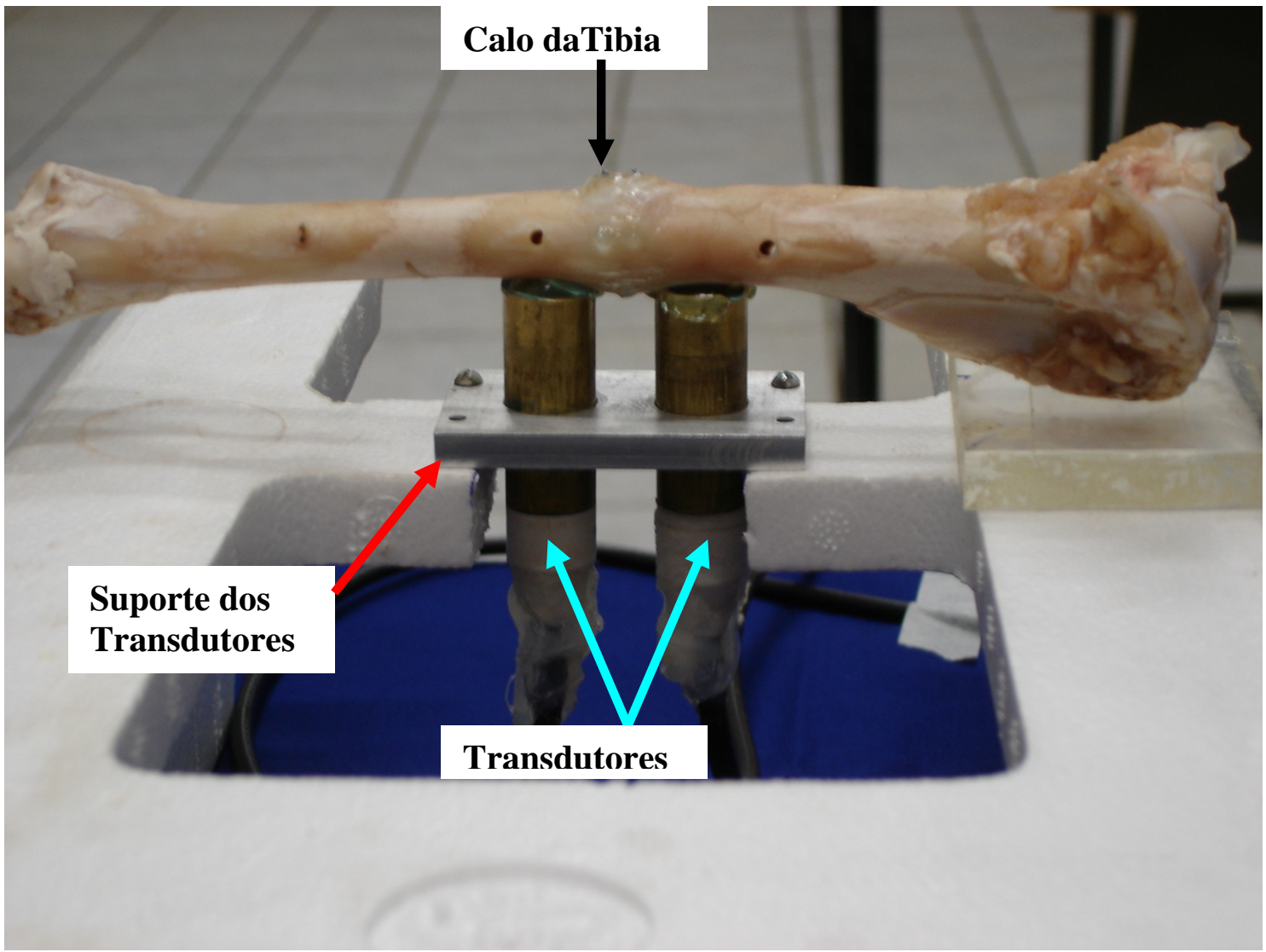

Figura 4.3.17. Técnica de contato longitudinal para análise do calo ósseo na tíbia de carneiro. 


\subsection{Modelo experimental de cálculo da BUA.}

Será inserido um modelo para análise da BUA e será chamada de BUAnews. No capítulo teórico sobre atenuação do ultra-som (capítulo 2, seção 2.2) foi apresentada a forma de como se obtém o valor da BUA.

O valor BUAnews é obtido da seguinte forma: é encontrada a função de transferência do calo e da tíbia dos mesmos animais como mostrado até a equação 13 do capítulo 2 (seção 2.2). Então, de acordo com a equação 14 teríamos duas equações da seguinte forma:

$$
\begin{aligned}
& \left|H(f)_{c}\right|=e^{-\alpha_{c}(f)} \\
& \left|H(f)_{t}\right|=e^{-\alpha_{t}(f)}
\end{aligned}
$$

sendo que, os sub-índices $c$ corresponde ao calo como um todo (material do calo mais a cortical) e $t$ corresponde a tíbia (não tratada) e $\alpha$ são os seus respectivos coeficientes de atenuação.

Fazendo a razão entre a equação 14a pela equação 14b, obtemos:

$$
\frac{H_{c}(f)}{H_{t}(f)}=\frac{e^{-\alpha_{c}}}{e^{-\alpha_{t}}}
$$

reescrevendo a equação 14c da seguinte forma:

$$
\frac{H_{c}(f)}{H_{t}(f)}=e^{-\left(\alpha_{c}-\alpha_{t}\right)}
$$

podemos fazer a seguinte substituição:

$$
\frac{H_{c}(f)}{H_{t}(f)}=e^{-\alpha_{x}}
$$

onde $\alpha_{x}$, será considerado um coeficiente de atenuação relativo sendo igual a: 


$$
\alpha_{\mathrm{x}}=\alpha_{\mathrm{c}}-\alpha_{\mathrm{t}}
$$

O coeficiente de atenuação relativo $\alpha_{x}$ é dado pela subtração do coeficiente de atenuação do calo total $\left(\alpha_{c}\right)$ pelo coeficiente de atenuação da tíbia $\left(\alpha_{t}\right)$, este coeficiente relativo estará expressando o conteúdo do material que se forma ao redor da tíbia fraturada (a fibrocartilagem).

A partir da equação 14e é feita a finalização do processo de obtenção da BUA como explicado no capítulo teórico (equações 15 e 16). Então, obtém-se o valor da BUAnews, que é uma atenuação relativa entre a atenuação do calo pela atenuação da tíbia saudável.

\subsubsection{Procedimento para as análises ultra-sônicas}

Para a técnica de inserção convencional com acoplamento com água, inicialmente mantém-se o teflon em um banho térmico (30min.) com água a $24^{0} \mathrm{C}$.

A água dentro da cuba de acrílico é mantida a temperatura aproximada de $24^{\circ} \mathrm{C}$.

Primeiro faz-se a medida do tempo de percurso do US na água a $24^{\circ} \mathrm{C}$, depois é colocado o teflon dentro da cuba e mede-se também o seu tempo de percurso. Depois de feita esta medida, retorna-se o teflon para dentro do seu banho térmico, garantindo que a temperatura do teflon permaneça constante. A medida do teflon serve apenas para o controle do equipamento para garantir a reprodutibilidade das medidas e também observar qualquer variação que possa ocorrer.

Após as medidas de tempo da água e do teflon é colocada a amostra óssea dentro do tanque acústico, então, é feita a medida do tempo de percurso do sinal ao atravessar a amostra. As medidas das amostras ósseas foram repetidas seis vezes, mantendo a peça fixa.

As temperaturas dos banhos foram mantidas pela retirada e adição de água mais quente, esperando-se um tempo para o equilíbrio próximo da temperatura desejada, quando eram realizadas as análises. Embora com manutenção grosseira a temperatura da água variava em torno de $1,5^{0} \mathrm{C}$.

$\mathrm{Na}$ técnica de contato com acoplamento com gel, as medidas eram feitas em temperatura ambiente controlada, em torno dos $24^{0} \mathrm{C}$. Utilizou-se este valor de temperatura 
para uma melhor comparação com a técnica de inserção convencional. Foi realizada uma aquisição de seis sinais temporais sem fazer o re-posicionamento da peça.

\subsubsection{RESULTADOS E DISCUSSÕES}

\subsubsection{Resultados para a Técnica de Inserção}

\subsection{Velocidade do som como função da espessura}

Na figura 4.3.18, são apresentados os resultados para a velocidade do som como função da espessura para a tíbia e para o calo, nas duas orientações.

O coeficiente de correlação para o calo90 e calo180 foi de $-0,85$ e $-0,83$ ( $p<0,0001$ e $\mathrm{p}=0,0004)$, respectivamente. Na tib90 e tib180 foi de $-0,03$ e $-0,20$ ( $p=0,90$ e $p=0,47$, respectivamente, sendo que estes últimos não apresentaram nenhuma correlação estatística relevante e isso se deve ao fato de que a tíbia normal estaria se comportando como um material homogêneo, ou seja, independente da espessura a velocidade do som se mantém praticamente constante na tíbia saudável. 


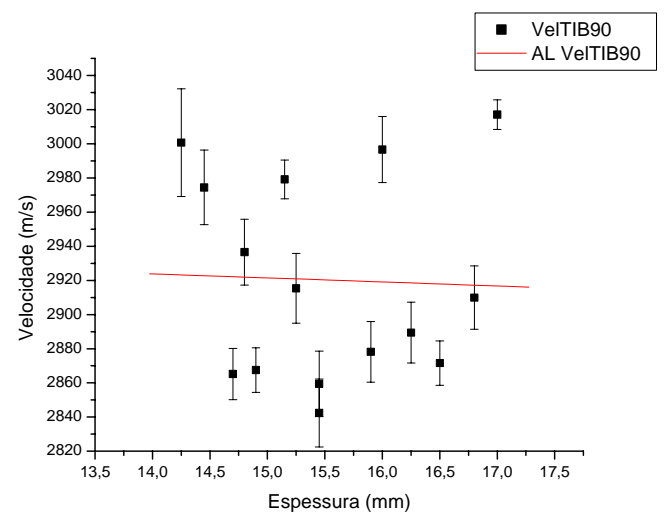

a)

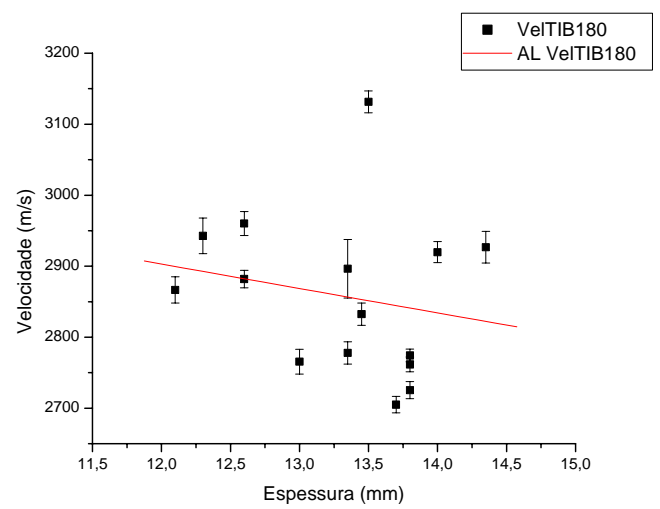

c)

Figura 4.3.18. Gráficos da velocidade do som em função da espessura (e seus respectivos ajustes lineares) para a tib90, calo90, tib180 e calo180, em a, b, c e d, respectivamente.

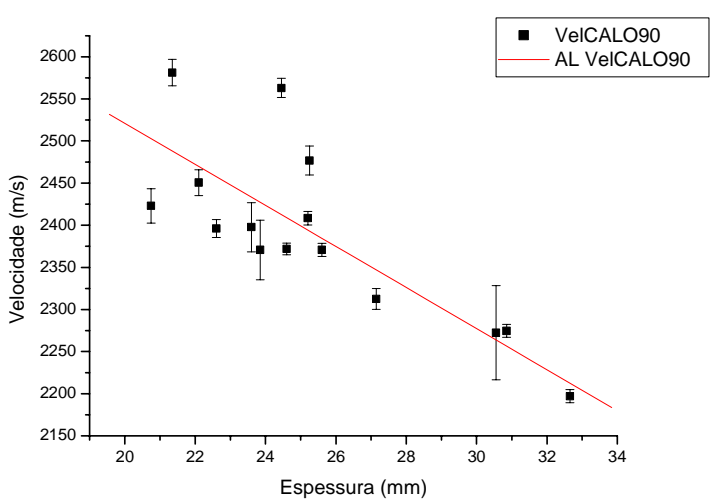

b)

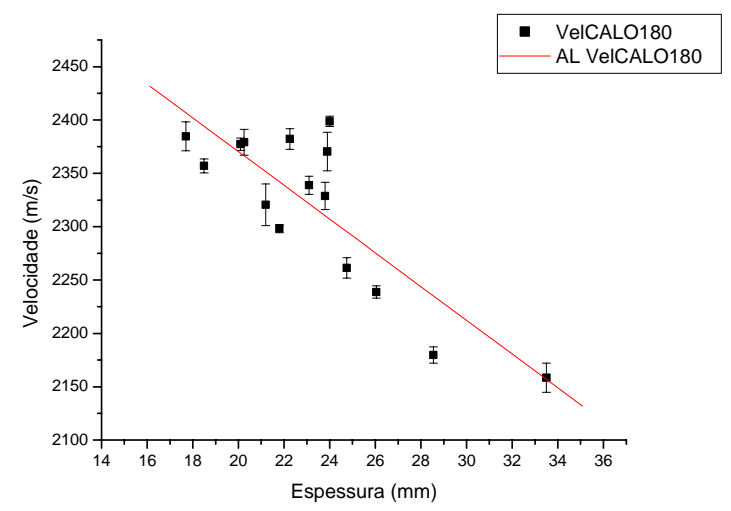

d)

\subsection{Velocidade do som no calo em função da velocidade na tíbia do mesmo animal}

Na figura 4.3.19, é apresentado o gráfico da velocidade no calo (Vcalo) relacionada com a velocidade da sua respectiva tíbia (Vtib) e seus ajustes lineares.

É observada na figura 4.3.19, a existência da correlação entre a velocidade do calo e a velocidade na tíbia correspondente, apresentando coeficientes de correlação de $-0,73$ e $-0,69$ $(\mathrm{p}<0,005)$ para o calo 180 e 90, respectivamente. É possível observar a existência da correlação entre ossos do mesmo animal. Estes carregam informações estruturais semelhantes como os apontados em trabalhos com ossos onde não existe diferença entre as velocidades 
para mesmos sítios anatômicos, por exemplo, comparando a velocidade na mão dominante e não dominante como foi feito por Baroncelli et al. (2001).

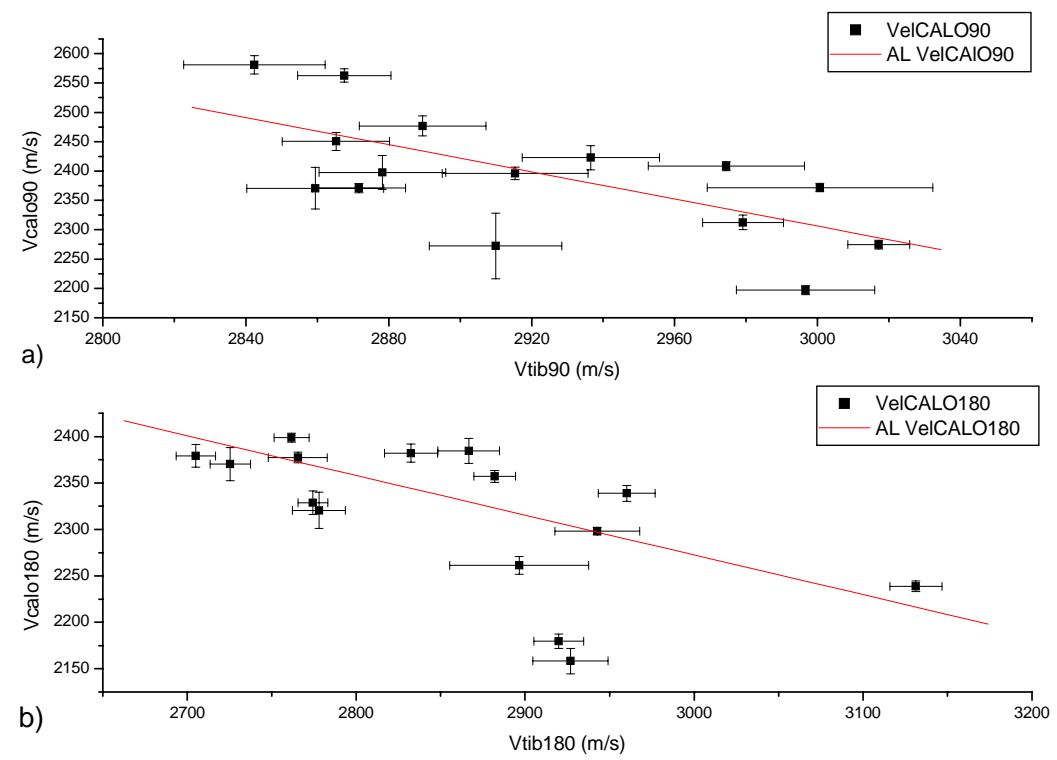

Figura 4.3.19. Gráficos da velocidade do som no calo (nas duas orientações: $90^{\circ} \mathrm{em} \mathrm{a}, 180^{\circ} \mathrm{em}$ b) como função da velocidade na sua respectiva tíbia e com seus ajustes lineares.

Na figura 4.3.20, em b, é apresentado o gráfico da velocidade do calo180 em função do calo90 e, em a, o gráfico da velocidade da tib180 em função da tib90, ambos com seus respectivos ajustes lineares. Os gráficos apresentam um bom coeficiente de correlação de 0,85 e 0,84 $(\mathrm{p}<0,0001)$ para o calo e tíbia, respectivamente. Esses valores mostram a boa correlação entre as diferentes direções utilizadas. Observa-se que a tíbia e o calo apresentam praticamente o mesmo coeficiente de correlação. 


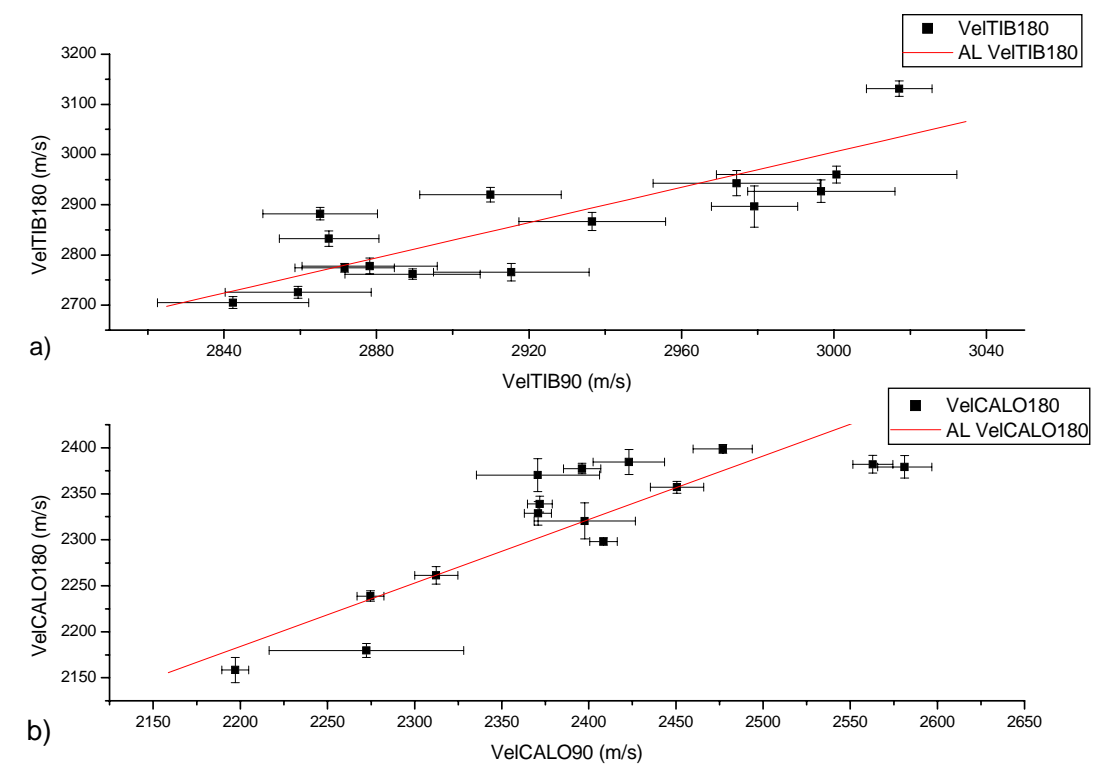

Figura 4.3.20. a) Gráfico da velocidade do som na tib180 em função da tib90, com seu respectivo ajuste linear. b) Gráfico da velocidade do som no calo180 em função do calo90, com seu respectivo ajuste linear.

\subsection{Comparação entre a velocidade do som na tíbia em função de dias pós fratura}

Na figura 4.3.21, é apresentado o gráfico da velocidade do calo em função dos dias pós fratura, cada ponto representa a média das velocidades entre os cinco animais de cada grupo. O ponto de 120 dias pós-fratura corresponderia ao valor da velocidade da tíbia saudável na determinada orientação, sendo as velocidades: Vcalo90 (120 dias) igual a $2975,44 \mathrm{~m} / \mathrm{s}$ e Vcalo180 (120 dias) igual a 2963,42 m/s.

Na figura 4.3.21, encontra-se a tendência nas duas orientações (calo90 e calo180) da velocidade do calo aumentar conforme passa o tempo pós-fratura, sendo que ambas apresentam um coeficiente angular positivo da velocidade em função do tempo.

O grupo de 45 dias apresenta uma velocidade aproximadamente igual à velocidade do grupo de 60 dias, as medidas foram refeitas como também, os cálculos, isso para eliminar qualquer possibilidade de algum erro no momento da aquisição do sinal temporal, mas os valores não mudaram. Então, acredita-se que este erro esteja associado com as propriedades intrínsecas de cada amostra. Como os grupos eram pequenos, cinco animais para cada grupo, 
não foi possível fazer uma melhor análise. Então, seria necessário fazer outros grupos para comparar com os resultados obtidos.

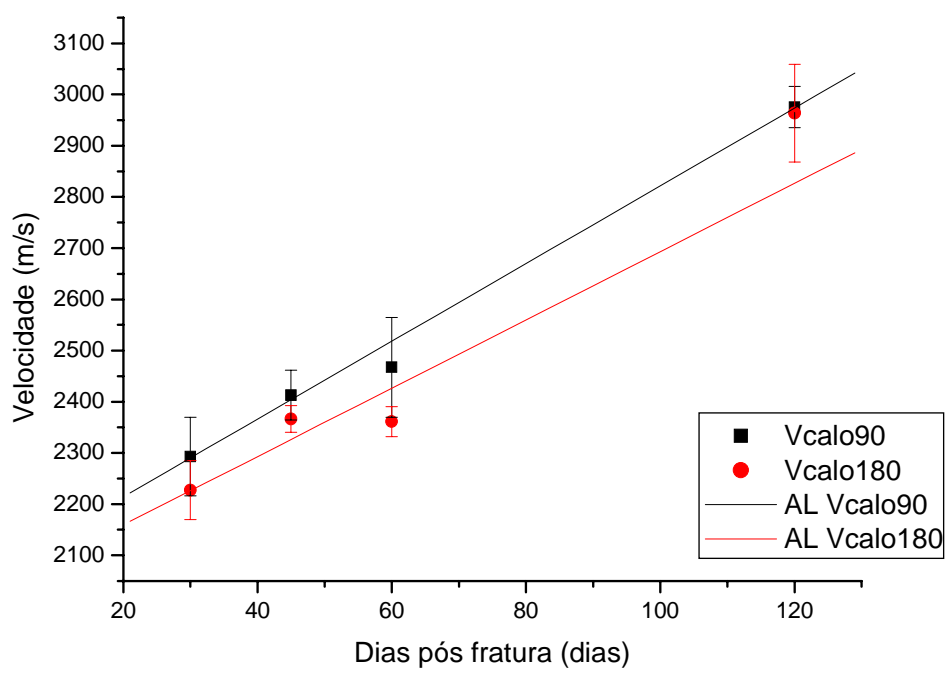

Figura 4.3.21. Variação da velocidade do som em cada grupo de animais em função de dias pós-fratura com os seus respectivos ajustes lineares.

O fato da velocidade, para os calos, possuir a tendência não exponencial como a espessura, mas sim linear, de se aproximar da velocidade da tíbia saudável, foi observado por Siegel, Anast e Fields (1958), onde concluíram que a velocidade no osso fraturado possui uma tendência de se aproximar da velocidade do osso saudável conforme a passagem do tempo pós-fratura.

\subsection{BUAtot como função da espessura}

Na figura 4.3.22, são apresentados os valores da BUAtot como uma função da espessura da amostra para a tíbia e o calo nas duas orientações. 


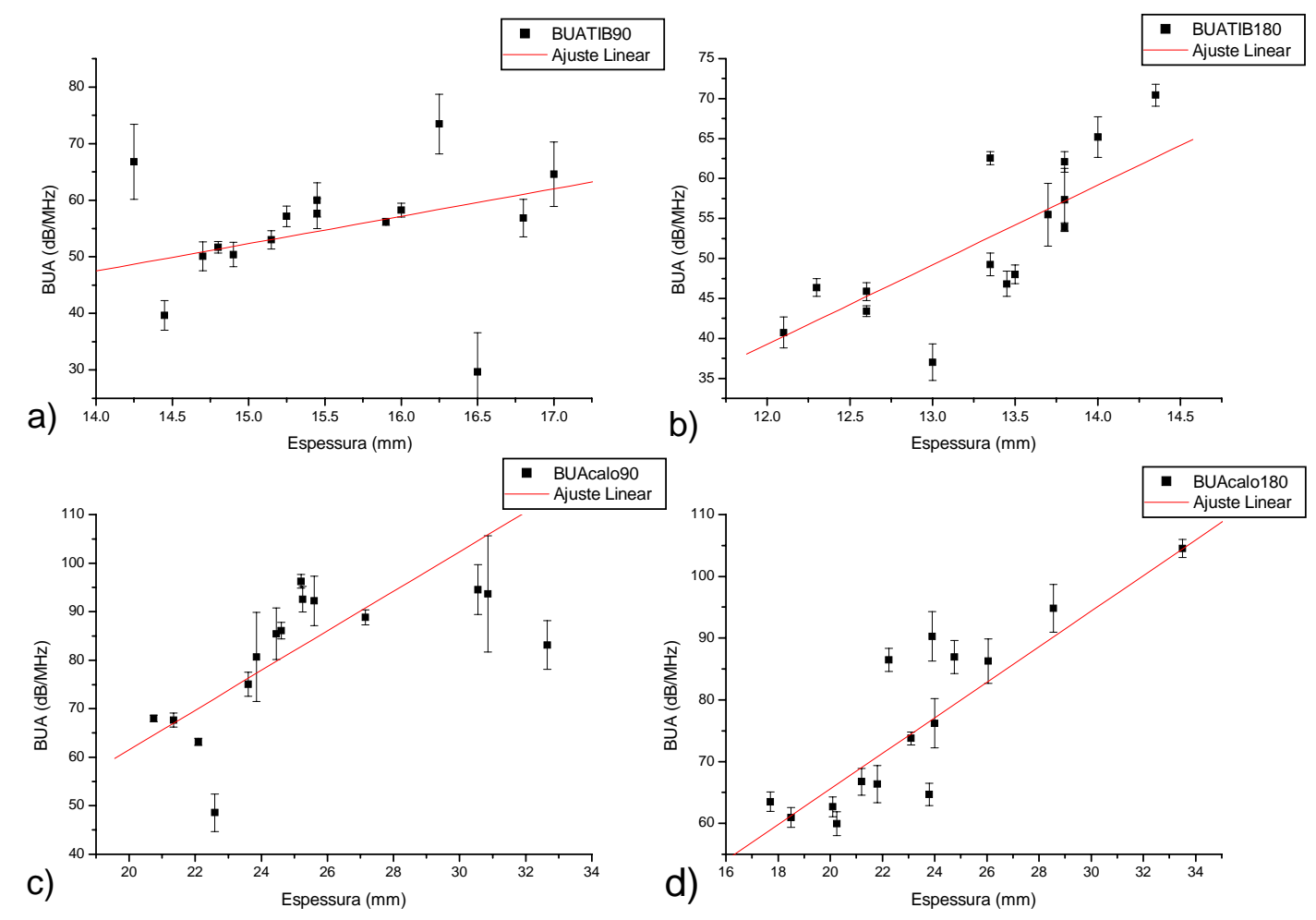

Figura 4.3.22. Valores médios da BUA (sem discriminação da tensão) como função da espessura da amostra óssea. Em a e b para as tíbias nas orientações 90 e 180 graus, respectivamente. Em c e d para os calos nas orientações 90 e 180 graus, respectivamente.

Para os gráficos da figura 4.3.22, tem-se o valor médio da BUAtot como função da espessura da amostra. Todos apresentaram uma correlação positiva entre as variáveis, sendo que, para a tib90, tib180, calo90 e calo180 o coeficiente de correlação foi de 0,63 (p=0,01), 0,75 ( $\mathrm{p}=0,001), 0,78(\mathrm{p}=0,0005)$ e 0,90 ( $\mathrm{p}<0,0001)$, respectivamente. A dependência com a espessura mostrou-se altamente significativa, principalmente para os calos 90 e 180, onde além da cortical existem material fibroso e cartilagem, que vão produzir uma atenuação diferente quando comparado só com a tíbia e produzir um espalhamento do sinal ultra-sônico. Na figura 4.3.22 a e b, a BUAtot das tíbias nas duas orientações cresceu conforme aumentou o valor do diâmetro da amostra, pois quanto maior o diâmetro maior a quantidade de osso cortical, assim maior será a atenuação da amostra. 


\subsection{BUAtot dos calos como função da BUAtot da respectiva tíbia}

Na figura abaixo, são apresentados os gráficos da BUAtot dos calos como função da BUAtot da sua respectiva tíbia e orientação.

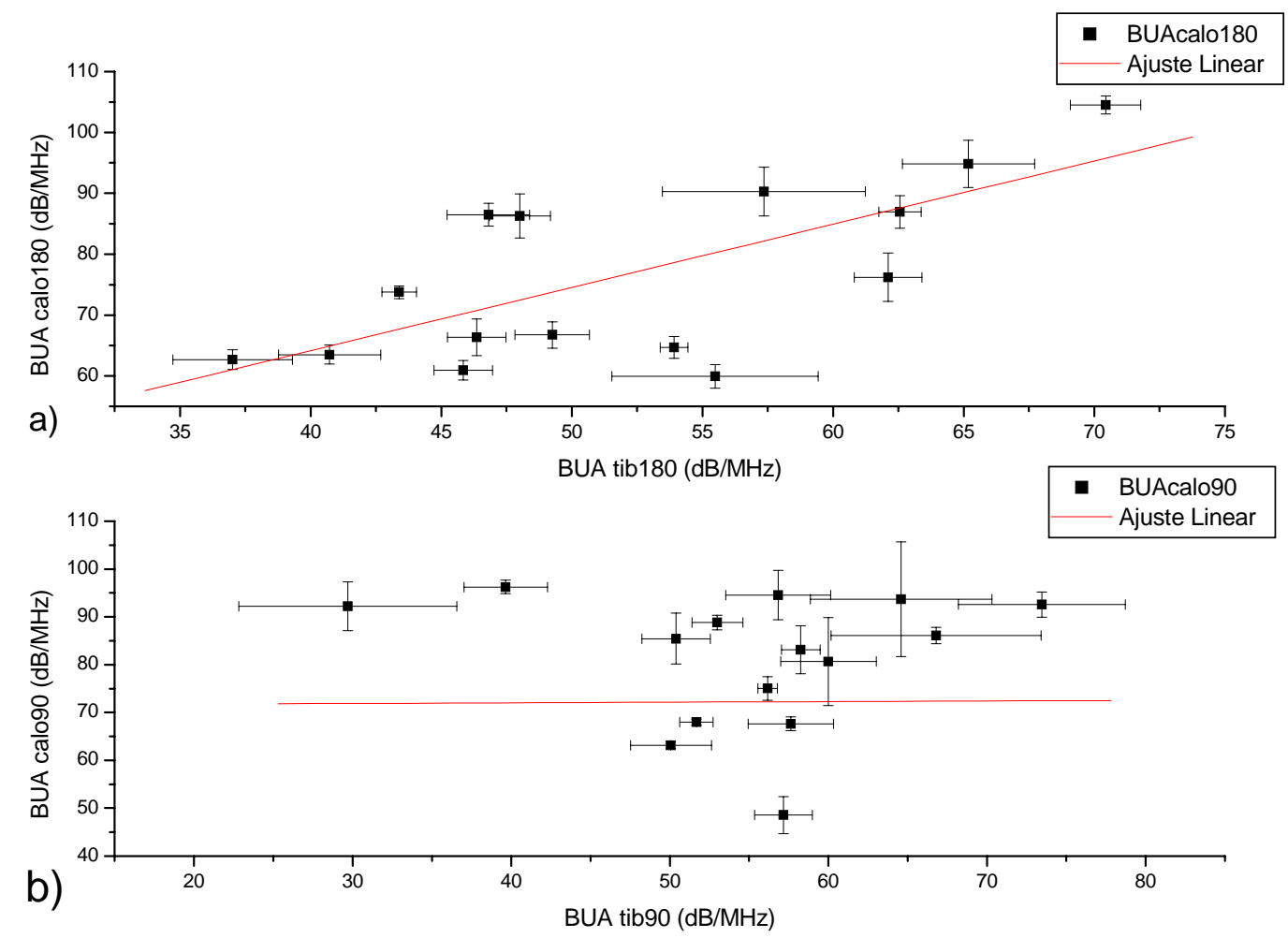

Figura 4.3.23. BUAtot do calo como função da BUAtot da tíbia do mesmo animal e na mesma orientação, em a e b para calo 180 e 90, respectivamente.

Para a orientação 90 graus a BUAtot do calo versus a BUAtot da tíbia (figura 4.3.23b) não apresentaram nenhuma correlação estatisticamente significante. Enquanto, para a orientação 180 graus (figura 4.3.23a) o coeficiente de correlação foi de 0,73 (p=0,002).

\subsection{BUAtot como função da respectiva velocidade do som}

Para a figura 4.3.24, foram feitos os gráficos da BUAtot como função da sua respectiva velocidade, para a tib90, tib180, calo90 e calo180 em a, b, c e d, respectivamente. 
Para as tíbias (figura 4.3.24 a e b) não existiu nenhuma correlação estatisticamente significante, apresentaram um $p$ igual a 0,77 e 0,32 para as tib90 e 180, respectivamente. Enquanto, para os calos 90 e 180 o coeficiente de correlação foi de $-0,47(p=0,05)$ e 0,81( $\mathrm{p}=0,0002)$, respectivamente (figura 4.3.24c e 24d).

Na figura 4.3.25, são apresentados os gráficos da BUAtot e da velocidade em função da espessura em a e b, respectivamente. Sendo que, não foi feita discriminação entre tíbia saudável e calo (tíbia tratada).

Para o gráfico da BUAtot em função da espessura (figura 4.3.25a) o coeficiente de correlação foi de 0,87 ( $\mathrm{p}<0,0001)$. É possível observar que os valores de BUAtot referentes as espessuras igual ou maiores que $20 \mathrm{~mm}$ são os valores dos calos avaliados, sendo possível observar que conforme aumentou a espessura houve um aumento no valor da BUAtot.

Na figura 4.3.25b, o coeficiente de correlação entre a velocidade e a espessura foi de 0,82 ( $\mathrm{p}<0,0001$ ). Neste gráfico, têm-se duas regiões distintas: uma com valores de velocidade acima de $2600 \mathrm{~m} / \mathrm{s}$ e outra abaixo. A região acima de $2600 \mathrm{~m} / \mathrm{s}$, são os valores obtidos para as tíbias saudáveis e na região abaixo são os valores obtidos para as tíbias tratadas (os calos), pois estes possuem maior espessura.
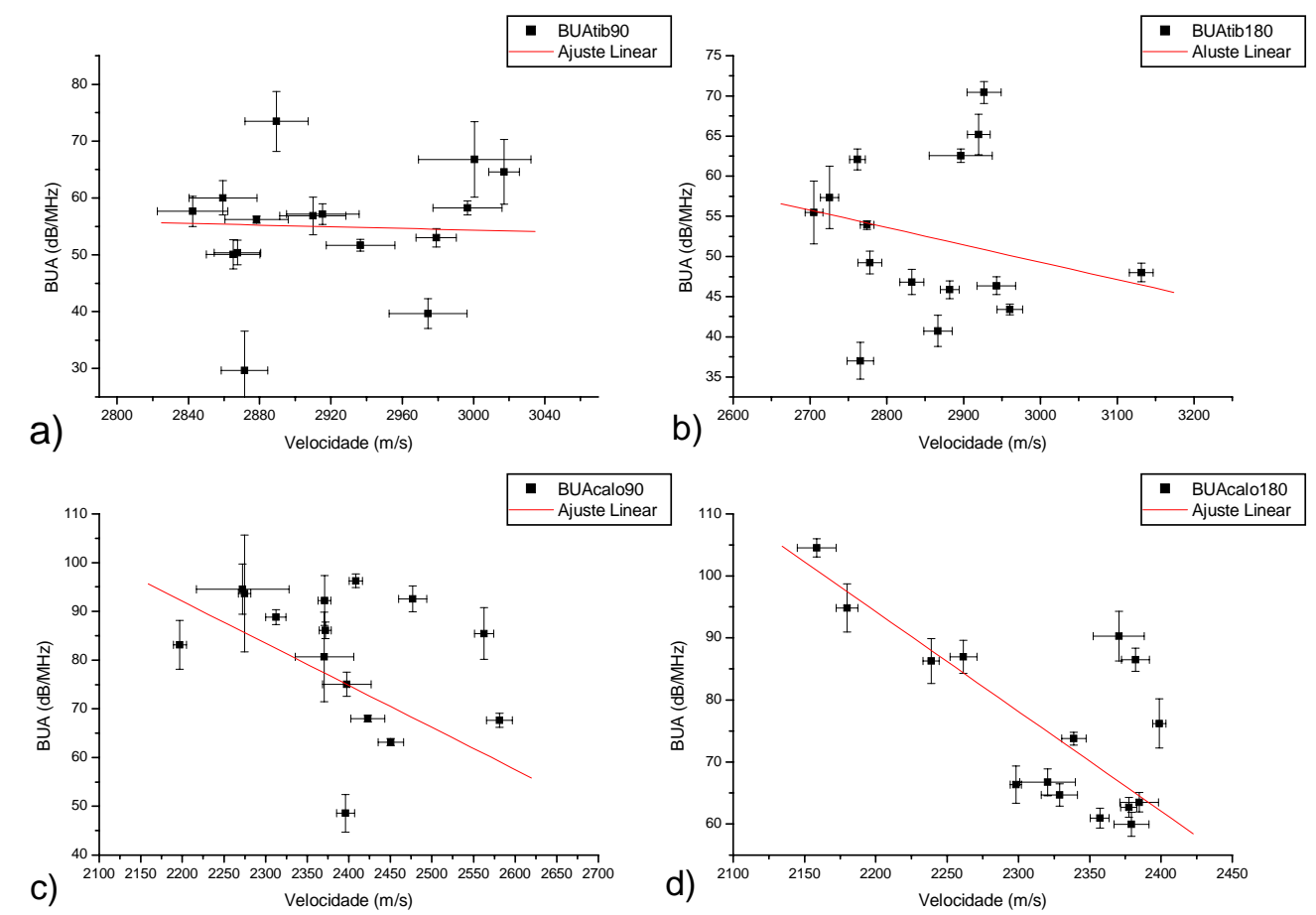

Figura 4.3.24. Valores da BUAtot como função da respectiva velocidade. Em: a e b para as tíbias na orientação 90 e 180 graus, respectivamente. Em: c e d para os calos na orientação 90 e 180 graus, respectivamente. Todos com seus ajustes lineares. 

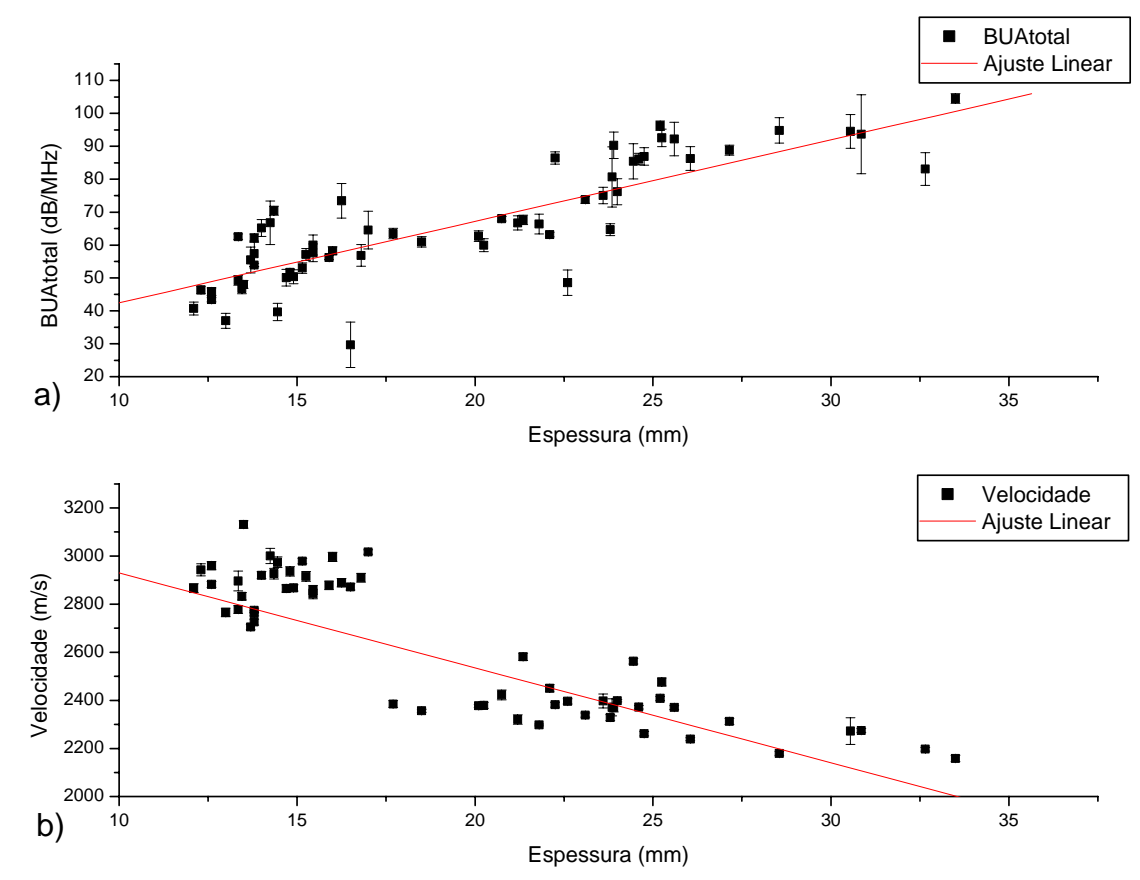

Figura 4.3.25. Gráficos da BUAtot e da velocidade como função da espessura das amostras em a e b, respectivamente, com seus respectivos ajustes lineares. A BUAtot apresentou um coeficiente de correlação de $0,87(\mathrm{p}<0,0001)$ e a velocidade de $-0,82(\mathrm{p}<0,0001)$.

Para a figura 4.3.26, foi feito o gráfico de todos os valores obtidos da BUAtot (tíbia e calo) como função da velocidade do som (tíbia e calo). A figura abaixo apresenta um $\mathrm{R}=$ $0,75(\mathrm{p}<0,0001)$

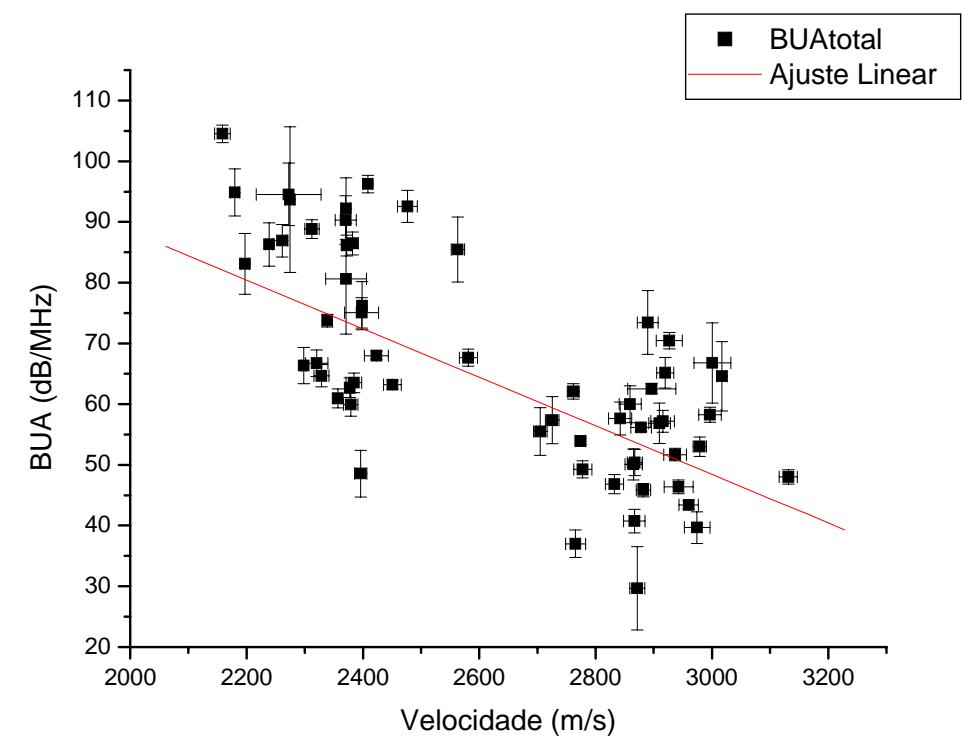

Figura 4.3.26. Todos os valores da BUAtot como função de todos os valores de velocidade do som. 
Este gráfico apresenta uma boa correlação estatística entre os valores de velocidade e BUA, quando colocados todos os valores obtidos (para o calo e para a tíbia saudável). Os valores de velocidade que estão aproximadamente em $2900 \mathrm{~m} / \mathrm{s}$ estão associados às tíbias saudáveis e os valores que estão abaixo de $2600 \mathrm{~m} / \mathrm{s}$ estão relacionados aos calos. É possível observar que as tíbias saudáveis apresentam baixos valores de BUAtot, mas existem valores que são maiores (acima de $70 \mathrm{~dB} / \mathrm{MHz}$ ) por terem um grande diâmetro, isso quer dizer que possuem mais osso cortical. Os valores altos de BUA são associados aos calos. Os calos que realmente possuem maior valor de BUAtot são os que apresentam maior diâmetro (animais de grupo de 30 dias pós-fratura). Os calos de grande diâmetro possuem uma grande quantidade de fibrocartilagem que é um material que atenua menos que o osso cortical, mas pode existir uma perda, principalmente por espalhamento nos valores da BUAtot do calo de 30 dias.

\subsubsection{Resultados para a técnica de contato}

\subsection{Velocidade do som como função da espessura}

Os gráficos da figura 4.3.27, são da velocidade do som como função da espessura para a tib90, tib180, calo90 e calo180, com seus respectivos ajustes lineares.

O coeficiente de correlação para o calo90 e calo180 foi de $-0,61(p=0,01)$ e $-0,42$ $(p=0,09)$, respectivamente. Enquanto, na tib90 e tib180 foi de $0,46(p=0,10)$ e $0,45(p=0,14)$, respectivamente. Nestes resultados, o único que apresentou um coeficiente de correlação estatisticamente relevante foi o calo90 (figura 4.3.27c).

O comportamento dos calos (figura 4.3.27 c e d) foi o esperado, mesmo o calo180 não apresentando um fator de correlação estatisticamente relevante, pois quanto menor a espessura do calo maior a velocidade do som na amostra.

Nos gráficos a e b da figura 4.3.27, conforme ocorreu o aumento da espessura da amostra maior foi o valor da velocidade das tíbias. Embora, a variação seja pequena o esperado seria que a velocidade permanecesse aproximadamente constante, mas esta variação de velocidade pode estar associada à variação da espessura da cortical em cada amostra. 
a)
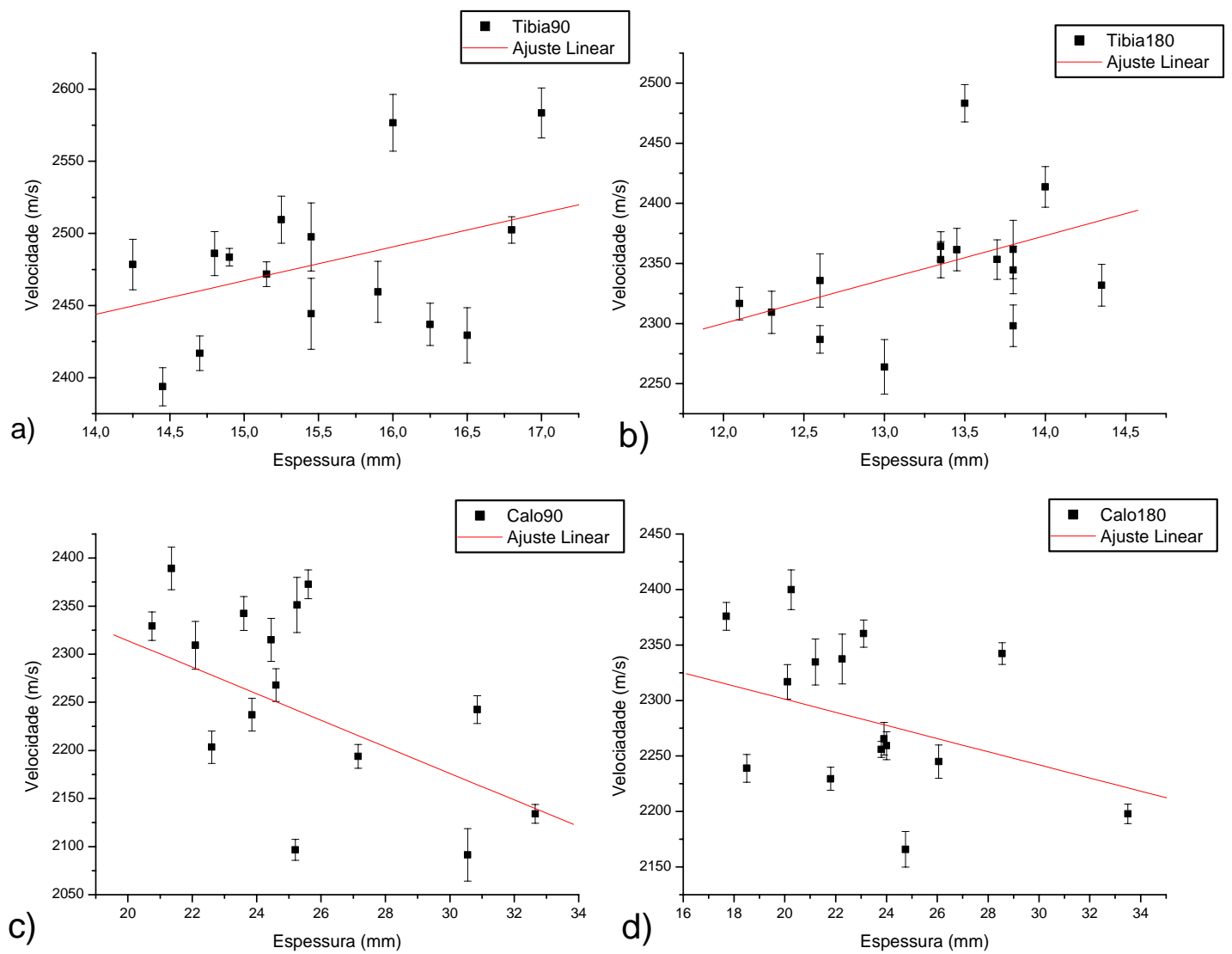

Figura 4.3.27. Gráficos da velocidade do som em função da espessura (e seus respectivos ajustes lineares) para a tib90, tib180, calo90 e calo180, em a, b, c e d, respectivamente. Para a técnica de contato.

\subsection{Velocidade do som no calo em função da velocidade na tíbia do mesmo animal}

Na figura 4.3.28, são apresentados os gráficos da velocidade no calo relacionado com a velocidade da sua respectiva tíbia e seus ajustes lineares. Na figura 4.3.29, são apresentados os gráficos da velocidade do calo180 como função da velocidade do calo90, em a. Na figura 4.3.29b, tem-se o gráfico da tib180 como função da tib90. 


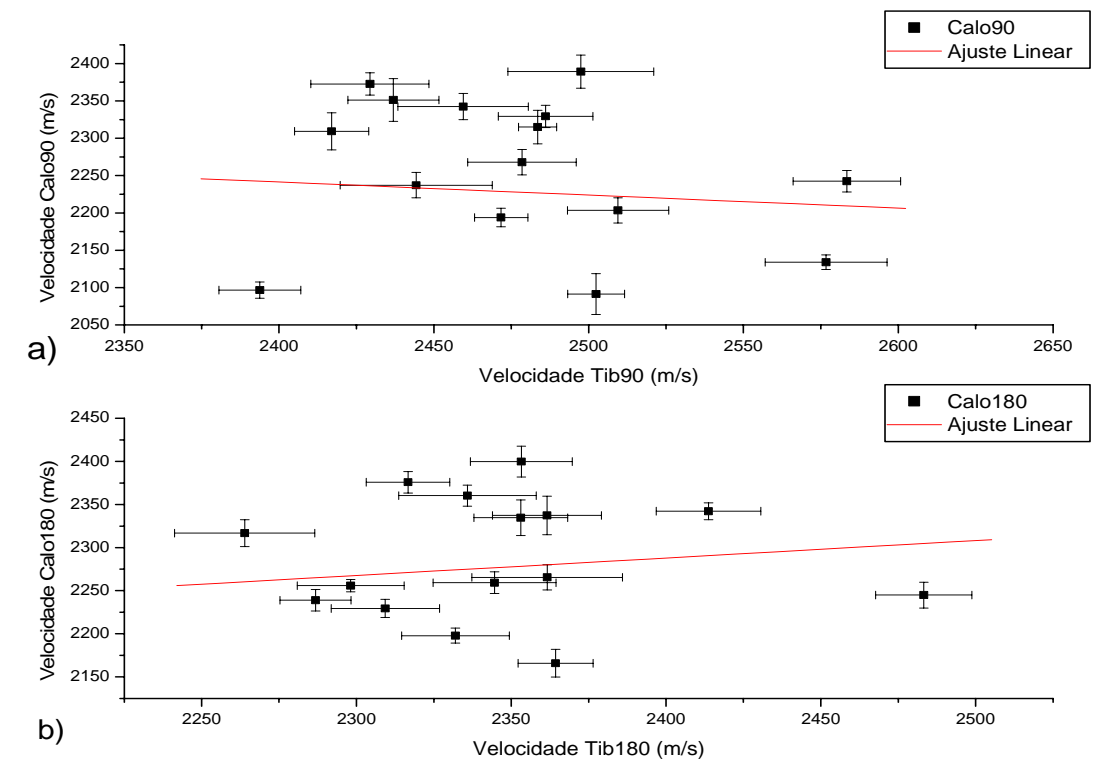

Figura 4.3.28. Gráficos da velocidade do som no calo (nas duas orientações: $90^{\circ} \mathrm{em}$ a, $180^{\circ} \mathrm{em}$ b) como função da velocidade na sua respectiva tíbia e com seus respectivos ajustes lineares.

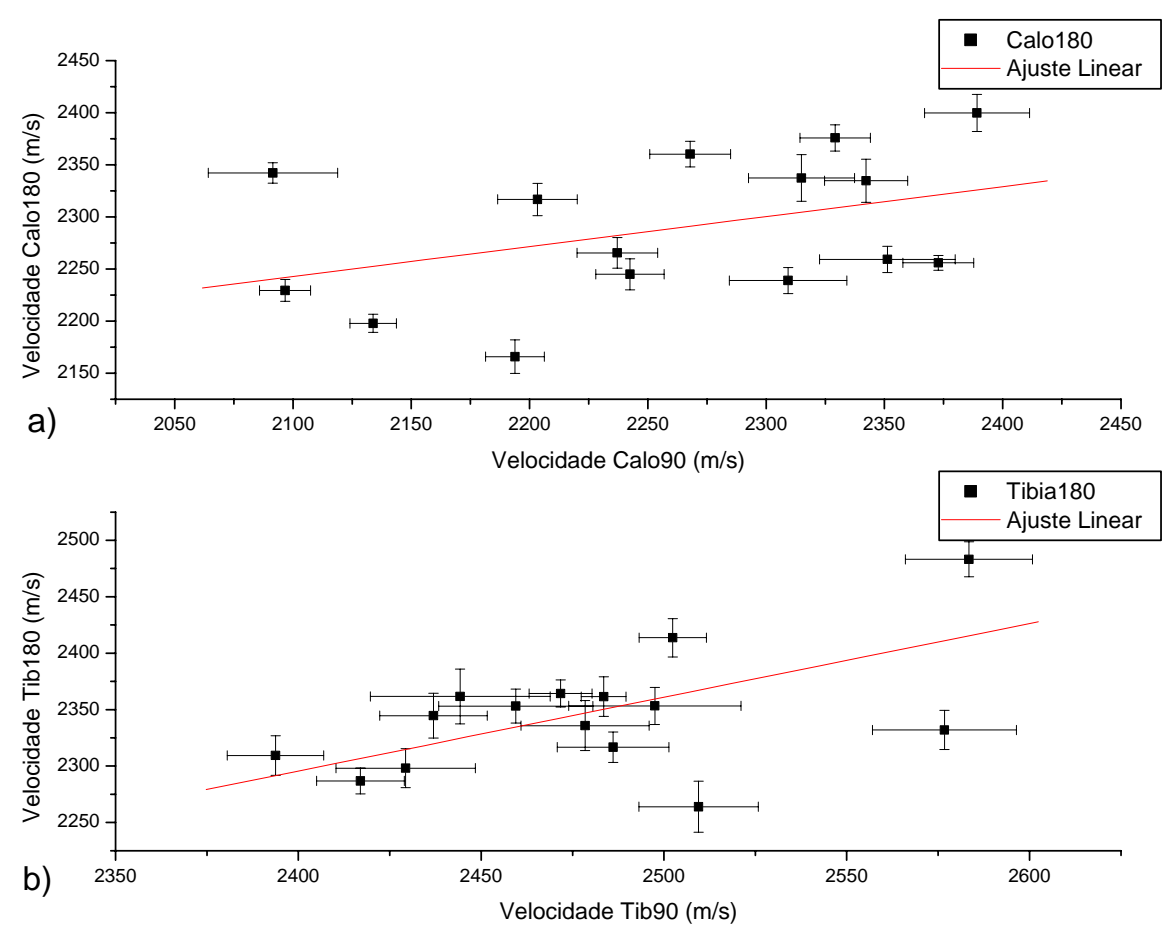

Figura 4.3.29. a) Gráfico da velocidade do som no calo180 em função do calo90, com seu respectivo ajuste linear. b) Gráfico da velocidade do som na tib180 em função da velocidade na tib90, com seu respectivo ajuste linear. 
Os coeficientes de correlação obtidos para os gráficos da figura 4.3.28, foram -0,11 $(\mathrm{p}=0,68)$ e $0,16(\mathrm{p}=0,57)$ para a e $b$, respectivamente. Para os gráficos da figura 4.3.29, foram de $0,40(p=0,13)$ e $0,64(p=0,009)$, para a e b, respectivamente.

De acordo com a figura 4.3.28, não existiu correlação entre as velocidades dos calos com as velocidades das suas respectivas tíbias.

Na figura 4.3.29b, foi o único caso em que existiu correlação estatística entre as velocidades da mesma amostra, quando foi variada apenas a orientação.

\subsection{Comparação entre a velocidade do som na tíbia em função de dias pós-fratura}

Na figura 4.3.30, é apresentado o gráfico da velocidade no calo em função dos dias pós-fratura, cada ponto representa a média das velocidades entre os cinco animais de cada grupo. O ponto, que representa 120 dias pós-fratura, corresponderia ao valor da velocidade na tíbia saudável naquela orientação, sendo as velocidades: VelCalo90 (120 dias) igual a 2505,61m/s e VelCalo180 (120 dias) igual a 2444,25m/s.

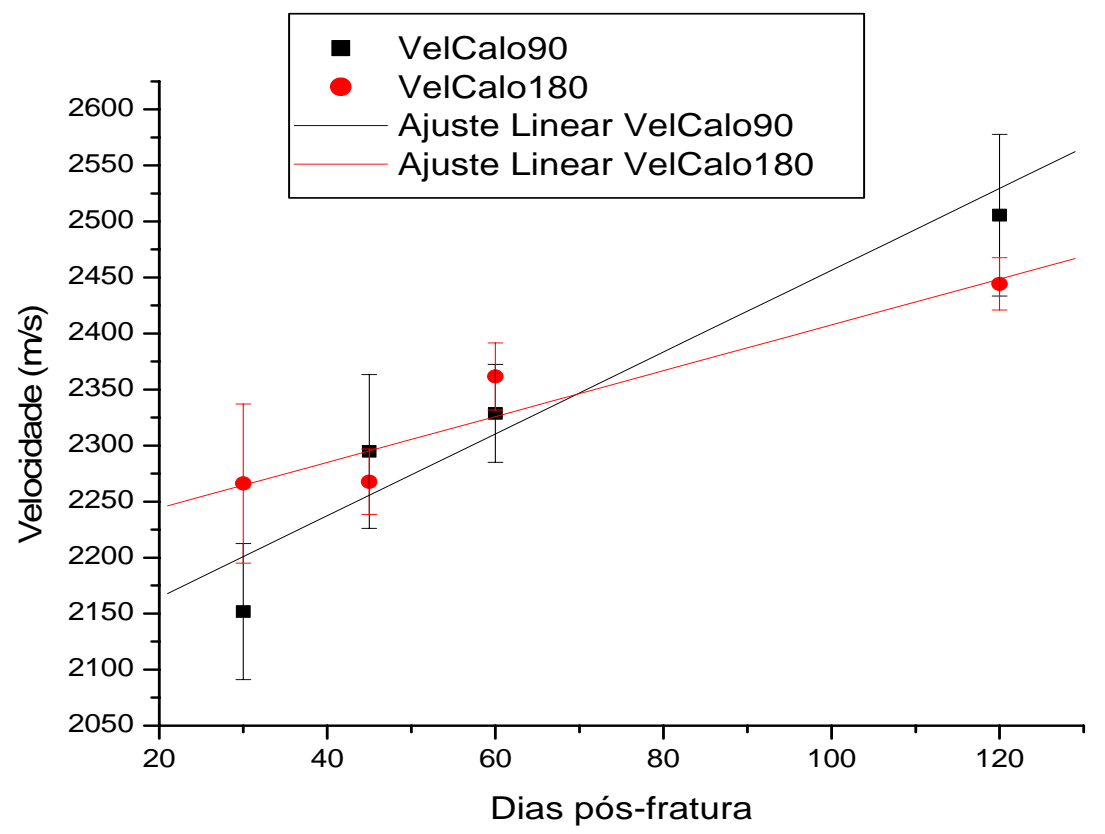

Figura 4.3.30. Variação da velocidade do som em cada grupo de animais em função de dias pós-fratura com os seus respectivos ajustes lineares. 
É observada a tendência das velocidades, nas duas orientações (calo90 e calo180), de se aproximar do valor da tíbia saudável conforme passa o tempo pós-fratura, sendo que ambas apresentam um coeficiente angular positivo. O coeficiente de correlação foi de $0,95(p=0,04)$ para a VelCalo90 e de 0,95 ( $\mathrm{p}=0,05)$ para a VelCalo180.

Os valores médios das velocidades dos calos, medidos pela técnica de contato, nas duas orientações são aproximadamente iguais aos da tíbia saudável (velocidade do ponto 120 dias da figura 4.3.30). Na técnica de inserção essa variação foi muito maior (figura 4.3.21), apresentando valores bem distintos.

\subsection{BUAtot como função da espessura}

Na figura 4.3.31, são apresentados os valores da BUAtot como função da espessura da amostra para a tíbia e o calo nas duas orientações, avaliada pela técnica de contato.

a)
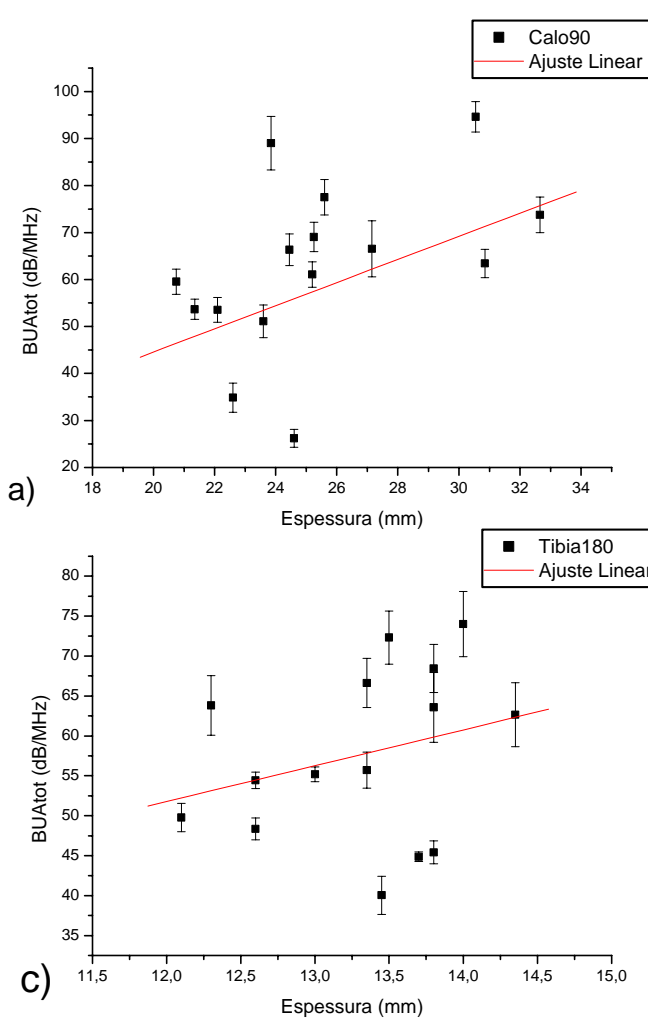
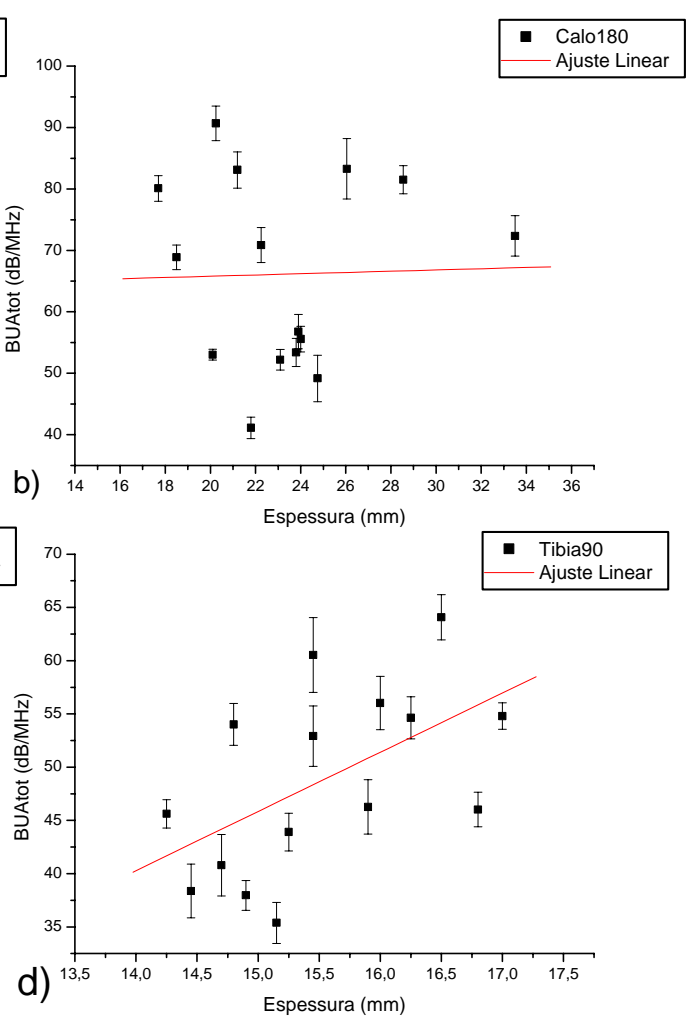

Figura 4.3.31. Valores médios da BUAtot (sem discriminação da tensão) como função da espessura da amostra óssea. Em: a e b para calos nas orientações 90 e 180 graus, respectivamente. Em: c e d para as tíbias nas orientações 180 e 90 graus, respectivamente. 
Os gráficos da figura 4.3.31, apresentaram um coeficiente de correlação de 0,57 $(\mathrm{p}=0,03), 0,28(\mathrm{p}=0,31), 0,47(\mathrm{p}=0,07)$ e $0,02(\mathrm{p}=0,92)$ para a tib90, tib180, calo90 e calo180, respectivamente. Estes valores não possuem nenhum significado estatisticamente relevante, entretanto, o único que apresentou um valor relevante foi a tib90. Contudo, mesmo não possuindo uma correlação estatisticamente relevante, pode-se observar que para os calos (figura 4.3.31 a e b) conforme aumenta a espessura da amostra aumenta o valor da BUAtot, sendo que, calos de grande espessura possuem uma composição maior de fibrocartilagem e osso cortical, provocando possíveis atenuações por espalhamento. Para as tíbias (figura 4.3.31 c e d), o comportamento apresentado pela tib90 e tib180 era o esperado, quanto maior o diâmetro da amostra maior a quantidade de cortical que esta possui, conseqüentemente apresentará um valor de BUAtot maior.

Essas variações encontradas nestes resultados (figura 4.3.31), podem estar associadas às perdas que ocorrem devido à técnica utilizada (técnica de contato), perdas por espalhamento, problemas devido ao contato entre os transdutores e a amostra e irregularidades na superfície curva da amostra (algumas amostras apresentavam alguns sulcos, que eram preenchidos com o gel de acoplamento).

\subsection{BUAtot dos calos como função da BUAtot da respectiva tibia}

Na figura abaixo, são apresentados os gráficos da BUAtot dos calos como função da BUAtot da sua respectiva tíbia e orientação.

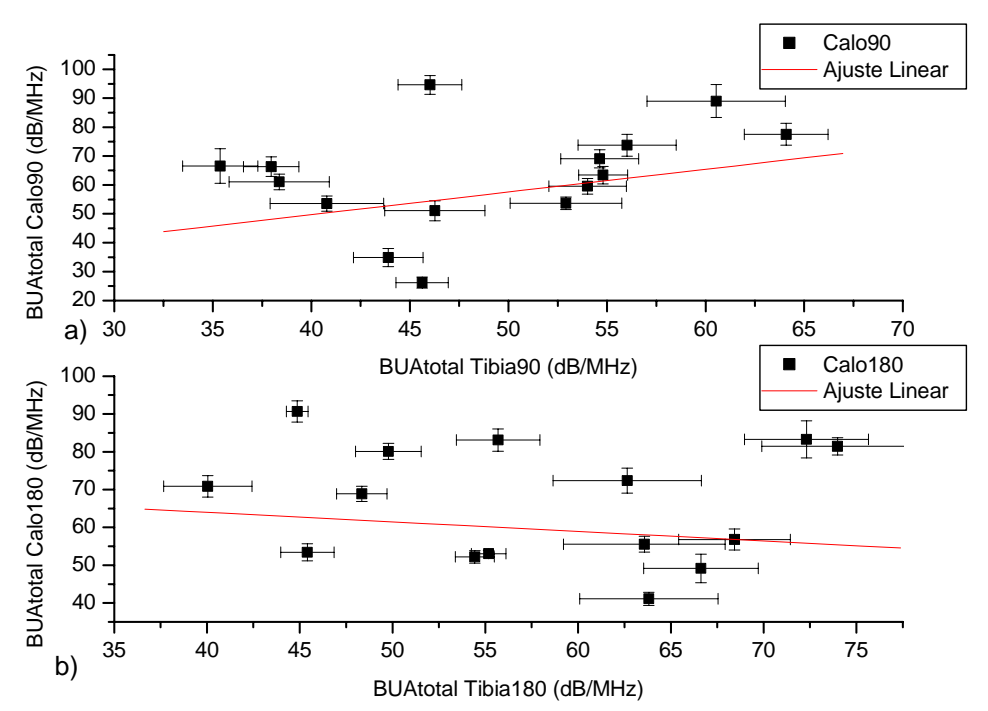

Figura 4.3.32. BUAtot do calo como função BUAtot da tíbia de mesmo animal e na mesma orientação,em a e b para calo 90 e 180, respectivamente. 
Na figura 4.3.32, não foi encontrada nenhuma correlação estatisticamente significante para nenhum dos calos nas orientações avaliadas (calo90 e calo180). Então, não se constatou nenhuma correlação significante entre as amostras dos mesmos animais.

\subsection{BUAtot como função da respectiva velocidade do som}

Para a figura 4.3.33, foram feitos os gráficos da BUAtot como função da sua respectiva velocidade, para a tib180, tib90, calo180 e calo90, em a, b, c e d,respectivamente.

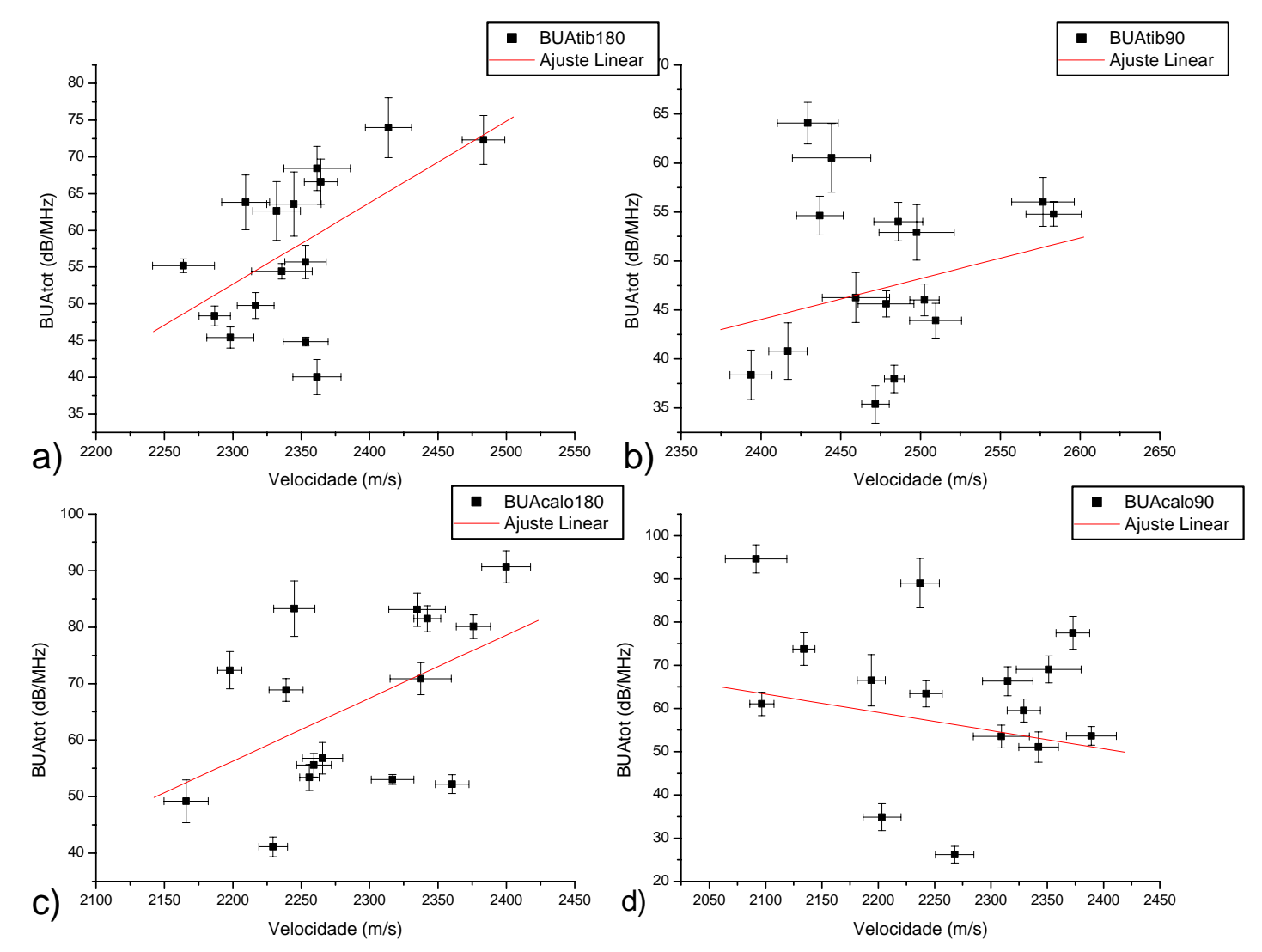

Figura 4.3.33. Valores da BUAtot como função da respectiva velocidade. Em: a e b para as tíbias na orientação 180 e 90 graus, respectivamente. Em: c e d para os calos na orientação 180 e 90 graus, respectivamente.

Os coeficientes de correlação obtidos para a tib180 e tib90 foram 0,55 (p=0,03) e 0,27 $(p=0,33)$, respectivamente. As BUAs dos calos (figura 4.3.33 c e d) apresentaram os seguintes 
coeficientes de correlação: 0,50 $(\mathrm{p}=0,05)$ e $-0,22(\mathrm{p}=0,44)$ para o calo180 e calo90, respectivamente.

Na figura 4.3.34, são apresentados os gráficos da BUAtot e da velocidade como função da espessura em a e b, respectivamente. Entretanto, não foi discriminado entre tíbia saudável e calo (tíbia tratada).

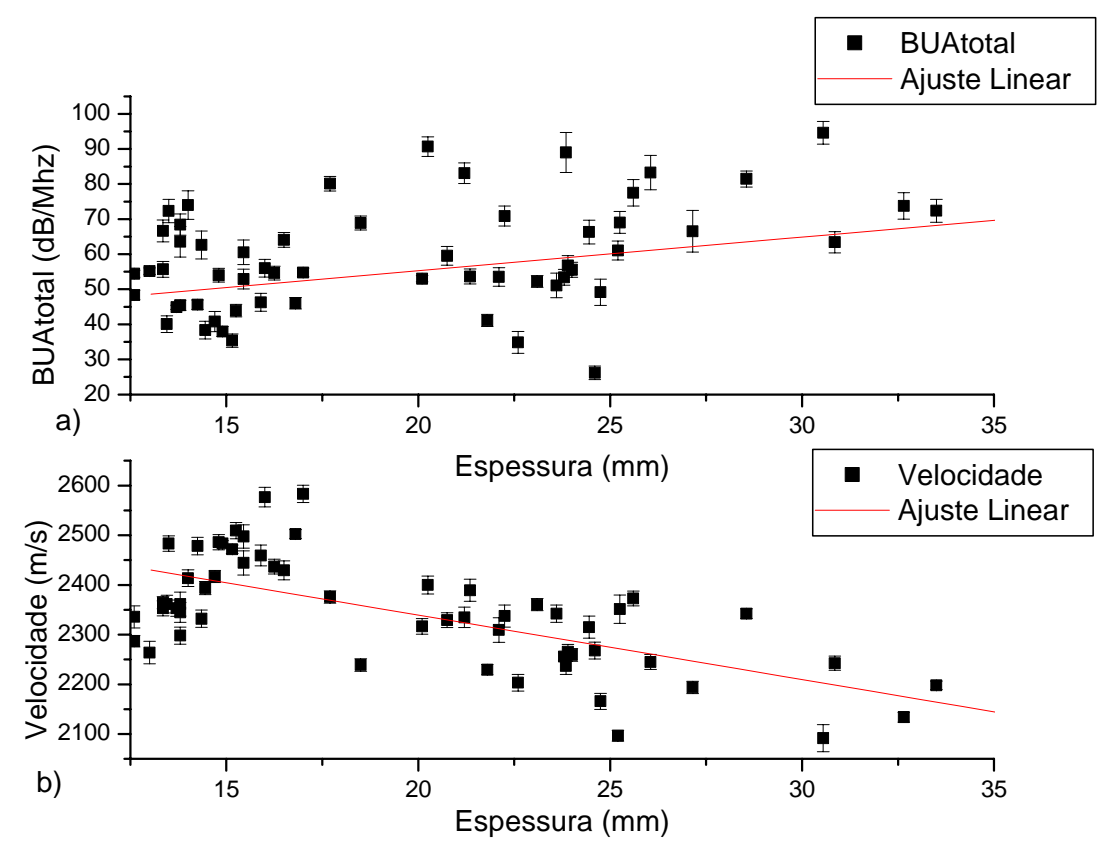

Figura 4.3.34. Valores de todas as BUAs e velocidades como função da espessura, sem a discriminação entre calo ou tíbia saudável.

Para o gráfico da BUAtot em função da espessura (figura 4.3.34a) o coeficiente de correlação foi de $0,39(\mathrm{p}=0,002)$. Valores de espessura superior a $20 \mathrm{~mm}$ são referentes aos calos (calo90 e calo180) avaliados. Conforme ocorreu o aumento da espessura também aumentou o valor da BUAtot, como pode ser observado na figura 4.3.34a.

Na figura 4.3.34b, o coeficiente de correlação entre a velocidade e a espessura foi de 0,69 ( $<<0,0001)$. Pode ser observado que, a partir da espessura de 20mm, conforme aumenta a espessura o valor da velocidade diminui. Esta é a região das espessuras dos calos. Quanto menor o calo maior a velocidade. 


\subsubsection{Velocidade avaliada pela técnica de contato longitudinal nas amostras}

Na figura 4.3.35, são apresentados os gráficos para a velocidade do som nas tíbias e nos calos, medidos através da técnica de contato longitudinal. Para os grupos de 60, 45 e 30 dias em a, b e c, respectivamente.

Na figura 4.3.36, é apresentado o gráfico da média entre as velocidades dos animais de cada grupo para a tíbia e o calo.

Através dos gráficos da figura 4.3.35, é possível observar que, a velocidade na tíbia foi maior que a velocidade no calo para os três grupos. A maior diferença entre as velocidades foi a do grupo de 30 dias pós-fratura (figura 4.3.35c), pois os animais do grupo de 30 dias possuem uma maior quantidade de calo ósseo, quando comparados com os animais dos outros grupos.

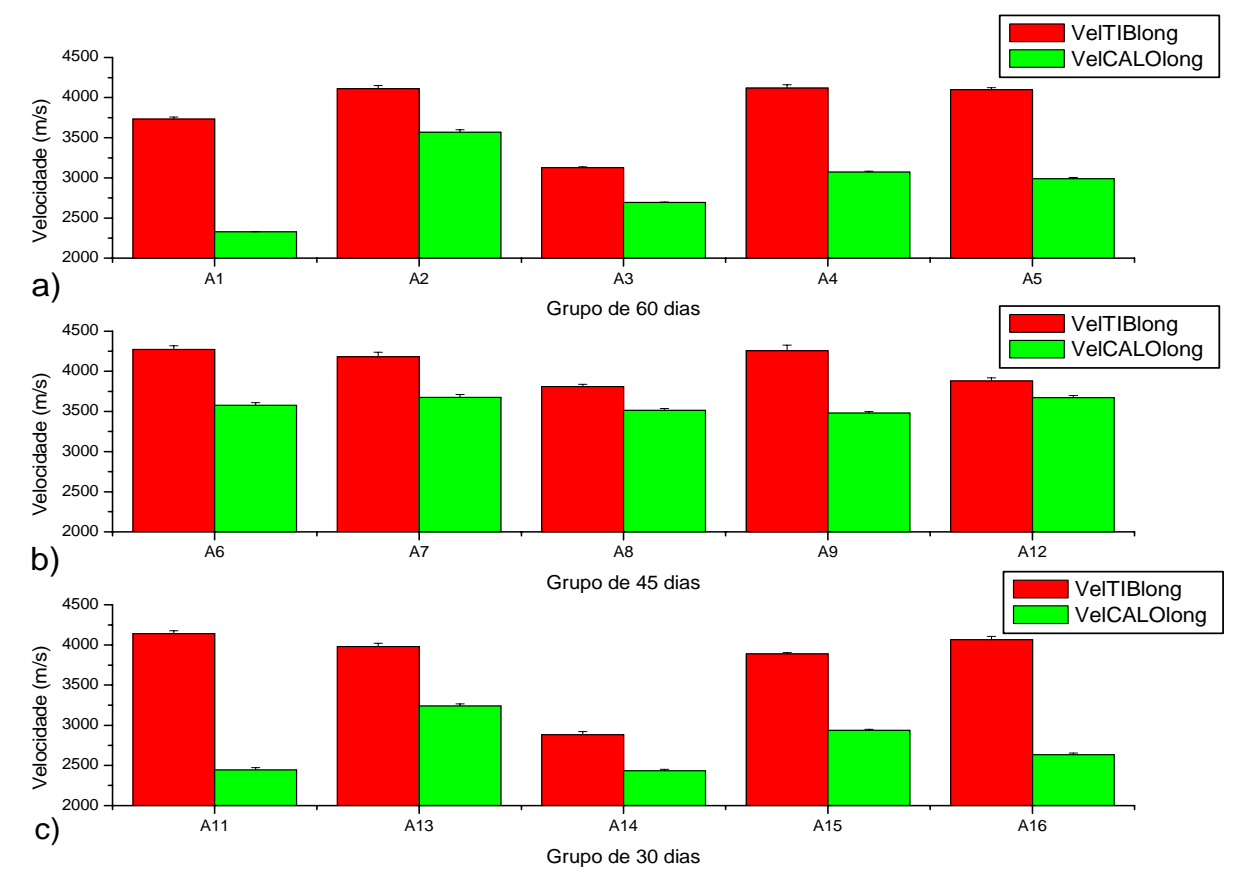

Figura 4.3.35. Média das velocidades na tíbia e no calo, avaliados pela técnica de contato longitudinal. Para os grupos de 60, 45 e 30 dias, em a, b e c, respectivamente. 


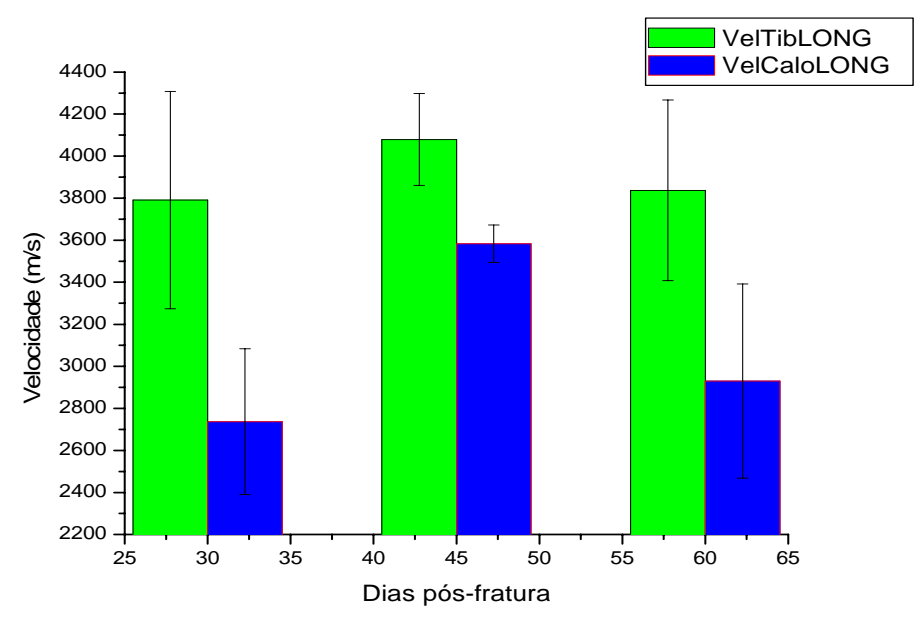

Figura 4.3.36. Média das velocidades entre os animais de cada grupo de dias pós-fratura, para a tíbia e o calo, avaliados pela técnica de contato longitudinal.

\subsubsection{RESULTADOS DA TÉCNICA BUAnews}

Nesta seção serão apresentados os resultados obtidos a partir da técnica BUAnews (seção 4.3.2.6.3 deste capítulo), como uma nova forma de analisar a atenuação presente no calo ósseo.

A espessura que será utilizada nas análises é uma nova espessura, sendo que, esta é o valor da espessura do calo subtraída da espessura da sua respectiva tíbia, já que a técnica BUAnews está avaliando apenas o conteúdo do material que compõe o calo ósseo.

\subsection{BUAnews como função da espessura}

Na figura 4.3.37, são apresentados os gráficos da BUAnews para o calo 90 e 180 como uma função da sua respectiva espessura para ambas as técnicas de contato e inserção.

De acordo com a figura 4.3.37b, foi obtido uma boa correlação estatística entre a BUAnews do calo90 e suas respectivas espessuras para ambas as técnicas (contato e inserção). Para a técnica de inserção o coeficiente de correlação foi de 0,72 (p=0,002) e para a técnica de contato foi de $0,77(\mathrm{p}=0,0006)$. Na figura 4.3.37a, para o calo180 a técnica de 
inserção não apresentou um coeficiente de correlação estatístico satisfatório, sendo que, seu valor foi de $0,22(\mathrm{p}=0,41)$. Entretanto, a técnica de contato para o calo180 foi o melhor coeficiente de correlação como função da espessura apresentando um valor de 0,93 $(\mathrm{p}<0,0001)$.

Mesmo o BUAnews para o calo180 ,na técnica de inserção, não sendo estatisticamente relevante, todos os gráficos apresentam um valor de BUAnews crescente conforme o aumento da espessura das amostras.

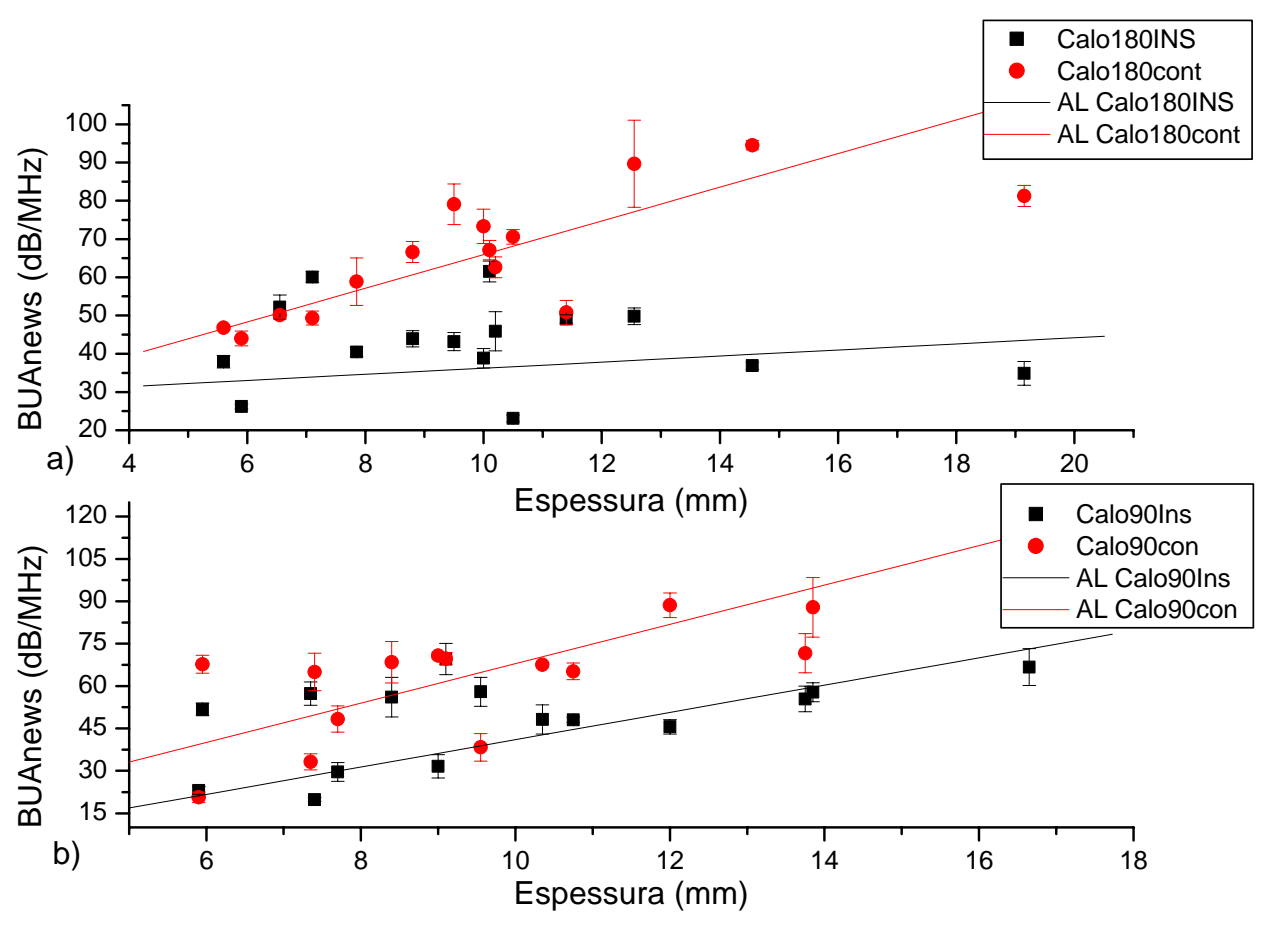

Figura 4.3.37. BUAnews para o calo 90 e 180 como função das suas respectivas espessuras. Em a: BUAnews do calo180 para as técnicas de contato e inserção, em b: BUAnews do calo90 para as técnicas de contato e inserção. Todos com seus respectivos ajustes lineares.

Na figura 4.3.38, tem-se o gráfico para o BUAnews com todos os valores obtidos sem discriminar entre a orientação 90 e 180 graus, fazendo apenas a diferença entre as técnicas se é de contato (CaloCon) ou de inserção (CaloIns).

Os coeficientes de correlação obtidos através da figura 4.3.38 foram estatisticamente relevantes, apresentando valores de $0,36(\mathrm{p}=0,05)$ e $0,87(\mathrm{p}<0,0001)$ para o CaloIns e CaloCon, respectivamente. 


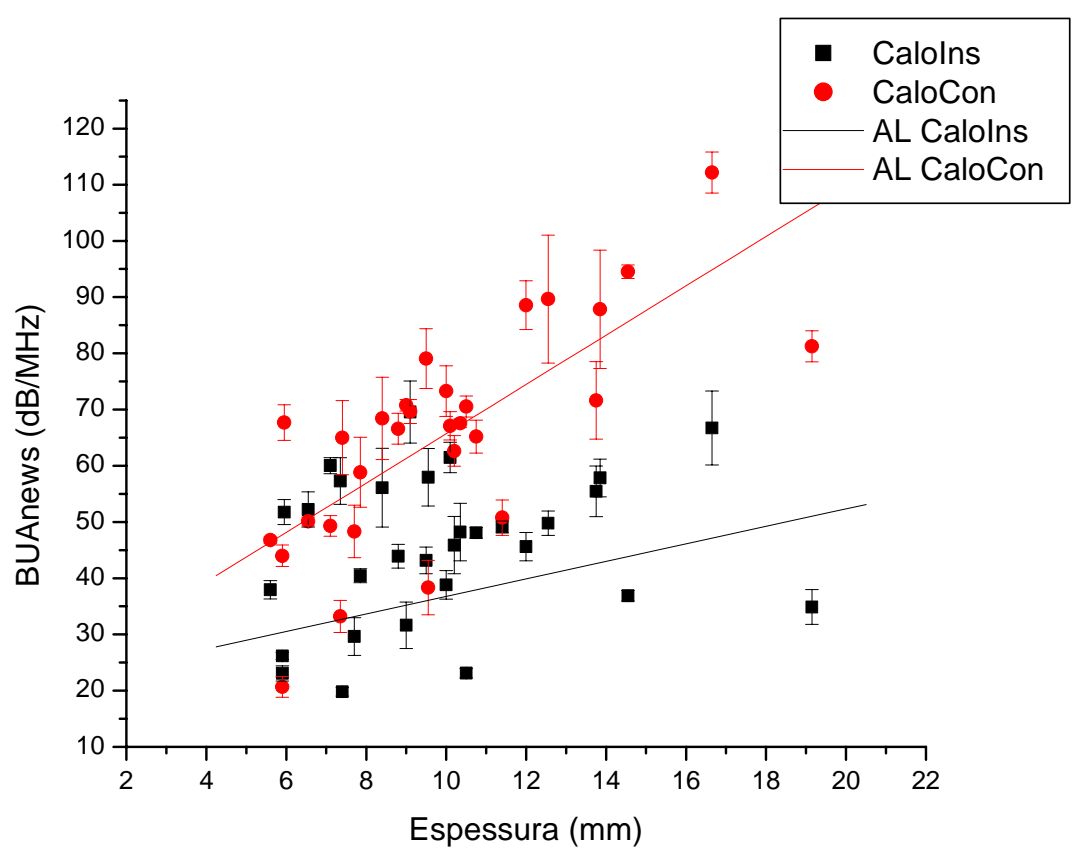

Figura 4.3.38. Gráfico da BUAnews dos calos para as técnicas de contato (CaloCon) e inserção (CaloIns) como função da suas espessuras e com seus ajustes lineares.

\subsubsection{CONSIDERAÇÕES FINAIS}

Os valores encontrados para a velocidade do som utilizando a técnica de contato transversal (figura 4.3.27) foram menores que os obtidos pela técnica de inserção (figura 4.3.18), isto sendo observado para ambos, a tíbia e calo.

$\mathrm{Na}$ tabela 4.3.2, são apresentados os valores encontrados na literatura para a velocidade do som em tíbias humanas saudáveis.

Comparando os resultados das figuras 4.3.18 e 4.3.27, com os valores da tabela 4.3.2, é observado que os valores encontrados para a tíbia são menores do que os da tabela 4.3.2 com uma diferença aproximada de 1000m/s quando comparados com a técnica de inserção, e de $1400 \mathrm{~m} / \mathrm{s}$ quando comparados com a técnica de contato transversal. Este fato pode estar relacionado com a técnica utilizada. Os pesquisadores, referidos na tabela 4.3.2, usaram a técnica de transmissão sobre a superfície cortical, onde os transdutores (emissor e receptor) são colocados, perpendicularmente, sobre a tíbia (in vivo), separados por uma distância prédeterminada e paralelos entre si, medindo o tempo de vôo do sinal ultra-sônico pela cortical. 
Enquanto, a técnica de transmissão utilizada neste estudo, os transdutores são colocados de lados opostos com seus centros alinhados, assim, o sinal ultra-sônico atravessa não só a cortical, mas também a medula óssea fornecendo um valor para a velocidade da amostra como um todo e não somente da cortical da tíbia.

Tabela 4.3.2 - Valores da velocidade do som em tíbias humanas saudáveis, de acordo com a literatura.

\begin{tabular}{c|c} 
Pesquisadores & Velocidade e SD $(\mathbf{m} / \mathbf{s})$ \\
\hline Weiss (2000) & $3914 \pm 111$ \\
Sievänen (2001) & $3825 \pm 143$ \\
Foldes (1999) & $3867 \pm 145$ \\
Bouxsein (1999) & $3865 \pm 207$ \\
Rosenthall (1996) & $3909 \pm 141$ \\
Pande, (2000) & $3840 \pm 164$ \\
Tromp (1999) & $3861 \pm 140$ \\
Njeh (2001a) & $3894 \pm 150$ \\
Lee (1997) & $3865 \pm 207$
\end{tabular}

Njeh, C.F. et al. (2001a) relatam que, a espessura da parede da cortical da tíbia (humana) mede entre 5 e $8 \mathrm{~mm}$, comparando este valor com as espessuras da tíbia de carneiro (diâmetro) da tabela 4.3.1, é observado que são aproximadamente a metade da espessura da tíbia de carneiro de maior espessura. Pode-se extrair, deste fato, que existirá uma maior dispersão nas medidas feitas na tíbia de carneiro.

Njeh et al (1999), Baroncelli et al (2001) e Foldes; Rimon; Keinan; e Popovtzer (1995), observaram que as velocidades para amostras de pequena espessura (menor ou igual ao comprimento de onda) possuem uma velocidade variável, sendo que, para espessuras maiores (que o comprimento de onda) a velocidade ficou constante tanto para materiais plásticos (homogêneos) quanto para materiais biológicos (osso).

Entretanto, quando usada a técnica de contato longitudinal para a análise da velocidade do som sobre a cortical das tíbias de carneiro (seção 3.3), os valores obtidos para a velocidade da tíbia estão próximos dos valores apresentados na tabela 4.3.2. Então, existe uma influência importante no valor da velocidade quanto à técnica e o método experimental utilizados, como referido por Strelitzki e Evans, 1998. 
Na tabela 4.3.3, são apresentados os valores da velocidade do som para falanges humanas avaliadas pela técnica de contato transversal encontrados na literatura.

Tabela 4.3.3 - Valores da velocidade do som (transversal) nas falanges humanas, encontradas na literatura.

\begin{tabular}{c|c} 
PESQUISADORES & Velocidade do som \pm SD (m/s) \\
\hline Pluskiewicz (1997) & $2024,72 \pm 53,03$ \\
\hline Baroncelli (2001) & $2099,8 \pm 46,1$ \\
\hline Blanckaert (1999) & $1980,5 \pm 82,1$ \\
\hline Reginster (1998) & $1953,0 \pm 96,6$ \\
\hline Pluskiewicz (2004a) & $2016 \pm 88$ \\
\hline Drozdzowska (2004a) & $1968 \pm 69($ homem) \\
\cline { 2 - 2 } & $1946 \pm 75$ (mulher)
\end{tabular}

A falange possui uma espessura próxima a da tíbia de carneiro, entretanto, os valores na tabela 4.3.3, consideram a velocidade do som no dedo, isso quer dizer, deve-se levar em consideração a existência de tecido mole ao redor do osso. (Baroncelli, 2001).

Comparando os valores da tabela 4.3 .3 com os resultados obtidos na seção 3.2.1, podemos fazer uma comparação entre os valores da velocidade do som na tíbia de carneiro e na falange dos dedos da mão, pois é utilizada a mesma técnica. Os resultados, da seção 3.2.1, mostram um valor de velocidade um pouco maior que os da tabela 4.3.3. Entretanto, isto pode estar associado à ausência de tecido mole ao redor da tíbia como avaliado por Kotzki (1994), que conclui que, quanto maior a camada de gordura ao redor da amostra menor será o valor de velocidade e Chappard et al (2000), dizem que, o erro causado, pelo tecido mole, no valor da velocidade pode afetar o coeficiente de variação em curto prazo. Então, os valores de velocidade obtidos para a tíbia pela técnica de contato transversal estão condizentes com os valores encontrados na literatura.

A velocidade do som, nos calos, possui uma grande dependência com a espessura, pois quando o calo ainda é recente sua constituição é predominantemente de material fibroso, chamada de fibrocartilagem o qual possui estrutura e velocidade diferentes comparadas com a do osso cortical. Com o passar do tempo esta fibrocartilagem é substituída por osso esponjoso e depois por osso cortical, fazendo com que a velocidade no calo se aproxima do valor da tíbia saudável como observado por Siegel, Anast e Fields (1958). Este fato foi observado para os calos nas duas técnicas avaliadas. As figuras 4.3.18 e 4.3.21 mostram os resultados obtidos 
para a técnica de inserção, para a técnica de contato os resultados estão nas figuras 4.3.27 e 4.3.30. Para a análise longitudinal da velocidade os valores obtidos para as velocidades nas tíbias foram maiores que os valores nos calos (figuras 4.3 .35 e 4.3.36).

A técnica de inserção mostrou uma melhor resposta quanto às variações de velocidade quando comparadas com a técnica de contato transversal. Nas seções 3.1.2 (técnica de inserção) e 3.2.2 (técnica de contato transversal), foram feitas as mesmas análises sobre a velocidade do som na tíbia e calo. Os resultados obtidos pela técnica de inserção apresentaram altos coeficientes de correlação e os obtidos pela técnica de contato não apresentaram resultados estatisticamente relevantes.

Para os resultados da BUA temos as seguintes considerações.

Não existiu nenhum padrão entre as orientações como visto nas figuras 4.3.14 e 4.3.15, para a técnica de inserção, e nas figuras 4.3.23 e 4.3.24, para a técnica de contato transversal. Não sendo então, possível determinar a melhor orientação para análise.

A relação entre a BUAtot e a espessura da amostra apresentou bons coeficientes de correlação quando analisados pela técnica de inserção e sendo estatisticamente relevantes. Entretanto, para a técnica de contato já não existiu correlação estatística entre a BUAtot e a espessura das amostras. Embora isso tenha ocorrido, pode ser observado que para os calos, nas duas orientações e para as técnicas de contato e de inserção, a tendência da BUAtot é de crescer conforme aumenta o tamanho da amostra. Essas variações estão relacionadas com a variação do material constituinte do calo, que é composto de fibrocartilagem e osso cortical e do formato do calo.

Para as tíbias, na técnica de inserção, conforme aumentou a espessura teve um aumento da BUAtot, nas duas orientações. Na técnica de contato, para a tib90 a BUAtot aumentou conforme cresceu a espessura, mas para a tib180 foi o contrário, apresentando um coeficiente angular negativo. Era esperado o mesmo comportamento entre as tíbias independentes da técnica utilizada, como aconteceu para os calos.

Não foi encontrada correlação estatisticamente significante entre a BUAtot do calo e a BUAtot da tíbia do mesmo animal, em ambas técnicas e orientações. Entretanto, apenas na figura 4.3.23a, (BUAtot do calo180, técnica de inserção), existiu correlação significativa.

Na análise individual da BUAtot como função da velocidade do som para a técnica de contato transversal (figura 4.3.33), não existiu nenhuma correlação estatisticamente relevante entre elas. Para técnica de inserção (figura 4.3.24), não existiu correlação entre a BUAtot e as velocidades das tíbias. Contudo, existiu correlação entre a BUAtot e a velocidade nos calos. 
Quando inseridos todos os valores da BUAtot como função da espessura, sem discriminar entre tíbia e calo, tanto para a técnica de inserção (figura 4.3.25a) quanto para a de contato transversal (figura 4.3.34a), existiu uma correlação muito boa em ambas.

Nas figuras 4.3.25b e 4.3.34b, tem-se os gráficos da velocidade do som como função da espessura, sem discriminar entre velocidade da tíbia e calo, para a técnica de inserção e contato transversal, respectivamente. Os resultados para a velocidade em ambas as técnicas foram melhores que os resultados obtidos para a BUAtot.

Nesta forma de análise (figura 4.3.25 e 4.3.34), os resultados obtidos pelas duas técnicas foram muito bons.

Fazendo a comparação entre as formas de cálculo da BUA adotadas neste trabalho, BUAtot, técnica de inserção e de contato e a BUAnews, para o calo ósseo é possível observar que, mesmo em alguns casos onde não existiu uma correlação estatisticamente relevante, como os apresentados na figura 4.3.31 a e b, para a BUAtot (técnica de contato), o valor da BUA sempre cresceu com o aumento da espessura do calo ósseo.

A técnica de contato na análise da BUAnews apresentou um coeficiente de correlação melhor que na técnica de inserção tanto para o calo90 quanto o calo180, sendo de 0,77 $(p=0,0006)$ e $0,93(p<0,0001)$, respectivamente. 


\subsection{VALORES DA BUA (BUAtot e BUAsel) E DA VELOCIDADE DO SOM (Vzero e Vpico) PARA O CALCANHAR DE VOLUNTÁRIOS COM DIFERENTES IDADES.}

\subsubsection{INTRODUÇÃO}

Nesta seção, serão apresentados os resultados obtidos para a BUA (BUAtot e BUAsel) e velocidade do som (Vzero e Vpico) para os voluntários de faixa etária entre 19 a 77 anos. As medidas foram feitas no calcanhar do pé direito.

A velocidade do som e a BUA foram calculadas pela técnica de contato com acoplamento com gel ultra-sônico (utilizando o suporte para contato). Foram calculadas a BUAtot e BUAsel, como explicado no capítulo 2, seção 2.2.3.5. Para as velocidades será usada, Vzero e Vpico, como explicado no capítulo 2, seção 2.1.5..

Foram feitas seis repetições para cada voluntário (sem movimentar o pé), sendo que, os resultados apresentados serão os valores médios com o seu respectivo desvio padrão. A tensão de trabalho foi de $224 \mathrm{~V}$, pois esta é a tensão gerada pelo equipamento que está mais próxima dos valores encontrados na literatura (Langton e Njeh (2004)). Foram utilizados os seguintes transdutores: $1 \mathrm{MHz}$ (par NO), $2 \mathrm{MHz}$ (par LM), 0,75MHz (par CD), 1,5MHz (par PQ) e $0,5 \mathrm{MHz}$ (par RS).

\subsubsection{FICHA DOS VOLUNTÁRIOS}

Foi elaborada uma ficha de cadastro de voluntários a partir de dados que eram freqüentemente encontradas na literatura, tais como: idade, altura, massa "peso", índice de massa corpórea, sexo tendo como referência (Cvijetic et al. (2003), Naganathan et al. (2002), Karlsson et al. (2001), Drozdzowska e Pluskiewicz (2001), Cepollaro et al. (1999), Peretz et al. (2000), Hadji et al. (2000), Njeh et al. (2000b), Lequin et al. (2000), Wünsche et al. (2000), Zochling et a.l (2002), Pluskiewicz et al. (2004a), Pluskiewicz et al. (2004b), Drozdzowska et al. (2004a), Valerio et al. (2004), Hartman et al. (2004a) e Camozzi et al. 
(2004)), densitometria óssea, tendo como referência (Peretz et al. (2000), Njeh et al. (2000b), Naganathan et al. (2002), Karlsson et al. (2001), Cepollaro et al. (1999), Chang (2004), Hartman et al. (2004b), Toyras et al. (1999), Serpe e Rho (1996), McCloskey et al. (1990a), Forst, Blake e Fogelman (2001b), Toyras et al.. (2002), Hans et al. (1995) e Funke et al. (1995)), reposição hormonal, utilizado na referência (Hadji et al. (2000)) e se faz atividade física regular, tendo como referência (Cvijetic et al. (2003) e Karlsson et al. (2001)).

O índice de massa corpórea (BMI) foi calculado utilizando a seguinte equação:

$$
B M I=\frac{\operatorname{massa}(\mathrm{kg})}{\operatorname{altura}(\mathrm{m}) * \operatorname{altura}(\mathrm{m})}
$$

onde a massa é dada em kilogramas e a altura em metros.

Como atividade física regular se adotou atividade feita no mínimo de duas vezes por semana com duração de pelo menos uma hora.

Na ficha de cadastro de voluntários foram incluídos os seguintes dados: tamanho do calcanhar (se é pé direito ou esquerdo), diâmetro do dedo, o valor do índice de massa corporal, a técnica utilizada (inserção convencional ou a de contato), a temperatura, e a freqüência do par de transdutores que foi utilizada. Algumas destas variáveis não foram objetos de análise neste trabalho.

O modelo desta ficha de cadastro de voluntários está no ANEXO A.

\subsubsection{CALCANHAR.}

Na figura 4.4.1 é apresentada a região de interesse de incidência do sinal ultra-sônico no calcanhar.

Considerando-se que os pés variam de tamanho e forma de pessoa para pessoa, faz-se o acerto do posicionamento do pé para que a incidência do pulso fique dentro da região de interesse. Para fazer essa correção no momento da aquisição do sinal, deve-se colocar algum apoio para levantar o pé e também se necessário movê-lo para frente e ou para trás corrigindo assim o seu posicionamento. O acerto é feito visualmente. 


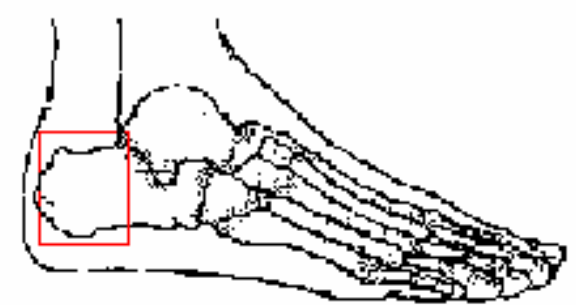

Figura 4.4.1. A região de interesse de incidência do sinal ultra-sônico no calcanhar.

\subsubsection{CARACTERÍSTICAS DOS VOLUNTÁRIOS}

Foram analisados 49 voluntários com idade entre 19 e 77 anos, sendo 35 mulheres e 14 homens. Todos se declararam saudáveis e nenhum deles possuía qualquer doença óssea diagnosticada. Os voluntários idosos são de um grupo de terceira idade (acima de 40 anos) de uma cidade vizinha de Ribeirão Preto - SP (Santa Cruz da Esperança). Devido à distância e a dificuldade em levar o equipamento para as análises foi feita apenas a técnica de contato convencional com acoplamento por gel ultra-sônico. Os voluntários jovens (idade inferior a 39 anos) eram estudantes do Departamento de Física e Matemática da Universidade de São Paulo de Ribeirão Preto. Dentre todos os voluntários apenas dois fazem reposição hormonal, três já fizeram o exame de densitometria óssea e oito fazem atividade física regular.

Na figura 4.4.2, são apresentados os gráficos da espessura do calcanhar e da BMI como função da idade dos voluntários, com seus respectivos ajustes lineares. Entretanto, é possível observar que os voluntários mais idosos (acima de 50 anos) são os que apresentam maior espessura para o calcanhar e também maior BMI do que os jovens. Embora, a espessura do calcanhar seja maior para os voluntários mais velhos isso não quer dizer que possuam maiores valores de velocidade e BUA, pois existe uma composição de tecido mole ao redor do calcanhar, isso quer dizer que, essa espessura maior pode estar relacionada a maior quantidade de gordura e tecido mole ao redor do calcâneo. 


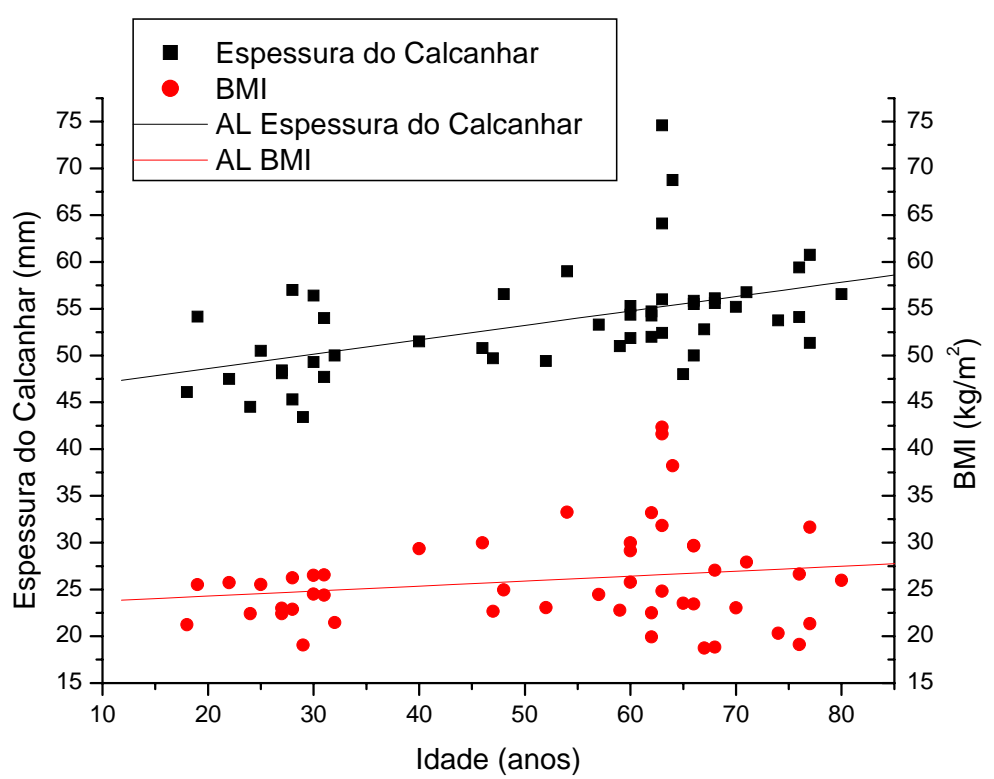

Figura 4.4.2. Espessura do calcanhar e BMI como função da idade dos voluntários e com seus respectivos ajustes lineares.

\subsubsection{ANÁLISE DA REPRODUTIBILIDADE EM CURTO PRAZO DOS RESULTADOS DA BUA E DA VELOCIDADE DO SOM PARA O CALCANHAR DE UM ÚNICO VOLUNTÁRIO.}

\subsubsection{Introdução}

Nesta seção será avaliada a reprodutibilidade dos valores obtidos da BUAtot, BUAsel, Vzero e Vpico, medidas pelas técnicas de contato e inserção, para o calcanhar de um único voluntário. As aquisições foram feitas num período de um mês, em cinco dias diferentes, sendo tomados seis sinais em cada dia e para cada par de transdutores. Este voluntário tem como características: idade de 30 anos, massa de 84kg e índice de massa corpórea de 26,5 $\left(\mathrm{kg} / \mathrm{m}^{2}\right)$.

Na técnica de inserção convencional a temperatura de trabalho foi de $30^{\circ} \mathrm{C}$ em concordância com o apresentado por Langton e Njeh (2004), a tensão de trabalho foi de 224V, 
pois esta é a tensão gerada pelo equipamento que está mais próxima dos valores encontrados na literatura (Langton e Njeh (2004)).

Na técnica de inserção, o pé foi posicionado entre os transdutores e permanecia, durante cinco minutos, em repouso até a aquisição dos sinais temporais.

\subsubsection{Resultados obtidos das BUAs (BUAtot e BUAsel,) e das velocidades do som (Vzero e Vpico).}

Na figura 4.4.3, tem-se o gráfico dos valores médios da BUAtot e BUAsel, com seus respectivos desvios padrão, avaliados pela técnica de contato e inserção convencional, para o calcanhar de um único voluntário como função da freqüência dos transdutores.

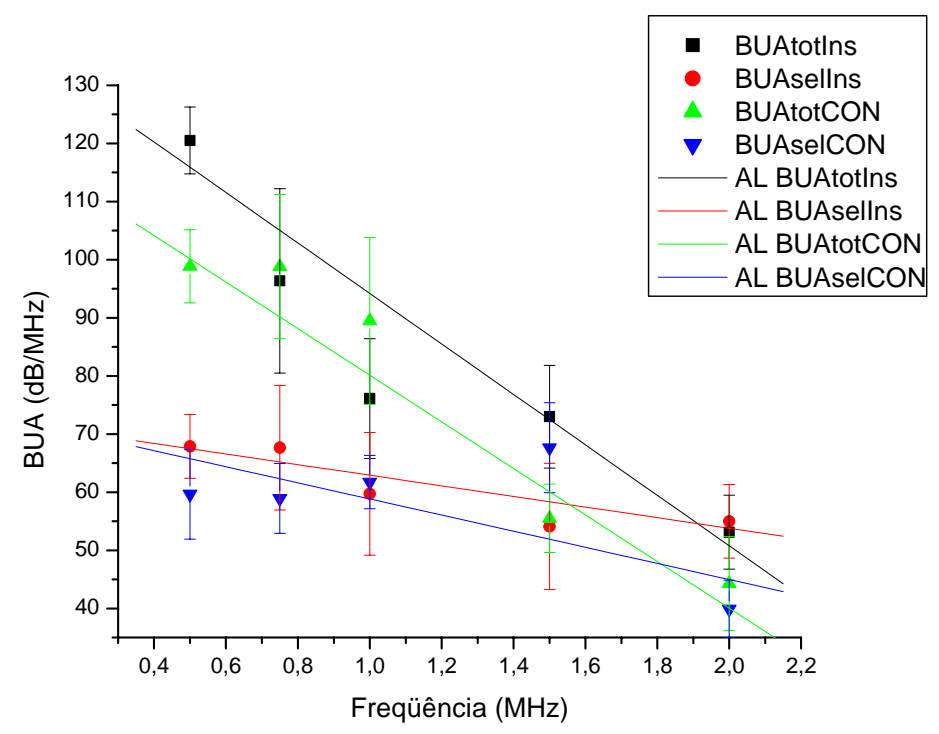

Figura 4.4.3. Resultados da BUAtot e BUAsel, avaliadas pelas técnicas de contato (CON) e inserção convencional (Ins), para o calcanhar de um único voluntário como função da freqüência dos transdutores.

Conforme apresentado na figura 4.4.3, os valores de BUA para a técnica de inserção foram maiores que os valores da técnica de contato, independente da forma de análise, se foi utilizado o sinal total ou a janela temporal do sinal. Foi possível observar que, os valores para a BUAtot, para a técnica de inserção e contato, foram maiores que os respectivos valores da BUAsel. Entretanto, quando comparados os valores da BUAtotIns com BUAtotCON os seus valores são bem distintos (diferentes), sendo que, os da BUAtotIns são maiores e a única 
exceção foi para o par de 0,75MHz, onde seus valores médios são próximos, independentes da técnica. Essa variação, entre as técnicas utilizadas, está em concordância com o que foi apresentado por Strelitzki e Evans (1998), observaram que a BUA possui uma grande dependência com a estrutura interna do osso, mas perceberam que a técnica usada pode causar uma diferença na atenuação. Para a técnica de inserção (em um tanque com água) a perda foi de aproximadamente 0,6 dB/MHz, enquanto que na técnica de contato (transdutor encostado na amostra) foi de $10 \mathrm{~dB} / \mathrm{Mhz}$, assim produzindo um erro considerável na medida.

A variação da BUAtotIns e BUAtotCON (figura 4.4.3), em função da freqüência dos transdutores é mais acentuada, quando comparados com seus respectivos valores da BUAsel, apresentando resultados bem distintos para cada freqüência. Contudo, conforme aumenta a freqüência diminui-se o valor da BUA. Para, BUAselIns e BUAselCON a inclinação é menos acentuada, apresentando valores aproximadamente iguais entre as freqüências dos transdutores, principalmente para os pares de baixa freqüência (RS, $C D$ e $A B$ ). Os coeficientes de correlação entre BUAtotIns, BUAselIns, BUAtotCON e BUAselCON como função da freqüência dos transdutores foram, respectivamente: $-0,97(p=0,007),-0,94$ $(\mathrm{p}=0,01),-0,97(\mathrm{p}=0,003)$ e $-0,75(\mathrm{p}=0,14)$. Portanto, o único que não apresentou um fator estatisticamente relevante foi a BUAselCON, mas apresentou uma inclinação negativa estando de acordo com o esperado.

Na tabela 4.4.1, são apresentados os valores médios da BUA com seus respectivos desvios padrão, encontrados na literatura, sendo que, os valores são para voluntários normais, análise feita no calcanhar e ampla faixa etária.

Os valores de BUA, apresentados na tabela 4.4.1, foram obtidos através de equipamentos comerciais, os quais, possuem freqüências nominais de $0,5 \mathrm{MHz}$ e $1,0 \mathrm{MHz}$.

Comparando os valores da tabela 4.4.1 com os resultados da figura 4.4.3, observa-se, para mesma faixa etária do nosso voluntário, os valores médios para BUAtot (inserção ou contato) nas freqüências de $0,5 \mathrm{MHz}$ e $1,0 \mathrm{MHz}$, estão próximos tanto na média quanto no desvio padrão. De acordo com a tabela 4.4.1, os coeficientes de variação são da ordem de 1,3\% até 29\% nos trabalhos de Karlsson et al. (2001) e Waud et al. (1992), respectivamente. $\mathrm{Na}$ figura 4.4.3, para a freqüência de $0,5 \mathrm{MHz}$ os valores de BUAtot foram: $120,5 \pm 5,75$

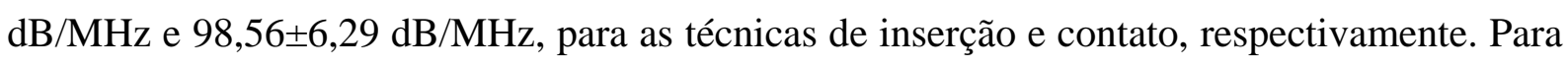

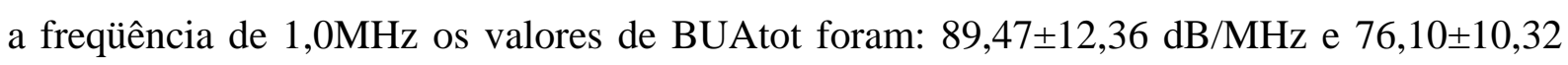
$\mathrm{dB} / \mathrm{MHz}$, para as técnicas de inserção e contato, respectivamente. Os coeficientes de variação, dos transdutores de $0,5 \mathrm{MHz}$, são iguais a 4,8\% e 6,4\% e dos transdutores de $1,0 \mathrm{MHz}$ foram de: $13,5 \%$ e 13,8\%, para as técnicas de inserção e contato, respectivamente. 
Estes resultados, demonstram que os coeficientes de variação obtidos para este voluntário estão condizentes com o que é encontrado na literatura em relação a variação da média em curto prazo. Contudo, a técnica de contato apresentou a maior variação percentual com relação a média.

Tabela 4.4.1 - Valores médios e desvio padrão da BUA encontrados nas referências. Valores para o calcanhar de voluntários normais e faixa etária (em anos).

\begin{tabular}{lcc}
\hline PESQUISADOR & BUA (dB/MHz) & $\begin{array}{c}\text { Faixa Etária } \\
\text { (anos) }\end{array}$ \\
\hline Agren, et al (1991) & $70,2 \pm 2,9$ & $55,7 \pm 2,2$ \\
\hline Zagzebski, et al (1991) & $89,4 \pm 11,6$ & $20-47$ \\
\hline Damilakis, et al (1992) & $66,1 \pm 3,4$ & $25-87$ \\
\hline Waud, et al (1992) & $66,0 \pm 19,0$ & $35-83$ \\
\hline Herd, et al (1993) & $66,0 \pm 17,0$ & $20-45$ \\
\hline Kotzki, et al (1994) & $120,0 \pm 11,0$ & $29-47 / 75-97$ \\
\hline Ross, et al (1995) & $63,2 \pm 13,4$ & $73,7 \pm 5,1$ \\
\hline Graafmans, et al (1996) & 75,0 & $40 \pm 10$ \\
\hline Hans, et al (1996) & $101,7 \pm 9,5$ & $80,4 \pm 3,7$ \\
\hline Lochmüller, et al (1998) & $95,0 \pm 14,7$ & $82,4 \pm 9,3$ \\
\hline Hadji, et al (1999a) & $114,6 \pm 11,4$ & $30-39$ \\
\hline Pluskiewicz, et al (1999) & $108,7 \pm 9,5$ & $36-79$ \\
\hline Hadji, et al (1999b) & $116,0 \pm 9,8$ & $45,8 \pm 6,2$ \\
\hline McCloskey, et al (1990b) & $79,6 \pm 1,1$ & $22-44$ \\
\hline Hadji, et al (2000a) & $109,4 \pm 10,8$ & $48-79$ \\
\hline Landin-Wilhelmsen, et al & $118,6 \pm 13,9$ & $25-34$ \\
\hline Ko00) & $105,0 \pm 7,0$ & $34,0 \pm 7,4$ \\
\hline Karlsson, et al (2001) & $134,1 \pm 1,8$ & \\
\hline Drozdzowska, et al (2001) & $95,9 \pm 10,9$ \\
\hline Naganathan, et al (2002) & $89,7 \pm 5,8$ \\
\hline Welch, et al (2004) & $90,1 \pm 17,6$ & \\
\hline
\end{tabular}


Conforme as barras de erro apresentadas na figura 4.4.3, as maiores variações estão para a técnica de contato (BUAtot e BUAsel) e para o par de transdutores de $2 \mathrm{MHz}$, atingindo valores de até $18 \%$ de variação em relação à média, entretanto, os outros transdutores não apresentaram valores maiores que $14 \%$ da média.

Na figura 4.4.4, tem-se o gráfico dos valores médios da Vzero e Vpico, com seus respectivos desvios padrão, avaliados pela técnica de contato e inserção convencional, para o calcanhar de um único voluntário como função da freqüência dos transdutores.

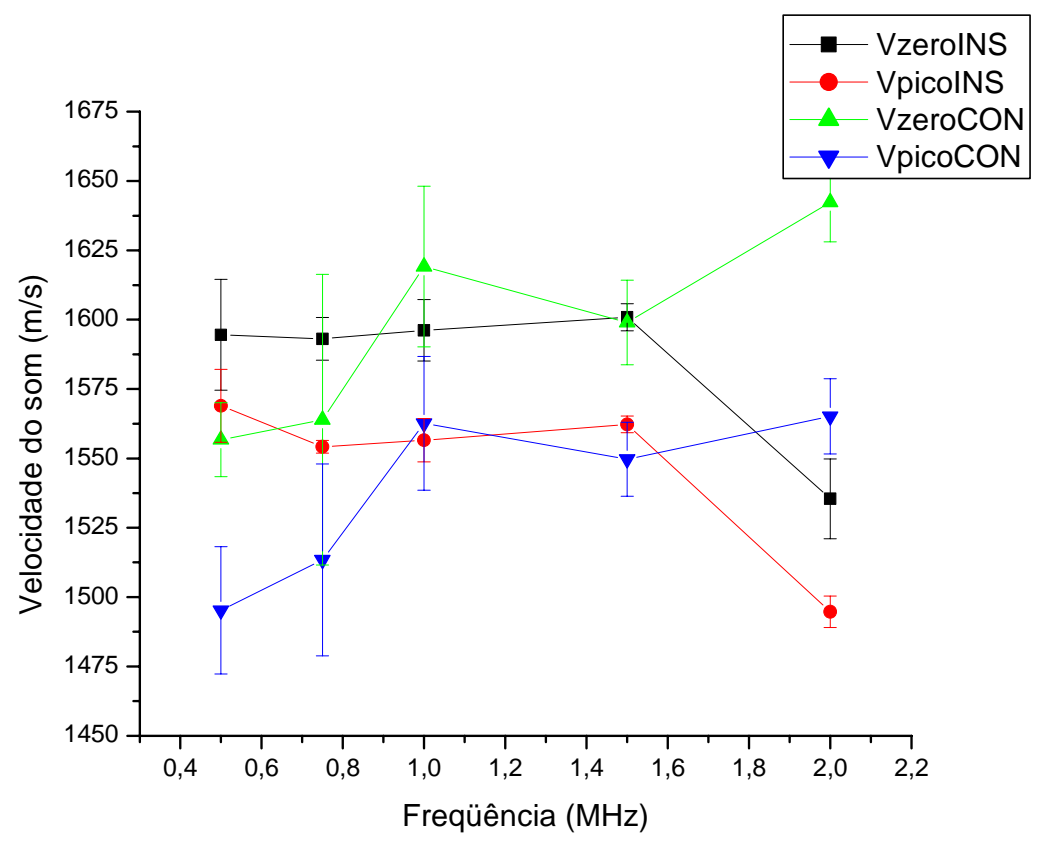

Figura 4.4.4. Valores da média das velocidades do calcanhar de um único voluntário, com seus respectivos desvios padrão, como função da freqüência dos transdutores.

Os valores de velocidade Vzero, apresentados na figura 4.4.4, obtidos pela técnica de inserção e contato são, aproximadamente iguais e o mesmo ocorre para os valores de Vpico. Os transdutores de 1,0 e 1,5MHz são os que possuem valores médios mais próximos, enquanto, os transdutores de $2 \mathrm{MHz}$ apresentam a maior diferença entre as técnicas. A variação observada pode ser devido à relação sinal ruído do nosso sistema. Na técnica de contato o ruído no sinal recebido foi maior que do sinal obtido pela técnica de inserção.

Os coeficientes de variação obtidos pela técnica de inserção para as velocidades (Vzero e Vpico) não foram superiores a 1,2\% da média, contudo, para a técnica de contato os valores aproximaram-se de 3,3\%. Sendo, estes coeficientes de variação baixos, obtemos uma boa reprodutibilidade para as medidas de velocidade, e principalmente, quando analisada a velocidade de primeiro pico a dispersão se tornou ainda menor. 
Comparando os valores das velocidades da figura 4.4.4 com os da tabela 2.1.1 do capítulo 2 (seção 2.1.7), observa-se que as velocidades da tabela 2.1.1 variam de 1400 a 1600 $\mathrm{m} / \mathrm{s}$ em média, sendo comparáveis com os valores da figura 4.4.4.

\subsubsection{RESULTADOS DA BUA E DA VELOCIDADE DO SOM PARA O CALCANHAR DE VOLUNTÁRIOS AVALIADOS PELA TÉCNICA DE CONTATO.}

Serão apresentados os resultados obtidos para a BUA (BUAtot e BUAsel) e velocidade do som (Vzero e Vpico) para os voluntários de faixa etária entre 19 a 77 anos. As medidas foram feitas no calcanhar do pé direito, entretanto, o transdutor emissor estava incidindo sobre o lado externo do pé.

\subsubsection{Resultados da Velocidade do Som para os Voluntários.}

Nas figuras 4.4.5, 4.4.6 e 4.4.7, são apresentados os resultados da velocidade do som como função da idade, do BMI e da espessura do calcanhar, respectivamente.

Os coeficientes de correlação, entre a velocidade do som e a idade foram, para Vzero e Vpico, -0,64 ( $\mathrm{p}<0,0001)$ e -0,55 ( $\mathrm{p}=0,0002),-0,54(\mathrm{p}=0,0001)$ e $-0,30(\mathrm{p}=0,05),-0,68$ $(\mathrm{p}<0,0001)$ e $-0,66(\mathrm{p}<0,0001),-0,45(\mathrm{p}=0,002)$ e $-0,17(\mathrm{p}=0,28)$, e $-0,39(\mathrm{p}=0,01)$ e $-0,12$ $(\mathrm{p}=0,44)$, para os transdutores de $0,5 \mathrm{MHz}, 0,75 \mathrm{MHz}, 1,0 \mathrm{MHz}, 1,5 \mathrm{MHz}$ e $2 \mathrm{MHz}$, respectivamente. Apresentam a tendência em diminuir o valor da velocidade do som com o aumento da idade (figura 4.4.5). Embora, a dispersão ao redor da linha do ajuste linear seja grande, principalmente para os pares de 1,5 e 2,0 MHz, foi possível observar a variação em função da idade, para todos os transdutores, lembrando que os voluntários foram considerados, a princípio saudáveis, sem nenhuma patologia óssea. 


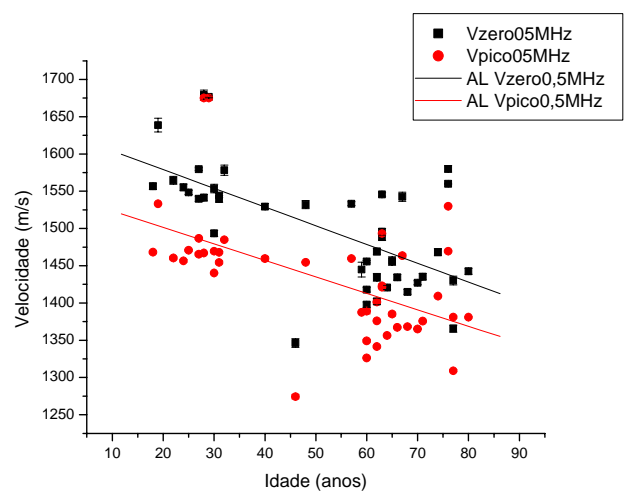

a)

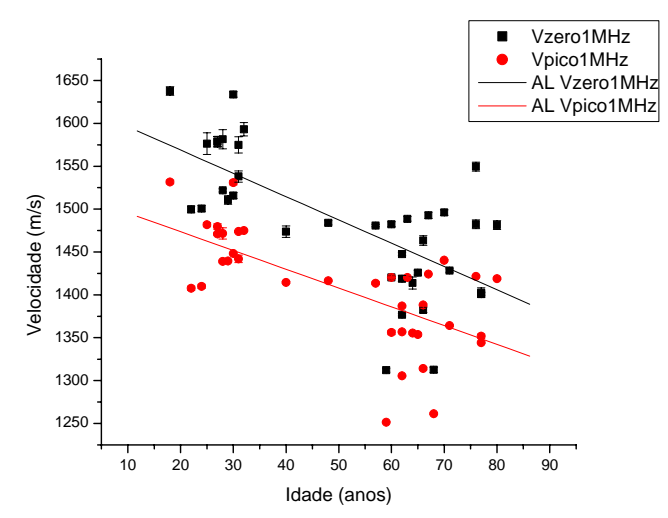

c)

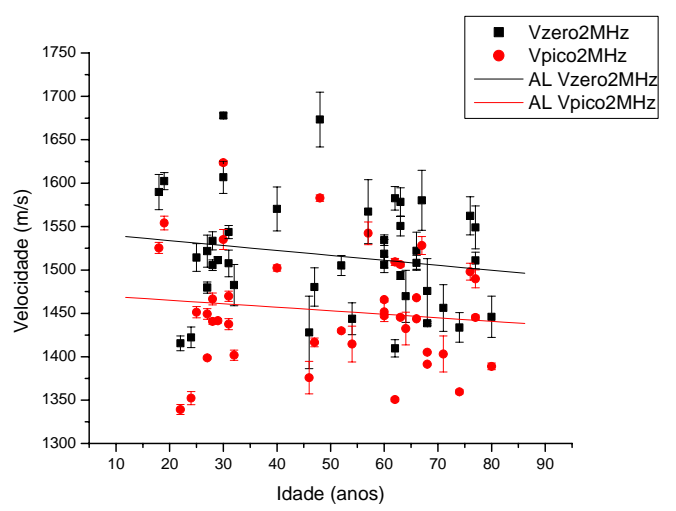

e)

Figura 4.4.5. Velocidade do som (Vzero e Vpico) em função da idade dos voluntários com seus respectivos ajustes lineares. Em: a) Transdutores de 0,5MHz, b) Transdutores de 0,75MHz, c) Transdutores de 1,0MHz, d) Transdutores de 1,5MHz e em e) Transdutores de 2,0MHz.

A diferença média entre os valores de velocidade do som Vzero e Vpico foi de aproximadamente de $100 \mathrm{~m} / \mathrm{s}$. Essa mudança no referencial do sinal temporal, além de provocar uma diminuição nos valores de velocidade do som, deixou a variação em função da idade menos sensível. Por exemplo, para os transdutores de $1 \mathrm{MHz}$ a perda em velocidade como função da idade (por ano) foi de $0,17 \%$ para o Vzero e de $0,14 \%$ para o Vpico. 
Entretanto, as perdas percentuais em função da idade estão condizentes com o que se encontra na literatura (Waud, Lew e Baran (1992), Herd et al (1993), Hadji et al (1999a), Hadji et al (1999b), Pluskiewicz e Drozdzowska (1999), Hadji et al (2000a), Kim et al (2000) e Wehbe et al (2003)). Contudo, os pares de 1,5 e 2,0 MHz, são os que apresentam a menor sensibilidade com a variação da idade.

Comparando os valores das velocidades da figura 4.4.5 com os da tabela 2.1.1 do capítulo 2 (seção 2.1.7), observa-se que as velocidades da tabela 2.1.1 variam de 1400 a 1600 $\mathrm{m} / \mathrm{s}$ em média, sendo comparáveis com os valores da figura 4.4.5. Mesmo sem ter a definição precisa do referencial no sinal temporal, foi possível obter valores médios da velocidade do som próximos dos encontrados na literatura.

De acordo com a figura 4.4.6, o coeficiente de correlação entre a velocidade do som e BMI não se apresenta conclusivo. Para os transdutores de $2 \mathrm{MHz}$ o coeficiente de correlação foi de $-0,05(p=0,73)$ e $-0,06(p=0,67)$, para a Vzero e Vpico, respectivamente. Os transdutores de 1,5MHz apresentaram um coeficiente de correlação de -0,28 (p=0,06) e -0,20 $(p=0,21)$ para a Vzero e Vpico, respectivamente. Entretanto, para os transdutores de $1 \mathrm{MHz}$ os coeficientes de correlação foram iguais a $-0,26(p=0,12)$ e $-0,22(p=0,19)$, para Vzero e Vpico, respectivamente. $O$ coeficiente de correlação foi de $-0,20(p=0,18)$ e $-0,16(p=0,30)$, para Vzero e Vpico, nos transdutores de 0,75MHz. Já para os transdutores de 0,5MHz, para Vzero e Vpico, o coeficiente de correlação foi de $-0,28(p=0,06)$ e $-0,28(p=0,06)$, respectivamente.

Os valores dos coeficientes de correlação entre a velocidade do som (Vzero e Vpico) e BMI, foram todos negativos independente do par de transdutores utilizados.

Magkos et al (2005), encontrou um coeficiente de correlação, entre a velocidade do som e a BMI, igual a 0,09 ( $<<0,05)$. No trabalho de Pluskiewicz e Drozdzowska (1999), o coeficiente de correlação entre a velocidade e a BMI foi de 0,09 $(\mathrm{p}<0,05)$. LandinWilhelmsen et al (2000), determinaram o coeficiente de correlação, para um grupo de 184 homens, de -0,12 e para um grupo de 1319 mulheres de 0,04, sendo que, o fator de relevância não foi especificado em nenhum dos casos. Conforme, apresentados por estes autores e discussões em seus trabalhos, não existe boa correlação entre a velocidade do som e a BMI. Entretanto, foi possível observar existência de coeficientes negativos e positivos nos valores encontrados na literatura. 


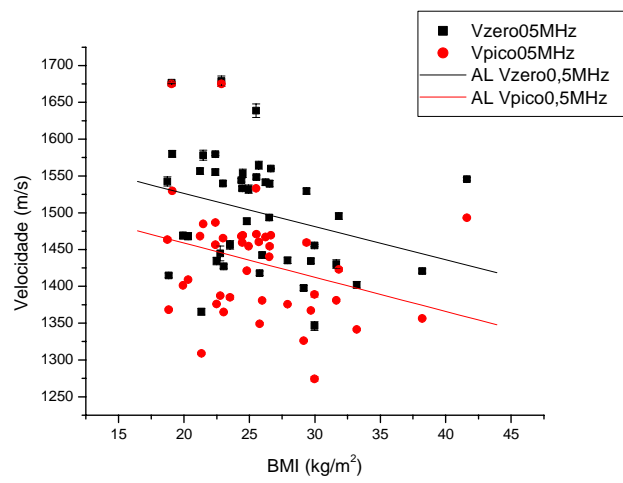

a)

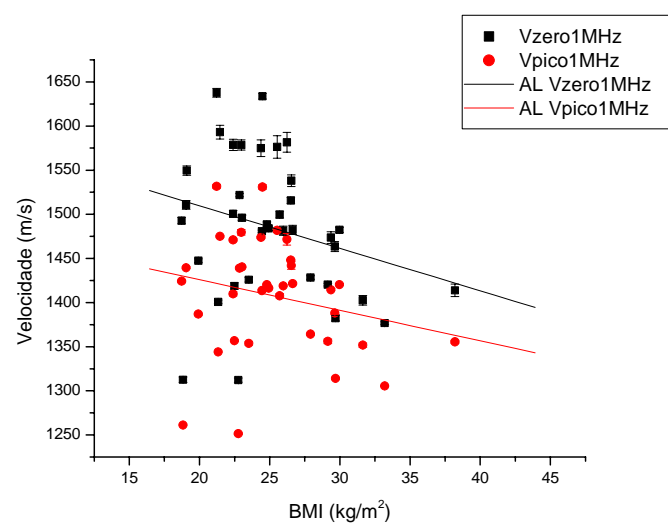

c)

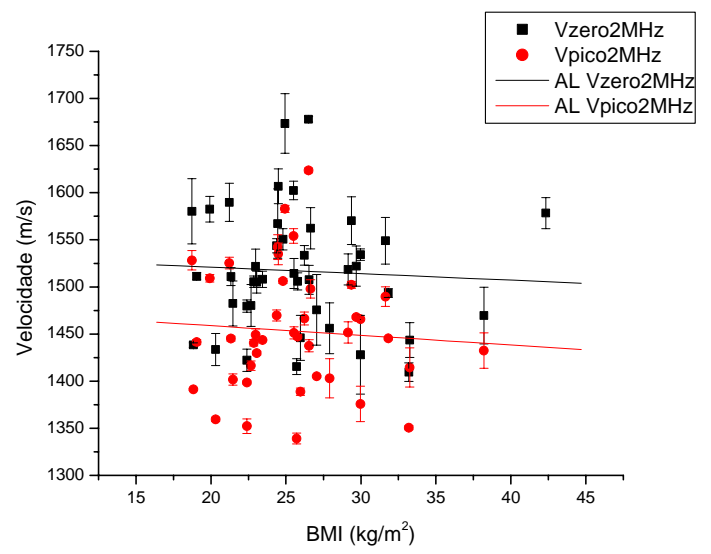

e)

Figura 4.4.6. Velocidade do som (Vzero e Vpico) em função do BMI dos voluntários com seus respectivos ajustes lineares. Em: a) Transdutores de 0,5MHz, b) Transdutores de 0,75MHz, c) Transdutores de 1,0MHz, d) Transdutores de 1,5MHz e em e) Transdutores de 2,0MHz.

Na figura 4.4.7, são apresentados os valores da velocidade do som em função da espessura do calcanhar dos voluntários, para todos os pares de transdutores com seus respectivos ajustes lineares.

O par de transdutores de $0,5 \mathrm{MHz}$ apresentou coeficientes de correlação iguais a $-0,39$ $(\mathrm{p}=0,009)$ e $-0,36(\mathrm{p}=0,02)$, para Vzero e Vpico, respectivamente. Contudo, os transdutores 
de $0,75 \mathrm{MHz}$ possuem coeficiente de correlação igual a $-0,28(\mathrm{p}=0,05)$ e $0,10(\mathrm{p}=0,52)$, para Vzero e Vpico, respectivamente. Para os pares de 1, 1,5 e 2MHz os coeficientes de correlação de Vzero e Vpico em função da espessura do calcanhar foram: -0,35 ( $p=0,03),-0,34(p=0,04)$, $-0,24(\mathrm{p}=0,11),-0,39(\mathrm{p}=0,01), 0,19(\mathrm{p}=0,23)$ e $0,16(\mathrm{p}=0,30)$, respectivamente.

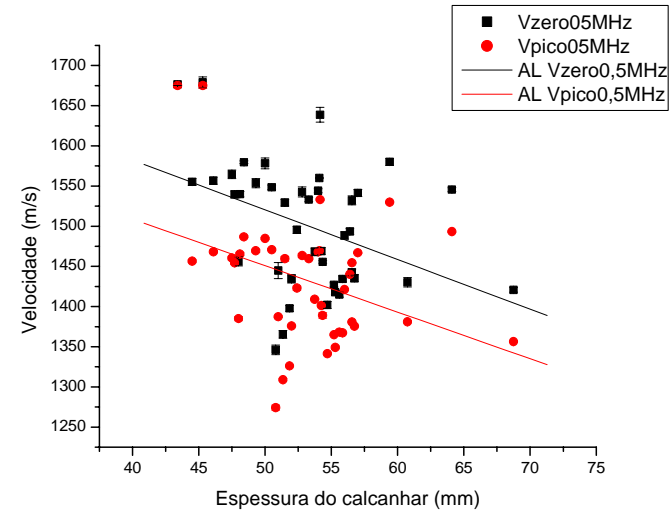

a)

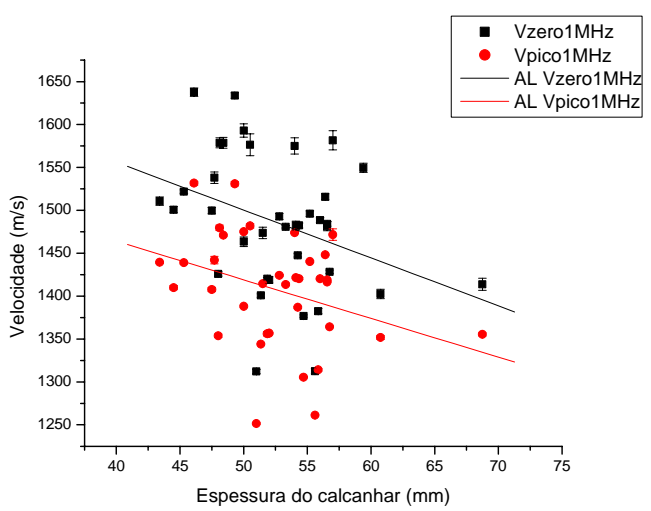

c)

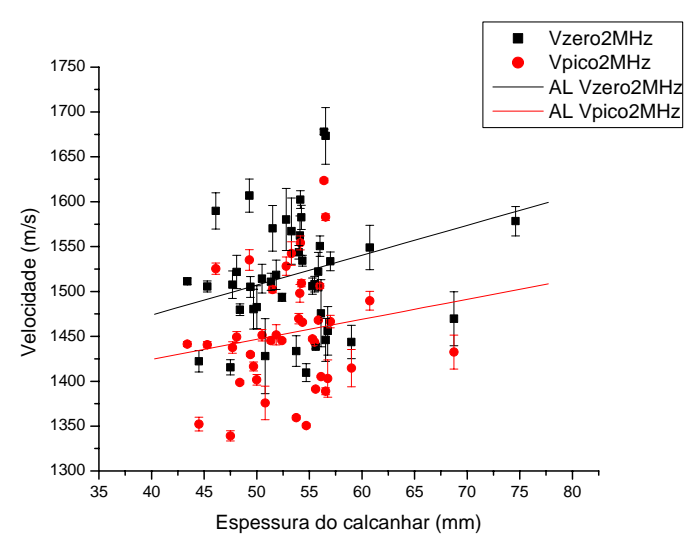

e)

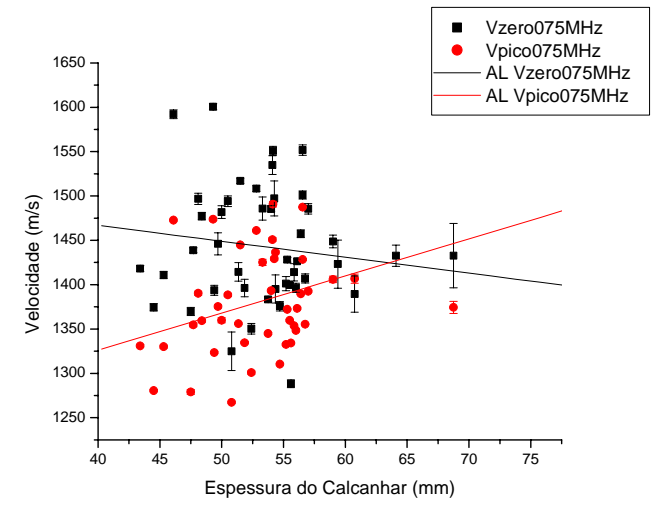

b)

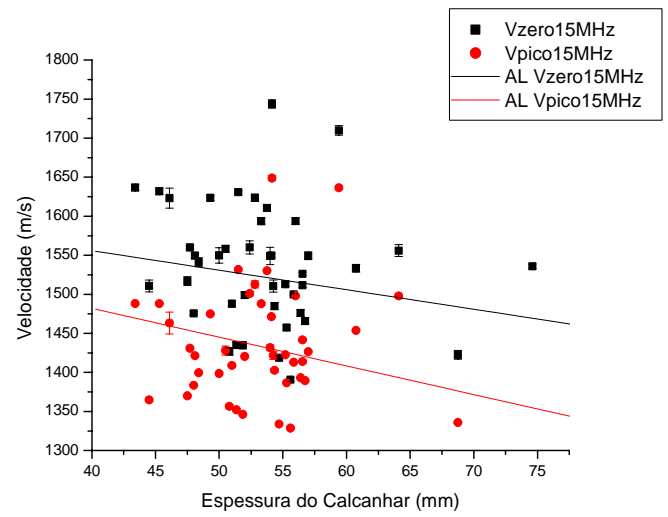

d) 
Destacam-se, nesses valores de coeficientes, os da Vpico (0,75MHz) e Vzero e Vpico (2MHz), pois estes apresentaram valores positivos de seu coeficiente de correlação e inclinações positivas. Entretanto, para os outros valores existe um coeficiente negativo, embora, não haja em todos uma estatística significantemente relevante.

Kotzki et al (1994), num total de 30 calcanhares, obtiveram um coeficiente de correlação entre a velocidade no calcanhar e a espessura igual a $-0,27(\mathrm{p}<0,0001)$. Toyras et al. (1999), analisaram um grupo de 34 mulheres, obtiveram como coeficiente de correlação (entre a velocidade do som e a espessura do calcanhar) o valor de $-0,35(\mathrm{p}=0,04)$.

Conforme apresentado por Kotzki et al (1994) e Toyras et al. (1999), nossos valores estão condizentes com aqueles apresentadas em seus trabalhos, exceto o par de $2 \mathrm{MHz}$, que apresentou um coeficiente de correlação positivo em sua variação.

\subsubsection{Resultados da BUA para os Voluntários.}

Na figura 4.4.8, são apresentados os gráficos da BUA (BUAtot e BUAsel) como função da idade, para todos os pares de transdutores.

Comparando os valores de BUA da figura 4.4.8 com os da tabela 4.4.1, pode-se notar que nossos resultados são, em geral, da mesma ordem de grandeza, embora a variação relativa entre eles seja muito superior ao aceitável.

Na tabela 4.4.2, é apresentada a variação dos valores da BUA, obtidos por diversos autores, para diferentes grupos de faixa etária. Sendo que, os mais jovens apresentam maiores valores de BUA.

Neste trabalho, para o par de 0,5MHz, a variação da BUA foi de (58-152) dB/MHz e (40-108) dB/MHz para BUAtot e BUAsel, respectivamente, lembrando, neste grupo a idade varia entre 19 e 77 anos. Estes resultados, para os três pares de transdutores de menor freqüência, são similares. Entretanto, para os pares de $1,5 \mathrm{MHz}$ e 2,0MHz observou-se o contrário, ocorreu uma variação positiva com a idade e os voluntários idosos apresentam maiores valores de BUA.

É observada, na literatura, a existência da correlação negativa entre a BUA e a idade. Hadji et al (1999a), estudou um grupo de 108 mulheres alemãs de idade entre 30 a 39anos, as quais apresentaram uma diminuição da BUA em função da idade de 0,27\% ao ano. 
Pluskiewicz e Drozdzowska (1999), avaliaram um grupo de 601 mulheres saudáveis obtendo uma variação percentual igual a $0,42 \%$ ao ano de diminuição no valor da BUA. Hadji et al (2000a), estudou um grupo de 1314 mulheres de idade entre 48 a 79anos, sendo que, apresentaram uma diminuição da BUA em função da idade de $0,4 \%$ ao ano. No estudo feito por Kim et al (2000), a variação da BUA em função da idade foi de 0,20\% ao ano.

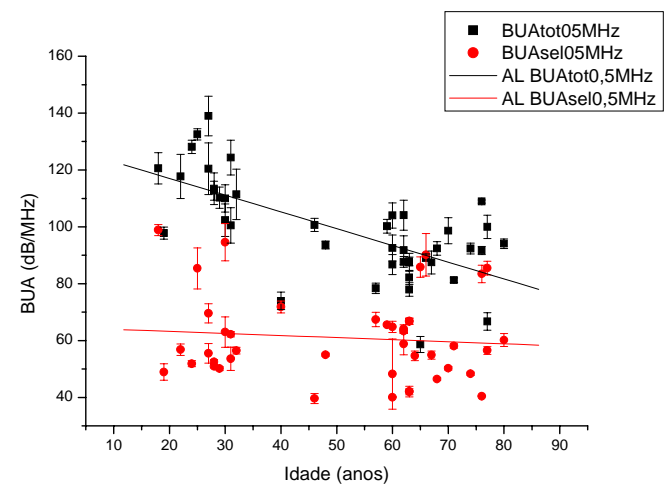

a)

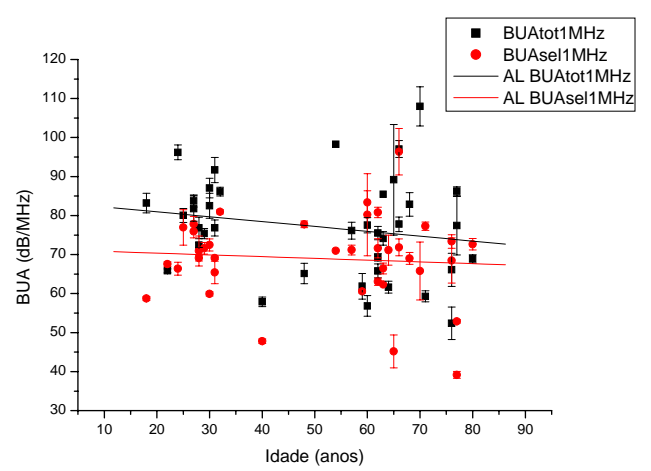

c)

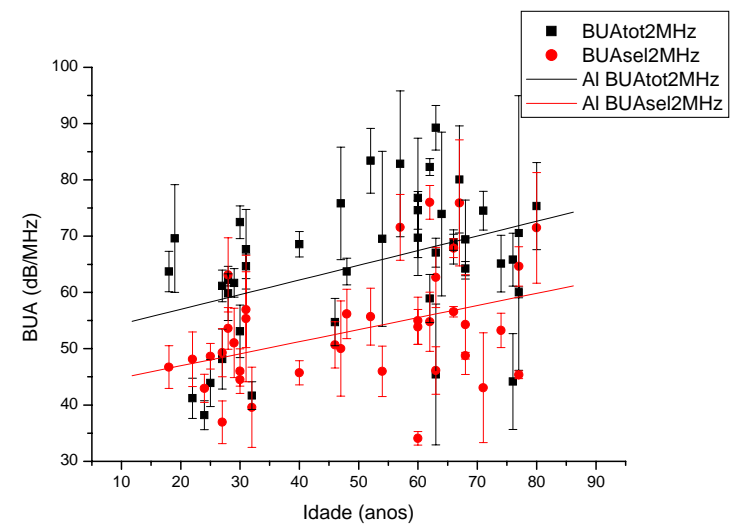

e)

Figura 4.4.8. BUA (BUAtot e BUAsel) em função da idade dos voluntários com seus respectivos ajustes lineares. Em: a) Transdutores de 0,5MHz, b) Transdutores de $0,75 \mathrm{MHz}$, c) Transdutores de $1,0 \mathrm{MHz}, \mathrm{d}$ ) Transdutores de 1,5MHz e em e) Transdutores de 2,0 MHz.

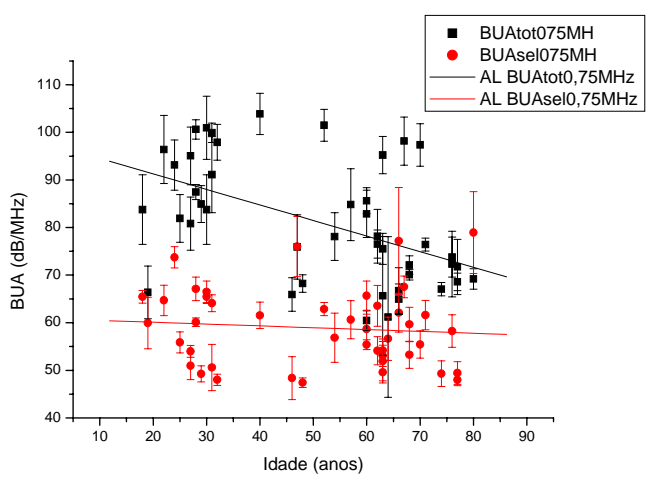

b)

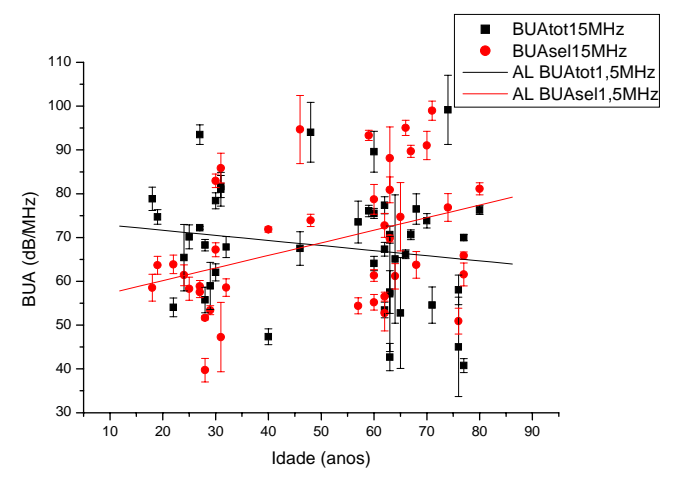

d) 
Tabela 4.4.2 - Variação dos valores da BUA para uma faixa etária ampla determinada por diversos pesquisadores.

\begin{tabular}{ccc}
\hline Autor & Faixa etária (anos) & $\begin{array}{c}\text { Variação da BUA } \\
(\mathbf{d B} / \mathbf{M H z})\end{array}$ \\
\hline Waud, (1992) & $(35-83)$ & $(31-121)$ \\
\hline Damilakis, (1992) & $(25-87)$ & $(50-120)$ \\
\hline Funke, (1995) & $(11-81)$ & $(50-100)$ \\
\hline Graafmans, (1996) & $(40 \pm 10)$ & $(39-102)$ \\
& $(20-45)$ & $(54-111)$ \\
\hline Herd, (1993) & $(41-71)$ & $(39-123)$ \\
\hline
\end{tabular}

Na tabela 4.4.3, é apresentada a perda percentual anual da BUA, dos voluntários, para os transdutores utilizados neste trabalho. Observando que para os transdutores de 0,50, 0,75 e 1,0 MHz, existe um decréscimo no valor da BUA conforme aumenta a idade dos voluntários e seus valores são próximos dos encontrados na literatura. Entretanto, para os pares de transdutores de 1,5 e 2,0 MHz, foi observado um aumento no valor da BUA conforme aumentava-se a idade.

Tabela 4.4.3 - Porcentagem da perda anual nos valores da BUAtot e BUAsel, medidos no calcanhar, para todos os pares de transdutores utilizados neste trabalho.

\begin{tabular}{|c|c|c|}
\hline \multirow{2}{*}{$\begin{array}{c}\text { Freqüência dos } \\
\text { Transdutores (MHz) }\end{array}$} & \multicolumn{2}{|c|}{ Porcentagem de perda anual (\%) } \\
\cline { 2 - 3 } & BUAtot & BUAsel \\
\hline 0,50 & $-0,59$ & $-0,07$ \\
\hline 0,75 & $-0,33$ & $-0,04$ \\
\hline 1,00 & $-0,12$ & $-0,04$ \\
\hline 1,50 & $-0,11$ & 0,29 \\
\hline 2,00 & 0,26 & 0,21 \\
\hline
\end{tabular}




\section{CONCLUSÃO}

As análises efetuadas sobre as amostras controle mostraram que o sistema desenvolvido fornece medidas adequadas de velocidade e atenuação em freqüência, comprovando a estabilidade da instrumentação desenvolvida nas situações onde as relações geométricas e propriedades da amostra puderam ser mantidas sob controle e consideradas mais estáveis.

Nos resultados para a medida de velocidade em materiais plásticos e alumínio foi observado que os valores obtidos pela técnica de inserção convencional aproximam-se mais do valor esperado do que os obtidos pela técnica de contato. Este fato se deve predominantemente à camada de acoplamento, de acrílico, dos transdutores cuja espessura não foi considerada na equação para o cálculo de velocidade. Não houve, a princípio, uma preocupação específica quanto ao valor verdadeiro da velocidade e sim para o grau de variabilidade encontrado nas medidas. Conseqüentemente a medida de velocidade sofre a influência do tamanho, da espessura da camada de acoplamento e da freqüência central dos transdutores utilizados conforme também relatado por Langton e Njeh, 2004.

Na análise proporcionada pelo teflon, as velocidades encontradas não apresentaram dependência com a amplificação do sistema e nem com as diferentes tensões utilizadas, tanto para a técnica de inserção convencional, como a de contato.

Nos resultados para os voluntários, adotando Vzero ou Vpico como referência nas medidas, os valores de velocidade apresentaram-se próximos daqueles encontrados na literatura. A dispersão foi comparável nas duas formas de cálculo, podendo se prever, com certa segurança uma diminuição da velocidade medida no calcanhar com o aumento da idade, embora esta dependência não se deva exclusivamente às propriedades ósseas, mas tenha como componente indesejável a espessura de tecido mole que envolve o calcâneo. Uma diminuição da velocidade calculada é prevista com o avanço da idade, uma vez que o BMI cresce com o aumento da idade, como visto em nossos resultados e relatado por Kotzki, (1994). Os resultados obtidos tendem a se degradar para os transdutores de maior freqüência uma vez que os sinais são fortemente atenuados e também componentes indesejáveis podem ser introduzidas pelos transdutores de 0.75 e $2.0 \mathrm{MHz}$ uma vez que apresentam duas regiões distintas e predominantes no espectro em frequência. 
A técnica de contato em geral apresentou maior dispersão do que a de inserção e isto se deve à existência de um maior grau de indeterminação nas posições do transdutor, sendo parâmetro de relevância a distância entre os mesmos. Estes problemas se acentuam principalmente nos experimentos envolvendo medidas de velocidade do som para as tíbias, embora não exista, neste caso, a presença de tecido mole sobre o osso. Nestes experimentos pode-se perceber uma certa constância para a velocidade medida nas tíbias saudáveis, principalmente quando se usa a técnica de inserção, e uma diminuição da velocidade medida nas tíbias na presença dos calos, para qualquer uma das técnicas usadas. O que se pode avaliar é que o tecido fibroso do calo ósseo apresenta velocidade menor do que o tecido ósseo cortical.

Variações ocorridas nos valores absolutos de velocidade do som para as tíbias, usando as duas técnicas, podem estar associados também à divergência e ao eixo do campo ultrasônico do par EF de transdutores. Na incidência de 90 graus as amostras possuem uma região de incidência do sinal ultra-sônico de aproximadamente 15,5mm em média, cobrindo totalmente a área do transdutor que possui $12 \mathrm{~mm}$ de diâmetro. Enquanto, para a orientação 180 graus a região de incidência da peça é de aproximadamente 13,3mm em média, sendo que, existem algumas peças que possuem uma região de $12 \mathrm{~mm}$, igual ao diâmetro do transdutor.

Nos valores encontrados, na análise da BUAsel para o teflon, foi observado que existe uma melhor resposta do sistema e uma menor variação, quando comparados com a BUAtot. A análise baseada na BUAsel, quando aplicada a janela no sinal temporal exclui algumas reflexões (das interfaces) e possíveis ruídos devido ao sistema. O quanto isto pode excluir informações importantes é um fato a ser considerado merecendo maiores estudos. Esta forma de avaliação mostrou uma concordância maior com os valores de BUA relatados na literatura. A BUAtot apresentou valores maiores que a BUAsel, isto devido à consideração do sinal como um todo e as reflexões que se somam ao longo do percurso aumentam a complexidade do sinal recebido e, conseqüentemente, alteram os valores calculados.

As variações, a longo prazo observadas para o teflon, podem ter sido influenciadas pela variação da distância e alinhamento entre os transdutores, da posição da amostra e da temperatura ambiente e do banho térmico.

É observado, que os valores obtidos para BUAtot e BUAsel, além de possuírem a dependência com o tamanho da amostra, o que seria esperado, possuem uma grande dependência com os transdutores utilizados. A influência da tensão sobre a BUAsel foi menor 
que na BUAtot, sendo que, na BUAsel os valores obtidos são aproximadamente constantes, entre as três tensões.

A análise da BUA, para as tíbias de carneiro, se trata de um procedimento original, para a qual não foi encontrada nenhuma referência bibliográfica. Também não se encontrou referências para a aplicação da BUA em ossos longos (predominantemente cortical) mesmo sabendo que estes sofrem variações com a osteoporose, como comentado por Njeh et al (1999), onde diz que a osteoporose provoca um decréscimo da espessura da cortical e deterioração da competência mecânica do osso.

A técnica BUAnews mostrou bons coeficientes de correlação, nas análises por contato e por inserção, entretanto, esta forma de análise avalia o material constituinte do calo e não o osso como um todo como ocorre na análise transversal da amostra óssea, podendo apresentar algumas informações a mais com relação a este material.

Os valores de BUAtot apresentam dependência com a variação da idade dos voluntários, o mesmo não ocorrendo para a BUAsel que praticamente não sofreu variação, sendo pouco sensível. Isto ocorreu para os transdutores de 0,5, 0,75 e 1,0MHz. Para os pares de 1,5 e 2,0MHz sua variação em função da idade foi baixa sendo até positiva para o par de $2 \mathrm{MHz}$, contrariando o observado na bibliografia.

A BUAsel apresenta valores médios menores e uma variação também menor do que os outros. A baixa variação em torno da média, dos valores da BUAsel, traz uma boa perspectiva com relação a diminuição das flutuações encontradas na técnica. Apesar da BUAsel mostrarse pouco influenciada pela variação da idade dos voluntários, seria interessante rever a região de seleção do sinal para que se tenha certeza do que realmente pode ou não ser excluído na janela do sinal temporal para o cálculo da BUA.

A utilização neste trabalho dos pares de transdutores com várias freqüências demonstraram, realmente, que os de freqüências altas não são bons para este tipo de análise óssea. Para os resultados de BUA as freqüências de 1,5 e $2 \mathrm{MHz}$ parecem não trazer informações consistentes, possivelmente devido a forte atenuação do sinal. Os pares de transdutores de mais alta freqüência são os que apresentam a pior resposta em todas as análises feitas no trabalho.

A técnica de contato transversal apresentou valores adequados do coeficiente de correlação para as velocidades e para a BUAtot na tíbia e nos calos, Contudo, se torna inviável para uma aplicação in vivo considerada a dificuldade de acesso ao osso.

Se procurarmos, na última década, serão encontrados centenas trabalhos envolvendo a USO. Trabalhos como: de Magkos et al. (2005), em que consideram que a USO pode ser 
utilizada na avaliação do risco de fratura, de Welch et al. (2004), onde concluem que o US do calcanhar pode proporcionar algumas informações sobre o osso saudável, explicando a perda óssea tardia, de Drozdzowska e Pluskiewicz (2001), concluíram que a técnica é boa e serve para acompanhar a evolução da condição óssea das filhas de mães osteoporóticas, de Kim et al. (2000), dizem que a técnica é um método proveitoso para estudos populacionais, mas para tanto um método de medida padrão e um critério de diagnóstico são necessários e de Hadji et al. (2000a), comentam que o QUS proporciona um gradiente do risco de fratura comparável com a densitometria óssea por raios $\mathrm{X}$ no esqueleto axial, e demonstram que esta técnica continua sendo aplicada com várias finalidades, principalmente para: triagem populacional, análises de novas patologias ósseas, avaliação de doenças ósseas que acometem crianças, variação do status ósseo devido a reposição hormonal e é claro o diagnóstico da osteoporose, como comentado na introdução deste trabalho (capítulo 1).

Podemos concluir com nossos resultados que a técnica de inserção possui uma dispersão menor que a técnica de contato. A velocidade do som é uma forma de análise do status ósseo que é menos sensível as variações devido a posição do calcanhar e se apresentou consistente em ambas as técnicas (contato e inserção convencional) e pode ser um bom parâmetro para monitoração se for possível excluir a influencia de tecido mole ao redor do calcâneo, para isto um sistema pulso eco deve ser usado para dimensionar esta espessura. As formas de cálculo da BUA (BUAtot, BUAsel e BUAnews) apresentadas sofreram influências principalmente da variação da posição da amostra óssea, contudo a BUAsel mostrou-se mais eficiente, pois mesmo quando ocorria a mudança de par de transdutores a variação no valor médio foi pequeno. As distribuições dos valores de BUA apresentam uma dispersão equivalente aquelas relatadas pela literatura, o que são explicáveis provavelmente pelas propriedades individuais dos transdutores como pudemos verificar, além das variações considerando a repetibilidade das posições seja do calcâneo ou da tíbia.

Pode-se notar que quando se avaliam os resultados de média a técnica guarda informações sensíveis às características ou propriedades do sistema ósseo, principalmente àquelas que se relacionam com a transformação óssea ao longo da idade, entretanto, existe uma variabilidade intrínseca à técnica que não se pode relacionar às propriedades individuais de uma dada amostra, uma vez que os sinais analisados são sensíveis às posições relativas do conjunto amostra/transdutor. Isto certamente restringe ou limita o uso da técnica quando se trata de quantificar as condições ósseas (osteoporose) para um dado indivíduo. 


\section{REFERÊNCIAS.}

Adam C, Eckstein F, Milz S, Schulte E, Becher C e Putz R. The distribution of cartiage thickness in the kneejoints of old-aged individuals - measurement by. A-mode ultrasound. Clinical Biomechanies.1998; (13): 1-10p.

Agren M, Karellas A, Leahey D, Marks S e Baran D. Ultrasound attenuation of the calcaneus: a sensitive and specific discriminator of osteopenia in postmenopausal women.

Calcif Tissue Int. 1991; (48): 240-244p.

Alves JM. Caracterização do tecido ósseo por ultra-som para diagnóstico de osteoporose. Tese de doutorado. São Carlos: IFSC-USP; 1996.

Baroncelli G, Federico G, Bertelloni S, Terlizzi F, Cadossi R e Saggese G. Bone. Quality assessment by quantitative ultrasound of proximal phalanxes of the hand in healthy subjects aged 3-21 Years. Pediatric Research 2001; (49): 713-718p.

Blanckaert F, Cortet B, Coquerelle P, Flipo R, Duquesnoy B e Delcambre B. Ultrasound velocity through the phalanges in normal and osteoporotic patients. Calcif Tissue Int. 1999; (64): 28-33p.

Bouxsein ML, Coan BS e Lee SC. Prediction of the strength of the elderly proximal femur by bone mineral density and quantitative ultrasound measurements of the heel and tibia. Bone. 1999; (25): 49-54p.

Camozzi V, Carraro V, Zangari M, Zangari M, Fallo F, Mantero F, et al. Use of quantitative ultrasound of the hand phalanges in the diagnosis of two different osteoporotic síndromes: Cushing`s syndrome and postmenopausal osteoporosis. J Endrocrinol Invest. 2004; (6): 510-515p.

Castro CH, Pinheiro MM, Szejnfeld VL. Pros and cons of the bone ultrasonography of calcaneal. Ver. Assoc. Med. Bras. Jan-Mar. 2000 46(1):63-69p.

Censo Demográfico, 2002. Instituto Brasilerio de Geografia e Estatística (IBGE). Disponível em: www.ibge.gov.br. 
Cepollaro C, Gonnelli S, Pondrelli C, Montagnani A, Martini S, Bruni D, et al. Osteogenesis imperfecta: Bone turnover, bone density, and ultrasound parameters. Calcif Tissue Int. 1999; (65):129-132p.

CEPOR - Centro de Pesquisa de Osteoporose do Rio de Janeiro. www.cepor.com

Cetin A, Erturk H, Celiker R, Sivri A, Hascelik Z. The role of quantitative ultrasound in predicting osteoporosis defined by dual X-ray absormetry. Rhematol. Int. Feb. 2001; 20(2):55-59p.

Chaffai S, Peyrin F, Nuzzo S, Porcher R, Berger G. e Laugier P. Ultrasonic characterization of human cancellous bone using transmission and backscatter measurements: relationships to density and microstructure. Bone. 2002; (30): 229-237p.

Chang SF. Explore the effectors of mineral density in community women. J Nurs Res. 2004;(4): 327-336p.

Chappard C, Camus E, Lefebvre F, Guillot G, Bittoun J, Berger G, et al. Evaluation of error bounds on calcaneal speed of sound caused by surrounding soft tissue. Journal of clinical densitometry. 2000; (3): 121-131p.

Cheng S, Fan B, Wang L, Fuerst T, Lian M, et al. Factors affecting broadband ultrasound attenuation results of the calcaneus using a gel-coupled quantitative ultrasound scanning system. Osteop. Intern. 1999; (6): 495-504p.

Clarke AJ, Evans AJ, Truscott JG, Milner R e Smith MA. A phantom for quantitative ultrasound of trabecular bone. Physics. Medicine Biololy. 1994; (39): 1677-1687p.

Cvijetic S, Baric I, Bolanca S, Juresa V e Ozegovic D. Ultrasound bone measurement in children and adolescents correlation with nutrition, puberty, anthropometry, and physical activity. Journal of Clinical Epidemiology. 2003;(56): 591-597p.

Damilakis J, Dretakis E e Gourtsoyiannis N. Ultrasound Attenuation of the Calcaneus in the Female Population: Normative Data. Calcif Tissue Int. 1992; (51): 180-183p. 
Damilakis J, Dretakis E e Gourtsoyiannis N. Imaging ultrasonometry if the calcaneus: dependence on calcaneal area. Calcif Tissue Int. 2000; (1): 24-28p.

Dong J, Zhang Z e Guo S. Measurement of tibia bone content and fracture threshold by quantitative ultrasonography in normal and fracture women in Taiyuan. Zhonghua Fu Chan Ke za Zhi. 1999; 34(2):71-73p. Chinese.

Drozdzowska B e Pluskiewicz W. Quantitative ultrasound at the calcaneus in premenopausal women and their postmenopausal mothers. Bone. 2001; (29): 79-83p.

Drozdzowska B, Pluskiewicz W, Boron A e Adamczyk P. Quantitative ultrasound at the hand phalanges in subjects with poor visual acuity. Maturistas. 2004a; (48): 265-269p.

Drozdzowska B. Skeletal status assessed by quantitative ultrasound at the calcaneus in females with bronchial asthma on prolonged corticosteroid therapy. Maturistas. 2005; (4) 386-392p.

Ekman A, Michaelsson K, Ljunghall, Mallmin H. Almost all institutionalized women are osteoporotic, when measured by hell and finger ultrasound. J. Intern. Med. Feb.; 2001; 249(2):173-180p.

Evans J e Tavakoli M. Ultrasonic attenuation and velocity in bone. Phys. Med. Biol. 1990; (35): 1387-1396p.

Feltrin GP, Nardin M, Marangon A, Khadivi Y, Calderone M e De Conti G. Quantitative ultrasound at the hand phalanges: comparison with quantitative computed tomograghy of the lurr bar spine in postmenopausal women. Eur. Radiol. 2000; 10(5): 826-831p.

Foldes AJ, Rimon A, Keinan D e Popovtzer M. Quantitative ultrasound of the tibia: a novel approach for assessment of bone status. Bone. 1995; (17): 363-367p.

Frost ML, Blake GM, Fogelman I. Can the WHO criteria for diagnosing osteoporosis be applied to calcaneal quantitative ultrasound?. Osteopor. Intern. 2000a; 11(4):321-330p. 
Frost ML, Blake GM e Fogelman I. Does quantitative ultrasound imaging enhance precision and discrimination? Osteoporos Int. 2000b; (11): 425-433p.

Frost ML, Blake GM e Fogelman I. Does the combination of quantitative ultrasound and dual-energy x-ray absorptiometry improve fracture discrimination? Osteoporos Int. 2001a; (12): 471-477p.

Frost ML, Blake GM e Fogelman I. Quantitative ultrasound and bone mineral density are equally srongly associated with risk factors for osteoporis. Journal of bone and mineral research. 2001b; (16): 406-416p.

Fossum TW. Cirurgia de Pequenos Animais. Edit. Loca. (2001) - São Paulo.

Funke M, Kopka L, Vosshenrich R, Fischer U, Ueberschaer A, Oestmann J, et al. Broadbamd ultrasound attenuation in the diagnosis of osteoporosis: correlation with osteodensitometry and fracture. Radiology. 1995; (194): 77-81p.

Gluer C, Wu C, Jergas M, Goldstein S e Genant H. Three quantitative ultrasound parameters reflect bone structure. Calcif Tissue Int. 1994; (55): 46-52p.

Gnudi S, Ripamonti C e Malavolta N.Quantitative ultrasound and bone densitometry to evaluate the risk of nonspine fracture: a prospective study. Osteop. Intern. 2000; 11(6): 518-523p.

Graafmans W, Lingen A, Ooms M, Bezemer P e Lips P. Ultrasound measurements in the calcaneus: precision and its relation with bone mineral density of the heel, hip, and lumbar spine. Bone. 1996; (19): 97-100p.

Greenfield DM, Craven J, Huddleston A, Kehrer L, Wishko D e Stern R. Measurement of the velocity of ultrasound in human cortical bone in vivo. Radiation Physics. 1981; (138): 701-710p.

Greenfield DM e Eastell R. Risk factors for ankle fracture. Osteopor. Intern. 2001; 12(2): 97-103p. 
Hadji P, Hars O, Bock K, Albert U, Beckmann M, Emons G, et al. Age changes of calcaneal ultrasonometry in healthy german women. Calcif Tissue Int. 1999a; (65): 117-120p.

Hadji P, Hars O, Wuster Chr., Bock K, Alberts, Bohnet H, et al. Stiffness index identifies patients with osteoporotic fractures better than ultrasound velocity or attenuation alone. Maturitas. 1999b; (31): 221-226p.

Hadji P, Hars O, Gorke K, Emons G e Schulz K. Quantitative ultrasound of os calcis in postmenopausal women with spine and hip fractures. Journal of Clinical Densitometry. 2000a; (3): 233-239p.

Hadji P, Hars O, Schuler M, Bock K, Wuster C, Emons G, et al. Assessment by quantitative ultrasonometry of the effects of hormone replacement therapy on bone mass. Am J Obstet Gynecol. 2000b; (182): 529-534p.

Hamanaka Y, Yamamoto I, Takada M, Matsushita R, Ota T, Yuh I, Morita R. Comparison of bone mineral density at varius skeletal sites with quantitative ultrasound parameters of the calcaneus for assessment of vertebral fractures. J Bone Miner Metab. 1999; (3): 195-200p.

Han S e Davis J. A comparison between the patella and the calcaneus using ultrasound velocity and attenuation as predictors of bone mineral density. Phys. Med. Biol. 1997; (42):1947-1955p.

Hans D, Arlot M, Shott A, Roux J, Kotzki P e Meunier P. Do ultrasound measurements on the os calcis reflect more the bone microarchitecture than the bone mass?: A two-dimensional histomorphometric study. Bone. 1995; (16): 295-300p.

Hans D, Dargent-Molina P, Schott AM, Sebert AM, Cormier C, Kotzki PO, et al. Ultrasonographic heel measurements to predict hip fracture in elderly women: the EPIDOS prospective study. 1996; (348): 511-514p.

Hartman C, Brik R, Tamir A, Merrick J e Shamir R. Bone quantitative ultrasound an nutritional status in severely handicapped institutionalized children an adolescents. Clinical Nutrition. 2004a;(23): 89-98p.

Hartman C, Hino B, Lerner A, Eshach-Adiv O, Berkowitz D, Shaoul R, et al. Bone quantitative ultrasound and bone mineral density in children with celiac disease. J Pediatr Gastroenterol Nutr. 2004b;(5): 504-510p. 
He P. Direct measurement of ultrasonic dispersion using a broadband transmission technique. Ultrasonics. 1999; (37): 67-70p.

Heaney R, Avioli L, Chesnut C, Lappe J, Recker R, Brandenburger G. Osteopororotic bone fragility. Detection by ultrasound transmission velocity. JAMA. 1989; (261); 2986-2990p.

Heldan MCC, Medeiros PM, Szejnfeld LV. Quantitative ultrasound of the calcaneus in Brasilian Caucasian women: normative data are similar to the manufacture's normal range. Osteoporosis Intern. 2000; (11): 923928p.

Herd R, Blake G, Ramalingam T, Miller C, Ryan P e Fogelman I. Measurements of postmenopausal bone loss with a new contact ultrasound system. Calcif Tissue Int. 1993; (53): 153-157p.

Herdade SB. Curso Fundamentos da Ultra-Sonografia. São Paulo (1998). Apostila do IEE-USP.

Hill CR. Physical Principles of Medical Ultrasonics. Ellis Horwood Limited. Chischester-England. 1986. Capítulo 4.

Hodgskinson R, Njeh CF, Whithead MA e Langton CM. The non-linear telationship between BUA and porosity in cancellous bone. Phys. Med Biol. 1996; (41): 2411-2420p.

Hoffmeister BK, Whitten AS e Rho JY. Low-Megahertz properties of bovine cancellous bone. Bone. 2000; (26): 635-642p.

Hollevoet N, Goemaere S, Mortier F, Van Bouchaute P, Kaufman JM e Verdonk R. The role of osteoporosis in distil radius fractures. Acta Orthop. Belg. 2000; 66(2): 163-168p.

HTMG. Piezoelectric ceramics: Principles and applications. Pennsylvania (2004). APC International Ltd. 
Ingle B e Eastell R. Site-specific bone measurements in patients with ankle fracture. Osteoporos Int. 2002; (13): 342-347p.

Jaworski M e Lorene RS. Progress in measurement of the calcaneus using ultrasonic methods in children and adolescents. Przegl Lek. 2000; (2): 93-99p.

Karlsson MK, Magnusson H, Karlsson C e Seeman E. The duration of exercise as a regulator of bone mass. Bone. 2001;(28): 128-132p.

Kaufman JJ e Einhorn TA. Perspectives ultrasound assessment of bone. Journal of Bone and Mineral Research. 1993; (8): 517-525p.

Kim C, Kim Y, Choi C, Park J, Lee M, Lee S, et al. Prevalece and risk factors of low quantitative ultrasound values of calcaneus in Korean elderly women. Ultras. in Med. \&. Biol. 2000; (26): 35-40p.

Kotzki P, Buyck D, Hans D, Thomas E, Bonnel F, Favier F, et al. Influence of fat on ultrasound measurements of the os calcis. Calcify Tissue Int. 1994; (54): 91-95p.

Krautkrämer J e Krautkrämer H. Ultrasonic testing of materials. 4롤 Edição, Springer-Verlag, 1990.

Krenkau FW. Diagnóstico por Ultra-som - Princípios e Instrumentos. 4ª Edição, Artes Médicas, Porto alegre, 1996.

Landin-Wilhelmsen K, Johansson S, et al. Calcaneal ultrasound measurements are determined by age and physical activity. Studies in two Swedish random population samples. J. Intern. Med. 2000; (2): 269-278p.

Langton CM, Whitehead MA, Langton DK e Langley G. Development of a cancellous bone structural model by stereolithography for ultrasound characterization of the calcaneus. Med. Eng. Phys. 1997; (19): 599-604p.

Langton C.M. e Njeh C.F.. The physical measurement of bone. Institute of Physics-Series in Medical Physics and Biomedical Engineering. 2004. 
Lee S, Coan B e Bouxsein M. Tibial ultrasound velocity measured in situ predicts the material properties of tibial cortical bone. Bone. 1997; (21): 119-125p.

Lequin M, Rijn R, Robben S, Hop W e Kuijk C. Normal values for tibial quantitative ultrasonometry in Caucasian children and adolescents (aged 6 to 19 years). Calcify Tissue Int. 2000; (67): 101-105p.

Lim Y, Chan L e Lam K. Broadband ultrasound attenuation reference database for southeast asian males and females. Original article. 2005; (34): 545-547p.

Litniewski J, Nowicki A e Sawicki A. Detection of bone disease with ultrasound - comparison with bone densitometry. Ultrasonics. 2000; (38): 693-697p.

Lochmuller E, Eckstein F, Kaiser D, Zeller J, Landgraf J, Putz R, et al. Prediction of vertebral failure loads from spinal and femoral dual-energy x-ray absorptiometry, and calcaneal ultrasound: an in situ analysis with intact soft tissues. Bone. 1998; (23): 417-424p.

Magkos F, Manios Y, Babaroutsi E e Sidossis L. Contralateral differences in quantitative ultrasound of the heel: the importance of side in clinical pratice. Osteoporosis International. 2005; (8): 879-886p.

Mckelvie M e Palmer S. The interaction of ultrasound with cancellous bone. Phys. Med. Biol. 1991; (36): 13311340p.

McCloskey E, Murray S, Miller C, Charlesworth D, Miller C, Fordham J, et al. Assessment of broadband ultrasound attenuation in the os calcis in vitro. Clinical Science. 1990a; (78): 221-225p.

McCloskey E, Murray S, Miller C, Charlesworth D, Tindale W, O`dohrty D, et al. Broadband ultrasound attenuation in the os calcis: relationship to bone mineral at other skeletal sites. Clinical Science. 1990b; (78): 227-233p.

Michalska D, Zikan V, Stepan J, et al. X-ray densitometry and ultrasonography of the heel bone -- sensitivity and comparison with densitometry of the axial skeleton. Cas Lek Cesk. 2000; (8): 231-236p. 
Montagnani A, Gonnelli S, Cepallaro C, Mangeri M, Monaco R, Bruni D e Gennari C. Quantitative ultrasound at the phalanges in healthy Italian men. Osteopor. Intern. 2000; 11(6):499-504p.

MORGAN. Guide to morden piezoelectric ceramics. Ohio (2004). Morgan Matroc, Inc.

Moro CA, Paccola CAJ e Paulin JBP. Desenvolvimento de um fixador externo de flexibilidade variável. Revista brasileira de engenharia. 1989; (6): 562-568p.

Naganathan V, Zochling J, March L e Sambroook PN. Peak bone mass increased in the hip in daughters of women with osteoarthritis. Bone. 2002;(30): 287-292p.

Nicholson PHF, Lowet G, Langton CM, et al. A comparison of time-domain and frequency-domain approachs to ultrasonic velocity measurements in trabecular bone. Phys. Med. Biol. 1996; (41): 2421-2435.

Nicholson PHF, Strelitzki R, Cleveland RO e Bouxsein ML. Scattering of ultraosund in cancellous bone: predictions from a theoretical model. Journal Biomechanics. 2000; (33): 503-506p.

Nicholson PHF e Bouxsein ML. Bone marrow influences quantitative ultrasound measurements in human cancellous bone. Ultrasound in Med. \& Biol. 2002a; (28): 369-375p.

Nicholson PHF e Bouxsein ML. Effect of temperature on ultrasonic properties of the calcaneus in situ. Osteoporos Int. 2002b; (13): 888-892p.

Njeh C e Langton C. The effect of cortical endplates on ultrasound velocity through the calcaneus: an in vitro syudy. The british journal of radiology. 1997; (70): 504-510p.

Njeh C, Hans D, Wu C, Kantorovich E, Sister M, Fuester T, et al. An in vitro investigation of the dependence on sample thickness of the speed of sound along the specimen. Medical engineering \& Physics. 1999; (21): 651659p. 
Njeh C e Genant H. Bone loss. Quantitative imaging techniques for assessing bone mass in rheumatoid arthritis. Arthritis Res.2000a;(2): 446-450p.

Njeh C, Shaw N, M Janet, Boivin C e Southwood T. Use of quantitative ultrasound to assess bone status in children with juvenile idiopathic arthritis. Journal of Clinical Densitometry. 2000b; (3); 251-260p.

Njeh C, Saeed I, Grigorian M, Kendler D, Fan B, Shepherd J, et al. Assessment of bone status using speed of sound at multiple anatomical sites. Ultrasound in Med. \& Biol. 2001a; (27): 1337-1345p.

Njeh C, Fuerst T, Diessel E e Genant H. Is quantitative ultrasound dependent on bone structure? A reflection. Osteoporos Int. 2001b; (12): 1-15p.

Pande K, Bernard J, McCloskey E, Takats D e Kanis J. Ultrasound velocity and Dual-energy x-ray absorptiometry in normal and pagetic bone. Bone. 2000; (26): 525-528p.

Panichkul S, Sripramote M e Sriussawaamorn N. Diagnostic performance of quantitative ultrasound calcaneus measurement in case finding for osteoporosis in Thai postmenopausal women. J. Obstet. Gynaecol. Res. 2004;(30):418-426p.

Peretz A, Penaloza A, Mesquita M, Dratwa M, Verhas M, Martin P, et al. Quantitative ultrasound and dual x-ray absorptiometry measurements of the calcaneus in patients on maintenance hemodialysis. Bone. 2000;(27): 287292p.

Philipov G, Holsman M e Philips PJ. The clinical role of quantitative ultrasound in assessing fracture risk and bone status. Medicini Journal Australian. 2000; (4): 208-211.

Pluskiewicz W e Nowakowska J. Bone status after long-term anticonvulsant therapy in epileptic patients: evaluation using quantitative ultrasound of calcaneus and phalanges. Ultrasound in Med. \& Biol. 1997; (23): 553-558p. 
Pluskiewicz W e Drozdzowska B. Ultrasonic measuremnt of the calcaneus in polish normal and osteoporotic women and men. Bone. 1999; (24): 611-617p.

Pluskiewicz W e Drozdzowska B. Quantitative ultrasound (QUS) at the calcaneus and hand phalanges in polish healthy postmenopausal women. Ultrasound in Med. \& Biol. 2001; (27): 373-377p.

Pluskiewicz W, Halaba Z, Chelmecka L, Drozdzowska B, Jakimczyk D e Karasek D. Skeletal status in survivors of acute lymphoblastic leukemia assessed by quantitative ultrasound at the hand phalanges: a longitudinal study. Ultrasound in Med.\& Biol. 2004a;(30): 893-898p.

Pluskiewicz W, Przedlacki J, Drozdzowska B, Wlodarczyk D, Rowinska J e Adamczyk P. Quantitative ultrasound at hand phalanges in adults with end-stage renal failure. Ultrasound in Med. \& Biol. 2004b; (30): 455-459p.

Pocock NA, Culton NL, Gilbert GR, Hoy ML, Babicheva R, Chu JM et al. Potencial roles for quantitative ultrasound in the management of osteoporosis. Med. J. Aust. 2000; 173 (7):355-358p.

Prevrhal S, Fuerst T, Fan B, Njeh C, Hans D, Uffmann M et al. Quantitative ultrasound of the tibia depends on both cortical density and thickness. Ostopor. Intern. 2001; 12(1): 28-34p.

Reginster J, Dethor M, Pirenne H, Dewe W e Albert A. Reproducibility and diagnostic sensitivity of ultrasonometry of the phalanges to assess osteoporosis. International journal of Gynecology \& Obstetrics. 1998; (63): 21-28p.

Rena RJM. A mulher e a osteoporose - como prevenir e controlar. Editora Iátria. $1^{\mathrm{a}}$ edição, 2003.

Rho JY, Flaitz D, Swarnakar e Acharya RS. The characterization of broadband ultrasound atenution and fractal analysis by biomechanical properties. Bone. 1997; (20): 497-504p.

Rodrigues MES. Análise do risco de fratura óssea por ultrassonometria e ensaio mecânico de compressão. Dissertação de Mestrado. São Carlos. EESC/FMRP/IQSC; 2003. 
Rosenthall L, Caminis J e Tenenhouse A. Correlation of ultrasound velocity in the tibial cortex, calcaneal ultrasonography, and bone mineral densitometry of the spine and femur. Calcif Tissue Int. 1996; (58): 415-418p. Ross P, Huang C, Davis J, Imose K, Yates J, Vogel J, et al. Predicting vertebral deformith using bone densitometry at various skeletal sites and calcaneus ultrasound. Bone. 1995; (16): 325-332p.

Serpe L e Rho J. The nonlinear transition period of broadband ultrasound attenuation as boné density varies. J.Biomechanics. 1996; (29): 963-966p.

Siegel DM, Anast GT e Fields T. The determination of fracture healing by measurement of sound velocity across the fracture site. Surgery, Ginecology \& Obstetrics. 1958; (September): 327-332p.

Sievanen H, Cheng S, Ollikainen S e Uusi-Rasi K. Ultrasound velocity and cortical bone characteristics in vivo. Osteoporos Int. 2001; (12): 399-405p.

Sobota. Atlas de Anatomia Humana. 20aㅡ Edição. Editora Guanabara Koogan. Volume 2. 1993.

Sone T, Imai Y, Tomomitsu T e Fukunaga M. Calcaneus as a site for the assessment of bone mass. Bone. 1998; (22): 155-157p.

Strelitzki R e Evans JA. Diffraction and interface losses in broadband ultrasound attenuation measurements of the calcaneun. Physiol. Meas. 1998; (19): 197-204p.

Strelitzki R, Paech V e Nicholson PHF. Measurement of airborne ultrasonic slow waves in calcaneal cancellous bone. Medical Engineering \& Physics. 1999; (21): 215-223p.

Swenson MJ e Reece WO. Dukes fisiologia dos animais domésticos. 11. ed. Rio de Janeiro: Guanabara Koogan, 1996. 
Tavokoli MB e Evans JA. Dependence of the velocity and attenuation of ultrasound in bone on the mineral content. Phys. Med. Biol. 1991; (36): 1529-1537p.

Tavokoli MB e Evans JA. The effect of bone structure on ultrasonic attenuation and velocity. Ultrasonics. 1992; (30): 385-395p.

Toyras J, Kroger H e Jurvelin J. Boné properties as estimated by mineral density, ultrasound attenuation, and velocity. Bone. 1999; (25): 725-731p.

Toyras J, Nieminen M, Kroger H e Jurvelin J. Boné mineral density, ultrasound velocity, and broadband attenuation predict mechanical properties of trabecular boné differently. Bone. 2002; (31): 503-507p.

Tromp AM, Smit JH, Deeg DJH e Lips P. Quantitative ultrasound measurements of the tibia and calcaneus in comparison with DXA measurements at varius skeletal sites. Osteoporosis Int. 1999; (9): 230-235p.

Warden SJ, Bennel KL, Matthews B, Brown DJ, McMeeken JM e Wark JD. Quantitative ultrasound assessment of acute bone loss following spinal cord injury: a longitudinal pilot study. Osteoporosis International. 2002; (13): 586-592p.

Wasnich R, Ross P, Heilbrun L e Vogel J. Selection of the optimal skeletal site for fracture risk prediction. Clinical Orthopaedics and Related Research. 1987; 262-268p.

Waud C, Lew R e Baran D. The relationship between ultrasound and densitometric measurements of bone mass at the calcaneus in women. Calcif Tissue Int. 1992; (51): 415-418p.

Wear K e Garra B. Assessment of bone density using ultrasonic backscatter. Ultrasound in Med. \& Biol. 1998; (24): 689-695p.

Wehbe J, Cortbaoui C, Chidiac RM, Nehme A, Melhi R, Bedran F, et al. Age-associated changes in quantitative ultrasonometry (QUS) of the os calcis in Lebanese women-assessment of a Lebanese reference population. 2003; (3): 232-239p. 
Weiss M, Ben SA, Hagag P e Ish-Shalon S. Discrimination of proximal hip fracture by quantitative ultrasound measurement at the radius. Osteoporosis Intern. 2000a; 11(5): 425-433.

Weiss M, Ben SA, Hagag P, Rapoport M e Ish-Shalon S. Effect of estrogen replacement therapy on speed of sound at multiple skeletal sites. Maturitas. 2000b; 35(3): 237-243p.

Welch A, Camus J, Dalzell N, Oakes S, Reeve J e Khaw K. Broadband ultrasound attenuation (BUA) of the heel bone and its correlates in men and women in the EPIC-Norfolk cohort: a cross-sectional population-based study. Osteoporos Int. 2004; (15): 217-225p.

Wells P. Biomedical Ultrasonics. Academic Press, New York (1977).

Wünsche K, Wunsche B, Fahnrich H, Mentzel H, Vogt S, Abendroth K, et al. Ultrasound bone densitometry of the os calcis in children and adolescents. Calcif Tissue Int. 2000;(67):349-355p.

Valerio G, Puente A, Buono P, Esposito A, Zanatta M, Mozzillo E, et al. Quantitative ultrasound of proximal phalanxes in patients with type 1 diabetes mellitus. Diabetes Research and Clinical Practice. 2004;(64): 161166p.

Xu W e Kaufman JJ. Diffraction correction methods for insertion ultrasound attenuation estimation. IEEE Transactions on Biomedical Engineering. 1993; (40): 563-570p.

Zadik Z, Sinai T, Zung A e Reifen R. Longitudinal monitoring of bone measured by quantitative multisite ultrasound in patients with crohn`s disease. Journal of Clinical Gstroenterology. 2005;(2): 120-123p.

Zagzebski J, Rossman P, Mesina C, Mazess R e Madsen E. Ultrasound transmission measurements through the os calcis. Calcif Tissue Int. 1991; (49): 107-111p.

Zochling J, Sitoh Y, Lau T, Cameron I, Cumming R, Lord S, et al. Quantitative ultrasound of the calcaneus and falls risk in the institutionalized elderly: sex differences and relationship to vitamin d status. Osteoporos Int. 2002; (13): 882-887p. 


\section{ANEXO}

(01) NOME:

(02) IDADE (anos):

(03) ALTURA (m):

(04) PESO (kg):

(05) FAZ REPOSIÇÃO HORMONAL?

$\operatorname{SIM}(\quad) \quad$ NÃO( )

(06) FAZ ATIVIDADE FÍSICA REGULLAR?

$\operatorname{SIM}(\quad)$

NÃO ( )

OBS: é considerada atividade física regular a atividade feita no mínimo de duas vezes por semana com duração de uma hora.

(07) JÁ FEZ O EXAME DE

$\operatorname{SIM}(\quad)$

NÃO ( )

DENSITOMETRIA ÓSSEA?

CASO SUA RESPOSTA SEJA SIM PARA A PERGUNTA ANTERIOR (07), RESPONDA A PERGUNTA ABAIXO (08), CASO SEJA NÃO ENTREGUE A FICHA PARA O TÉCNICO.

(08) O QUE FOI DIAGNOSTICADO?

( ) NORMAL ( ) OSTEOPENIA OSTEOPOROSE

\section{DADOS A SEREM PREENCHIDOS PELO TÉCNICO}

TAMANHO DO CALCANHAR (mm)

DIAMETRO DO DEDO (mm)

INDICE DE MASSA CORPORAL:

TÉCNICA UTILIZADA:

TEMPERATURA $\left({ }^{0} \mathrm{C}\right)$

( ) INSERÇÃO

( ) INSERÇÃO

( ) CONTATO

FREQUENCIA UTILIZADA (MHz)

( ) 0,5

( ) 0,75

( ) 1,0

( ) 1,5

( ) CONTATO
DIREITO

ESQUERDO

MEDIO 